\title{
Kultureller Wandel in Französisch-Polynesien vor dem Hintergrund ausländischer Einflussnahme und endogener Entwicklung - Ausgangssituation für nachhaltige Tourismusprojekte der indigenen Bevölkerung der Maohi
}

\author{
Dissertation \\ zur Erlangung des philosophischen Doktorgrades der Philosophischen Fakultät der Georg- \\ August-Universität Göttingen \\ vorgelegt von Tatjana Thimm \\ Matrikelnummer: 19807225 \\ geb. am 3.6.68 in Köln \\ Hauptfach: Geographie \\ 1. Nebenfach: Romanische Philologie \\ 2. Nebenfach: Volkswirtschaftslehre
}

Göttingen, den 08.02.2001

1. Gutachter: Prof. Dr. W. Kreisel

2. Gutachter: Prof. Dr. H.-J. Nitz

3. Gutachterin Prof. Dr. C. Erdmann

Rigorosum am 11.07.2001 


\section{INHALTSVERZEICHNIS}

ZITAT 5

DANK 6

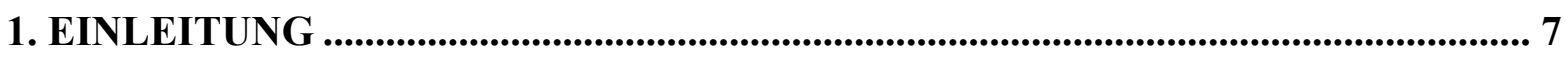

1.1 Zielsetzung dieser Arbeit ........................................................................................................................... 7

1.2 Forschungsgebiet...................................................................................................................................... 7

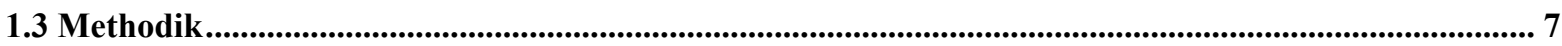

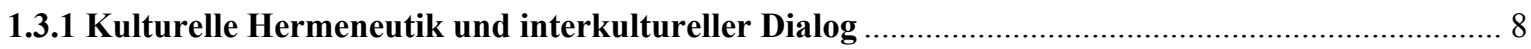

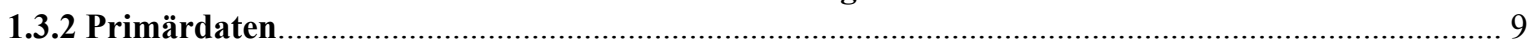

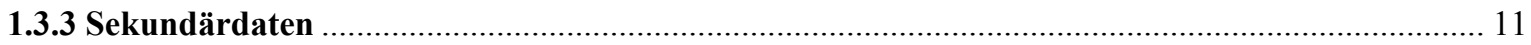

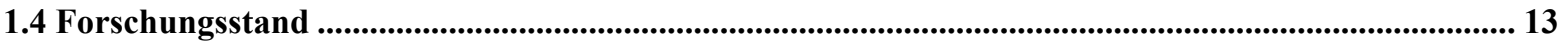

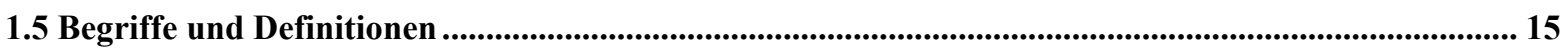

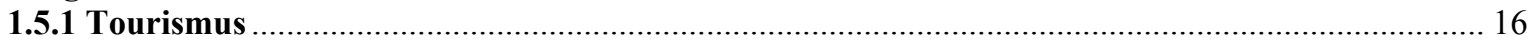

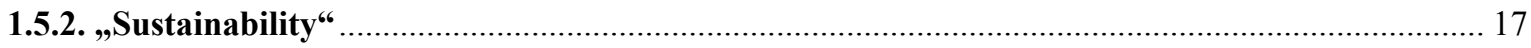

1.5.3 Tourismus im Kontext einer nachhaltigen Entwicklung …………………………………........ 23

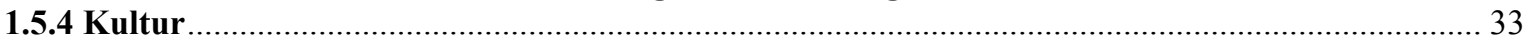

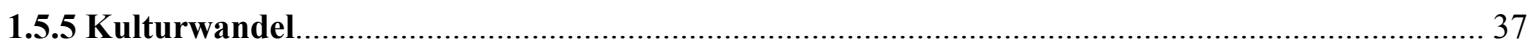

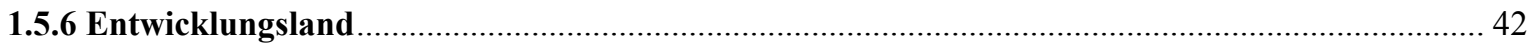

1.6 Aufbau der Arbeit............................................................................................................................................ 43

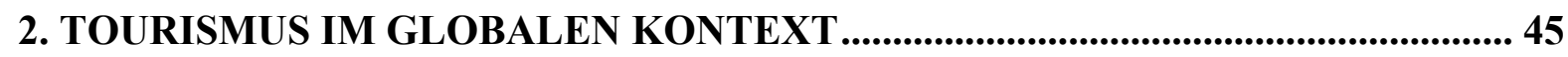

2.1 Tourismus als weltwirtschaftlich relevanter Faktor.............................................................................. 45

2.2 Phasen touristischer Entwicklung ................................................................................................................... 46

2.3 Typologie der Reisenden ............................................................................................................ 49

2.4 Die Nachfrager- und Anbieterstruktur..................................................................................................... 54

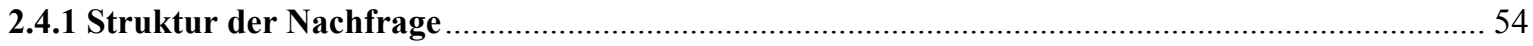

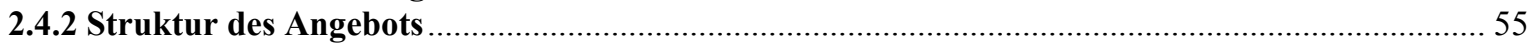

2.5 Reisemotivation und „Imaginäre Geographie“................................................................................ 55

2.6 Zukunftsfähigkeit und heutige Form des Welttourismus .............................................................................. 57

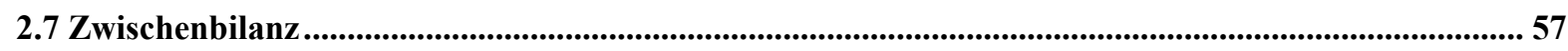

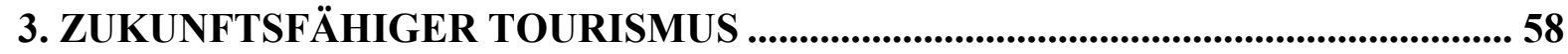

3.1 Das Leitbild eines zukunftsfähigen Tourismus - eine Hypothese ……....................................................... 58

3.2 Trends in der westlichen Konsumhaltung ...................................................................................................... 60

3.3 Chancen für einen zukunftsfähigen Tourismus ……................................................................................ 63

3.4 Zwischenbilanz ........................................................................................................................................... 64 
4.1 Die wirtschaftliche Bedeutung des Tourismus in Entwicklungsländern ............................................... 66

4.2 Der neue Pragmatismus in der aktuellen Diskussion über Tourismus in Entwicklungsländern ........ 67

4.3 Akteure und Rezeption des Tourismus in Entwicklungsländern .................................................... 72

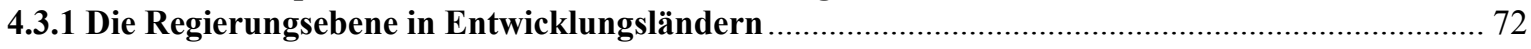

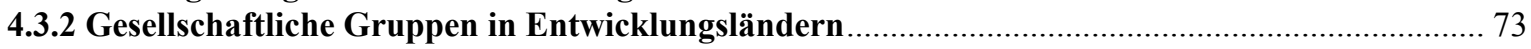

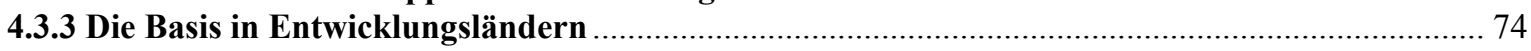

4.4 Chancen für einen zukunftsfähigen Tourismus in Entwicklungsländern .............................................. 75

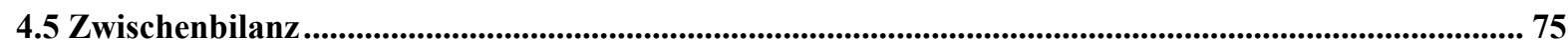

5. INDIGENE VÖLKER UND TOURISMUS................................................................... 77

5.1 Ergebnisse bisheriger Forschungsvorhaben zu indigenen Völkern und Tourismus ............................. 79

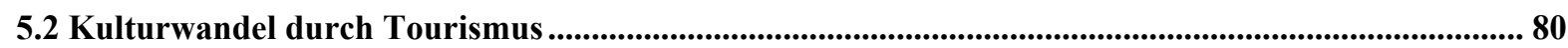

5.3 Beispiele zukunftsfähiger Tourismusprojekte indigener Gruppen ........................................................8 81

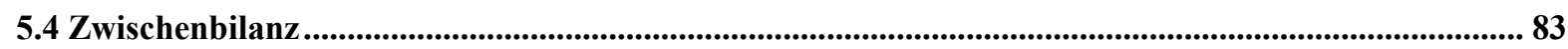

6. FALLBEISPIEL: DIE MAOHI IN FRANZÖSISCH-POLYNESIEN ........................ 84

6.1 Französisch-Polynesien: geographische, wirtschaftliche, politische und ethnische Rahmenbedingungen

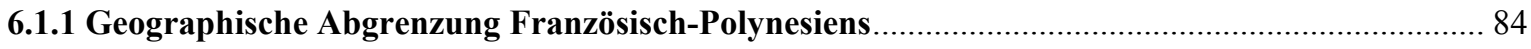

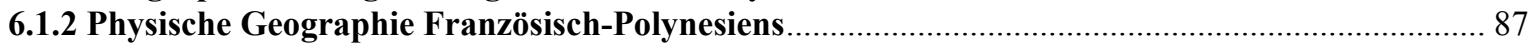

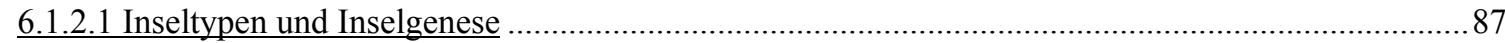

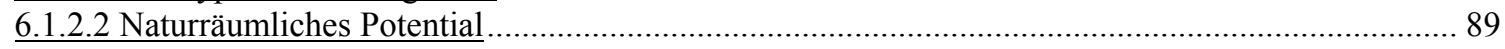

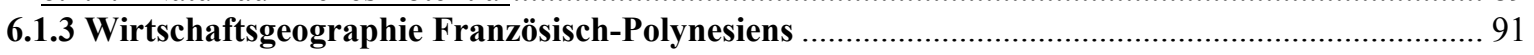

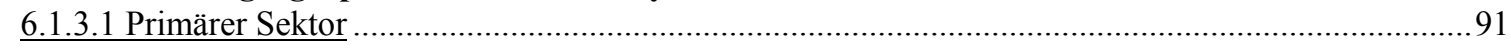

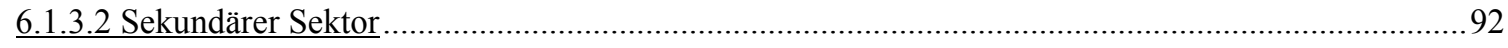

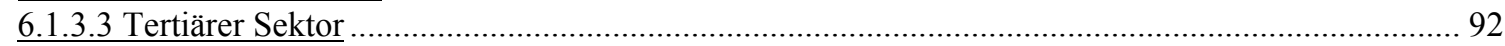

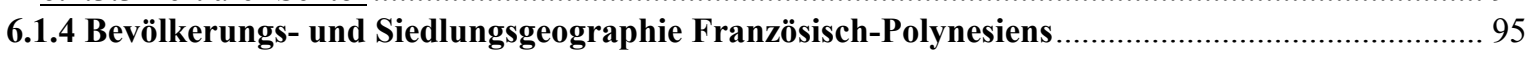

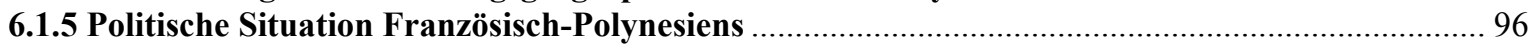

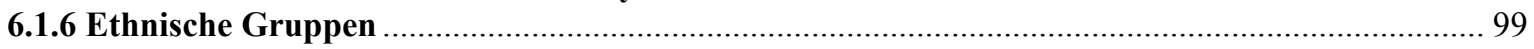

6.1.7 Französisch-Polynesien - ein koloniales Entwicklungsland? .......................................... 102

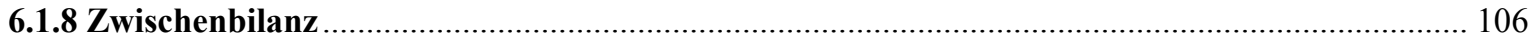

6.2 Die voreuropäische Kultur in Französisch-Polynesien .................................................................... 107

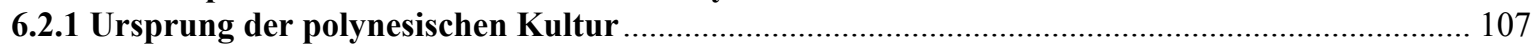

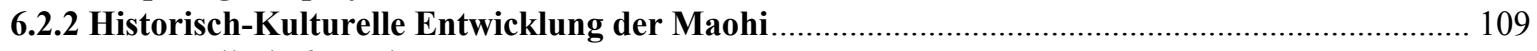

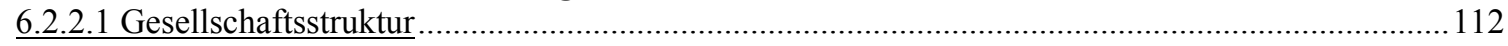

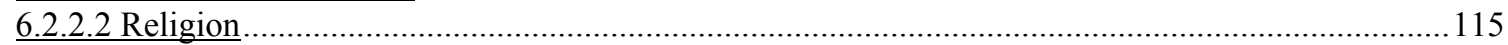

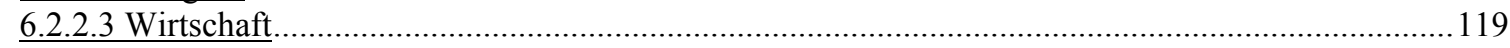

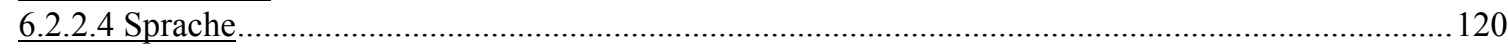

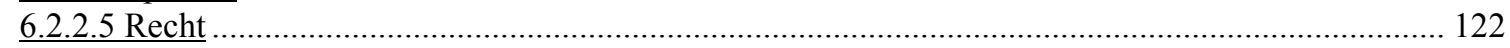

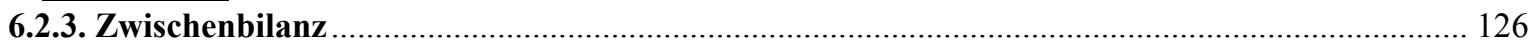

6.3 Der Akkulturationsprozess in Französisch-Polynesien ..................................................................... 128

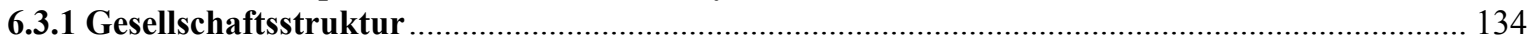

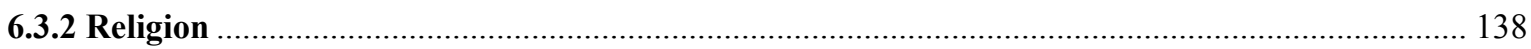

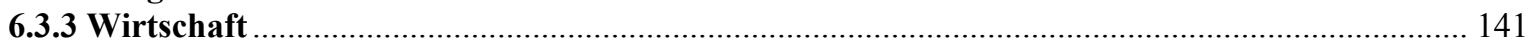

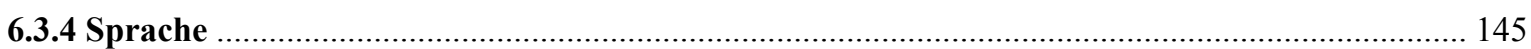

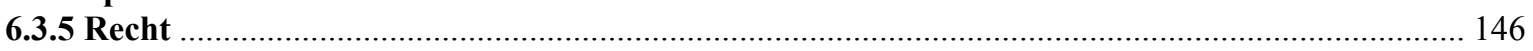


6.3.6 Die Atomtests - gravierender Akkulturationsfaktor in Französisch-Polynesien........................ 150

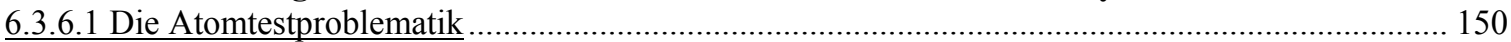

6.3.6.2 Das nukleare Testprogramm der französischen Regierung ....................................................... 151

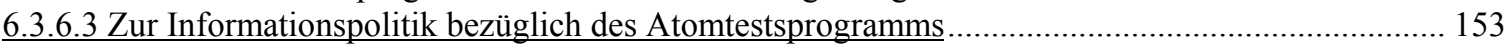

6.3.6.4 Die nuklearen Tests in der Diskussion ................................................................................ 154

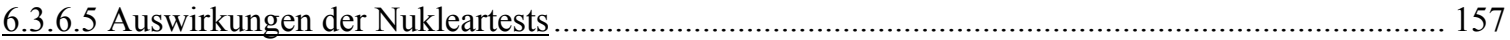

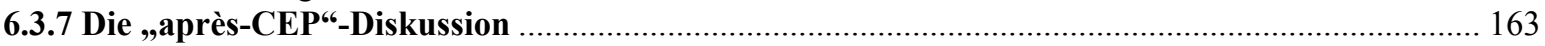

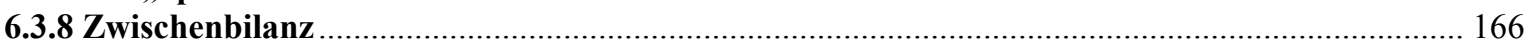

6.4 Reaktionsformen auf den akkulturativen Prozess in Französisch-Polynesien .................................... 170

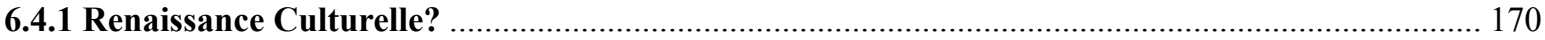

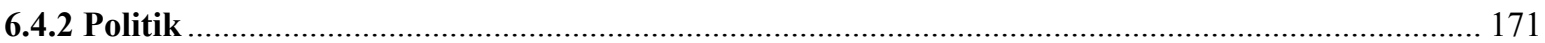

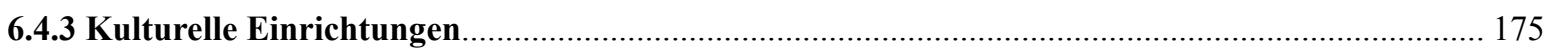

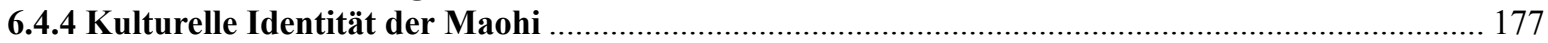

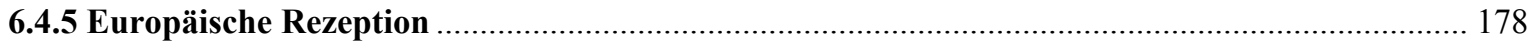

6.4.6 Rezeption des Bildes vom Europäer durch die Maohi................................................... 183

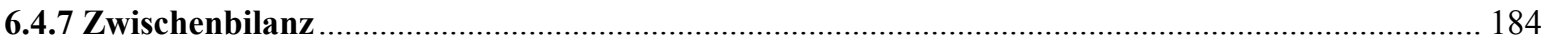

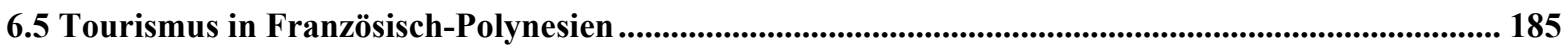

6.5.1 Struktur und Tendenzen des Tourismus in Französisch-Polynesien ..................................... 185

6.5.2 Partizipation der Maohi am touristischen Prozess in Französisch-Polynesien ......................... 192

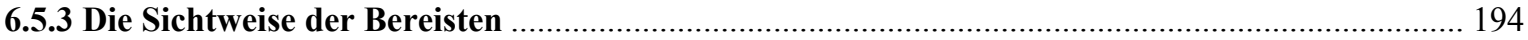

6.6 Tourismusprojekte der Maohi in Französisch-Polynesien................................................................... 196

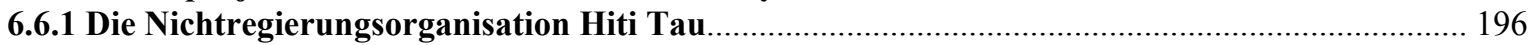

6.6.2 Tourismusprojekte des Netzwerks Hiti Tau und andere Initiativen von Maohi ....................... 199

6.6.3 Bewertung von Tourismusprojekten der Maohi nach Kriterien der Nachhaltigkeit ................ 200

6.6.3.1 Bewertung auf der lokalen Ebene ..................................................................................201

6.6.3.2 Bewertung auf der globalen Ebene .......................................................................................213

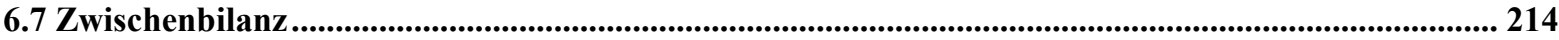

7. AKKULTURATIVE PROZESSE UND TOURISMUS IN ANDEREN REGIONEN

DES PAZIFIK - EIN VERGLEICH .................................................................................... 215

8. KANN TOURISMUS FÜR INDIGENE VÖLKER EINE ZUKUNFTSFÄHIGE

ENTWICKLUNG BEDEUTEN? - EIN AUSBLICK..................................................... 223

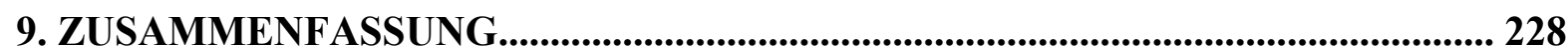

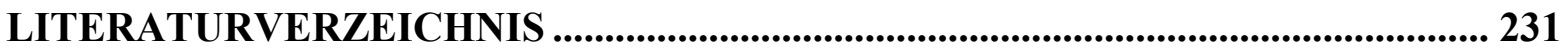

VERZEICHNIS DER ABBILDUNGEN UND TABELLEN IM TEXT ...................... 258

VERZEICHNIS DER ANLAGEN IM ANHANG ................................................. 260

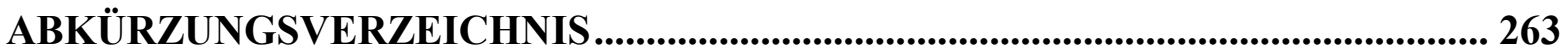

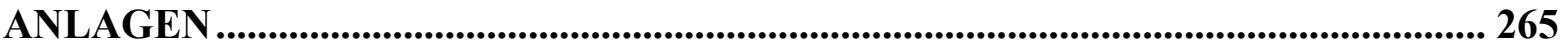




\section{ZITAT}

„Die fremde Kultur muss auch dann ernst genommen werden, wenn sie unseren Kategorien von Wissenschaftlichkeit und Rationalität nicht entspricht. “ (MÜNZEL 1987) 


\section{Dank}

Mein ganz besonderer Dank gilt den Menschen in Französisch-Polynesien, die durch ihre Gastfreundschaft, Hilfeleistungen und ihren unvoreingenommen Gedankenaustausch wesentlich zu dieser Arbeit beigetragen haben. Stellvertretend seien hier nur einige wenige genannt: Gabriel Tetiarahi, Ralph Sanford, Reverend Temarama, Hubert Bremond, Frederic Cella, Micheline und Artur Hunter.

Nicht weniger bedeutend war die fachliche und persönliche Unterstützung von Prof. Dr. Werner Kreisel, der immer wieder neue Impulse für meine Arbeit gab. Gleichzeitig möchte ich auch Herrn Prof. Dr. Hans-Jürgen Nitz (Zweitgutachter) und Frau Prof. Dr. Claudia Erdmann (Drittgutachterin) für Anregungen und konstruktive Kritik danken.

Diese Dissertation widme ich meinem Mann, Christoph Reimann, der auf seine besondere Weise das Zustandekommen dieser Arbeit gefördert hat. 


\section{EINLEITUNG}

\section{$\underline{\text { 1.1 Zielsetzung dieser Arbeit }}$}

Ziel der vorliegenden Dissertation ist die Identifizierung und Bewertung von Konzepten und räumlichen Auswirkungen einer Form des Tourismus, die den Ansprüchen der sozialen und ökologischen Verträglichkeit genügt und von indigenen Gruppen initiiert wurde. Das Fallbeispiel „Französisch-Polynesien“ liefert die empirische Grundlage für Bewertungen eines verträglichen Tourismus im indigenen Kontext. Hierzu ist es zunächst notwendig, den historisch-kulturellen Wandel in Französisch-Polynesien zu beleuchten, da dadurch die länderspezifische Ausgangssituation für heutige touristische Projekte der autochthonen Bevölkerung der Maohi entstand. Interdisziplinäre Fragestellungen werden mit einbezogen, um der Komplexität der Thematik gerecht zu werden.

\section{$\underline{1.2}$ Forschungsgebiet}

Das Forschungsgebiet wurde auf das Territoire D’Outre-Mer Französisch-Polynesien begrenzt, um die Überschaubarkeit und die Durchführbarkeit der gewählten Methode zu gewährleisten. In zwei mehrwöchigen Aufenthalten (1997 und 1999) wurden die empirischen Untersuchungen vor Ort durchgeführt, wobei hier wiederum der geographische Schwerpunkt auf den Gesellschaftsinseln lag.

\section{$\underline{1.3 \text { Methodik }}$}

Methodisch wurde eine Vorgehensweise gewählt, die - ausgehend von den sekundären wissenschaftlichen Quellen - zentrale Fragestellungen vor Ort überprüft. Bei den empirischen Verfahren, deren Ergebnisse vorwiegend indikativen Charakter haben, wurden Fragebögen und Interviewleitfäden eingesetzt. Zu diesem Zweck wurden folgende Zielgruppen gebildet:

- die Reisenden

- die Betreiber der touristischen Infrastruktur/Unternehmen

- die Experten

- die Bereisten 
Die Abgrenzung der Zielgruppen bzw. die Zuweisung einer interviewten Person/Gruppe erwies sich in der Realität als nicht eindeutig durchhaltbar: So gibt es „,bereiste Experten“, „,bereiste Betreiber der touristischen Infrastruktur“, „,reisende Experten“ etc. In solchen Fällen musste in Bezug auf die primäre Zuordnung eine Entscheidung getroffen werden.

\title{
1.3.1 Kulturelle Hermeneutik und interkultureller Dialog
}

Es darf nicht unerwähnt bleiben, dass die oben genannte Methodik westlichem Denken entspringt und keinen Anspruch auf vollständige Lösung der dieser Arbeit zu Grunde liegenden Fragestellung erheben darf. Sicherlich genügt sie wissenschaftlichen Ansprüchen in Empirie und Theorie, doch bleiben Bereiche, die sich erkenntnistechnisch auf interkulturellen Dialog stützen müssen (z. B. Befragung der Zielgruppe „Bereiste“) fragmentarisch und durch westlichwissenschaftliche Erkenntnisformen in ihrer Aussage begrenzt. Die Interpretation der Antworten kann daher in diesen Bereichen fehlerbehaftet sein:

\footnotetext{
„Denn wir können die Tatsache nicht leugnen, dass Forscher, Forschungsmethodik und Definition des Forschungsgegenstandes der jeweils eigenen kulturellen Perspektive verhaftet sind und verhaftet bleiben müssen.“(WEBER-SCHÄFER 1997, S. 246)

oder anders gewendet:
}

\begin{abstract}
„Vom Verstehen [des Fremden] sprechen wir immer dann - nicht nur in der Ethnologie, sondern ebenso in der Psychologie-, wenn wir einen Anderen von seiner Subjektivität her erfassen und begreifen wollen. Damit ist jedoch schon das Dilemma des Verstehens ausgesprochen, denn weder subjektiv noch objektiv können wir zur Subjektivität des Anderen vordringen. [...] Der interpretative Akt ist immer nur unsere deutende Annäherung an die Subjektivität des Anderen.“(s. SCHMIED-KOWARZIK 2000, S. 64 f.)
\end{abstract}

SCHMIED-KOWARZIK (2000, S. 67) geht in seiner philosophischen Wissenschaftskritik sogar noch weiter:

„[...] denn sie [die Wissenschaftler] leben in dem Glauben, dass unsere wissenschaftliche Erfassung der Wirklichkeit eine schlechthin letztgültige ist, der gegenüber sich das magische und mystische Denken als prälogisch erweist [...] Insgesamt ist unsere wissenschaftliche Rationalität ebenfalls nur eine Sinndeutung der Wirklichkeit unter vielen. Sie erweist sich zwar im Kontext unserer Lebenspraxis als den anderen Sinndeutungen in vielen Bereichen überlegen, aber in einigen Bereichen und vor allem im Kontext fremder Lebenszusammenhänge zugleich als völlig unterentwickelt [...], dass heißt die wissenschaftliche Deskription erreicht niemals den existenziell-praktischen Grund, aus dem heraus [...] Mitglieder einer fremden Kultur denken und handeln."

Gefangen im eigenen kulturellen hermeneutischen Zirkel verfälschen wir ,das Fremde“ bereits im Versuch, es zu verstehen. Daher bleibt die Erkenntnisfähigkeit beschränkt auf ein schärferes Profil der eigenen Andersartigkeit: 
„Der interkulturelle Vergleich als Versuch einer Analyse des Fremden, um das Eigene besser verstehen zu können, ist dasjenige Unternehmen der europäischen Moderne, in dem diese nicht ihre Universalität, sondern ihre Einzigartigkeit entdeckt.“ (WEBER-SCHÄFER 1997, S. 255)

Dies bedeutet in der Verallgemeinerung, dass sicherlich Fragmente einer fremden Kultur erfasst werden können, allumfassende Erklärungsmodelle aber immer eurozentrisch und daher mit den oben genannten Einschränkungen behaftet sind oder um es mit den Worten des Ethnologen Nigel BARLEYs (1998, S. 38) auszudrücken:

\begin{abstract}
„Aber einfach dadurch, dass er [der Ethnologe] über eine bestimmte Volksgruppe die maßgebende Monographie schreibt, konfrontiert er diese Leute mit einem Selbstbild, das wohl oder übel von seinen eigenen Vorurteilen und vorgefassten Ansichten geprägt ist, weil es ja im Verhältnis zu fremden Völkern so etwas wie eine objektive Realität nicht gibt.“
\end{abstract}

Diesem grundsätzlichen Problem ihres Faches wendet sich auch die Ethnologin Brigitta HAUSER-SCHÄUBLIN zu und bezeichnet den ethnologischen Erkenntnisprozess als eine Gratwanderung:

„Und die Abgründe, an denen die Gratwanderung vorbeiführt, sind: Zurückfallen in individuelle und kulturelle Vorverständnisse, auch Vorurteile auf der einen Seite, und going native sowie idealisierte Darstellung und Selbstidentifikation mit dem Fremden auf der anderen Seite.“(s. HAUSER-SCHÄUBLIN 1999, S. 139.)

Claude LÉVI-STRAUSS (1996, S. 380) hinterfragt sogar den Erkenntniswert seiner Forschung:

„Stillschweigend unterstellen wir unserer eigenen Gesellschaft, ihren Sitten und Normen eine privilegierte Position, denn ein Beobachter, der einer anderen sozialen Gruppe angehört, wird über dieselben Erscheinungen ein ganz anderes Urteil fällen. Wie könnten unsere Forschungen unter solchen Umständen das Prädikat ,wissenschaftlich' beanspruchen? Um die Objektivität zu wahren, müssten wir uns derartiger Urteile enthalten.“

\title{
1.3.2 Primärdaten
}

Die Primärdatenerhebung wurde für die Zielgruppen „Reisende“ und „Betreiber der touristischen Infrastruktur" mit Hilfe von standardisierten Fragebögen durchgeführt, die teils offene, teils geschlossene Fragen enthielten und einer statistischen Auswertung zugeführt wurden.

Für die beiden anderen Zielgruppen erwiesen sich Fragebögen als relativ unwirksames Instrument. Es wurde daher zur Datengewinnung die Form des informellen, strukturierten Interviews gewählt. Diese persönlichen Interviews wurden absichtlich ohne Aufzeichnungsgerät und in den meisten Fällen ohne zeitgleiches, schriftliches Festhalten des Gesagten geführt, um die Interviewpartner so wenig wie möglich durch eine Betonung der „Interviewsituation“ zu 
beeinflussen. Die schriftliche Fixierung geschah daher im Anschluss. Den Interviews lag jeweils ein „Interviewleitfaden“ zu Grunde, d.h. einige Kernfragen wurden immer abgefragt, damit eine Vergleichbarkeit gegeben war. Wie es dem Charakter von informellen Interviews entspricht, gingen einige Gespräche weit darüber hinaus oder entwickelten sich in andere Richtungen. Allen Befragten wurde Anonymität zugesichert. Die Befragungen wurden überwiegend in französischer Sprache geführt, bei den Reisenden zum Teil auch in englischer Sprache. Die Ergebnisse der Befragung der „Bereisten“ wurde ausgewertet, die Befragung der Zielgruppe „Experten“ geschah nur zu Recherchezwecken.

Außerdem wurde in Anlehnung an die ethnologische Methode der ,teilnehmenden Beobachtung“ Gesehenes und Gehörtes kritisch wahrgenommen und reflektiert. Nicht uninteressant waren in diesem Zusammenhang auch die Reaktionen meines mitreisenden Mannes als „Testtourist““. Darüber hinaus verbrachte ich ca. 50\% ${ }^{1}$ der Zeit in insgesamt vier Maohi-Familien, um aus dieser Perspektive gekoppelt mit vielen, intensiven Diskussionen einen tieferen Einblick in die indigene Kultur zu erlangen.

In allen Fällen habe ich es vermieden, meine Interviewpartner/-innen als „Studienobjekte“ zu betrachten oder zu behandeln, sondern vielmehr als gleichberechtigte Interviewpartner ernst zu nehmen. Während die Befragung der Zielgruppe „Experten“ unproblematisch verlief, da sie es gewöhnt waren, zu Fragen Stellung zu nehmen, war bei der Zielgruppe der „Bereisten“ eine besondere Sensibilität geboten. Gleichzeitig habe ich mich auf das Stellen von Fragen beschränkt, weder Ratschläge noch Lösungsansätze nach dem „westlichen Expertenmuster“ angeboten und meine Sicht der Dinge im Wesentlichen nur bei entsprechender Nachfrage geäußert. $^{2}$

Die Grenzen qualitativer und quantitativer Methoden zeigten sich insbesondere bei der Zielgruppe der „Bereisten“, und zwar speziell der autochthonen Bevölkerung. Der indigene Kontext erschwert oftmals eine Erklärung nach westlichen Denkmustern und birgt die Gefahr der Missinterpretation. Um diesen Effekt, der mit „,kultureller Hermeneutik“ (s. u. Exkurs) vielleicht am treffendsten beschrieben wird, abzumildern, habe ich die indigene Sichtweise bei der Entwicklung des Fragebogens für die Zielgruppe der Bereisten mit einbezogen. Darüber hinaus wurden Maohi in die definitorische Diskussion involviert.

\footnotetext{
${ }^{1}$ Die andere Hälfte der Zeit verbrachte ich in einigen in dieser Arbeit beschriebenen Tourismusprojekten.

${ }^{2}$ Fragebögen und Interviewleitfaden in deutsch, s. Anl. $1 a-d$ im Anhang
} 


\subsubsection{Sekundärdaten}

Wissenschaftliche Dokumente sowie „graue Literatur“ sind zu „Französisch-Polynesien“ im Vergleich zu den englischsprachigen Gebieten des Pazifik und insbesondere zu dem vorliegenden Thema relativ rar. Insbesondere unter dem Gesichtspunkt der Nachhaltigkeit besteht für Französisch-Polynesien eine Forschungslücke.

Die Recherchen vor Ort konzentrierten sich auf das Centre Universitaire de Polynésie Française der Université Française du Pacifique und das Centre Polynésien des Sciences Humaines. Weitere in Tahiti ansässige Forschungseinrichtungen und Institutionen wie

- Office Territoriale d'Action Culturelle, OTAC

- Société des Etudes Océaniennes

- Association des Historiens et Géographes de Polynésie Française

- Chambre de Commerce

- Service du Tourisme

- Institut Territorial de la Statistique

- Institut d'Emission des Départements D’Outre-Mer

- Conseil Economique Social et Culturel

- O.R.S.T.O.M. de Tahiti

waren wertvolle Quellen für Sekundärliteratur.

Eine unschätzbare Ergänzung waren diesbezüglich auch Gespräche mit:

- Alex W. du Prel (Chefredakteur von Tahiti Pacifique)

- Bernard Poirine (Docteur des Sciences Economiques, Centre Universitaire de Polynésie Française)

- Jean-Pierre Tchung (OTAC)

- Philippe Savignat (Chambre de Commerce)

- Patrick Chaussin (Service du Tourisme)

- Hubert Bremond (vormals Centre Polynésien des Sciences Humaines) 
- den Vertretern/-innen von Hiti Tau ${ }^{3}$ (an dieser Stelle sei stellvertretend der Vorsitzende dieser Maohi-NGO, Gabriel Tetiarahi, genannt).

Die vielen Diskussionen mit Vertretern und Mitgliedern Hiti Taus gaben Einblick in die Arbeit und Sichtweise von Maohi-Basisgruppen in Französisch-Polynesien und erlaubten neben Stellungnahmen von offizieller Seite und Expertenmeinungen eine interessante Ergänzung, um nicht zu sagen, eine Möglichkeit der Objektivierung in Bezug auf die Beurteilung des Tourismus in Französisch-Polynesien.

In Frankreich wurde in folgenden Einrichtungen recherchiert:

- O.R.S.T.O.M: Paris, Bordeaux etc..

- Institut d'Emission d'Outre-Mer, Paris

- Hiti Tau France

- Sorbonne

- Nouvelle Sorbonne

- Bibliothèque Nationale (François Mitterrand)

Im universitären Bereich sind hier Professor VON KROSIGK und Pierre JADIN vom Institut für Politische Wissenschaften der Universität Erlangen-Nürnberg als maßgebliche Experten zu nennen.

Als anerkannter Experte im NGO-Bereich ist für Deutschland an dieser Stelle Ulrich DELIUS zu nennen, der als Referent der Gesellschaft für bedrohte Völker sich seit Jahren mit ethnischen Problemen in Französisch-Polynesien beschäftigt.

${ }^{3}$ Hiti Tau ist ein Netzwerk der Ureinwohner Französisch-Polynesiens, der Maohi (vgl. Kap. 6.6.1) 


\subsection{Forschungsstand}

In dieser Form fand im Rahmen der geographischen Forschung in Deutschland die Thematik „Indigene Völker und Tourismus“ im Zusammenhang mit Nachhaltigkeit relativ wenig Beachtung. Auch in Frankreich gibt es -bezüglich Französisch-Polynesien - umfassende Untersuchungen entweder nur zum Tourismussektor, meist aus rein ökonomischer Sicht, oder in der Regel ältere ethnologische Abhandlungen zum Prozess der Akkulturation.

Die Arbeiten von JAFARI (1974) und SMITH (1989) z. B. reflektieren soziokulturelle Effekte im Zusammenhang mit Tourismus.

Christine KAHRMANNs Dissertation „Warten auf den reichen Strand“ sei in diesem Zusammenhang als ein neueres Beispiel aus der Ethnologie zur Problematik „Tourismus und indigene Völker“ genannt (vgl. KAHRMANN 1996). Hierbei wurde erstmals umfassend die Sichtweise der „Bereisten“ auf Fidschi, den Cookinseln und Hawaii erforscht. Ein weiteres regionales Forschungsbeispiel ist die Dissertation von Helmut DWORSCHAK 1994: „Zum Verhältnis von Tourismus und indigener Kultur“. Sein soziologischer Ansatz bezieht sich räumlich auf die Karibik.

Schon 1992 entwickelten TOURISM CONCERN und WORLD WILDLIFE FOUND „Principles for sustainable tourism“, die insbesondere ökonomische und ökologische, weniger soziokulturelle Aspekte beinhalten.

Die 1993 von der WTO aufgestellten „Principles for sustainable tourism“ wiederum, die sich konkret an lokale Planer richten, gewichten ökologische Aspekte geringer.

Bezüglich der Entwicklung nachhaltiger Tourismusmodelle sind VORLAUFER 1996, BECKER/JOB/WITZEL 1996 und HEIN 1997 zu nennen.

VORLAUFER bringt nachhaltige Tourismusformen in Zusammenhang mit der Entwicklungsländerproblematik insbesondere unter ökologischen und ökonomischen Aspekten. Das Autorenteam BECKER/JOB/WITZEL behandelt den soziokulturellen Aspekt als gleichwertig und stellt Indikatoren zur Bewertung der Nachhaltigkeit auf. HEIN schließlich erarbeitet den systemischen Charakter von Nachhaltigkeit. 
Ebenfalls systemisch, aber unter geringerer Beachtung des soziokulturellen Aspektes ist das Nachhaltigkeitsmodell von MESSERLI 1994, das von BAUMGARTNER 1998 verändert und auf den Tourismus angewandt wurde.

Ein sehr ausgereiftes, weil umfassendes Konzept ist das des „Integrativen Tourismus“ des Instituts für Integrativen Tourismus und Freizeitforschung (IITF, 1998). Der ökologischen, ökonomischen und soziokulturellen Dimension werden noch Aspekte von „Managementsystemen“, „Politik“ und „die institutionelle Dimension“ hinzugefügt.

Als aktuelle Indikatorensysteme der Nachhaltigkeit (vgl. auch BAUMGARTNER/RÖHRER 1998, S. 23, HENSELING/EBERLE/GRIESSHAMMER 1999 und BIRKMANN/KOITKA /KREIBRICH/LIENENKAMP 1999) sind zu nennen:

- die Agenda 21

- der Genuine Progress Indicator GPI von DALY und COBB

- die Umweltökonomische Gesamtrechnung der statistischen Bundesämter

- der „Ökologische Rucksack“ - Materialintensität pro erzeugter Dienstleistungseinheit - des Wuppertal-Instituts

- der „Ökologische Fußabdruck“ als Konzept angeeigneter Tragfähigkeit (Wackernagel)

- das Indikatorensystem innerhalb des Projekts „Sustainable Netherlands“ von der Niederländischen Sektion der Umweltorganisation Friends of the Earth

- der Indikatorensatz der OECD

- die Eco-Capacity des Niederländischen Rats für Umweltforschung

- der Leitfaden der gtz: „Tourismus in der Technischen Zusammenarbeit““

- die CSD-Indikatorenliste

- die Nachhaltigkeitsindikatoren des WWF

- die EUROSTAT-Liste der EU

- grundlegende Ansätze von ILO, WHO und FAO

- Nachhaltigkeitsziele und -indikatoren des Forum Umwelt und Entwicklung

- „Zauberscheiben“ der FEST-Indikatoren

Darüber hinaus entwickelten einzelne Länder oder Regionen ihre eigenen Nachhaltigkeitsziele und -indikatoren. HENSELING, EBERLE, GRIESSHAMMER (1999, S. 108) unterscheiden in Bezug auf die Nachhaltigkeit, die Makro-, Meso-, und Mikroebene, für die jeweils völlig unterschiedliche Indikatorensysteme Gültigkeit haben können. BIRKMANN/KOITKA 
/KREIBRICH/LIENENKAMP (1999, S, 62) differenzieren zudem in Kernindikatoren, erweiterte Kernindikatoren und spezifische Indikatoren, die mit zunehmender Detailliertheit der zu untersuchenden Problematik ihre Anwendung finden.

Für die Beurteilung nachhaltiger Tourismusformen wurde in dieser Arbeit maßgeblich das oben erwähnte Modell von BECKER/JOB/WITZEL verwendet sowie einige praktische Fragestellungen aus dem gtz-Leitfaden „Tourismus in der Technischen Zusammenarbeit“ von $1999^{4}$.

Im Bereich Universität/Forschungseinrichtungen oder ähnliche Institute ist das englischsprachige Ausland mit der Ecotourism Society, USA, dem International Centre for Ecotourism an der Griffith Universität in Australien und dem Centre for Ecotourism an der Universität Pretoria in Südafrika Vorreiter (vgl. LOHMANN 1999, S. 41). In Europa sind insbesondere der Arbeitskreis für Tourismus und Entwicklung in Basel, der Studienkreis für Tourismus und Entwicklung in Starnberg und das Institut für Integrativen Tourismus und Freizeitforschung in Wien zu nennen. Neben einer Vielzahl von Einzelforschern existieren darüber hinaus NGOs und Internationale Organisationen, die sich peripher oder schwerpunktmäßig mit Fragen des nachhaltigen Tourismus beschäftigen, so z. B. UN (CSD), WTO, WTTC, Conservation International Ecotourism Department, ECTWT, Tourism Concern etc.

\section{$\underline{1.5 \text { Begriffe und Definitionen }}$}

Zentrale Begriffe der vorliegenden Arbeit bedürfen der definitorischen Klärung. Im Sinne des interkulturellen Dialogs wurde die Bedeutung von Tourismus, Sustainability, Kultur, Kulturwandel und Entwicklung auch bei den Maohi angefragt, um die indigene Sichtweise schon in definitorisch-konzeptionelle Ansätze zu integrieren (sie sind in kursiver Schrift nachgestellt). Das „Phänomen Tourismus“ rechtfertigt eine Betrachtung aus verschiedensten wissenschaftlichen Blickwinkeln, da die Unzulänglichkeit z. B. rein wirtschaftswissenschaftlicher Modelle erwiesen ist (s. HENNIG 1999, S. 158).

\footnotetext{
${ }^{4}$ Vgl. Anl. 26 im Anhang
} 


\subsubsection{Tourismus}

Die Begriffe Fremdenverkehr und Tourismus werden in der Folge weitgehend synonym verwendet.

MÜLLER (1999, S. 58 ff.) gibt einen Überblick über die Änderungen der Definition des Begriffes Tourismus im Wandel der Zeit:

„Überwindung des Raumes durch Menschen, die zu einem Ort hinstreben, an dem sie keinen ständigen Wohnsitz haben“" (GLUECKSMANN 1930, S. 15).

„all jene Personen, die zwei Bedingungen erfüllen: Erstens, dass sie von ihrem ständigen Wohnort während einer Zeit entfernt sind, die weniger als ein Jahr beträgt, und zweitens, dass sie während der Zeit ihrer Abwesenheit Geld in de Besuchsorten ausgeben, welches sie dort nicht verdient haben" (OGLIVIE 1933, S. $5 / 6)$.

„Fremdenverkehr ist der Inbegriff der Beziehungen und Erscheinungen, die sich aus der Reise und dem Aufenthalt Ortsfremder ergeben, sofern durch den Aufenthalt keine Niederlassung begründet und damit keine Erwerbstätigkeit verbunden wird“ (HUNZIKER/KRAPF 1942, S. 21).

„Fremdenverkehr oder Tourismus ist die Gesamtheit der Beziehungen und Erscheinungen, die sich aus der Reise und dem Aufenthalt von Personen ergeben, für die der Arbeitsort weder hauptsächlicher und dauernder Wohnnoch Arbeitsort ist“" (KASPAR 1991, S. 18).

Diese Arbeit schließt sich der Definition von KASPAR an, die für alle heutigen, gängigen Tourismusformen gelten kann und sich international durchgesetzt hat.

Ein wesentliches Merkmal eines für Hiti Tau relevanten Tourismus ist das Prinzip der Gegenseitigkeit. Es wird von dem als Gast betrachteten Touristen eine Akzeptanz der Andersartigkeit der Maohi-Kultur erwartet und die Bereitschaft zum vorbehaltlosen Austausch $^{5}$.

Zur näheren Definition des „Touristen“ vgl. Kap. 2.

\footnotetext{
${ }^{5}$ Interview mit Gabriel Tetiarahi, 1999. Dieser und die nachfolgenden kursiv gesetzten Kommentare von Maohi zu westlichen Konzepten und Begriffen wie Tourismus, Kultur oder Entwicklung verdeutlichen die indigene Sichtweise. Vgl. zum Inhalt dieses Kommentars auch die kulturelle Norm der Reziprozität in Kap. 5.1.
} 


\subsection{2. „Sustainability“}

In der Folge sollen die Begriffe „sustainability“, Nachhaltigkeit ${ }^{6}$ und Zukunftsfähigkeit synonym gebraucht werden.

Ein mit „sustainability“ in Zusammenhang stehender Begriff ist derjenige der „Tragfähigkeit“. Unter Tragfähigkeit wird hier „,diejenige Menschenmenge eines Raumes" verstanden,

„die in diesem unter Berücksichtigung des dort erreichten Kultur- und Zivilisationsstandes auf agrarischer (agrarische T.), natürlicher (naturbedingte T.) oder gesamtwirtschaftlicher (gesamte T.) Basis unter Wahrung eines bestimmten Lebensstandards auf längere Sicht leben kann" (LESER u. a. 1989, Bd. II, S. 302).

Hieran angelehnt wurde der Begriff der „,kulturellen Tragfähigkeit“ als Maßstab der Belastbarkeit einer Kultur gegenüber Fremdeinflüssen.

Die Tragfähigkeit (kulturell und ökonomisch) ist ein entscheidendes Moment der „sustainability“, bedeutet sie doch die quantitative Voraussetzung einer zukunftsfähigen Entwicklung. Wird die Tragfähigkeit eines Raumes langfristig massiv überschritten, ist die Zukunftsfähigkeit nicht mehr gegeben.

Obwohl schon 1972 durch den Club of Rome erwähnt, erlangte das Konzept von „sustainability“ insbesondere durch den Brundtland-Bericht ${ }^{7}$ erstmals erhöhte Aufmerksamkeit in der wissenschaftlichen Debatte. Hier wurde auch eine der ersten - sehr allgemein gehaltenen Definitionen gegeben:

„Dauerhafte Entwicklung ist Entwicklung, die die Bedürfnisse der Gegenwart befriedigt, ohne zu riskieren, dass künftige Generationen ihre eigenen Bedürfnisse nicht befriedigen können.“ (HAUFF 1987, S. 46).

Die internationale Auseinandersetzung zu diesem Thema erreichte ihren vorläufigen Höhepunkt im Rahmen der UN-Konferenz über Umwelt und Entwicklung in Rio, 1992, und der Klimafolgekonferenz in Berlin 1995.

Die Definition von „Sustainable Development“ in der Studie Zukunftsfähiges Deutschland (BUND/MISEREOR 1996, S. 24) veranschaulicht die Notwendigkeit, sich diesem Konzept umfassend und unter Integration mehrerer Faktoren, zu nähern:

\footnotetext{
${ }^{6}$ Der Begriff der Nachhaltigkeit wurde erstmalig von dem sächsischen Oberberghauptmann VON CARLOWITZ im Jahre 1713 in dessen Buch „Sylvicultura Oeconomica“ verwendet.
}

\footnotetext{
${ }^{7}$ Vgl. hierzu aus ausführlich HARBORTH 1992, S. $231 \mathrm{ff}$
} 
„,Sustainable Development' ist die Bezeichnung für eine Entwicklung, in der die Bedürfnisse heutiger Generationen befriedigt werden sollen, ohne die Bedürfnisse kommender Generationen zu gefährden. Mit diesem Leitbegriff verbindet sich die Erkenntnis, dass umweltpolitische Probleme nicht isoliert von der wirtschaftlichen und sozialen Entwicklung betrachtet werden können, sondern ein ganzheitlicher Ansatz erforderlich ist. Umwelt und Entwicklung sind zwei Seiten einer Medaille. Die alte Entwicklungsmaxime, zunächst ökonomischen Wohlstand zu erreichen und die sozialen und ökologischen Folgekosten später zu reparieren, ist hinfällig geworden. Das neue Denken erfordert eine Integration von ökologischen, sozialen und ökonomischen Belangen.“

Dieser definitorische Ansatz erfährt in der Studie eine Konkretisierung durch die Konzepte „Umweltraum“ und „Ökologische Rucksäcke“:

Ist der Umweltraum der Raum,

„,den die Menschen in der natürlichen Umwelt benutzen können, ohne wesentliche Charakteristika nachhaltig zu beeinträchtigen (BUND/MISEREOR 1996, S. 27)“,

so ergeben sich Ökologische Rucksäcke dann, wenn Umweltbelastungen z.B. durch entsprechende Außenhandelsstrukturen, wie sie zwischen Industrieländern und Entwicklungsländern bestehen, in Letztere ausgelagert werden (vgl. BUND/MISEREOR 1996, S. 134). Das Konzept des Umweltraumes verdeutlicht darüber hinaus sehr anschaulich die Prinzipien der inter- und intra-generationalen Gerechtigkeit der Nachhaltigkeit (vgl.

RENN/KNAUS/KASTENHOLZ 1999, S. 20).

Effizienz und Suffizienz sind zwei wesentliche Strategien zur Umsetzung der Nachhaltigkeit. Neben der effizienteren Nutzung von Material und Energie, die unter anderem durch den technischen Fortschritt vorangetrieben wird, bedeutet Suffizienz eine Verringerung des materiellen Konsums (vgl. RENN/KNAUS/KASTENHOLZ 1999, S. 43).

Das Konzept der „,sustainability“ bleibt daher zunächst ein visionäres, und die Annäherung hieran kann nur in kleinen Schritten erfolgen. Sein systemischer und holistischer Ansatz hebt es über das Konzept der Tragfähigkeit hinaus. In den verschiedenen wissenschaftlichen Disziplinen, in die dieses Konzept Eingang gefunden hat, entwickelten sich entsprechende Varianten und Modifikationen.

Die oben genannten Definitionsansätze zu ,sustainability“ werden dem systemischen Charakter dessen, was gemeint ist, nicht in ausreichender Form gerecht. Modelle, die „sustainability“ als ein System sich wechselseitig beeinflussender Faktoren begreifen, nähern sich dem Begriff, insbesondere in der visuellen Umsetzung, auf bessere Art und Weise. 
Ein interessantes modulares Modell bietet der Entwurf von WITZEL (BECKER/JOB/WITZEL 1996, S. 5):

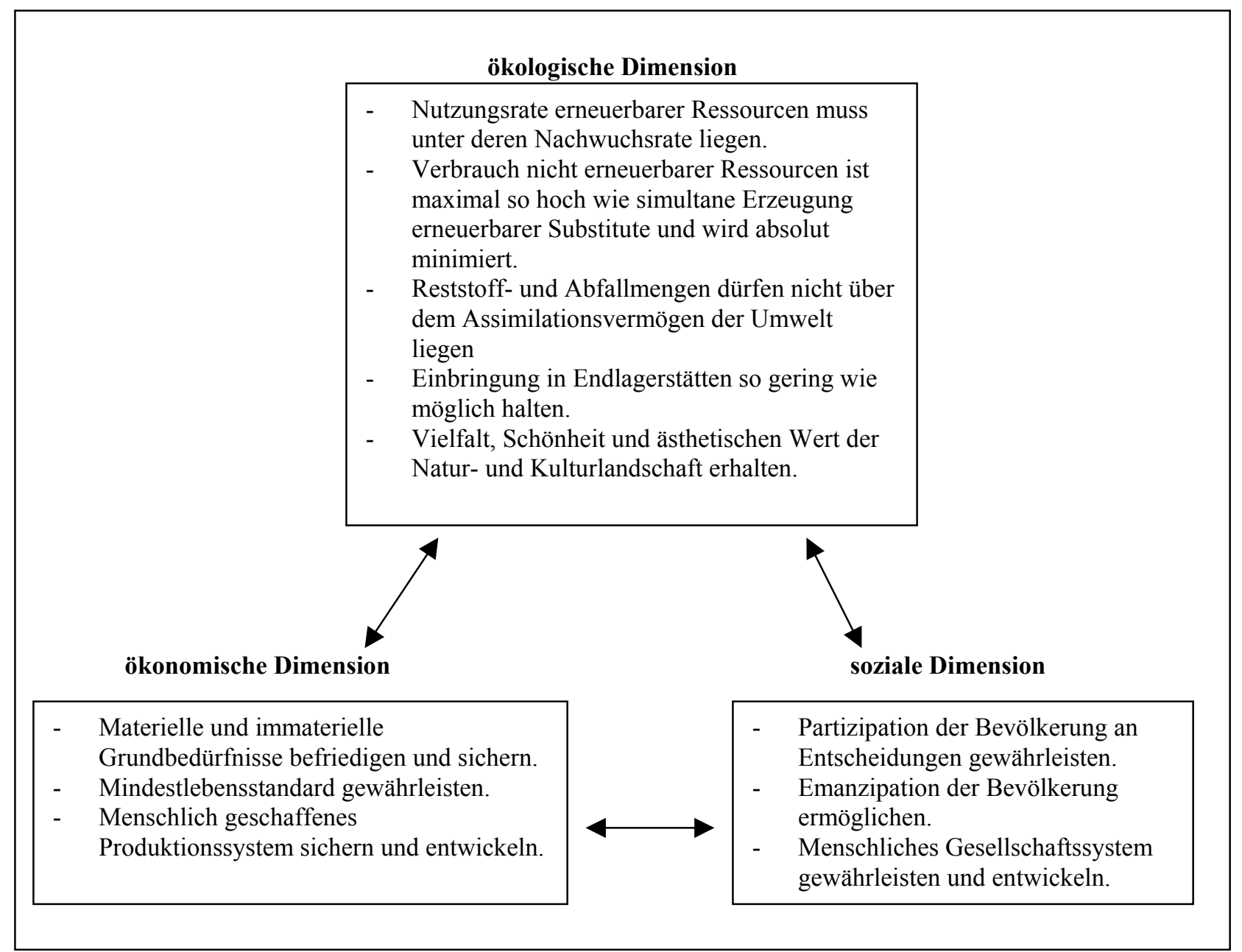

Abb. 1: Kriterien für eine nachhaltige Entwicklung (Entwurf: WITZEL 1995)

Dieses Modell orientiert sich an der Nachhaltigkeitsdefinition des Rates der Sachverständigen für Umweltfragen (1994, S. 9, zitiert in BECKER/JOB/WITZEL 1996, S. 1):

„Dauerhafte Entwicklung schließt sonach eine umweltgerechte, an der Tragfähigkeit der ökologischen Systeme ausgerichtete Koordination der ökonomischen Prozesse ebenso ein wie entsprechende soziale Ausgleichsprozesse zwischen den in ihrer Leistungskraft immer weiter divergierenden Volkswirtschaften.“

Kranken viele Operationalisierungsansätze zur Bestimmung nachhaltiger Entwicklung an einer einschränkenden Reduktion auf „Umweltverträglichkeit““, so wird dieses Modell dem holistischen Anspruch der Nachhaltigkeitsidee durch gleichberechtigten Einbezug der ökonomischen und sozialen Dimensionen neben der ökologischen eher gerecht. 
Ein anderes Nachhaltigkeitsmodell, das dem von BECKER/JOB/WITZEL in seinen grundlegenden Aussage sehr nahe kommt, ist dasjenige von BIRKMANN/KOITKA /KREIBRICH/LIENENKAMP (1999, S. 16):

Ökologische Verträglichkeit:

- Erhaltung der Pufferkapazität der Biosphäre

- nachhaltige Nutzung der erneuerbaren Ressourcen

- minimale Nutzung nicht erneuerbarer Ressourcen

Soziale Verträglichkeit:

- gerechte Verteilung von Lebenschancen und materiellem Wohlstand zwischen Nord und Süd und zwischen den Generationen

Wirtschaftliche Verträglichkeit:

- Wachstum der Lebensqualität und Befriedigung materieller Grundbedürfnisse 
Das Modell von Wolfgang Hein (HEIN 1997, S. 371) veranschaulicht in seiner Visualisierung schwerpunktmäßig den systemischen Charakter von ,sustainability”:

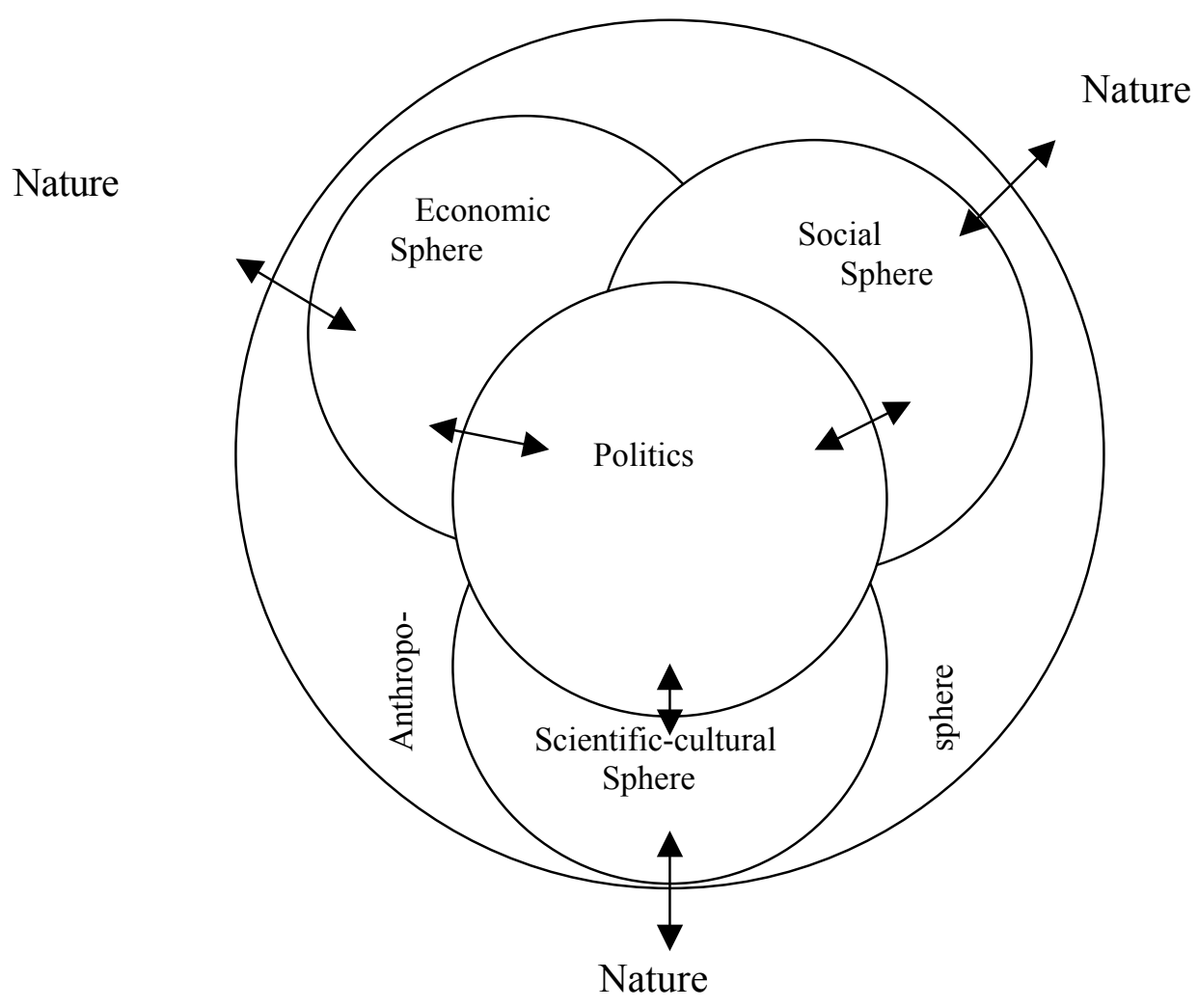

Abb. 2: Sustainable Development as a Process of Interaction between Nature and the Anthroposhere with its different Subsystems

Dieses Modell veranschaulicht den Prozesscharakter und die Wechselwirkungen von „Sustainablility“. Obwohl HEIN ein sehr umfassendes Modell entwickelt hat, ist es denkbar, dass die definitorische Diskussion sich noch weiter entwickeln kann, insbesondere, was die Steuerbarkeit angeht. HEIN selbst stellt dies als das zentrale Problem heraus:

„Influencing development processes of emergent complex systems is the basic problem of ,sustainable development'.“ (HEIN 1997, S. 370)

An dieser Stelle soll auf ein wesentliches Merkmal der Nachhaltigkeitsdebatte ${ }^{8}$ anhand einer Reaktion des Sudanesen Mohamed SULIMAN (1995) auf die Studie „Zukunftsfähiges Deutschland“ hingewiesen werden, nämlich auf die Schwierigkeit der politischen Durchsetzung:

\footnotetext{
${ }^{8} \mathrm{Zu}$ weiteren Definitionsversuchen der Nachhaltigkeit vgl. Anl. 2 im Anhang
} 
„How are you going to implement your project 'Sustainable Germany’? ... Without strong political muscles you cannot realise a sustainable Germany. “9

SULIMAN identifiziert hier ein zentrales, praktisches Problem, das - bei allem Fortschritt in der wissenschaftlichen Debatte - bleibt.

In diesem Zusammenhang ist es auch wichtig, auf die Akteure einer nachhaltigen Entwicklung hinzuweisen, die BIRKMANN/KOITKA/KREIBRICH/LIENENKAMP (1999, S. 85) wie folgt benennen:

- öffentliche Hand (Politik und Verwaltung)

- private Haushalte

- Wissenschaft

- Nichtregierungsorganisation

- Wirtschaft

Auf der Basis eines Leitbildes für eine nachhaltige Entwicklung können erste Ergebnisse nur auf lokaler, allenfalls regionaler Ebene erwartet werden. Erst eine langfristige „Politik der kleinen Schritte“ kann auch zu tief greifenden politischen Änderungen führen, wenn ,sustainability“ mehrheitsfähig wird.

PEARCE und WARFORD (1993) analysieren ausführlich eine Reihe von Faktoren, die sich der Umsetzung von Nachhaltigkeit in den Weg stellen: Bevölkerungswachstum,

Ressourcenknappheit, politische Fehlplanung, einseitige Weltmarktabhängigkeit, sozial ungleich gewichtete Verteilung von Landbesitz und starke Verarmung.

Zur konkreten Messung der Nachhaltigkeit wurde eine Vielzahl von Indikatorensystemen (vgl. Kap. 1.4.) entwickelt und zu deren Vermarktung eine inzwischen unübersichtliche Anzahl an Gütezeichen und -siegeln kreiert (vgl. hierzu ausführlich HAUSSMANN/MIES/SOLLNER und WACKER 1992).

${ }^{9}$ SULIMAN, Mohamed: „Sustainable Germany, a Blue-Print for Progress“. März 1995. 


\subsubsection{Tourismus im Kontext einer nachhaltigen Entwicklung}

Unter anderem historisch bedingt existieren diverse Definitionen zu einem Tourismus, der sowohl eine ökologische als auch eine soziale Verträglichkeit aufweist. Sanfter Tourismus, nachhaltiger bzw. zukunftsfähiger Tourismus meinen dasselbe und sollen daher in der Folge synonym benutzt werden.

Es existiert außerdem eine Reihe von parallelen Begriffen zu ,sanftem Tourismus“, wie „qualitativer Fremdenverkehr“, „,anderes Reisen“, ,angepasster Tourismus“, ,alternativer Tourismus“, „Ökotourismus“, „Tourismus mit Einsicht“, u.a. (KIRSTGES 1995, S. 12).

Einer der Ersten, der die Diskussion und Definition dazu in Gang gebracht hatte, war der Zukunftsforscher Robert JUNGK, der erstmals „hartes“ und „,sanftes“ Reisen anhand einer simplen Gegenüberstellung gegeneinander abgrenzte (vgl. JUNGK 1980, S. 155):

\begin{tabular}{|l|l|}
\hline Hartes Reisen & Sanftes Reisen \\
\hline Massentourismus & Einzel-, Familien- und Freundesreisen \\
\hline Weniger Zeit & Viel Zeit \\
\hline Schnelle Verkehrsmittel & $\begin{array}{l}\text { Angemessene (auch langsame) } \\
\text { Verkehrsmittel }\end{array}$ \\
\hline Festes Programm & Spontane Entscheidungen \\
\hline Außengelenkt & Innengelenkt \\
\hline Importierter Lebensstil & Landesüblicher Lebensstil \\
\hline „Sehenswürdigkeiten“ & Erlebnisse \\
\hline Bequem und passiv & Anstrengend und aktiv \\
\hline Wenige oder keine geistige Vorbereitung & $\begin{array}{l}\text { Vorhergehende Beschäftigung mit dem } \\
\text { Besuchsland }\end{array}$ \\
\hline Keine Fremdsprache & Sprachenlernen \\
\hline Überlegenheitsgefühl & Lernfreude \\
\hline Einkaufen („Shopping“) & Geschenke bringen \\
\hline Souvenirs & $\begin{array}{l}\text { Erinnerungen, Aufzeichnungen, neue } \\
\text { Erkenntnisse }\end{array}$ \\
\hline Knipsen und Ansichtskarten & Fotografieren, Zeichnen, Malen \\
\hline Neugier & Takt \\
\hline Laut & Leise \\
\hline
\end{tabular}

Tab. 1: Hartes und Sanftes Reisen

Auffallend ist bei JUNGKs Ansatz die fehlende Radikalität, die die Tourismusdiskussion gerade in der entwicklungspolitischen Szene lange Zeit in zwei mehr oder minder verfeindete Lager der Befürworter und Ablehner gespalten hatte. Natürlich ist sein Modell weit von eindeutig quantifizierbaren Indikatoren entfernt, stellt aber doch eine erste Annäherung an die Problematik 
dar und ist in diesen Grundzügen durchaus heute noch gültig. An seinem Konzept orientierte sich u. a. MÜLLENMEISTER (zitiert in STEINECKE 1992, S. 59 f.) und fordert insbesondere Kreativität der Akteure im Tourismus, um den Massentourismus zu bewältigen.

Hatte Jost KRIPPENDORF (vgl. KRIPPENDORF 1975, 1989 und 1996) als führender Tourismuskritiker der 70er und 80er Jahre schon auf die ökologischen Gefahren des Massentourismus hingewiesen und insbesondere ENZENSBERGER schon in den 60er Jahren auf die soziale Problematik aufmerksam gemacht (vgl. ENZENSBERGER 1964), so wurden umfassende Konzepte zu dem, was bis dahin meist etwas unscharf als ,sanfter Tourismus“ bezeichnet wurde, erst im Zuge der in den 90er Jahren verstärkt einsetzenden „sustainability“Debatte entwickelt.

Die erste international konsensfähige Definition, die den „Sanften Tourismus“ durch den „Nachhaltigen Tourismus“ ersetzte, fand die World Conference on Sustainable Tourism im April 1995:

Nachhaltiger Tourismus ist:

„langfristig ökologisch tragbar wirtschaftlich machbar sowie ethisch und sozial gerecht für die Einheimischen."

(s. OPASCHOWSKI 1998, S. 19)

Diese Definition ist auf Grund des internationalen Konsens zu minimalistisch, um hinreichend zu sein.

In diesem Zusammenhang sei darauf hingewiesen, dass es in der Realität keinen ,sanften Tourismus“, sondern immer nur einen ,sanfteren Tourismus“ geben kann, da Tourismus immer Umwelt und Sozialgefüge stört. Hinzu kommt der überwiegende „Massencharakter“ des Tourismus, dessen Eindämmung z. B. durch Kontingentierung oder gar Verbot des Reisens realitätsfern ist. HEIN (1997) bezeichnet Ökotourismus gar als die Quadratur des Kreises:

...,,the way in which 'ecotourism' is frequently presented could make us believe that this economic activity in fact succeeds in realizing what might appear to be squaring the circle: unspoilt nature appears as the basic commodity which is 'sold' to ecotourists, and tourism enterprises should have a very direct self-interest in making sure the attractiveness of the environment is not reduced by its touristic 'consumption'."

Diese Sichtweise führte auch zu dem extremen Slogan „tourism destroys tourism“ (BOO 1990 zitiert nach LEDBURY 1997). 
Die globalen, quantitativ weiterhin steigenden Reiseströme (vgl. Kap. 2) sind ein Faktum. Würden alle Reisenden ab sofort sanft reisen, führte dies zu einem „sanften Massentourismus“, einem Paradoxon. Daraus folgt, dass die Kriterien eines sanften Tourismus nur schritt- und teilweise umgesetzt werden können und letztendlich im besten Fall schadensbegrenzend sind (vgl. KIRSTGES 1992, S. 73 f.). 
Ein Modell der Zusammenhänge zwischen der Intensität der Nutzung und der Tragfähigkeit einer touristischen Ressource, sowie der Entwicklung des einzel- und gesamtwirtschaftlichen Nutzen entwickelte VORLAUFER (1996, S. 230):

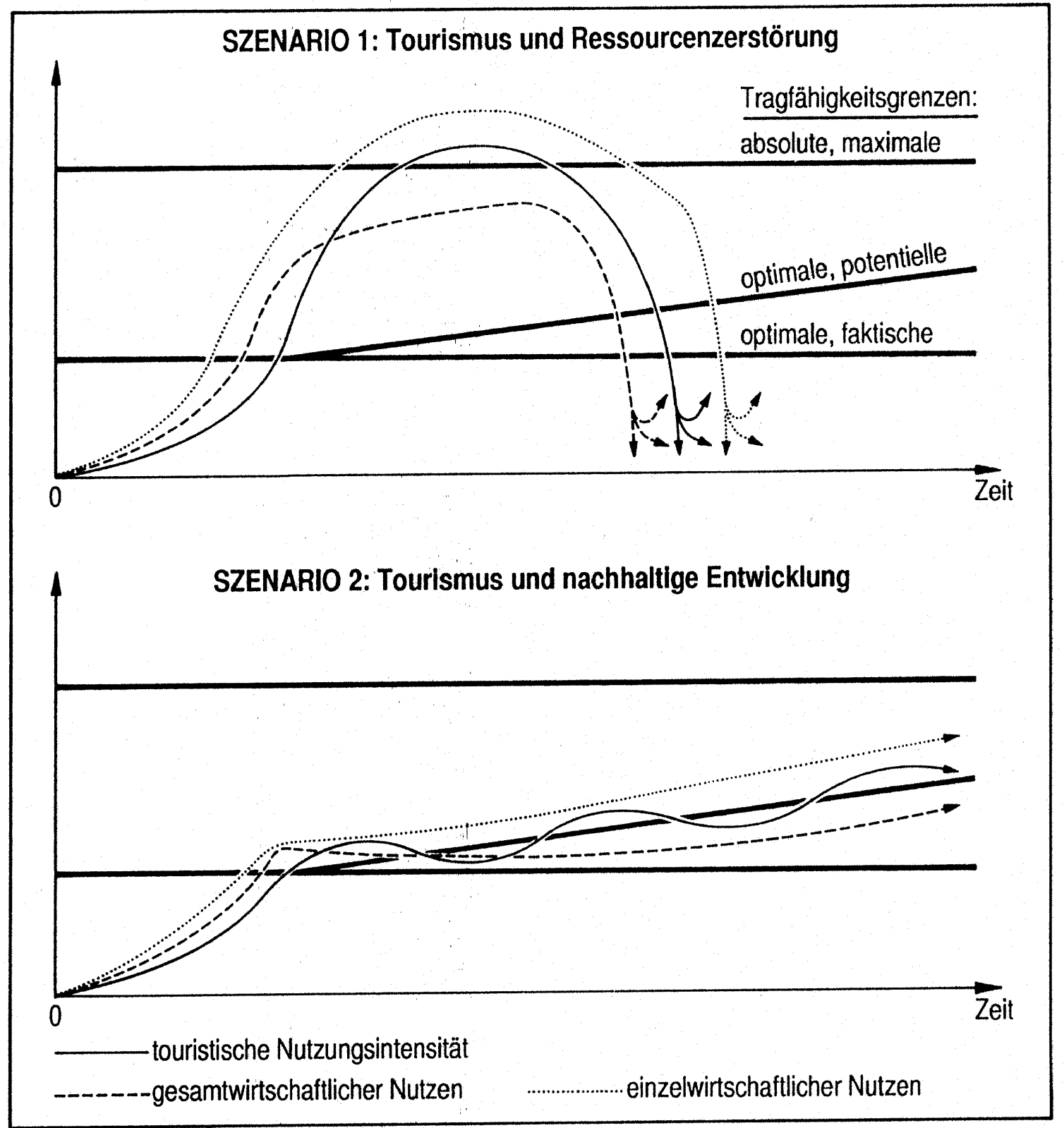

Abb.3: Das Modell der Zusammenhänge zwischen der Intensität der Nutzung und der Tragfähigkeit einer natürlichen touristischen Ressource und der Entwicklung einzel-und gesamtwirtschaftlichen Nutzens

Es zeigt die Bedeutung eines an nachhaltiger Entwicklung orientierten Tourismus im Hinblick auf die langfristige Tragfähigkeit eines Raumes.

KRIPPENDORF forderte schon in den 80ern in seinen „Elf Thesen“ einen bewussteren Umgang mit dem Tourismus von allen relevanten Akteuren und bezog außerdem im Rahmen eines 
„ganzheitlich-orientierten“ Tourismus neben der ökonomischen und ökologischen auch die soziokulturelle Betrachtung mit ein (vgl. KRIPPENDORF 1989, S. 18 ff.).

Einen wichtigen Beitrag zur Messbarkeit der Nachhaltigkeit liefern HOPFENBECK und ZIMMER (1993) mit ihren Analysen zur carrying capacity (Belastungsgrenzen). Sie benennen verschiedene Ansätze, die jeweils der Ermittlung konkreter Kennzahlen zur Bestimmung der Belastungsgrenze eines touristischen Zielgebietes dienen, so z. B. die Kapazitätsgrenzen nach BORG und COSTA (1992 angewandt auf Venedig, zitiert in HOPFENBECK/ZIMMER 1993, S. 272):

- eine physikalische Belastungsgrenze:

bei Überschreiten dieser Grenze werden die örtliche Umwelt und die örtlichen kulturellen Ressourcen geschädigt;

- eine ökonomische Belastungsgrenze:

bei Überschreiten sinkt die Qualität der Urlaubseindrücke dramatisch;

- eine soziale Belastungsgrenze:

die Anzahl an Besuchern, die eine Kunststadt aufnehmen kann, ohne dass dadurch die anderen sozialen und ökonomischen Funktionen dieser Stadt beeinträchtigt werden

HOPFENBECK/ZIMMER (1993, S. 270 ff.) zeigen außerdem, dass sich die einzelnen Freizeitaktivitäten unterschiedlich auf die Kapazität einer Region auswirken, das heißt einen unterschiedlichen ,impact“" auf das jeweilige Gebiet haben.

SCHLOEMER (1999) entwickelte einen praktikablen Ansatz zur Erfolgskontrolle von nachhaltigem Tourismus, der die Abschnitte Planung, Durchführung, Bedingungen und Zielerreichung einer Evaluation unterzieht. Es ergibt sich ein einfaches Raster der Wirkungskontrolle, das eine leichte Vergleichbarkeit erlaubt.

Die exakte Messbar- oder Berechenbarkeit der soziokulturellen Komponente bei einer Betrachtung von nachhaltigen Tourismusprojekten im indigenen Kontext hingegen dürfte sich als schwierig gestalten, bzw. kann wegen der Komplexität der Thematik als unmöglich gelten. 
Alle bisherigen Definitionsansätze eines ,,sanften Tourismus“ sind für die Problematik, die dieser Arbeit zu Grunde liegt, noch nicht ausreichend. Deswegen wird auf ein umfassenderes - den Aspekt der nachhaltigen Entwicklung beinhaltendes - Definitionsmodell von BECKER, JOB und WITZEL Bezug genommen (vgl. BECKER, JOB und WITZEL 1996, S. 134-138):

\section{Ökologische Dimension A}

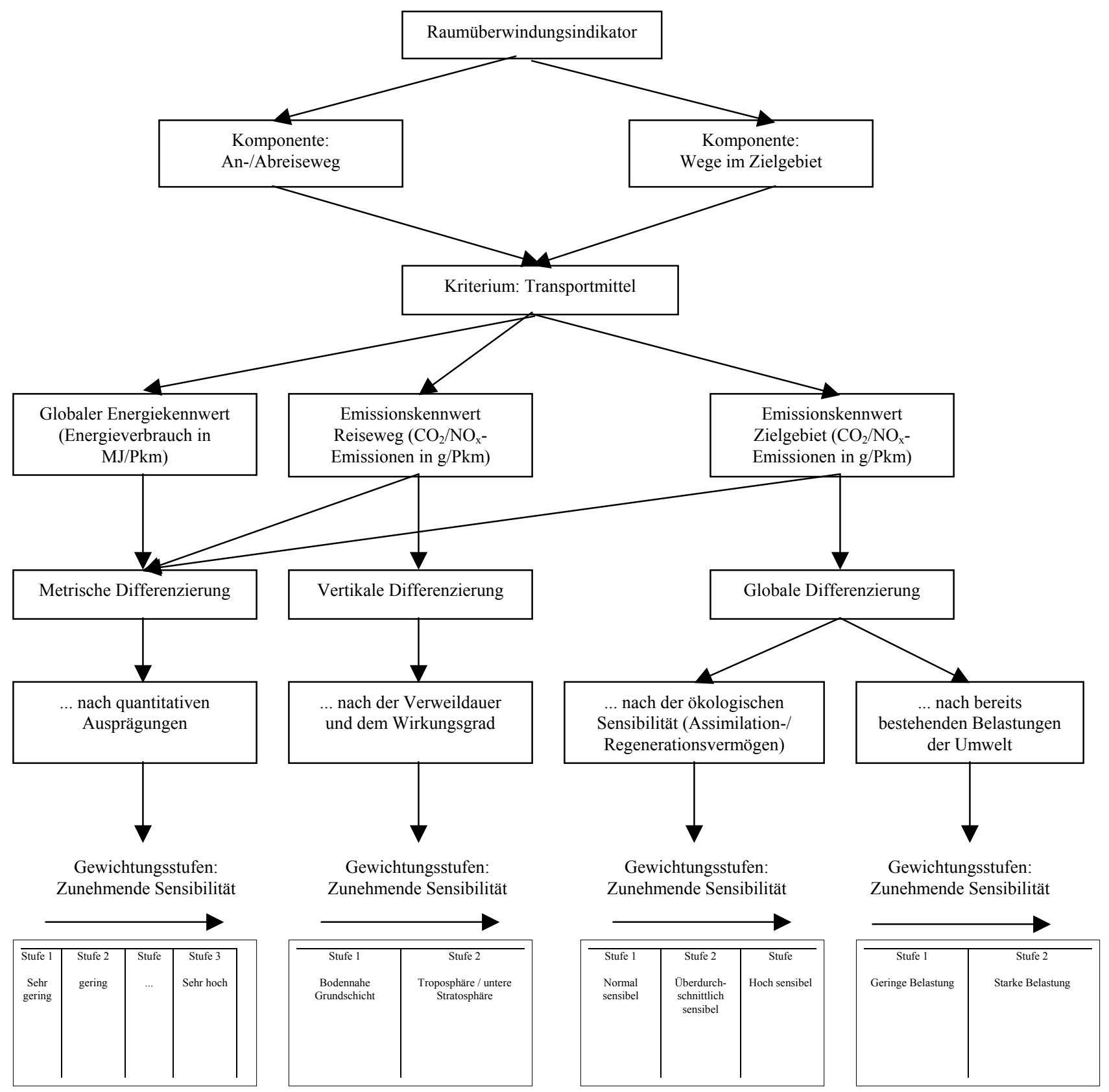




\section{Ökologische Dimension B}

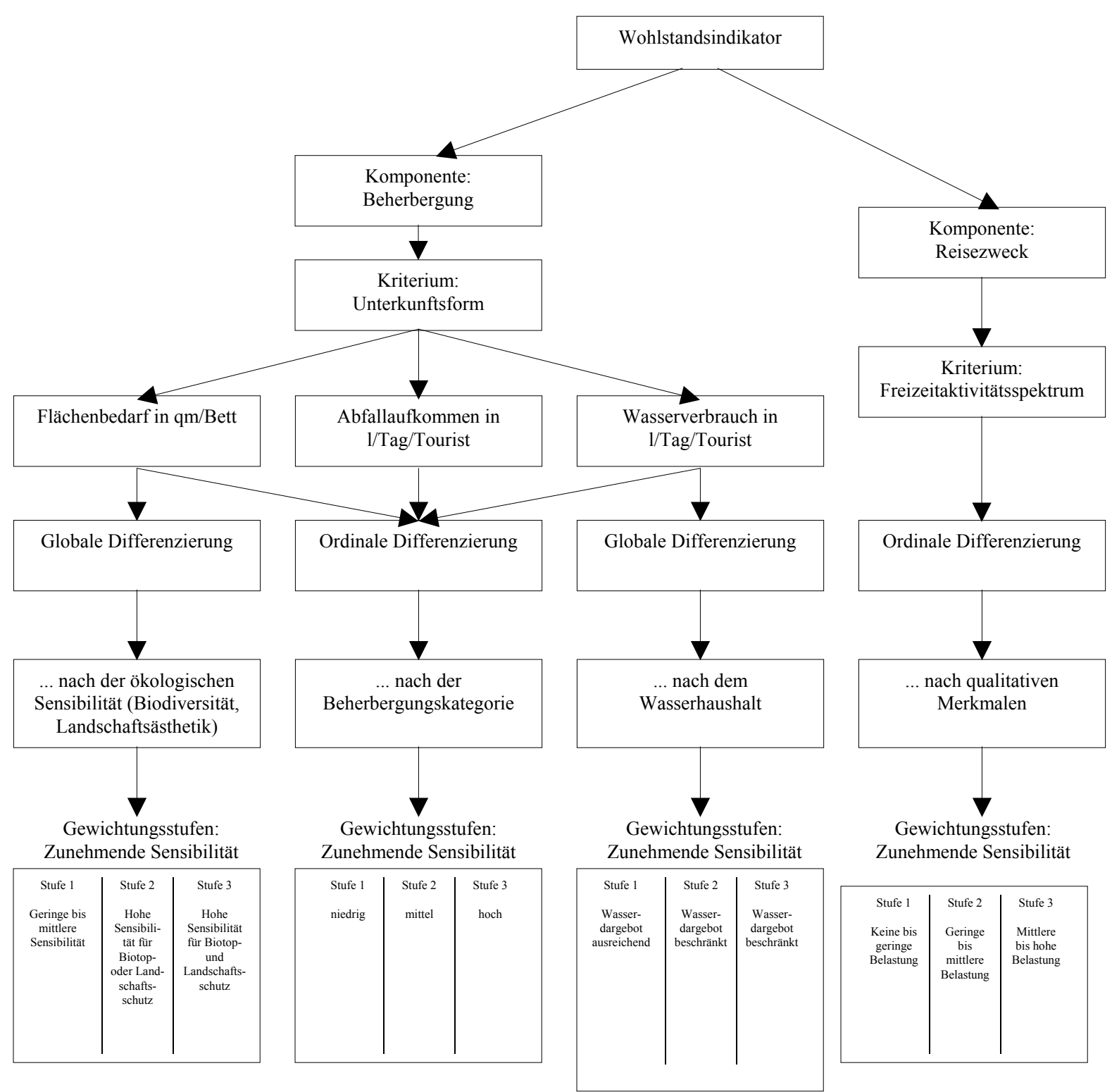

Abb. 4a: Schlüsselindikatoren einer touristischen Nachhaltigkeitsbilanz: Ökologische Dimension (Entwurf: Hömme, Job, Lambrecht 1995) 
Ökonomische Dimension A

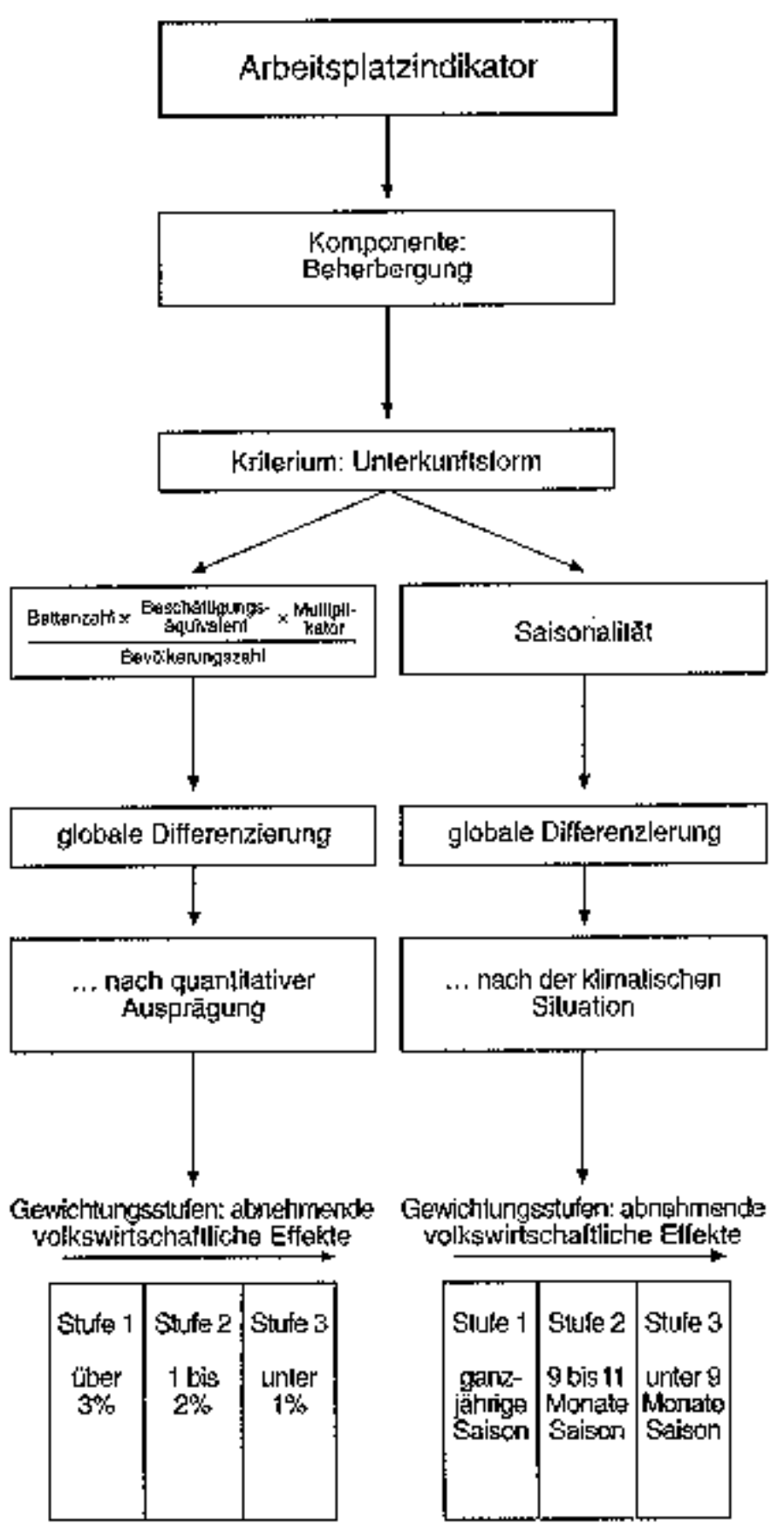




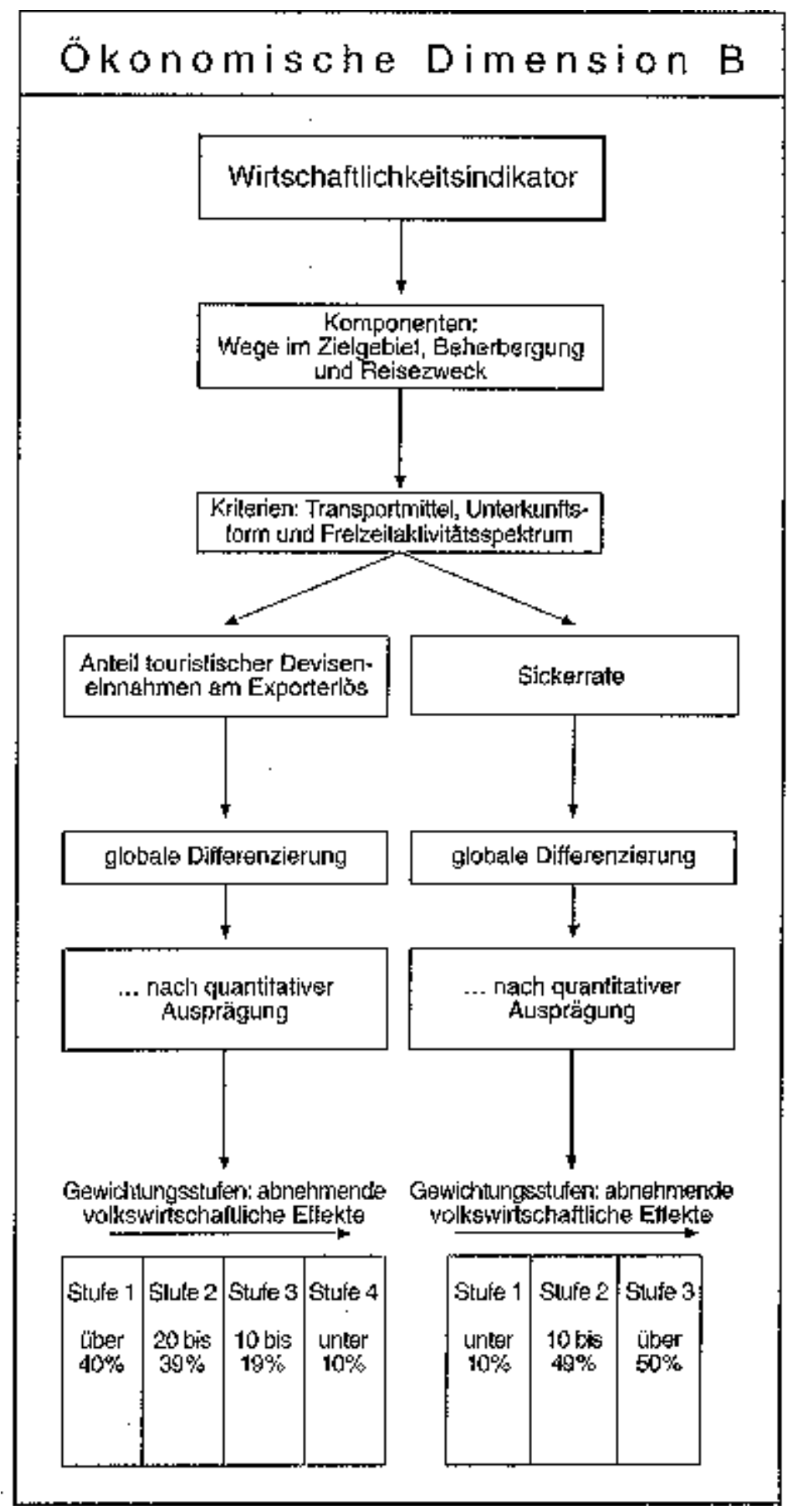

Abb. 4b: Schlüsselindikatoren einer touristischen Nachhaltigkeit: Ökonomische Dimension (Entwurf: Job, Lambrecht, Losang 1995) 


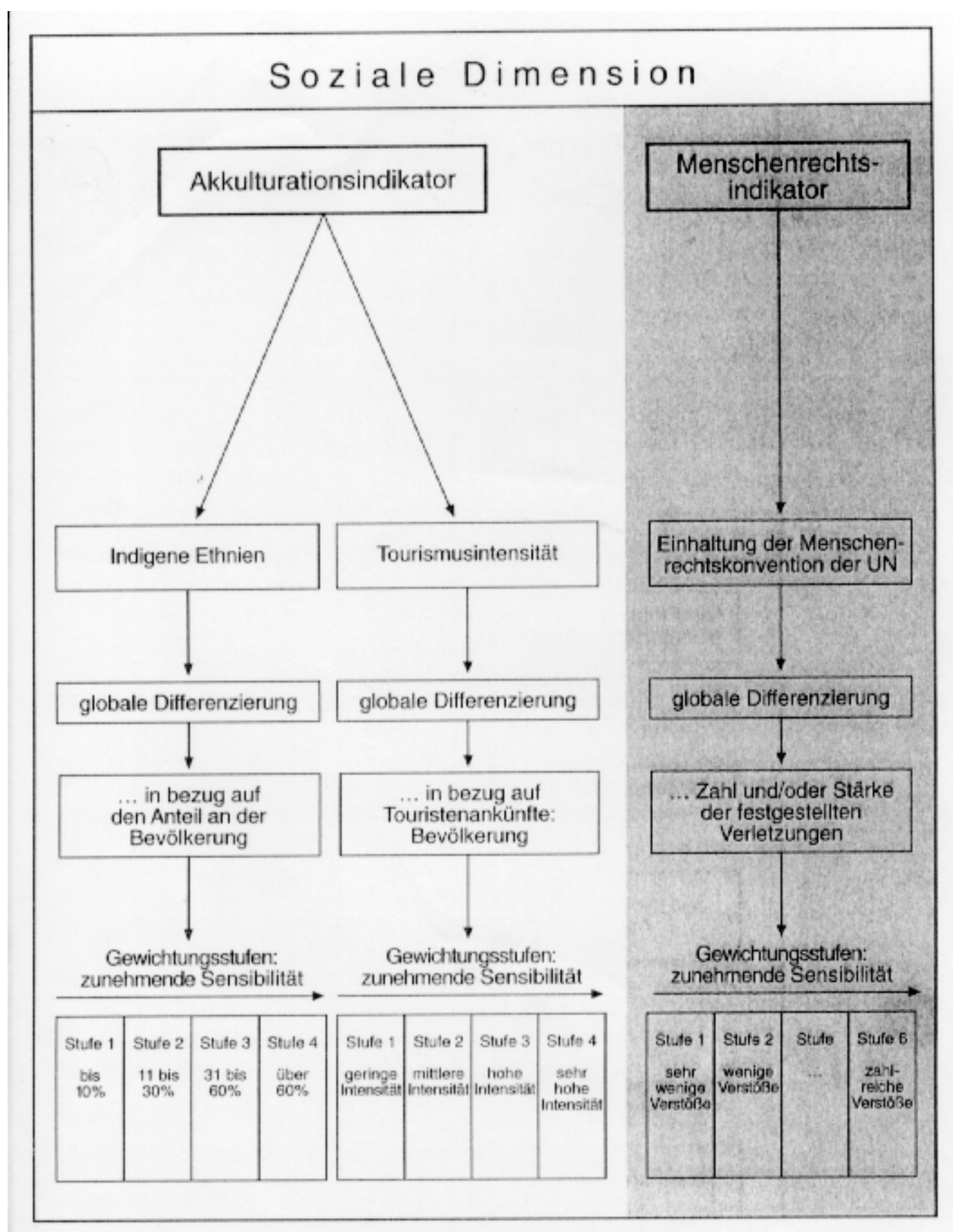

Abb. 4c: Schlüsselindikatoren einer touristischen Nachhaltigkeitsbilanz: Soziale Dimension (Entwurf: Job, Lambrecht, Losang 1995)

Das Modell von BECKER, JOB, WITZEL soll - neben dem gtz-Leitfaden „Tourismus in der Technischen Zusammenarbeit“ (vgl. Anl. 26 im Anhang) - in jeweils modifizierter Form in Kap. 6 auf das Fallbeispiel Französisch-Polynesien angewendet werden.

Gabriel TETIARAHI (Hiti Tau) und Hubert BREMOND (Betreiber eines „Ökocampingplatzes“) sehen die Nachhaltigkeit unter ähnlichen Aspekten, wie von OPASCHOWSKI benannt (s.o.) ${ }^{10}$

\footnotetext{
${ }^{10}$ Interview mit Hubert Bremond, 1999/Interview mit Gabriel Tetiarahi 1999
} 
Als Teilbereiche des nachhaltigen Tourismus können die beiden Sonderformen „Ökotourismus“ und „Ethnotourismus“ verstanden werden:

„Ökotourismus [wird definiert als] eine Form verantwortungsbewussten Reisens in naturnahe Gebiete, die negative Umweltauswirkungen und soziokulturelle Veränderungen zu minimieren sucht, zur Finanzierung von Schutzgebieten beiträgt und Einkommensmöglichkeiten für die lokale Bevölkerung schafft." (s.

ARBEITSGRUPPE ÖKOTOURISMUS 1995, zitiert nach NIEKISCH 1997, S. 15)

„Unter Ethnotourismus versteht man jede spezielle Form der freizeitbezogenen Ortsveränderung über einen begrenzten Zeitraum hinweg, deren Ziel der Aufenthalt bei einer fremden ethnischen Gruppe, speziell einer politisch und ökonomisch marginalen - oft tribalen - Gruppe ist. Ethnotourismus beschreibt also den Teil des Tourismus, der zielgerichtet die Reise zu ,fremden, ursprünglichen Kulturen’ im klassischen völkerkundlichen Verständnis propagiert.“(s. KIEVELITZ 1989, S. 29)

Ökotourismus unterscheidet sich von nachhaltigem Tourismus durch die ausschließliche Konzentration auf naturnahe Zielgebiete, während Ethnotourismus einer Ethnie als Bereiste bedarf. Beide Formen können - müssen aber nicht notwendigerweise - spezielle Varianten eines nachhaltigen Tourismus sein.

\subsubsection{Kultur}

Die Bezeichnung Kultur stammt von „cultura“ (lat.: Anbau, Pflege, Ausbildung, Verehrung):

„The word culture, in turn, goes back to classical or perhaps pre-classical Latin with the meaning of cultivation or nurture, as it still persists in terms like agriculture, horticulture, cult, cultus, and in recent formations like bee culture, oyster culture, pearl culture, bacillus cultures.“ (s. KROEBER/KLUCKHOHN 1952, S. 283)

Erst im 17. und 18. Jahrhundert wurde „Kultur“ mit Begriffen wie „Entwicklung“ und „Fortschritt“ in Verbindung gebracht. (vgl. SEITHEL 2000, S. 44 f.) Heute wird der Begriff insbesondere in Abgrenzung zu biologischen Vorgaben als derjenige Teil des menschlichen Lebens begriffen, der vom Menschen frei gestaltet werden kann. Eine andere Auffassung von Kultur zielt auf intellektuelle Reflexion des gesellschaftlichen Geschehens (Kunst, Theater, Literatur), aber auch ,Szene-Kultur“.

Sämtliche Konzeptbeschreibungen von Kultur müssen den Gesichtspunkt der kulturellen Hermeneutik im Blick behalten (s.o.). Die Problematik, sich dem Konzept der Kultur zu nähern äußert sich nicht zuletzt in über 150 verschiedenen Definitionen von Kultur (vgl. KROEBER/KLUCKHOHN 1952). Nach wie vor setzen sich Wissenschaftler verschiedener Disziplinen (u. a. Ethnologie, Soziologie und Psychologie) mit der Diskussion um diesen Begriff 
auseinander. KROEBER und KLUCKHOHN 1952 gaben einen der besten Überblicke von den Anfängen des Begriffs Kultur bis in die 50er Jahre. Sie arbeiteten intensiv zur Entstehungsgeschichte des Begriffs und brachten ihn selbst immer wieder mit „Mustern“ und „Strukturen“ in Verbindung, was auf eine deterministische Interpretation hinweist.

Kultur wird oft auch über seine Oppositionen näher eingegrenzt: Kultur - Natur, Kultur Zivilisation, Kultur - Gesellschaft (vgl. BRUMLIK 1990, S. 185).

POSNER (1986, S. 240 ff.) liefert ebenfalls einen Abriss der Entstehungsgeschichte des Begriffs: Schon CICERO bezeichnete die Philosophie als die „Kultivierung des Geistes“ (in Anlehnung an den Ackerbau): „Cultura animi philosophia est““. Dieses Bild griff HERDER Ende des 18. Jahrhunderts wieder auf in seinen „Ideen zur Philosophie der Geschichte der Menschheit"; es wurde in dieser Form ein grundlegendes Konzept für sämtliche Teilwissenschaften, die sich mit „Kultur“ beschäftigten. Analog zur Aufsplittung der Anthropologie in spezielle Teilbereiche variierte in der Folge auch der Kulturbegriff. ${ }^{11}$

MÜHLBERG (1983, S. 215) untersucht die Geschichte des Begriffs „Kultur“ in der Tradition der marxistisch-leninistischen Weltanschauung:

...,,bezeichnet der Kulturbegriff das Wechselverhältnis zwischen Gesellschaftsfortschritt und Entwicklung der Individuen vom Abschluss der Anthropogenese bis in die Gegenwart. In ihm ist zusammengefasst, dass die Weltgeschichte sich in verschiedene Stufen des Wechselverhältnisses von Gesellschaft und Individuen gliedert.“

GROH (1997, S. 21 ff.) gibt einen detaillierten Überblick über die andauernde Auseinandersetzung mit dem Begriff:

ASSMANN (1992) z. B. liefert einen informationstheoretischen Ansatz, das „,kulturelle Gedächtnis“. Kollektives Wissen würde verloren gehen, wenn es nicht in Form von „extrakorporal gespeicherten Informationen“ erhalten bliebe. Hiermit ist nichts anderes gemeint als Bauwerke, Literatur (auch mündlich tradierte), Dokumentationen, Artefakte etc... Über diese Symbole lassen sich Kulturen definieren. Die Semiotik ${ }^{12}$ betrachtet die kulturelle Interaktion insbesondere als einen Austausch von Zeichen. Kultur ist demnach im wesentlichen ein Akt der Kommunikation (vgl. ECO 1972, BARTHES 1985 und POSNER 1989).

\footnotetext{
${ }^{11}$ POSNER (1989, S. 251) benennt detailliert die einzelnen Vertreter der symbolic, semantic, semiotic und cultural anthropology
} 
POSNER (1991, S. 39) definiert Kultur im Sinne der Semiotik:

„Kulturen sind Zeichensysteme; sie erfordern von den Lebewesen die Fähigkeit zum Vollzug von Zeichenprozessen spezieller Art und bringen ihnen den Vorteil, dass sie bei der Bewältigung ihrer Lebensprobleme zusätzlich zu der durch den genetischen Kode vererbten Information auf die Lebenserfahrung ihrer unmittelbaren Vorfahren und Zeitgenossen zurückgreifen können.“

Auch Konzepte aus der Mathematik wurden übernommen, um sich dem Kulturbegriff zu nähern: BAUDRILLARD (1986) wandte die fraktale Geometrie auf gesellschaftliche Prozesse an. Einige theoretische Ansätze der Psychologie (FREUD 1913 und ELIAS 1969) würdigten „wilde“, „primitive“ Kulturen herab und betrachteten sie als tiebgesteuert und minderwertig oder krank (neurotisch), sahen sie als Gegensatz zur Zivilisation.

GROH selbst hält „Kultur“ für nicht wirklich fassbar:

„Der Kulturbegriff entzieht sich der Definierbarkeit im herkömmlichen wissenschaftlichen Sinne. Will man dennoch über Kultur reden oder schreiben, so muss eine gewisse Unschärfe in Kauf genommen werden." (s. GROH 1997, S. 94)

Er begründet dies mit dem Phänomen, das in Kap. 1.3.1 als „kulturelle Hermeneutik“ beschrieben wurde:

„Die Behandlung von Kultur im wissenschaftlichen Rahmen ist - verständlicherweise - geprägt von der Sichtweise derer, die diese Behandlung vornehmen. Diese Fokussierung ist insofern, eurozentrisch', als die etablierte Wissenschaft eindeutig europäischen Ursprungs ist.“(s. GROH 1997, S. 95)

Auf die Schwierigkeit, sich mit dem Kulturbegriff auseinander zu setzen, weist auch GEERTZ (1997, S. 53 f.) hin:

„Wie die meisten einflussreichen Ideen in den Humanwissenschaften wurde diese Vorstellung [von Kultur] praktisch in demselben Augenblick attackiert, indem sie artikuliert wurde; je klarer die Artikulierung, desto intensiver die Attacke. Schon allein auf die Vorstellung von einem kulturellen Schema hagelte es Fragen, und sie hageln immer noch. Es gab Fragen im Hinblick auf die Kohärenz von Lebensweisen und das Ausmaß, in dem sie zusammenhängende Ganzheiten bildeten. [...] Es gab Fragen nach Kontinuität und Wandel, nach Objektivität und Beweis, Determinismus und Relativismus, Einzigartigkeit und Verallgemeinerung, Beschreibung und Erklärung, Konsens und Konflikt, Andersheit und Vergleichbarkeit - und im Hinblick auf die schiere Möglichkeit, dass jemand, ob von innen oder von außen, etwas so Gewaltiges wie eine ganze Lebensweise erfasst und die Worte ihrer Beschreibung findet.“

Auch POSNER (1991, S. 37) kommt zu einem ähnlichen Urteil:

\footnotetext{
${ }^{12}$ Semiotik bedeutet: „Allgemeine Theorie bzw. Lehre von den sprachlichen und nichtsprachlichen Zeichensystemen, innerhalb deren natürliche Sprachen nur ein Zeichensystem unter anderen (wissenschaftlichen, religiösen u. a.) darstellen.“ (s. BUSSMANN 1983, S. 460).
} 
„Auch den Wissenschaftlern, die Kultur zu begreifen versuchen, zerrinnt diese leicht zwischen den Fingern. Was sie in der Hand behalten, sind theoretische Konstrukte, die jeweils nur Teilaspekten von Kultur gerecht werden können. [...] Sie führen zu ganz unterschiedlichen Gegenstandskonstruktionen, Methoden und Theoriebildungen, die weitgehend unverbunden nebeneinander betrieben werden.“

POSNER (ebenda, S. 37 f.) teilt einzelne Teilbereiche der Kultur einzelnen wissenschaftlichen Disziplinen zu: die Gesellschaft den Sozialwissenschaften, insbesondere der Soziologie; die Zivilisation den Geisteswissenschaften, insbesondere Ethnologie, Kunst- und Literaturwissenschaft und die Mentalität der Linguistik.

Der Versuch, das Konzept Kultur zu erfassen, ist dennoch ungebrochen. Eine sehr kondensierte Definition beschreibt Kultur als „alles Materielle und Nichtmaterielle, was im menschlichen Dasein nicht von Natur aus vorgegeben ist, sondern
von Menschen durch ,Innovationen’ zielgerichtet hinzugefügt wurde. Die Definition von Kultur ist
dementsprechend: ,Gesamtheit der Ergebnisse von Innovationen'“. (s. RUDOLPH 1988, S. 43)

LINTON (1974, S. 33) setzte sich ausführlich mit dem Begriff Kultur als zentralem Konzept in Psychologie, Soziologie und Anthropologie ausführlich auseinander und kam zu folgender Definition:

„Eine Kultur ist das Gesamtgebilde aus erlerntem Verhalten und Verhaltensresultaten, dessen einzelne Elemente von den Mitgliedern einer bestimmten Gesellschaft geteilt und weitergegeben werden.“

Außerdem stellt LINTON (1974, S. 12) den Zusammenhang her zwischen Kultur, Gesellschaft und Individuum:

„Obwohl ein einzelnes Individuum für den Fortbestand und die Funktionsfähigkeit der Gesellschaft, zu der es gehört, oder der Kultur, an der es teilhat, selten von großer Bedeutung ist, bildet doch das Individuum mit seinen Bedürfnissen und Möglichkeiten die Grundlage aller sozialen und kulturellen Erscheinungen. Gesellschaften sind organisierte Gruppen von Individuen, und Kulturen sind letzten Endes nichts anderes als die organisierten, sich wiederholenden Reaktionen der Mitglieder einer Gesellschaft. Aus diesem Grunde ist das Individuum der logische Ausgangspunkt für jede Untersuchung des Gesamtgebildes.“

Kultur ist also ein kollektiv verbindliches - wenn auch nicht starres - Normensystem, das individuenübergreifend gesellschaftliche Werte- und Handlungsmuster prägt, eben die „Gesamtheit ideeller und materieller Lebensäußerungen“(s. BRAUN/RÖSEL 1992, S. 250). Mensch, Gesellschaft und Welt werden darüber definiert. Kultur übermittelt somit Wissen, aber auch Handlungsmuster, die durch ihren normativen Charakter Stabilität und Orientierung (auch 
im psychologischen Sinne) für Gruppe und Individuum ${ }^{13}$ liefern. Identität und Authentizität werden garantiert durch den Fortbestand tradierter kultureller Elemente, die zwar - je nach Art der Kultur in unterschiedlichem Maße - Beeinflussungen von außerhalb verarbeiten können, deren massive Überformung aber zu gesellschaftlicher Orientierungslosigkeit oder Desintegration führen kann:

„Die Kultur als Ganzes liefert den Mitgliedern aller Gesellschaften einen unerläßlichen Leitfaden für alle Lebenslagen. [...] Die Tatsache, dass die meisten Mitglieder der Gesellschaft auf eine gegebene Situation in einer gegebenen Art und Weise reagieren, ermöglicht es jedem, das Verhalten der anderen mit einem hohem Grad von Wahrscheinlichkeit, wenn auch nicht mit absoluter Sicherheit, vorauszusagen. Diese Vorhersagbarkeit ist Voraussetzung für jede Art organisierten sozialen Lebens. [...] In jeder Gesellschaft ist das Leben gemäß den örtlichen Kulturmustern organisiert und lässt wenige Möglichkeiten offen, von ihnen abzuweichen. [‥] Das Vorhandensein kultureller Muster ist nicht nur für das Funktionieren jeder Gesellschaft notwendig, sondern gleichermaßen auch für ihr Weiterbestehen.“(s. LINTON 1974, S. 23 f.)

Gabriel Tetiarahi betrachtet Kultur als die Möglichkeit „, anders zu sein“, sich zu unterscheiden und andere Werte und eine andere Lebensweise zu realisieren ${ }^{14}$.

\subsubsection{Kulturwandel}

Kultureller Wandel ist der Überbegriff für jegliche Art kultureller Transformation, sei sie nun akkulturativer Natur oder nur ein Austausch von Kulturelementen ${ }^{15}$ und in allen Kulturen jederzeit existent:

„Kultureller Wandel findet in jeder Kultur statt. Er ist eine Form der Anpassung des Menschen an veränderte Lebensumstände, z. B. der Umwelt oder speziell der Natur“"(s. SAFAI-GRODD 1987, S.167).

Die obige Definition vernachlässigt ein wichtiges Moment des Kulturwandels, nämlich die freie Entscheidungsfähigkeit des Menschen. Somit ist kultureller Wandel immer eine Veränderung auf Grund exogener Faktoren und endogener Kräfte.

Das Phänomen des Kulturwandels wird in verschiedensten wissenschaftlichen Disziplinen (Ethnologie, Soziologie, Psychologie, Geschichtswissenschaften) untersucht, deren Ansätze von

\footnotetext{
${ }^{13}$ Zur besonderen Bedeutung von Kultur für die Bildung der Persönlichkeit vgl. auch LINTON 1974, S. 71 ff.

${ }^{14}$ Interview mit Gabriel Tetiarahi, 1999

${ }^{15}$ Kulturaustausch meint hier z. B. die selektive Übernahme von Elementen einer fremden Kultur ohne Zwang, dass heißt im Gegensatz zur Akkulturation ist keine Dominanz derjenigen Kultur vorhanden, aus der Elemente übernommen werden. Als Beispiele können Trends insbesondere aus Musik (kubanischer Son), Mode (,Ethnostil“) oder Tanz (Tango-/Salsawelle) gelten.
} 
reinen Abfolgen des kulturellen Wandels über differenzierte Erklärungsmuster bis hin zu komplexen Theoriegebäuden reichen.

Theorien zum Kulturwandel lassen sich bis in die Antike zurückverfolgen (z. B. HESIOD, LUKREZ). Sie hatten meist einen zyklischen Ansatz und entstanden im Zusammenhang mit der Geschichtsschreibung. Akkulturation ${ }^{16}$ ist eine mögliche Form des Kulturwandels, der insbesondere bei dem Kontakt außereuropäischer und europäischer Kulturen genannt wird. Der Begriff stand zunächst eher mit den Sozialwissenschaften (REDFIELD, LINTON, HERSKOVITS) in Beziehung, bevor er ein grundlegendes Konzept der Ethnologie wurde (vgl. FISCHER 1988), vgl. auch die Kapitel 5.2 und 6.3.

THURNWALD (1966, zitiert nach SAFAI-GRODD 1987, S. 168) benannte für den Kulturwandel die folgenden Faktoren als ausschlaggebend:

- die Einstellung und Beziehung zwischen ,gebendem“ und „nehmendem“ Volk.

- Aufbau und Tradition des „empfangenden“ Volkes

- Die Umstände, unter denen eine solche Übertragung stattfindet

GROH (1997, S. 99 ff.) betrachtet Kulturwandel als einen Synthesevorgang: Bei zwei äquivalenten Kulturelementen setzt sich das effektivere durch, das heißt bestehen zum Beispiel zwei alternative Handlungsmuster, wird das „,brauchbarere“ (oft dasjenige der dominanten Kultur im Kulturkontakt) gewählt.

Neuerdings ist eine Renaissance der neodarwinistischen Evolutionstheorie als

Erklärungsmodell des kulturellen Wandels zu beobachten. Dies ist nicht unumstritten:

„Die Frage nach den Ursachen kultureller Vielfalt ist immer noch nicht zufrieden stellend beantwortet worden. Gegenwärtig greift man verstärkt auf die neodarwinistische Evolutionstheorie zurück, um diesem Mangel abzuhelfen. Indessen wird einer solchen Anlehnung der Sozialwissenschaften an den Darwinismus und die biologische Evolutionstheorie oft der Vorwurf gemacht, den Wandel von Kultur mit einem einzigen Prinzip erklären zu wollen, nämlich mit dem ,Überleben des Geeignetsten'. Darwinistische Theorien zeichneten so ein Bild der Kulturgeschichte, welches sich von der Eurozentrik bisheriger sozialwissenschaftlicher Evolutionstheorien nur unwesentlich unterscheidet.“(s. BIERSTEDT 1997, S. 11)

${ }^{16}$ „Semantisch beinhaltet das Wort Akkulturation eine reziproke Relation zwischen zwei Kulturen. Der Begriff an sich ist wertfrei (wie übrigens auch der Begriff Kulturwandel als solcher). Er hat aber eine Bedeutungseinschränkung erfahren, weil in vielen Fällen die Einflussnahme einseitig ist. Die daraus resultierende Assimilation kann zum Auslöschen der einen betroffenen Kultur führen; andererseits besteht aber auch die Möglichkeit, dass andere Faktoren ins Spiel kommen, die den Anpassungstendenzen bzw. dem Anpassungsdruck entgegenwirken und zu Eigenständigkeit beitragen“" (s. RAMASWAMY 1985, S. 40). Zu weiteren Diskussionen zum Begriff „Akkulturation“ vgl. ausführlich Kap. 6.3). 
Kulturwandel im evolutionstheoretischen Sinne ist verursacht durch eine Änderung der Häufigkeitsverteilung kultureller Merkmale in einer gegebenen Gesellschaft. Innovationen verändern den jeweiligen Kulturpool. Die Entscheidung für oder gegen die Neuerung wird (in Anlehnung an DARWIN) als Auslese bezeichnet. Die Theorie mag allerdings weder die relative Stärke einiger kultureller Elemente gegenüber anderen hinreichend erklären, noch erlaubt sie trotz ihrer klaren Logik - eine Vorhersage des kulturellen Wandel (vgl. BIERSTEDT 1997, S. 12 f.). Dieser Ansatz ist der Versuch, naturwissenschaftliche Regelmäßigkeiten auf sozialwissenschaftliche Prozesse zu übertragen, und zog sich den Vorwurf des biologischen Determinismus zu.

Frühe Vertreter eines zielgerichteten kulturellen Wandels orientiert an DARWIN waren SPENCER 1899, MOGAN 1877 und ENGELS 1948 (klassische Evolutionisten). Neuere Interpretationen dieser Theorie finden sich bei WHITE 1943, STEWARD 1949, SAHLINS und SERVICE 1960 (Neo-Evolutionisten), sowie bei FLANNERY und MARCUS 1983, MAIOSELS 1987, JOHNSON und EARLE 1987, und RAMBO 1991), die als Ziel des kulturellen Wandels eine Steigerung der gesellschaftlichen Komplexität angaben. Dem gegenüber stand die anti-evolutionistische Ethnologie, die auf einer Trennung von Geschichte und Evolution bestand und kulturellen Wandel als rein geisteswissenschaftliches Phänomen erklärt haben wollte. Die Kultur der Fremden sollte nicht erklärt, sondern verstanden werden. Vertreter dieser Richtung sind insbesondere ANKERMANN, SCHMIDT, GRAEBNER RICKERT, WINDELBAND, DILTHEY (vorletztes Jh.), sowie GIRTLER 1985, CLIFFORD 1988, STELLRECHT 1993 und STAGL 1981 (vgl. BIERSTEDT 1997, S. 24 ff.).

Auch bei TEILHARD DE CHARDIN findet sich die These, Kultur lediglich als Fortsetzung biologischer Prozesse zu sehen:

„Wenn man [...] die Kultur (nicht als fertiger Zustand gesellschaftlicher Gliederung verstanden, sondern als Prozess, der eben diese Gliederung bewirkt) zurückführt auf ihre biologischen Ursprünge, dann erkennt man, daß sie im Grunde nichts anderes ist als eine zoologische Sonderentwicklung.“ (zitiert nach. SCHIWY 1989, S. 469)

ANTWEILER (1988, S. 4 f.) trug zur Systematisierung von Begriffen bei, die jeweils eine spezielle Richtung oder Theorie des Kulturwandels beinhalteten. Die evolutionistischen bzw. neo- oder postdarwinistischen Richtungen (s. o) werden klassifiziert in: 
- Populationsbiologie (z. B. CAVALLI-SFORZA \& FELDMANN 1981, TERRELL 1981)

- Evolutionsökologie (z. B. DYSON-HUDSON \& LITTLE 1981, ELLEN 1982)

- Katastrophentheorie (z. B. FRIEDMANN 1982, RENFREW 1978)

- Selbstorganisation (z. B. ADAMS 1975, BÜHL 1987, VALJAVEC 1983)

- Makroevolution (z. B. DIENER 1980, NONINI 1985)

- Sozialpsychologische Lerntheorie (z. B. CLOAK 1975, PRINGLE 1951)

- Koevolution (z. B. BAJEMA 1973, DURHAM 1982)

Diese Ansätze können mit kulturmaterialistischen (z. B. HARRIS 1979, PRICE 1977) und strukturell-marxistischen Theorien (z. B. CLAESSEN et al. 1985) laut ANTWEILER als evolutionistisch zusammengefasst werden, dass heißt sie beziehen sich mehr oder weniger direkt auf Grundideen DARWINs oder übernehmen das biologische Modell der Evolution als Analogie.

ANTWEILER selbst (1988, S. 246 ff.) wendet sich insbesondere dem Begriff der kulturellen Selektion als Erklärungsmodell für kulturellen Wandel zu:

„Kulturelle Selektion ist danach die differentielle, transgenerationale Weitergabe kultureller Merkmale in Gesellschaften, unabhängig von den - sehr verschiedenen - zu Grunde liegenden Faktoren. Somit ist es möglich, die gesamte Breite der sozialen, psychischen und tw. biotischen Faktoren, die dabei eine Rolle spielen, $\mathrm{zu}$ würdigen, was besonders in generationsübergreifender Perspektive von Bedeutung ist.“

Wichtig für ANTWEILER ist hierbei auch das Prinzip der kulturellen Variation, das die Selektion erst ermöglicht (analog zu Mutation/Evolution in der Biologie).

In Zusammenhang mit Projekten der Entwicklungszusammenarbeit spricht man auch vom „gelenkten Kulturwandel“: In der Annahme, durch ein entsprechendes Projekt die Lebenssituation der Menschen zu verbessern, wird kultureller Wandel entweder in Kauf genommen oder in die gewünschte Richtung ,gelenkt“ (vgl. SAFAI-GRODD 1987, S. 163).

ERDHEIM (1988, zitiert in GROH 1997, S. 140 ff.) klassifiziert in Anlehnung an LÉVISTRAUSS Kulturen in „kalt“" und „heiß“. Kultureller Wandel vollzieht sich demnach durch ständiges ,aufheizen“, dass heißt durch Synthese mit anderen Kulturen nimmt die Elaboriertheit ständig zu. Die Anlehnung an die Wärmelehre kommt nicht von ungefähr, auch GROH (1997, S. 147 ff.) zieht Parallelen zwischen Kulturwandel und Entropie ${ }^{17}$.

\footnotetext{
${ }^{17}$ Der Entropie-Effekt besagt, dass in thermodynamischen Systemen Prozesse irreversibel ablaufen. Die Prozesse bewegen sich dabei auf einen Zustand immer größerer „Unordnung“ zu, deren Maßeinheit die Entropie ist.
} 
Die am intensivsten in der Wissenschaft (Soziologie, Ethnologie, Psychologie) diskutierte Form

des Kulturwandels ist die Akkulturation (s. o.). Sämtliche Formen von Akkulturationsverläufen

können in einer Gesellschaft - meist unter Dominanz des einen oder anderen - gleichzeitig

stattfinden (vgl. BRAUN/RÖSEL 1992, S. 256 f.). Wichtig ist in diesem Zusammenhang ist, dass

eine Kultur immer eine gewisse Elastizität hat:

„Kulturen haben sehr wohl die Kraft, Fremdes zu assimilieren, in ihre eigene Lebensform zu integrieren oder in Neues zu ,übersetzen'. Mehr noch: Sie haben dies immer getan. Die Vision ,authentischer' Kulturen, die sich unberührt von der Außenwelt aus ihren historischen Wurzeln speisen, ist eine romantische Fiktion, ebenso der Mythos der ,Naturvölker' oder der ,primitiven' afrikanischen Kunst“ (s. BREIDENBACH/ZUKRIGL 1998).

In diesem Sinne argumentiert auch BÜHL (1987, S. 2 und 12):

\begin{abstract}
„Die Pauschalanklage der ,Kulturzerstörung' oder des ,Kulturzerfalls' wird auch nicht überzeugender, wenn sie auf Entwicklungsländer projiziert wird, die angeblich in der ewigen Blüte ihrer völlig homogenen und harmonischen Kultur weitergelebt hätten, wenn sie nicht durch Kolonisation und einen ,strukturellen' Imperialismus aus der Bahn geworfen worden wären. Für Entwicklungs- und Industrieländer gleich fatal ist, dass damit der Zusammenhang zwischen der politischen, wirtschaftlichen und gesellschaftlichen Organisation mit der kulturellen Selektions- und Adaptionsfähigkeit einer Kultur, mit der Streuung und Mobilisierbarkeit ihrer kreativen Begabungen übersehen wird. [...] ...dass der Universalismus sich vielfach dialektisch mit dem Regionalismus verbindet, ja dass eine Kultureinheit oft nur dann zu einem tragfähigen Einheits- und Selbstbewusstsein kommt und dass sie ihre authentischen Entwicklungskräfte erst findet, wenn sie sich dem Kulturkontakt und der Herausforderung stellt. [...] dass Kultur weniger als eine historische, einmal erbrachte Leistung, quasi als ein museales Endprodukt zu betrachten ist, sondern als ein in Bewegung befindliches, funktionsfähiges bzw. adaptionsfähiges System.“
\end{abstract}

Die Brechung einer Globalkultur durch lokale Besonderheiten wird auch als „Glokalisierung“ bezeichnet und gilt als eine neue moderne Richtung zur Erklärung des kulturellen Wandels (vgl. ausführlich BREIDENBACH/ZUKRIGEL 1998). Hierbei wird deutlich, dass das ökonomische Prinzip der Globalisierung eben nicht 1:1 auf Kulturen übertragbar ist, da diese aus ihren regionalen Kontexten heraus der Globalkultur ihre lokale Prägung geben:

„Die Annahme von universalistischen Werten oder Verhaltensweisen der Mehrheitsgesellschaft bedeutet nicht, dass partikularistische Orientierungsmuster im Sinne einer nivellierten Weltkultur , aufgehoben' werden [...] dass heißt dass auch die Mehrheitsgesellschaft von ihren Minderheiten kulturell beeinflusst wird.“ (s. ROBERTSON-WENSAUER 2000, S. 27)

\title{
Ähnlich formuliert auch MÜLLENMEISTER (1998, S. 48):
}

„Vollzieht sich die Verwestlichung doch keineswegs durchgängig, wie man nach dem ersten Eindruck glauben möchte. Werden doch vielerorts nur ausgewählte Kultursegmente übernommen - häufig die auffälligsten andere dagegen abgelehnt. Und werden doch nicht wenige der akzeptierten Kulturgüter den eigenen Traditionen angeglichen, eingeschmolzen, umgeformt.“ 
Grundlegende Muster von Akkulturationsverläufen, einer speziellen Form des Kulturwandels (s. o.), werden in Kapitel 6.3 beschrieben.

\subsubsection{Entwicklungsland}

Die Problematik zur Definition des Begriffs „Entwicklungsland“ wird ausführlich bei NOHLEN/NUSCHELER 1992 erfasst. In vollem Bewusstsein der Tatsache, dass

„Entwicklungsland“ ein unglücklicher, weil „Zurückgebliebensein“ suggerierender Begriff ist, wird dennoch in Ermangelung von brauchbareren Alternativen in dieser Arbeit daran festgehalten. „Länder des Südens“ oder „Dritte Welt“ sind mindestens ebenso unglücklich, weil der erste Begriff geographisch ungenau ist und der zweite noch mehr Abwertung enthält als „Entwicklungsland“. Der von Mostafa ARKI (s. ARKI 1990, S. 42) verwendete Begriff der „unterentwickelt gehaltenen Länder (ugL)“ findet wegen der einseitigen Sichtweise ebenfalls keine Verwendung. Auch von der Formulierung ,die Länder der sogenannten Dritten Welt“ wird auf Grund von sprachpraktischen Überlegungen Abstand genommen. Der Begriff „Entwicklung ${ }^{18 ، ~-~ a l s ~ s o l c h e r ~ a u c h ~ e i n ~ p r o b l e m a t i s c h e r, ~ w e n n ~ m a n ~ s i c h ~ i m ~ i n d i g e n e n ~ K o n t e x t ~}$ bewegt - muss auch immer im Rahmen seines Entstehungskonzeptes, einem westlichen, gesehen werden. Eine Operationalisierung des Begriffes „Entwicklungsland“ und die Bewertung Französisch-Polynesiens anhand dieser Kriterien befindet sich in Kap. 6.1.7.

Hubert BREMOND vertritt eine Sichtweise von Entwicklung, die insbesondere den Naturschutz ${ }^{19}$ favorisiert.

Eine andere Sicht ist diejenige Gabriel TETIARAHIs:

„Für manche Leute bedeutet Entwicklung hier, dass man den Müll auch in den Mülleimer wirft, mich interessiert aber vorwiegend die menschliche Entwicklung. “20

bzw:

„Pour nous, les ONG, Hiti Tau en particulier, le développement c'est autre chose que des résultats financiers économiques qu'il faut accumuler et qu'il faut répondre et justifier devant une agence de financement ou devant l'Union Européenne ou devant ces donateurs qui veulent bien croire qu'au modèle de développement qu'il faudra créer en Polynésie il faudra ajouter de nouveaux acteurs. Pour nous c'est d'abord une éducation à un autre système de

\footnotetext{
${ }^{18}$ „Was unter Entwicklung zu verstehen ist, macht einen guten Teil der Entwicklungsproblematik selbst aus. Der Begriff ist weder vorgegeben noch allgemein gültig definierbar, noch wertneutral, sondern abhängig von Raum und Zeit, sowie insbesondere von individuellen und kollektiven Wertvorstellungen.“ (s. NOHLEN 1989, S. 197)

${ }^{19}$ Interview mit Hubert Bremond, 1999

${ }^{20}$ Interview mit Gabriel Tetiarahi, 1999
} 
vie, à un autre mode de vie, et c'est surtout une épreuve de décolonisation des esprits. " (s. TETIARAHI 1999, S. 60)

Für Angèle TERIITAU steht die Selbstbestimmung im Vordergrund:

„Le Maohi ne doit plus être figurant de son propre devenir, mais bel et bien acteur de son développement. Ce n'est qu'à cette condition que l'idée même d'un développement soutenable aura un sens. " (s. TERIITAU 1999, S. 59)

\section{$\underline{1.6 \text { Aufbau der Arbeit }}$}

Kapitel 1 enthält die Einleitung der Arbeit mit methodischen, definitorischen und aufbautechnischen Erläuterungen, wobei im definitorischen Teil die indigene Sichtweise mit einbezogen wurde.

In Kapitel 2 werden die besondere Stellung des Tourismus als weltweiter, wirtschaftlicher Faktor dargestellt und Typologien der Reisenden und Phasen der touristischen Entwicklung erläutert. Einer Analyse der Anbieter- und Nachfragestruktur folgt eine Bewertung der heutigen Form des Welttourismus unter Kriterien der Zukunftsfähigkeit.

Zentraler Punkt von Kapitel 3 ist die Entwicklung eines Leitbildes eines zukunftsfähigen Tourismus und dessen Realisierungschancen angesichts der westlichen Konsumhaltung.

Die Entwicklungsländerproblematik steht im Mittelpunkt der Betrachtungen in Kapitel 4. Die wirtschaftliche Bedeutung und die Rezeption von Entwicklungsländertourismus in den Herkunfts- und Reiseländern werden reflektiert und bewertet.

Kapitel 5 veranschaulicht die spezifische Situation von indigenen Völkern, die mit Tourismus konfrontiert werden. Auch werden neben klassischen Reaktionsmustern auf $u$. a. durch den Tourismus ausgelöste Formen des Kulturverlustes Beispiele von Tourismusprojekten indigener Gruppen erläutert und bewertet.

Das Kapitel 6 ist der zentrale Teil der Arbeit. Nach einer geographischen, wirtschaftlichen, politischen und ethnischen Einordnung des Forschungsgebietes wird ausführlich die voreuropäische Kultur Französisch-Polynesiens, diejenige der Maohi, dargestellt. Anhand der fünf Kulturfaktoren Religion, Sprache, Rechtswesen, Gesellschaftsstruktur und Wirtschaft wird in der Folge der Akkulturationsprozess in Französisch-Polynesien analysiert, wobei der 
Tourismus einer der Faktoren war und ist, die Kulturverlust zur Folge hatten. Die Untersuchung des Akkulturationsprozesses ist bewusst - auch im Hinblick auf die beiden Nebenfächer interdisziplinär angelegt, da Erkenntnisse der Sprachwissenschaft ebenso einfließen wie wirtschaftliche und ethnologische Fragestellungen. Der zentrale Blickwinkel der Geographie wird durch die Darstellung der räumlichen Bezüge gewahrt.

Neben der „Opfer- bzw. Verliererrolle“ der Maohi im klassischen Tourismussektor in Französisch-Polynesien existieren aber auch eigeninitiative Ansätze im Bereich Ökotourismus/nachhaltiger Tourismus.

1999 begann die Basisgruppe Hiti Tau derartige Tourismusprojekte zu konzipieren und durchzuführen, die unter den Gesichtspunkten der Nachhaltigkeit einer Bewertung zugeführt werden.

Kapitel 7 zieht Vergleiche zu anderen pazifischen Staaten, in denen ähnlich Akkulturationsverläufe und auch touristische Strukturen zu beobachten sind.

In Kapitel 8 werden - ausgehend vom Fallbeispiel Französisch-Polynesien - generelle Entwicklungschancen für indigene Völker durch nachhaltige Tourismusformen diskutiert.

Kapitel 9 fasst die wesentlichen Ergebnisse der Arbeit zusammen. 


\title{
2. TOURISMUS IM GLOBALEN KONTEXT
}

\section{$\underline{\text { 2.1 Tourismus als weltwirtschaftlich relevanter Faktor }}$}

Der Tourismus ist im globalen Kontext zu einem gewichtigen ökonomischen Faktor avanciert:

\begin{abstract}
„Die touristischen Einnahmen erreichten so 1965 erst 6,3\%, 1992 aber schon 8,15\% des Wertes aller Warenexporte. Kein einzelnes Welthandelsgut erreichte eine ähnliche Bedeutung für den internationalen Zahlungsverkehr. Zudem stellt der Fremdenverkehr z. B. 1991 15,27\% des Wertes aller internationalen Dienstleistungen (WTO 1993). Das World Travel and Tourism Council (WTTC) bezeichnet den Fremdenverkehr daher als 'The World's Largest Industry' mit einer auch in absehbarer Zukunft großen Wachstumsdynamik. Schon 1990 erwirtschaftete dieser Sektor 5,9\% des globalen BSP und setzte etwa 2,9 Billionen US-Dollar um; er tätigte mit ca. 351 Milliarden US-\$ etwa 6,7\% der weltweiten Kapitalinvestitionen; er stellte mit 118 Millionen Beschäftigten 6,5\% aller Arbeitsplätze und schafft Arbeit für weitere 295 Millionen Personen in den der Fremdenverkehrswirtschaft vorgelagerten Branchen. Etwa 12,3\% aller Verbraucherausgaben entfielen auf die Tourismuswirtschaft.“(s. VORLAUFER 1996, S. 8)
\end{abstract}

1999 erreichte die weltweite Anzahl der internationalen Touristenankünfte mit 656,9 Millionen einen neuen Rekord. 1998 wurden im Tourismus 532 Milliarden US-Dollar eingenommen (s. WTO 2000).

Das World Tourism Council (WTTC) prognostiziert in einer 1995 erstellten Studie zur globalen wirtschaftlichen Bedeutung des Tourismus folgende Zahlen für 2005 (s. MUNDT 1998, S. 412):

\begin{tabular}{|l|c|c|}
\hline & 2005 & 1995 \\
\hline Zahl der Beschäftigten & 338 Millionen & 212 Millionen \\
\hline In \% aller Beschäftigten & 12,5 & 11,1 \\
\hline Wirtschaftsleistung & 7,2 Billionen US\$ & 3,4 Billionen US\$ \\
\hline In \% des BSP & 11,4 & 10,9 \\
\hline Konsum & 3,9 Billionen US \$ & 1,9 Billionen US\$ \\
\hline In \% des Gesamtkonsums & 11,7 & 11,4 \\
\hline Investitionen & 1,6 Billionen US\$ & 701 Mrd. US\$ \\
\hline In \% aller Investitionen & 11,8 & 11,4 \\
\hline Steuern & 1,4 Billionen US\$ & 655 Mrd. US\$ \\
\hline In \% des globalen Steueraufkommens & 11,6 & 11,1 \\
\hline Exporte & 1,4 Billionen US\$ & 646 Mrd. US\$ \\
\hline In \% aller Exporte & 11,9 & 12,6 \\
\hline
\end{tabular}

Tab. 2: Weltweite Entwicklung des Tourismus

Auf Grund seiner wachsenden weltwirtschaftlichen Bedeutung gilt der Tourismus auch als „Leitökonomie der zweiten Moderne“, die nach der Industriegesellschaft (der „ersten Moderne“) zu neuen Ansätzen im Dienstleistungsbereich führt (vgl. ROMEISS-STRACKE 1998, S. 10). 


\subsection{Phasen touristischer Entwicklung}

Die touristische Entwicklung vollzieht sich in der Regel in verschiedenen Phasen. Zwei entsprechende Modelle dieser Phasen sind in der Folge dargestellt. COOPER und JACKSON (1989, S. 378, zitiert in DWORSCHAK 1994, S. 19) entwickelten ein Modell, das sich an wirtschaftlichen Produktionszyklen orientiert:

\section{Abb. 5: Entwicklungsphasen touristischer Erschließung}

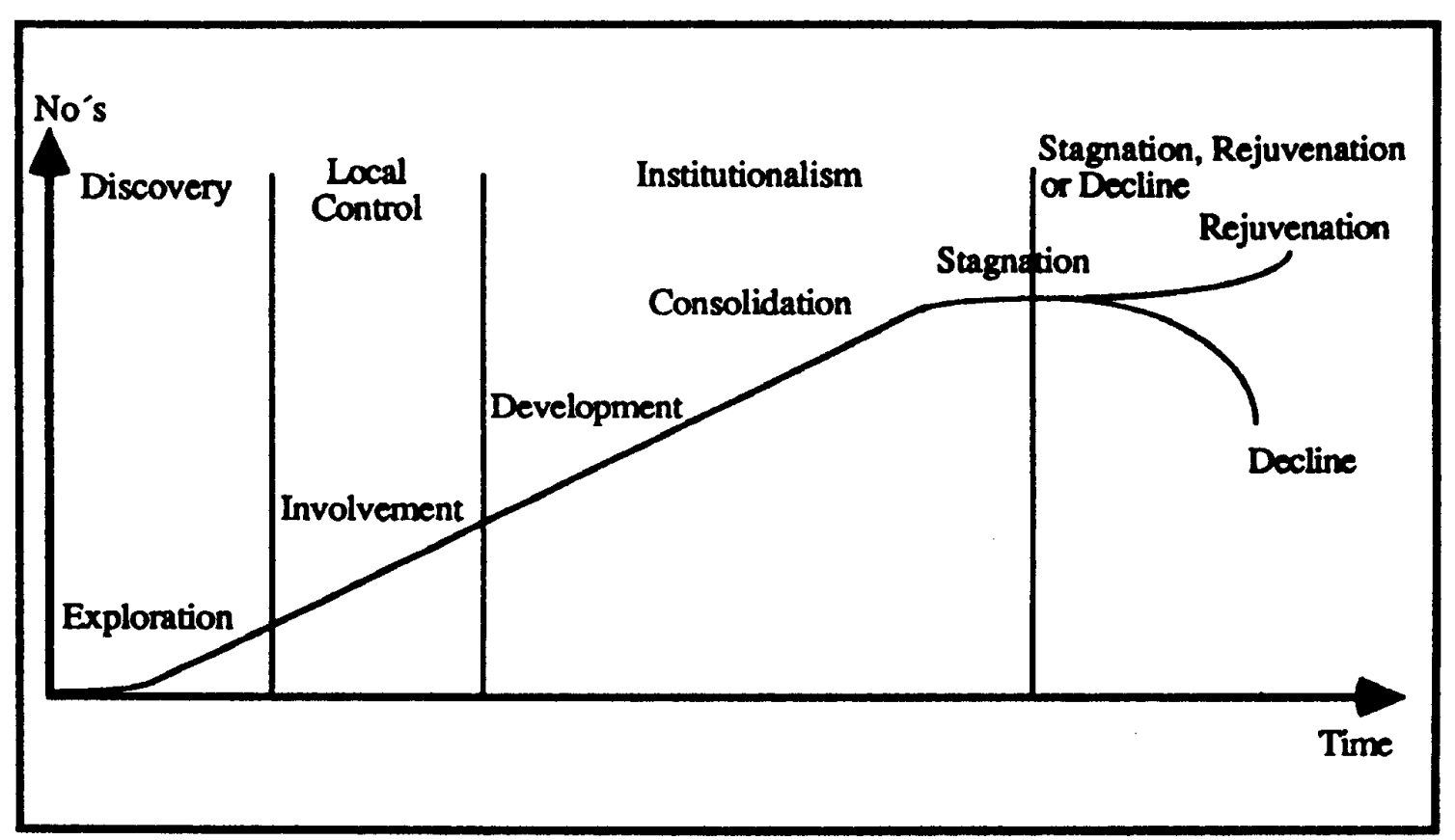

„Exploration“ ist hier noch eine relativ extensive Phase; auch während des Status „Involvement“ ist die touristische Aktivität noch weitgehend unter lokaler Kontrolle. Diese geht verloren mit zunehmender Einbettung in die globale Tourismusmaschinerie (,Development“) bis zur völligen Integration („Consolidation“). Ab der Phase „Stagnation“, die Ansätze der ökologischen, ökonomischen und kulturellen Desintegration aufweist, gibt es die Alternativen „Decline“ und „Rejuvenation“. „Decline“ führt auf Grund der in der Stagnationsphase aufgetretenen Probleme zum Rückgang der Touristenzahl, während „Rejuvenation“ durch Spezialisierung den touristischen Standort z. B. durch spezielle Angebote halten oder sogar eine weitere Steigerung der Touristenankünfte bewirken kann (vgl. DWORSCHAK 1994, S. 19).

Die Entwicklung einiger Touristendestinationen bestätigt dieses Modell, dennoch ist es zu statisch und deterministisch, um der komplexen Realität gerecht zu werden. 
Ein Modell von VORLAUFER (1996, S. 198/199) ist vom Aufbau her ähnlich, zeigt aber die entstehenden räumlichen Muster und Verflechtungen:
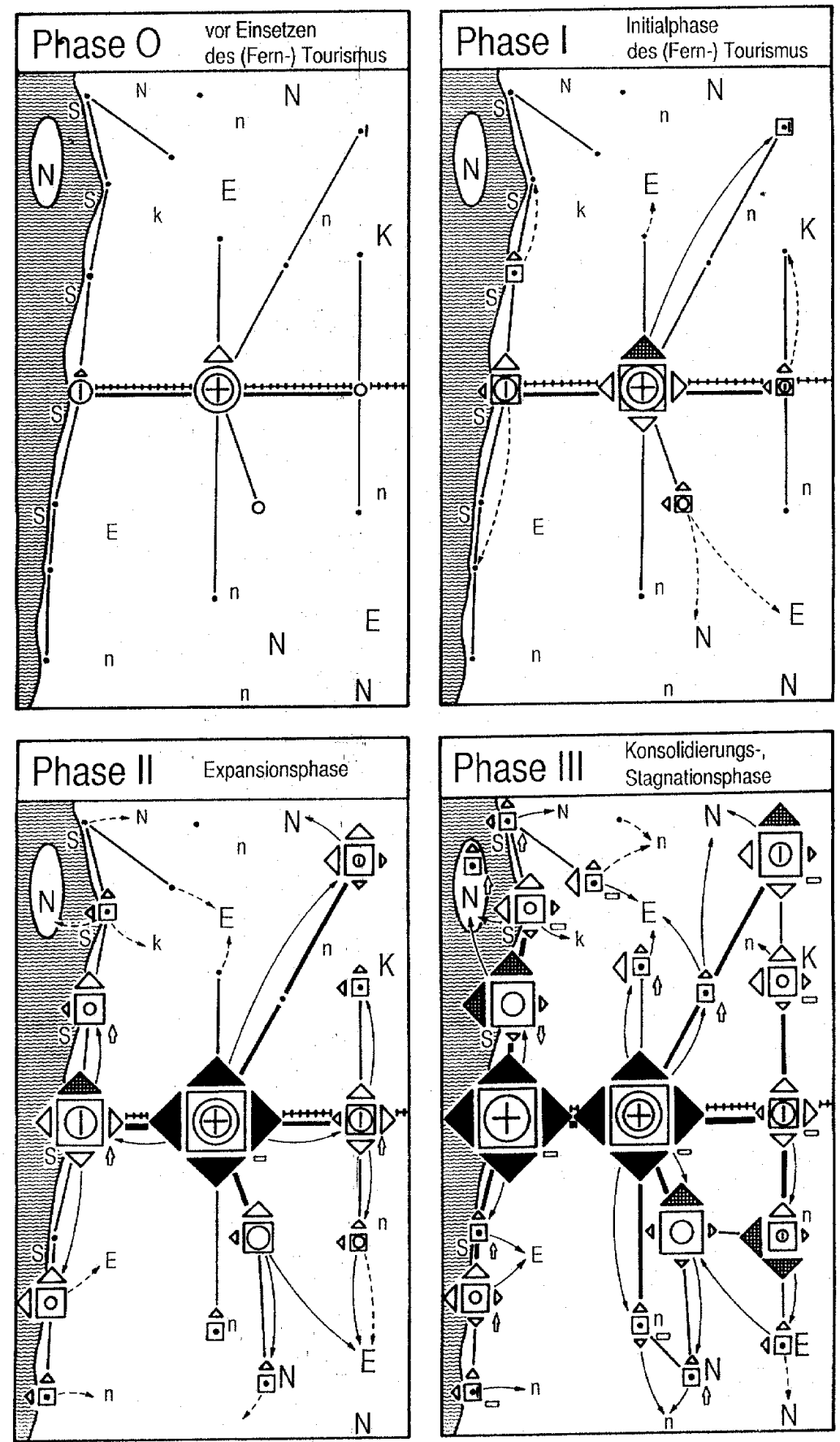


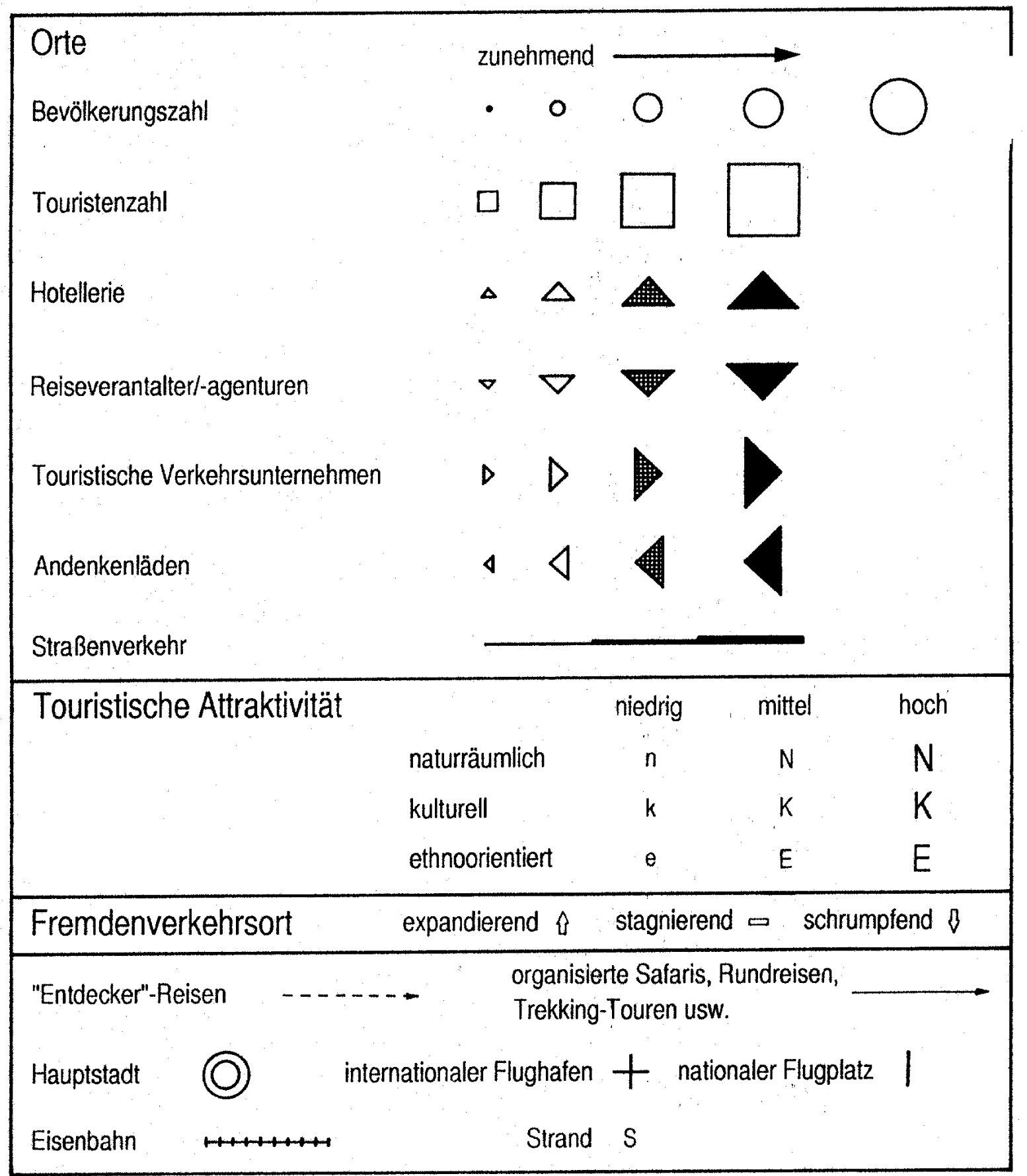

Abb. 6: Modell der raumzeitlichen Entfaltung des internationalen Tourismus in einem Entwicklungsland (Entwurf: Karl Vorlaufer; Zeichnung: U. Beha)

Das Modell ist sehr viel komplexer und berücksichtigt die Interaktion verschiedener Faktoren. 
VORLAUFER (1996, S. 207) entwickelte noch ein zweites Modell, das Elemente von COOPER/JACKSON aufweist, aber soziale- und kulturelle Tragfähigkeit integriert und die Entwicklungen von Authentizität/Identität und die touristische Entwicklung korreliert:

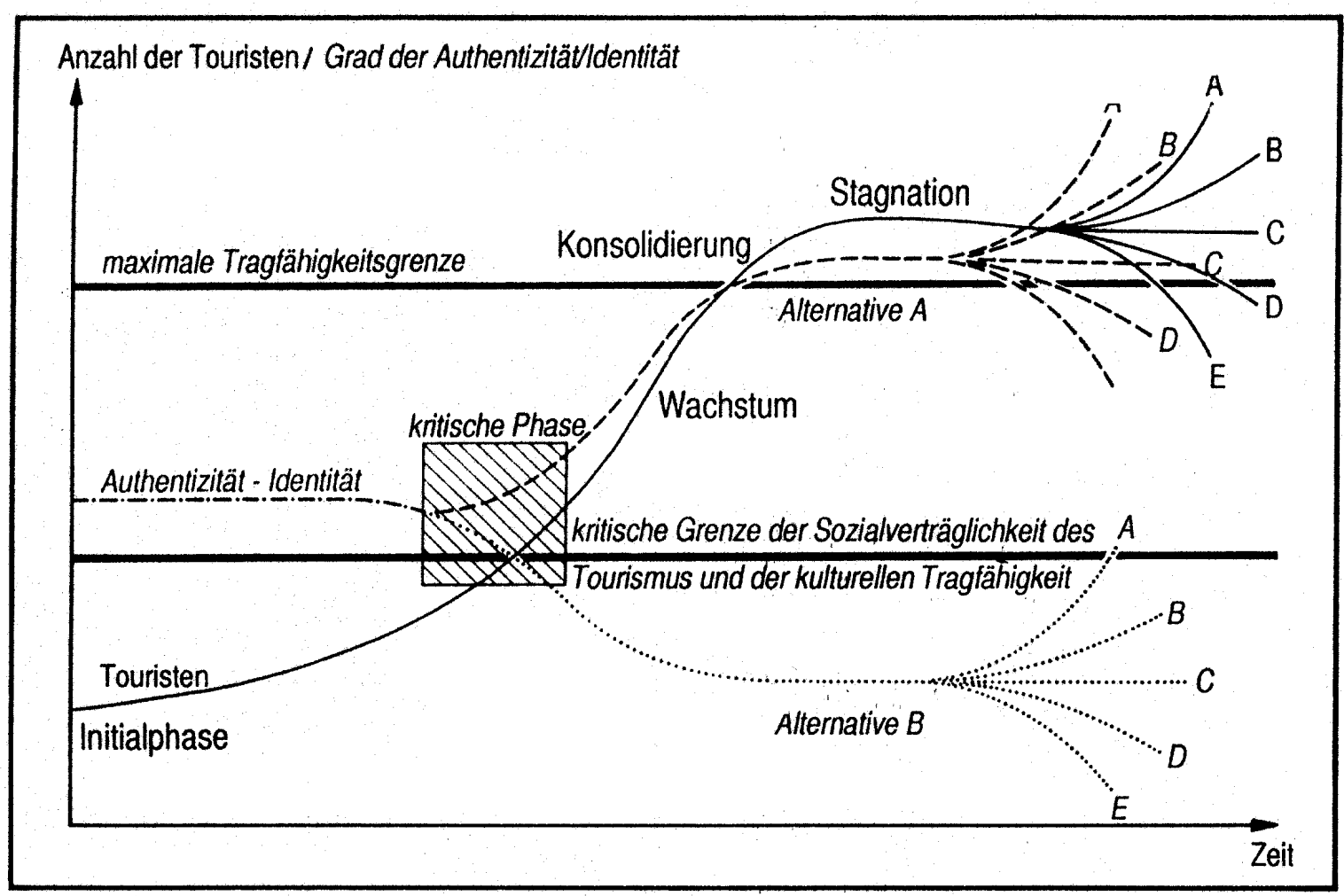

Abb. 7: Modell der Entwicklungsphasen des Fremdenverkehrs in ihren möglichen Zusammenhängen mit der Veränderung kultureller Authentizität und Identität (Entwurf: K. Vorlaufer; Zeichnung: U. Beha)

Dieses Modell ist für die vorliegende Arbeit von Relevanz, da der Bezug zu autochthoner Bevölkerung ebenso hergestellt ist wie zu Faktoren der Nachhaltigkeit/Zukunftsfähigkeit.

\section{$\underline{\text { 2.3 Typologie der Reisenden }}$}

Es existieren verschiedene Klassifizierungsmodelle der Reisenden. Ein frühes Modell ist das von COHEN (1972):

\section{Der organisierte Massentourist}

Er reist nur in Gruppen, die seiner gewohnten Umgebung entsprechen (in seiner „familiar environmental bubble“), und wird am Tourismusort stets von professionellen Reiseführern geleitet. 
Der individuelle Massentourist

Er organisiert einen Teil seines Reiseweges, ist aber zum weitaus überwiegenden Teil Teilnehmer von gebuchten Gruppenaktivitäten.

Der touristische Erkundertyp

Er organisiert die gesamte Reise selbst, wird aber nie zum integrativen Bestandteil der Gastgesellschaft und zieht sich gern in eine ihm vertraute Umgebung zurück.

Der touristische Drifter-Typ

Er bemüht sich um Integration in die Gastland-Gesellschaft und lehnt es vom Grundsatz her ab, sich in eine ihm gewohnte Umgebung zurückzuziehen. 
Eine andere Form der Typisierung nimmt ROMEISS-STRACKE (zitiert in IWERSENSIOLTSIDIS/IWERSEN 1991):

\begin{tabular}{|c|c|c|}
\hline Тур & Anteil an der Nachfrage & Charakteristika \\
\hline $\begin{array}{l}\text { Тур А } \\
\text { Die aktiven Genießer }\end{array}$ & $\begin{array}{l}\text { ca. } 30-40 \% \text {, Tendenz } \\
\text { leicht steigend, ab dem } \\
\text { Jahr } 2000 \text { stagnierend }\end{array}$ & $\begin{array}{l}\text { Auf Genuss, körperliches Wohlbefinden und } \\
\text { Spaß orientiert, anspruchsvolles } \\
\text { Konsumverhalten, sportlich aktiv, „Technik- } \\
\text { Freaks“, mäßig ausgeprägtes } \\
\text { Umweltbewusstsein, Selbstdarstellung in } \\
\text { entsprechenden Lebensstilräumen, Reisen als } \\
\text { wichtige Lebensäußerung }\end{array}$ \\
\hline $\begin{array}{l}\text { Тур В } \\
\text { Die Trendsensiblen }\end{array}$ & $\begin{array}{l}\text { ca. } 20 \% \text {, Tendenz stark } \\
\text { steigend }\end{array}$ & $\begin{array}{l}\text { Freizeit und Urlaub als persönliche } \\
\text { Bewusstseinserweiterung, orientiert am } \\
\text { Zeitgeist, Konsumverhalten sehr gezielt und } \\
\text { kritisch, politisch und kulturell interessiert, sehr } \\
\text { umweltbewusst und ökologisch informiert, } \\
\text { spontan }\end{array}$ \\
\hline $\begin{array}{l}\text { Tyр C } \\
\text { Die Familiären }\end{array}$ & $\begin{array}{l}\text { C a. } 20 \% \text {, Tendenz } \\
\text { abnehmend }\end{array}$ & $\begin{array}{l}\text { Freizeit und Urlaub mit Familie, Verwandten, } \\
\text { Freunden (Zeit miteinander verbringen), Preis- } \\
\text { /Leistungs-Denken, Qualitätsbewusstsein im } \\
\text { Konsumverhalten, Gruppenerlebnisse in } \\
\text { vertrauten Situationen (Gemütlichkeit), Ansätze } \\
\text { von Umweltbewusstsein, mäßig aktiv nach } \\
\text { außen }\end{array}$ \\
\hline $\begin{array}{l}\text { Tyр D } \\
\text { Die Nur-Erholer }\end{array}$ & $\begin{array}{l}\text { ca. } 30 \% \text {, Tendenz stark } \\
\text { abnehmend }\end{array}$ & $\begin{array}{l}\text { passive Erholung in Freizeit und Urlaub aus } \\
\text { Gewohnheit, wenig ausgeprägtes } \\
\text { Konsumverhalten, Desinteresse an Mode und } \\
\text { gesellschaftlichen Trends, Umweltbewusstsein } \\
\text { von wenig bis stark, wenig } \\
\text { experimentierfreudig }\end{array}$ \\
\hline
\end{tabular}


Der Einteilung von HENNIG (1999, S. 68 ff.) in Anlehnung an SCHULZE (1992) wird in dieser Arbeit der Vorzug gegeben. HENNIG ordnet verschiedene soziale Milieus touristischen Verhaltensweisen zu:

Niveaumilieu: ältere Bildungsschicht, klassische Studienreisende, Unterhaltungsbetrieb und Touristenmassen werden abgelehnt, bevorzugte Reiseziele: Rom, Ägypten, Burgund

Selbstverwirklichungsmilieu: jüngere Menschen der gehobenen Bildungsschichten, Suche nach „untouristischen Orten“, Ziele des Massentourismus werden abgelehnt, bevorzugte Reiseziele: Gomera, Hochprovence, Himalaja

Integrationsmilieu: mittlere Bildungsschichten, Neues wird eher abgelehnt als begrüßt, gute, touristische Infrastruktur wird vorausgesetzt, bevorzugte Reiseziele: Adria, Balearen, Gardasee, österreichische Berge

Harmoniemilieu: mehrheitlich Angehörige älterer Jahrgänge mit niedriger Schulbildung, Neues macht Angst, man sucht die Wiederholung des Bekannten, bevorzugte Reiseziele im Inland oder deutschsprachigen Ausland: Schwarzwald, Südtirol

Unabhängig von den sozialen Milieus wird von HENNIG die Gruppe der Jugendlichen ausgegliedert, die nach Spannung und Abwechslung sucht. Ferienorte mit großem Unterhaltungsangebot und vielfältigen Aktivitätsmöglichkeiten werden bevorzugt. Die Zugehörigkeit zu mehr als einem Milieu, beziehungsweise die Fluktuation einzelner Individuen zwischen den Milieus ist möglich.

VORLAUFER (1996, S. 43 f.) bezieht sich auf eine 1993er Studie des BMZ, wenn er folgende Merkmale deutscher Entwicklungsländerreisender beschreibt:

- Alter 20-49; Männeranteil und Gruppe der 20-29jährigen sehr hoch

- Hohes Einkommen

- Hoher Bildungsstand sowie Sprachkenntnisse

- Hohe Sensibilität gegenüber Umwelt, Politik und Kultur

Fast 40\% dieser Touristen zeigten ein Interesse an politischen, wirtschaftlichen und sozialen Problemen der Einheimischen des Reiselandes. Außerdem reisten Sie gerne auf Eigeninitiative und bevorzugten landestypische Unterkünfte. 
In einer Übersicht bringt VORLAUFER (1996, S. 45) Phasen touristischer Entwicklung,

Touristentypen, sowie die Auswirkungen in einen Zusammenhang:

\begin{tabular}{|c|c|c|c|}
\hline Charakteristika & $\begin{array}{l}\text { Stufe/Phase der } \\
\text { a) Entdeckung } \\
\text { b) Exploration }\end{array}$ & $\begin{array}{l}\text { Stufe/Phase der } \\
\text { a) Reaktion und Initiative in den } \\
\text { Destinationen } \\
\text { b) Involvierung }\end{array}$ & $\begin{array}{l}\text { Stufe/Phase der } \\
\text { a) Institutionalisierung } \\
\text { b) Entwicklung und } \\
\text { Konsolidierung }\end{array}$ \\
\hline Zahl der Touristen & sehr klein & klein & groß \\
\hline Touristentypen & $\begin{array}{l}\text { Forschungsreisende, } \\
\text { „Weltenbummler“ (drifter) }\end{array}$ & $\begin{array}{l}\text { Forschungsreisende, } \\
\text { „Weltenbummler“, „Pioniere des } \\
\text { Massentourismus““ }\end{array}$ & $\begin{array}{l}\text { Pauschal- und Einzelreisende } \\
\text { Massentourismus }\end{array}$ \\
\hline Reisestil & $\begin{array}{l}\text { erforschend, } \\
\text { müßiggängerisch, } \\
\text { mehrzweck- und } \\
\text { mehrzielorientiert }\end{array}$ & $\begin{array}{l}\text { erforschend, müßiggängerisch, } \\
\text { mehrzweck- und mehrzielorientiert }\end{array}$ & $\begin{array}{l}\text { schnell- und zielgerichtet } \\
\text { reisend; einzelzweck- und } \\
\text { einzelzielorientiert }\end{array}$ \\
\hline $\begin{array}{l}\text { Interesse der (meisten) Touristen } \\
\text { an der Gesellschaft }\end{array}$ & sehr groß & groß & oberflächlich \\
\hline $\begin{array}{l}\text { Kontakte zwischen Besuchern } \\
\text { und Einheimischen }\end{array}$ & $\begin{array}{l}\text { unmittelbar, persönlich } \\
\text { (face-to-face) }\end{array}$ & $\begin{array}{l}\text { noch vornehmlich unmittelbar, } \\
\text { persönlich (face-to-face) }\end{array}$ & vermittelt, unpersönlich \\
\hline $\begin{array}{l}\text { Anpassungsverhältnis zwischen } \\
\text { Besuchern und Einheimischen }\end{array}$ & $\begin{array}{l}\text { Besucher passen sich } \\
\text { vollständig an }\end{array}$ & $\begin{array}{l}\text { Besucher und Einheimische passen } \\
\text { sich jeweils teilweise an }\end{array}$ & $\begin{array}{l}\text { Einheimische passen sich den } \\
\text { Besuchern an }\end{array}$ \\
\hline $\begin{array}{l}\text { Verhalten, Einstellung der } \\
\text { Einheimischen gegenüber } \\
\text { Tourismus }\end{array}$ & euphorisch & positiv bis gleichgültig & $\begin{array}{l}\text { gleichgültig bis feindlich (bis } \\
\text { zum „Protest der Bereisten“) }\end{array}$ \\
\hline $\begin{array}{l}\text { Erwartung touristischer } \\
\text { Dienstleistungen durch } \\
\text { Besucher }\end{array}$ & keine & erhofft, erwartet gewisse Leistungen & $\begin{array}{l}\text { verlangt Leistungen } \\
\text { „westlichen“ Standards }\end{array}$ \\
\hline $\begin{array}{l}\text { dominante Kulturmuster in den } \\
\text { Gastländern }\end{array}$ & traditionell & $\begin{array}{l}\text { traditionell, mit erster Akzeptanz } \\
\text { fremder kultureller Werte }\end{array}$ & $\begin{array}{l}\text { westliche Zivilisation } \\
\text { aufgestülpt auf Traditionen, } \\
\text { tradierten Werten }\end{array}$ \\
\hline Umweltbelastungen & fehlend & punktuell gering & $\begin{array}{l}\text { punktuell extrem, flächenhaft oft } \\
\text { groß }\end{array}$ \\
\hline Umwelt-, Denkmalschutz & fehlend & punktuell beginnend & $\begin{array}{l}\text { punktuell stark, flächenhaft oft } \\
\text { beträchtlich }\end{array}$ \\
\hline $\begin{array}{l}\text { Organisationsgrad der } \\
\text { Tourismuswirtschaft }\end{array}$ & $\begin{array}{l}\text { spontan, improvisierend, } \\
\text { „informell““ }\end{array}$ & $\begin{array}{l}\text { gelegentliche Organisation; } \\
\text { angemessene, aber unkoordinierte } \\
\text { Verbesserungen }\end{array}$ & $\begin{array}{l}\text { voll organisiert, standardisiert, } \\
\text { „formell“" }\end{array}$ \\
\hline wirtschaftliche Bedeutung & $\begin{array}{l}\text { volks- und } \\
\text { regionalwirtschaftlich } \\
\text { unbedeutend }\end{array}$ & $\begin{array}{l}\text { regionalwirtschaftlich wachsend, } \\
\text { volkswirtschaftlich wenig bedeutend }\end{array}$ & $\begin{array}{l}\text { volks-, vor allem } \\
\text { regionalwirtschaftlich große bis } \\
\text { dominante Bedeutung }\end{array}$ \\
\hline $\begin{array}{l}\text { Kontrolle der } \\
\text { Tourismuswirtschaft }\end{array}$ & lokale Bevölkerung & $\begin{array}{l}\text { lokale Bevölkerung, erste } \\
\text { einheimische Katalysatoren in } \\
\text { Kooperation mit (u. Abhängigkeit } \\
\text { von) Auswärtigen als } \\
\text { „Brückenköpfe“ (Vertragspartner) } \\
\text { der Quellgebiete }\end{array}$ & $\begin{array}{l}\text { Auswärtige (nationale Eliten, } \\
\text { ausländische Investoren) }\end{array}$ \\
\hline Raumwirksamkeit, Raummuster & ephemer, flüchtig & punktuell fixiert & $\begin{array}{l}\text { linien- und flächenhafte } \\
\text { Erschließung, Fixierung }\end{array}$ \\
\hline
\end{tabular}

Abb. 8: Nach van DOORN (1979, zitiert bei PEARCE 1989; nach BUTLER (1980); in Anlehnung an COHEN (1972)

Diese Übersicht zeigt insbesondere, dass die Auswirkungen des Tourismus in höchst

differenzierter Weise zu betrachten sind: so verändert eine kleine Anzahl an Touristen das

dominante Kulturmuster in den Gastländern noch nicht und die Raumwirksamkeit des Tourismus

ist in jeder Hinsicht gering. Mit zunehmender Touristenzahl nimmt das Interesse der

Einheimischen an den Touristen ab und die Reisetätigkeit wird nach westlichen Standards

reglementiert. 


\subsection{Die Nachfrager- und Anbieterstruktur}

\subsubsection{Struktur der Nachfrage}

Der Sektor Tourismus ist im Wesentlichen nachfragegesteuert, d.h. insbesondere gesamtgesellschaftliche Trends wirken sich auf das jeweilige Angebot aus - Werbeaktivitäten hingegen kaum (s.u.). Der deutsche Markt z. B. lässt sich grob in drei Hauptsegmente gliedern: ein großes Segment der Billigreisen zu niedrigen Preisen, ein noch größeres Segment der klassischen Pauschalreisen ${ }^{21}$ mit durchschnittlichen Preisen und ein kleineres, aber wachsendes Segment der Spezialreisen zu hohen Preisen. Während die „Mitte“ der durchschnittlich teuren Spezialreisen an Marktanteilen einbüßt, der Bereich der Billigreisen konstant bleibt, ist derzeit ein langsamer, aber stetiger Zuwachs im Segment Spezialreisen zu beobachten.

Eine Form der Spezialreise ist der Naturtourismus. Die Nachfrage hiernach ist auch mittelfristig nur gering bis mittel, mit Ausnahme der Form, bei der sich der Reisende nur beiläufig für Naturattraktionen interessiert:

Abb. 9: Erwartungen und Einstellungen von Naturtouristen

\begin{tabular}{|c|c|c|c|c|c|}
\hline Typus & Hauptinteresse & intakte Natur & $\begin{array}{l}\text { Anforderungen an } \\
\text { Führer }\end{array}$ & Komfortansprüche & Nachfragepotential \\
\hline $\begin{array}{l}\text { Der „engagierte“" } \\
\text { Naturtourist }\end{array}$ & $\begin{array}{l}\text { Naturerlebnis, } \\
\text { spezielle Interessen }\end{array}$ & sehr wichtig & $\begin{array}{l}\text { spezielle ökologische } \\
\text { Kenntnisse }\end{array}$ & niedrig & gering \\
\hline $\begin{array}{l}\text { Der ,interessierte } 6 \text { } \\
\text { Naturtourist }\end{array}$ & $\begin{array}{l}\text { Naturerlebnis, } \\
\text { ökosystemare } \\
\text { Zusammenhänge }\end{array}$ & wichtig & $\begin{array}{l}\text { gute ökologische } \\
\text { Kenntnisse }\end{array}$ & niedrig bis hoch & mittel \\
\hline $\begin{array}{l}\text { Der „,beiläufige“6 } \\
\text { Naturtourist }\end{array}$ & $\begin{array}{l}\text { leicht zugängliche / } \\
\text { erschließbare } \\
\text { Naturattraktionen }\end{array}$ & weniger wichtig & $\begin{array}{l}\text { unspezifische } \\
\text { ökologische Kenntnisse }\end{array}$ & $\begin{array}{l}\text { hoch (IL); } \\
\text { niedrig (EL) }\end{array}$ & hoch \\
\hline $\begin{array}{l}\text { Der Sport-/ } \\
\text { Abenteuertourist }\end{array}$ & aktivitätszentriert & $\begin{array}{l}\text { Natur als } \\
\text { Kulisse }\end{array}$ & $\begin{array}{l}\text { Orts- und technische } \\
\text { Kenntnisse }\end{array}$ & niedrig & $\begin{array}{l}\text { mittel bis hoch } \\
\text { (Tauchen) }\end{array}$ \\
\hline $\begin{array}{l}\text { Der Jagd-/ } \\
\text { Angeltourist } \\
\end{array}$ & aktivitätszentriert & $\begin{array}{l}\text { Natur als } \\
\text { Kulisse }\end{array}$ & $\begin{array}{l}\text { Orts- und technische } \\
\text { Kenntnisse }\end{array}$ & niedrig & gering \\
\hline $\begin{array}{l}\text { Der kulturell } \\
\text { interessierte } \\
\text { Naturtourist } \\
\end{array}$ & $\begin{array}{l}\text { Natur-Kultur- } \\
\text { Erlebnis }\end{array}$ & wichtig & $\begin{array}{l}\text { gute ökologische und } \\
\text { sehr gute kulturelle } \\
\text { Kenntnisse }\end{array}$ & niedrig & mittel \\
\hline
\end{tabular}

Quellen: AGÖT 1995 und STRASDAS et al. 1997

Die Struktur des deutschen Reisemarktes (vgl. auch KIRSTGES 1992, S. 70 ff.) ist in modifizierter oder im Verlauf in zeitverzögerter Form auf die Hauptnachfrageländer im Bereich Tourismus, dass heißt die westlichen Industrienationen (touristische Quellgebiete), in der Tendenz übertragbar.

\footnotetext{
${ }^{21}$ Bei einer Pauschalreise bucht der Reisende über einen Mittler (z. B. Reisebüro) mehrere Einzeldienstleistungen gleichzeitig, die oft als packages angeboten werden, während der Indivudualreisende sich die einzelnen Teile seiner Reise selbst organisiert (vgl. FREYER 1993, S. 54 f).
} 
Interessant ist in diesem Zusammenhang auch, dass Marketing und Steigerungsraten im touristischen Geschäft im Wesentlichen kaum einander bedingen. Ein immenser Werbeaufwand verändert die Nachfragestruktur nicht wesentlich (vgl. WTO 1994).

\subsubsection{Struktur des Angebots}

Hieraus folgt, dass die Anbieter ihr Angebot auf die Reisenden ausrichten müssen und durch Veränderung oder Erweiterung des Angebotes die Nachfrage in der Regel kaum steuern können. Die Anbieter touristischer Dienstleistungen lassen sich mit abnehmender direkter Abhängigkeit von den Touristen in folgende Gruppen einteilen (s. gtz 1999, S.19):

- Tourismuswirtschaft im engeren Sinn (Transport, Beherbergung, Vermittlung)

- Ergänzende Tourismuswirtschaft (z. B. Reisebuchverlage, Kreditkartenfirmen, Hersteller von Kunsthandwerk etc.)

- Peripher oder saisonal von Touristen abhängige Wirtschaftszweige (z. B. Fotoindustrie, Tankstellen, Lebensmittelgeschäfte, Ärzte etc.)

- Zulieferer für touristische Betriebe (z. B. Bauunternehmen, Lebensmittelproduzenten etc.)

\section{$\underline{2.5 \text { Reisemotivation und ,Imaginäre Geographie }{ }^{622}}$}

Eine viel zitierte Antwort nach der Frage der Motive des Reisens ist die These der „Flucht vor den Belastungen der Industriegesellschaft“ (s. HENNIG 1999, S. 72 f.). KRIPPENDORF (1975 und 1984) und ENZENSBERGER (1964) zählen zu ihren wichtigsten Vertretern. Auch PRAHL (1977) spricht von einer arbeitspolaren Gegenwelt. Dies mag zwar in einigen Fällen durchaus ausschlaggebend sein, kann aber nicht auf alle Reisenden generell übertragen werden. Ein tiefergehendes Motiv ist der Wunsch nach Unterbrechung des Gewohnten:

\footnotetext{
„Die Bewegung, die Reisen grundlegend charakterisiert, ist universell verbreitet und in allen Kulturen nachweisbar: der Impuls, die Ordnungsstruktur des Alltags zu verlassen und in andere Wirklichkeiten einzutreten. [...] Insofern steht es [das Reisen] den Ritualen und Festen, dem Spiel, dem Mythos und dem Theater nahe; es ist allen Formen menschlicher Symbolproduktion und Fantasietätigkeit verwandt, die aus der Gebundenheit ans jeweils Gegebene hinausführt. [...] Die Erfahrung des Nicht-Gewöhnlichen erneuert das Bedürfnis nach der Stabilität der bekannten Abläufe.“ (s. HENNIG 1999, S. 73 und S. 91).
}

Dieses Motiv ist sehr viel umfassender als eine reine Flucht-These.

\footnotetext{
${ }^{22}$ Zum Konzept der „Imaginären Geographie“ vgl. ausführlich HENNIG 1999, S. 94-101.
} 
In diesem Zusammenhang ist das Konzept der „Imaginären Geographie“von entscheidender

Bedeutung: Nicht das Erleben der Realität im Reiseland wird angestrebt, sondern die Bestätigung der Fiktion. Die Wahrnehmung vor Ort ist daher selektiv und verzerrt:

„Vor der Reiseerfahrung steht die Fiktion; daher hat das Wiedererkennen im Tourismus fundamentale Bedeutung. [...] Das Ziel ist nicht der naturwissenschaftliche Blick auf die Umgebung; man sucht vielmehr die aus dem ästhetischen Kanon der Zeit bekannten Motive. Die Kunst, der Traum, das Vorstellungsbild sollen Wirklichkeit werden. Die touristische Wahrnehmung liefert kein , realistisches' Bild der besuchten Gebiete. Sie konstruiert eigene Erfahrungsräume, die wesentlich durch Fantasie und Projektion geformt werden. Natur und Kultur, Ökonomie und Lebensgewohnheiten des Reiselandes gehen in die Wahrnehmung nur als Elemente unter anderen ein. [...] Touristen suchen die sinnliche Erfahrung imaginärer Welten, die Realität der Fiktion.“ (s. HENNIG 1999, S. 54, 55 und 95)

oder

„Die Kunst des Reisens besteht nicht mehr darin, gesellschaftliche Fassaden, Kulissen und Inszenierungen zu durchdringen und zum, wirklichen Leben' vorzustoßen, sondern eher umgekehrt, das , wirkliche Leben' durch die Inszenierung einer in sich stimmigen, interessanten, originellen und möglichst fesselnden Erlebniswelt zu überhöhen.“ (s. GÜNTHER 1996, S. 107)

Empirisch belegt ist diese These unter anderem durch die Untersuchungen von FISCHER in Samoa. Die von FISCHER befragten Reisenden nahmen West-Samoa ganz im Sinne des klassischen Südseeklischees wahr: Freundliche Menschen, angenehmes Klima, Palmen, Strand und Wasser (vgl. FISCHER 1984). Die Touristen nehmen bevorzugt diejenigen Elemente der Realität wahr, die ihrer Fiktion entsprechen. Die Reiseerfahrung wird analog zu den eigenen Bedürfnissen inszeniert (vgl. hierzu auch ausführlich Kap. 6.4.5). Die innere, „Imaginäre Geographie" reist immer mit:

„In die Fremde wurde und wird das hineinprojiziert, was man zu Hause nicht oder nicht mehr findet: ,das Echte' und schließlich das ,echte Selbst'. [...] sei anzumerken, dass die Suche nach dem Echten den Motor des Tourismus darstellt. Diese Suche bezeichnet stets eine Differenz, die das, Wahre', das authentische Erleben oder die ,wirkliche Identität’ hervorzubringen vorgibt.“ (s. WÖHLER 1999, S. 2.)

Folgerichtig ist das Marketing der touristischen Anbieter genau darauf abgestimmt:

„Der Tourismus zehrt von den großen Erzählungen und Mythen des Reisens, von den Traumbildern verlorener Paradiese. Die Konstruktion von Urlaubsparadiesen erzeugt reale Traumwelten, und die Institutionalisierung der Imagination belebt das touristische Geschäft.“ (s. VESTER 1999, S. 118)

Die oft beobachtete Suche der Touristen nach dem „Authentischen“ (s. o.) steht dazu nicht wirklich im Widerspruch. „Echtheit“ ist in bereisten Regionen in der Regel inszeniert (vgl. HENNIG 1999, S. 170 f.): 
„Das Ursprüngliche, Selbstverständliche und Sichere, das wir in unserem Leben kaum noch finden, wird in anderen Kulturen gesucht. [...] Dass sie [die Reiseziele] ,intakt' und ,authentisch wirken, ist Ergebnis bewusster Maßnahmen im Interesse des Fremdenverkehrs. [...] Der Begriff des ,Echten' ist viel zu unbestimmt, als dass er sinnvoll zum Kriterium für Urlaubserfahrungen gemacht werden könnte. Zudem ist alles soziale Leben vermittelt, der Traum von der reinen Ursprünglichkeit naiv.“

Mag die intellektuelle Kritik an einer solchen Form der Reisemotivation, die unter anderem den Erfolg von Freizeit- und Ferienparks erklärt, auch vernichtend sein, die Masse hat entschieden:

„Als professioneller Kulturkritiker könnte man es sich leicht machen: Das kann nur Fassadenfirlefanz und Kitschinszenierung, Verführungs-Maschinerie und Instant-Tourismus, Hollywood und Walt Disney sein. Doch die Wirklichkeit sieht anders aus. Viele Kritiker verwechseln Illusion mit Illusionierung. Der Massenansturm der Besucher zwischen Faszination, Begeisterung und Happiness zeigt deutlich: Die Abstimmung findet mit den Füßen statt. Die Besucher wollen sich unbeschwert treiben und unterhalten lassen und vor allem unbeschwert genießen.“ (s. OPASCHOWSKI 1998, S. 15)

\section{$\underline{\text { 2.6 Zukunftsfähigkeit und heutige Form des Welttourismus }}$}

Begreift man die in Kap.1 beschriebenen Definitionen und Modelle eines zukunftsfähigen Tourismus als Leitbilder sozialer und umweltrelevanter Verträglichkeit, so ist festzustellen, dass der Tourismus als weltweites Phänomen real von diesen Idealen weit entfernt ist, bzw. in seiner Struktur der Zukunftsfähigkeit entgegengesetzte Effekte bewirkt. Der Charakter des derzeitigen Welttourismus ist überwiegend expansiv und auf kurz-, höchstens mittelfristige ökonomische Ziele ausgerichtet. Die ökologische Komponente wird erst bei der Beeinträchtigung der ökonomischen zur Kenntnis genommen: erst wenn Umweltschäden das touristische Potential einer Region bedrohen, werden sie behoben. Die soziale, bzw. kulturelle Komponente hat ihren ökonomischen Wert meist nur in folkloristischer Form, die monetär direkt umsetzbar ist.

\section{$\underline{\text { 2.7 Zwischenbilanz }}$}

Die derzeitige Struktur des Welttourismus ist von einem zukunftsfähigen Tourismus, den es als globalen Massentourismus auch gar nicht geben kann, nicht nur weit entfernt, sondern lässt auch kaum Spielraum, einen zukunftsfähigen Tourismus politisch durchzusetzen. Dennoch lässt sich ein, wenn auch kleines, Nachfragepotential nach nachhaltigen Tourismusformen in den (westlichen) Hauptreiseländern identifizieren. Hierfür, wie für andere Formen des Reisens, die sich durch einen hohen Spezialisierungsgrad ausweisen, kann ein Wachstum prognostiziert werden. Das globale Potential einer zukunftsfähigen Form des Tourismus bleibt kurz- und mittelfristig auf einen geringen Prozentsatz des Welttourismus beschränkt. 


\section{ZUKUNFTSFÄHIGER TOURISMUS}

\section{$\underline{\text { 3.1 Das Leitbild eines zukunftsfähigen Tourismus - eine Hypothese }}$}

Ein visionäres Leitbild eines zukunftsfähigen Tourismus (vgl. auch Ausführungen in Kap. 2) steht unwidersprochen zu einer Momentaufnahme der Struktur des heutigen Welttourismus in einem konträren Verhältnis. Dennoch macht es Sinn, dieses Leitbild zu entwerfen, da es eine mögliche Orientierung bzw. alternative Richtung aufzeigt.

Folgende Faktoren bestimmen - neben den in Kap. 1 erläuterten allgemeinen Kriterien der Nachhaltigkeit - ein solches Leitbild. Sie sind nicht von ungefähr einem Konzept von Fair Trade (s. VON WOGAU, 1998) entnommen:

- Einbindung der Partner vor Ort

- Organisation und Evaluierung der Reisen in Deutschland

- Vor- und Nachbereitung der Reisen

- Mindestdauer der Reisen: 3 Wochen

- Optimale Teilnehmerzahl: 8-12 Personen

- Entwicklungspolitisch und kulturell qualifizierte Reiseleitung

- Unterkunft in Abstimmung mit den Gastgebern

- Mischung zwischen klassischen touristischen Aktivitäten und Einbezug in Lebens- und Arbeitsweise der Gastgeber

- Darstellung der Schadstoff bzw. Energiebilanz im Reiseangebot zwecks Sensibilisierung der Reisenden

- Faire Preise für die Gastgeber

Ergänzend seien an dieser Stelle auch die Zielsetzungen „fairen Reisens“ von Fair Trade genannt, die auch die Wahl der o.g. Faktoren verdeutlichen:

- zusätzliches Einkommen für die Produzentengemeinschaften im Süden auf der Basis einer fairen Wertschöpfung

- nachhaltige Beziehungen

- Stärkung der Identität der Handelspartner aus dem Süden

- Austausch und kulturelle Begegnung und hierdurch Intensivierung der kulturellen Verständigung durch persönliche Begegnung 
- Intensivierung der Beziehungen zwischen den Handelspartnern, zu denen außer einer informativen Dokumentation direkte menschliche Beziehungen kommen

- Absatzförderung der Produkte der Handelspartner

Aus der langjährigen Erfahrung mit fair gehandelten Produkten aus Entwicklungsländern hat Fair Trade eine Modifizierung bestehender Konzepte vorgenommen und den Besonderheiten des „Produktes Reise“ angepasst. Auch dies ist ein weiterer Beweis für den neuen Pragmatismus in der entwicklungspolitischen Diskussion: Es wird sowieso gereist - warum also nicht versuchen, die bestehende touristische Nachfrage dahingehend zu modifizieren, dass sie sozial- und umweltverträglicher wird? Dazu kommt, dass Ökotourismusprojekte in zunehmendem Maße von NGOs aus dem Süden initiiert (vgl. Kap. 5.3) und bei ausländischen Geberinstitutionen beantragt werden, nicht zuletzt, weil es sich um eine Form der Einkommenserzielung handelt, die oft relativ einfach mit bestehenden Wirtschaftsformen (z. B. landwirtschaftliche Produktion) sinnvoll verbunden werden kann.

Ein ungelöstes Problem bleibt die Schadstoff- bzw. Energiebilanz der Flugreise, die theoretisch nur durch eine prinzipiell sehr niedrige Flugreisefrequenz pro Person in den Griff zu bekommen wäre. Aus einer zukunftsfähigen Perspektive wären Fernreisen per Flugzeug weitgehend abzulehnen.

Die Entwicklung von Indikatoren zur Evaluierung fairer Reisen ist weitaus schwieriger als die Evaluierung anderer fair gehandelter Produkte z. B. aus der Landwirtschaft. Im Rahmen der Implementierung eines Fair Travel Konzeptes sind von Fair Trade auch begleitende Impaktstudien vorgesehen, um letztendlich Bemessungsgrenzen bezüglich der Auswirkungen auf Wirtschaft und Sozialstruktur zu entwickeln. 


\section{$\underline{3.2}$ Trends in der westlichen Konsumhaltung}

Es führt zu interessanten Ergebnissen, in diesem Zusammenhang auch die aktuellen gesellschaftlichen Megatrends ${ }^{23}$ zur Konsumhaltung zu beleuchten und zu untersuchen, ob nicht Nachfrageverschiebungen auftreten, die den oben erwähnten Kriterien eines zukunftsfähigen Tourismus entgegen kommen.

Als einen wesentlichen Trend bezeichnet INGLEHART (1998, S. 452) den gesellschaftlichen Wertewandel hin zu postmaterialistischen Einstellungen:

„Postmoderne Werte führen zu nachlassendem Vertrauen in religiöse, politische und sogar wissenschaftliche Autoritäten; und sie führen zu einem wachsenden, weit verbreiteten Wunsch nach Partizipation und Selbstverwirklichung. “

Ganz allgemein weisen alle modernen Gesellschaftssysteme eine zunehmende Komplexität auf, die sich in der Zukunft weiter fortsetzen wird:

„Jeder von uns kann Wachsen von Komplexität in seinem Alltagsleben spüren. Als ein Zuwachs an Optionen: des Lebens, der Entscheidungen, der Widersprüche. Als ein ständiges Mehr an Wahlmöglichkeiten, Informationen, Ambivalenzen. Und Verlust von Eindeutigkeit.“ (HORX 1999, S. 40)

Alles, was - wenn auch nur zeitweise - der Reduktion von Komplexität dient, wird dankbar angenommen:

„In unreifen oder überkomplexen Strukturen ist der ,Komplexitätsreduzierer' stets ein Gott, der die Menschen wieder mit sich selbst und der Umwelt ins Gleichgewicht bringt." (HORX 1999, S. 49)

Genau bei dieser Nachfrage nach Reduktion einer zu komplex gewordenen Alltagswelt setzt auch der Tourismus an: Urlaubswelten (da häufig sonnenreich) sind nicht nur oft klimatische Gegensätze zu den meisten Herkunftsländern, sie vermitteln auch ein vereinfachtes

Lebensmodell, reduziert auf Grundbedürfnisse und eine überschaubare Anzahl an Aktivitäten.

Einen starken Trend sieht ROMEISS-STRACKE (1989, S. 33) im hedonistischen Lebensstil. Konsum, Freizeit und Urlaub rücken immer mehr ins Zentrum des Lebensinteresses.

\footnotetext{
${ }^{23}$ Ergänzend sei erwähnt, dass es zu jedem Trend auch schon gleich den Gegentrend gibt, Trendforschung also sich ständig selbst überholt (vgl. ROMEISS-STRACKE 1998, S. 65 ff.)
} 
Mit der ständigen zeitlichen Ausdehnung des Bereichs „Freizeit“" hat sich auch eine Verschiebung in Bezug auf dessen inhaltliche Gestaltung ergeben. Die zunehmend hedonistische Lebensauffassung hatte einen Wertewandel zur Folge, der wie folgt zusammengefasst werden kann (vgl. KIRSTGES 1992, S. 80):

- wachsende Freizeitorientierung

- wachsende Erlebnisorientierung

- wachsende Genussorientierung

- wachsende Gegenwartsorientierung

- wachsende Natur- und Umweltorientierung

Diese Trends, empirisch mehrfach abgesichert ${ }^{24}$, setzen sich auch in die Zukunft zunächst fort. Interessant ist hierbei, dass sich gerade bei zunehmender Orientierung nach Erlebnis/Inhalten, Gegenwart, sowie Umwelt und Natur auch verstärkte Nachfrageschübe für zukunftsfähige Tourismusformen ergeben könnten, da diese mit den o.g. Faktoren korrespondieren.

OPASCHOWSKI sieht allerdings zurzeit eine Abschwächung dieses Trends und spricht schon vom „Abschied vom ,sanften Tourismus"“ (s. OPASCHOWSKI 1998, S. 18), da unter ökonomischen Einschränkungen der Privathaushalte die Diskrepanz zwischen einer prinzipiellen Sensibilität in Bezug auf sanften Tourismus und dem tatsächlichen Verhalten immer größer wird. Das eingeschränkte Reisebudget lässt intellektuelle Einsichten zu Lippenbekenntnissen werden, das Verhalten hinkt dem Bewusstsein hinterher. Dies ist am besten konkret fassbar anhand des Faktors Umwelt: Politisch und gesellschaftlich auf allen Ebenen präsent hat sich ein „Bewusstsein“ schon seit längerem gebildet. Die Verhaltensänderungen, die diesem folgen müssten, haben in den letzten Jahren dagegen abgenommen (vgl. OPASCHOWSKI 1998, S. 23 ff.).

OPASCHOWSKI (1999, S. 16 f.) fasst die gegenwärtigen und zukünftigen Reisewünsche der Deutschen in drei simplen Anforderungen zusammen:

- Sonnengarantie

- Kontrasterlebnis

- Gutes Preis-Leistungsverhältnis

\footnotetext{
${ }^{24}$ Vgl. hier insbesondere für den Tourismus relevante Untersuchungen von Horst W. OPASCHOWSKI am BAT-Freizeitforschungsinstitut in Hamburg oder für allgemeine gesellschaftliche Trends den „Popcorn-Report“ von F. POPCORN. München. 1992.
} 
Ferntouristische Ziele liegen nach OPASCHOWSKI (1999) kurzfristig nicht im Trend, langfristig aber schon.

Die Studie Megatrends im Tourismus des Umweltbundesamtes fasst die aktuellen touristischen Trends mit der Formel „schnell, häufig, kurz und weit weg“ prägnant zusammen (s. KREISEL, HOPPE, REEH 2000, S. 57). Megatrends im Tourismus gelten hierbei als integrative Bestandteile der allgemeinen gesellschaftlichen Megatrends, die sich allerdings nicht völlig eindeutig lokalisieren lassen. Mehrere Trends und Gegentrends bestehen nebeneinander; Trends schwächen sich ab oder werden wieder stärker und im Zuge der Individualisierung entstehen Einzeltrends. Generell gilt: Immer mehr Menschen reisen immer individueller und weiter weg, Kurzreisen nehmen zu, Erlebnis, Genuss und Event stehen im Vordergrund, Qualität wird gefordert (vgl. ebenda, S. 57 ff.). Die Autoren stellen außerdem heraus, dass die allgemeine Sensibilisierung bezüglich der Umweltproblematik auch im Tourismus zu finden ist, sowohl auf Seiten der Anbieter als auch der Nachfrager. Diese generelle Aufgeschlossenheit gegenüber der Umweltthematik kann aber (noch?) nicht als Mega-Trend gelten (vgl. ebenda, S. 68 ff.).

Als generelle aktuelle Trends im Tourismus definiert Steinecke (2000, S. 11 f.):

- das steigende Anspruchsniveau der Urlauber

- der Wunsch nach Zusatznutzen

- der zunehmende Wunsch nach Individualität

- die große Flexibilität und Kurzfristigkeit

- die wachsende Preissensibilität

- die komplexen Motiv- und Aktivitätsbündel

- die ständige Diversifizierung der Zielgruppen

Diversifizierung von Zielgruppen und zunehmender Wunsch nach Individualität sind Trends, die nachhaltigem Tourismus nicht widersprechen. 


\section{$\underline{\text { 3.3 Chancen für einen zukunftsfähigen Tourismus }}$}

Auf Grund der Eigenschaft des „Nachfragegesteuertseins“ und der Bedeutung gesamtgesellschaftlicher Trends bestehen „Nischenchancen“ für einen zukunftsfähigen Tourismus. Mit einem zu erwartenden weiter steigenden Bildungsniveau, Erlebnisstreben, Individualismus und Umweltbewusstsein kann ein kleines Marktsegment insbesondere von kleineren und mittleren Anbietern besetzt werden (vgl. auch Fazit von Kap. 2).

Auch auf der ITB 1999 (6. - 10.3.) konnte eine verstärkte Formierung von Verbänden und Organisationen beobachtet werden, die sich einem zukunftsfähigen Tourismus widmen. Diese Art der Anbieter, sowie die wissenschaftliche und bildungspolitische Begleitung zukunftsfähiger Tourismusformen unterliegen einem Aufwärtstrend und einem zunehmenden Grad der Vernetzung. So traten auf der ITB 1999 zehn NGOs aus umwelt-, sozial- und entwicklungspolitischen Bereichen in der Initiative „Tourismus - Umwelt und Entwicklung“ gemeinsam auf:

- Gemeinsamer Arbeitskreis Tourismus und Ethnologie (GATE) e.V.

- Bund für Umwelt und Naturschutz Deutschland (BUND) e.V.

- Ökologischer Tourismus in Europa (Ö.T.E.)

- Institut für Integrativen Tourismus \& Freizeitforschung (IITF)

- respect - Zentrum für Tourismus \& Entwicklung

- Dortmunder Arbeitskreis Raumplanung und Tourismus (D.A.R.T.)

- Naturfreunde Bundesverband Deutschland (NFD) e.V.

- Naturfreunde Internationale (NFI)

- gruppe neues reisen (gnr)

- Verkehrsclub Deutschland (VDC)

- forum anders reisen

- Verträglich Reisen

Zu aktuellen Entwicklungen auf der internationalen Ebene vgl. auch Kap. 4.2.

Um ein Nachfragepotential für das oben beschriebene Leitbild einer Form des zukunftsfähigen Reisens zu ermitteln, hat Fair Trade eine telefonische Befragung von 500 Besitzern, Mitarbeitern 
und Kunden von Eine-Welt-Läden durchgeführt (Fragebogen, s. Anl. 3 im Anhang). 69 Antworten waren verwertbar.

Ca. 70\% der Befragten planten allerdings innerhalb der nächsten 3 Jahre keine Reise in ein Drittweltland. Vorherrschende Reisemotive waren insbesondere Kultur und Bildung, Kontakte zur einheimischen Bevölkerung, Abschalten und Ausspannen. Das nächst stärkere Motiv war ökologisch Reisen/Natur erleben. Immerhin über 50\% derjenigen, die innerhalb der nächsten 3 Jahre eine Reise in ein Drittweltland planen, konnte sich vorstellen, für eine Reise nach dem FairTravel-Konzept zwischen DM 4000,- und DM 5000,- auszugeben, während 80\% prinzipiell an einer solchen Reiseform interessiert wären. Ca. 70\% dieser Teilgruppe interessierten sich auch für die Produkte der Fair Trade Partner wie Kaffee und Textilien (vgl. VON WOGAU 1998).

\section{$\underline{\text { 3.4 Zwischenbilanz }}$}

Die Angebote für zukunftsfähige Tourismusformen verbessern sich ständig in ihrer Qualität. Auch ein Nachfragepotential ist vor dem Hintergrund der jüngsten Trends in der westlichen Konsumhaltung, die allgemein auch die Nachfrager der touristischen Quellgebiete beeinflusst, ganz prinzipiell vorhanden. Auch mittelfristig wird dieser Form des Reisens im globalen Kontext nur eine Nischenfunktion zukommen. Internationales Lobbying und die Sensibilisierung der Öffentlichkeit schreiten nur langsam voran. Dennoch bietet das - wenn auch kleine - vorhandene Nachfragepotential die Chance, dieser Form des Tourismus weiter Auftrieb zu verschaffen. Es bedarf intensiverer Marktforschung, um die exakten Zielgruppen eines zukunftsfähigen Tourismus zu erfassen und zu erschließen. 


\section{TOURISMUS IN ENTWICKLUNGSLÄNDERN}

Sind die globalen ökonomischen, ökologischen und soziokulturellen Effekte des Tourismus schon von großer Relevanz auf allen gesellschaftlichen Ebenen, so sind sie in Entwicklungsländern auf Grund schwächerer (Wirtschafts-)Strukturen von noch durchschlagenderer Kraft - im positiven wie im negativen Sinne.

Im globalen Vergleich fallen die Anteile an Touristenankünften für Afrika (1,6\%), Asien/Pazifik (10,3\%) und Lateinamerika (4\%) äußerst gering aus. Die weitaus meisten Touristenankünfte verzeichnet nach wie vor Europa mit ca. 48\% (vgl. WTO 2000, S. 11).

In vielen Entwicklungsländern weist der Tourismus einen steigenden Anteil am Bruttoinlandsprodukt auf und hält bis zu 50\% des BIP (vgl. VORLAUFER 1996, S. 127). Auch arbeitsmarktpolitisch hat der Sektor bei bis zu 40\% direkt und indirekt abhängigen Beschäftigten eine hohe Relevanz (vgl. VORLAUFER 1996, S. 144).

Die Struktur des Tourismus weist in den Entwicklungsländern vergleichbare Strukturen und Tendenzen auf(vgl. VORLAUFER 1996, S. 127 ff und S. 171 ff.):

- Neben der Existenz großer Hotelkomplexe transnationaler oder nationaler Ketten - nicht selten mit staatlichem Engagement, besteht eine Tendenz zur Entfaltung klein- und mittelbetrieblicher Hotellerie, sofern sie sich nach Beginn der touristischen Nutzung eines Raumes, wo sie meist eine Pionierfunktion haben, ihre speziellen Nischen finden

- Großen Hotelprojekten liegt oftmals eine Allianz einheimischer Bourgeoisie mit ausländischen Investoren zu Grunde

- Kleinbetriebe haben - auch im Entwicklungsländertourismus - steigende Marktchancen, sofern sie ihr Marketing durch Vernetzung und Kooperation bündeln und verstärken

- Im Bereich der Reiseveranstalter und -agenturen ergibt sich eine analoge Struktur: Incoming-Agenturen, die mit den ausländischen Quellgebieten verflochten sind und kleine und Kleinstagenturen, die - oft regional begrenzt - fehlendes Kapital durch flexiblere Angebote und bessere Regionalkenntnisse wettmachen

- Wirtschaftlich mit dem Tourismus verflochten sind darüber hinaus Handel und Verkehr, ebenfalls mit unterschiedlichen Betriebsgrößen und - im Falle des Transportes - meist staatlich subventioniert.

- Flächennutzungskonkurrenz kann bei großen Hotelanlagen mit entsprechendem Flächenbedarf auftreten; meist ist hiervon die Landwirtschaft betroffen. Essentieller in diesem Zusammenhang ist allerdings die Konkurrenz um Wasser (z. B. Errichtung von Golfplätzen in Gebieten, in denen Wasser bereits knapp ist).

- Ein klassisches Merkmal touristischer Erwerbsformen in Entwicklungsländern ist der hohe Anteil des informellen Sektors, der oft über 50\% ausmacht.

- Der Tourismus konnte durch die Erschließung peripherer Räume bisher nicht wesentlich zum Abbau regionaler Disparitäten beitragen, in einigen Fällen aber die Verschärfung verlangsamen. 


\section{$\underline{\text { 4.1 Die wirtschaftliche Bedeutung des Tourismus in Entwicklungsländern }}$}

Die wirtschaftlichen Effekte des Tourismus in Entwicklungsländern sind sehr differenziert im Zeitverlauf und länderspezifisch zu betrachten. Je nach Verflechtung mit transnationalen Ketten und ausländischen Investoren und auch in Abhängigkeit von inländischen Möglichkeiten der touristischen Zulieferung (Nahrungsmittel, Kunstgewerbe, Baugewerbe etc.) kann der Nettodeviseneffekt positiv oder negativ ausfallen. Zwar führt der Tourismus von Industrieländern in Entwicklungsländer zunächst zu einem Devisenabfluss aus Ersteren, wird aber durch einen tourismusbedingten Devisenabfluss aus den Entwicklungsländern zurück in die Industrieländer wiederum teilweise, ganz oder überkompensiert. Folgende Faktoren beeinträchtigen einen positiven Nettodeviseneffekt:

- Einfuhr von Konsumgütern für die Touristen, z. B. Lebensmittel, Treibstoff

- Kapitaltransfer ausländischer Unternehmen der Tourismusbranche

- Kosten für touristische Investitionsgüter und Infrastruktur

- Kosten für Gehälter ausländischer Führungskräfte und Werbung

Der Kapitalabfluss ins Ausland (leakage) ist umso stärker, je geringer die Integration der Touristen in die Wirtschaft des jeweiligen Entwicklungslandes ist (s. HENNIG 1999, S. 154).

Eine Gefahr besteht auch bei sogenannten ,negativen Demonstrationseffekten“, wo die einheimische Bevölkerung das Konsumverhalten der Touristen nachahmt und eine zusätzliche Nachfrage nach ausländischen Importgütern entsteht.

Der Tourismus ist ein Wirtschaftszweig mit unterschiedlicher Kapitalintensität, aber immer hoher Arbeitsintensität. Auch hier können die Effekte zweischneidig sein: zum einen ist eine Entlastung des Arbeitsmarktes möglich, zum anderen kann Migration aus den ländlichen Gebieten die Vernachlässigung der dortigen Landwirtschaft zur Folge haben.

Backward linkages entstehen im Tourismus in Entwicklungsländern insbesondere in der Landwirtschaft (vgl. VORLAUFER 1996, S. 127 ff.), aber: 
Die Nachfrage nach touristischen Formen, die eine gewisse Nähe zu nachhaltigem Tourismus haben können, Natur- und Kulturtourismus, bilden in den meisten Entwicklungsländern durchaus Potentiale. Die in Kap. 2 beschriebenen Erwartungen des Naturtouristen können erfüllt werden. Darüber hinaus ist insbesondere bei Reisenden mit Ziel Entwicklungsland das Interesse an der jeweiligen Kultur des Landes hoch (vgl. gtz 1999, S. 30). Ein nicht zu vernachlässigender Faktor der touristischen Nachfrage ist Wissenschafts ${ }^{25}$ - und/oder Projekttourismus in Entwicklungsländer. Zunehmend ist neben den klassischen touristischen Quellgebieten, den westlichen Industrieländern, in fast allen Entwicklungsländern auch eine Zunahme der Binnennachfrage zu beobachten (ebenda, S. 31 f.).

Diese Nachfrager zeichnen sich in der Regel durch ein relativ hohes Einkommens- und Bildungsniveau aus und sind als Touristentyp dem Niveaumilieu und dem Selbstverwirklichungsmilieu (vgl. Kap.2) zuzuordnen.

In diesem Zusammenhang sei auch auf einen zunehmenden Süd-Süd-Tourismus hingewiesen, der insbesondere in den ASEAN-Staaten ${ }^{26}$ zu beobachten ist. Darüber hinaus weisen Länder wie Indien einen hohen Binnentourismus ${ }^{27}$ auf, der sich zu einem großen Teil aus Pilgertourismus speist.

\subsection{Der neue Pragmatismus in der aktuellen Diskussion über Tourismus in}

\section{Entwicklungsländern}

Die Diskussion um „Reisen in die Dritte Welt“, die in den 60er Jahren einsetzte, wurde zunächst durch eine Welle der Euphorie auf Grund der ökonomischen Möglichkeiten bestimmt, als deren Vertreter u. a. FENTRUP und MEINKE zu nennen sind. HÄUSLER (1995, S.1 ff.) definiert die Anfänge der 70er Jahre als „Ernüchterungsphase“ (vertreten durch JAFARI, SCHAWINSKI und LEEMANN), in der negative Auswirkungen thematisiert wurden, und eine „Aktionsphase“

Mitte/Ende der 70er, die durch eine verstärkte Bildungs- und Informationspolitik zur Sensibilisierung in Sachen Entwicklungsländertourismus gekennzeichnet war. Die 80er Jahre bezeichnet HÄUSLER als „Phase der Organisation“ auf Grund der Entstehung von

\footnotetext{
${ }^{25}$ Vgl. zum Thema „Wissenschaftlicher Tourismus“ ausführlich BUCHWALD/DILGER 1989.

${ }^{26}$ Vgl. hierzu ausführlich HANEFELD 1997.
} 
Organisationen und Netzwerken (z. B. Tourismus mit Einsicht) und zunehmender Forschung nicht zuletzt auf der Basis der Definition des „Sanften Reisens“ von Robert JUNGK, aber auch als Phase des Widerstandes, des sogenannten „Aufstands der Bereisten“ (z. B. Goa). In den 90er Jahren begann man die Konzepte der 80er umzusetzen und die Tourismusbranche selbst brachte verstärkt das Schlagwort „Ökologie“ in die eigenen Programme ein.

Bis Mitte der 90er Jahre kann die Diskussion über Tourismus in Entwicklungsländern als relativ festgefahren betrachtet werden. Befürworter und Kritiker stehen sich fast unbeweglich gegenüber. KRIPPENDORF ist als einer der wenigen Vertreter zu nennen, die sich um eine differenzierte Betrachtung bemühen. Auch die staatliche Entwicklungszusammenarbeit stellte 1978 die Förderung von Tourismus in Entwicklungsländern offiziell zurück (vgl. VIELHABER 1998, S. 57).

${ }^{27}$ Vgl. hierzu ausführlich TÜTING 1997. 
VORLAUFER (1996) setzt Rezeption und zeitliche Einbettung der EntwicklungsländerTourismusdebatte in den Kontext der entwicklungstheoretischen Diskussion:

Abb. 10: Entwicklungstheorien und Tourismus

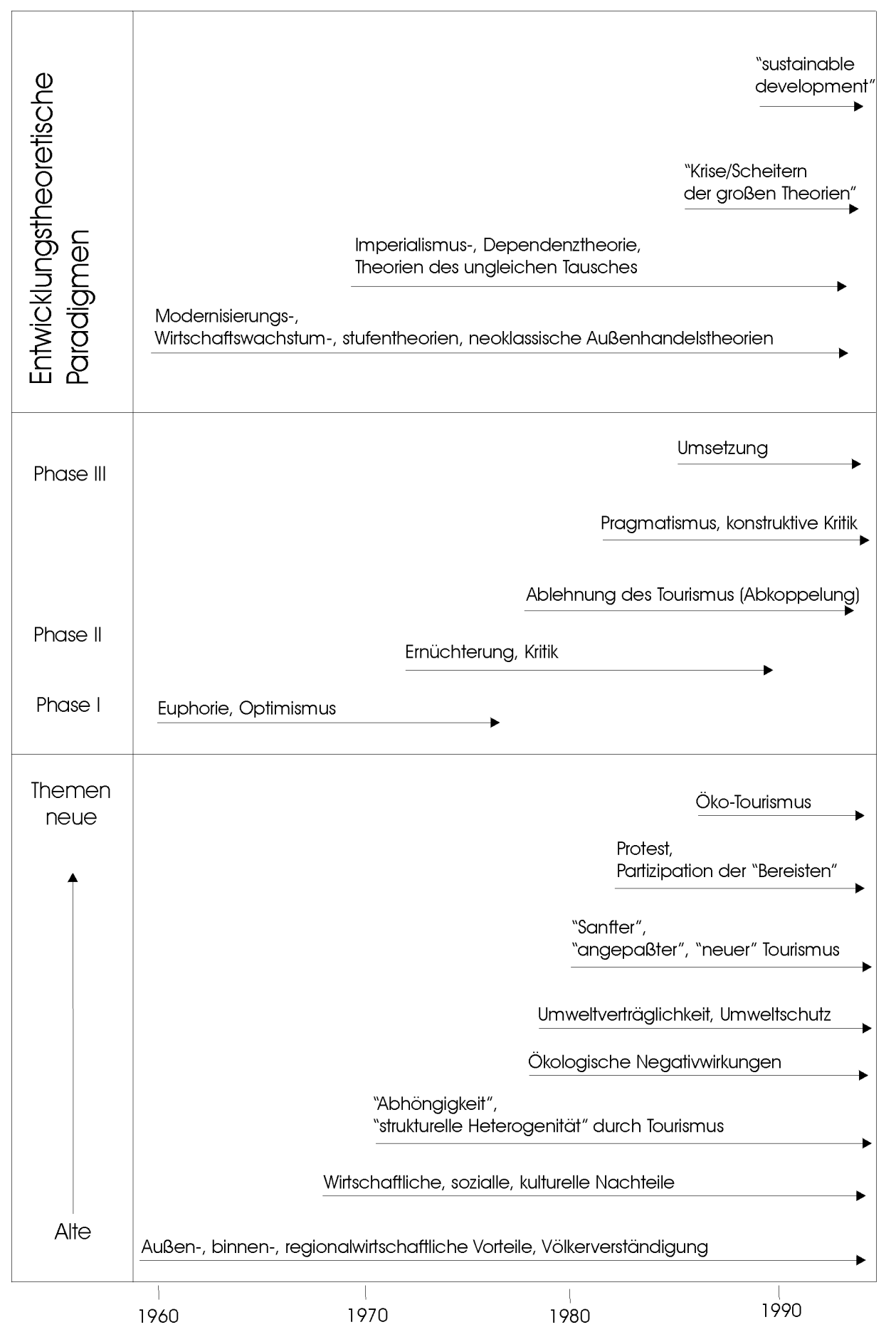

Abb.10 Phasen und Leitthemen der wissenschaftlichen und entwicklungspolitischen Diskussion um den Entwicklungsländer-Tourismus im Rahmen der Rezeption der vorherrschenden entwicklungstheoretischen Paradigmen (Entwurf: Karl Vorlaufer; Zeichnung: U. Beha)

Neben dem Ergebnis, dass es nicht möglich ist, Tourismus in Entwicklungsländern grundsätzlich positiv oder negativ zu bewerten, kommt VORLAUFER zu dem Schluss, dass nach dem 
„Scheitern der großen Theorien“ ein neuer Pragmatismus die heutige wissenschaftliche und entwicklungspolitische Diskussion bestimmt:

„Die Bewertung der von Tourismus ausgehenden negativen und positiven Wirkungen wird dadurch erschwert, dass ,Entwicklung' infolge unterschiedlicher politischer, ideologischer und wissenschaftstheoretischer Positionen und Interessen nicht wertfrei beurteilt werden kann, die verschiedenen Entwicklungsziele oft inkompatibel sind und die auch im Zeitverlauf der Entfaltung einer Tourismuswirtschaft unterschiedlichen und zudem räumlich sehr differenzierten wirtschaftlichen, soziokulturellen und ökologischen Auswirkungen, die räumlich und zeitlich variablen Vor- und Nachteile des Fremdenverkehrs, quantitativ nicht erfasst und miteinander vergleichend bewertet werden können.“(VORLAUFER 1996, S. 4.)

Als ein konkretes Beispiel hierfür steht auch die Diskussion in „blätter des iz3w“, 1996, Nr. 214, S. 13-34:

Nach der pragmatischen Feststellung „Fernreisen gehören so selbstverständlich zu unserem Leben wie Farbfernsehen und Tiefkühlprodukte" kommt man zu dem Schluss:

„Eine ernst zu nehmende Tourismuskritik muss an verschiedenen Seiten ansetzen. Sie muss dem Bedürfnis der Menschen nach Reisen Rechnung tragen und über verträgliche Tourismusformen nachdenken. Sie muss die Systemfrage stellen und radikale Veränderungen hier bei uns einfordern, damit sinnvolle Reiseformen nicht dem Belieben des Einzelnen überlassen bleiben, sondern sich von selbst aus den gesellschaftlichen Verhältnissen ergeben. ... Eines muss Tourismuskritik jedoch nicht: Verzicht predigen. Reisen an sich ist nichts schlechtes. Kommt nur darauf an, was wir daraus machen." (blätter des iz3w, 1996, S. 13, Editorial)

Das Informationszentrum Dritte Welt spricht sogar von der „Produktivkraftentfaltung im Tourismussektor“, während Stellen staatlicher Entwicklungszusammenarbeit, beispielsweise die gtz meint: „Der Schutz der biologischen Vielfalt wäre ohne die Einnahmen aus dem

Fremdenverkehr nicht zu finanzieren“(MIERSCH 1997, S. 82). Die touristische Nachfrage nach „Tierattraktionen“ bedingt deren Erhalt. Der hiernach bestimmte monetäre Wert der Tiere ist außerdem vielfach größer als deren direkter Verkauf. Von der Positivargumentation für Tiere ist es nicht weit, auch positive Aspekte für Menschen zu finden, die über wirtschaftliche Vorteile hinaus gehen:

„das (wenngleich oberflächliche) Interesse der Touristen an der heimischen Kultur bewirkt bei den Gastgebern oft eine Rückbesinnung auf das kulturelle Erbe; selbst schon weniger beachtete Kulturgüter erfahren oft eine positive Neubewertung und Wiederbelebung.“( (s. VORLAUFER 1996, S. 203)

Zwischen den Polen fortschrittsgläubiger Euphorie und rigoroser Ablehnung in Bezug auf touristische Prozesse finden sich in der entwicklungspolitischen Diskussion neue und immer differenziertere Graustufen der Argumentation. Eine bloße Schwarz-Weiß-Malerei wurde abgelöst durch feinere Abstufungen und neue Blickwinkel. Die Tourismuskritik muss sich auch daran messen lassen, ob sie in der Lage ist, wirkliche Alternativen zu liefern, was sich als Quadratur des Kreises erweisen könnte: 
„Hierbei ist zum einen zu fragen, ob die Kritik Alternativen für Massen und nicht zu ihnen entwirft, und zum anderen, ob diese Alternativen auch dann noch Alternativen bleiben, wenn sie massenhaft in Anspruch genommen werden.“ (s. BERTRAM 1997, S. 226)

Auch wird die Tourismuskritik selbst kritisch unter die Lupe genommen:

„Wir waren lange unfähig zu sehen, dass Tourismus nur einer von vielen Faktoren des soziokulturellen Wandels in unseren Gesellschaften ist, und dass dieser Wandel nicht immer von irgend jemandem mit einer bestimmten Absicht initiiert wurde, sondern auf vielfältigen Ursachen beruht. Die Schwäche, dies einzusehen, betraf sowohl das liberale wie auch das linksorientierte Lager in der Tourismusdebatte." (s. GONSALVES, 1997, S. 232)

OPASCHOWSKI (1989, S. 47 f.) unterscheidet nach Roman BLEISTEIN vier Phasen der Tourismuskritik, die oben genannten Ausführungen im Wesentlichen bestätigen. Als massiver Kritiker der Tourismuskritik wirft er den Tourismuskritikern vor:

„Tourismuskritik spielt sich nur im Kopf ab, plädiert vehement für ein anderes Bewusstsein und sagt nicht konkret, wie Reiseverhalten massiv verändert werden kann. Der kritische Reisende wird gesucht und am Ende der aufgeklärte Tourist gefunden, der das Gleiche nur mit einem anderen Bewusstsein macht. Tourismus ist ein Spiegelbild unserer Gesellschaft. Wer den Tourismus verändern will, muss auch die Gesellschaft verändern, dass heißt Einfluss auf die Strukturen des Alltags und die Freizeitwünsche und Feriensehnsüchte der Menschen nehmen.“(OPASCHOWSKI 1989, S. 47)

Ähnlich argumentiert SCHERER (1995, S. 108):

„Die Tourismuskritik ist so alt wie der Tourismus, ihr Prinzip unverändert: Der ,gute' Reisende ist man selbst, ,Touristen', ,Neckermänner', das sind stets die anderen. Nirgends blieb die Tourismuskritik romantischer als in Deutschland. Ihrem Dogma vom unschuldigen Paradies, einer Idee des 18. Jahrhunderts, entsprach die Doktrin vom Urlaub als Wiederherstellungsmaschinerie einer unerträglichen Alltags- und Arbeitswelt.“

Im Rahmen einer sinnvollen Förderung von touristischen Projekten in der

Entwicklungszusammenarbeit (EZ) ist in diesem Fall die staatliche EZ den meisten NGOs voraus $^{28}$; speziell in Lateinamerika existieren einige Erfolg versprechende Projektansätze (vgl.

Kap. 5.3). Insbesondere den bisherigen Vorreitern der Kritik an Tourismus in

Entwicklungsländern fällt es enorm schwer, die Förderung touristischer Kleinprojekte auf

Wunsch ihrer Partner zu fördern. Speziell bei den kirchlichen Hilfswerken Misereor und Brot für die Welt ist die derzeitige Förderung solcher Projekte zurzeit noch sehr gering. Neue Wege beschreitet allerdings das Programm „Fair Travel“", das auch von diesen Hilfswerken getragen wird und sich zurzeit in der Erprobungsphase befindet (vgl. Kap. 3.1).

Auf der internationalen Ebene hingegen entwickelten kirchliche und nichtkirchliche NGOs schon in den 80er Jahre Konzepte für entwicklungsrelevante Tourismusprojekte. Das Nord-Netzwerk

\footnotetext{
${ }^{28}$ vgl. Deutsche Gesellschaft für Technische Zusammenarbeit (gtz) GmbH: „Tourismus in der Technischen Zusammenarbeit." Eschborn. 1999.
} 
TEN (Third World Tourism European Ecumenical Network) empfahl damals schon zusammen mit der Süd-NGO ECTWT (Ecumenical Coalition on Third World Tourism) Kriterien für förderungswürdige Tourismusprojekte in Entwicklungsländern (vgl. HAMMELEHLE 1995, S. $100 \mathrm{ff}$.$) .$

Der CSD $^{29}$-Prozess (vgl. auch Kap. 7) reflektiert unter anderem Zusammenhänge zwischen Tourismus und nachhaltiger Entwicklung auf internationaler Ebene. Die Diskussion in der UNKommission für nachhaltige Entwicklung wird auf nationaler Ebene insbesondere von dem Arbeitskreis Tourismus des Forums Umwelt und Entwicklung, einem Zusammenschluss deutscher Nichtregierungsorganisationen zur kritischen Begleitung des Rio-Folgeprozesses, geführt (vgl. hierzu ausführlich KAMP 1998 und ORLOVIUS-WESSELY 1999).

\section{$\underline{4.3 \text { Akteure und Rezeption des Tourismus in Entwicklungsländern }}$}

Im Folgenden seien Akteure und Rezeption von Tourismus in Entwicklungsländern auf drei Ebenen wiedergegeben: a) der Regierungsebene in Entwicklungsländern, b) der Ebene bestimmter gesellschaftlicher Gruppen in den Entwicklungsländern, c) der dortigen Basis.

Ausgeklammert werden soll hier die nähere Betrachtung der Ebene „Indigene Völker und Tourismus“, da diese in ausführlicher Weise in Kapitel 5 beleuchtet wird.

\subsubsection{Die Regierungsebene in Entwicklungsländern}

Kaum eine Regierung in einem Entwicklungsland nimmt einen konsequent kritischen Standpunkt zu den Negativeffekten des Tourismus im eigenen Land, geschweige denn zur globalen Dimension des Problems ein. Der Devisenbeschaffer Tourismus, die „weiße Industrie“, weist einen nach wie vor verlockenden Weg der wirtschaftlichen Entwicklung.

Einzelbeispiele wie Bhutan (vgl. KREZDORN 1997, S. 137 - 143), die durch eine rigorose Kontingentierung die Touristenanzahl begrenzen oder die Galapagosinseln (vgl. AMEND 1997,

\footnotetext{
${ }^{29} \mathrm{CSD}=$ Commission on Sustainable Development, diese UN-Kommission für Nachhaltige Entwicklung ist ein nach der Konferenz in Rio geschaffenes Gremium, das die Umsetzung der Agenda 21 überwacht.
} 
S. 235 - 240), die ohne eine Begrenzung der Touristenzahlen ihr eigenes touristisches Potential selbst zerstören würden, sind nur Ausnahmen im globalen Trend. Dennoch hat auch auf mancher Regierungsebene ein Umdenken eingesetzt: In Thailand zum Beispiel, wo der Sextourismus imageschädigend für das ganze Land wirkt, ebenso wie in anderen Ländern, in denen insbesondere die ökologischen Effekte des Tourismus ihn selbst bedrohen. Kennzeichnend für die meisten Ansätze, tourismusindizierte Probleme zu entschärfen, ist eine Zuspitzung dieser bis zu dem Punkt, an dem real ökonomische Verluste eintreten. Vorher ist der Handlungsbedarf eher gering.

Der Handlungsspielraum von Entwicklungsländerregierungen wird allerdings durch weltwirtschaftliche Abhängigkeitsstrukturen vielfach eingeschränkt.

Dennoch kommt der Regierungsebene (inklusive kommunaler oder halbstaatlicher Einrichtungen) in Entwicklungsländern als Akteur im Tourismus eine wichtige Rolle zu, da die Schaffung von touristischen Rahmenbedingungen in ihren Verantwortungsbereich fällt (s. gtz 1999, S. 21 f.):

- Verkehrsinfrastruktur

- Einreise- und Devisenbestimmungen

- Sicherheit

- Gesundheitliche Versorgung

- Schutz der touristischen Attraktionen

- Wirtschaftsordnung/Finanzpolitik

- Förderung und Beratung

- Marketing/Ausbildung

- Umweltgesetzgebung

\subsubsection{Gesellschaftliche Gruppen in Entwicklungsländern}

Die gesellschaftliche Differenzierung ist je nach Kultur und Land natürlich unterschiedlich. Doch überall gibt es zwischen Basis und Regierungsebene verschiedene gesellschaftliche Interessengruppen, die wiederum mit Basis und Regierungsebene in enger Wechselwirkung stehen. Neben politischen Parteien, größeren Familienverbänden, speziellen Schichten (extremes Beispiel hierfür: Kastenwesen in Indien) und religiösen Gemeinschaften sind dies auch 
zunehmend Nichtregierungsorganisationen. Insbesondere vom westlichen Ausland gefördert, gelten sie als Partner partizipativer Entwicklungsansätze und in ihrer zunehmenden weltweiten Vernetzung als Hoffnungsträger zur Überwindung der weltweiten Armut.

Nichtregierungsorganisationen ihrerseits stehen zu anderen gesellschaftlichen Gruppen in enger Beziehung, z. B. zu religiösen Gemeinschaften, und entdecken, ebenso wie Ihre westlichen Geldgeber, zunehmend auch den Tourismus als „einkommenschaffende Maßnahme“, der in seiner zukunftsfähigen Variante durchaus in entwicklungspolitische Konzepte passt.

\subsubsection{Die Basis in Entwicklungsländern}

Die Basis in Entwicklungsländern ist Nährboden sämtlicher gesellschaftlicher Gruppen und wählt in demokratischen Staaten die Regierung. Nicht selten existiert daher eine extrem protouristische Einstellung der Regierung, die von der Basis mehrheitlich gestützt wird, da kurzfristige wirtschaftliche Interessen bei beiden Ebenen überwiegen. Fällt die wirtschaftliche Partizipation der Basis am Tourismus gering aus oder verringert sie sich zusehends, ist dies der Ausgangspunkt für ein Umkippen der Stimmung. Die Ausrichtung - auch der Basis - im Tourismus vorwiegend ökonomische Interessen zu verfolgen, sollte nicht moralisch gewertet werden, denn sie entspringt - in Ermangelung anderer wirtschaftlicher Alternativen - nicht selten rein materieller Not. 


\subsection{Chancen für einen zukunftsfähigen Tourismus in Entwicklungsländern}

Neben einzelnen Studien, die Tourismus und selbstbestimmte Entwicklung in Entwicklungsländern als sich einander ausschließende Faktoren betrachten ${ }^{30}$, gibt es auch eine Reihe hoffnungsvoller Ansätze (konkrete Beispiele: vgl. Kap. 5.3 und gtz 1997). Mangels ökonomischer Alternativen ist der Tourismus sowohl auf volkswirtschaftlicher Ebene, als auch aus dem Blickwinkel einer NGO - natürlich immer auch in Abhängigkeit der natürlichen Ressourcen - oft der einzige Lichtblick hinsichtlich der Erzielung eines - auch langfristig - guten Einkommens. Traditionelle oder wieder belebte andere Formen des Einkommenserwerbs wie zum Beispiel Landwirtschaft und Kunsthandwerk können durch geschickte Kombination mit touristischem Engagement von diesem profitieren:

\footnotetext{
„Der Tourismus ist sicherlich weit davon entfernt, die Lösung für die Probleme der Entwicklungsländer zu sein. $\mathrm{Zu}$ vielschichtig und verschieden sind die konkreten Einzelsituationen, als dass es die Lösung, den Ansatz, das Konzept gäbe. Andererseits ergeben sich bei nüchterner Betrachtung für die Entwicklungszusammenarbeit interessante Möglichkeiten, Tourismus zur Umsetzung entwicklungspolitischer Zielsetzung zu nutzen. Wir möchten die Hypothese wagen, dass Investitionen in ,Nachhaltigen Tourismus' vor allem in marginalen Gebieten mit attraktiver naturräumlicher Ausstattung und hoher Biodiversität auf Grund eines hohen entwicklungspolitischen Nutzens eine sinnvolle Ergänzung für EZ-Vorhaben mit Schwerpunkt auf Land- oder Forstwirtschaft oder Ländlicher Regionalentwicklung darstellen können.“ (s. gtz 1997, S. 2)
}

\section{$\underline{4.5 \text { Zwischenbilanz }}$}

Es verfestigt sich in der wissenschaftlichen und der allgemeinen Dritte-Welt-Debatte zusehends die Einsicht, dass Tourismus sich auch in Entwicklungsländern zu einer nicht wegzudiskutierenden wirtschaftlichen Größe entwickelt hat. Tourismus wird in Entwicklungsländern in der Regel auf allen gesellschaftlichen Ebenen im Prinzip bejaht, nur über die Form gibt es Differenzen. In vielen Entwicklungsländern stellt sich zunächst auch gar nicht die Frage der Form oder gar Nachhaltigkeit, da die unmittelbare Einkommenserzielung für alle Beteiligten prioritär ist. Auf Grund der geringeren Stärke und Differenzierung der Volkswirtschaften vieler Entwicklungsländer können potentielle Negativeffekte des Tourismus nicht abgefangen werden, bzw. die Tourismusprojekte nicht derart in bestehende wirtschaftliche Strukturen integriert werden, dass die Gesamtentwicklung positiv verläuft. Interessant in der gesamten Diskussion über Tourismus in Entwicklungsländern ist die grundsätzlich verschiedene Rezeption in westlichen Industrieländern und den Entwicklungsländern selbst. Die Kritik am Tourismus wird in den touristischen Quellgebieten und Geberländern der Entwicklungshilfe sehr viel massiver formuliert. Da inzwischen NGO-Partnerorganisationen von Einrichtungen der

\footnotetext{
${ }^{30} \mathrm{vgl}$. hierzu ausführlich SCHERRER 1988
} 
Entwicklungszusammenarbeit eigene Tourismusprojekte konzipieren und durchführen, befindet sich die Diskussion um Tourismus in Entwicklungsländer im Moment in einer Umbewertung. 


\section{INDIGENE VÖLKER UND TOURISMUS}

Bedeutet die Verengung der Betrachtung des Phänomens Tourismus auf Entwicklungsländer schon eine Verschärfung der Problematik, so wird dies durch die Fokussierung auf den Ausschnitt „Indigene Völker und Tourismus“ nochmals gesteigert.

Insbesondere in der Ethnologie finden sich in der jüngeren Vergangenheit verschiedene Forschungsvorhaben zum Spannungsfeld „Indigene Völker und Tourismus“(vgl. Kap.1). Ebenso wie in der allgemeinen entwicklungspolitischen Diskussion setzte die pragmatische Auseinandersetzung der Ethnologie mit dem Themenkomplex Tourismus relativ spät ein.

Tourismus ist nur eine von vielen Formen des interkulturellen Kontakts, die in der jeweiligen Intensität variieren:

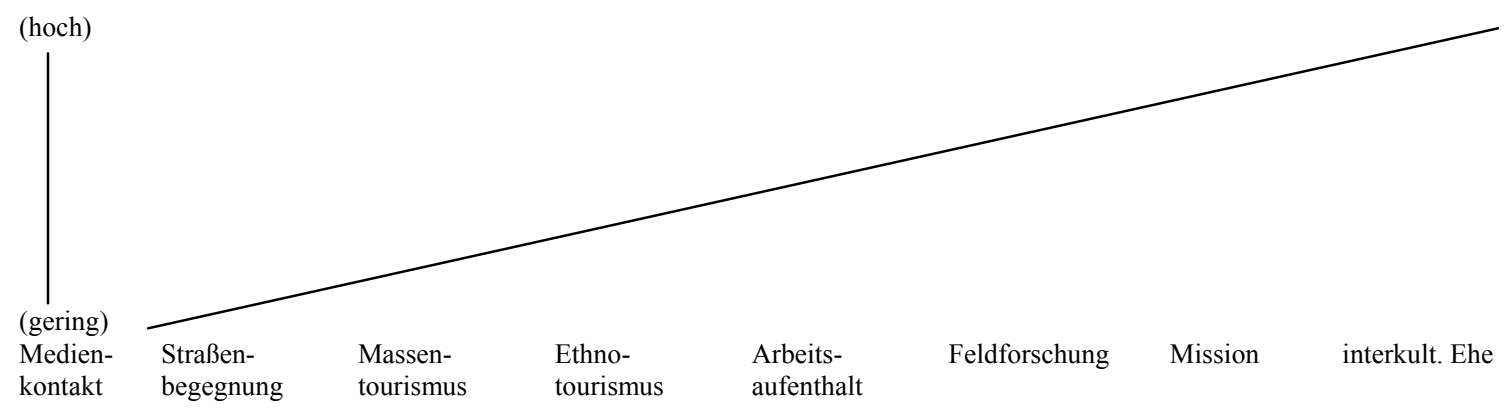

Abb. 11: Intensität interkultureller Kontaktformen (s. KIEVELITZ 1989, S. 33) 
Die Motive dieses interkulturellen Kontaktes unterscheiden sich bei Reisenden und Einheimischen gewaltig:

\section{A. Reisende}

Psychische Motive

- Wunsch nach intensiver Exotik

- Wunsch nach intensiven sinnlichen Eindrücken

- Bildung

- Herausforderung durch besondere Abenteuer

- Rollenwechsel

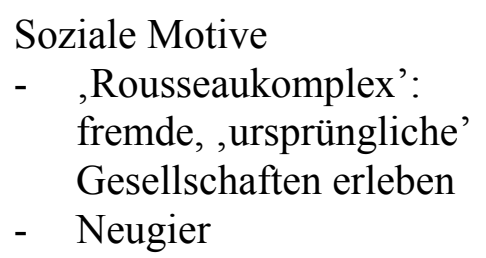

Kulturelle Motive

- Ausbruch aus urbanem Lebensstil

- Kennenlernen fremder Kulturen

- Statusverbesserung

\section{B. Einheimische}

Ökonomische Motive

- Arbeitsplatzsuche

- Ausbruch aus ländlicher Armut

- höherer Verdienst im Tourismus-Sektor

- ,attraktivere“, nicht landwirtschaftliche Tätigkeit

Wichtige Einflussfaktoren sind dabei die folgenden:

- Zeitfaktor

- benutzte Sprache verbal nonverbal

- Rückgriff auf kulturelles Repertoire

- Selbst-, Fremd- und Situationsbild

- Botschaft

- Subjekt-Objekt-Beziehung

Abb. 12: Motivstrukturen des Ethnotourismus (s. KIEVELITZ 1989, S. 43)

Touristen haben es selbst in der Hand, die „Qualität“ ihrer kulturellen Kontakte zu den Gastgebern zu verbessern: die alltäglichen Kontakte in der Stadt oder einem ländlichen Gebiet beim Einkaufen, beim Essen in einheimischen Restaurants oder der Inanspruchnahme lokaler Dienstleistungen (z. B. Transport) lassen sich - die Überwindung der Sprachbarriere vorausgesetzt - durch längere, sensible Gespräche immerhin intensivieren (vgl. PARDON 1997, S. 145). 
Insbesondere Touristen aus dem „Selbstverwirklichungsmilieu“(vgl. Kap. 2.3) gehen mit der Problematik der kulturellen Kontakte im Rahmen von Reisen noch relativ sensibel um.

\subsection{Ergebnisse bisheriger Forschungsvorhaben zu indigenen Völkern und Tourismus}

Reisen per se ist vielfach kulturimmanent: So wird gereist zwecks Handel, Verwandtschaftsbesuch und aus religiösen Motiven. Tourismus als westliches Konsummuster ist jedoch in dieser Form indigenen Völkern fremd und oft - neben den Medien - der stärkste Faktor im Kulturwandel.

Als ein wichtiger Forschungsbeitrag zu diesem Thema ist die Arbeit von Christiane KAHRMANN zu nennen: „Hoffen auf den reichen Strand“ - Tourismus in der Südsee von 1995. KAHRMANN untersucht vergleichend Wahrnehmung und Reaktionen zum Tourismus in Fidschi, den Cook-Inseln und Hawaii. Fazit ihrer Arbeit ist, dass die kulturelle Norm der Reziprozität ${ }^{31}$ der indigenen Bevölkerung im Zuge touristischer Kommerzialisierung verloren gehen muss.

In diesem Zusammenhang ist auch Helmut DWORSCHAKs Arbeit „Kulturdiskurse: Zum Verhältnis von Tourismus und indigener Kultur“"von 1994 zu nennen. DWORSCHAK untersucht die kulturverändernde Wirkung des Tourismus auf die Musik der Karibik. Ähnlich wie KAHRMANN kommt er zu einer überwiegend negativen Bewertung touristischer Veränderungsprozesse im Hinblick auf indigene Kultur.

HENNIG (1999, S. 124 ff.) führt mehrere Beispiele an, die zeigen, dass Tourismus auf indigene Gruppen auch positiv wirken kann im Rahmen von zusätzlichem Einkommen, mehr Prestige und Verstärkung der Stellung der Frauen oder Jugendlichen, Rückbesinnung auf Traditionen, Erhöhung des Selbstwertgefühls, da die Fremden herkommen, weil es ein besonderer Ort ist etc.. Anhand des Beispiels nepalesischer Sherpa belegt er (in der Argumentation genau gegensätzlich zu KAHRMANN), dass die kulturelle Norm der Reziprozität nicht verloren gehen muss, sondern sich veränderten Bedingungen anpassen kann:

\footnotetext{
${ }^{31}$ KAHRMANN bezieht sich hier unter anderem auf SAHLINS. Die kulturelle Norm der Reziprozität ist ein insbesondere in Polynesien verbreitetes - Prinzip der Gegenseitigkeit. Die Großzügigkeit, die anderen entgegengebracht wird, verlangt nach entsprechender Gegenleistung. Das in Kap. 1.5.1 erwähnte Zitat von Gabriel TETIARAHI drückt genau diesen Sachverhalt aus.
} 
„Mit der Entwicklung des Tourismus verschwanden diese traditionellen Muster nicht. Vielmehr setzte sich ein ,strategischer und innovativer Gebrauch von Reziprozität' durch. Die alten Sitten fanden neue Formen, doch ihr Kern hatte Bestand.“

Tourismus kann also immer nur im konkreten kulturellen Kontext bewertet werden. Es existiert keine Einheitlichkeit in seiner Wirkung auf die indigene Kultur.

\section{$\underline{5.2}$ Kulturwandel durch Tourismus}

„Der Tourismus, als ein Ausdruck des modernen Kults des Unterschieds, neigt unausweichlich dazu, eben jene Differenzen umzubringen, die unseren wachsenden Durst nach dem Andersartigen stillen würden.“

(BENVENUTO 1999)

Dies ist ein bekanntes Argument zu den negativen Effekten des Kulturwandels durch Tourismus, auch vor dem Hintergrund der aktuellen Globalisierungsdebatte. In diesem Zusammenhang sei erwähnt, dass Kulturwandel jederzeit stattfand und immer noch stattfindet:

„Das Bild der reinen, homogenen und integrierten Kultur der jeweils Anderen entpuppt sich immer mehr als Projektion der mit der fragmentierten Realität der Moderne hadernden Westler.“

(s. BREIDENBACH und ZUKRIGL 1998)

Unter dieser Prämisse müssen sämtliche Modelle des Kulturwandels und entsprechende Reaktionsmuster (vgl. hierzu ausführlich Kap. 1.5.5, Kap. 6.3 und Kap. 6.4.1) gesehen werden.

GROH 1997 (S. 345 ff.) problematisiert, dass die Begegnung zwischen Touristen und Bereisten im kulturellen Sinne immer eine ungleiche ist: Je größer das „Kompatibilitätsgefälle“, desto desaströser der Effekt für die nicht dominante Kultur. Er relativiert dies mit dem Hinweis darauf, dass Tourismus auch Kultur braucht:

" [...] bleibt hier zunächst festzuhalten, dass auf Grund der Dominanzkonstellation der Besucher eine Verantwortung hinsichtlich der Fortexistenz der betroffenen Kultur hat. Die Abhängigkeit ist allerdings nicht ganz einseitig; der Tourismus ist, wie andere Industriezweige auch, auf Ressourcen angewiesen - die für das Funktionieren des Tourismus zentrale Ressource heißt Kultur. Dabei liegt jedoch ein Paradoxon vor: Die Ressource wird auf Grund der Dominanzkonstellation zerstört. Tourismus bewirkt Synthese. Zumindest innerhalb des Teilbereiches der besuchten Gesellschaft wird die traditionelle Kultur zurückgedrängt. Es stellt sich ein folkloristisch-homöostatisches Niveau ein, das zum einen in so weit fortgeschrittener Synthese besteht, wie es für die Akzeptanz durch die Dominanzkultur erforderlich ist, das zum anderen aber noch einige Kulturelemente enthält, die die Dominierenden zu konsumieren wünschen.“

Die Idee der Glokalisierung (vgl. Kap. 1.5.5) verweist auch auf das kulturrevitalisierende Potential des Tourismus:

„Tourismus funktioniert in der Dialektik von Enttraditionalisierung und Retraditionalisierung des kulturellen Lebens. [...] Die McDonaldisierung der Gastrokultur produziert gleichzeitig die Wiederentdeckung der 
regionalen Küche. Die Hotelburgen für die Massen lassen die Chalets für die Individualisten aus dem Boden sprießen. Die Zerstörung der Umwelt schafft die neue Sensibilisierung für deren Bewahrung. Die Virtualisierung der Wirklichkeit führt zum Wunsch nach neuen Authentizitäten.“(s. RICHTER 1998, S. 146147.)

Der Tourismus tritt selten als alleiniger kulturverändernder Faktor auf und ist (z. B. im Vergleich zu Massenmedien) nicht unbedingt die stärkste Kraft im Kulturwandel.

\section{$\underline{\text { 5.3 Beispiele zukunftsfähiger Tourismusprojekte indigener Gruppen }}$}

Längst gibt es Initiativen indigener Gruppen, die als NGO organisiert zukunftsfähige

Tourismusprojekte anbieten. Prominentes Beispiel ist hierfür Sua Bali, ein sozialverträgliches Tourismusprojekt, das 1996 auf der ITB beim ersten To Do Wettbewerb des Studienkreises für Tourismus und Entwicklung, ausgezeichnet wurde.

Vergleichbare Initiativen entstehen zurzeit in immer mehr Ländern. Kriterien der Zukunftsfähigkeit werden dabei in unterschiedlichen Abstufungen erfüllt: Von der rein ökonomischen Kontrolle über ein touristisches Projekt (vgl. ERDMANN 1991 und 1995, Beispiel Aborigines), über Kombinationen von Ökologie und Tourismus (vgl. BURKHARD 1996 und JUNGSCHAT 1997, beide Beispiel Costa Rica ${ }^{32}$; STRADAS/BEHRENS-EGGE 1997, Beispiele Elfenbeinküste und Zentralafrikanische Republik), bis hin zu ausgefeilten Konzepten, die ökonomische, ökologische und soziokulturelle Anforderungen erfüllen müssen (vgl. KREIB 1997, GEPA Fair Travel Programm).

Das Involvement der indigenen Bevölkerung geht von partizipativen Ansätzen, die von einer projektleitenden (meist Nord-)NGO gefördert werden bis zu Kleintourismusprojekten, die von indigenen Gruppen wirklich selbst initiiert wurden, die aber durch Beratung von außen weiter optimiert werden.

Das Projekt Cuyabeno ist ein Beispiel für die bewusste Förderung der Partizipation der indigenen Bevölkerung an den Vorteilen des Tourismus in Ecuador: forstwirtschaftliche Schutzmaßnahmen werden mit klassischem Naturtourismus verbunden. Die Projektleitung findet hier unter anderem durch die gtz statt (vgl. KASPAREK 1998, S. 69 und AMEND 1997, S. 235 - 240). In den

\footnotetext{
${ }^{32}$ In Lateinamerika entwickeln sich zunehmend Projekte des Ökotourismus. Entsprechend zahlreich sind auch entsprechende Untersuchungen, die allerdings den soziokulturellen Faktor nur indirekt oder marginal berücksichtigen (vgl. KOLBE 1998, BRENNER 1998 und BOUCKE 1998).
} 
Provinzen Pastaza und im Gran Sumaco arbeiten die Indígena-Organisationen OPIP (Organización de Pueblos Indígenas des Pastaza) und Ricancie erfolgreich an der Realisierung nachhaltiger Tourismusprojekte (vgl. SCHMALL 1997, S. 241 - 247 und Vortrag Dina BAUER 2000, 12.3.00, ITB, Berlin)

Zu den funktionierenden Projekten, bei denen Einheimische den Tourismus kontrollieren und den Erhalt der Umwelt gleichwertig mit einbeziehen, gehört das Annapurna Conservation Area Project (ACAP), dessen partizipative Konzeption den Lebensstandard der lokalen Bevölkerung hob (vgl. ausführlich TÜTING 1989, S. 112 - 132 und JOB/LEISCH 1997, S. 129 - 136).

Ein weiteres Kleinprojekt ohne negative Auswirkungen auf die soziokulturelle Struktur im Dorf Lahu, Thailand, beweist die Machbarkeit von nachhaltigem Tourismus im indigenen Kontext (vgl. PARDON 1997, S. 147).

Auch in Belize und Venezuela finden sich viel versprechende Projektansätze, die von lokalen NGOs vorangetrieben werden (vgl. RATTER 1997, S. 219 - 228 und SCHOLZ 1997, S. 249 258).

Ein weiteres positives Beispiel sind das Aboriginal Art and Culture Centre in Alice Springs (Australien), das von 25 Aborigines des Arrernte-Stammes betrieben wird (vgl. VON FUNKE 1999) und das ebenfalls von Aborigenes geleitete Ökotourismusprojekt in Manyallaluk (vgl. GERDES 1998).

O’GRADY (1982, S. 64 - 68) beschreibt verschiedene interessante Ansätze im Senegal (Lower Casamance Program), sowie in Bali, wo Touristenunterkünfte in kleinen Dorfgemeinschaften errichtet oder einzelne Zimmer in bestehenden Häusern für Touristen zur Verfügung gestellt wurden und der Gewinn direkt der lokalen Bevölkerung zufloss.

Weit fortgeschritten in Konzeption und Umsetzung sind die Tourismusprojekte des Thai Volunteer Service and Responsible Ecological Social Tours (TVS-REST) mit ihrem Programm: Community Based Sustainable Tourism (CBST). Seit 1994 werden touristische Kleingruppen in Dorfgemeinschaften untergebracht, die dadurch ihr Einkommen erhöhen können. Gleichzeitig nehmen die Touristen am Leben der Einheimischen teil und haben die Möglichkeit, Natur und Kultur von der lokalen Bevölkerung selbst näher gebracht zu bekommen (vgl. Vortrag von Nicole HÄUSLER, 12.3.00, ITB, Berlin). 


\section{$\underline{\text { 5.4 Zwischenbilanz }}$}

Der Tourismus stellt ohne Zweifel eine - insbesondere wirtschaftliche - Alternative für indigene Gruppen dar. Verläuft er selbstbestimmt, können auch soziokulturelle Negativeffekte minimiert werden. Realistisch betrachtet ist der Tourismus vielfach das kleinste Übel, oft sogar die einzige Möglichkeit, ausreichendes Einkommen zu erwirtschaften. Geht es um die kurz- oder mittelfristige Existenz, steht die ökonomische Komponente zwangsweise im Vordergrund.

Kulturen haben sich immer - auch durch Kontakt mit anderen Kulturen - verändert und sind in unterschiedlicher Weise fähig, Fremdes zu übernehmen oder modifiziert in die eigene Kultur zu übertragen. Wird dabei eine gewisse Grenze der Intensität bzw. Geschwindigkeit des Kulturwandels überschritten, kippt der Effekt meist in negative Folgen:

\footnotetext{
„Der Untergang von Lebensformen und Weltbildern ist jedoch nichts Neues, neu ist nur die Geschwindigkeit dieser Entwicklungen im globalen Zeitalter. Isolierte, autonome Partikularismen, falls es sie jemals in Reinform gegeben hat, haben in unserer Zeit keine Überlebenschance. Durch die Tendenz zur Kreolisierung wird die kulturelle Vielfalt der Lebensformen aber nicht eingeebnet, sondern nimmt neue, ihre Vorgänger zum Teil integrierende Formen an.“ (s. BREIDENBACH und ZUKRIGL 1998, S. 232)
}

Risiko und Chancen im Tourismus liegen für indigene Gruppen nahe bei einander. Bei ausgewogener Berücksichtigung der ökonomischen, ökologischen und soziokulturellen Komponente können in Eigeninitiative entwickelte, kleindimensionierte Tourismusprojekte durchaus eine selbstbestimmte Entwicklung ermöglichen. 


\section{FALLBEISPIEL: DIE MAOHI IN FRANZÖSISCH-POLYNESIEN}

\subsection{Französisch-Polynesien: geographische, wirtschaftliche, politische und ethnische}

\section{$\underline{\text { Rahmenbedingungen }}$}

\subsubsection{Geographische Abgrenzung Französisch-Polynesiens}

Französisch-Polynesien umfasst als Überseeterritorium Frankreichs 132 Inseln, die eine

Landfläche von $3941 \mathrm{~km}^{2}$ in einer Wasserfläche von ca. vier Mio. $\mathrm{km}^{2}$ aufweisen und deren Lage im Gradnetz durch $7^{\circ}-29^{\circ}$ südlicher Breite und $131^{\circ}-156^{\circ}$ westlicher Länge definiert ist.

Somit kann die Lage Französisch-Polynesiens sowohl in Bezug auf den gesamten Pazifik als auch in Bezug auf das Polynesische Dreieck, das durch die „Eckpunkte" Hawaii, Neuseeland und Osterinsel begrenzt wird, als zentral bezeichnet werden.

$A b b .13$ (s. u.) veranschaulicht die Unterteilung Französisch-Polynesiens in fünf Archipele und deren administrative Gliederung. 


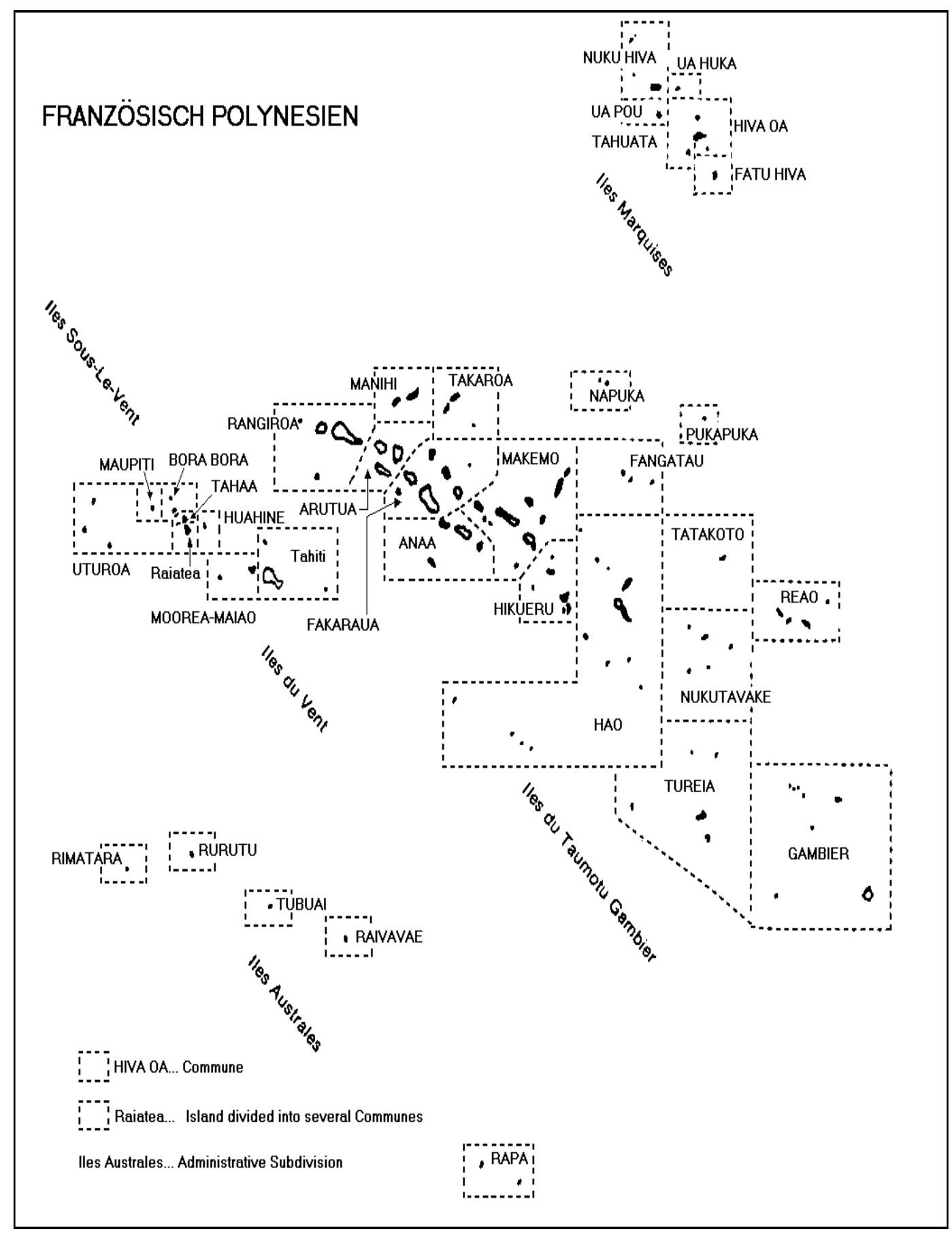

Abb. 13: nach CROCOMBE, R. G. (Hrsg.): Politics in Polynesia. Suva: Institute of Pacific Studies of the University of the South Pacific. 1983. S. 191. 
Diese fünf Archipele mit ihren Hauptinseln sind:

- $\quad$ die Gesellschaftsinseln (14 Inseln), die sich ihrerseits in die „Inseln über dem Wind" (engl. Windward Islands; frz. Îles du Vent) und die „Inseln unter dem Wind" (engl. Leeward Islands; frz. Îles sous le Vent) ${ }^{33}$ unterteilen lassen. Zur ersten Gruppe zählen z.B.: Tahiti $\left(1042 \mathrm{~km}^{2}\right)$, Moorea $\left(132 \mathrm{~km}^{2}\right)$, Maiao, Tetiaroa und Mehetia, während Raiatea und Tahaa, Huahine, Bora, Maupiti, Mopelia (Maupihaa), Moto One (Bellingshausen) sowie Manuae (Fenua Ura; Scilly) den Inseln unter dem Wind zuzuordnen sind.

- $\quad$ die Tuamotuinseln (78 Inseln, $915 \mathrm{~km}^{2}$ ): z.B: Anaa, Makemo, Hao, Reao, Napuka, Mururoa, Rangiroa, Apataki und Fakarava.

- $\quad$ die Gambierinseln (heute oft auch Mangarevainseln genannt, 9 Inseln, $30 \mathrm{~km}^{2}$ ): z.B.: Mangareva, Taravai, Aukena, Akamaru und Temoe.

- $\quad$ die Marquesasinseln (13 Inseln): z.B.: Hivaoa, Nukuhiva (482 km²), Fatuhiva, Eiao, Uapou, Uahuka, Fatuhuku, Tahuata, Motane und Hatutu.

- $\quad$ die Australinseln (auch Tubuaiinseln, 9 Inseln): z.B.: Tubuai, Rurutu, Rimatara, Raivavae und $\operatorname{Rapa}^{34}$.

(vgl. IH-Länder aktuell 1998)

\footnotetext{
${ }^{33}$ Die Namensgebung dieser Inseln kommt nicht von ungefähr: die Inseln über dem Wind sind dem SO-Passat ausgesetzt, während die Inseln unter dem Wind in relativ windgeschützter Lage liegen (vgl. ARNBERGER 1988, S. $263 \mathrm{ff}$.).

${ }^{34}$ Rapa wird in manchen Klassifikationen keinem der fünf Archipele zugerechnet, sondern einzeln aufgeführt (vgl. SIEMERS 1989, S. 333).
} 


\subsubsection{Physische Geographie Französisch-Polynesiens}

In ihrer Funktion als Grundlage des menschlichen Kultur- und Wirtschaftsraums seien im

Folgenden einige Aspekte der physischen Geographie Französisch-Polynesiens kurz dargestellt.

\subsubsection{Inseltypen und Inselgenese}

Die in $A b b .14$ dargestellte klassische Einteilung der pazifischen Inseln nach BUCHHOLZ (1984, S. 106) in fünf verschiedene Inseltypen kann auch auf Französisch-Polynesien angewendet werden:

Abb. 14

A ,Hohe" Insel

B Saumriffbildung beim Absinken des Kegels

C Reliktform einer „Hohen" Insel

D Atoll

E Gehobene Koralleninsel ${ }^{35}$

\section{A}

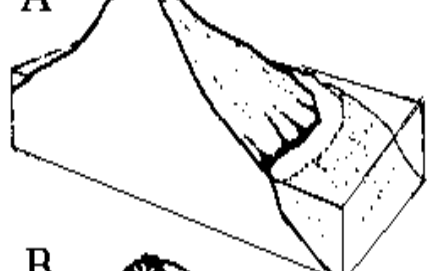

$\mathrm{B}$

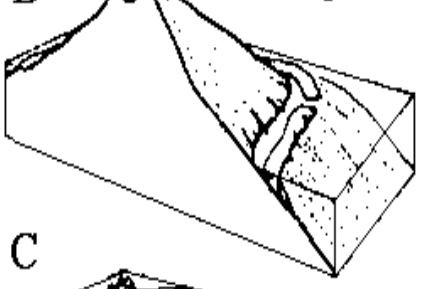

$\mathrm{C}$

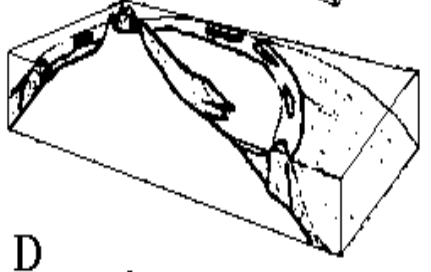

$\mathrm{D}$

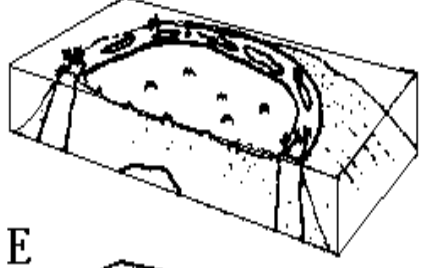

Im Folgenden ist die Unterscheidung in high islands (entspricht in etwa A-C, vulkanischer Ursprung noch erkennbar) und low islands (entspricht ungefähr D-E,

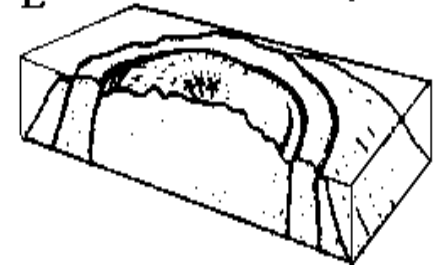
weder Vulkanruine noch Schlot sind erhalten) vollkommen ausreichend.

\footnotetext{
${ }^{35}$ Eine differenziertere Darstellung insbesondere der verschiedenen Stadien der Riffbildung bei KREISEL 1991, S. $21 \mathrm{ff}$.
} 
Die Genese dieser Inseltypen ist ein Produkt innerozeanischen Vulkanismus', der als ozeanischer Intraplattenvulkanismus durch die Theorie der hot spots (,thermale Flecken") eine mögliche und inzwischen weitgehend akzeptierte Erklärung findet. Dieser Theorie liegt die Vorstellung zu Grunde, dass „die Wärmeabgabe des Erdmantels auf eine geringe Anzahl schmaler Zonen beschränkt ist" (HOHL 1981, S. 263).

Hot spots als heiße, stationäre, ,eng begrenzte Aufschmelzungszonen im Erdmantel" (VINK u. a. 1985, S. 62) verursachen ein Aufschmelzen der Lithosphäre, die in der Folge domartig aufquellt (Plumes oder Wärmebeulen) und deren thermische Aktivität auch über geologisch relevante Zeiträume bestehen bleibt. Nur in diesen Zonen steigt die Schmelze ,,auf dem oberen Mantel diapirartig ${ }^{36}$ mit etwa zwei Metern jährlich in die Asthenosphäre bis an die Basis der Lithosphäreplatten auf" (HOHL 1981, S. 263). Bei entsprechendem Druck reißt die ozeanische Kruste und es entsteht durch die nach oben dringenden Schmelzen ein Vulkan. Da gemäß der Theorie der Plattentektonik die kontinentale Drift der Scholle gegeben ist, die thermalen Zentren jedoch stationär bleiben, kommen durch die Kontinentaldrift ,ständig neue Bereiche über den hot spots zu liegen" (HOHL 1981, S. 263). Somit entstehen entlang der Driftrichtung linienartige Vulkanreihen mit zum Teil noch aktiven Endpunkten (z. B. Hawaii), deren Alter entgegen der Drift sukzessiv zunimmt (vgl. KREISEL 1991, S. 633).

Bezüglich der Entstehung der pazifischen Inseln gilt die Annahme mehrerer hot spots als bestätigt:

„Pour l'essentiel, ils correspondent à des constructions volcaniques hors-axe que l'on tente d'expliquer par la théorie des points chauds en les regroupant en alignements dont l'âge progresse régulièrement à un taux et dans une direction similaire au mouvement absolu de la plaque pacifique. Cependant, cette modélisation pose de nombreux problèmes et peu d'alignements sont en accord avec l'existence d'un seul point chaud." (s.

MUNSCHY, ANTOINE, GUILLE, GUILLOU 1998, S. 11)

Im Zuge der Riffbildung wird aus einem high island ein low island, weshalb oft als Hauptunterscheidungskriterium zwischen high island und low island der vorwiegend vulkanische Ursprung des Ersteren und der vorwiegend koralline Ursprung des Letzteren betont wird. Als Beispiel für die verschiedenen Stadien einer Vulkaninsel lassen sich für Französisch-Polynesien die Marquesasinseln als vorwiegend „Hohe" Inseln (A s.o.), die Gesellschaftsinseln als zunehmend erodierte Formen (B s.o.), die „Vulkanruine" von Bora Bora als Reliktform (C s.o.) und die Tuamotuinseln als typische low islands (D bzw. E s.o.) anführen (vgl. BUCHHOLZ

\footnotetext{
${ }^{36}$ Unter einem Diapir versteht man einen ,geologischen Körper, der auflagernde Schichten durchbricht (Aufbruch)“ (HOHL 1981, S. 587).
} 
1984, S. 98 ff. und WIRTHMANN 1964, S. 185 ff.). Die riffbildenden Korallen wirken einer weiteren Erosion durch das Meer entgegen, wobei sie durch isostatische Hebung und eustatische Schwankung des Meeresspiegels an die Meeresoberfläche geraten können ${ }^{37}$ (vgl. KELLETAT 1999, S. 79).

Legt man die verallgemeinerte Einteilung in high islands und low islands zu Grunde, so sind die Gesellschafts-, Marquesas-, und Australinseln vorwiegend der ersten Gruppe und die Tuamotuinseln den low islands zuzuordnen, wobei die Gambierinseln beide Inseltypen aufweisen.

\subsubsection{Naturräumliches Potential}

In Abhängigkeit von dem Wirkungsgefüge Oberflächengestalt, Klima, natürliche Vegetation und Böden weisen high islands und low islands ein grundsätzlich unterschiedliches naturräumliches Potential auf:

Während bei Ersteren prinzipiell die Möglichkeit zur Aufschüttung einer Küstenebene durch Abtragungsmaterial von Flüssen (bei entsprechendem Niederschlag) gegeben ist, bietet der humusarme sandige Kalkboden eines low island zunächst eine schlechtere Grundlage für den menschlichen Kulturraum (vgl. WIRTHMANN 1964, S. 182 ff.) ${ }^{38}$.

Der tropischen Klimazone zugeordnet, weist Französisch-Polynesien nur in Bezug auf die low islands die typischen Charakteristika dieses Klimatyps in Idealform auf: hohe Luftfeuchtigkeit (bis zu 80\%), monatliche Mitteltemperatur über $20^{\circ} \mathrm{C}$, ca. 2800 Stunden Sonnenscheindauer im Jahr, eine Periode verstärkten Niederschlags von November bis April, eine durchschnittliche Niederschlagsmenge von $1625 \mathrm{~mm}$ im Jahr, ganzjährig wehenden Passat und einen Tidenhub von höchstens $40 \mathrm{~cm}$ (im Extremfall, normalerweise annähernd null). Bei den high islands hingegen überlagert das reliefbedingte Mesoklima das Makroklima, da sich Lokalklima und Vegetation auf der Luvseite deutlich von der leewärtigen Situation unterscheiden: die luvwärtige Regenmenge übersteigt den Durchschnittswert der für dieses Makroklima angegebenen Menge bei weitem, während die Leeseite bei relativer Armut in den Trockenzeiten von Dürre bedroht sein kann. Entsprechendes gilt für die natürliche Vegetation: Luvwärts dominiert immergrüner Regenwald, leewärts Trockenwald, wobei diese Differenzierung nicht ausreichend ist, da

\footnotetext{
${ }^{37}$ Einzeldarstellungen bezïglich der Korallenriffe in Französisch-Polynesien, sowie der dadurch bedingten (auch marinen) Fauna und Flora bei DELESALLE, B. u. a. (Hrsg.): French Polynesian coral reefs, reef knowledge and field guides. 5th International Coral Reef Symposium. Tahiti 1985. Paris 1985.
}

\footnotetext{
${ }^{38}$ Eine differenziertere Darstellung zu Klima, Geomorphologie, Bodenbildung, Wasserstress, natürlicher Vegetation und landwirtschaftlichem Potential der Atolle Französisch-Polynesiens geben die Autoren JAMET und TRICHET 1988, S. 275-293.
} 
zusätzlich die zunehmende Höhe Auswirkungen auf Artenvielfalt und Vegetationsdichte hat. High islands können nicht zuletzt auf Grund der Verwitterung des basaltischen Untergrunds eine hohe Bodenfruchtbarkeit aufweisen, während der Kalkuntergrund der low islands auf Grund seiner Nährstoffarmut nur für bestimmte Nutzpflanzen geeignet ist (z. B. Kokospalme). Relativ zu anderen Regionen des tropischen Raumes - in dem ferrallitische Böden vorherrschen (Latosol, Laterit, Roterden) mit weitgehender Nichteignung für großflächige Landwirtschaft - ist die Situation der high island Böden noch als positiv zu werten, da unter anderem der ferrallitische Anteil erst in höheren Lagen von Bedeutung ist (vgl. BUCHHOLZ 1984, S. 100 ff.).

OLIVER (1974, S. 20 ff. stark gekürzt unter besonderer Berücksichtigung der für die Polynesier relevanten Nutzpflanzen) rekonstruiert die heute von Autochthonen und Europäern anthropogen überformte ursprüngliche, charakteristische Vegetation wie folgt:

a) high islands:

- $\quad$ Im Bereich der Küstenebenen: Farne (z. B. Acrostichium), Gräser (z. B. Lepturus, Paspalum), sechs - für die ersten Siedler wirtschaftlich nutzbare - Baumarten: Hibiscus, Thespesia, Barringtonia, Calophyllum, Hernandia, Inocarpus (tahitian chestnut), sowie die Leguminosenarten Mucuna, Sophora und Canavalia. Weitere kleinere Baumarten, Sträucher, Kräuter, Kletter- und Schlingpflanzen dienten der autochthonen Bevölkerung zu medizinischen Zwecken, religiösen Handlungen (vgl. Kap. 3.2.2) oder als Ergänzung zur Hauptnahrung.

- $\quad$ in den höhergelegenen Gebieten (Leelage): die Akazienart Serianthes (deren Holz sich außerordentlich gut zum Bootsbau eignete), zum Teil früchtetragende Sträucher wie Planchonella, Abrus, Buettneria, sowie die heute nicht mehr nachweisbare Baumwollart Gossypium purpurascens.

- $\quad$ in höhergelegenen Gebieten (Luvlage): typische tropische Regenwaldvegetation, allerdings artenarmer und mit einer höheren Anzahl endemischer Arten ausgestattet als die entsprechenden Gebiete auf dem Festland. Von besonderer Bedeutung für die Kultur der Polynesier waren der große Bambus (Schizostachyum glaucifolium), der Bergwegerich (Musa fehi) und die Kastanie (Inocarpus edulis).

b) low islands:

- $\quad$ Gras- und Strauchvegetation, Alphitonia, Glochidion, Wikstroemia, Timonius, Kokosnuss. 
In seltenen Fällen griffen die Polynesier auf marine Vegetation in Form von Algen und Tang als Ergänzungsnahrung zurück.

Ebenfalls als relativ artenarm ist die prähumane Fauna auf den Inseln Französisch-Polynesiens zu bezeichnen. Vermutlich existierte kein einziges Säugetier, wenige Reptilien (z. B. Lygosima cyanurum) und Süßwasserfische (z. B. Kuhlia marginato). In seiner Artenzahl höher lag der Bestand an Vögeln und Meeresfauna, der ebenfalls zur Nahrungsversorgung herangezogen werden konnte. Die Ursache für die relative Artenarmut ist die Besiedlungsrichtung von West nach Ost, die zur Folge hat, dass die Artenvielfalt mit zunehmendem Längengrad abnimmt.

BUCHHOLZ (1984, S. 15) bezeichnet die Möglichkeit, dieses naturräumliche Potential landwirtschaftlich in Wert zu setzen, als sehr begrenzt, da auf Grund der starken Reliefierung der high islands kaum größere zusammenhängende Flächen landwirtschaftlich genutzt werden können und zudem die korallinen Böden relativ unfruchtbar sind. Dies gilt insbesondere unter heutigen mikro- und makroökonomischen Gesichtspunkten, was nicht ausschließt, dass ein exakt an die oben beschriebenen naturräumlichen Gegebenheiten angepasstes sozioökonomisches System im Rahmen der spezifischen Tragfähigkeit eines insularen Lebensraums bleibt (vgl. auch Kap. 1 und insbesondere 6.2.3).

\subsubsection{Wirtschaftsgeographie Französisch-Polynesiens}

Die klassische Definition der drei Wirtschaftssektoren zu Grunde gelegt ${ }^{39}$ wird die Wirtschaftsgeographie Französisch-Polynesiens im folgenden Abschnitt untersucht. Der Anteil am Bruttoinlandsprodukt betrug 1996 ca. 5\% für den primären, ca. 10\% für den sekundären und ca. 85\% für den tertiären Sektor (vgl. IH-Länder aktuell 1998 und ITSTAT 1998).

\subsubsection{Primärer Sektor}

In Bezug auf das Bruttoinlandsprodukt haben Landwirtschaft und Fischerei nur eine geringe Bedeutung (s. o.). Als Hauptanteil der Exportgüter sind sie innerhalb des primären Sektors allerdings von großer Wichtigkeit: 1988 wurden 1996 93,5\% des Gesamtexporterlöses durch die

\footnotetext{
${ }^{39}$ a) primärer Sektor (Urproduktion von Rohstoffen): Landwirtschaft, Forstwirtschaft, Fischerei, reiner Bergbau (ohne Aufbereitung); b) sekundärer Sektor (Be- und Verarbeitung von Rohstoffen): Industrie (einschließlich Energiegewinnung und Aufbereitung von Bergbauprodukten), Bauwesen, Handwerk und Heimarbeit; c) tertiärer Sektor (Dienstleistungssektor): Handel, Verkehr, Verwaltung, Bildungs- und Schulwesen sowie die „freien Berufe“: Ärzte, Rechtsanwälte, Architekten etc. (vgl. LESER u. a. 1989, Bd. II, S. 101, 200, und 286).
} 
Perlenzucht erzielt. Als zweitwichtigster Exportartikel wird Kokosnussöl (s. auch Kap. 6.1.3.2) angeführt (Ertrag von Kokosnüssen 1995: 86.000 t). Weitere Exportprodukte des primären Sektors von eher untergeordneter Bedeutung sind: Gemüse, tropische Früchte (z. B. Ananas, Bananen), Kaffee und Vanille. Der Viehbestand beschränkt sich auf Rinder (ca. 7.000), Pferde (ca. 2000), Schweine (ca. 42.000), Ziegen (ca. 16.000), Schafe (ca. 2.000), sowie Geflügel.

Die in den 80er Jahren neu entdeckten Kobalt- und Phosphatvorkommen (z. B. auf Mataiva, Tuamotuinseln) sind bisher nicht über die Prospektionsphase (geschätzte jährliche Förderungsmenge: 400.000 - 600.000 t) hinausgekommen und ein seit 1908 auf Makatea (auch Tuamotuinseln) ausgebeutetes Phosphatvorkommen ist seit 1966 erschöpft (vgl. IH-Länder aktuell 1/91, S. 2 f. und DOUMENGE 1988, S. 149 f.).

\section{$\underline{\text { 6.1.3.2 Sekundärer Sektor }}$}

Innerhalb des sekundären Sektors werden im Wesentlichen landwirtschaftliche Produkte weiterverarbeitet und zu einem Großteil exportiert, d.h. es werden insbesondere Kokosnussöl ${ }^{40}$ (1996: 6828 t), Perlmutt (523 t), Getränke (1996: 170 t), Fischprodukte (117 t) und Blumen (31,9 t) ausgeführt. Die Gewinnung elektrischer Energie (Tahiti) belief sich 1996 auf 359 Mio. KWh. Das Bauwesen und das Kunsthandwerk haben insbesondere im Zusammenhang mit dem Tourismus (s.u.) eine größere wirtschaftliche Bedeutung (vgl. ITSTAT 1998).

\subsubsection{Tertiärer Sektor}

Als ein potentiell prosperierender Wirtschaftszweig soll der Tourismus (vgl. hierzu ausführlich Kap. 6.5) weiter ausgebaut werden, was auch verstärktes Wachstum im Bauwesen und Verkehrssektor induzieren wird. Durch den Ausbau des Flughafens von Faa'a wuchs die Bedeutung Papeetes im pazifischen Flugverkehrsnetz. Dieses wechselseitige „Hochschaukeln" dieser drei Sektoren wirkte sich auch auf die übrige Verkehrsinfrastruktur aus: Das ca. $800 \mathrm{~km}$ lange, zu einem Drittel asphaltierte Straßennetz, wird ständig verbessert und erweitert. Handel, Verwaltung, CEP (s. u.) und sonstige Dienstleistungen tragen über $80 \%$ zum BIP bei. (vgl. hierzu ausführlich die Kapitel 6.3.6, 6.3.7 und 6.5.1)

\footnotetext{
${ }^{40}$ Das Kokosnussöl (Monoï) wird durch Auspressen von Kopra - getrocknetes, grob zerkleinertes, festes Nährgewebe der Kokosnuss - gewonnen. Es dient zur Glycerinherstellung und wird als Grundstoff für Kunstharze verwendet.
} 
Der sekundäre und tertiäre Sektor konzentrieren sich räumlich auf Tahiti, bzw. die Hauptstadt Papeete, und auch der primäre Sektor weist bei der weiträumigen Verteilung der Inselgruppen Französisch-Polynesiens keine Homogenität auf, da z. B. die Kokospalme auf den südlicheren Australinseln (insbesondere Rapa und Marotiri) nicht mehr gedeiht (vgl. BUCHHOLZ 1984, S. 225).

Die Haupteinfuhrprodukte Französisch-Polynesiens sind Nahrungsmittel, mineralische Produkte, sowie Maschinen und Fahrzeuge, wobei sich diese Importstruktur u. a. zum einen durch das weitgehende Verschwinden der Selbstversorgerlandwirtschaft zu Gunsten weltmarktorientierter Produkte (vgl. Kap. 6.3.3 und 6.3.7) - z. B. Wassermelonen, Kartoffeln auf den Australinseln, Ananas auf Moorea, Blumen auf Tahiti (was den Zwang zum Nahrungsmittelimport bedeutete) und das Entstehen des CEP erklärt (vgl. DOUMENGE 1988, S. 148 ff.).

Die wirtschaftlichen Potentiale Französisch-Polynesiens sind prinzipiell als gering einzustufen. Die minimale Größe des Terrains, ein begrenztes naturräumliches Potential und die weite Enfernung von größeren Absatzmärkten scheinen wirtschaftliche Prosperität generell zu begrenzen (s. u. v. KROSIGK 1988 und vgl. auch Kap. 6.3.7). Der in der Vergangenheit beobachtete Tertiärisierungsschub (s. u.) kann nicht darüber hinweg täuschen, da er überwiegend artifizieller Natur ist. 
In Bezug auf die Beschäftigungsstruktur lässt Tab. 3 einen Strukturwandel im zeitlichen Ablauf erkennen, der sich bis in die heutige Zeit fortsetzt:

Tab. 3: Beschäftigungsstruktur nach Sektoren in \%

\begin{tabular}{||l|c|c|c||}
\hline & 1962 & 1977 & 1998 \\
\hline Primärsektor & 46,1 & 17,5 & 4,2 \\
\hline Sekundärsektor & 19,2 & 18,5 & 17,2 \\
\hline Tertiärsektor & 34,7 & 64,5 & 78,5 \\
\hline $\begin{array}{l}\text { Lohn/Gehaltsempfänger } \\
\text { insgesamt }\end{array}$ & 26509 & 42803 & 51656 \\
\hline \hline
\end{tabular}

nach: NOHLEN u. NUSCHELER (Hrsg.) 1983, S. 408 und ITSTAT 1998

Die klar erkennbare Tertiärisierung (vgl. auch Kap. 6.3.3) lässt sich zum einen auf den zunächst seit den 50er Jahren zunehmenden Tourismus, in der Hauptsache aber auf einen aufgeblähten, überdimensionierten Verwaltungsapparat zurückführen.

Der entscheidende Veränderungsfaktor aber - nicht nur in Bezug auf die Tertiärisierung der Wirtschaftsstruktur Französisch-Polynesiens - war die Errichtung des CEP (Centre d'Expérimentation du Pacifique). Diese Effekte sollen im Detail weiter unten untersucht werden (vgl. auch Kap. 6.3.6, 6.3.7 sowie BLANCHET 1985).

Die Kleinstaatlichkeit Französisch-Polynesiens, die wie der gesamte Pazifik geprägt ist von „geographischer Fragmentierung, ethnischer Heterogenität und kolonialen Strukturen“ (s. KROSIGK 1988, S. 83), wirkt sich auf alle Wirtschaftsbereiche aus und verstärkt oder bedingt gar bestehende Nachteile wie (s. KROSIGK 1988, S. 93):

- ,diseconomies of scale

- begrenzte Vorkommen an natürlichen Ressourcen

- Abhängigkeit von einer begrenzten Palette an Exportprodukten

- große Entfernungen zu Auslandsmärkten

- immer wiederkehrende Naturkatastrophen (in Französisch-Polynesien insbesondere Wirbelstürme)

- hoch empfindliche ökologische Systeme und leicht verwundbare Umwelt“ 


\subsubsection{Bevölkerungs- und Siedlungsgeographie Französisch-Polynesiens}

Die Bevölkerung Französisch-Polynesiens (1996: 215.396 Einwohner) konzentriert sich gemäß der Beschäftigungs- und Einkommensmöglichkeiten auf die Gesellschaftsinseln und hier wiederum auf Tahiti. Tab. 4 zeigt das gesamte Verteilungsmuster (welches sich bis heute prozentual noch etwas mehr Richtung Tahiti/Gesellschaftsinseln verschoben hat, ansonsten im Wesentlichen aber gleich geblieben ist):

Tab. 4: Verteilung der Bevölkerung nach Inselgruppen

\begin{tabular}{|c|c|c|c|c|c|c|c|}
\hline & 1956 & 1962 & 1967 & 1971 & 1977 & 1981 & 1996 \\
\hline $\begin{array}{l}\text { Gesellschaftsinseln } \\
\text { (,über dem Wind") } \\
\text { in \% }\end{array}$ & $\begin{array}{r}41919 \\
54,9\end{array}$ & 49795 & 66095 & 84552 & 101392 & 10140 & 160627 \\
\hline $\begin{array}{l}\text { Gesellschaftsinseln } \\
\text { (,unter dem Wind") } \\
\text { in \% }\end{array}$ & $\begin{array}{r}15427 \\
20,2\end{array}$ & $\begin{array}{r}16177 \\
19,1\end{array}$ & 15337 & 15718 & 16311 & 25042 & 26647 \\
\hline $\begin{array}{l}\text { Marquesasinseln } \\
\text { in } \%\end{array}$ & $\begin{array}{r}4165 \\
5,5\end{array}$ & $\begin{array}{r}4838 \\
5,7\end{array}$ & $\begin{array}{r}5174 \\
5,3\end{array}$ & $\begin{array}{r}5593 \\
4,7\end{array}$ & $\begin{array}{r}5419 \\
3,9\end{array}$ & $\begin{array}{r}6116 \\
4,1\end{array}$ & $\begin{array}{r}7993 \\
3,7\end{array}$ \\
\hline $\begin{array}{l}\text { Australinseln } \\
\text { in } \%\end{array}$ & $\begin{array}{r}4106 \\
5,4\end{array}$ & $\begin{array}{r}4371 \\
5,2\end{array}$ & $\begin{array}{r}5053 \\
5,1\end{array}$ & $\begin{array}{r}5079 \\
4,3\end{array}$ & $\begin{array}{r}5208 \\
3,8\end{array}$ & $\begin{array}{r}5628 \\
3,8\end{array}$ & $\begin{array}{r}6550 \\
3,0\end{array}$ \\
\hline $\begin{array}{l}\text { Tuamotu-/Gambier- } \\
\text { inseln } \\
\text { in } \%\end{array}$ & $\begin{array}{r}10710 \\
14,0\end{array}$ & $\begin{array}{r}9370 \\
11,1\end{array}$ & $\begin{array}{r}6719 \\
6,8\end{array}$ & $\begin{array}{r}8226 \\
6,9\end{array}$ & $\begin{array}{r}9052 \\
6,6\end{array}$ & $\begin{array}{r}10768 \\
7,2\end{array}$ & $\begin{array}{r}13579 \\
6,3\end{array}$ \\
\hline Summe & 76327 & 84551 & 98378 & 119168 & 137382 & 148955 & 219521 \\
\hline
\end{tabular}

nach ZIEMER in NOHLEN u. NUSCHELER (Hrsg.) 1983, S. 406 und ISTAT 1998

Bezüglich der Verteilung auf die einzelnen Inseln muss dieses Verteilungsmuster weiter differenziert werden: Gemäß den naturräumlichen Gegebenheiten (vgl. Kap. 6.1.2) werden fast ausschließlich die Küstenstreifen der Inseln bewohnt, wobei der nordwestliche Küstenstreifen Tahitis im Zuge der Verstädterung zu einer Großagglomeration mit durchgehender Bebauung von Mahina bis Paea gewachsen ist. Das jährliche Bevölkerungswachstum beträgt 1,9\% (19881996) (ITSTAT 1996); regional bestehen hier allerdings Unterschiede (vgl. CLARIN 1974, S. 703-727). Das Bevölkerungswachstum auf den Gesellschaftsinseln verläuft schneller als auf den übrigen Inselgruppen Französisch-Polynesiens. In der Zeit nach dem 2. Weltkrieg bis weit in die 70er Jahre hinein ist in Bezug auf die Gesamtbevölkerung ein erheblicher Verjüngungsprozess festzustellen (1971: 58,5\%<20 J.), der in etwas abgeschwächter Form bis heute anhält (vgl. RALLU 1980, S. 385 ff.). 1996 waren 51,8\% der Bevölkerung unter 24 Jahre (vgl. ITSTAT 1998, S. 38 und Anl. $4 b$ im Anhang). 
Die Bevölkerungsstruktur weist in ihrer ethnischen Zusammensetzung ca. 67\% Polynesier, ca. 5\% Asiaten (überwiegend Chinesen), ca. 12\% Europäer und 14\% métis oder demis (Mischlinge aus überwiegend französisch-polynesischen Ehen) auf ${ }^{41}$ (vgl. Kap. 6.1.6). Hinsichtlich der Religionszugehörigkeit lassen sich ca. 54\% Protestanten, ca. 30\% Katholiken, sowie Adventisten, Mormonen, Sanitos, Zeugen Jehovas etc. ausmachen, d.h. nach offiziellen Angaben sind alle Einwohner - einschließlich derjenigen nicht-europäischen Ursprungs - zum christlichen Glauben konvertiert (vgl. IH-Länder aktuell 1998). Die Migration in den linearen Urbanraum Papeetes (vgl. Anl. 4a), der von Mahina bis Paea der schmalen Küstenebene folgt, ist auf Grund der potentiell höheren Einkommensmöglichkeiten (pull-Faktor) im Vergleich zu peripheren landwirtschaftlich geprägten Räumen ungebrochen. Mit der Errichtung des CEP wurden die Tuamotuinseln ein Subzentrum der Migration (vgl. DOUMENGE 1988, S. 144 ff.).

\subsubsection{Politische Situation Französisch-Polynesiens}

Die Überseegebiete Frankreichs lassen sich in vier verschiedene Kategorien einteilen, die sich im Wesentlichen im Grad ihrer Autonomie bzw. ihrer politischen - und damit wirtschaftlichen (bzw. umgekehrt) - Abhängigkeit von Frankreich unterscheiden ${ }^{42}$ :

- $\quad$ Departement d'Outre-Mer (DOM): Gebiete, die als Teile des Mutterlandes gelten (Guadeloupe, Martinique, Französisch-Guayana, La Réunion)

- $\quad$ Territoires d'Outre-Mer (TOM): Überseeterritorien mit beschränkter Selbstverwaltung (Französisch-Polynesien, Neukaledonien, Wallis und Futuna, Französische Süd- und Antarktisgebiete).

- $\quad$ Gebietskörperschaften mit Sonderstatus (Mayotte, Saint-Pierre-et-Miquelon)

\footnotetext{
${ }^{41}$ Hierbei muss beachtet werden, dass 1983 die Kategorien im Rahmen der Volkszählung von 1983 (vgl. Résultats du recensement de la population en Polynésie francaise, 15 octobre 1983. Paris 1984. zitiert nach SHINEBERG 1988, S. 83) geändert wurden, da im Vergleich zu der Zählung von 1977 die demi durch „Polynesier-Europäer“ ersetzt wurden, was zur Folge hatte, dass viele frühere demi sich bei der 1983er Zählung eher aus kulturellen Gründen den Polynesiern zuordneten. Zudem wurden zwei weitere Kategorien neben den bestehenden eingeführt: Polynesier-Chinesen (ca. 6.400 Personen, was prozentual leicht unter den Chinesen liegt) und Polynesier-Andere, welche zahlenmäßig nur 1.400 Personen ausmachten (vgl. SHINEBERG 1988, S. 83 f).
}

${ }^{42}$ s. Frankreich-Website www.frankreich-experte.de (Stand: 2000) 
Der verwaltungstechnische und damit politische Status Französisch-Polynesiens wird als Territoire d'Outre-Mer (TOM) bezeichnet, d.h. es besitzt als Überseeterritorium Frankreichs eine beschränkte Selbstverwaltung, also den - verglichen mit anderen Überseegebieten Frankreichs höchsten Grad an innerer Autonomie, der sich in einer lokalen Exekutive (Ministerrat, Conseil de Gouvernement, dessen Präsident die Territorialversammlung aus ihren Reihen wählt) und einer beratenden Territorialkammer (Legislative, 41 Sitze, auf fünf Jahre durch allgemeine Wahlen gewählt) manifestiert, durch deren Beschluss Französisch-Polynesien theoretisch aus dem französischen Staatsverband ausscheiden könnte. Neben Ministerrat und Territorialversammlung übt ein Wirtschafts- und Sozialkomitee Regierungsfunktion aus. Des Weiteren entsendet die Territorialversammlung je einen Abgeordneten in den Senat bzw. in den Wirtschafts- und Sozialrat und zwei in die Nationalversammlung nach Paris, sowie eine Vertretung der Interessen Französisch-Polynesiens in das Europa-Parlament nach Straßburg (vgl. IH-Länder aktuell 1998).

In Fragen der Außenpolitik sowie der inneren und äußeren Sicherheit behält sich Paris die direkte Zuständigkeit vor (vgl. JADIN 1990, S. 12-14 und SIEMERS 1989, S. 334 f.), das heißt im Einzelnen:

- Außenbeziehungen

- Einwanderung und Ausländerfragen

- auswärtige Kommunikation in der Seefahrt, See- und Luftverkehr, Post und Fernsprechverbindungen

- Währung, Kredit, Wechsel

- auswärtige Finanzbeziehungen und Außenhandel

- Verteidigung

- Einfuhr, Handel und Ausfuhr militärischer Ausrüstungsgüter, Waffen und Munition

- Strategische Rohstoffe; Aufrechterhaltung der öffentlichen Ordnung

- Zivilschutz

- Staatsbürgerschaft

- gerichtliche Organisation des Personenstandes

- Zivilrecht

- allgemeine Prinzipien des Arbeitsrechtes

- Justiz, Justizorganisation, Strafrecht

- staatliche Beamte

- Organisation der Kommunen, verwaltungsmäßige und finanzielle Kontrolle der Kommunen

- höheres Schulwesen und Universitäten

- audiovisuelle Kommunikation

- Souveränitäts- und Eigentumsrechte zu Wasser, zu Lande und zu Luft über öffentliche und private Besitzungen des französischen Staates (vgl. PIERMONT 1986, S. 16 ff.). 
Die hierdurch manifestierte Gewährleistung französischer nationaler Interessen nimmt der Hochkommissar Frankreichs, der dem in Funktion der Exekutive von der Territorialversammlung gewählten Ministerrat vorsitzt und insbesondere die Bereiche Verteidigung, Außenpolitik und Justiz kontrolliert (s. o.), wahr (vgl. SCHWARZENBECK 1983, S. 42 ff.).

Somit bleibt Französisch-Polynesien staatsrechtlich ein integraler Teil Frankreichs. Die Einwohner besitzen die französische Nationalität und dürfen an Wahlen in Frankreich teilnehmen.

Das Autonomiestatut erfuhr einen zweimaligen Ausbau (1977 und 1984), was die Erweiterung der Befugnisse auf den Gebieten Handel und Entwicklung, sowie die Ersetzung des früheren siebenköpfigen Regierungsgremiums durch den Ministerrat zur Folge hatte (vgl. hierzu auch GOMANE 1989, S. 334-338).

Im Europäischen Kontext führte die Existenz Französisch-Polynesiens immer wieder zu Paradoxien hinsichtlich des eigenen Autonomiestatuts und der Integration in den Europäischen Markt. Als ÜLG ${ }^{43}$ (Überseeische Ländereien und Gebiete) sind die TOM anders als die DOM außerhalb des territorialen Geltungsbereiches der EU. Dennoch können die Einwohner Französisch-Polynesiens als französische Staatsbürger an Wahlen zum Europäischen Parlament teilnehmen:

„Die Paradoxien eines Assoziierungsstatuts, das sie zwar territorial außerhalb des Geltungsbereichs der Römischen Verträge - wenn auch eingefügt in die ,unteilbare Republik' - stellt, sie aber auf der individualrechtlichen Ebene über die Europäische Staatsbürgerschaft zum integralen Teil der EG transformiert, musste zum Konflikt mit dem Projekt Europäischer Binnenmarkt herausfordern.“ (s. KROSIGK/JADIN 1994, S. 239)

Französisch-Polynesien wehrte sich mit der Durchsetzung einer Sondervereinbarung erfolgreich gegen die Umsetzung der Niederlassungsfreiheit. Die „Erklärung zu Gebieten in äußerster Randlage der Gemeinschaft“ im Anhang des Vertragswerkes von Maastricht lässt prinzipiell Sondervereinbarungen zu.

Brüssel bzw. Europa werden von der Bevölkerung Französisch-Polynesiens mit enormer Skepsis betrachtet. Die Wahlbeteiligung an Europawahlen beinhaltet bis zu ca. 90\% Protest-Enthaltungen (vgl. KROSIGK/JADIN 1994, S. 242 ff.).

\footnotetext{
${ }^{43}$ Ein weiterer Konflikt besteht in den nicht harmonisierten Vertragswerken der AKP-Staaten und der ÜLG
} 
Die führende Partei nach den letzten Wahlen vom 13.5.96 zur Territorialversammlung ist die lokale gaullistische Partei RPR ${ }^{44}$, Tahoeraa Huiraatira, von Gaston FLOSSE mit 38,7\%.

Zweitstärkste Kraft ist Oscar TEMARUS FLP45, Tavini Huiraatira (24,8\%), die radikal für die Unabhängigkeit eintritt. Die Nouvelle Partie, Ai'a Api erhielt 15,8\%, Nouvelle Étoile, Fe’tia Api 5,5\%, Vrai Cap, Te Avei’a Mau, 5,3\%, Alliance 2000 3\% und Te Henua Enata Kotoa (Marquesas) 1,2\% (vgl. IH-Länder aktuell 1998, S. 1; TAGUPA 1974, S. 135-145; sowie Kap. 6.4.2).

\subsubsection{Ethnische Gruppen}

Einleitend seien die vier ethnischen Hauptgruppen Französisch-Polynesiens (vgl. Kap. 6.1.4) noch einmal genannt (polynesische Bezeichnung in Klammern):

- die Polynesier (maohi)

- die demis (Mischlinge aus Polynesiern und Europäern, ta'ata afa)

- die Europäer (popa'a)

- die Chinesen (tinito)

Initiiert durch den Kontakt mit den Europäern birgt das Resultat der ethnischen Umstrukturierung in Französisch-Polynesien ein großes Konfliktpotential, da die kulturellen Unterschiede auf relativ engem Raum (konzentriert auf Papeete) zusammentreffen. Als Nachfahren der autochthonen Bevölkerung sind die Maohi zwar der Anzahl nach in der Mehrheit, in Bezug auf die Verteilung gesellschaftlicher Güter (Wohnung, Nahrung, Kleidung) und Privilegien sowie den Zugang zu Bildungseinrichtungen und damit entsprechend gut bezahlten Arbeitsplätzen jedoch marginalisiert, was unter anderem dadurch bedingt ist, dass sie immer noch den größten Anteil der ländlichen Bevölkerung stellen. Als Verlierer eines Wirtschafts- und Gesellschaftssystems, das sich an den euro-amerikanischen Normen der Marktwirtschaft orientiert und traditionelle Strukturen massiv überformte, weisen die Maohi in Papeete zudem den höchsten Prozentsatz an Alkohol- und Drogenabhängigen auf, sowie die höchste Selbstmordrate, wohnen verstärkt in den inner- und außerstädtischen Marginalsiedlungen (vgl. TETIARAHI 1989a, S. 83) und erreichen nur zu ca. 20\% einen höheren Schulabschluss (vgl. TETIARAHI 1989a, S. 86). Die Akkulturation führte die Autochthonen in einen Teufelskreislauf: Durch Imitation europäischen Konsumverhaltens (Kauf von Autos, Hi-Fi- und Videoanlagen etc...) auf Kredit (der von

\footnotetext{
${ }^{44} \mathrm{RPR}=$ Rassemblement pour la République

${ }^{45}$ FLP $=$ Front de Libération de la Polynésie
} 
europäischen Banken gewährt wird) oder durch den Verkauf landwirtschaftlicher Parzellen tragen sie selbst nicht unerheblich zur Verschlechterung der eigenen Situation bei (vgl. TETIARAHI 1989a, S. 84), da sie ihre ohnehin schlechte Einkommenssituation (vorwiegend Hilfsarbeitertätigkeiten, Sozialhilfe und Kindergeld, vgl. DELIUS 1990, S. 13, einschließlich Kinderarbeit) mit dem vermeintlichen Wohlstand nur zu übertünchen suchen und dadurch weiterhin ihre finanzielle Situation verschlechtern.

Die Nachkommen der ersten Mischehen zwischen Europäern und Polynesierinnen, die demis, bilden heute als Minderheit eine gesellschaftliche Mittelschicht, die durchaus vom importierten Wohlstand profitiert und zum Teil auch über höhere Posten in der Wirtschaft verfügt. Sie sind durch ihre Verbundenheit mit beiden Kulturen - besser als die Maohi in der Lage, sich anzupassen.

Der asiatische Bevölkerungsanteil (vorwiegend Chinesen, die in zwei Einwanderungswellen im 19. Jh. und einer weiteren im 20. Jh. nach Französisch-Polynesien immigrierten (vgl. Kap. 6.3.1) ansonsten Indonesier und Vietnamesen) stieg zwar später, aber dafür umso höher auf der gesellschaftlichen Leiter auf, da heute entscheidende Schaltstellen der Wirtschaft von Chinesen besetzt sind. Zwischen demis und Chinesen besteht eine gewisse Konkurrenz, die sich zunehmend zu Gunsten der sowohl im bestehenden Bildungssystem als auch im nachfolgenden Berufsleben (insbesondere Import-Export-Geschäft, sowie Einzelhandel) erfolgreichen Asiaten verschiebt (vgl. DELIUS 1990, S. 15).

Die Chinesen sind es auch, die internationale Handelsbeziehungen aufrechterhalten und ausbauen und zwar sowohl mit asiatischen Metropolen wie Hongkong, als auch mit EU-Staaten und den USA (vgl. TETIARAHI 1989a, S. 86).

Die Europäer (hauptsächlich Franzosen) sind in der höheren Verwaltung, als Investoren und in den freien Berufen tätig und waren früher insbesondere durch den CEP beschäftigt und stehen somit bezüglich des Einkommens und des Sozialprestiges an höchster Stelle.

Das Wohlstandsgefälle zwischen dem mehrheitlichen autochthonen Bevölkerungsteil und den drei anderen ethnischen Gruppen Französisch-Polynesiens ist die Ursache eines Konfliktpotentials, das sich entsprechend der Zunahme dieses Gefälles verschärft. Eine der stärksten gewalttätigen Eskalationen in diesem Zusammenhang war die Plünderung und InBrand-Setzung des Geschäftszentrums von Papeete im Rahmen eines Streiks der Hafenarbeiter am 23.10.1987 (vgl. DELIUS 1990, S. 16).

Auch das Stadt-Land-(Lebensstandard-)Gefälle steht in Zusammenhang mit der ethnischen Zugehörigkeit (dass heißt die relative Armut drückt sich nicht nur räumlich, sondern auch ethnisch aus): 
„Some social inequalities have a rather disturbing, ethnic connotation: indigenous rural populations appear relatively impoverished in comparison to those in urban areas who are mostly non-indigenous settlers or are of mixed race ... In French Polynesia, the mayor imbalance is between the coastal couronnes of the Windward Islands (Tahiti and Moorea) which are almost fully urbanised than the archipelagos on the territorial periphery. Because of their proximity to Tahiti, the Leeward Islands seem less underprivileged than Tuamotu, Gambier, the Austral Islands and the Marquesas" (DOUMENGE 1988, S. 151).

In Bezug auf die den ethnischen Konflikten zu Grunde liegenden sozialen Unterschiede wird als eine der Hauptursachen immer wieder die Form der westlich-marktwirtschaftlichen

Wirtschaftsstruktur angegeben (vgl. auch Kap. 6.3):

„For every tradition-respecting pacific islander capitalization, i. e. the capacity to create surplus, is heresy as it creates social inequalities" (DOUMENGE 1988, S. 151).

Es ist eine Gesellschaft der „Zwei Geschwindigkeiten“ entstanden:

„Fehlerhafte Verteilungsmechanismen in Frankreichs überseeischem Engagement - der öffentliche Dienst in Übersee wird besser bezahlt als in der Metropole, der gesetzliche Mindestlohn liegt dagegen unter metropolem Niveau - haben die sozialen Polaritäten verstärkt.[...] Das Leben im Mangel, in dem sich die koloniale Landbevölkerung vormals egalitär vereint sah, ist einer, société à deux vitesses' gewichen. Auf der einen Seite stehen all jene, ob Einheimische oder zugewanderte Métros, ob im öffentlichen Dienst oder in Spitzenpositionen der privaten Wirtschaft, welche die neuen Möglichkeiten integrativer und hochsubventionierter Entwicklung optimal zu nutzen wussten. [...] Scharf davon abgesetzt befinden sich auf der anderen Seite die Marginalisierten und Desaktivierten. Sie haben ihre alten Arbeitsplätze in der Landwirtschaft verloren und sind in die urbanen Zentren gezogen. Arbeitslos oder unterbeschäftigt, nicht selten auch in der Schattenwirtschaft tätig, leben sie von der Sozialhilfe. Der Einzug der Moderne hat ihre alten Werte zerstört, ohne ihnen einen wirklichen Zugriff auf die Neue Welt zu geben. (s. JADIN 1994, S. 210f).

In der neuen, modernen Gesellschaftsstruktur sind es die demi, die sich neben den Europäern am besten zurechtfinden:

„Les Chinois vivent également en communauté relativement fermée, quoique ceci ait tendence à changer avec les nouvelles générations. En revanche, les Demi, qui circulent facilement, grâce à leur qualité poly-ethnique, entre les différents groupes sociaux, semblent constituer un trait d'union entre ces entités culturellement différentes.“ (s. LANGEVIN 1990, S. 13) 


\subsubsection{Französisch-Polynesien - ein koloniales Entwicklungsland?}

Der Begriff der Entwicklung und somit der des Entwicklungslandes variiert in seiner Definition im historischen Ablauf sowie gemäß den zu Grunde liegenden Normen und ist daher

„weder vorgegeben noch allgemein gültig definierbar, noch wertneutral, sondern abhängig von Raum und Zeit sowie insbesondere von individuellen und kollektiven Wertvorstellungen" (NOHLEN 1989, S. 196, sowie Kap.1).

Bei der Abgrenzung der in sich weiterhin differenzierten Entwicklungsländer ${ }^{46}$ von den Industrieländern können folgende Indikatoren herangezogen werden, die der heutigen Auffassung, dem Begriff der Entwicklung bzw. des Entwicklungslandes durch eine möglichst große Multidimensionalität näher zu kommen, Rechnung tragen:

a) ökonomische Indikatoren:

- $\quad$ niedriges Pro-Kopf-Einkommen

- $\quad$ niedrige Spar- und Investitionstätigkeit

- $\quad$ geringe Kapitalintensität, gemessen am Kapitalaufwand pro Beschäftigtem

- $\quad$ geringe Produktivität der Arbeit

- $\quad$ niedriger technischer Ausbildungstand

- $\quad$ mangelndes Know-how von Unternehmern und Managern

- Vorherrschaft des primären Wirtschaftssektors in Form 1) der Beschäftigung eines überwiegenden Teils der Erwerbstätigen in der Landwirtschaft und 2) der Dominanz weniger Produkte des Primärsektors in der Produktionsstruktur, teilweise eines Monokulturprodukts

- $\quad$ mangelnde oder nicht ausreichende materielle Infrastruktur

b) soziale Indikatoren:

\footnotetext{
${ }^{46}$ Eine weitergehende Einteilung der Entwicklungsländer (LDCs: Less Developed Countries) ist z. B. die folgende Differenzierung in OPEC-Länder (Organization of the Petroleum Exporting Countries), Kriterium: Verfügungsgewalt über die Ressource Erdöl und daraus resultierender Exporterlöse; LLDCs (Least Developed Countries), Kriterium: ärmste Entwicklungsländer; MSACs (Most Seriosly Affected Countries), Kriterium: leiden besonders unter den Erdölpreissteigerungen, der weltwirtschaftlichen Rezession und Dürrekatastrophen; Landlocked Countries, Kriterium: geographische Benachteiligung, da Binnenländer oder Inseln; AKP-Staaten, Kriterium: EGAssoziierung; und NICs (Newly Industrialized Countries) bzw. Schwellenländer, Kriterium: Halbindustrialisierung, bisher allerdings keine allgemein gültige Definition. Die Kriterien, die dieser Subgruppierung der Entwicklungsländer zu Grunde liegen, überlappen sich zum Teil in Bezug auf einzelne Länder (vgl. NOHLEN 1989, S. 173).
} 
- $\quad$ niedrige Lebenserwartung bei Geburt und hohe Kindersterblichkeit bis zum vierten Lebensjahr (Indikatoren für den niedrigen Gesundheitszustand, dass heißt defizitäres Gesundheitssystem nach westlichem Standard)

- $\quad$ niedrige Kalorien- und Proteinaufnahme pro Tag (Indikator für die ungenügende Ernährung)

- $\quad$ hoher Anteil des Analphabetismus unter der erwachsenen Bevölkerung und Desertionsquote $^{47}$ (Indikator für die unzureichenden Leistungen im Bereich der Erziehung).

c) soziokulturelle Indikatoren:

- $\quad$ nicht abgeschlossener nation-building-process ${ }^{48}$

- $\quad$ geringe soziale Mobilität

- $\quad$ Vorherrschen traditioneller Verhaltensmuster, beruhend auf zugeschriebenen Rollen in fest abgegrenzten sozialen Bereichen (z. B. Familie, Ethnie) und auf persönlichen Beziehungen, dass heißt fehlende Rollenverständnisse und Handlungsformen, die Voraussetzungen für rationales wirtschaftliches Handeln sind.

- $\quad$ geringe soziale Differenzierung, dass heißt die Möglichkeiten der Befriedigung individueller Bedürfnisse, individuellen Aufstiegs, beliebiger Wahlbeziehungen etc. sind gering (s. NOHLEN 1989, S. 202 f.)

In Bezug auf die Ursachen, die zur Unterentwicklung bzw. zum Zustand des Entwicklungslandes geführt haben, unterscheidet man endogene von exogenen Faktoren. Je nach Gewichtung dieser Faktoren werden sie zu diversen Erklärungsmustern für die Unterentwicklung herangezogen, die die Grundlage für die heutige Vielzahl der Entwicklungstheorien und -strategien (z. B. Modernisierungstheorie, Dependenztheorie) bildet (vgl. NOHLEN 1989, S. 196 f.).

Festzuhalten bleibt, dass der Begriff der Entwicklung und des Entwicklungslandes in seiner Multidimensionalität nicht eindeutig und hinreichend definierbar ist und durch die oben genannten Faktoren eine erste Annäherung erfährt, da z. B. ökologische Indikatoren, die

\footnotetext{
${ }^{47}$ „Anteil der Kinder/Jugendlichen in \% der jeweiligen Altersgruppe, die vor Erreichung einer bestimmten Klasse oder eines Schulabschlusses die Schule verlassen“(NOHLEN 1989, S. 163).

${ }^{48}$ Der nation-building-Ansatz geht in der wissenschaftlichen Literatur vor allem auf die Arbeiten K.W. DEUTSCHs zurück, der unter Zugrundelegung der entsprechenden historischen Prozesse in Westeuropa die Faktoren darstellte, die zur Herausbildung einer nationalen Einheit ausschlaggebend waren. Gemäß DEUTSCH sind dies insbesondere Industrialisierung und ökonomisches Wachstum, welche über sozialen Wandel, wachsende innergesellschaftliche Kommunikation, verstärkte soziale Mobilisierung der Bevölkerung und gesellschaftlicher Modernisierung schließlich zur Herausbildung einer Nation führte (vgl. NOHLEN 1989, S. 482).
} 
durchaus als Kriterium herangezogen werden können, nicht genannt sind. Im Folgenden soll dennoch die obige Indikatorenliste zur Beantwortung der Frage, ob Französisch-Polynesien als koloniales Entwicklungsland aufgefasst werden kann, herangezogen werden.

In Bezug auf die ökonomischen Indikatoren gilt für Französisch-Polynesien das Pro-KopfEinkommen als extrem hoch, so dass es sogar zu den high-income countries der pazifischen Inselstaaten gerechnet wird (vgl. Anl. 5 im Anhang). Da diese Größe bei dem starken Einkommensgefälle von Europäern über Asiaten und demis bis zu der autochthonen Bevölkerungsmehrheit als Durchschnittswert die Realität in starkem Maße verzerrt, kann für weite Bevölkerungsanteile (fast ausschließlich Maohi) der Status eines niedrigen Pro-KopfEinkommens gelten. Gerade für diese mehrheitliche Bevölkerung trifft ebenfalls der Indikator der niedrigen Spar- und Investitionstätigkeit, ein niedriger technischer Ausbildungsstand, sowie in etwas abgeschwächterem Maße auch das Vorherrschen des primären Wirtschaftssektors sowohl in Bezug auf die Beschäftigung (tendenziell sind die Maohi in höherem Maße im landwirtschaftlichen Bereich beschäftigt) als auch in der wenig differenzierten landwirtschaftlichen Produktpalette zu (vgl. Kap. 6.3.3).

Die infrastrukturelle Erschließung kann für die Hauptinsel Tahiti nicht als mangelhaft beschrieben werden, nimmt jedoch mit zunehmender räumlicher Entfernung dazu in starkem Maße ab. Unter den ökonomischen Indikatoren können ein mangelndes Know-how von Unternehmern und Managern (da vorwiegend europäischer Standard), sowie eine geringe Kapitalintensität und Produktivität der Arbeit nicht als Indikatoren der Unterentwicklung in Bezug auf Französisch-Polynesien herangezogen werden.

Ebenso wie die ökonomischen Indikatoren müssen auch die sozialen Indikatoren entsprechend dem ethnischen Spektrum Französisch-Polynesiens differenziert werden: In Anbetracht der generellen sozialen Benachteiligung der Autochthonen treffen die Indikatoren niedriger Gesundheitsstand, ungenügende Ernährung und Analphabetismus in etwas stärkerem Maße für sie als für die übrigen Ethnien zu, wobei eine hohe Desertionsquote (vgl. Kap. 6.3.4) als Charakteristikum dieser Bevölkerungsgruppe gelten kann. Dennoch kann von sozialer Unterentwicklung in extremem Maße (dass heißt im Sinne von Verelendung) nur in Bezug auf völlig marginalisierte Bevölkerungsschichten gesprochen werden (z. B. Slumbewohner von Faa’a), deren Anzahl allerdings wächst.

Bezüglich der soziokulturellen Indikatoren können ein nicht abgeschlossener nation-buildingprocess, die geringe Möglichkeit zur sozialen Mobilität und auch sozialen Differenzierung (Letztere auch wieder insbesondere in Bezug auf die Maohi) als zutreffend gelten, wobei auch gewisse Verhaltensmuster der Autochthonen (kulturelles Restgut) als Voraussetzung für wirtschaftlich-rationales Handeln zum Teil nicht vorhanden sein dürften. 
Zusammenfassend ist festzustellen, dass Französisch-Polynesien nach oben genannten ökonomischen, sozialen und soziokulturellen Faktoren durchaus als Entwicklungsland zu bezeichnen ist.

Ein weiterer Indikator, der für den Status Französisch-Polynesiens als Entwicklungsland spricht, ist die Tatsache, dass von internationalen Hilfsorganisationen Projekte der Entwicklungszusammenarbeit in Französisch-Polynesien getätigt werden, die sich bis in das Jahr 1959 zurückverfolgen lassen können (z. B. Leistungen des damaligen EWG-Entwicklungsfonds). Die NGO Hiti Tau (vgl. ausführlich Kap. 6.6.1) erhält Zuwendungen von mehreren ausländischen Geberorganisationen aus Europa, Neuseeland und Australien.

Unter Zugrundelegung oben genannter Faktoren kann der Zustand der spezifischen Unterentwicklung Französisch-Polynesiens als vorwiegend exogen verursacht, dass heißt letztendlich als Folge der Akkulturation durch die Europäer, begriffen werden, wobei möglicherweise zu nennende endogene Faktoren (Insellage, etc..) ebenfalls nur durch die europäische Einflussnahme zu gegenwärtigen „Entwicklungshemmern" in der Tradition des europäischen Verständnisses von Entwicklung wurden (vgl. Kap. 6.3 ).

In der Summe ist Französisch-Polynesien auf Grund o.g. Faktoren durchaus der Gruppe der Entwicklungsländer zuzuordnen; einige Attribute der ersten Welt bleiben aber erhalten, so dass eine Art klassifikatorischer Zwitter besteht:

„Auf Grund der de jure Zugehörigkeit dieser Gebiete [der DOM-TOM] zur Ersten Welt und ihrer aus geographischen, geschichtlichen, wirtschaftlichen und soziokulturellen Faktoren gespeisten de facto Zugehörigkeit zur Dritten Welt entstand eine Zone der definitorischen Unsicherheit." (s. JADIN 1994, S. 207)

Bei allem Überwiegen der exogenen Faktoren, darf nicht unerwähnt bleiben, dass die Mehrheit der Bevölkerung Französisch-Polynesiens im Rahmen des Referendums von 1956 selbst für einen Verbleib zu Frankreich stimmte und somit, wenn auch vorwiegend passiv, die heutige Situation Französisch-Polynesiens mit unterstützt hat:

„Am Ursprung des französischen Entwicklungsexperimentes stand eine originelle Initiative. Gegen den allgemeinen Drang der Kolonialvölker nach Unabhängigkeit und Emanzipation forderten die heutigen DOM [wie auch Französisch-Polynesien 1956 in seinem Referendum] am Ende des Zweiten Weltkrieges ihre politische Assimilation. Die wohl stärkste treibende Kraft bei diesem Schritt war die soziale Misere.[...] Die Entscheidung der DOM für die politische Assimilation geschah in einem Klima der Euphorie und dokumentiert ein fast naives Vertrauen in die Großzügigkeit des Mutterlandes. Sie bedeutet aber auch den definitiven Verzicht auf die Realisierung eigener Entwicklungsideale. An ihre Stelle trat die frühe und unkritische Übernahme von Wertemustern, wie sie den westlichen Industrienationen, in diesem Fall Frankreich zu Eigen sind. Vorbereitet und gefördert wurde dieser gesellschaftliche Wertewandel durch den traditionellen französischen Drang zum eigenen Zivilisationsexport, der sich als ,mission civilisatrice‘ durch zwei koloniale Expansionsphasen gezogen hat.“" (s. JADIN 1994, S, 206) 


\subsubsection{Zwischenbilanz}

Dieser kurze Abriss über die wesentlichen geographischen, wirtschaftlichen und politischen Strukturmerkmale Französisch-Polynesiens suggerieren auf den ersten Blick ein starkes wirtschaftliches Potential, einen hohen Lebensstandard und demokratische Möglichkeiten, die im Rahmen der gewährten Autonomie eine begrenzte Selbstverwaltung erlauben. Bei näherer Betrachtung ist festzustellen, dass dies insbesondere bei einer Differenzierung nach ethnischen Gruppen nicht stimmt. Die Partizipation am Wohlstand betrifft in Französisch-Polynesien nicht alle Ethnien gleichermaßen. Auch die Wirtschaftskraft erweist sich als künstlich am Leben erhaltene dependente Transferökonomie (vgl. Kap. 6.3.3 und 6.3.7) - eins von vielen Merkmalen, die eher auf entwicklungsländertypische Strukturen hinweisen. In den folgenden Kapiteln soll die historische Analyse erfolgen, die den Status quo erklärt und vor deren Hintergrund die Bewertung von alternativen Entwicklungsansätzen möglich wird. 


\section{$\underline{\text { 6.2 Die voreuropäische Kultur in Französisch-Polynesien }}$}

Die Auseinandersetzung mit der voreuropäischen Kultur in Französisch-Polynesien ist wichtig für das Verständnis der Tragweite des abgelaufenen Akkulturationsprozesses.

In Kap. 1 wurde Kultur als „Gesamtheit der Ergebnisse von Innovationen“ definiert. Kultur kann in diesem Zusammenhang auch als Identitätsmuster einer bestimmten Ethnie aufgefasst werden, während Zivilisation eine bestimmte Stufe der kulturellen Evolution ausdrückt. Anders ausgedrückt: Zivilisation ist eine mögliche Dimension von Kultur, gemessen am eigenen Selbstverständnis in Bezug auf den Stand der Technik, Umgangsformen und dem Grad der wissenschaftlichen Erkenntnis.

Zunächst einmal ist festzustellen, dass es sich bei den voreuropäischen Polynesiern (auch Polyneside ${ }^{49}$ ), die der geographischen Bezeichnung Polynesien ihren Namen gaben (vgl. Polynesisches Dreieck, vgl. Kap. 2.1), um eine Menschengruppe mit einer hohen kulturellen Homogenität, dass heißt um eine Ethnie ${ }^{50}$ handelte.

\subsubsection{Ursprung der polynesischen Kultur}

Die Herkunft der Polynesier wurde intensiv diskutiert (vgl. BELLWOOD 1978, BROCKWAY 1983, HANDY 1930, HEINE-GELDERN 1932, GREEN 1967, KREISEL 1991) und soll hier nur kurz wiedergegeben werden.

Neben der vernachlässigbaren - da unwahrscheinlichen Theorie - einer „selbstständigen Entstehung" wurden im Wesentlichen zwei mögliche Herkunftsgebiete der Polynesier diskutiert: Südostasien und Amerika.

\footnotetext{
49 „Die Polyneside sind von hohem kräftigem Wuchs, vorwiegend ovale Gesichtsform, mittelbreite Nasen, welliges Haar, dunkelbraune Augen und mittelbraune (oft samtartige) Haut. Ihr Verbreitungsgebiet umfaßt Polynesien bis zur Osterinsel, Teile Mikronesiens und Neuseeland (Maori)“(s. HIRSCHBERG 1988, S. 371).

50 „Ethnie (=Ethnos), eine Menschengruppe mit gemeinsamer Abstammung, Stammesüberlieferung und WirBewusstsein. Zusätzliche Kriterien wie Sprache, Rechts-, Siedlungs-, Religions-, und/oder Kulturgemeinschaft, einheitliche materielle Kultur u.a. sind in ihrer jeweiligen Bedeutung stark veränderlich und können nicht allein zur Feststellung und Benennung einer ethnischen Einheit herangezogen werden. Eine Ethnie wird durch Traditionsträger (Häuptling, Medizinmann, Künstler) repräsentiert. Die Eigenweltlichkeit wird durch Identifikation mit Gruppenmitgliedern und Negation der Fremdethnien konstituiert“" (s. HIRSCHBERG 1988, S. 134).
} 
Heute gilt eine Besiedlung von Südostasien aus als die wahrscheinlichste Variante, was einen (auch mehrfachen) Kulturkontakt mit der präkolumbischen amerikanischen Bevölkerung nicht ausschließt (vgl. Anl. Ø).

In mehreren Besiedlungswellen wurde schließlich auch das Gebiet des heutigen FranzösischPolynesien erreicht, wobei die Überwindung solcher Distanzen nur durch hoch entwickelte navigatorische Fähigkeiten möglich war (vgl. z. B. DODD 1972, FEINBERG 1988, HILDER 1962 und SHARP 1970). Ob die Gesellschafts- oder die Marquesasinseln zuerst besiedelt wurden und somit als ursprüngliches Zentrum der heutigen Kultur und insbesondere der Sprache der Autochthonen gelten können, ist immer noch umstritten. Die bisher ältesten archäologischen Funde finden sich auf Uahuka, Marquesasinseln (Funde, die älter als 1300 v. Chr. sein müssen, vgl. EMORY 1988; S. 53 ff. $^{51}$ ). Die nächstältesten (eventuell sogar noch ältere) befinden sich, auf Maupiti (Gräber, bis ca. 1190 v. Chr., vgl. OLIVER 1974, S. 1121) und Huahine (Werkzeuge, Jagdwaffen, Bootsrumpf, bis ca. 1200 v. Chr.; vgl. EMORY 1988, S. 36 ff.), beide Gesellschaftsinseln, was allerdings bei der bisher geringen archäologischen Tätigkeit (vgl. Kap. 6.2.2) nicht als endgültiger Beweis für eine Besiedlung der Marquesas- vor den Gesellschaftsinseln angesehen werden darf.

Aus sprachwissenschaftlicher Sicht ist es zudem bisher unklar, ob das Marquesische eine spätere Abwandlung des Tahitischen (vgl. Kap. 6.2.2.4) ist oder umgekehrt (vgl. EMORY 1988, S. 33 f.).

Sprachwissenschaftliche (vgl. Kap. 6.2.2.4), archäologische und genetische Untersuchungen bestätigen die Herkunft der Polynesier aus Asien. ${ }^{52}$

\footnotetext{
${ }^{51}$ „Chronologically the Marquesas are the oldest, followed by Vaitootia, as far as we know today. Polynesians who had East Polynesian culture left the Marquesas and at least one group of people settled at Huahine. Artefacts from the Maupiti burial site, especially the adze forms, indicate that the Maupiti site is chronological slightly later than the Huahine“ (SINOTO, Y. H. und MCCOY, P. C.: „Excavations of an archaic habitation site on Huahine. Society Islands, preliminary report”. 1975 excavation manuscript. Zitiert nach EMORY 1988, S. 53 f).

${ }^{52}$ Sowohl die Victoria University (Neuseeland) als auch die University of Cambridge bestätigten durch DNATests die Besiedlung der pazifischen Inseln aus Richtung Asien (vgl. FR, 10.1.98 und NZZ, 19.8.98).
} 


\subsubsection{Historisch-Kulturelle Entwicklung der Maohi ${ }^{53}$}

In diesem Abschnitt werden folgende Kulturmerkmale der Polynesier herausgegriffen und einer näheren Untersuchung unterzogen: Gesellschaftsstruktur, Religion, Wirtschaftsstruktur, Sprache und Recht, wobei festzuhalten ist, dass sich die Rekonstruktion dieser voreuropäischen Kultur in mehrfacher Hinsicht als problematisch erweist,

- $\quad$ da die Authentizität und Objektivität der Berichterstattung in Ermangelung schriftlicher Quellen der Polynesier selbst und durch zum Teil sich widersprechende und mit europäischen Interpretationen und Projektionen behaftete Aufzeichnungen der ersten Entdecker und Missionare nicht gegeben ist (selbst bei bewusster Kenntnis der eigenen kulturellen Prägung und damit Sichtweise kann der Beobachter seinen subjektiven Blickwinkel nicht verlassen, sondern allenfalls relativieren) ${ }^{54}$;

- $\quad$ da selbst beim Bemühen um eine objektive Beschreibung seitens der Ethnologen es durch beabsichtigte oder unbeabsichtigte „Fehlauskünfte" der „Beforschten" (z. B. durch Überoder Untertreibung oder Höflichkeitsantworten, die das wiedergeben, was nach Meinung des Auskunftgebenden vom Frager als Antwort erwünscht oder erwartet wird) zu als richtig erachteten Fehlinformationen kommen kann;

- $\quad$ da die europäische Terminologie nicht unbedingt das wiedergibt (oder auf Grund falschem/anderem Verständnis nicht wiedergeben kann), was in der polynesischen Realität einem bestimmten Begriff entspricht;

\footnotetext{
${ }^{53}$ Das Wort Maohi erscheint erstmalig 1851 in einem „Tahitian and English Dictionary“ der Missionare der London Missionary Society und wird als adjektivische Form mit „,common, native, not foreign“ übersetzt. Im Gegensatz zu dem Wort $t a$ 'ata, welches eine pejorative Nebenbedeutung hat, beinhaltet der Begriff Maohi einen positiven Aspekt, was durch die Übersetzung in Tepano JAUSSENs 1861 erschienener Grammaire et Dictionnaire de la langue Maorie. Dialecte tahitien. deutlich wird: „Maori ou Maohi (nom propre des indigènes de la Polynésie et en conséquence) bon, parfait“ und auch „vrai, authentique“. Räumlich bezieht sich die Bezeichnung Maohi nach OLIVER exakt auf die autochthonen Gruppen der Gesellschaftsinseln, wurde aber später auf das gesamte Gebiet Französisch-Polynesiens ausgedehnt, um die Autochthonen von Nicht-Autochthonen zu unterscheiden. Gerade die traditionelle Bedeutung ,authentisch“" von Maohi lässt heutige autochthone Gruppen diesen Begriff in bewusster Abgrenzung zu den Europäern gebrauchen (vgl. LAVONDES 1985, S. 140 f.). In der vorliegen Arbeit soll der Begriff im Folgenden synonym mit dem der Polynesier und Autochthonen gebraucht werden, dass heißt alle drei Ausdrücke bezeichnen in diesem Fall die ursprüngliche, voreuropäische Bevölkerung im Gebiet des heutigen Französisch-Polynesien.
}

\footnotetext{
${ }^{54} \mathrm{vgl}$. hierzu auch KUNTZ-BRUNNER, R.: Der Triumph der Subjektivität. In: Deutsches Allgemeines Sonntagsblatt Nr. 13. 29.03.91.
} 
- $\quad$ da auch eine Rekonstruktion auf archäologischer Basis noch lückenhaft ist (s. u.);

- $\quad$ da es die (dass heißt nur eine einzige einheitliche) voreuropäische Kultur in FranzösischPolynesien nicht gibt, sondern ihrerseits schon ein Produkt mehrfachen Kulturwandels ${ }^{55}$ ist;

- da der erstmalige Beginn jeder wissenschaftlich-ethnologischen Beschreibung schon eine Einflussnahme auf die entsprechende Ethnie darstellt, so dass das gesuchte ursprüngliche Original schon dadurch zerstört ist, dass es entdeckt wurde ${ }^{56}$.

Somit führte die Interpretation der auf verschiedensten Grundlagen (Variationen in der ethnologischen Vorbildung und religiösen Weltsicht des Aufzeichners, Zeitpunkt der Aufzeichnung, sowie oben genannte Punkte) entstandenen Quellen zu unterschiedlichen und keineswegs lückenlos zufrieden stellenden Ergebnissen bei der Rekonstruktion der voreuropäischen Kultur in Französisch-Polynesien.

Die ersten Aufzeichnungen von Bedeutung in Bezug auf die historisch-kulturelle Entwicklung der autochthonen Kultur Französisch-Polynesiens gehen auf den Spanier RODRIGUEZ und den Bounty-Meuterer MORRISON ${ }^{57}$ zurück. Während RODRIGUEZ' Extracto, in dem Bräuche und Riten der Maohi beschrieben sein sollen, in Lima verloren ging, liefert der zweite Teil von MORRISONs Aufzeichnungen erste ethnologische Informationen. Im Zuge der Mission war es der britischen Missionar Reverend ELLIS ${ }^{58}$, der im Zeitraum 1817-1825 die Kultur der

\footnotetext{
${ }^{55}$ „Kulturen und Gesellschaften dürfen nicht nur als Systeme, sie müssen zugleich auch als Prozesse aufgefasst werden. Die zeitliche Dimension ist für ihr Verständnis unabdingbar. Das trifft auch für primitive Kulturen und Gesellschaften zu, die man, verleitet durch die schlechte Quellenlage, gerne als ,geschichtslos' zu interpretieren neigt. Auch sie sind ja von handelnden Menschen getragen, auch in ihnen findet man, wie die Ethnohistorie beweist, einen mehr oder minder raschen Wandel aller Phänomene. Unter Kulturwandel versteht man demgegenüber einen qualitativen Wandel der Gesamtkultur oder eines ihrer maßgeblichen Teilbereiche“" (s. HIRSCHBERG 1988, S. 275 f.).
}

\footnotetext{
${ }^{56} \mathrm{Zu}$ weiteren Problemen des Verstehens und der „wissenschaftlichen“ Untersuchung fremder Ethnien vgl. H. FISCHER: Feldforschungen. Berlin. Reimer. 1988.
}

\footnotetext{
${ }^{57}$ MORRISON, James: The Journal of James Morrison Boatswain's Mate of the Bounty describing the Mutiny and subsequent Misfortunes of the Mutineers together with an Account of the Island of Tahiti. London. The Golden Cockerel Press. 1935.

${ }^{58}$ ELLIS, W.: Polynesian Researches During a Residence of Nearly Eight Years in the Society and Sandwich Islands. London: Second Edition, 1831.
} 
Autochthonen, wenn auch durch die europäisch-protestantische Brille, erstmalig umfassend beschreibt. Sein Glaubensbruder Reverend ORSMOND sammelte von 1817 bis 1856 Material über das traditionelle überlieferte Wissen einschließlich der Genealogien der herrschenden Häuptlinge, das allerdings erst 1928 durch seine Enkelin HENRY ${ }^{59}$ veröffentlicht wurde. Die Arbeit von MOERENHOUT ${ }^{60}$ war ein Vorläufer des Werkes von ADAMS ${ }^{61}$, welches zunächst als außerordentlich authentische Materialsammlung galt, dann aber der Autor der Faktenmanipulation beschuldigt wurde (vgl. GUNSON 1963, S. 416). Eine poetische Bearbeitung erfährt das gleiche Material durch LA FARGE ${ }^{62}$.

Von den bisher genannten Primärquellen sind die Sekundärquellen abzugrenzen, die im Wesentlichen in der Tradition der Primäraufzeichnungen ADAMS und COOKS ${ }^{63}$ standen. In einem zwanzigjährigen Forschungsprojekt sammelte und studierte OLIVER Daten vor Ort und präsentierte das Ergebnis seiner Arbeit in seinem dreibändigen Werk Ancient Tahitian Society ${ }^{64}$ (1974).

Die archäologische Forschung begann erst 1923 mit bisher relativ wenigen Ausgrabungen ${ }^{65}$ (vgl. EMORY 1988, S. 33).

\footnotetext{
${ }^{59}$ HENRY, Teuira: Ancient Tahiti Based on Material Recorded by J.M. ORSMOND. Honolulu: 1928. Bernice P. Bishop Museum Bulletin 48.

${ }^{60}$ MOERENHOUT; J. A.: Voyage aux Îles du Grand Océan. 1837.

${ }^{61}$ ADAMS, H.: Tahiti, Memoires of Arii Taimai. Memories of Marau Taaroa, Last Queen of Tahiti. New York: Scholars' Facsimiles and Reprints, 1947.

${ }^{62}$ LA FARGE, J.: Reminiscences of the South Seas. London: 1914. ${ }^{63}$ BEAGLEHOLE, J. C. (Hrsg.): The Journals of Captain Cook on His Voyages of Discovery. Cambridge: Hakluyt
Society, 1955.
}

${ }^{64}$ Dieses Standardwerk über die voreuropäische Kultur in Französisch-Polynesien (Schwerpunkt Gesellschaftsinseln) ist bisher das weitaus detailreichste.

\footnotetext{
${ }^{65} \mathrm{Zu}$ nennen wären hier die vom Bernice P. Bishop Museum of Honolulu 1923 initiierten archäologischen Grabungen, die mit einigen Unterbrechungen bis heute fortgeführt werden. Anfängliches Ziel war es, vorwiegend Streufunde an der Oberfläche einer jeden Insel zu dokumentieren und lohnende Ausgrabungsorte ausfindig zu machen, wobei die Lokalbevölkerung aufgerufen war dabei mitzuwirken. Die ersten Grabungen begannen erst 1960, wobei ab 1963 CNRS (Centre Nationale de la Recherche Scientifique) und ab 1964 ORSTOM (Office de la Recherche Scientifique et Technique Outre-Mer) von französischer Seite mitbeteiligt waren. Hierbei entdeckte man 1962 auch die Gräber auf Maupiti, wobei die Grabbeigaben denen der Moa-Jäger (autochthone Bevölkerung Neuseelands vor den heutigen maori) ähnelten (was Anlass zu der Vermutung gab, die Moa-Jäger kämen von den Gesellschaftsinseln).

1972 wurden die Funde auf Huahine (s. o.) und 1977 (diesmal auch unter Mitbeteiligung des Musée de Tahiti, vgl. Kap. 6.2) und auf Raiatea gemacht. Letztere (Werkzeuge, insbesondere Fischhaken) hatten ein ähnlich hohes Alter wie diejenigen Funde von Maupiti und Huahine. Auch auf Moorea wurden bisher Funde dieser (vermutlich) frühesten Besiedlungsperiode entdeckt. Bis zur Gegenwart klafft eine erhebliche Lücke an Fundmaterial, was unter
} 
Unter diesen Umständen kann die folgende, kurze Kulturskizze nur eine erste Annäherung sein, die durch weitere wissenschaftliche Ergebnisse (insbesondere auch im Vergleich mit anderen polynesischen Gesellschaften und im historischen Gesamtkontext Polynesiens) noch weiter fundiert oder abgewandelt werden wird.

\section{$\underline{\text { 6.2.2.1 Gesellschaftsstruktur }}$}

Die Gesellschaftsstruktur in Französisch-Polynesien war auf den ersten Blick eine hierarchische „Aristokratie mit monarchischen Zügen" (KOCH 1959, S. 60). Diese Hierarchie setzte sich allerdings nicht bis zu einem Gesamtherrscher über dasjenige Gebiet fort, was heute mit Französisch-Polynesien gemeint ist, sondern endete auf Distriktebene. Eine Regierungsform, die einem zentralregierten Nationalstaat vergleichbar wäre, ist aus dem voreuropäischen FranzösischPolynesien also nicht bekannt, sondern gleichberechtigte, politisch autonome Distrikte, die über jeweils eigene Priester, Handwerker, Tempelstätten verfügten (vgl. HEERMANN 1987, S. 59). Innerhalb der Distrikte bildeten sich Siedlungsstrukturen heraus, die seit Beginn der Besiedlung bis zum Kontakt mit den Europäern im Wesentlichen die gleichen geblieben sind. GREEN (1967, S. 216-217 ${ }^{66}$ ) rekonstruiert für die voreuropäische Zeit ein Bild von Streusiedlungen, die sich in Abhängigkeit des naturräumlichen Potentials vorwiegend in den Küstenebenen, aber auch zum Teil weiter im Landesinneren befinden und sich qualitativ nicht wesentlich voneinander unterscheiden.

Neben der generellen Zweiteilung der Menschen in raa (Berechtigung an religiösen Handlungen teilzunehmen) und noa (gewöhnliche Menschen; vgl. NEWBURY 1988, S. 59), bestand folgende Struktur der autochthonen Gesellschaft:

- $\quad$ ari’i nui: Fürsten des Adels, meist Distriktfürste, Mitglieder der ältesten Familien; die Stellung in der Gesellschaft wird auf das älteste Kind vererbt

- $\quad$ ari'i ri'i: engste Verwandte des ari'i nui, Mitglieder des Hochadels, meist Herrscher über kleinere Distrikte

anderem darauf zurückzuführen ist, dass durch Vegetation und Landwirtschaft die stratigraphischen Verhältnisse in den obersten Schichten gestört sind (vgl. EMORY 1988, S. 33 ff.).

${ }^{66}$ GREEN et. al: Archaeology on the island of Moorea, French Polynesia. Anthropological Paper No. 51, pt. 2, American Museum of Natural History, New York, 1967 (zitiert nach EMORY 1988, S. 38.) 
- $\quad$ ra'atira: Grundbesitzer, Verwalter kleinerer Distrikte, Handwerker, Haus- und Bootsbauer, Priester und Gelehrte

- $\quad$ ta ${ }^{\prime} a t a^{67}$ (was nichts anderes als Mensch heißt) : Pächter, größter Teil der Bevölkerungsgruppe, zum Teil als „Hörige" bezeichnet

tautau: Dienerschaft (zum Teil als Sklaven bezeichnet), erledigten häusliche Arbeiten der Adelsschicht, oft Kriegsgefangene

In diese Schichtung der polynesischen Gesellschaft wurde das einzelne Individuum zwar hineingeboren, doch war dieses System nicht völlig starr, so konnten insbesondere Angehörige der ra'atira, aber auch der ta'ata und sogar der tautau durch besondere Fähigkeiten großes Ansehen und Einfluss bei den ari'i gewinnen. Die Heirat zwischen den einzelnen Gesellschaftsgruppen war allerdings verboten.

Entsprechend seiner Zugehörigkeit zu einer der fünf Gesellschaftsgruppen waren auch die Rechte und Pflichten (z. B. auch die Möglichkeiten zur Landnutzung des gemeinsamen Stammeslandes (vgl. Kap. 6.2.2.5), festgelegt. Auch auf der Ebene ari'i - untergeordnete Gesellschaftsgruppe bestanden Rechte und Pflichten, was die gegenseitige Verbundenheit ausdrückt. Die Tatsache, dass die ari'i von sämtlichen anderen Gesellschaftsgruppen ihres Herrschaftsbereiches ${ }^{68}$ miternährt wurden, da diese verpflichtet waren, dem ari'i sowohl Nahrungsmittel, Textilien, Baumaterial etc. als auch Krieger bereitzustellen, lässt zunächst eine recht einseitige Abhängigkeit vermuten, doch bestand die Gegenleistung der ari'i nicht nur in Zuwendungen aus dem eigenen Vorrat in entsprechenden Notzeiten, sondern auch in „Dienstleistungen" im rechtlichen und religiösen Bereich (vgl. HEERMANN 1987, S. 64).

Die oben dargestellte Gesellschaftsstruktur war im Zeitablauf nicht in dieser Form starr fixiert. Zunächst kann man für die Anfänge der polynesischen Kultur in Französisch-Polynesien eine

\footnotetext{
${ }^{67}$ Genauso häufig findet sich in der Literatur (z. B. OLIVER 1974, S. 749 ff.) für diese Gesellschaftsschicht, oder auch für die ra'atira die Bezeichnung manahune, was als weiterer Beweis dafür angesehen werden kann, das diese eine frühere von den ari'i kulturell überformte polynesische Bevölkerungsgruppe war (s. u.). Eine Erklärung für diese Vermischung von Bezeichnungen bietet ebenfalls OLIVER (S. 768 f.), der dies auf eine Verwechslung der Bezeichnungen für die gesellschaftliche Stellung mit der Bezeichnung für eine berufliche Tätigkeit zurückführt. Was letztendlich was war ist heute nicht mehr genau nachvollziehbar.
}

\footnotetext{
${ }^{68}$ Dieser Herrschaftsbereich bestand zumeist aus mehreren Distrikten, die sich ihrerseits weiter in Unterdistrikte, lokale Siedlungseinheiten - meist aus einer einzigen Großfamilie, ansonsten aus mehreren Kleinfamilien (hierbei waren sowohl Polygamie als auch Einehe bekannt) bestehend - differenzieren lassen.
} 
simplifizierte, nicht in diesem Maße differenzierte gesellschaftliche Schichtung annehmen, zum anderen waren auch Befugnisse, Macht und gesellschaftliches Ansehen der jeweiligen Angehörigen einer gesellschaftlichen Gruppe einem stetigen, leichten Wandel unterworfen, was u. a. zu inselspezifischen Unterschieden führte. Dementsprechend finden sich in der Literatur auch leichte Abwandlungen dieser Darstellung, die sich aber im Wesentlichen, nämlich der Beschreibung einer gesellschaftlichen Schichtung, nicht voneinander unterscheiden (vgl. NEWBURY 1988, S. 59).

Die Dynamik und inselspezifische Unterschiedlichkeit der Herrschaftsstruktur verdeutlicht das folgende Zitat von HENRY (1928; zitiert nach NEWBURY 1988, S. 61):

„From time immemorial each little kingdom of the Leeward Islands has generally been ruled by one ari'i nui and several subordinate chiefs, but Tahiti and Moorea were called 'Plebeian Tahiti' in former times because they were realms of democratic people ruled by warrior chiefs. Later on came branches of the highest royal family of Opoa in Raiatea, who by marriage became rulers of the people in their respective districts, until gradually all the land became subjugated to the dynasty of Pomare, the people of each class retaining possession of their hereditary lands."

Polygamie (s. o.) war insbesondere unter den ari'i und den ra'atira verbreitet, „Scheidungen" relativ unkompliziert. Über ihre Kinder hatten die Eltern zudem ein beträchtliches Verfügungsrecht (durch alle gesellschaftlichen Schichten hindurch), da sie im Säuglingsalter getötet, verschenkt, ausgetauscht und adoptiert werden konnten, wobei im Alter von acht bis zwölf Jahren die Entscheidung, bei welcher Familie sie wohnen möchten, oftmals allerdings ganz den Kindern übertragen wurde. Hinter dem Brauch der Kindestötung (hierbei lag die Entscheidung vorwiegend bei der Mutter) stand zum einen das geringe Prestige, welches dem Kinderreichtum zukam, zum anderen wurde die Tragfähigkeit des Siedlungsgebietes nie durch einen entsprechenden Bevölkerungsdruck überschritten (ökologische Funktion). Negative Auswirkungen hatte allerdings die Tatsache, dass in der Hauptsache die weiblichen Säuglinge getötet wurden, da es dadurch zwangsweise zu einem zahlenmäßigen Missverhältnis zwischen Männern und Frauen kam (vgl. KOCH 1959, S. 75 f.).

Des Weiteren hatten Frauen im Allgemeinen nicht die gleiche Stellung in der Gesellschaft wie Männer, da es ihnen z. B. verboten war, mit den Männern zusammen zu essen oder das heiligste Innere der Marae (vgl. Kap. 6.2.2.2) zu betreten. Andere Darstellungen hingegen bezeugen sogar das Vorhandensein weiblicher Häuptlinge (vgl. LEVY 1988, S. 23).

Ein wichtiger Aspekt der voreuropäischen Gesellschaft der Maohi war das Senioritätsprinzip, dass heißt die Ältesten standen in der familiären und gesellschaftlichen Hierarchie ganz oben, ihnen wurde großer Respekt entgegengebracht (vgl. WERNHART 1993, S. 19).

SAHLINS (1958) nimmt für die Gambier- und Marquesasinseln eine etwas vereinfachte soziale Schichtung in nur zwei bis drei Gesellschaftsstufen an. 
Im Vergleich zu Melanesien, dessen Gesellschaftsstruktur insbesondere auf Clans, d. h. „autonome Verwandtschafts- und Nachbarschaftsgruppen (kinship-residential groups)“(s. KREISEL 1991, S. 44) gründete, war die hierarchische oder auch vertikale Sozialstruktur in ihren Grundzügen in Gesamt-Polynesien vergleichbar:

\begin{abstract}
„Zusammenfassend kann man sagen, dass eine Oberschicht (arii in Neuseeland und Tahiti oder ali'i in Hawaii) und Tributpflichtige (iatoai in Neuseeland) oder Gemeinfreie (maka'ainana in Hawaii) gab, daneben eine Art Hörigen- oder Sklavenschicht (manahune, menehune, kauwa). Darüber hinaus hatte sich eine eigene Priesterkaste herausgeblidet; die kahuna (Hawaii) oder tohunga.“ (s. KREISEL 1991, S. 45 f.).
\end{abstract}

\title{
6.2.2.2 Religion
}

Die Rekonstruktion der Religion und sogar Religionsgeschichte in Französisch-Polynesien erweist sich als einfacher als diejenige, der anderen vier hier beleuchteten Aspekte von Kultur, da die Stammbäume der ari'i mündlich tradiert sind, was in der Genealogie ${ }^{69}$ als lineage bezeichnet wird, da sich die Mitglieder der Verwandtschaftsgruppe der ari'i in direkter Linie auf einen - hier göttlichen - Urahn zurückführen lassen ${ }^{70}$.

Entsprechend der hohen Machtposition der ari'i wurden zuweilen die lineage manipuliert, um Titel und Besitzansprüche geltend zu machen (vgl. NEWBURY 1988, S. 62). Auf Grund ihres göttlichen Ursprungs standen die ari'i nie unter dem gesellschaftlichen Zwang, ihre Macht rechtfertigen zu müssen. Zum einen hatte dies zur Folge, dass einige ari’i - sich der Würde und Ehre ihres Amtes bewusst - sich bemühten, ein vorbildliches Leben zu führen, zum anderen nützten andere ari'i ihre Machtposition derart aus, dass es (z. B. auf Mangareva) zu Aufständen gegen die Herrschenden kam (vgl. SAHLINS 1970, S. 203 ff.).

NEVERMANN (1968, S. 62 ff.) unterscheidet drei Perioden der polynesischen Geschichte unter besonderer Berücksichtigung religiöser Vorstellungen:

- $\quad$ die Periode der manahune (auf Tahiti auch menehune; ca. ab dem 1. Jahrhundert n. Chr.): Die Adelsschicht der ari' $i$ hatte sich noch nicht herausgebildet, es existierten aber bereits Vorstellungen von der Seele, der Glaube an die Lebenskraft (ora), sowie mana und

\footnotetext{
${ }^{69}$ Als Genealogie bezeichnet man „,die Lehre von der Abstammung, von den Geschlechtern. In der Ethnologie wird Genealogie allgemein auch als technischer Begriff für die graphische Darstellung von Stammbäumen, Stammtafeln, Ahnentafeln usw. gebraucht. Diese dienen Abstammungsgruppen als eine Art Verfassung." (s. HIRSCHBERG 1988, S. 176).

${ }^{70}$ „Ein guter Häuptlingsstammbaum musste mit der Entstehung der Welt beginnen, die Genealogie der Götter und sagenhaften Helden einschließen und beim lebenden Fürsten enden“"(s. NEVERMANN 1968, S. 37).
} 
tapu $^{71}$. Weiterhin wurden die Aitu (Orts-, Tätigkeits- und Familiengötter), die Ahnen und höhere Götter namens Mafuike, Tingirau, Sina, Tuna, Uenuku als übernatürliche Wesen verehrt.

Götterbilder und Kultplätze sowie ein Priestertum existieren noch nicht, dafür verschiedene Formen des Schamanismus ${ }^{72}$. Auf den Marquesasinseln ist zu dieser Zeit der Fruchtbarkeitskult (Kult ${ }^{73}$ um den Schöpfergott und Bringer der Fruchtbarkeit, Tiki) von großer Bedeutung.

\begin{abstract}
${ }^{71}$ mana und tapu sind zwei „klassische“ Prinzipien in der religiösen Vorstellungswelt der Völker des pazifischen Raumes. Die Vielzahl europäischer Erklärungs- und Übersetzungsversuche zeugt von einer begrenzten Möglichkeit zum völligen Verstehen dieser Begriffe: „Supernatural power; influence (CODRINGTON), magical power; psychic force (MARETT), impersonal religious force; totemic principle (DURKHEIM); divine force (HANDY), effective; miracle; authority; prestige (TREGEAR), true (HOCART), not only a force, a being; it is also an action, a quality, and a state. In other words the term is at once a noun, an adjective and a verb" (HUBERTUS und MAUSS). Das Verständnis von mana variiert nicht nur von Autor zu Autor, sondern auch in Polynesien selbst von Region zu Region (vgl. FIRTH 1970). GRESCHAT 1980, S. 78 ff beschreibt Mana als „Treibstoff des Lebens“. Mana kann zusammenfassend definiert werden als unsichtbare übernatürliche Kraft, die in Göttern und Menschen, belebten und unbelebten Dingen wirken kann. Mana kann erworben, verloren, übertragen, entfernt oder als Gabe erhalten werden und wird auf eine für Europäer unzureichend nachvollziehbare Weise intuitiv erfasst. Es ist ein nicht-intellektuelles Prinzip. In Bezug auf Menschen könnte auch der Begriff „Charisma“ als erste Annäherung verstanden werden. (PUTIGNY beschreibt Mana und Tapu in verschiedensten Kontexten wie Tod, Tikis, Richtungsfindung, Namensgebung bis hin zu Telepathie und Telekinese). Tapu steht mit mana insofern in Zusammenhang, da alles, was mana (in möglicherweise unterschiedlicher Graduierung) enthält, einem gewissen tapu (verboten, da heilig, geweiht) untersteht, d.h. aus dem alltäglichen Leben ausgegrenzt, unantastbar und dadurch geschützt ist. Durch tapu werden bestimmte Handlungsarten vorgeschrieben oder verboten; ein Nichtbeachten eines tapu wurde strengstens bestraft. Mana und tapu können auf Grund ihrer ordnenden, regulativen Funktion der Gesellschaftsstruktur auch als Komponenten des Kulturfaktors Recht aufgefasst werden (vgl. HEERMANN 1987, S. 57 f. und SEGER 1982, S. 28).
\end{abstract}

\footnotetext{
${ }^{72}$ Der Schamanismus ist ein besonders in archaischen Religionen beobachtetes Phänomen, was durch die Person des Schamanen geprägt wird, der als „kultische Person“ durch ekstatische Techniken mit transzendenten Wesen in Verbindung treten kann. Ebenso gehören das Erleben anderer Wirklichkeitsebenen und das Eintreten in visionäre Bereiche zum Wesen schamanistischer Betätigung. Die wichtigste Funktion des Schamanen ist die des Heilers; daneben fungiert er aber auch als Wahrsager, Opferpriester, Totenführer, Jagd- und Regenzauberer, Zeremonienmeister, Hüter religiöser Traditionen und Mythen, Sänger, Tänzer, Künstler u. a.: „Das Amt legitimiert sich durch Erbschaft oder Berufung“" (s. HIRSCHBERG 1988, S. 416). Als entscheidenden Unterschied zwischen einem Schamanen und einem Priester definiert OLIVER (1974, S. 94 f.) Ersteren als jemanden, durch den Geister/höhere Wesen zu den Menschen sprechen (dass heißt der Schamane ist vorwiegend Medium), während dem Priester eine aktivere Rolle zukommt, da er als menschlicher Vertreter $z u$ den Geistern spricht.
}

\footnotetext{
${ }^{73}$ Kult: „das rituelle sakrale Tun nach festgelegten Normen im Auftrag und zum Nutzen einer Gemeinschaft.“ Kult ist abzugrenzen von Magie und bloßem Ritus, da erstere - im Gegensatz zum Kult - das gemeinschaftliche Verständnis der Handlung nicht voraussetzt und Letzterer - ebenfalls im Gegensatz zum Kult - die Unterwerfung unter eine religiöse Dimension nicht unbedingt erfordert (vgl. HIRSCHBERG 1988, S. 269). Folgende rituelle Objekte sind aus dem heutigen Französisch-Polynesien bekannt: Federn, Blut, Bananenbaum (mei'a, s. o.), Rosenholz (Thespesia populnea: miro, amae), Ti (Cordyline terminalis), Wasser, sowie weitere Pflanzenarten (vgl. OLIVER 1974, S. 107 ff., hier auch die Beschreibung von rituellen Handlungen). Als wichtigste Kulte, die ihre Bedeutung in der Zeit wechselten, sind diejenigen der Götter Taaroa, Tane und Oro zu nennen, sowie die „Sekte“ der arioi, die sich innerhalb des Oro-Kultes weitgehend verselbstständigt hatte (vgl. OLIVER 1974, S. $881 \mathrm{ff}$.).
} 
- $\quad$ die erste Periode der ari'i (auch ariki): NEVERMANN führt das Entstehen dieser Gesellschaftsschicht (s. o.) auf eine weitere große Einwanderungswelle von Polynesiern, die ihren Höhepunkt Anfang des 8. Jh. n. Chr. erreicht, zurück. Aus der sagenhaften Urheimat Hawaiki (wahrscheinlich in Südostasien zu lokalisieren) überformten sie mit ihrem neuen Götterglauben die bestehende menehune-Religion ${ }^{74}$. Unter Übernahme oder Modifizierung einiger Elemente aus dieser früheren Religionsform (die aitu verlieren an Bedeutung und die Häuptlinge und Ahnen werden zu Göttern aufgewertet) setzte sich der Glaube an die Götter (atua, hohe Götter im Gegensatz zu aitu) Tane (oberster Gott), Tu (Kriegsgott), und Rongo (Schützer des Landbaus, des Friedens und aller friedlichen Künste, Gegenpol zu Tu) durch. Die Form der Verdrängung der menehune-Religion ist insofern relativ hart, da die Anhänger des alten Glaubens als „götterlos" geächtet wurden.

Kennzeichnend für diese Periode sind weiterhin die Vorstellung von einem Jenseits (Reinga), einem Paradies (Pulotu), eine weitere Durchdringung von Religion und gesellschaftlichem Status (Häuptlinge und Priester sind durch tapu geschützt), das Entstehen von komplexen Schöpfungsmythen, die ebenso wie die Häuptlingsstammbäume mündlich tradiert werden.

In dieser idealtypischen Reinform findet sich diese Periode nicht im Gebiet des heutigen Französisch-Polynesiens, sondern auf Mangaia und Neuseeland, d.h. für FranzösischPolynesien muss - auch von Archipel zu Archipel oder von Insel zu Insel - eine Variante des beschriebenen Ideals angenommen werden. Interessant erscheint noch die Tatsache, dass in der Spätphase dieser Periode auf den Tuamotuinseln der Geheimkult um die Verehrung eines einzigen Gottes Io entsteht, der aber keine weite Verbreitung findet.

die zweite Periode der ari' $i$ : Tangaroa wird als neuer Hauptgott über Tane, Tu, und Rongo gestellt. Weltentstehungsmythen und Häuptlingsstammbäume werden auf ihn bezogen. Kultplätze (Marae ${ }^{75}$, vgl. Anl. 7 im Anhang) und Kultbilder gewinnen an architektonischem und künstlerischem Wert. Die bis dahin bestehende Praxis der

\footnotetext{
${ }^{74}$ Dies kann als Kulturwandel, bzw. Diffusion im oben definierten Sinne aufgefasst werden.

${ }^{75}$ Die Schöpfungsmythen erklären das Entstehen der Marae als ein wichtiges Element der Ordnung, das als feste Institution die Kommunikation mit den Göttern erleichterte, so dass mit Marae in seiner ursprünglichen Bedeutung jeder durch Menschen minimal strukturierte Ort (also auch einfach ein abgetrenntes Areal), der Interaktion mit den Göttern diente als Marae bezeichnet wurde (vgl. OLIVER 1974, S. 95 ff.). Von den Marae zu unterscheiden sind die „Versammlungsplattformen“ und die „Plattformen für Bogenschützen“ (sportlicher Wettkampf im Weitschießen), die in ihrer Baukonstruktion sich auf den ersten Blick nicht wesentlich von den Marae unterscheiden, wohl aber in ihrer Funktion (EMORY 1988, S. 49 f.).
} 
Menschenopfer sowie der Kannibalismus wurden weitgehend eingeschränkt. Kulturelles Zentrum - auch weit über den Raum des heutigen Französisch-Polynesien hinaus - der neuen Religionsvariante, die sich ca. ab dem 10. Jh. n. Chr. auszubreiten beginnt, ist Raiatea $^{76}$ (welches interessanterweise später auch zeitweiliges Zentrum des ersten organisierten Widerstandes gegen das Christentum, der mamaia-Bewegung (vgl. Kap. 6.3.2) ist).

die dritte Periode der ari 'i charakterisiert sich durch das Aufkommen vieler Varianten der alten Kulte und Religionsvorstellungen, aber auch durch das Entstehen vieler neuer Richtungen, so dass unterschiedlichste religiöse Strömungen parallel existieren (vgl. hierzu auch Anl. 9 im Anhang), was bedingt durch die entsprechenden Fehden und Kriege, die die verschiedenen Gruppen gegeneinander führten, zu einer generellen Schwächung des kulturellen Systems führte. Es entstand zum Beispiel auf Tahiti und Raiatea der auf einer mythischen Person beruhende Oro-Kult, der in kriegerischen Auseinandersetzungen mit den Anhängern Tangaroas und Tanes zum Untergang Raiateas als religiösem Kulturzentrum führte. ${ }^{77}$

Nachgewiesen sind auch Vorstellungen von einer Seele (varua), die vom materiellen Körper (tino) unterschieden wurde und die sich im Traum oder Trancezustand zeitweilig und nach dem Tode ganz vom Körper trennt (vgl. OLIVER 1974, S. 62). Eine differenzierte und erst in jüngerer Zeit verschriftlichte Vorstellung vom Universum ist ebenfalls überliefert. Dieses Konzept beinhaltet verschiedene Sphären, die sich vom Reich der Toten über die Welt der Lebenden bis in göttliche Bereiche graduell entwickeln (vgl. MANU-TAHI 1992).

Obwohl jeder Einzelne der Gesellschaft zur Kommunikation mit den Göttern fähig war, existierten ,hauptberufliche" Priester (s. o.), die den Kontakt zu den Göttern hielten und durch die Kenntnis des geheimen Wissens darum (vgl. Kap. 6.2.2.5) und um religiöse Handlungen, die vorwiegend in den Marae verrichtet wurden, eine starke gesellschaftliche Machtstellung innehatten. Oftmals herrschte unter den Priestern eine hierarchische Arbeitsteilung mit

\footnotetext{
${ }^{76}$ Die frühere und heutige poetische Bezeichnung Raiateas ist Havai'i, was Anlass zu der Vermutung gibt, das mindestens eine Besiedlungswelle Hawaii von Raiatea aus erreichte. Nach EMORY (1988, S. 51) war es sogar die spätere Häuptlingsschicht Hawaiis.

${ }^{77}$ In Bezug auf die erste und zweite Periode der ari'i ist es durchaus legitim, von zumindest partiellen Kulturwandeln zu sprechen, da die jeweiligen religiösen Systeme in Teilbereichen nachhaltig innovativ verändert wurden.
} 
„Hochpriestern", „Priestern", „Novizen", „reinen Handlangern" etc... (vgl. OLIVER 1974, S. 94 f. und Anl. $10 \mathrm{im}$ Anhang).

Das Prinzip von mana und tapu ist in ganz Polynesien anzutreffen, ebenso der Götterkanon und einflussreiche Priester, die als Mittler zwischen Menschen und Göttern fungierten (vgl. KREISEL 1991, S. 48 ff.).

\section{$\underline{\text { 6.2.2.3 Wirtschaft }}$}

Die traditionelle Subsistenzwirtschaft ${ }^{78}$ bestand in der Hauptsache aus Gartenbau (Taro, Yams, Süßkartoffel, Maulbeerbaum) und wurde sowohl durch Jagd- (verwilderte Schweine, Eidechsen, Vögel) und Sammelwirtschaft (Banane, Brotfrucht, Kokosnuss, Pandanuss-Frucht, Apfel, Mango sowie verschiedene Wurzeln und Knollen), eine „Haustierhaltung” (Hunde, Geflügel, Schweine) als auch durch Fischfang (Angel-, Speer-, Netzfischerei) ergänzt. Generell waren die Arbeitsteilung und damit die ökonomische Spezialisierung, ebenso die Techniken zur Nahrungsspeicherung, begrenzt (vgl. CROCOMBE 1987, S. 219 ff.). Wann sich welches neue agrarische Produkt oder eine verbesserte Nutzungsweise wo entscheidend durchgesetzt hat, ist im Einzelnen schwer nachzuprüfen (Ausnahmen: Süßkartoffel wurde mit höchster Wahrscheinlichkeit aus Südamerika übertragen, Taro ist durch archäologische Funde bis in die frühesten Zeiträume der Besiedlung nachgewiesen, ebenso die Existenz eines Bewässerungssystems). Somit war die Wirtschaftsweise der Bewohner im Gebiet des heutigen FranzösischPolynesien an die entsprechenden naturräumlichen Gegebenheiten (Landbau in den fruchtbaren Küstenebenen, Ergänzungsraum Meer, vgl. hierzu auch Kap. 6.1.2.2) angepasst (vgl. HEERMANN 1987, S. 69 f. und WIRTHMANN 1964, S. 180). Der Wirtschaftsraum war in Distrikte (mata'eina'a) eingeteilt - z. B. in Tahiti in neun (vgl. Anl. 11a, b im Anhang) -, deren räumliches und religiöses Zentrum meist ein Marae bildete (vgl. Kap. 6.3.2, TETIARAHI 1988, S. 102 und Anl. 7 im Anhang).

Im gesamten Gebiet Polynesiens herrschte nicht zuletzt auf Grund der nautischen Fähigkeiten der Bewohner ein reger Tauschhandel, der nicht nur landwirtschaftliche, sondern auch handwerkliche und künstlerische Produkte (vorwiegend aus Stein, Holz und Knochen, da der Gebrauch von Metallen unbekannt war) mit einschloss, so dass die These einer isolierten

\footnotetext{
${ }^{78}$ Unter Subsistenzwirtschaft wird hier eine Wirtschaftsform verstanden, die zwar primär auf die Eigenversorgung ausgerichtet ist, aber einen, anteilsmäßig geringen, Tauschhandel nicht ausschließt. Eine Form von „Geld“, die diesen zu ersetzen begann, ist im Gebiet Französisch-Polynesiens nicht nachgewiesen.
} 
inselspezifischen kulturellen Entwicklung ${ }^{79}$ in Bezug auf Polynesien nur für wenige (extrem periphere) Regionen und auch dort nur in abgeschwächtem Maße zu vertreten ist.

Die Subsistenzwirtschaft war in voreuropäischer Zeit im gesamten Raum der pazifischen Inseln das vorherrschende Wirtschaftsprinzip; die Wahl der überwiegend angebauten Nutzpflanzen war auch klimatisch bedingt:

„In den tropischen Inselgruppen Polynesiens dominierte meist neben Taro und Yams die Kokospalme, während in den sub- bis außertropischen Gebieten (Hawaii, Osterinsel, Neuseeland) sowie in größeren Höhenlagen die Süßkartoffel vorherrschte. In Hawaii spielten daneben Taro und Brotfruchtbaum eine Rolle, in Samoa traten Taro und Brotfruchtbaum mehr in den Vordergrund. Tongas Landwirtschaft basierte auf dem Anbau von Yams.“(s. KREISEL 1991, S. 55).

\section{$\underline{6.2 .2 .4 \text { Sprache }^{80}}$}

Der Anteil der polynesischen Sprachen an den weltweit gesprochenen Sprachen und damit ihre Bedeutung ist extrem gering. Die Stellung des Polynesischen in einem globalen System der Sprachenklassifizierung kann wie folgt beschrieben werden:

- $\quad$ Sprachstamm: Austrier (zum Vergleich: Indoeuropäer und Sinotibeter befinden sich auf der gleichen Klassifikationsebene)

- $\quad$ Großfamilie: Austronesier (in Abgrenzung zu Munda und Mon Khmer)

- $\quad$ Familie: Polynesisch-Melanesisch (in Abgrenzung zum Indonesischen; die Verwandtschaft des Marquesischen und Tahitischen besteht im Lexikon u. a. zum Sprachgebiet Javas und Malaysias)

\footnotetext{
${ }^{79}$ Diese Problematik wird z. B. von VAYDA (1969) angedeutet.

${ }^{80}$ Sprache wird in der Sprachwissenschaft als ein ,auf mentalen Prozessen basierendes, gesellschaftlich bedingtes, historischer Entwicklung unterworfenes Mittel zum Ausdruck bzw. Austausch von Gedanken, Vorstellungen, Erkenntnissen und Informationen, sowie zur Fixierung und Tradierung von Erfahrung und Wissen" definiert und ist „eine artspezifische, nur dem Menschen eigene Ausdrucksform, die sich von allen anderen möglichen Sprachen (Tiersprachen, künstlichen Sprachen etc.) unterscheidet durch Kreativität, die Fähigkeit zu begrifflicher Abstraktion und die Möglichkeit zu metasprachlicher Reflexion“ (BUSSMANN 1983, S. 475). Dieses ausführliche Zitat soll die Bedeutung von Sprache als dem kulturtragenden Element verdeutlichen, da sich bis heute verschiedene Kulturen - u. a. die Maohi - im Wesentlichen über ihre Sprache definieren und von anderen abgrenzen (vgl. Basken, Katalanen, Iren etc...).
} 
Für das Gebiet Französisch-Polynesiens existieren bisher keine umfassenden sprachgeographischen Untersuchungen, die eine detaillierte Momentaufnahme und damit Konservierung eines bestimmten Sprachzustandes in der Zeit ermöglicht hätten.

Nach KREISEL (1991, S. 76 ff.), der zusammenfassend das heutige Kernpolynesisch (unter Zugrundelegung eines früheren Proto-Polynesisch und in Abgrenzung zum Tongischen) zunächst in Ost-Polynesisch (in Abgrenzung zum Samoischen), dieses weiterhin in Zentral-Polynesisch (unter Ausklammerung der Sprache der Osterinsel) differenziert, ist das Gebiet des heutigen Französisch-Polynesien (innerhalb des Zentral-Polynesischen) sprachgeographisch zwei Regionen zuzuordnen: dem Marquesischen (Marquesas) und dem Tahitischen (Gesellschafts-, Tuamotu-, Gambier- und Australinseln, vgl. auch Anl. 12 im Anhang). Hierbei differiert allerdings die exakte Aufteilung bzw. Entstehung der polynesischen Sprachen von Autor zu Autor (vgl. BIGGS 1967, S. 303-322). Auf den fünf Archipelen sind nochmals lokale Sprachvarianten (oder Dialekte ${ }^{81}$ ) festzustellen.

Es wird gemeinhin angenommen, dass die Expansion der Sprache mit der Expansion der Landwirtschaft gekoppelt ist. Die Ergebnisse der Archäologie und der Genese der Sprachen im pazifischen Raum bestätigen beide eine von Asien ausgehende Besiedlungsrichtung (vgl. BELLWOOD 2000, S. 71 und Kap. 6.2.1).

Zur Sprache gehört ihre Manifestation in der Literatur. Da die Polynesier zu den schriftlosen Kulturen gehören, ist ihre Form der Literatur eine mündlich tradierte, die als Oraltradition $^{82}$ (ein Beispiel hierfür s. Anl. 13 im Anhang) bezeichnet wird. Diese mündlich tradierte Literatur erfüllte u. a. den Zweck der Geschichtskonservierung in Form von Weltentstehungsmythen,

\footnotetext{
${ }^{81}$ Die Unterscheidung in Sprache und Dialekt ist in vielen Fällen willkürlicher Natur. Innersprachlich kann kein Unterschied konstruiert werden. Die Formen von Sprache auf den einzelnen Archipelen Französisch-Polynesiens rechtfertigen die Bezeichnung Dialekt insofern, als dass diese lokalen Varianten (mit Ausnahme des Tahitischen) nicht den Status einer offiziellen Sprache haben, zurzeit noch nicht alle kodifiziert sind und im Bewusstsein der Sprecher nicht in allen Fällen die Funktion eines identitätstragenden Faktors haben (sondern eher das Polynesische insgesamt).

${ }^{82}$ Oraltradition: „Die mündliche Überlieferung von Mythen, Erzählungen, Märchen und Legenden, Rätseln, Sprichworten, Liedern, Beschwörungsriten, Zauberformeln und Fabeln. Ehe man sie schriftlich festlegte, wurde sie ausschließlich memorisiert. Die Oraltradition verwendet meist feierliche oder rituelle Formen, Ausdrücke, die in der Umgangssprache kaum vorkommen. Oft wird die Oraltradition von professionellen Erzählern ... weitergegeben. Sie haben das Lob der Mächtigen zu verkünden, beherrschen die gefürchtete Waffe des Spottes und sind Hüter des Wissens. Die Oraltradition wird jedoch in den meisten Fällen auch von der Gemeinschaft überwacht. Eines ihrer wichtigsten Elemente stellen die Mythen dar. Die moderne Ethnologie hält die Mythenforschung für einen wesentlichen Bestandteil und die Bedingung zum Verständnis des kulturellen und religiösen Weltbildes eines Volkes. ... Mit dem Problem des historischen Wertes der Oraltradition befassten sich viele Ethnologen; die Wertung reicht von der vollkommenen Ablehnung bis hin zur Gleichstellung mit schriftlichen Quellen“"(s. HIRSCHBERG 1988, S. 350 f.).
} 
Genealogien $^{83}$ (vgl. Kap. 6.2.2.2), Legenden (vgl. DAVIS 1985, S. iii-vi) und variierten von der Lyrik über das Rezitativ bis zu Gesängen. Als Ironie des Schicksals ist es zu verstehen, dass Ethnologen im Bemühen autochthone Sprachen und orale Literatur zu bewahren, diese schriftlich fixierten und sie damit ihres wesentlichen Elementes, nämlich der mündlichen Überlieferung beraubten. Neben dem allgegenwärtigen Problem der Übersetzung taucht hier wieder das - nicht widerspruchsfrei lösbare - Problem der Konservierung fremder Kulturelemente durch Europäer auf, ohne sie in ihrem Wesen, in ihren spezifischen Charakteristika, zu zerstören (vgl. Kap. 6.2.2).

Eine andere Erscheinung, die in ihrem Bilderreichtum als Vorform einer Schrift gedeutet werden könnte (vgl. Entstehung chinesischer und ägyptischer Schriftzeichen), aber eher dem Bereich der Kunst zuzuordnen ist, sind die Petroglyphen: Auf einzelnen Felsen oder Marae-Steinen werden oft in konzentrischer Anordnung Menschen, Fische und Schildkröten (welche sehr oft als Tieropfer in den Marae dargebracht wurden) dargestellt. Weitere Motive der Darstellung waren Kanus, und sogar die komplette Trauerkleidung inklusive Maske und Kopfputz beim Tod eines Häuptlings (vgl. Anl. 14 im Anhang).

Die Sprachen in Polynesien sind sich heute - trotz der großen Entfernungen ihrer Sprechergruppen - derart ähnlich, dass sich Hawaiianer und Tahitianer durchaus verstehen können.

\section{$\underline{6.2 .2 .5 \text { Recht }}$}

Gerade bei der Betrachtung des Faktors Recht wird zum einen das Problem der Rekonstruktion (s. o.: keine schriftliche Kodifizierung) und zum anderen das Verständnis auf Grund der Verzerrung durch die europäische Nomenklatur erschwert. So existiert zu manchen Rechtsbereichen keine rein individuelle oder rein gemeinschaftliche Rechtsform, sondern beides gleichzeitig auf verschiedenen Ebenen und in verschieden gewichteten Kombinationsmöglichkeiten. Zudem war „Eigentum" nicht mit „Verfügungsrecht" gleichzusetzen und in einigen Fällen existierten zu ein und der selben Sache mehrere „Eigentümer" (vgl. KOCH 1959, S. 65 f.). Der Übersicht halber erfolgt hier eine Aufteilung in verschiedene Rechtsbereiche:

- $\quad$ Siedlung- und Bebauungsland: die geringe Bevölkerungskonzentration ließ Dörfer geringer Größe entstehen (vgl. Kap. 6.2.2.1), wobei eine Verwandtschaftsgruppe auf

\footnotetext{
${ }^{83}$ „Généalogies commentées des arii des Îles de la Sociéte“" herausgegeben von der Société des Études
} 
Dorfebene „Eigentümer" eines bestimmten Häuserkomplexes war, während die Nutzungsrechte und das Recht auf Zugang zu den einzelnen Häusern abhängig vom gesellschaftlichen Status der einzelnen Mitglieder der „Eigentümergruppe” war (vgl. CROCOMBE 1987, S. 222). Als wirkliches Kollektiveigentum können die Versammlungs- und Gästehäuser bezeichnet werden, während Wohnhäuser - in Größe und Festigkeit der Bauweise steigend mit dem Gesellschaftsprestige des Bewohners - als Individualeigentum anzusehen sind.

- $\quad$ es existierte weiterhin geheiligtes Land, welches zu keinem ,weltlichen" Zwecke genutzt werden durfte und gemeinschaftlich zu den entsprechenden rituellen Zwecken betreten wurde. Davon zu unterscheiden ist Land, welches ebenfalls als geheiligt und unbetretbar erachtet wurde, auf welchem aber keine rituellen Handlungen stattfanden, so z. B. meistens die inneren unfruchtbaren und unzugänglichen Gebiete FranzösischPolynesiens. (vgl. CROCOMBE 1987, S. 223). Solche „Naturobjekte ohne wirtschaftlichen Nutzwert" konnten auch in Form eines Kaps ( 'o'utu), eines Berges (mou'a) oder eines Wasserlaufes (vai) einem ari’i von höchstem Rang ,gehören" (vgl. Koch 1959, S. 65).

kultiviertes Land war entsprechend dem Siedlungs- und Bauland meist in der Hand einer Verwandtschaftsgruppe von ari'i oder ra'atira, konnte aber für bestimmte Pflanzen oder Vegetationszyklen auch an gesellschaftlich niedriger stehende (bei entsprechender Gegenleistung für die Übertragung der Nutzungsrechte in Form von Abgaben an Nahrungsmitteln, Fanganteilen, sowie der Verpflichtung zum Kriegsdienst, vgl. Kap. 6.2.2.1) abgetreten werden (vgl. CROCOMBE 1987, S. 222 f.).

Die „Verfügungs-" oder „Nutzungsrechte" von Land, das sich im Besitz einer Verwandtschaftsgruppe befindet, sind durch ein komplexes System geregelt, in das unter anderem die Faktoren Zustand des betreffenden Stück Landes und insbesondere genealogische Stellung desjenigen, der das Verfügungsrecht beansprucht, einfließen.

Die ari'i und die ra'atira konnten ihren alleinigen Nutzungsanspruch auf ein Stück Land mittels eines speziellen tapu (rahui) durchsetzten oder aber dadurch eine gewisse Population (Fauna oder Flora, bes. auch Fische) vor der Übernutzung schützen, so dass das tapu - neben seinem 
religiösen Hintergrund - hierbei auch eine ökologischen und damit langzeitökonomische Funktion (Sicherung des Bestandes) ausübt (vgl. Kap. 3.2.2). Eine wichtige Rolle in Bezug auf den Zusammenhang zwischen Religion und Recht spielten auch die Marae: Die ari'i hatten spezielle Familienmarae, die sich auf dem ihnen eigenen Land befanden und damit zusätzlich den Besitz rechtfertigten, da diese Marae mit dem entsprechenden Land nur innerhalb der Familie an den ältesten Sohn vererbt wurden, dass heißt die Geschichte des Marae war mit der Genealogie der Familie verknüpft, welche nun wiederum geheim gehalten wurde, da durch dieses Wissen der Erbanspruch nachgewiesen werden konnte. Durch Erbschaft konnten Gebiete mit ihren jeweiligen Marae auch arrondiert werden (im Normalfall wurde allerdings an den ältesten Sohn vererbt, so dass das Land als ganzes erhalten blieb), bei Landteilungen wurden entsprechend neue Marae gebaut. Eine weitere Form von Übertragung von Land war die Enteignung eines ra'atira bei einem schweren Vergehen durch den ihm übergeordneten ari'i (vgl. KOCH 1959, S. 62 ff.). In der Regel blieb das Land im Zeitablauf immer Eigentum der gleichen Familie (oder Sippe) und neu hinzugewonnenes Land wurde mit Steinen des Familienmarae - die als Grenzsteine respektiert und nicht mehr versetzt wurden - markiert, was die Verbundenheit zwischen Land, Familie und Marae ausdrückte ${ }^{84}$ (vgl. DELIUS 1991, S. 57).

Die Fischereirechte sind mit den Landrechten insofern gekoppelt, als dass die Gewässer dem Land zugeordnet sind, an das sie grenzen und entsprechend genutzt werden (vgl. KOCH 1959, S. 67).

Jagd- und Sammelrechte waren entsprechend der untergeordneten wirtschaftlichen Bedeutung dieses Wirtschaftszweiges vermutlich allen gesellschaftlichen Gruppen zuteil, wobei die wissenschaftlichen Quellen über diesen Bereich die geringste Auskunft geben (vgl. KOCH 1959, S. 66 f.).

„Verbrauchsgüter" (sämtliche Nahrungsmittel, s. o.) und „Gebrauchsgüter" waren mit steigender Qualität verstärkt den oberen Gesellschaftsschichten zu Eigen. Zudem können die tautau (s. o.) als „Eigentum an Menschen" bezeichnet werden, wobei der Begriff „Sklave" nicht ganz zutrifft, da sie relativ leicht ihre Freiheit wiedererlangen konnten. Das mündlich tradierte Wissensmonopol (vgl. Kap. 3.2.2) kann als eine Form des ,geistigen Eigentums" einiger weniger (Zauberer, Priester, zum Teil ari’i) aufgefasst werden.

\footnotetext{
${ }^{84}$ Ein weiteres Beispiel für diese Verbundenheit ist die Tatsache, dass bei der Geburt eines jeden Kindes die Plazenta in ein geheiligtes Blatt gewickelt und in der Erde des Familienlandes vergraben wurde (vgl. DELIUS 1991, S. 57).
} 
Betont werden soll an dieser Stelle noch einmal die Form der Eigentumsübertragung, die im Wesentlichen aus Vererbung, Schenkung, in geringerem Maße Krieg und natürlich Handel bestand, wobei gerade das Land als unverkäuflich galt, da es in der Vorstellung der Maohi als lebensspendendes Element genauso wenig veräußert werden konnte wie z. B. ein Ahne (vgl. DELIUS 1991, S. 57). Es existierte prinzipiell immer ein „Abgeben" untereinander als „Versicherung auf Gegenseitigkeit" (Reziprozität), weswegen Diebstahl auch schwer geahndet wurde (vgl. KOCH 1959, S. 90 f.).

Diese kollektivistische Haltung gegenüber Eigentum, dem Land und seiner Nutzung ist für Polynesien durchaus typisch. Das Beispiel Tonga verdeutlicht die Parallelen:

„Wesentliche Elemente des tradierten Eigentumsbegriffs waren:

- das Partizipationsprinzip; das heißt, die Notwendigkeit aktiver Teilnahme des Einzelnen am Familiengeschehen bzw. der Familie an den Belangen der übergeordneten Gruppe, und - die Sozialbindung; das heißt, die Bindung des Eigentums an die Bedingung, dass das Land tatsächlich (im langfristigen Interesse aller) genutzt wurde.“ (s. Wiemer 1985, S. 137)

WIEMER 1985 (S. 140) unterscheidet bezüglich Tonga außerdem - analog zu FranzösischPolynesien - in Kontrollrechte, die als Verfügungsrechte von (hierarchisch höherstehenden) Einzelpersonen ausgeübt werden konnten und Nutzungsrechte, die in der Regel im Familienverband wahrgenommen wurden. 


\subsubsection{Zwischenbilanz}

OLIVER (1974, S. 1074 ff.) beschreibt die Gesellschaft der Maohi als eine differenzierte, komplexe Kultur (in Bezug auf den polynesischen Raum äußerst hoch entwickelt und differenziert), die auch genügend Raum für „Sport, Musik, Tanz und Schauspiel“ ließ, wobei er im Hinblick auf die historisch-kulturelle Gesamtentwicklung den traditionellen Mustern eine hohe Persistenz gegenüber Innovationen und Diffusionen einräumt.

Die hier untersuchten fünf - miteinander in Interaktion stehenden - Kulturfaktoren deuten in jedem Fall auf ein voreuropäisches sozioökonomisches System hin, das selbsttragend, den naturräumlichen Ressourcen optimal angepasst und daher - die autonome Selbstversorgung garantierend - stabil war:

„Before the arrival of the Europeans, the maohi lived in harmony with the environment, taking from the land and sea only what was necessary to feed themselves. The ocean was almost their only source of protein. Because retrieval of these resources was vital, customary regulations ruled their relation with the sea and rivers."

(TETIARAHI 1988, S. 103).

Um einer Romantisierung (die das obige Zitat vermitteln könnte) der voreuropäischen Kultur der Maohi zu entgehen, seien in der Folge auch systemimmanente, also kulturinterne Faktoren ${ }^{85}$ erläutert, die eine Akkulturation durch die Europäer begünstigten.

So existierten z. B. im religiösen System der Maohi kurz vor der Ankunft der Europäer schon verschiedene Strömungen parallel, was ein Diffundieren der neu hinzukommenden europäischen Religionsform erleichterte ${ }^{86}$. Auch die in der Gesellschaftsstruktur erkennbare Hierarchie erleichterte anfangs ein Durchsetzen europäischer Kulturelemente (Sprache, Wirtschaftsweise, Recht; vgl. Kap. 6.3). Obwohl schon vor dem Kontakt mit den Europäern mehrfache Kulturwandel bei den Maohi stattfanden, führte erst dieser Kontakt zur Akkulturation.

BUCHHOLZ (1984, S. 17) führt dies auch auf vorwiegend interne Strukturen ${ }^{87}$ (d.h. eine hohe Störbarkeit des ökologischen und soziokulturellen Systems zurück:

\footnotetext{
${ }^{85}$ RAMASWAMY (1985, S. 173) beurteilt zudem die Erfassung und Erforschung dieser endogenen Faktoren als sehr begrenzt.

${ }^{86}$ Die relativ schnelle und leichte Diffusion des Christentums ist auf eine relativ hohe Kulturadäquatheit zurückzuführen: Im Vergleich zum Rechts- und Wirtschaftssystem der Europäer konnte deren Religion als eine weitere Form der schon bestehenden Strömungen bzw. zum Teil in Mischung mit denen relativ leicht diffundieren. Generell gilt: je größer die Kulturadäquatheit, desto „erfolgreicher“ die Innovation bzw. Diffusion (vgl. hierzu auch SCHÖNHERR und SIMSON 1985, S. 75-81).
}

${ }^{87}$ Auch für CONNELL (1982, S. 252 ff.) sind die geringe Landfläche und Marktgröße, die starke Fragmentierung, d.h. vorwiegend interne Strukturen von Inselstaaten Ursachen für deren bis heute andauernde „Unterentwicklung“ (vgl. hierzu auch Kap. 6.1.7 und 6.3.7) 
„Die Kleinheit von Landfläche und Bevölkerungszahl bedeutet auch eine mangelnde Elastizität und Widerstandskraft sowohl der naturökologischen Systeme als auch der Gesellschaften. Eingedrungene Pflanzenschädlinge führen rasch zur Ausrottung ganzer Arten. Vergiftung des Bodens durch zu hohen Einsatz von Pestiziden und Herbiziden schädigen fast immer den gesamten Inselbereich. Eingeschleppte Krankheitskeime, auch leichter Krankheiten, dezimieren die Bevölkerung oder entvölkern sogar ganze Inseln. Im gesellschaftlichen Bereich zeigt sich die mangelnde Widerstandskraft z. B. am Vordringen zahlreicher fremder Kirchen oder Denominationen oder an der Veränderung der traditionellen Herrschaftsstrukturen. Auf Inseln mit einer starken Zuwanderung aus Kolonialländern setzte durchweg unmittelbar eine erhebliche ethnische Überformung ein.

Fast alle Inselstaaten bewegen sich im Grenzbereich der kritischen Masse, die erforderlich ist, um eine elastische Reaktion auf Störungen und äußere Einflüsse zu gewährleisten und eine wirklich eigenständige Entwicklung zu ermöglichen."

Dennoch ist das komplexe Ursachenbündel der Akkulturation meiner Ansicht nach nur zu einem geringeren Teil systemimmanent in der voreuropäischen Kultur der Maohi zu suchen, da die externen Ursachen überwiegen: Der permanente Kontakt einer militärisch-technisch überlegenen und nach ökonomisch-marktwirtschaftlichen Prinzipien ausgerichteten Zivilisation, die zudem ausdrücklich zum Ziel hatte, die Ureinwohner zu unterwerfen, musste zwangsweise zur Akkulturation der „Steinzeitkultur" führen und hätte andere, gegen äußere Einflüsse resistentere soziokulturelle Strukturen, ebenso überformt, auch wenn dies mit größeren Schwierigkeiten verbunden gewesen wäre oder länger gedauert hätte. Die im folgenden Kapitel beschriebenen Konsequenzen wären weitgehend die gleichen. 


\title{
6.3 Der Akkulturationsprozess in Französisch-Polynesien
}

Frühe Vertreter der Diskussion um den Begriff der Akkulturation waren REDFIELD, LINTON und HERSKOVITS in den 30er Jahren des vorigen Jahrhunderts. REDFIELD et al. definierten Akkulturation wie folgt:

\begin{abstract}
„Acculturation comprehends those phenomena which result when groups of individuals having different cultures come into continuous first-hand contact with subsequent changes in the original culture patterns of either or both groups $[. .$.$] under this definition acculturation is to be distinguished from culture change, of which it is but one$ aspect, and assimilation, which is at times a phase of acculturation. It is also to be differentiated from diffusion, which while occurring in all instances of acculturation, is not only a phenomena which frequently takes place without the occurrence of the types of contact between peoples specified in the definition above, but also constitutes only one aspect of the process of acculturation." (s. REDFILED et al. zitiert in BERRY 1980, S. 9)
\end{abstract}

Die Definition des Social Science Research Council von 1954 setzt für den akkulturativen Prozess ebenfalls den Kontakt zweier zunächst autonomer, kultureller Systeme voraus. Weiterhin vergleichbar zur Definition von REDFIELD, LINTON und HERSKOVITS sind die Ansätze von BROOM/SIEGEL/VOGT/WATSEN (1954) oder TESKE/NELSON (1974). SPINDLER (1955), BRUNER (1956), GRAVES (1967) und SAMORA/DEANE (1956) stehend für ein Verständnis von Akkulturation in Form einer graduellen Angleichung an die dominante Kultur. Dem widersprechen DOHRENWEND/SMITH (1962), MCFEE (1968) und STONEQUIST (1937), die u. a. die Entstehung neuer Kulturelemente, die weder der dominanten, noch der nichtdominanten Kultur zuzuordnen sind, postulieren (s. KEEFE 1980, S. 85 f.).

SZAPOCZNIK und KURTINES (1980, S. 142) stellen heraus, dass sich akkulturative Prozesse schneller bei Männern als bei Frauen und schneller bei Jugendlichen als bei Erwachsenen vollziehen.

TORRES-MATRULLO (1980, S. 112 f.) betont insbesondere das psychologische Element der Akkulturation. Modifizierende Faktoren im akkulturativen Verlauf sind neben der individuellen Persönlichkeit Alter, sozialer Status, Art und Stärke der Diskriminierung, Resistenz/Zusammenhalt der Familie gegenüber äußeren Einflüssen, Notwendigkeit mit der dominanten Kultur zu interagieren.

Grundlegende Voraussetzung beim akkulturativen Prozess ist außerdem immer die Dominanz einer Kultur (dies ist der wesentliche Unterschied zum Kulturaustausch, ebenfalls einer Form des Kulturwandels, vgl. Kap. 1.5.5): 
„Mit Akkulturation wird das Phänomen beschrieben, bei dem ,unterschiedliche Kulturen durch Interaktion ihrer Mitglieder aufeinander treffen und in einen Austausch geraten', wobei eine Kultur sich in der dominanten Position befindet.“(s. KOHNEN, S. 12)

BERRY (1980, S. 14) klassifiziert verschiedene Variationen der Akkulturation in Zusammenhang mit der jeweiligen Beziehung zur dominanten Kultur:

Dichotomous answers to questions of acculturation:

\begin{tabular}{|l|l|l|}
\hline Varieties of Acculturation & Retention of Cultural Identity? & $\begin{array}{l}\text { Positive Relationship to } \\
\text { Dominant Society? }\end{array}$ \\
\hline Assimilation & No & Yes \\
\hline Integration & Yes & Yes \\
\hline Rejection & Yes & No \\
\hline Deculturation & No & No \\
\hline Multiculturalism & Yes & Yes \\
\hline Pluralism & Yes & Yes \\
\hline Melting Pot & No & Yes \\
\hline Pressure Cooker & No & Yes \\
\hline Withdrawel & Yes & No \\
\hline Segregation & Yes & No \\
\hline Marginality & No & No \\
\hline Ethnocide & No & No \\
\hline
\end{tabular}

BERRY (1980, S. 11 ff.) weist darüber hinaus darauf hin, dass Akkulturation sich immer auf zwei Ebenen vollzieht: derjenigen der Gruppe und der individuellen. Außerdem ist Akkulturation oft mit Stress im psychologischen Sinne verbunden, da die nicht-dominante Kultur ihre Orientierungsmuster verliert:

„Bei einem Individuum, das sein Leben in einer Gesellschaft mit einer einigermaßen stabilen Kultur verbringt, wird die Persönlichkeit mit dem Älterwerden immer stärker integriert. [...] Ein solcher Mensch befindet sich in einem unendlich viel glücklicheren Zustand als einer, der sich gezwungen sieht, Verhaltensmuster zu befolgen, die mit dem Wert- und Einstellungssystemen nicht übereinstimmen, wie er sie durch seine frühesten Erfahrungen erworben hatte. Das Resultat solcher Unvereinbarkeiten kann man oft bei Menschen beobachten, die sich an schnell wechselnde Kulturbedingungen, wie zum Beispiel die in unserer eigenen Gesellschaft bestehen, haben anpassen müssen. Noch offenkundiger ist das im Falle jener Menschen, deren Leben in einer bestimmten Kultur begann und dann in einer anderen fortgeführt werden muss. Das sind die ,Menschen am Rande', deren schwierige Lage jeder kennt, der sich mit dem Phänomen der Kulturübernahme (Akkulturation) befasst hat. Die in der ersten Lebenszeit entstandenen Wert- und Einstellungssysteme solcher Menschen werden geschwächt und überlagert, da ihnen die Bekräftigung durch den fortwährenden Ausdruck im sichtbaren Verhalten fehlt. Andererseits aber werden sie offenbar nur selten, wenn überhaupt je ganz eliminiert und noch 
weniger durch neue Systeme des kulturellen Milieus ersetzt, in dem der Betreffende sich bewegen muss. Der in eine andere Kultur Verpflanzte kann lernen, gemäß der Kultur seiner neuen Gesellschaft zu handeln, ja sogar zu denken, er kann jedoch nicht lernen, so zu fühlen. Wenn immer eine Entscheidung gefordert wird, ist er hilflos, da ihm die festen Bezugspunkte fehlen.“"(LINTON 1974, S. 116 f.)

OLMEDO (1980, S. 27 ff.) entwickelte zur Beschreibung von Akkulturation ein komplexes, mathematisches, multivariables Modell, das auch Messungen/Berechnungen des

Akkulturationsgrades erlaubt.

Die Akkulturation $^{88}$ ist nur eine mögliche Form des Kulturwandels (vgl. Kap. 1.5.5; 5.2 und

6.4.1), dem die Faktoren der Gewohnheits- und Traditionsbildung und der sozialen Kontrolle als Konstanten des Identitätsbewusstseins entgegenwirken. Da die Akkulturation durch eine Diffusion, also durch externe Faktoren verursacht wird, ist sie abzugrenzen von der anderen möglichen Form des Kulturwandels, der Adaption $^{89}$, die durch innovative Anpassung an äußere Gegebenheiten von innen heraus erfolgt ${ }^{90}$ (vgl. Kap. 6.2). Zum Konzept der Assimilation (s. u.) hat GORDON (1964, S. 71) ein differenziertes Modell entwickelt und es u. a. auf die gesellschaftlichen Gruppen Schwarze, Juden, Katholiken und Puertoricaner in den USA angewandt:

\footnotetext{
${ }^{88}$ Der Begriff der Assimilation wird oft mit dem der Akkulturation verwechselt, der Zusammenhang ist wie folgt: Bezeichnet die Akkulturation den Vorgang des Kulturwandels bedingt durch externe Faktoren, so ist die Assimilation ,ein mögliches und oft ideologisch erwünschtes Resultat des vollständigen Akkulturationsprozesses“. Assimilation kann sich als beabsichtigte Interessenpolitik der überlegenen Kultur (hier der europäischen Zivilisation) zu einer „Übernahme des größeren Teils einer anderen Kultur“ ..., zu einem „Verlust des eigenständigen kulturellen Erbes“ ..., zu einer Übernahme „,nicht nur der Verhaltensmuster, sondern auch der inneren Werte der Kultur, mit der die empfangene in Kontakt gekommen ist“ führen. Des Weiteren kann der Begriff der Assimilation ausgehend von ,voller Ablehnung über Teilassimilation bis zur Vollassimilation“ in verschiedene Grade differenziert werden. „Die Ablehnung von Assimilation führt zu Indigenisierungsreaktionen und antiakkulturativen Bewegungen (Nativismus, Milenarismus, Chiliasmus, Nationalismus, Unabhängigkeitsbewegungen)“, ,,Revitalisierungsbewegungen “(s. HIRSCHBERG 1988, S. 35 ff; weitere Ausführungen dazu vgl. auch Kap. 6.4).

${ }^{89}$ Adaptionen, also „kulturelle Veränderungen, die auf spontan in einer Gesellschaft entstandenen Kräften beruhen, können entweder die Reaktion auf eine Störung des ökologischen Gleichgewichts oder das Resultat divergierender gesellschaftlicher Tendenzen sein, die ihrerseits möglicherweise mit ... Neuerungen (Inventionen, s. o.) in Verbindung stehen, die von einer Gesellschaftsgruppe propagiert werden“" (RAMASWAMY 195, S. 172 f.)

${ }^{90}$ RAMASWAMY (1985, S. 170 f.) definiert als eine weitere Variante des Kulturwandels, die hier nur ergänzend erwähnt sei, den Kulturaustausch, der ,auf der Ebene gegenseitigen Kennenlernens abläuft, wobei zweckorientierte, bestimmten Eigeninteressen entspringende Einflussnahme ausgeschaltet ist" und der für Französisch-Polynesien, wie für die meisten Kulturkontakte der Europäer mit ihnen fremden Kulturen nicht wirksam wurde.
} 


\begin{tabular}{|l|l|l|}
\hline Subprocess or Condition & Type or Stage of Assimilation & Special Term \\
\hline $\begin{array}{l}\text { Change of cultural patterns to } \\
\text { those of host society }\end{array}$ & $\begin{array}{l}\text { Cultural or behavioral } \\
\text { assimilation }\end{array}$ & Acculturation \\
\hline $\begin{array}{l}\text { Large-scale entrance into } \\
\text { cliques, clubs, and institutions } \\
\text { of host society, on primary } \\
\text { group level }\end{array}$ & Structural assimilation & None \\
\hline $\begin{array}{l}\text { Large-scale intermarriage } \\
\text { peoplehood based exclusively } \\
\text { on host society }\end{array}$ & Martial assimilation & Amalgamation \\
\hline $\begin{array}{l}\text { Development of sense of } \\
\text { Absence of prejudice }\end{array}$ & $\begin{array}{l}\text { Attitude receptional } \\
\text { assimilation }\end{array}$ & None \\
\hline $\begin{array}{l}\text { Absence of discrimination } \\
\text { conflict }\end{array}$ & Behavior receptional assimilation & None \\
\hline absimilation & Civic assimilation & None \\
\hline
\end{tabular}

Gemäß diesem Modell ist in Französisch-Polynesien insbesondere der Prozess der cultural/behavioral assimilation, den GORDON mit der Akkulturation (s.o.) gleichsetzt, zu beobachten. Bei der jüngeren Generation ist außerdem durch verstärkte interethnische Eheschließungen eine gewisse Amalgamation erkennbar.

PADILLA (1980, S. 48 ff.) hält GORDONs Modell für nicht ausreichend differenziert genug:

„Acculturation is a complex interactional process involving both members of the cultural group undergoing change and members of the host culture. GORDON $(1964,1978)$ has clearly placed acculturation within his framework of assimilation suggesting that an individual can conceivably acculturate, but not be assimilated into the host culture. However, GORDON has not spelled out in sufficient detail how the members of both cultural groups interact in the acculturation - assimilation process. “

PADILLA (ebenda) entwickelte daher unter besonderer Berücksichtigung der Konzepte cultural awareness und ethnic loyalty eine multidimensionale Matrix, die die Interaktion beider Gruppen im Kulturkontakt berücksichtigt.

Kultureller Wandel kann als charakteristisches Merkmal einer jeden Kultur aufgefasst werden (vgl. auch Kap. 1.5.5), da eine Kultur, oder zumindest einige Teilbereiche einer ständigen Trans- 
formation unterworfen sind, auch wenn einige Wandlungsprozesse derart peripher sind, dass sie in Bezug auf das Kulturganze keine sichtbaren Veränderungen bewirken (vgl. hierzu HIRSCHBERG 1988, S. 275 f., RAMASWAMY 1985, S. 170 ff., sowie Kap. 5.2) $)^{91}$.

Im Folgenden soll nun nachgewiesen werden, dass die in Kap. 6.2 beschriebene Kultur in allen fünf Dimensionen ihrer Kultur fast vollständig akkulturiert wurde durch den dauerhaften Kontakt mit der völlig gegensätzlichen europäischen Zivilisation ${ }^{92}$ (vgl. auch die Zeittafel, s. u.). Räumlich konzentriert sich dieser Prozess zunächst vorwiegend auf die Gesellschaftsinseln, bzw. auf Tahiti (vgl. hierzu auch KLINKHAMMER 1991, S. 43-87).

\section{Zeittafel (1521 - Gegenwart)}

- 1521 MAGELLAN „streift" das Gebiet der Tuamotuinseln (bes. Pukapuka), weitere Entdecker (z. B. MENDANA, QUIROS, SCHOUTEN, LE-MAIRE, ROGGEVEEN, BYRON) folgen seinem Beispiel

- 1743-1803 POMARE I (Lebenszeit)

- 1767 Samuel WALLIS läuft Tahiti an und nimmt es für Großbritannien in Besitz; erste Berichte

- 1768 Louis Antoine de BOUGAINVILLE läuft im Auftrage LUDWIGs XV. die Gesellschaftsinseln an

- 1769-1777 James COOK stattet den Gesellschaftsinseln zum Teil im Auftrag der Royal Society mehrere Besuche ab; Beginn wissenschaftlicher Forschung

- 1772 Die Spanier unter DON BOENECHA besuchen Tahiti

- 1774 Cook bringt den Maohi OMAI von Huahine für drei Jahre nach Europa, wo dieser als exotische Lebensform herumgereicht und zum Stereotyp des ,edlen Wilden" aufgebaut wird, wobei er sich in dieser Rolle allerdings zum Teil selbst gefällt

- 1789 Landung der Bounty unter BLIGH

- 1793 Beginn des Schweinehandels mit Australien

- 1797 Beginn der Missionierung; 30 Geistliche der London Missionary Society (Protestanten puritanischer Prägung) gelangen nach Tahiti; erste Bekehrungen finden allerdings erst 1813 statt

- 1803-1821 Regierungszeit POMARE II (* 1782)

- 1815 Massenbekehrung von Tahitianern zum Christentum

- 1817-1825 Der britische Missionar ELLIS macht bedeutende Aufzeichnungen über die Kultur der Autochthonen.

- 1819 Erstellung eines Strafkodex durch die Missionare

- 1824 Wahl POMARES III (vierjähriger Sohn von POMARE II) durch die Missionare (,Regenten"); Tod 1827

${ }^{91}$ BARGATZKY (1978) differenziert und definiert weiterhin die Begriffe Innovationsbereitschaft, Innovator, Diffusionsagent.

92, ,Kulturwandel gab es auch bei relativ isoliert lebenden ethnischen Gruppen schon immer. ... Mit dem kolonialen Kulturkontakt hat dieser Wandel aber eine ganz neue und oft nur schwer reversible Dynamik angenommen“ (ANTWEILER 1992, S. 34). 
- 1827 Krönung POMARES IV, Tod:

- 1833 Niederlage der mamaia-Bewegung

- 1836 Beginn der französischen, katholischen Mission, zwei Missionare

- 1842 Admiral PETIT THOUARS erklärt Tahiti zum Protektorat Frankreichs

- 1847 Neben dem Tuamotuarchipel zählen jetzt weitere Teile der Gesellschaftsinseln und einige der Australinseln zum Protektorat

- 1860 Die Société des missions évangéliques de Paris ersetzt die London Missionary Society.

- 1880 Französisch-Polynesien wird französische Kolonie (offizielle Bezeichnung: Etablissement Français de l'Océanie, E.F.O.) in Einigung mit England (Frankreich verzichtet im Gegenzug auf militärische Ansprüche auf den Neuen Hebriden), nicht zuletzt, um eine beginnende deutsche Einflussnahme auf den Inseln unter dem Wind zu unterbinden. Es schließt sich ein kontinuierlicher Ausdehnungsprozess des kolonialen Status bis auf das gesamte heutige Gebiet Französisch-Polynesiens an, der erst 1901 als endgültig abgeschlossen gelten kann.

- 1891 GAUGUIN erreicht Tahiti

- 1907-1912 Zweite größere Einwanderungswelle chinesischer Emigranten

- 1908 Beginn des Phosphatabbaus auf Makatea

- 1914 Papeete wird von deutschen Kriegsschiffen bombardiert

- 1940 Frankreich wird in den zweiten Weltkrieg verwickelt, Hunderte von Tahitianern gehen freiwillig in die französische Armee (300 von ihnen sterben)

- 1941 POUVANA'A A OOPA, charismatischer Oppositioneller und Veteran des Ersten Weltkriegs, wird auf Grund seiner Kritik an der französischen Regierung zu einer Gefängnisstrafe verurteilt.

- 1942 Bora Bora wird amerikanischer Marine- und Luftstützpunkt

- 1945 Die Einwohner Französisch-Polynesiens erhalten die französische Staatsbürgerschaft

- 1947 Frankreich streicht Französisch-Polynesien unilateral von der UN-Liste der nichtselbstregierten Staaten mit der Begründung, es sei keine Kolonie, sondern ein Teil Frankreichs

- 1950 Offizielle Gründung der RDPT

- 1957 Französisch-Polynesien wird Überseeterritorium Frankreichs

- 1958 (28.09.) In einem Referendum entscheidet sich die Bevölkerung FranzösischPolynesiens zu 64,4\% für einen Verbleib bei Frankreich und gegen die Unabhängigkeit

- 1964 Die Chinesen in Französisch-Polynesien erhalten die französische Staatsbürgerschaft

- 1966 Beginn der Nuklearversuche durch den CEP

- 1977 und 1984 Erweiterung des Autonomiestatuts

- 1980 Tahitisch wird als offizielle Sprache Französisch-Polynesiens anerkannt.

- 1985 (10.07.) Die Rainbow Warrior wird vom französischen Geheimdienst im Hafen von Auckland versenkt

- 1992 (08.04.) Der französische Premierminister Pierre BEREGOVOY kündigt ein auf ein Jahr begrenztes Atomtest-Moratorium an; Gründung der Maohi-NGO Hiti Tau

- 1995 CHIRAC kündigt eine weitere Reihe von Atomtests für 1995/1996 an

- 1996 (1.2.) Die Autonomie Französisch-Polynesiens wird ein weiteres Mal erweitert

- 1996 (12.5.) Gaston FLOSSE wird bei den Wahlen zu Territorialversammlung ein weiteres Mal im Amt bestätigt; Die für die Unabhängigkeit eintretende FLP Oscar TEMARUs gewinnt an Gewicht

- 1999 Hiti Tau initiiert touristische Mikroprojekte, um - in Kombination mit anderen traditionellen Wirtschaftsweisen - Alternativen zur bestehenden dependenten Transferökonomie zu schaffen und die Kultur der Ureinwohner zu wahren 


\subsubsection{Gesellschaftsstruktur}

Mit der „Entdeckung“ der Gesellschaftsinseln 1767 durch Samuel WALLIS entstand zunächst nur ein sporadischer Kulturkontakt, der bis zum Beginn des permanenten Kontakts mit den Europäern (einsetzend ab 1797 mit Beginn der Missionierung) nur einige wenige Diffusionen zur Folge hatten, die sich allerdings schon bald auf die Gesellschaftsfraktur auszuwirken begannen: In Bezug auf den Bereich des Kriegswesens erwies sich der relativ unbedeutende Häuptling des Distrikts Pure (in welchem sich der bevorzugte Ankerplatz der Europäer, die Bucht Matavai befand), TU (der von den Europäern in Unkenntnis der traditionellen Gesellschaftsstruktur irrtümlich für den König Tahitis gehalten wurde und sich später POMARE ${ }^{93}$ I nannte) als außerordentlich annahmefreudig für die europäischen Diffusionen: so übernahm TU von COOK zunächst im Tauschhandel und in Form von Geschenken eiserne Äxte, Stoffe, Nägel, Ziegen, Perlen und Fischhaken. Von BLIGH erhielt er dann erstmalig Feuerwaffen, mit denen er seine Hegemonie nicht nur über Tahiti, sondern auch über die Nachbarinseln auszudehnen suchte (vgl. ZIEHR 1980, S. 271 ff.). Auf die Meuterer der Bounty, die sich bei ihrer Rückkehr nach Tahiti unter TUs Schutz stellten und ihn im Kampf gegen die anderen ari'i Tahitis unterstützten, gehen folgende Diffusionen zurück: Der Einsatz einer Nachtwache bei einer Belagerung, sowie weitere Veränderungen in der Form der Kriegsführung; des Weiteren europäische Namensgebung für Frauen und Kinder und Veränderungen im Bootsbau (vgl. BARGATZKY 1978, S. 241 ff.). Die ersten Versuche der Meuterer der Bounty zur Destillation von Branntwein verhalfen dem Alkohol zu einer weit über Tahiti hinaus reichenden Popularität, der zunehmend die traditionelle Kawa-Wurzel, deren berauschende Wirkung hauptsächlich den ari'i vorbehalten war, verdrängte und bald in Funktion einer Volksdroge einen Wandel der Lebensgewohnheiten breiter Schichten der Bevölkerung nach sich zog (vgl. BARGATZKY 1978, S. 266 ff.).

Durch geschickte Ausnutzung der europäischen Interessen (sowohl der Entdecker als auch der Missionare) erlangte die Familie der POMARES letztendlich die Vorherrschaft über Tahiti: Hatte POMARE I schon mit Hilfe der überlegenen europäischen Waffentechnik und Militärstrategie anderen Distrikthäuptlingen seine Überlegenheit demonstriert, so nahm sein Sohn (POMARE II) den christlichen Glauben an, wodurch ihm die volle Unterstützung der britischen Missionare zuteil wurde. Durch den Sieg über seine Gegner kann die traditionelle Gesellschaftsstruktur (zunächst nur Tahitis) als weitgehend zerstört betrachtet werden, da die frühere „Hierarchie“, die immerhin noch gegenseitige Abhängigkeitsverhältnisse beinhaltete, nun einer ,absolutistischen“

\footnotetext{
${ }^{93}$ Die Transkription dieses Namens ist im Englischen Domare und im Französischen Pomaré. In der vorliegenden Arbeit wird die französische Version benutzt.
} 
von Europäern gesteuerten Regierungsform Platz machte, wodurch zunächst eine wirklich starre hierarchische Gesellschaftsstruktur entstand ${ }^{94}$.

Die Zerstörung der traditionellen Gesellschaftsstruktur manifestierte sich konkret im Verschwinden des Unterschiedes zwischen raa und noa (vgl. Kap. 6.2.2.1), im Verwischen der Unterschiede zwischen den unteren Gesellschaftsschichten (vgl. NEWBURY 1988, S. 67) und in der Aufkündigung der gegenseitigen Hilfe von Herrschern und Beherrschten.

Ab diesem Zeitpunkt kann man auch von einer Umkehr der „Ausnutzungspolitik“ sprechen, da ab jetzt vorwiegend die Missionare ihre Interessen mit Hilfe POMAREs durchsetzten: Neben einer neuen Gesetzgebung (vgl. Kap. 6.3.2) wählten sie 1824 (s. o.) den minderjährigen Sohn POMAREs II, POMARE III, zum König und sprachen sich selbst den Rang von Regenten zu. Das Tauziehen französischer und englischer Interessenpolitik ${ }^{95}$, das hinter dem der entsprechenden Missionen stand (in stärkerem Maße Frankreich, aber auch England, nutzte unabhängig von der jeweiligen Regierungsform die Mission zum Ausbau ihrer Großmachtbestrebungen aus als ,instruments of empire-building", vgl. ADLOFF und THOMPSON 1971, S. 16), endete 1842 mit der Erklärung des Protektorats seitens Frankreichs. In dem Maße in dem die ari'i an politischem und wirtschaftlichem Einfluss verloren, stieg ihre finanzielle Abhängigkeit von den Franzosen, die nicht nur der Familie POMARE, sondern auch den Häuptlingen der Tuamotu- und Australinseln finanzielle Zuwendungen zukommen ließen (vgl. NEWBURY 1988, S. 71). 1880 war auch dem Aufstieg der Familie POMARE ein Ende gesetzt, da POMARE V - der nur noch als Marionette herrschte - sein „Reich“ offiziell an Frankreich abtrat. ${ }^{96}$ (vgl. HEERMANN 1987, S. 124 ff.).

In der Folgezeit dehnte Frankreich unter militärischer Niederschlagung einiger vereinzelter Revolten und Widerstände der autochthonen Bevölkerung seine Kolonie bis 1901 auf das heutige Französisch-Polynesien aus (vgl. ADLOFF und THOMPSON 1971, S. 16). Erst nach dem

\footnotetext{
${ }^{94}$ Hierbei ist anzumerken, dass die Vorherrschaft einer Dynastie nicht als die wesentliche Veränderung der autochthonen Gesellschaftsstruktur angesehen werden darf, da dies auch schon vorher zeitweilig auf einigen Inseln der Fall war (vgl. NEWBURY 1988, S. 62), sondern die durch die europäische Anwesenheit begünstigte Durchsetzungskraft (bedingt durch Waffentechnik und Strategie) der neuen Herrscher, so dass man in diesem Sinne von einer europäisch induzierten Diffusion sprechen kann.

${ }^{95}$ Nach dem Sieg Frankreichs im Kampf um die Vormachtstellung mangelte es nicht an Rechtfertigungen für die vorherige britische Einflussnahme in Verbindung mit einer Verurteilung der französischen Hegemonie. Eine besonders eindrucksvolle Rechtfertigungsschrift ist das Werk des auf Tahiti eingesetzten britischen Missionars und Konsuls Georg PRITCHARD, der, von den Franzosen abgesetzt, The aggressions of the French at Tahiti and Other Islands in the Pacific verfasste. Das Manuskript wurde durch Zufall von Paul DE DECKER 1977 entdeckt und von ihm 1983 veröffentlicht.

${ }^{96}$ Eine Erklärung hierfür lieferten die entsprechenden Bedingungen: „Erlass seiner Schulden und Gewährung einer Leibrente zur Finanzierung seines Alkoholkonsums, der selbst noch auf seinem aufwendigen Grabmal als Symbol seiner wohl herausragendsten Eigenschaften verewigt ist: Ein Gefäß aus Stein, das auffällig an eine Likörflasche erinnert“" (HEERMANN 1987, S. 126).
} 
zweiten Weltkrieg im Zuge der Errichtung des Überseeterritoriums Frankreich (1957) und insbesondere mit dem Ausbau des Autonomiestatuts (1977 und 1984) war eine teilweise Loslösung vom Zentralismus Frankreichs, der nach Errichtung der Kolonie mit nur leichten Abwandlungen beide Weltkriege überdauerte, möglich (vgl. Kap. 6.1), was Formen westlicher Demokratie und Mitbestimmung in der Gesellschaft - auch für die autochthone Bevölkerung ermöglichte.

Nicht nur in Bezug auf die Regierungsform und soziale Schichtung, sondern auch in Bezug auf ihre demographische und ethnische Struktur vollzog sich ein tief greifender Wandel in der Gesellschaft: Nach einer anfänglichen Dezimierung der autochthonen Bevölkerung (Nichtresistenz gegen europäische Krankheiten, Kriege) ist zunächst eine Stabilisierung und ca. ab 1920 ein konstanter Anstieg der Gesamtbevölkerung (inklusive der Autochthonen) bis heute zu verzeichnen (vgl. Anl. 15 im Anhang). Auf Grund der Einwanderung von Chinesen kam es zu einer weiteren Umstrukturierung der Gesellschaft, was die heutige ethnische Zusammensetzung (vgl. Kap. 6.1.4) samt einer gewissen ethnisch bedingten Arbeitsteilung zur Folge hatte. Grob verallgemeinert lassen sich die Polynesier dem landwirtschaftlichen Sektor, die métis ${ }^{97} \mathrm{dem}$ Landwirtschafts- und Dienstleistungsbereich zuordnen, während die Asiaten vorwiegend im „,unteren" und die Europäer im „oberen" Bereich des Dienstleistungssektors anzutreffen sind (vgl. hierzu auch Kap. 6.1.3) ${ }^{98}$.

In diesem Zusammenhang ist es wichtig anzumerken, dass der heutige Status quo der Gesellschaftsstruktur theoretisch - auf Grund einer prinzipiell demokratischen Struktur Französisch-Polynesiens - nicht unabänderbar erscheint. Gesellschaftliche Prinzipien der voreuropäischen Kultur, die sich für den außenstehenden westlichen Beobachter als Klientelismus äußern, gingen mit westlichem Demokratieverständnis eine spezielle Melange ein:

„Wer eine Bilanz über das halbe Jahrhundert assimilatorischer und hochsubventionierter nachholender
Entwicklung der französischen Übersee ziehen will, muss sorgfältig differenzieren. Als ein Ergebnis
französischer Präsenz verfügen die DOM-TOM, im Gegensatz zu vielen Staaten der Dritten Welt, über

${ }^{97}$ NEWBURY (1988, S. 72) führt die demis oder métis in ihrer Herkunft in Bezug auf die voreuropäische autochthone Kultur auf die ari'i zurück. Ein zahlenmäßig geringer Teil von Ihnen machte als Inhaber des Status eines ari' $i$ in Kombination mit europäischer Bildung in Anpassung an die neuen Verhältnisse in den Bereichen Verwaltung und Wirtschaft Karriere. Ein Grund, warum gerade die demis und nicht die eigentliche Elite der autochthonen Gesellschaft von den Veränderungen profitierte, mag in der (zum Teil heute noch) mangelnden Beherrschung des Französischen der maohi liegen, die auf Grund der dürftigen schulischen Infrastruktur nicht die gleichen Chancen hatten, Französisch zu erlernen, wie die meist zweisprachig aufwachsenden demis. Hinzu kommt allerdings eine bewusst von der französischen Verwaltung betriebene Politik, den Einfluss der autochthonen Häuptlinge auf allen Ebenen weitgehend klein zu halten (vgl. NEWBURY 1988, S. 73 f.).

${ }^{98}$ Gérald COPPENRATH (1967) liefert eine genaue Aufschlüsselung der Migrationsmotivation, des Berufsspektrums der nach Französisch-Polynesien emigrierten Chinesen (die den weitaus größten Teil der Asiaten ausmachen) und der Akkulturationseffekte, die sie in einer schon der Akkulturation ausgesetzten Gesellschaft ihrerseits betrafen. 
ausgefeilte demokratische Grundstrukturen und eine formale politische Partizipation. Andererseits findet man die DOM-TOM in Korruption und Klientelismus verstrickt. Die lokale Administration wurde vielfach ausgehöhlt und zur Versorgungsanstalt für die jeweilige politische Anhängerschaft umfunktioniert. Politische Mandatsträger sind in Affären von Wahlbetrug und Bestechung verwickelt. Westliches Demokratieverständnis und lokale Herrschaftstraditionen haben sich in den DOM-TOM zu einer speziellen Form politischer Kultur verschmolzen, die, Anpassung und Widerstand zugleich, sich dem Verständnis des Außenstehenden nur schwer erschließen.“( (s. JADIN 1994, S. 209)

Eine mögliche Änderung der Verhältnisse ist von denjenigen, die daran ausgiebig partizipieren und davon profitieren (und das sind in diesem Fall alle ethnischen Gruppen), nicht unbedingt erwünscht:

„Die insularen Gesellschaften sind heute quer durch alle Schichten vom Assistentialismus gezeichnet. Aus der eurozentrischen Perspektive der französischen Administration wird immer wieder auf die dort vorherrschende Mentalität der Passivität verwiesen. Andererseits kann mit der gleichen Berechtigung festgestellt werden, dass es sich hierbei um eine gelungene individuelle Strategie der Anpassung an äußere, vom Zentralstaat vorgegebene Rahmenbedingungen handelt. So entwickelt die Bevölkerung eine erstaunliche Energie und einen großen Einfallsreichtum, wenn es darum geht, den Zugriff auf staatliche Subventionen zu optimieren oder das soziale Netz noch intensiver zu nutzen.“ (s. JADIN 1994, S. 210)

Der gesellschaftliche Wandel wirkte sich auch auf das Verhältnis der Geschlechter aus. Im Wesentlichen führte er zu einem Machtverlust des Maohi-Mannes:

„Les hommes tahitiens ont, dans le bouleversement de la société ancienne, perdu leur statut sacré et, pour la plupart (exception faite des pasteurs et des diacres) leur pouvoir religieux exclusif. [...] L'homme ma'ohi a donc perdu les différents status qui lui conféraient le prestige dans sa famille et s'est trouvé privé de ses ,ancrages' extérieurs à la maisonnées qui lui donnait l'autorité à l'intérieur de celle-ci.“(s. LANGEVIN 1990, S. 160 f.)

Die Maohi-Frau hingegen hatte die Chance, ihre ökonomische Situation wesentlich zu verbessern, ohne sich aus dem traditionellen Kontext unbedingt lösen zu müssen:

„De plus, grâce à certains facteurs nouveaux, inhérents à la société polynésienne actuelle, tels que le tourisme, elle [la femme] a l'occasion aujourd'hui de développer ses activités artisanales, comme le tressage, de façon rentable. Cela lui offre un double avantage puisqu'elle peut, tout en se procurant de l'argent, indispensable à la maisonnée, perpétuer une activité typiquement tahitienne en ne sortant pas de son cadre traditionnel." (s. LANGEVIN 1990, S. 161)

Kinder werden auf entlegeneren Inseln nach wie vor innerfamiliär (hier ist die weitere Verwandtschaft eingeschlossen) adoptiert, auch das Senioritätsprinzip (vgl. Kap. 6.2.2.1) ist existent.

Die größten Umbrüche finden generell mit der neuen Generation statt:

Elle [la génération actuelle] se désintéresse des activités anciennes et cesse, dans la mesure où elle le peut matériellement, de résider dans l'enceinte familiale pour vivre dans des unités résidentielles plus réduites; elle éduque ses enfants dans la langue française et beaucoup de jeunes demis parlent aujourd'hui mieux le français 
que le tahitien. L'économie des jeunes ménages prend pour base les salaires de l'homme et de la femme, tandis que la pêche est devenue un passe-temps du week-end. Les vieillards ne sont plus écoutés et ils ne transmettent plus les anciennes légendes de peur que la génération actuelle ne le considère comme un ,tissu de mensonges' et ne se moque d'eux. [...] La connaissance des généalogies et légendes familiales est de plus en plus rare dans la génération actuelle des adultes et parfaitement ignorée des jeunes qui comprennent mal le langage utilisé par les vieux lorsqu'ils y font allusion. En résumé, la jeune génération tahitienne souhaite vivre à l'européenne, ou, mieux, à l'americaine, et elle ne conserve souvent certains aspects de la tradition que dans la mesure où elle n'a pas encore la possibilités matérielle de s'en défaire ou bien par folklore familial.“ (LANGEVIN 1990, S. 162)

\subsubsection{Religion}

Der Beginn der Missionierung der Gesellschaftsinseln 1797 durch die Missionare der London Missionary Society ersetzte den vorher nur unregelmäßigen und sporadischen Kulturkontakt mit den Europäern durch einen permanenten ${ }^{99}$. Schon im Jahre 1820 gilt mit dem Sieg Pomare II (vgl. Kap. 6.3.1) - nach etwas über fünfzig Jahren Kontakt mit der europäischen Zivilisation - die Christianisierung offiziell als abgeschlossen (hierbei widersetzten sich die Bewohner der Marquesasinseln der Diffusion des Christentums am längsten). Die Errichtung von Missionsstationen orientierte sich dabei oft an den Orten der Marae (vgl. Anl. 8 im Anhang). Die Realität sah allerdings anders aus: Verschiedene Manifestationen der zur Zeit des europäischen Kontaktes bestehenden „Religionsformen" blieben erhalten oder bildeten interessante Mischformen (s. u.) mit dem christlichen Glauben, wobei dieser oft aus vordergründigen Motiven ohne innere Überzeugung angenommen wurde, dass heißt die Christianisierung hatte zunächst einen oberflächlichen Charakter, und die Missionare erreichten ihr Ziel eines „Gottesstaates“ auf Erden nicht.

Daran änderte die Rigorosität, mit der die britischen Missionare den Wahrheitsanspruch ihrer eigenen Religion u. a. 1819 durch die Errichtung eines Strafkodex durchsetzten wollten, nichts:

„Auszug aus dem Strafkodex der Missionare der London Missionary Society*

(Für Tahiti, Raiatea, Tahaa, Bora Bora, Maupiti und Huahine [Gesellschaftsinseln] 1819-22)

$\S 2$. Blasphemie oder Idolatrie, Rückkehr zur Götzendienerei. Strafe: Todesstrafe.

$\S 16$. Übernahme einer neuen Lehre oder Lehrform, die von der wahren apostolischen Religion, die die Missionare verkünden, abweicht: gilt als Häresie. Strafe: Nach Entscheidung der hierin allein kompetenten Missionare außerhalb des Zivilkodex.

$\S 21$. Alle Richter und Häuptlinge müssen getauft sein. ...

\footnotetext{
${ }^{99}$ Einige Autoren (z. B. BARGATZKY 1978, S. 275) bezeichnen den kurz vorher einsetzenden Handel mit Schweinefleisch, das Pomare II gegen Waffen und Munition von Kaufleuten aus Sydney tauschte, als den ersten permanenten Kulturkontakt.
} 
$\S 23$. Tatauierung. Strafe: Zwangsarbeit

...Laszive Lieder, Spiele und Vergnügungen, Erscheinen von Frauen im Gotteshaus mit Blumen im Haar. Strafe: Zwangsarbeit. ...

Quelle: WERNHART, K. R.: Auswirkungen der Zivilisationstätigkeit und Missionierung in den Kulturen der Autochthonen - am Beispiel der Gesellschaftsinseln. In: Europäisierung der Erde. Wiener Beiträge zur Geschichte der Neuzeit, Band 7, 1980, S.145-146

*Diese Missionsgesellschaft hatte sich zu Beginn des 19. Jahrhunderts eine beherrschende Stellung auf den Gesellschaftsinseln verschafft." zitiert nach KREISEL 1989, S. 47.

Als erste Gegenreaktion auf das strenge Regime (Strafkodex, Zwang zu Abgaben an die Mission) der Missionare - und damit als erster Einbruch ihrer Machtposition - ist die Entstehung der mamaia-Bewegung ${ }^{100}$ zu verstehen: Als Mischform des Oro-Kultes mit christlicher Heilserwartung wendete sie sich gegen die Mission und errang in ihren Anfängen einige Teilerfolge, unterlag aber 1833 letztendlich militärisch. Hinter dieser ersten Gegenbewegung steht ein Protest gegen die sozialen Bedingungen (s. o.), der in dieser pseudochristlichen Bewegung eine Manifestationsmöglichkeit findet. Die Ankunft der französischen katholischen Missionare (1836, Tahiti) hatte einen doppelten Effekt: Nach kurzem Erfolg durch die Möglichkeit zur Füllung des durch die Niederschlagung der mamaia-Bewegung entstandenen religiösen Vakuums, erhielt gerade diese durch den nun beginnenden Kampf zwischen britischer und französischer Mission neue Zuläufer (vgl. HEERMANN 1987, S. 124 ff.).

Nach Errichtung des französischen Protektorats gab die London Missionary Society ihre Tätigkeit auf und übertrug ihre Aufgaben 1862 endgültig der französischen Société des Missions Evangéliques (vgl. ADLOFF und THOMPSON 1971, S. 15).

Die größten Erfolge der Christianisierung wurden dort erzielt, wo ari'i zu einheimischen christlichen Priestern ausgebildet wurden (vgl. Kap. 6.3.4), und damit durch deren höherer gesellschaftlicher Stellung und rangbedingtem mana die biblische Lehre eine schnellere Verbreitung und Akzeptanz fand. Diese gezielte Manipulation der vorgefundenen Gesellschaftsstruktur wird oft als Erklärung für die vergleichsweise immer noch schnelle (man hatte erwartet, dass die räumliche Streuung der Inseln einer schnellen Diffusion des Christentums ein stärkeres Hindernis entgegensetzt) und bis heute erhaltene Christianisierung FranzösischPolynesiens herangezogen (vgl. ADLOFF und THOMPSON 1971, S. 184).

\footnotetext{
${ }^{100}$ Zur näheren Darstellung dieser Bewegung s.: FURNAS, J. C.: Anatomy of Paradise. o. J. S. 280-81.
} 
Das Resultat dieser Entwicklungen ist, dass auf Grund der vor der katholischen einsetzenden evangelischen Mission immer noch etwas mehr als die Hälfte der Einwohner FranzösischPolynesiens evangelischen Kirchen angehören, in der Hauptsache Maohi, während die katholische Kirche vorwiegend durch Europäer vertreten ist. Da in der evangelischen Kirche die Pastorenämter mehrheitlich von Maohi bekleidet werden und entsprechend die Gottesdienste in der Sprache der Autochthonen abgehalten werden, bezieht diese zunehmend eine engagiert sozialkritische Position und wird auch zu einem Sprachrohr der Bedürfnisse der Maohi (vgl. MAUER 1970; O’REILLY 1970; DELIUS 1990, S. 16 f.; sowie Kap. 6.4).

Bei aller kulturellen Überformung durch die Christianisierung sind in Französisch-Polynesien immer noch alte Religionsmuster präsent. Mana ist nach wie vor ein wichtiges Prinzip, ebenso eine spirituelle Verbundenheit zur Natur. In diesem Zusammenhang entstanden auch verschiedene Formen von Synkretismus ${ }^{101}$ :

„L'ensemble des recherches anthropologiques en matière de religion nous apprend que le processus d' acculturation chrétienne produit non pas une addition, une superposition de deux cultures, mais bien une fusion originale dans laquelle il est impossible de dissocier nettement les éléments de la religion traditionnelle et ceux de la religion chrétienne" (s. SAURA 1993, S. 332).

Maraes (vgl. Kap. 6.2.2.2) sind nach wie vor in Funktion, besonders in peripheren Regionen mit einem sehr hohen Bevölkerungsanteil an Maohi. Auf Tahiti Iti wurde mir ein Marae gezeigt, das für Touristen nicht zugänglich war und - nach Aussage von Gabriel TETIARAHI - Teilen der lokalen Bevölkerung nach wie vor als Gebetsstätte dient. Ähnliche Berichte und mündliche Aussagen zu den Maraes erhielt ich auf den Inseln unter dem Wind von verschiedenen Interviewpartnern (z. B. Alice TEUIRA, Hubert BREMOND).

In der Summe nimmt allerdings der Einfluss von Glaubensrichtungen ab und die Gesellschaft in Französisch-Polynesien unterliegt - wie die westlichen Industrienationen - der Verweltlichung:

„Il est certain que la religion a tout d'abord cessé d'occuper la place dominante qui était la sienne dans la Polynésie des années 1900 ou même 1950. L’incroyance se développe, la société se laïcise, les valeurs religieuses sont en baisse et l'encadrement socioculturel des Eglises ne concerne plus qu'une partie de la jeunesse polynésienne, surtout en zone urbaine. Paradoxalement, ce mouvement s'accompagne d'une diversification extrême des croyances et des pratiques dans le même milieux. On assiste à Papeete à une explosion de spiritualités nouvelles qui vont à la rencontre de la culture ma'ohi sur le terrain de la spontanéité et d'un certain désir d'authenticité véhiculé par les apôtres de la revendication de l'identité culturelle ma'ohi' (s. SAURA 1993, S. 308).

\footnotetext{
${ }^{101}$ Dies wurde durch mehrere Interviews mit Einheimischen bestätigt (z. B. Hubert BREMOND, Natea MONTILLIÉR und Gabriel TETIARAHI)
} 


\subsubsection{Wirtschaft ${ }^{102}$}

Neben dem Erscheinen neuer, bald begehrter europäischer Tauschobjekte (vgl. Kap. 6.3.1), ist die früheste ökonomische Diffusion in der Landwirtschaft festzustellen: ein Häuptling namens ERETI erlaubte BOUGAINVILLE 1771 einen Modellgarten anzulegen, was die Übernahme von Weizen, Gerste, Hafer, Reis, Mais, Zwiebeln, sowie einiger Gemüsesorten bedeutete (vgl. BARGATZKY 1978, S. 251 f.).

Ab 1790 hatten sich die von den Europäern eingeführten eisernen Werkzeuge weitgehend durchgesetzt (vgl. HEERMANN 1987, S. 124 und Kap. 6.3.1).

Die christliche Mission veränderte - zeitweilig und inselspezifisch unterschiedlich - auch die traditionelle Wirtschaftsstruktur, da Arbeitskräfte insbesondere zum Bau von Kirchen abgezogen wurden, landwirtschaftliche Tätigkeiten und Fischfang vernachlässigt und somit die ausreichende Nahrungsversorgung zeitweilig nicht gewährleistet war (vgl. ADLOFF und THOMPSON 1971, S. 185). Mit dem Status des französischen Protektorats, dann der Kolonie und schließlich des Überseeterritoriums erfolgte eine kontinuierliche Diffusion marktwirtschaftlich-europäischer Wirtschaftsformen mit der entsprechend extrem schnellen Integration in den Weltmarkt, die die traditionelle Subsistenzwirtschaft (vgl. Kap. 6.2.2.3) nur noch in Randbereichen FranzösischPolynesiens weiterbestehen ließ (dass heißt auf peripheren Inseln oder in der Peripherie der Metropolen). Schon Pomare II forderte den Anbau von exportorientierten, tropischen Landwirtschaftsprodukten, so dass gegen Mitte des 19. Jh. die Produktion von Orangen, Kopra und Baumwolle dominierte (vgl. NEWBURY 1988, S. 65 u. 70). 1962 bot FranzösischPolynesien das typische Bild einer auf das Mutterland export- und importfixierten Kolonie $^{103}$ : Konzentration auf wenige exportierte Rohstoffe, hohe Importabhängigkeit von Investitions-, Konsumgütern westlichen Standards, sowie eine steigende Migration in die wirtschaftlich aktivsten urbanen Zentren (vorwiegend Papeete) (vgl. Anl. $16 a$ im Anhang, sowie Kap. 6.1.4 und

\footnotetext{
${ }^{102}$ KÖHLER (1982, S. 596 ff.) misst verallgemeinernd in seiner Dissertation über Akkulturation in der Südsee (Fallstudie: Karolinen-Inseln) den ökonomischen Faktoren die größte akkulturative Wirkung zu und betont vor allem die Einseitigkeit des kulturellen Austausches (ein Fakt, der hier in Ergänzung auch für Französisch-Polynesien gelten kann): „Stets wird es die beherrschte, den Gesetzen der ökonomisch und damit militärisch überlegenen Gesellschaft unterworfene Ethnie sein, deren ökonomische Grundlagen entscheidend transformiert werden, während die den Kontakt bestimmende Produktionsweise in der Regel lediglich unbedeutende, weitgehend äußerliche Elemente aufnimmt: ,Von einem Kulturkontakt als einem zweiseitigen Prozess kann keine Rede sein. Was die EuroAmerikaner bestenfalls sich haben geben lassen, sind einige Exotika für den Schmuck ihrer Wände, eine periphere Bewusstseinserweiterung in ästhetischer Hinsicht', kurz also: 'In the Pacific region, at least, transculturation was strictly a one-way traffic"“.

${ }^{103}$ Entsprechendes gilt für die französischen Besitzungen Martinique und Guadeloupe in der Karibik, Réunion und Mayotte im Indischen Ozean, sowie Wallis und Futuna und Neukaledonien im Pazifik, die in ihrer ökonomischen und politischen Struktur fast ausschließlich auf Frankreich fixiert sind (vgl. SHINEBERG 1988, S. 78 f.).
} 
6.1.6). Frankreichs Verlegung des Atomtestgebietes auf Grund des Verlustes Algeriens nach Französisch-Polynesien hatte durch die Gründung des CEP (Centre d'Expérimentation du Pacifique) einen künstlichen Wirtschaftsboom ${ }^{104}$ mit der entsprechenden Aufblähung des tertiären Sektors (vom Mutterland subventioniertes extrem hohes Bruttoinlandsprodukt; zudem ungleiche Arbeitsteilung im Handel in Bezug auf die verschiedenen Ethnien vgl. Anl. 16b, $17 \mathrm{im}$ Anhang) und der Infrastruktur zur Folge, an dessen Reichtum allerdings nicht alle Bevölkerungsschichten teilhatten (vgl. Kap. 6.3.6.4 und 6.1.3). CHESNEAUX (1987, S. 160) fasst die heutige wirtschaftliche Situation Französisch-Polynesiens wie folgt zusammen:

„Sur le papier et à s'en tenir à son PIB (produit intérieur brut), la Polynésie est un des quinze pays les plus riches du monde. Mais son économie, dit un rapport officiel, ,est dopée par les transferts artificiels de type colonial, et caractérisée par l'importation presque total de l'énergie (99\%) et de l'alimentation (85\%), le déséquilibre commercial (déficit de 94,4\%), l'insuffisance des productions locales et l'inadéquation de la formation à l'emploi'".

Hierbei ist zu beachten, dass diese starke akkulturative Wirkung des CEP (vgl. Kap. 6.3.6) im Prinzip nur als eine Katalysatorfunktion aufgefasst werden darf, da die oben beschriebenen Effekte schon vorher in Gang gesetzt wurden und durch den CEP nur noch in hohem Maße verstärkt und beschleunigt wurden (vgl. SHINEBERG 1988, S. 79).

Neben der Verstärkung bestehender Veränderungsvorgänge in der Wirtschaftsstruktur überformten andere Effekte des CEP auch bestehende wirtschaftliche Strukturen, die ihrerseits schon einmal traditionelle Wirtschaftsformen in Französisch-Polynesien verdrängten: Der exportorientierte Anbau von Kaffee und Kokosnüssen sank 1964 um 75\% gegenüber dem Vorjahr, die Produktion von Vanille sank ebenfalls um 75\% im Zeitraum 1962-67, in welchem auch der Export von Kopra um 40\% fiel ${ }^{105}$. Zudem setzte der CEP ab 1960 dem Tourismus ein zeitweiliges Ende, der bis dahin durch den Bau von Hotelanlagen und des internationalen Flughafens in Faa'a boomte, da z. B. die Hotels von Militärpersonal zunächst als Unterkünfte und Erholungszentren belegt wurden (vgl. SHINEBERG 1988, S. 81). Der erstmaligen Überformung

\footnotetext{
${ }^{104}$ Eine detaillierte Analyse der Effekte der Errichtung des CEP im Zusammenhang mit einer gesamtwirtschaftlichen Analyse Französisch-Polynesiens bis Anfang der 80er Jahre liefert G. BLANCHET: L'économie de la Polynésie francaise de 1960 à 1980. Paris: ORSTOM. 1985.

${ }^{105} 1971$ versuchte man in Französisch-Polynesien ein Entwicklungsprogramm für die Landwirtschaft durchzuführen, welches zumindest Teilerfolge erzielte: Im Rahmen der betriebswirtschaftlichen Organisation, im Zugang zu Krediten wurden Verbesserungen eingeführt, aber das Ziel der allgemeinen Revitalisierung der Landwirtschaft vorwiegend zur Deckung der lokalen Nachfrage und damit zur Senkung der Importe wurde ebenso wenig erreicht wie die Verbesserung des Lebensstandards der Landwirte (vgl. RAVAULT 1988, S. 133 ff.).
} 
der Wirtschaftsstruktur durch exportorientierte Formen der Marktwirtschaft folgte eine zweite Umstrukturierung in Richtung einer überproportionalen Tertiärisierung (vgl. Kap. 6.1.3).

Diese neue Abhängigkeit der französisch-polynesischen Wirtschaft vom CEP manifestierte sich in entsprechenden wirtschaftlichen Einbrüchen z. B. 1967, als die Anzahl der Tests nach dem ersten Testjahr zunächst heruntergesetzt wurde; 1969, als die Tests auf Grund der Kürzungen im Militäretat Frankreichs eingestellt wurden; 1972, ebenfalls Einstellung der Tests und 1975 als die bisher atmosphärischen Tests unter die Erde verlagert wurden (vgl. SHINEBERG 1988, S. 82). Bezüglich der Schaffung des europäischen Binnenmarktes befürchten die Maohi im Zuge der Niederlassungsfreiheit (d. h. Zuzug von Europäern - z. Zt. haben nur französische Staatsbürger die Möglichkeit, sich in Französisch-Polynesien niederzulassen), der freien Wahl des Arbeitsplatzes und des unbeschränkten Geld- und Warenverkehrs begleitet von der entsprechenden Grundstücksspekulation einen Ausverkauf (und damit noch geringere Chancen auf Anerkennung ihrer traditionellen Landrechte, vgl. Kap. 6.3.5) Französisch-Polynesiens einhergehend mit einer weiteren Verschärfung der bestehenden sozialen Probleme: Marginalsiedlungen, Arbeitslosigkeit, geringe Anzahl an Schulabschlüssen der Autochthonen, weitere Verschlechterung der Chancen der Polynesier auf dem Arbeitsmarkt (vgl. Kap. 6.1.6 und 6.3.6).

Auch von verstärkten regionalen Förderungsmaßnahmen und Strukturhilfen durch die EU versprechen sich die Maohi - da von diesen Geldern bisher in der Regel vorwiegend die europäischen, asiatischen Bevölkerungsgruppen und die demis profitierten - nichts (vgl. DELIUS 1991, S. 56).

Die Überformung der traditionellen Wirtschaftsstruktur durch die Europäer, insbesondere durch den CEP, ließ die Autochthonen nicht am Wirtschaftsboom teilhaben:

„The CEP has brought us money, not wealth" (DOUMENGE 1988, S. 155).

Sie imitierten nur die europäische Wohlstandsform durch Aufnahme von Krediten (vgl. Kap. 6.1.6).

Die massive wirtschaftliche Überformung durch den CEP rechtfertigte sich allein durch geostrategische Interessen:

„Bekanntlich blieb es der V. Republik vorbehalten, die Hochsubventionierung in das Entwicklungsmodell DOM-TOM einzuführen. Erst die definitorische Auflösung des Kolonialreiches und die damit verbundene ,Wiederentdeckung' der DOM und der übrig gebliebenen TOM, sowie die kühle multiple Funktionalisierung in der de Gaulleschen Außen- und Sicherheitspolitik löste jene Flut von Subventionen aus, welche die überseeischen Gesellschaften so nachhaltig transformieren sollten. Auch hier waren es also nicht Überlegungen entwicklungspolitischer Natur, die bei diesem Schritt Pate standen. Vielmehr handelte es sich in FranzösischPolynesien, dem neuen Atomtestzentrum nach der Aufgabe des algerischen Reggane, darum, durch eine großzügige finanzielle Hilfe den Widerstand in der Bevölkerung zu brechen. In den DOM waren die 
Finanztransfers vor allem dazu gedacht, den Separatismus zu bekämpfen und die Bevölkerung wieder verstärkt auf eine profranzösische-assimilatorische Linie einzuschwören.“ (s. JADIN 1994, S. 208)

Die in der Folge entstandene dependente Transferökonomie Französisch-Polynesiens kann auch als MIRAB-System bezeichnet werden:

„Im Südpazifik hat sich in einigen Mikrostaaten (z. B. Cook-Inseln, Tokelau, Westsamoa) eine spezielle Adaptionstechnik entwickelt, die staatliches Überleben auch unter der Bedingung extremer Ressourcenknappheit ermöglicht. Bertram/Watters (1985/1986) haben die Existenzgrundlage dieser Staaten unter dem Begriff MIRAB (Migration, Remittance, Aid, Bureaucracy) zusammengefasst. [...] Mit dem MIRABSystem schließt sich in gewisser Weise der Kreis zur französischen Variante assimilatorischer und hochsubventionierter Entwicklung. Die Modelle basieren beide auf dem Prinzip der Transferökonomie. So klassifiziert auch Poirine (1992), in Anlehnung an Bertram/Watters, die französisch-polynesische Wirtschaft als ARAB-System (ARAB = Atomic Rent, Aid, Bureaucracy).“(s. JADIN 1994, S. 213)

Dieses Problem betrifft fast alle pazifischen Inselgruppen:

„Dabei ist die Abhängigkeit umso größer, je stärker der Gesamthaushalt aus auswärtigen Quellen finanziert wird: Der amerikanisch dominierte Bereich Mikronesiens ist beispielsweise völlig von den USA finanziert. Bei einem Ausbleiben der Zahlungen würde die gesamte Wirtschaft zusammenbrechen. Wenn nur ein einziges Geberland Zuschüsse gewährt, ist die Abhängigkeit am größten (USA: Mikronesien; Frankreich: Wallis und Futuna; Neuseeland: Tokelau)“(s. KREISEL 1991, S. 328).

Französisch-Polynesien partizipiert zwar durch die Möglichkeit zu Wahlen zum Europäischen Parlament am politischen Prozess in Europa, sperrt sich aber gegen eine wirtschaftliche Integration. So setzte Französisch-Polynesien Ausnahmeregelungen vom Maastrichter Vertrag durch:

„The overseas territories do not form part of the EU territory, are not members of the single European Market, and are not directly covered by treaty-based law. Residents from France's Pacific territories, however, are citizens of the European Union and carry European passports. They can vote for elections to the European Parliament, as well as French municipal, territorial and national elections." (s. CHESNEAUX/MACLELLAN 1998, S. 226)

Als Mitglied der AKP ${ }^{106}$-Staaten profitiert Französisch-Polynesien von Entwicklungshilfe durch den Europäischen Entwicklungsfond und von Handelspräferenzen auf der Basis des vierten Lomé-Abkommens (1990-2000). Die Ablehnung des Maastrichter Vertrages drückte sich in Französisch-Polynesien beim Referendum mit 75\% Neinstimmen aus. Die generelle AntiEuropäische Haltung speist sich unter anderem aus der Angst vor zu viel Zuwanderung im Zuge der Niederlassungsfreiheit innerhalb der EU (vgl. CHESNEAUX/MACLELLAN 1998, S. 225 ff.). 


\subsubsection{Sprache}

Seit BLIGH sind neben der Namengebung (vgl. Kap. 6.3.1) weitere leichte Veränderungen im Wortschatz der Maohi bekannt (vgl. BARGATZKY 1978, S. 265).

Die größte Umwälzung in Bezug auf die Sprache der Maohi ist deren Kodifizierung durch die Missionare, was zum einen zwar die Konservierung dieses Kulturelementes (einschließlich der darin enthaltenen Geschichtselemente) bis zum heutigen Tage zu Folge hatte, zum anderen gerade dadurch seiner mündlichen Komponente, beraubt wurde (vgl. Kap. 6.2):

„Omettre de prendre en compte les composantes intonatives et mimo-gestuelles du Reo Maòhi, c'est l'amputer de paramètres essentiels sans lesquels il ne peut fonctionner, c'est l'exposer à devenir, à plus ou moins brève échéance, une langue fermée, d'un usage muséographique réservé à quelques initiés.“"(s. RAAPOTO 1997, S. 70)

In seiner mündlichen Tradition ist das Maohi stark abhängig vom situativen Kontext. Gestik, Mimik und Betonung sind erzählerische Komponenten, die bei einer Verschriftlichung verloren gehen.

Bei der Kodifizierung belegte man die in der Sprache der Autochthonen vorgefundenen Phänomene mit der Terminologie der traditionellen europäischen Grammatik, ungeachtet dessen, ob diese das tatsächliche Äquivalent des entsprechenden europäischen grammatischen Phänomens waren. Dem Verlust der oralen Tradition wird aktuell durch Darbietungen im mündlichen Erzählen beim alljährlichen Heiva (vgl. Kap. 6.4.3) und neuerdings auch durch neue Überlegungen, das mündliche Element des Maohi auch in die Sprachvermittlung stärker mit einzubeziehen (vgl. RAAPOTO 1997), begegnet. Unter der englischen Mission wurde die einheimische Bevölkerung zunächst nur in ihrer eigenen Sprache alphabetisiert, da es den Missionaren leichter erschien, ihnen auf diesem Wege das Christentum näher zu bringen (vgl. NEWBURY 1988, S. 35). Hierbei wurde, um eine größere Wirkung zu erzielen, mit einem Multiplikatoreffekt gearbeitet: Auf Grund des chronischen Personalmangels wurden Tahitianer notdürftig zu Lehrern ausgebildet und zu den nahe gelegenen Inseln gesandt (vgl. Kap. 6.3.2). Die ab 1797 einsetzende katholische Mission forcierte die Unterrichtung in Französisch, was zu einem zeitweiligen Verbot der indigenen Sprache führte (vgl. LAVONDES 1985, S. 142 ff.). Gegenstand der ersten Übersetzungen waren neben vorwiegend biblischen Texten auch Lehrbücher, z. B. für Geschichte und Mathematik (vgl. BUSCHMANN 1843, S. 91 ff.). Seit der Protektorats- und Kolonialzeit setzten sich die Normen des französischen Bildungssystems durch. Bis heute ist das höhere Schulwesen und die universitäre Ausbildung durch Frankreich repräsentiert, wobei die Sekundarschulen staatliche oder kirchliche Trägerschaft aufweisen (vgl. IH-Länder aktuell 1/91, S. 4). Seit 1960 wurde in verstärktem Maße 
das Schulsystem verbessert und die Unterrichtung in französischer Sprache (beginnend in den Kindergärten) mit Unterstützung der Medien Radio und Fernsehen intensiviert. In extremen Fällen kam es zu fast rein polynesischsprachigen Eltern mit vorwiegend französischsprachigen Kindern (vgl. DANIELSSON 1983, S. 209 ff.).

Die Gegenreaktion hierauf war die Forderung nach einer stärkeren Berücksichtigung der autochthonen Sprache im Bildungssystem, was im Rahmen der ersten Erweiterung des Autonomiestatuts 1977 zu deren Einführung im Grundschulunterricht führte und 1980 zur Anerkennung als offizielle Sprache (vgl. O’REILLY 1982, S. 312).

Dennoch wirkt sich das in zu starkem Maße an europäischen Normen und Denkweisen orientierte Schulsystem zum Nachteil der autochthonen Bevölkerung aus, die nur zu ca. 19\% einen Abschluss erreichen (vgl. TETIARAHI 1989a, S. 86).

Ein Handikap der Sprachpflege bleibt die Tatsache, dass die Schaffung einer einheitlichen Norm der autochthonen Sprache im Gebiet Französisch-Polynesiens noch nicht abgeschlossen ist. Dies wirkt sich umso negativer aus, da sich die heutige Bevölkerung der Maohi kulturell weitgehend noch mittels ihrer Sprache bewusst von den anderen Ethnien abgrenzen kann. Darüber hinaus wird im Allgemeinen ein mangelndes Interesse der Jugendlichen am Erlernen des Maohi beklagt. Für den Erhalt der Sprache setzt sich die Academie Tahitienne ein, die 1986 erstmals eine Grammatik und 1999 den ersten Band eines Französisch-Tahitischen Wörterbuchs herausgab. Darüber hinaus werden lokale Autoren durch Literaturwettbewerbe gefördert. Eine eigene Academie ist jeweils für die Dialekte der Marquesas und der Tuamotus geplant ${ }^{107}$.

\subsubsection{Recht}

In Bezug auf das traditionelle Rechtssystem war die Rolle der Missionare durchaus auch bewahrender Natur: traditionelle Bereiche des Rechts, insbesondere des Landrechts wurden durch deren schriftliche Fixierung - insbesondere im Zeitraum 1819-1842 durch die Protestanten - festgehalten (vgl. TETIARAHI 1990b und Anl. 18 im Anhang), z. B. die Form des Familiengemeinschaftseigentums und ein Verkaufsverbot von Land an Europäer, wobei allerdings unter gewissen Umständen auch die Möglichkeit zum Privatbesitz festgelegt wurde (vgl. Kap. 6.2.2.5).

Nach der Übernahme Französisch-Polynesiens durch Frankreich zunächst als Protektorat (18421880), dann als Kolonie (1880-1957) und schließlich als Überseeterritorium (ab 1957 unter zweimaliger Erweiterung des Autonomiestatuts 1977 und 1984, vgl. Kap. 6.1.4) kollidierte das traditionelle Rechtssystem (vgl. Kap. 6.2.2.5) mit den Rechtsbegriffen europäischer Norm.

\footnotetext{
${ }^{107}$ Interview mit dem Leiter der Academie Tahitienne, 1999
} 
Insbesondere die traditionellen Formen von Gemeinschaftseigentum wurden in Bezug auf die Landwirtschaft als rückständig und entwicklungshemmend bewertet ${ }^{108}$.

Die im Protektoratsvertrag erteilte Garantie des Landbesitzes ${ }^{109}$ (für die Autochthonen) wurde von Anfang an nicht beachtet. Verschiedene 1845, 1847, 1851 und 1852 in Anlehnung an das französische Zivilrecht erlassene Gesetze legitimierten und garantierten schließlich den Austausch und Verkauf von Land und dessen Registrierung mit Besitzername, Parzellenname und -größe, so dass der schützende Einfluss der Missionare in Bezug auf das traditionelle Rechtssystem spätestens an dieser Stelle ein Ende fand. Die Folgen waren fatal: In Anlehnung an die Tradition ließen die Maohi ganze Familien und Verwandtschaftsgruppen als „Besitzer" eintragen, einige ari’ i missbrauchten die neue Möglichkeit und schwangen sich zu Alleinbesitzern von Land auf, in Missachtung der Nutzungsrechte der anderen Gesellschaftsgruppen. Diese Umstände in Kombination mit dem zunehmenden Landbesitz der Europäer gab Anlass zu andauernden Rechtsstreitigkeiten, mit denen die zunächst eingesetzten tahitianischen Richter des Tahitian High Court (To 'ohitu) überfordert waren, so dass diese Institution 1866 wieder aufgelöst wurde und 1874 endgültig das französische Zivilrecht auch auf das Landrecht angewendet wurde. Dies hatte zur Folge, dass ab 1877 die Registrierung von Land zur Pflicht wurde ${ }^{110}$, ansonsten fiel es in die Hände Frankreichs.

In Bezug auf die übrigen Rechtsbereiche, die zur Zeit des Protektorats und des Kolonialstatus vom entsprechenden Ministerium in Paris zentral kontrolliert wurden, ist zu sagen, dass die Gesetzgebung die Rechtssubjekte vielfach nicht erreichte und wenn doch, sich deren Verständnis oft entzog, da die komplizierte französische Rechtssprache nicht verstanden wurde. Somit hatte die französische Gesetzgebung zu dieser Zeit einen relativ geringen Einfluss auf das tägliche Leben der Autochthonen, die sich der Bibel und zum Teil weiterhin traditionellen Konzepten als Richtlinie bedienten. Auf die gleiche Art und Weise entzogen sich zunächst die Chinesen der

\footnotetext{
${ }^{108}$ Dies bezieht sich sowohl auf die nicht-marktwirtschaftlich-gewinnorientierte Wirtschaftsweise (Subsistenzwirtschaft), als auch auf die Besitzformen und Rechtsvorstellungen (Kollektivbesitz, zum Teil Individualnutzungsrechte) (vgl. RAVAULT 1988, S. 115 und Kap. 3.2.5).

${ }^{109}$ Protektoratsvertrag vom 9. September 1842 (Artikel 13):

„Ownership of the Queen's and the people's land will be guaranteed: the land will remain their property. Any dispute relating to ownership rights or pertaining to the rights of land owners will be decided by the country's special jurisdiction“" (TETIARAHI 1988, S. 104).
}

\footnotetext{
${ }^{110}$ Dies galt zunächst nur für die Inseln über dem Wind und wurde 1898 auf die gesamten Gesellschaftsinseln und 1902 auch auf die Marquesasinseln übertragen (vgl. TETIARAHI 1988, S. 106). 1920-25 wurde es auf den Ostteil der Tuamotuinseln und 1945 auf Rapa, Rurutu und Rimatara ausgedehnt (vgl. RAVAULT 1988, S. 112).
} 
rechtlich-behördlichen Kontrolle Frankreichs, wobei sie sogar noch einen Schritt weitergingen und zeitweise eigene Schulen und Gerichte unterhielten (vgl. DANIELSSON 1983, S. 195).

Bis 1984 wurden in verschiedenen Zeitabständen Verordnungen durch die Verwaltung erlassen, die die Rechte der autochthonen Bevölkerung schützen sollten. Da sie effektiv nie angewendet wurden, hat man sie 1984 letztendlich abgeschafft. Die Benachteiligung der autochthonen Bevölkerung durch die volle Implementierung und Diffusion des französischen Rechtssystems geschah nicht in Unkenntnis der traditionellen Regelungen, sondern als politisch wohl überlegte Taktik (vgl. TETIARAHI 1989a, S. 100 ff.).

Institutionalisiert ist das französische Recht heute in je einem erstinstanzlichen, einem Berufungsund einem Verwaltungsgericht in Papeete (vgl. IH-Länder aktuell 1/91, S. 4).

Verschiedene Transaktionen von Land wurden sogar unter Ausnutzung der traditionellen Rechtsvorstellung getätigt: In der vollen Überzeugung, dem Europäer nur die „Nutzungsrechte" übertragen zu haben (und in Unkenntnis des französischen Rechtssystems), ,,verkauften" viele Maohi ihr Land, das sie auch nicht durch Inanspruchnahme von Rechtsanwälten in den entsprechenden Prozessen zurückgewinnen konnten.

Als Rest des ursprünglichen Landrechtssystems existieren bis heute noch Formen des Gruppen/Gemeinschaftseigentums von vorwiegend autochthonen Bevölkerungsteilen. Ist das Individualeigentum räumlich insbesondere an der Südküste Tahitis, in ländlichen Distrikten Tahitis mit hohem Bevölkerungsanteil der demis (Papara, Afaahiti), sowie auf den Inseln, die unter zunehmendem Einfluss des Tourismus stehen (Moorea, Bora Bora, Raiatea und Tahaa), aber auch zum Teil auf Tubuai, und einigen Atollen der Tuamotu- und Marquesasinseln vorherrschend, so existiert in allen anderen Teilen Französisch-Polynesiens bis heute, vorwiegend in den peripheren Gebieten, hauptsächlich das Kollektiveigentum. Hierbei konzentriert sich der meist als Individualeigentum vorliegende und zum Teil unterbewirtschaftete Großgrundbesitz in der Hand von Weißen und demis, während die Minifundien hauptsächlich im Kollektivbesitz von den Maohi bewirtschaftet werden (vgl. RAVAULT 1988, S. 112 ff.) ${ }^{111}$. Das Resultat dieser Entwicklung ist ein bis heute andauernder Rechtsstreit um Landansprüche, der z. B. dadurch verkompliziert wird, dass Genealogien manipuliert werden, um Ansprüche nachzuweisen (vgl. Kap. 6.2.2.5). Selbst bei nach traditionellem Recht legitimen Landansprüchen

\footnotetext{
${ }^{111}$ Einige Fallbeispiel dargestellt von JORALEMON (1988, S. 154) widerlegen die Auffassung, dass die Minifundien in Kollektivwirtschaft im Gegensatz zur Individualbewirtschaftung der Latifundien (cash crops) wirklich entwicklungshemmend sind: „Collective land tenure systems among small-holder agriculturalists are commonly considered to inhibit agricultural development, specially individualistic cash-cropping. This view is shared by a large group of social scientists who assert that fundamental insitutional changes must take place in more traditional communities in order for them to develop economically. An anlysis of recently introduced potato cultivation on the French Polynesian island of Tubuai contradicts this widely held assumption“.
} 
ist es für die Maohi in oft jahrzehntelangen Gerichtsverfahren nicht möglich, ihre Ansprüche nachzuweisen und durchzusetzen, da sie sich lange Zeit in Unkenntnis oder Unverständnis der europäischen Gesetzestexte nicht gegen die andauernde Verletzung ihrer traditionellen Landrechte gewehrt hatten, und heute die damaligen Eigentumsverhältnisse kaum noch zu rekonstruieren sind. Auch Bürgerinitiativen und Landbesetzungen, die nicht nur die Wiedererlangung traditionellen Familienlandes zum Ziel hatten, sondern auch Protest gegen die ökologischen Schäden des Phosphatabbaus (auf Mataiva und Makatea), die atomaren Tests (vgl. Kap. 6.3.6.1) oder ehrgeizige Tourismusprojekte (Tupai, Moorea: Verpachtung an ausländische Investoren) ausdrückten (vgl. auch TETIARAHI 1989a, S. 81 ff.), war kein rechtlicher Erfolg beschieden.

Bis heute wird das durch die Europäer implementierte Rechtssystem dem komplexen und anders differenzierten Rechtsverständnis der Autochthonen nicht gerecht (vgl. DELIUS 1991, S. 56 ff.). Die Rechts- und hier insbesondere die Landrechtsproblematik gewinnt an Brisanz, wenn man die - auch heute noch bestehende - enge Verbundenheit der Urbevölkerung mit der Natur und dem Stück Erde, auf dem sie leben, mit in Betracht zieht. Da diese Verbundenheit auch durch eine spirituelle Komponente getragen wird, bedeutet die Profanisierung bzw. Missachtung traditioneller Landrechte gleichzeitig eine Missachtung religiöser Vorstellungen.

Insbesondere in Neuseeland und Hawaii - wie in den meisten Inselgebieten des Pazifik - geschah Vergleichbares. Der westliche Eigentumsbegriff kollidierte mit dem indigenen und die autochtone Bevölkerung wurde in Landrechtsfragen massiv übervorteilt. In anderen Regionen konnte die Urbevölkerung weiterhin über ihr Land verfügen:

„In manchen Inselgruppen gelang es den Einheimischen, im Besitz des Landes zu bleiben, z. B. in Tonga. In Fiji wurde der autochtonen Bevölkerung als Gegenleistung für die Anerkennung der britischen Souveränität der Landbesitz garantiert“" (s. KREISEL 1991, S. 115). 


\subsubsection{Die Atomtests - gravierender Akkulturationsfaktor in Französisch-Polynesien}

\subsubsection{Die Atomtestproblematik}

Bis hierhin unterscheidet sich der Prozess der Akkulturation in Französisch-Polynesien in seinem Kern durch nichts von Akkulturationsprozessen in anderen Gebieten des pazifischen Raumes ${ }^{112}$ (vgl. Kap. 6.3). Durch folgende spezielle, aktuelle Probleme wird Französisch-Polynesien allerdings zu einem Sonderfall: Zu den typischen Akkulturationserscheinungen kommt eine massive militärische Unterdrückung durch den Missbrauch Französisch-Polynesiens als nukleares Testgelände durch Frankreich, was zum einen die Hegemonie Frankreichs weiterhin aufrecht erhält, zum anderen entsprechenden Gegenreaktionen Schärfe (vgl. Kap. 6.4) verleiht. SHINEBERG (1988, S. 78) bewertet die Errichtung des Centre d'Expérimentation du Pacifique (CEP) als den tief greifendsten akkulturativen Wirkungsfaktor in Bezug auf die sozioökonomische Struktur Französisch-Polynesiens (vgl. auch Kap. 6.1.6 und 6.3.3). Objektive Information zur Atomtestproblematik in Französisch-Polynesien zu erhalten, ist unmöglich, da die Aussagen der französischen Regierung zu denjenigen der lokalen und internationalen Anti-Nuklear-Bewegungen in genauem Gegensatz stehen. Im Folgenden sei eine möglichst objektive Darstellung versucht, da nur vor deren Hintergrund die indigene Reaktion, die sich u. a. im politischen Engagement manifestiert, nachvollziehbar ist (vgl. Kap. 6.4). Die folgenden Erläuterungen der nuklearen Tests in Französisch-Polynesien beziehen sich in der Hauptsache auf eine Studie des NUCLEAR WEAPONS DATA CENTER ${ }^{113}$ (NWD 89-1, Working Paper, French Nuclear Testing, 1960-1988). Davon abweichende Quellen sind entsprechend gekennzeichnet.

\footnotetext{
${ }^{112}$ KÖHLER (1982) und RANFT-PANEK (1990) beschreiben die Akkulturation der autochthonen Bevölkerung auf den Karolinen bzw. in Neuseeland und kommen im Wesentlichen zu vergleichbaren Resultaten.

${ }^{113}$ Der Nuclear Weapons Data Center wird seit 1980 durch das Natural Resources Defense Council (Washington) finanziert. Die Sammlung und Verbreitung möglichst detaillierter Information zu den weltweiten Nuklearwaffen mit dem Ziel, eine verstärkte Diskussion auf Faktenbasis zu fördern, ist seine Hauptaufgabe.
} 


\subsubsection{Das nukleare Testprogramm der französischen Regierung}

Nach Beobachtung und Teilnahme an US-Tests in Nevada fiel 1954 die Entscheidung der französischen Regierung, zur Erhaltung der force de frappe die Atombombe selbst zu bauen, was ein geeignetes Testgelände erforderte: Infrastrukturelle Überlegungen ließen die Wahl zunächst auf Französisch-Algerien fallen ${ }^{114}$.

Nach der Unabhängigkeit Algeriens verlagerte Frankreich seine Tests 1962 auf die unbewohnten low islands Moruroa und Fangataufa der Tuamotuinseln. Im Verlaufe dieses Jahres wurde auch offiziell das Centre d'Expérimentation du Pacifique errichtet.

Der 1963 von mehreren Nationen unterzeichnete Limited Test Ban Treaty (LTBT) verurteilt den Test nuklearer Waffen in der Atmosphäre, submarin, und im Weltraum. Als Nichtunterzeichner weigerte sich Frankreich selbst unter Druck der US-Regierung auf atmosphärische Tests zu verzichten, unter anderem mit der Begründung, noch nicht über die technischen Voraussetzungen für unterirdische Tests zu verfügen.

1972 wies der damalige Präsident Georges POMPIDOU die Armee an, nach einem geeigneten Ort für weitere Versuche zu suchen. Nach ersten Untersuchungen auf Eiao, verkündete der Verteidigungsminister Robert GALLEY 1973, dass die Wahl auf Fangataufa gefallen sei. Erst seit 1974 werden - nicht zuletzt durch internationalen Druck der UN - sämtliche Tests auf Moruroa und Fangataufa unterirdisch durchgeführt.

1980 entsprach der Randbereich Moruroas einem „Schweizer Käse“, so dass DIRCEN die Entscheidung traf, sowohl auf Moruroa als auch auf Fangataufa den Testbereich vorwiegend in die Mitte der Lagune (,central zone") zu legen, was die Fortführung der Testserien ermöglichte. Die Möglichkeit der Durchführung von Atomtests dürfte der Hauptgrund für den Verbleib Französisch-Polynesiens bei Frankreich sein ${ }^{115}$, wobei als weitere Gründe der erklärte Wille der Bevölkerung (s. Referendum von 1958) bei Frankreich zu bleiben, die potentiellen wirtschaftlichen Ressourcen in der 200-Meilen-Meereswirtschaftszone und die Möglichkeit zu verschiedenen speziellen wissenschaftlichen Forschungen angeführt werden (vgl. LE PENSEC 1990, S. 12 f.).

\footnotetext{
${ }^{114}$ Zur Wahl standen weiterhin die Kerguelen Inseln im Indischen Ozean, Clipperton Island und die Tuamotuinseln im Pazifik.

${ }^{115}$ Ökonomische Interessen, die sich auf die Nutzung der 200-Seemeilen-Wirtschaftszone oder den „Anschluss an die vielgerühmte ökonomische und politische Machtverschiebung zum Pazifischen Becken“" (von KROSIGK 1986, S. 95) beziehen, spielen in diesem Zusammenhang eine eher untergeordnete Rolle.
} 
1960 - 1988 führte Frankreich mindestens 172 nukleare Tests durch. 1988 erreichten die Franzosen damit einen Anteil von 9,6 \% an allen bis dahin seit 1945 weltweit durchgeführten Atomtests, von denen der weitaus größte Teil auf Mururoa (Moruroa ${ }^{116}$ ) durchgeführt wurde (39 atmosphärische und 134 unterirdische Tests). Die Explosionsstärke variierte von einer bis zu 150 Kilotonnen TNT.

In Bezug auf Ort, Zeit und Art (ober- bzw. unterirdisch) können sechs verschiedene Testperioden Frankreichs unterschieden werden:

- $\quad$ 1960-1961: 4 atmosphärische Tests in Algerien

- 1961-1966: 13 unterirdische Tests in Algerien

- $\quad$ 1966-1974: 44 atmosphärische Tests durch $\mathrm{CEP}^{117}$ (39 über Moruroa, 5 über Fangataufa)

- $\quad$ 1975-1988: 111 unterirdische Tests durch CEP (108 auf Moruroa, 3 auf Fangataufa)

- $\quad$ 1989-1991: 18 unterirdische Tests durch CEP auf Moruroa

- $\quad$ 1995-1996: 8 unterirdische Tests durch CEP auf Moruroa

Von 1966 bis 1996 hatte Frankreich auf Moruroa und Fangataufa insgesamt 181 Tests unternommen. Ziel dieser Testreihen war die Entwicklung und Verbesserung von Nuklearsprengköpfen und Nuklearsystemen ${ }^{118}$, wobei die Anzahl der Tests pro zu entwickelndem Nuklearsprengkopf höher lag als zum Beispiel bei entsprechenden Testreihen in den USA.

\footnotetext{
${ }^{116}$ Der traditionelle Name Moruroa wurde vom französischen Militär in Mururoa umbenannt, mit dem Effekt, dass Gegner des Atomtestprogramms bewusst den alten Namen verwenden.

${ }^{117}$ Das Centre d'Expérimentation du Pacifique ist folgendermaßen organisiert:

- Die Base Interarmées des Sites (BIA) befindet sich auf den low islands Moruroa und Fangataufa, sowie den peripheren low islands Tureia, Tematangi und Reao. BIA ist verantwortlich für die Logistik, Vorbereitung der Tests, Sicherheit der Installationen. Maximal 3600 und minimal 3000 Mann Personal (ca. die Hälfte Militärs, weiterhin Wissenschaftler und Ingenieure) sind dort beschäftigt.

- Die Base Interarmées de Hao: in den 60er Jahren als Nachschubbasis für das nukleare Testmaterial wurde diese Basis bald aufgelöst und nach Moruroa verlegt.

- Weiterhin befinden sich ca. 1100 Mann Forschungs- und Verwaltungspersonal auf Tahiti (Papeete, Faa'a, Arue und Mahina).
}

Das gesamte in Französisch-Polynesien anwesende Militär verteilt sich auf Armee (ca. 1500 Mann), Marine (ca. 850 Mann, davon 250 auf 31 Schiffen), und die Luftwaffe (ca. 550 Mann).

\footnotetext{
${ }^{118}$ Hier sind z. B. zu nennen: TN 35 Sprengkopf für die S4 Mittelstreckenrakete (Intermediate-Range Ballistic Missile, IRBM), TN 75 Sprengkopf für die M 45 submarin abgeschossene Rakete (Submarine-Launched Ballistic Missile, SLBM), TN 76 Sprengkopf für die M 5 SLBM, Neutronenbombensprengköpfe (Enhanced Radiation Warhead, ERW, oder neutron bomb), ein Sprengkopf für die Hadès-Rakete.
} 
Die offizielle Ankündigung dieser Tests war nicht immer gegeben, was die Gesamtanzahl der Tests in Zweifel ziehen könnte. Sind die Testreihen in den Jahren 1960 bis 1970 noch relativ gut auch von offizieller Seite - dokumentiert, so ist spätestens ab 1975 ein Informationsdefizit festzustellen, welches die französischen Behörden trotz scharfer Proteste der anderen Pazifikund insbesondere der Pazifikanrainerstaaten (Neuseeland, Australien) nicht gewillt sind zu beheben. Somit wurde die Dokumentation der Testreihen zunehmend über seismische Aufzeichnungen von nicht-französischen Instituten vorgenommen ${ }^{119}$. CHIRAC beendete das von MITTERAND 1992 ausgesprochene Moratorium bezüglich der Atomtests und ließ 1995-1996 acht letzte Tests durchführen, bevor man in der Folge zu computersimulierten Tests überging (vgl. VRIES/SEUR 1997, S. 156 ff.). Bis 1998 wurden alle militärischen Einrichtungen zu den Atomtests auf Moruroa abgebaut. Hafen, Flugplatz und eine geringe Zahl an Fremdenlegionären blieb zurück. Darüber hinaus unterzeichnete die französische Regierung im März 1996 den AntiAtomwaffenvertrag (vgl. pazifik aktuell 1996, S. 13).

\subsubsection{Zur Informationspolitik bezüglich des Atomtestsprogramms}

Im Oktober 1985 gab die Direction des Centre d'Expérimentations Nucléaires (DIRCEN, eine dem CEP übergeordnete Institution, offizielles Organ der französischen Regierung ${ }^{120}$ ) auf

\footnotetext{
${ }^{119}$ Insbesondere durch das New Zealand Department of Scientific and Industrial Research (DSIR) und das Swedish National Defence Research Institute (FOA), die unabhängig voneinander die seismischen Daten der französischen Tests in Bezug auf Epizentrum, Zündungszeit und Explosionsstärke hin analysieren und auswerten.
}

120 Die Konstruktion und Herstellung der zu testenden nuklearen Sprengladungen obliegt der Direction des Applications Militaires (DAM), dem Zweig für militärische Anwendungsbereiche des Commissariat à l'Energie Atomique (CEA). Für die organisatorische Bewältigung und Verantwortung für das Testprogramm ist jedoch DIRCEN zuständig, welches direkt dem Französischen Verteidigungsministerium untersteht. DIRCEN wurde 1964 gegründet und setzt sich aus folgenden Abteilungen zusammen:

- Hauptquartier in Villacoublay in Frankreich

- Groupement Opérationnel des Expérimentations Nucléaires (GOEN), konkret ausführender Arm der Nukleartests

- Direction des Travaux et Services (DTS), mit Basis in Villacoublay, verantwortlich für die Logistik

- Service Mixte de Contrôle Biologique (SMCB), verantwortlich für die Strahlenüberwachung und Sicherheit von Tieren, Nahrungsmittel- und Trinkwasservorräten nahe des Testgeländes, Zweigstelle in Mahina, nahe Papeete, biologisches Kontrollschiff.

- Service Mixte de Sécurité Radiologique (SMSR), zusammengesetzt aus Personal der Armee und der CEA, verantwortlich für die Strahlensicherheit, dass heißt Vermeidung von Fallouts und Schutz der Bevölkerung, Zweigstelle auf Moruroa

- Centre d'Expérimentation du Pacifique (CEP)

Über die gesamte militärische Infra- und Entscheidungsstruktur Frankreichs in Französisch-Polynesien gibt Anl. 20 im Anhang Auskunft. 
Anfrage des NRDC (Natural Resources Defence Council) einen Report heraus, der Auskunft über die Anzahl der französischen Tests im Zeitraum 1960-1984 gibt und aus dem zu ersehen war, dass die Anzahl der tatsächlichen Tests um elf höher lag als die von nicht-französischen Instituten beobachteten, was beweist, dass es Frankreich gelungen war, ohne Wissen der Weltöffentlichkeit zu testen. Die Auskunft des Direktors von DIRCEN, ab 1985 ca. 8 Tests pro Jahr durchzuführen, entspricht der seitdem beobachteten Anzahl. 1988 ließ Außenminister Roland DUMAS zudem verlauten, dass am Ende jeden Jahres die Testanzahl bekannt gegeben würde (was bisher auch geschah). Der Kritik an den Atomtests begegnete Frankreich im Wesentlichen mit Politisierung und Verharmlosung:

„First the French military denied all information portrayed as anti-French political propaganda. Years after, however, some of these events were admitted, but under the assurances that present technology would render them impossible in the future." (s. VRIES/SEUR 1997, S. 211)

Erst 1999 gab der neue Direktor der Atomenergie Kommission Frankreichs, René PELLAT, zu, dass definitiv Risse in den Atollen Moruroa und Fangataufa bestehen (vgl. EUROPE-PACIFIC SOLIDARITY BULLETIN Nr. 3, 1999, S. 9).

\subsubsection{Die nuklearen Tests in der Diskussion}

DIRCEN stellte zunächst die „Idealität" Moruroas für atomare Tests in den Vordergrund mit dem Argument, dass die nächste Siedlung 800 km entfernt liegt und im Umkreis von 1000 km nur 5000 Menschen leben, was im Vergleich zu Kasachstan (4,2 Mio.) und Nevada (37,5 Mio.) relativ gering ist.

Französische Ingenieure führen hingegen die schleichende Zerstörung des low island an, da der Basaltsockel zunehmend durch die Explosionen bedingte Risse aufweise, wodurch im Extremfall radioaktive Strahlung freigesetzt werden könne. Nachgewiesen ist ein Absinken Moruroas um 1,5 m im Zeitraum 1976-1981, was schon Aufschüttungen zum Erhalt der Infrastruktur nötig machte. Eine Karte der Armee (veröffentlicht u. a. im August 1983 in Pacific Islands Monthly, S. 35, vgl. auch Anl. 19 im Anhang) zeigt deutliche Risse unter Wasser an den äußeren Seiten Moruroas. Die französische Regierung ihrerseits führt diese Risse auf ein natürliches Phänomen des Zusammenbruchs des Atolls unter seinem Eigengewicht zurück. Der Test vom 25. Juli 1979 ließ die Diskussion erneut aufflammen: Die seismischen Aufzeichnungen der Station Rarotonga auf den Cook-Inseln belegten die bisher größte seismische Erschütterung. Die Ursache hierfür war eine unbeabsichtigte frühzeitige Explosion der Sprengladung beim Hinunterlassen in den Sprengschacht. Somit erfolgte die Detonation schon bei $400 \mathrm{~m}$ und nicht erst bei der vorgesehenen Tiefe von $800 \mathrm{~m}$. Verschiedene nicht-französische Institute (z. B. die Victoria 
University, Neuseeland) rekonstruierten das Entstehen eines Explosionskraters von $140 \mathrm{~m}$ im Durchmesser und einen „Materialverlust" des Atolls von ca. einer Million Kubikmeter (korallines und basaltisches Material). Eine entsprechende Flutwelle verletzte sechs Menschen. Die französischen Behörden negierten die Fehlzündung des Tests und CEA bestritt einen Zusammenhang zwischen dem Test, der völlig normal verlaufen sei, und der Flutwelle, die natürlichen Ursprungs sei. Erst 1985 gab DIRCEN einen „Unfall” vom 25. Juli 1979 zu, ohne jedoch weitere Angaben dazu zu machen.

Die generelle Gefahr der radioaktiven Verseuchung der Lagune durch die Verlagerung der Tests in diesen Bereich wird insbesondere von nicht-offizieller Seite betont, was sowohl von François MITTERAND (1986) als auch von Gaston FLOSSE (1987; s. u.) negiert wird (vgl. hierzu auch Kap. 6.1).

Eine Reihe von Hurrikanen richtete auf Moruroa großen Schaden an. So soll am 11./12. März 1981 radioaktiver Abfall vom Nordrand des Atolls in die Lagune geschwemmt worden sein, was von offizieller Seite immerhin als möglich bezeichnet wird:

„some of the nuclear waste left by the atmospheric explosions made before 1975, may have crossed the lagoon to the eastern side of the atoll" (Pacific Islands Monthly, 10/81, S. 23).

Es bleibt festzustellen, dass seitdem die Tests in den Zeitraum Dezember - April verlagert wurden, das heißt außerhalb der Zeit, in der Hurrikane mit größerer Wahrscheinlichkeit auftreten. Es wurden auch Schutzwälle um Wohn- und Arbeitstrakte auf Moruroa errichtet (sowohl meerals auch lagunenwärts).

Bei dem gravierenden Streit um die Sicherheit des Moruroaatolls ${ }^{121}$ ließ der Einsatz wissenschaftlicher Expertenteams nicht lange auf sich warten: Drei Forscherteams besetzt mit internationalen Wissenschaftlern (TAZIEFF-Expedition 1982, ATKINSON-Expedition 1983, COUSTEAU-Expedition 1987) wiesen die Sicherheit unterirdischer Atomtests auf Moruroa nach. Es sei darauf hingewiesen, dass diese Untersuchungen extrem kurz waren, keinen Zugang zu den am stärksten kontaminierten Gebieten hatten und ausschließlich auf Datenmaterial beruhen, das vom französischen Militär zur Verfügung gestellt wurde.

Abgesehen von der zweifelhaften Objektivität der bisherigen Untersuchungen der Auswirkungen der Atomtests auf das Moruroaatoll bleiben noch eine Reihe von Fragen unbeantwortet (vgl. auch BORG 1989, S. 517). Eine unabhängige internationale Langzeitstudie der Effekte der

\footnotetext{
${ }^{121}$ Zur Diskussion über die Atomtestproblematik in Französisch-Polynesien insbesondere im Zeitraum von 19631973 vgl. TAGUPA 1974.
} 
französischen Atomtests - wie z. B. im Februar 1989 in einer Resolution des europäischen Parlaments gefordert und abgelehnt - harrt ihrer Durchführung.

Unbeirrt von internationalen Protesten ${ }^{122}$ setzte Frankreich zunächst seine Testreihen fort und zog nach dem Ende der Testmöglichkeit auf Moruroa und Fangataufa - auf Grund eines zu hohen Zerstörungsgrades - wieder die Kerguelen Inseln (s. o.) als Ausweichmöglichkeit in Betracht.

Nach einer Auszeit - angekündigt 1992 durch ein Moratorium MITTERRANDs - wurde jedoch unter weltweiten Protesten in 1995 - 1996 durch CHIRAC eine weitere Testphase angekündigt und durchgeführt. Der Widerstand gegen die Atomtests erreichte seinen Höhepunkt: eine Bootsflotte die „Flottille de la Paix“, die sich zusammensetzte aus Aktivisten verschiedener Nichtregierungsorganisationen, der evangelischen Kirche, der Gewerkschaften, der Unabhängigkeitsparteien und nicht zuletzt dem Greenpeace-Schiff „Rainbow Warrior II“ drang unter weltweiter Aufmerksamkeit der Medien in die 12-Meilen-Zone Moruroas ein und wurde vom französischen Militär aufgehalten. Der Widerstand ging weiter mit Demonstrationsmärschen und der Einrichtung eines „Village de la Paix“ auf Initiative von Hiti Tau und der Pomare Parti im Juli 1995 (vgl. VRIES/SEUR 1997, S. 156 f.). Der Protest richtete sich gegen weit mehr als gegen die durch die Tests zu befürchtenden Umweltschäden:

„In a very strong statement Hiti Tau (as a member of the UN working group on indigenous peoples) pointed out that by placing the bomb in the belly of Moruroa, the French Government had damaged the Maohi and Maohi identity. Again the inseparable and spiritual bond between indigenous peoples and their land was stressed. [...] Other declarations accused the French Government of having raped the Mother Land and the Maohi people." (Communiqué pour la presse, Hiti Tau und Déclaration solennelle, Tahiti 1995 zitiert nach VRIES/SEUR 1997, S. 157)

In den 60er und 70er Jahren waren Diskussion und Kritik an den Tests aus Mangel an öffentlicher Information und vor dem Hintergrund des Kalten Krieges gering. Erst mit der Versenkung der Rainbow Warrior 1985 und dem Reaktorunglück von Tschernobyl 1986 erwachte die öffentliche Meinung; Proteste und Streiks nahmen zu und gipfelten am 6. September 1995, einen Tag nach dem ersten Test der von CHIRAC angekündigten Serie, in der Inbrandsetzung des internationalen Flughafens in Faa'a (vgl. VRIES/SEUR 1997, S. 159).

Die weiteren Auseinandersetzungen verliefen friedlicher, wobei internationale Umweltgruppen und einheimische Aktivisten zunächst eine Allianz zu gegenseitigem Nutzen bildeten.

\footnotetext{
${ }^{122}$ Proteste gegen die französischen Atomtests gingen u. a. von den Unterzeichnerstaaten des Vertrages von Rarotonga aus, die jegliche militärische Aktivität im nuklearen Bereich verurteilen.
} 
Insbesondere durch die Anwesenheit von Greenpeace erlangten z. B. die Unabhängigkeitspartei Tavini Huiraatira von Oscar TEMARU oder die NGO Hiti Tau die Aufmerksamkeit der

Weltmedien. Dies veranlasste Gaston FLOSSE zu der Kritik, Greenpeace lasse sich instrumentalisieren für politische Ziele der Unabhängigkeitsbewegung. Greenpeace distanzierte sich entschieden von den Ausschreitungen des 6.9.95 und hatte gleichwohl auch seinen Nutzen von der Allianz mit lokalen Gruppen:

„CONKLIN and GRAHAM argue that ,traditional communities' have become an important weapon in the hands of evironmental groups. The environmentalists need the indigenous population because words such as bio-diversity, radiation, geological instability do not mean anything to most people and cannot be easily shown on television. Indigenous people can provide the human face to such scientific abstractions as radiation, biodiversity etc." (s. BRYSK 1994, S. 34)

Greenpeace war mit seiner Professionalität den lokalen Gruppen weit überlegen und nutzte die Medienpräsenz zunehmend für sich allein, zumal die Einheimischen an positiver Bewertung in den Medien verloren:

„With the increased politicisation of the struggle the image of the ,environmental noble savage' came to be replaced in the eyes of the media with that of a Polynesian shanty town activist on a scooter with a Heineken six-pack who ,misuses' the nuclear tests and the media attention to riot, destroy official French buildings and demand political independence.“(s. VRIES/SEUR 1997, S. 165)

\subsubsection{Auswirkungen der Nukleartests}

Neben dem überdimensionalen Tertiärisierungseffekt der Wirtschaft Französisch-Polynesiens durch die Errichtung des CEP, sind eine damit verbundene Überlastung der bestehenden und erweiterten Infrastruktur, Migrationswellen in das urbane Zentrum Papeetes ${ }^{123}$ in der Hoffnung auf Teilhabe am künstlichen Wirtschaftsboom mit den entsprechenden Folgewirkungen (Verstärkung des ohnehin bestehenden Stadt-Land-Gefälles, Auflösung traditioneller Familienstrukturen, Wohnungsnot und Slumbildung), sowie eine zunehmende Korruption vorzugsweise im Verwaltungssektor zu beobachten (vgl. TETIARAHI 1989a, S. 86). Dementsprechend hat Französisch-Polynesien eine der höchsten Urbanisierungsraten im pazifischen Raum (Anteil der in Städten, hier vorzugsweise Papeete, lebenden Bevölkerung in Relation zur Gesamtbevölkerung; vgl. SHINEBERG 1988, S. 78 sowie Kap. 6.1.4). Die hier erwähnten Auswirkungen auf das Siedlungsbild werden besonders deutlich in einem Vorort von Papeete, in Faa'a. Die Behörden kommen mit der Gewährleistung infrastruktureller Grundbedürfnisse (Wasseranschluss, Strom, Verkehrsverbindung) in den dortigen

\footnotetext{
${ }^{123}$ Das überproportionale Wachstum Papeetes dokumentiert TETIARAHI, G: Papeete: un exemple de croissance urbaine accélérée. In: Cahiers d’Outre Mer. Bordeaux: 1983. Heft 4, S. 324-372.
} 
Marginalsiedlungen nicht nach. Die daraus resultierende soziale Unzufriedenheit manifestiert sich u. a. in einem großen Zulauf für die FLP (Front de Libération de la Polynésie), deren Vorsitzender Oscar TEMARU zudem Bürgermeister von Faa'a ist ${ }^{124}$ (vgl. Kap. 6.1.5 und 6.4.2). Diese überwiegend negativen Effekte werden durch die zunächst positiven Effekte der Schaffung neuer Ausbildungs ${ }^{125}$ - und Arbeitsplätze nicht nur im Rahmen des CEP, sondern auch im verstärkt forcierten Tourismus und im durch Tourismus und CEP induzierten Bausektor (vgl. LUCAS 1989, S. 108 und Kap. 6.1.3) nicht aufgehoben, da die Qualität der Ausbildungs- und Arbeitsplätze und damit die entsprechenden Einkommenseffekte zu Gunsten der nichtautochthonen Minderheiten ausfallen (vgl. Kap. 6.3.3, 6.3.5 und 6.1.6).

Die Abhängigkeit von französischen Geldern, die im Zusammenhang des CEP flossen, führte zu einer wirtschaftlichen Abhängigkeit (vgl. auch Kap. 6.1.3), die eine politische Unabhängigkeit nur unter großen Verlusten erlauben würden:

„In Polynesia, the Tahitian People is a reality, but its economic base is too narrow to envisage any radical change in status in the short term, without a sharp fall in living standards for the great majority" (DOUMENGE 1988, S. 156).

Der CEP war maßgeblich daran beteiligt, dass sich Französisch-Polynesien zu einer dependenten Transferökonomie wandelte:

„Das frühere Gleichgewicht in der Not wurde von einem Ungleichgewicht im relativen Wohlstand abgelöst. Die Ursache für das außenwirtschaftliche Defizit liegt in Frankreichs überseeischer Integrations- und Entwicklungspolitik. Für Maurice (1986:82f.) waren es die staatlichen Aufträge, die zu einer überdimensionierten Nachfrage nach Investitions- und Gebrauchsgütern führten. Für deren Produktion waren die lokalen Wirtschaften nicht eingerichtet. Der verstärkte Rekurs auf Importe war somit vorgezeichnet. Diese These zeichnet jedoch nur einen Teil der Wirklichkeit. Folgenschwerer war wohl die Ausdehnung des öffentlichen Dienstes. Die dort gezahlten hohen Gehälter stimulierten die Abwanderung aus den traditionellen Produktionsbereichen. [...] Als Konsequenz stiegen die Lohnkosten auch im Privatsektor, eine Entwicklung, die weder durch Rentabilisierungsmassnahmen noch durch eine Produktverlagerung auf höherwertige Güter voll aufgefangen werden konnte. Ganze Exportbranchen verloren so gegenüber den regionalen Mitanbietern ihre Konkurrenzfähigkeit.“(s. JADIN 1994, S. 137)

Diese Entwicklung wird durchaus konträr bewertet. Während JADIN (1994) in dem Modell der dependenten Transferökonomie durchaus auch eine geschickte Anpassung der TOM in Relation zu ihren sonstigen ökonomischen Möglichkeiten sieht, feiert POIRINE (1995 und 1996) es gar als perfekte Lösung. Die Stimmen der Kritiker (TETIARAHI, DELIUS) verweisen in diesem

\footnotetext{
${ }^{124}$ Bezeichnend in diesem Zusammenhang ist auch die von Oscar TEMARU initiierte Errichtung eines im Stile der alten polynesischen Marae gehaltenen Monuments am Ortseingang von Faa'a: „A la mémoire des héros de Faa'a morts en 1844 au cours des combats contre les soldats français pour protéger leur île et indépendance"“ (s. CHESNEAUX 1987, S. 158).

${ }^{125}$ Die Schaffung von Ausbildungsplätzen wurde besonders im technischen Bereich, hier insbesondere im Bausektor und Kfz-Bereich induziert (vgl. SHINEBERG 1988, S. 79).
} 
Zusammenhang insbesondere auf die extrem ungleiche Partizipation der verschiedenen ethnischen Gruppen an diesem Prozess, in dem die Maohi wiederum die geringsten Vorteile daraus ziehen (können).

Problematisch ist in jedem Fall, dass die artifizielle wirtschaftliche Situation kein günstiges Klima zur Entfaltung endogener Produktivkräfte schafft. Initiativen auf neuen wirtschaftlichen Gebieten, wie z. B. touristische Mikroprojekte werden durch dieses Umfeld nicht begünstigt (vgl. hierzu ausführlich Kap. 6.5 und 6.6).

Seit 1966 werden von der französischen Regierung keinerlei Gesundheits- und Todesursachenstatistiken über Französisch-Polynesien veröffentlicht ${ }^{126}$, so dass sich die tatsächlichen und potentiellen gesundheitlichen und ökologischen Auswirkungen auf Grund der mangelnden Information im Bereich der Spekulation bewegen müssen. Einige unten aufgeführte Tatsachen lassen allerdings dennoch entsprechende Rückschlüsse (insbesondere, indem man Vergleiche zu den Studien über die Testgebiete der USA in Nevada und Mikronesien anstellt, da hier überproportional erhöhte Krebsraten (Nevada), sowie für Mikronesien typische Früh- und Spätschäden wie Abmagerung, Haarausfall, Missbildungen bei Neugeborenen, Totgeburten, Schilddrüsenerkrankungen, Tumore festzustellen sind) zu:

- $\quad$ am 11.09.1966 wird ein atmosphärischer Test durchgeführt, obwohl Wind aus östlicher Richtung vorherrscht, da die Anwesenheit von Staatspräsident de Gaulle, der den Test beobachten wollte, keinen weiteren Aufschub zuließ. In der Folge maß das neuseeländische nationale Strahlenschutzlabor einen radioaktiven Niederschlag von 135.000 Picocurie noch auf den Samoainseln (ca. 2000 km entfernt).

- $\quad$ nach Aussagen der französischen Regierung verbleiben nur 95\% der frei werdenden Radioaktivität bei unterirdischen Tests in den Sprenglöchern.

- Die Krebsrate in Französisch-Polynesien entspricht im Durchschnitt der eines westlichen Industrielandes. Ein direkter Zusammenhang zwischen Atomtests und Krebsrate wurde bis jetzt noch nicht wissenschaftlich nachgewiesen. VIGNERON (1989, S. 913 ff.) geht allerdings davon aus, dass höchstens 50\% der Krebsfälle in Französisch-Polynesien

\footnotetext{
${ }^{126}$ Die einzigen Veröffentlichungen, die in Bezug auf Strahlungsbelastung, die in Französisch-Polynesien von der französischen Regierung publiziert wurden, waren die jährlichen Berichte an die UNSCEAR (United Nations Scientific Committee on the Effects of Atomic Radiation), die Fallout-Tabellen enthielten, welche auf Grund der geringen Aussagekraft der Daten (und vermutlich bewusster Auslassungen und Fälschungen) für weitere wissenschaftliche Aussagen ungeeignet sind (vgl. DANIELSSON 1988, S. 272).
} 
erfasst werden. Als Ursachen für die Krebserkrankungen werden für Lungenkrebs der hohe Tabakkonsum (Ende der 60er Jahre: höchster Pro-Kopf-Verbrauch, Ursache hierfür die hohe Anzahl Soldaten), für Krebs im oberen Verdauungstrakt der hohe Alkoholkonsum, für Leber- und Hautkrebs vorwiegend die schlechte Lebensqualität in Papeete angegeben.

- $\quad$ die Erkrankungsraten an Ciguatera ${ }^{127}$ erfuhren in den Jahren 1960 bis 1984 einen extremen Anstieg: Die höchsten Raten im Zeitraum 1972-75 erreichten den zehnfachen Wert (bis zu 1200 Fälle auf 100.000 Einwohner pro Jahr) der Rate von 1960, wobei in Bezug auf die einzelnen Inselgruppen (Fälle pro 100.000 Einwohner im Zeitraum 19601984) die räumliche Verteilung wie folgt aussieht:

\begin{tabular}{|l|c|}
\hline \hline Archipel & $\begin{array}{c}\text { Durchschnittliche, jährliche } \\
\text { Erkrankungsrate je 100 000 Einwohner, } \\
1960-84\end{array}$ \\
\hline Gambier & 22700 \\
\hline Marquesas & 4300 \\
\hline Tuamotu & 1700 \\
\hline Gesellschaftsinseln & 500 \\
\hline Austral & 100 \\
\hline
\end{tabular}

Tab. 5, nach RUFF 1989, S. 203

Der Zusammenhang zwischen Ciguatera-Anstieg und Aktivitäten, die das Ökosystem massiv und langfristig schädigen, wie z. B. Errichtung militärischer Infrastruktur und

\footnotetext{
${ }^{127}$ „Ciguatera (vgl. auch Anl. 22 im Anhang) ist eine durch das Toxin der Alge namens Ciguatera ausgelöste Erkrankung. Die Alge lebt natürlicherweise auf Korallenbänken und befindet sich üblicherweise, wie dies auch von anderen giftigen Organismen bekannt ist (giftige Schlangen etc.) in einem ökologischen Gleichgewicht. Wird dieses Gleichgewicht jedoch gestört, so kann sich die Alge überproportional vermehren und damit zum Problem werden. Gestört werden Korallenriffe insbesondere durch mechanische Einwirkungen, beispielsweise Erschütterungen, Erdbeben, bauliche Maßnahmen. ... Ciguatera produziert ein Toxin, das sich über die Nahrungskette Plankton - Fisch anreichert und schließlich in den menschlichen Organismus gelangt. ... Infolge allergischer Reaktionen sind Todesfälle beschrieben“" (s. WRESKY 1987, S. 52).

„Ciguatera most commonly presents as an acute self-limited syndrome of vomiting, diarrhoea, and abdominal pain, accompanied by sensory and/or motor disturbances. Weakness may necessitate ventilatory support. Bradydysrhythmias, myocardial depression, and vasomotor collapse may occur. Ciguatera during pregnancy may result in abortion, premature labour, and neurological disease in the new-born, and the disease may be transmitted by breast-feeding. Ciguatera is occasionally fatal, but more commonly it runs for weeks, month, or years, with constitutional symptoms ..., no treatment is of proven efficacy. Subsequent attacks tend to be more severe than first attacks, and symptoms may recur with ingestion of non-toxic fish, alcohol, and other foods, or with factors such as intercurrent illness“ (s. RUFF 1989, S. 201).
} 
militärischer Manöver (Militärbasen, Raketeneinschläge, Testbeobachtungen, Hafeneinrichtungen, Flugplätze, Schiffs- und U-Bootbewegungen, Baggern, Schachtsprengungen, Bohrungen und Dumping), ist nicht nur für Französisch-Polynesien nachgewiesen. Bisher wurde allerdings keine Korrelation zwischen Radioaktivität und Ciguatera festgestellt, wobei dieser Zusammenhang auch kaum untersucht wurde (vgl. RUFF 1989, S. 201 ff. und RUFF 1990, S. 32-34).

Nach Untersuchungen des US-Physikers Norm BUSKE ,,sickern inzwischen radioaktive Substanzen aus dem Moruroaatoll ins Meer." ${ }^{128}$ Seine Messdaten gewann er anhand der schon vorliegenden Proben des COUSTEAU-Teams (vgl. Kap. 5.1.4): Wies COUSTEAU nur Caesium-134 nach, welches nach Aussagen vom CEP noch aus der Zeit der atmosphärischen Tests stammt, so wurden durch BUSKEs Untersuchungen in zwei der vierzehn Proben auch Caesium-134, welches nicht zu den radioaktiven Spaltprodukten von Atombombenexplosionen gehört, entdeckt: „Das Caesium-134, so vermutet BUSKE, entwich dem Beton, mit dem alle Bombenschächte vor der Explosion versiegelt werden. Beton birgt eine natürliche Caesium-Variante (Caesium-133), aus der bei nuklearen Explosionen der radioaktive Vetter mit der Massenzahl 134 entsteht" (Moruroa. Großes Geheimnis. in: DER SPIEGEL 41/90, S. 266). Zu vermuten ist nach BUSKE weiterhin, dass die radioaktiven Spaltprodukte Kobalt-60 und Strontium-90 entsprechend entweichen können. Dies findet weitere Bestätigung durch die Ergebnisse der mit dem Greenpeaceschiff Rainbow Warrior II - umgeben von französischen Kriegsschiffen durchgeführten Tests (ebenfalls mit BUSKE an Bord ${ }^{129}$ ), die Caesium- $134^{130}$ und Kobalt60 außerhalb der 12-Meilen-Zone Moruroas im November 1990 nachwiesen (GARRET 1990, S. 3 und WISE 1991, S. 2) und deren Überprüfung eingeladene Militärtechniker verweigerten (DANIELSSON 1991, S. 3).

\footnotetext{
${ }^{128}$ Cesium-134 at Moruroa. Search technical services. September 1990. Zitiert nach Moruroa. Großes Geheimnis. in: DER SPIEGEL 41/90, S. 262.
}

\footnotetext{
${ }^{129}$ Vgl. hierzu ausführlich: BUSKE, Norm: Radioactivity in plankton outside the 12-mile Exclusion Zone of the French Nuclear Test Site. Report of the 1990 Scientific Mission of the Rainbow Warrior. Davenport, 1991.

${ }^{130}$ RIBBE und TOMCZAK (1990, S. 536-542) simulieren mit einem Rechnermodell die Verteilung von Caesium137 nach einem Atomtest in Französisch-Polynesien und spekulieren über die potentiellen Auswirkungen auf die marine Umwelt.
} 
Fangataufa wird nach der Explosion einer Wasserstoffbombe 1968 wegen zu großer radioaktiver Verseuchung aufgegeben. Im selben Jahr wird im Zuge eines atmosphärischen Tests die Bevölkerung der 120 km nördlich von Moruroa gelegenen Insel Tureia radioaktiv verseucht (vgl. DELIUS 1986a, S. 158).

Die GREENPEACE-Studie Testimonies. Witnesses of French nuclear testing in the South Pacific (Greenpeace International, August 1990) beinhaltet eine Sammlung von Berichten ehemaliger polynesischer CEP-Mitarbeiter auf Moruroa und Fangataufa. Die hier trotz französischer Geheimhaltungspolitik dokumentierten Aussagen sprechen von unzureichenden Sicherheitsvorkehrungen beim Einsatz der einheimischen Hilfskräfte, was auch Todesfälle zur Folge hatte, vom Verbot, in der Lagune Moruroas zu fischen, und den entsprechenden Symptomen, die auftraten, wenn diese Fische trotzdem gegessen wurden, vom Verschwinden von Arbeitern, die schwer erkrankten, oder Schwerkranken, die nur gegen eine Unterschrift, die sie zur strikten Geheimhaltung verpflichtete, medizinisch in Paris behandelt wurden, von einer hohen Rate tot oder behindert geborener Kinder der Frauen polynesischer Arbeiter auf Moruroa und Fangataufa und auch in der Region der Mangarevainseln.

Prof. Dr. Eckhard GRIMMEL (Institut für Geographie der Universität Hamburg) beschreibt in einem Auszug aus einer Studie die Folgen der französischen Atomtest im Südpazifik (Hamburg 1985), wobei er zu dem Schluss kommt, dass

\footnotetext{
„die Mururoainsel auf Grund ihrer für Endlagerungszwecke ungünstigen geologischen Struktur und ihrer zusätzlichen atomaren Zerrüttung weder einen mittelfristigen ( $<500$ Jahre) noch einen langfristigen ( $>500$ Jahre) Abschluss der in ihren Gesteinsuntergrund eingebrachten Radionuklide vom Meer und somit von der Biosphäre gewährleistet. Jeder weitere Sprengtest würde nicht nur zusätzliche Radionuklide einbringen, sondern auch das ohnehin schon sehr schlechte Isolationspotential noch weiter reduzieren."
}

- Die 1997 erschienene Studie Moruroa and Us von VRIES/SEUR unterstützt die Aussagen der früheren GREENPEACE-Studie Testimonies. Witnesses of French nuclear testing in the South Pacific und führt durch eine detaillierte Befragung unter 737 ehemaligen polynesischen Arbeitern des Testgeländes weitere Beweise für die Schäden an Mensch und Natur durch die Testserien an. Die Studie wurde ins Tahitische übersetzt und von der Evangelischen Kirche in Französisch-Polynesien veröffentlicht. Ein Follow-up Committee bestehend aus Mitgliedern Hiti Taus und der Evangelischen Kirche wird weitere Treffen mit früheren Arbeitern des Testgeländes organisieren und versuchen, den Zugang zu den Akten, die die 
Bedingungen auf Moruroa beschreiben, zu erwirken (vgl. EUROPE-PACIFIC SOLIDARITY BULLETIN Nr. 2., 2000, S. 5).

- In den Jahren 1998/1999 gab es gleich zwei Gutachten, die zu einer sehr unterschiedlichen Beurteilung kamen: Während die von Frankreich beauftragte Untersuchung der Internationalen Atomenergie-Agentur nur eine geringe radioaktive Verseuchung bescheinigte, bezeichnet die „Independent Research and Information Commission on Radioactivity“ ihr Untersuchungsergebnis als eine erhebliche Gefährdung für die Bevölkerung (vgl. pazifik aktuell, Mai 1998 und Mai 1999).

- Am 20. Februar 1999 fand das Kolloquium „Essais nucléaires françaises en Polynésie: exigence de vérité et propositions pour l'avenir“" unter Teilnahme von Vertretern der evangelischen Kirche, Nichtregierungsorganisationen, des Centre de documentation et de recherche sur la paix et les conflits, den Grünen und Vertretern des französischen Parlaments in Frankreich statt. Insbesondere die Commission de recherche et d'information indépendantes sur la radioactivité legte neue Beweise für die Unzulänglichkeit der von der französischen Regierung finanzierten wissenschaftlichen Untersuchungen und eigene Erhebungen vor (vgl. CASTANIER 1999).

- $\quad$ Letztendlich lässt das Zurückhalten von Datenmaterial durch die französische Regierung nicht unbedingt auf deren Irrelevanz schließen, denn:

\footnotetext{
„Why should radiobiological data on the effects of the tests on seafood, marine life, vegetation and on the health of people on Moruroa, Fangataufa and neighbouring islands be classified as defence secrets, if there is nothing to hide?" (GARRET und ROBIE 1990, S. 2).
}

\subsubsection{Die ,après-CEP“'-Diskussion}

Seit 1992, mit Bekanntgabe des Atomtest-Moratoriums, und ganz aktuell wieder 1996 mit der endgültigen Einstellung der Tests ${ }^{131}$ gewann die ,après-CEP“-Diskussion an Dynamik. Vor dem Hintergrund, dass Frankreich seine Transferzahlungen jetzt einstellen oder massiv zurückfahren könnte, begann die Suche nach wirtschaftlichen Alternativen zur „CEP-Ökonomie“. Eng

\footnotetext{
${ }^{131} 1998$ raitifizierte Frankreich den 1996 von der UN-Vollversammlung verabschiedeten Vertrag über ein völliges Verbot von Atomtests (s. pazifik aktuell Mai 1998, S. 10 f).
} 
verbunden mit wirtschaftlichen Fragestellungen sind kulturelle und soziale Belange der Bevölkerung.

Einer der führenden Ökonomen auf diesem Gebiet, Bernard POIRINE, schließt eine ökonomische Entwicklung via Substitution der Importe aus, da entsprechende inländische Ressourcen nicht in ausreichendem Maße vorhanden sind und die Abhängigkeit von außerhalb inzwischen viel zu stark ist (vgl. POIRINE 1996, S. 129 f.). Nach dem Theorem der Komparativen Kostenvorteile ${ }^{132}$ sollte sich die Exportwirtschaft Französisch-Polynesiens ausrichten:

„Ceci rend absolument nécessaire la spécialisation et la recherche d'un avantage comparatif à l'exportation. Dans les économies insulaires, il n'y a pas de croissance rapide possible, en dehors de celle impulsée par une rente administrative ou militaire, si les exportations ne constituent pas l'activité principale, la locomotive de l'économie insulaire, qu'il s'agisse d'exportation de biens, de services financiers, ou de services touristiques." (s. POIRINE 1996, S. 130)

POIRINE spricht sich daher insbesondere für die Förderung der Sektoren Tourismus und Perlenzucht aus. Gleichzeitig betont er - insbesondere für Französisch-Polynesien - die Relevanz der traditionellen Kultur, die auf Grund der Verbundenheit im Gemeinwohl einem rein kapitalistischen Gewinnstreben nicht zugetan sei. Die Maohi verhalten sich ganz und gar nicht als homo oeconomicus und orientieren sich nicht so stark an materiellem Reichtum wie Europäer. Der Einbezug traditionellen, kollektiven Wirtschaftens (Kopra, Vanille, Perlen) und die Stärkung polynesischer, kultureller Eigenständigkeit sind wichtige Faktoren in seiner ökonomischen Argumentation (vgl. POIRINE 1995, S. 263 ff.).

1992 begann aus Anlass des Moratoriums und dem damit von der Mehrheit der Bevölkerung befürchteten baldigen Rückgang von Frankreichs Transferzahlungen unter Einbezug verschiedener gesellschaftlicher Gruppen die Diskussion um einen „Pacte de Progrès“ zur Zukunft Französisch-Polynesiens. Er wurde 1994 in der Nationalversammlung verabschiedet und sah verstärkt Investitionen in einzelnen Sektoren (u. a. im Tourismus) vor:

\footnotetext{
${ }^{132}$ Das Theorem der Komparativen Kostenvorteile (nach D. Ricardo) ,erklärt, welche Nationen mit welchen Gütern vorteilhaft int. Handelsbeziehungen unterhalten (sollten) und erlaubt damit, Aussagen über die Produktions- und Handelsstruktur und den Außenhandelsgewinn zu treffen. Es kommt dabei nicht auf die Existenz absoluter Kostenunterschiede an, etwa derart, dass Land 1 das Gut A kostengünstiger produzieren kann als das Land 2 und dieses dafür das Gut B kostengünstiger produziert als das Land 1, beide Länder sich folglich auf die jeweils absolut kostengünstigste Produktion spezialisieren und entsprechende Gütermengen miteinander austauschen, so dass das Konsumniveau nach Aufnahme des int. Handels in beiden Ländern höher ist als zuvor. Die zentrale Aussage des Theorems der Komparativen Kostenvorteile besteht darin, dass es selbst dann für beide Seiten zu vorteilhaftem Handel kommt, wenn z. B. Land 1 sowohl das Gut A als auch das Gut B kostengünstiger produzieren kann als Land 2, die Kostendifferenzen jedoch unterschiedlich hoch sind. Das Land 1 muss sich auf den Export solcher Güter spezialisieren, die es mit den geringsten relativen Kosten produzieren kann, ebenso Land 2“(s. NOHLEN 1989, S. 389).
} 
„Es handelt sich hierbei um ein Rahmenabkommen, das die Entwicklungslinien und - modalitäten des Territoriums für die nächsten zehn Jahre umreißt. Als erstes entwicklungspolitisches Grundsatzdokument eines Überseegebietes weist es über den unverbindlichen Rahmen einer Diskussion hinaus und gibt konkrete Aufschlüsse über die Richtung, in die sich die Kooperation zwischen Metropole und Übersee in Zukunft bewegen könnte.“" (s. JADIN 1994, S. 199)

Die von ca. 350 Personen in 38 Arbeitsgruppen erarbeiteten Ergebnisse folgten der Grundidee des Pacte de Progrès, die Abhängigkeit von den Transferzahlungen zu verringern und die lokalen Kräfte zu mobilisieren, und bestanden in der Folge u. a. aus Forderungen nach Förderung von Wirtschaft und Infrastruktur, Schaffung von Arbeitsplätzen, Verbesserung der sozialen Absicherungen und des Gesundheitswesens, Verringerungen der Einkommensunterschiede, Familienplanung, Verbesserung von Ausbildung und Forschung (Pacte de Progrès 1993, S. 8 f zitiert nach JADIN 1994, S. 200 f.). Die Französische Regierung verpflichtete sich im Gegenzug zu Sonderzahlungen, um den Umbau der Wirtschaft zu ermöglichen.

Diesem technokratischen Ansatz standen aber keine durchdachten Konzepte gegenüber, so dass das Geld nicht unbedingt sinnvoll ausgegeben wurde und strukturelle Probleme bestehen blieben (vgl. CHESNEAUX 1995, S. 86 ff. und S. 145). Der Pacte de Progrès war darüber hinaus konzeptionell nicht neu, teilweise wurden einfach Abschnitte aus der territorialen Planung übernommen. Das eigentliche Ziel, die Transferzahlungen der französischen Regierung auch weiterhin zu sichern, wurde erreicht (vgl. JADIN 1994, S. 204).

Präsident FLOSSE tritt in der ,,après-CEP“-Diskussion insbesondere für eine Inwertsetzung touristischer Potentiale ein (Landschaftspflege, Restaurierung von archäologischen Stätten, Bau von weiteren Hotelanlagen) und den Ausbau der Perlenzucht als Eckpfeiler einer Volkswirtschaft, die voraussichtlich ab 2005 ohne hohe Transferzahlungen Frankreichs auskommen muss (vgl. VRIES/SEUR 1997, S. 194).

Während bei den politischen Oppositionsparteien die ,après-CEP“-Diskussion eine Variation über die Frage der politischen Unabhängigkeit ist, gehen verschiedene Nichtregierungsorganisationen einen anderen Weg: Auf den Gebieten Landwirtschaft (Vanille, Kopra, Perlen), Produktion (Monoï) und Dienstleistungen (Tourismus) werden dezentral Kleinstprojekte von Basisgruppen initiiert und durchgeführt, die ihre Anschubfinanzierung durch ausländische Geberorganisationen über das Netzwerk der Einheimischenorganisation Hiti Tau erhalten. Der Erfolg dieser Mikroprojekte lässt sich noch nicht abschließend beurteilen, da das Netzwerk Hiti Tau (vgl. hierzu ausführlich Kap. 6.6.1) erst 1992 gegründet wurde und die Konsummuster längst westlich geprägt sind: 
„Tous ces projets économiques, mis en place récemment, ont encore à faire leurs preuves. Ils sont modestes et fragiles, non seulement parce qu'ils reposent souvent sur des initiatives individuelles ou familiales, mais parce que le climat social ambiant pousse à la consommation plus excessive encore à Tahiti qu'en métropole. Même dans les ONG, la fascination pour la high-tech et la consommation, n'est pas véritablement remise en cause: le mode de vie généré par le système-CEP reste encore le modèle et les propositions économiques alternatives ne réussissent pas toujours à le relativiser.“ (s. CHESNEAUX 1995, S. 140)

\subsubsection{Zwischenbilanz}

Zusammenfassend lässt sich feststellen, dass alle oben beschriebenen fünf Kulturelemente der autochthonen Bevölkerung als akkulturiert bzw. assimiliert bezeichnet werden können (was GAUGUIN zu seiner Zeit schon intuitiv erfasste und in seiner Kunst umsetzte (vgl. Kap. 6.4.5)). Der Grad der Akkulturation variiert dabei nicht nur in Bezug auf die einzelnen oben beschriebenen Faktoren, sondern auch bezüglich des Raumes: So sind die Bereiche Wirtschaft und Gesellschaftsstruktur stärker akkulturiert als das Recht und dieses wiederum viel stärker als Religion und Sprache. Man erinnert sich alter Rechte (insbesondere in Bezug auf die Landrechte, vgl. Kap. 6.2.2.5) und die Sprache der Autochthonen, über die sie sich heute fast ausschließlich definieren (vgl. Kap. 6.2.2.4) und von den anderen ethnischen Gruppen abgrenzen (können), überdauerte den Prozess der Akkulturation weitgehend und erhält in neuer Zeit sogar Förderung und Auftrieb:

„Grâce à sa langue, le polynésien, bien que dominé socialement et économiquement par les autres ethnies, ne se sent pas un étranger dans son propre pays." (O’REILLY 1982, S. 311 f.).

In welchem Ausmaß alte Muster früherer Glaubensvorstellungen in der heutigen Spiritualität der Ureinwohner in neuer Mischung mit christlichen Werten oder in Reinform existent sind, ist noch nirgends empirisch erfasst worden. Faktisch bestehen solche Muster aber nach wie vor weiter und sind in den periphereren Gebieten Französisch-Polynesiens stärker.

Auch der Grad der Akkulturation nimmt analog nahezu radial zu deren Zentrum Tahiti (Papeete) ab, wodurch die kulturelle Einheit Französisch-Polynesiens auch innerhalb kleinerer Teilregionen (z. B. Gesellschaftsinseln) als zerstört gelten kann. Reste traditioneller Strukturen finden sich umso eher, je räumlich-peripherer das Gebiet zu Papeete ist (vgl. BELL 1973, S. 103 ff.). Auch heute ist die Persistenz gegen europäische Einflüsse auf Grund des geringeren Informationsflusses eher in entlegenen Gebieten Französisch-Polynesiens gegeben. Ausnahmen bilden in Bezug auf die Effekte, die durch die Atomtests hervorgerufen werden, die „Subzentren" der Akkulturation: Moruroa und Fangataufa (vgl. Kap. 6.3.6). Eine weitere Verzerrung des von Tahiti 
ausgehenden Akkulturationsgefälles stellen die neueren Zentren des Tourismus dar: Moorea, Bora Bora und Huahine.

Des Weiteren zählen zu den räumlichen Konsequenzen der Akkulturation die Verlagerung des alten Kulturzentrums von Raiatea nach Tahiti, die Entstehung einer bis heute dualen Wirtschaftsstruktur (traditionelle Subsistenzwirtschaft besteht noch vereinzelt in der Peripherie), sowie regionale Disparitäten, da in Bezug auf Tahiti als Fokus aller wirtschaftlichen Aktivität das Hinterland weitgehend nur noch Versorgungsfunktionen ausübt. Zudem ist die subsistente Selbstversorgung einer Importabhängigkeit von $80 \%$ in Bezug auf Nahrungsmittel gewichen (vgl. Kap. 3.3 und DELIUS 1986a, S. 170).

Die zahlenmäßige Zunahme der nicht-autochthonen Bevölkerung schreitet zwar weiterhin fort, wird allerdings weder kurz- noch mittelfristig zu einer Verringerung des prozentualen Anteils der Maohi an der Gesamtbevölkerung führen, da diese den Zuwachs der Nicht-Autochthonen durch ein höheres Bevölkerungswachstum bisher prozentual ausgleichen konnten.

Zweiseitig ist die Rolle der Mission im Akkulturationsprozess: Einerseits führte sie - auch unter Manipulation der bestehenden Gesellschaftsstruktur - zur religiösen (in Ansätzen auch wirtschaftlichen und rechtlichen) Assimilierung der Autochthonen, andererseits sind der Mission bedeutende ethnographische Daten (hier sind insbesondere die Missionare DAVIS, ELLIS und ORSMOND zu nennen) und die Kodifizierung und damit Konservierung der autochthonen Sprache zu verdanken. Auf dieser Grundlage können unter anderem die heutigen Revitalisierungsbestrebungen operieren (vgl. Kap. 6.4). Interessant in diesem Zusammenhang ist auch die heutige Bedeutung insbesondere der evangelischen Kirche:

sie ,,bemüht sich besonders, die Traditionen und Werte der Maohi zu bewahren und die weitere Zerstörung der sozialen Beziehungen zwischen den Ureinwohnern zu verhindern. Angesichts wachsender materieller Zwänge und kultureller Entwurzelung stellt die Religion heute immer mehr ein Bindeglied zwischen den Maohi dar" (DELIUS 1990, S. 17).

Die hier dargestellten Konsequenzen der Akkulturation sind zum einen nicht untypisch für den pazifischen Raum, zum anderen noch nicht der Höhepunkt des akkulturativen Prozesses, der erst in der extremen militärischen Präsenz der Europäer, in der „Degradierung" FranzösischPolynesiens zum Entwicklungsland und in wachsenden ethnisch-sozialen Konflikten - dargestellt im folgenden Kapitel - sichtbar wird.

Sind ethnische Konflikte (z. B. Neukaledonien, Fidschi) und entwicklungsländertypische Strukturen (fast alle Staaten des pazifischen Inselraumes) kein Spezifikum FranzösischPolynesiens ${ }^{133}$, so übte (und übt) der CEP in Bezug auf die akkulturative Wirkung der

\footnotetext{
${ }^{133} \mathrm{vgl}$. hierzu ausführlich pogrom, Zeitschrift für bedrohte Völker, Nr. 134, 135 und 146.
} 
europäischen Einflussnahme einen immensen Verstärkungseffekt aus, was zur Verschärfung sämtlicher schon bestehender sozialer und räumlicher Disparitäten führte. Dies - insbesondere unter Berücksichtigung der Tatsache, dass im Zuge der europäischen Integration eine weitere Forcierung dieser Disparitäten zu befürchten ist - macht Französisch-Polynesien zu einem Sonderfall der Akkulturation: Zum einen werden die durch die Nuklearversuche bedingten akkulturativen Effekte in ihrer Stärke nur noch von den amerikanischen Versuchsgebieten im Pazifik übertroffen (z. B. Bikini, Eniwetok, Rongelap, Utirik), zum anderen sind die in den Kapiteln 6.3 dargestellten Konsequenzen der Akkulturation nur auf ihrem vorläufigen Höhepunkt angelangt, dass heißt der Akkulturationsprozess setzt sich über die Gegenwart hinaus weiterhin fort.

Abgesehen davon steht die Argumentation für einen Erhalt der französischen force de frappe auf tönernen Füßen, da die erklärten strategischen Ziele dieser Sicherheitspolitik,

„le principe de la 'dissuasion nucléaire indépendante' et la volonté de s'affirmer comme 'puissance mondiale moyenne’" (CHESNEAUX 1987, S. 131)

angesichts der derzeitigen weltpolitischen Lage übertrieben erscheinen, so dass

„,'est finalement Moruroa lui-même qui justifie Moruroa" (CHESNEAUX 1987, 1987, S. 132).

Angesichts der erheblichen militärischen Einflussnahme Frankreichs im Gebiet FranzösischPolynesiens, sowie dessen gesamtkultureller Überformung entbehrt der von CHESNEAUX (1987) geprägte Begriff der Franconésie nicht einer gewissen Grundlage.

Frankreichs Politik gegenüber Gegnern des nuklearen Testprogramms, seien es die Einwohner Französisch-Polynesiens selbst, die pazifischen Nachbarstaaten oder internationale Umweltorganisationen, lässt sich auf zwei Strategien reduzieren: Ignorieren oder „kaufen" (vgl. FIRTH 1987, S. 94).

Die einzige Form des Einlenkens mit Rücksichtnahme auf regionale Interessen bestand in der Verlagerung der Tests unter die Erde.

Die inzwischen fast restlos aufgeklärte Versenkung der Rainbow Warrior der internationalen Umweltschutzorganisation Greenpeace durch den französischen Geheimdienst am 10. Juli 1985 im Hafen von Auckland, Neuseeland ${ }^{134}$, wurde weltweit als terroristischer Akt seitens des französischen Staates gewertet und erreichte nicht das beabsichtigte, sondern das gegenteilige Ziel: Einen Zustrom an Sympathisanten für die Gegner des Testprogramms.

\footnotetext{
${ }^{134}$ Der genaue Vorgang des Geschehens wurde mehrfach beschrieben, z. B. bei FIRTH 1987, S. 83-93 und
} 
Das bis heute permanente Wirken der Akkulturationsfaktoren führte zur endgültigen kulturellen Identitätskrise der autochthonen Bevölkerung, die der Maohi RAAPOTO (1988, S. 3-4) in folgende Worte fasst:

\begin{abstract}
„What am I? Nothing, not yet; perhaps tomorrow. No, a civil status is no longer sufficient for me. I need another dimension. My name is written with the letters of the Latin alphabet, but my life will be written with my breath and the breath of all those who suffer from the lack of being. Surely, we are not; not yet.

They call me Tahitian, but I refuse this. I am not Tahitian. This denomination has an essentially demagogic, touristic, snobbish and rubbish vocation. 'Tahitian' is the pareu shirt whose material is printed in Lyon or in Japan; it's the Marquesian tiki called Tahitian as well as the tapa of Tonga, Uvea, or Samoa sold in Papeete under the Tahitian label, and which any foreigner is proud to exhibit in his apartment, somewhere in Europe, in the anonymity of a neighbourhood in France, Germany or elsewhere, to prove to whoever is willing to believe it that he's been to Tahiti. Tahiti is an exotic product made by the Western World for the consumption of their fellow-countrymen [...] An entire people is dying comfortably, without words, as in a silent movie, because others make the effort of speaking for them, on their behalf. In Tahiti, you spend your time electing beauty queens, drawing lotteries and getting your soul drunk. Tomorrow you'll find specimens of Tahitians exhibited under glass in museums with labels and bank-notes stuffing their mouth to make sure they'll never speak again".
\end{abstract}

(weitere Reflexionen zur Gegenwartsbetrachtung Französisch-Polynesiens vgl. Anl. $21 \mathrm{im}$ Anhang).

Der Vollständigkeit halber muss erwähnt werden, dass die Mehrheit der Bevölkerung die

Wiederaufnahme der Tests in 1995/1996 begrüßte, da dies wieder gut bezahlte

Arbeitsmöglichkeiten versprach. Natürlich ist dies auch im Zusammenhang mit der Des- bzw.

Nichtinformation durch die Französische Regierung zu sehen. Den Protesten gegen die

Atomtests, die in den europäischen Medien wie der Aufstand der gesamten Urbevölkerung

wirkten, schloss sich in Wahrheit nur ein geringer Prozentsatz der Gesamtbevölkerung an.

Erst vor dem Hintergrund der Atomtestproblematik sind die in der Folge dargestellten

Reaktionen auf den Akkulturationsprozess nachzuvollziehen und die Suche nach Alternativen zur dependenten Transferökonomie im richtigen Rahmen zu sehen. 


\section{$\underline{\text { 6.4 Reaktionsformen auf den akkulturativen Prozess in Französisch-Polynesien }}$}

\subsubsection{Renaissance Culturelle?}

Eine natürliche Reaktion auf Akkulturationsdruck und Assimilationserscheinungen sind entsprechende Gegenbewegungen (sog. „Indigenisierungsreaktionen" in Form von Revitalisierungsbewegungen ${ }^{135}$, oder Nationalismus meist in Verbindung mit den entsprechenden Unabhängigkeitsbewegungen, vgl. auch Kap. 6.3.6). Es stellt sich die Frage nach den Möglichkeiten, die sich angesichts der aktuellen Problematik ergeben, als polynesische Kultur zu überleben, eine Brücke zwischen Tradition und Moderne zu schlagen, die Möglichkeit, die eigene Identität neu zu definieren, um die Realität zu bewältigen. Da eine Vollassimilation nur bei Genozid oder Ethnozid ${ }^{136}$ gegeben ist, ergeben sich im Wesentlichen drei mögliche Reaktionen auf einen Kulturschock:

- Deprivation (voller Durchbruch einer kulturellen Identitätskrise mit den typischen Folgen: Passivität, Fatalismus, soziale Marginalisierung)

- $\quad$ Revitalisierung, dass heißt bewusste Rückkehr zu wirklichen oder subjektiv angenommenen original, indigenen Lebens- und Denkweisen, allerdings meist unter Vermischung mit Elementen der überformenden Kultur (vgl. HIRSCHBERG 1988, S. 35) - $\quad$ Neudefinition der eigenen kulturellen Identität unter Einbezug der realen Gegebenheiten Nach den ersten misslungenen Widerstandsversuchen gegen den akkulturativen Druck durch die mamaia-Bewegung (Form der Revitalisierung, vgl. auch Kap. 6.2.2.2) und durch den von 1844

\footnotetext{
${ }^{135}$ Der Vielzahl der verschiedenen Manifestationen von Revitalisationsbewegungen liegt der Grundgedanke der Wiederidentifizierung und -definition einer überformten Kultur über Elemente aus der eigenen Vergangenheit zu Grunde. Erwähnt seien nativistische Bewegungen, ,in denen ausgewählte Aspekte der bodenständigen Kultur bewusst wiederbelebt werden“ “.., was bewirken soll, „,dass die herrschenden unbefriedigenden Lebensbedingungen in einer für die Menschen befriedigenden Weise verändert werden. Die in der Erinnerung verherrlichten Lebensumstände werden zu Symbolen eines Zeitalters, in der die Gesellschaft glücklich war. Die Wiederbelebung traditioneller Kulturelemente ist ein Mittel, die Selbstachtung und das Zusammengehörigkeitsgefühl der Menschen wiederherzustellen, aufrecht zu erhalten und sich von den Mitgliedern anderer Gesellschaften abzuheben“ und millenaristischen oder chilistische Bewegungen, ,in denen die Hoffnung einer bedrängten Gesellschaft auf Befreiung von einer fremden Übermacht in einer dem christlichen Gedankengut entlehnten Vorstellung von einem zukünftigen glücklichen tausendjährigen Reich Ausdruck findet" (s. HIRSCHBERG 1988, S. 336 und S. 312). Weitere Formen von Revitalisationsbewegungen können z. B. adventistische Bewegungen, Cargo-Kulte, Krisenkulte, messianistische und prophetische Bewegungen, Revolutionen sowie Selbstfindungs- und separatistische Bewegungen sein.

${ }^{136}$ Bezeichnet der Begriff Genozid die physische Vernichtung einer Kultur, so bedeutet Ethnozid vollständigen Kulturverlust bei physischem Überleben z. B. durch Sklavenhandel, Zerstörung ursprünglicher politische Formen der Selbstbestimmung, Umerziehung, Wandlung der Wertvorstellungen, Assimilation oder Vertreibung etc... (vgl. HIRSCHBERG 1988, S. 136).
} 
bis 1846 dauernden Guerillakampf autochthoner Widerständler gegen die Protektoratserklärung ist in Französisch-Polynesien eine längere, mehr oder weniger stark ausgeprägte Deprivation festzustellen, die sich in zunehmender Passivität und entsprechendem Fatalismus der autochthonen Bevölkerung zeigte. Wie in anderen Kolonien Frankreichs existierte eine Zeit lang ein Miniaturparlament mit 18 Sitzen, der Conseil General, wobei die Autochthonen nur 3 Vertreter stellen durfte, was die Mitbestimmungsmöglichkeiten der autochthonen Bevölkerungsmehrheit zu dieser Zeit nur unwesentlich erweiterte (vgl. DANIELSSON 1983, S. 195). Seit Ende des zweiten Weltkrieges in ersten Ansätzen und in verstärktem Maße seit Ende der 80er Jahre zeichnet sich allerdings zunehmend das Phänomen einer Renaissance Culturelle, einem neueren Versuch der Identitätsfindung ab, die anhand folgender Aspekte/Erscheinungen untersucht werden soll:

Engagement der bestehenden Parteien, Kulturinstitute und sonstiger Interessengruppen bezüglich einer Wiederbelebung autochthonen Kulturgutes, sowie die Möglichkeit einer Neudefinition der kulturellen Identität der Maohi.

\subsubsection{Politik}

Nach der Umwandlung des kolonialen Status in den eines Überseeterritoriums (s. o.) machte die Bevölkerung mit einiger Zeitverzögerung von den neuen demokratischen Möglichkeiten Gebrauch: Bildeten sich zunächst nur zwei große Parteien heraus, die RDPT (Rassemblement Démocratique du Peuple Tahitien, aus frühen Oppositionsbewegungen 1950 in eine offizielle Partei umgewandelt ${ }^{137}$ ) und deren Opposition, die Union Tahitienne, so ist ab 1962 ein verstärkter Parteienpluralismus in Reaktion auf ein differenzierteres Meinungsspektrum und verstärktem Interesse der Bevölkerung an politischem Engagement durch Abspaltung und Neugründung festzustellen, von denen die meisten kleineren Parteien meist ebenso schnell verschwanden wie sie entstanden waren (vgl. ADLOFF und THOMPSON 1971, S. 50 f.; TAGUPA 1983, S. 38-57). Nach der Ablehnung der Unabhängigkeit im Jahre 1958 (s. o., die Gründe für diese Entscheidung waren das bei einer Unabhängigkeit notwendige Erheben einer

\footnotetext{
${ }^{137}$ Der Sprecher der RDPT, PPOUNÁA A OOPA, gewann 1953 in den ersten Wahlen zur Territorialversammlung 18 von 25 Sitzen. Auf Grund der begrenzten Regierungsmöglichkeiten der Territorialversammlung, sowie interner Streitigkeiten konnten die beabsichtigten Reformprogramme (Klärung der Landrechtsansprüche, Einführung einer Einkommenssteuer als Regulativ der Umverteilung etc...) nicht im beabsichtigten Maße durchgeführt werden. Am 8. Oktober 1958, kurz nach dem Unabhängigkeitsreferendum, wurde das Kabinett POUVANÁAs durch de Gaulle aufgelöst und POUVANÁA selbst vordergründig der Brandstiftung angeklagt und zu acht Jahren Gefängnis in Frankreich sowie anschließenden fünfzehn Jahren Verbannung aus Französisch-Polynesien verurteilt. Die ausschlaggebenden Gründe hierfür lagen vermutlich in einem zu großen Widerstandspotential gegen die französische Zentralmacht, die eine massive Behinderung der Errichtung des CEP befürchtete (vgl. DANIELSSON 1983, S. 199 ff.).
} 
bis dahin inexistenten Einkommenssteuer ${ }^{138}$ sowie die Frage des wirtschaftlichen Überlebens) war man sich auch kurz vor der Errichtung des CEP in der Politik darüber einig, dass Französisch-Polynesien

„,will remain an integral part of the French Republic, while admitting an evolution in the statute of the territory" (ADLOFF und THOMPSON 1971, S. 51).

Der Errichtung des CEP ging eine großzügige Wirtschaftshilfe in Höhe von 100 Millionen Franc CFP (Cour de Franc Pacifique) seitens der französischen Regierung voraus, woraufhin die ersten Einwände auf die Verkündung de Gaulles, CEP zu realisieren, entsprechend zurückhaltend ausfielen und de GAULLE ausdrücklich versicherte, dass alle notwendigen Sicherheitsmaßnahmen ergriffen würden (vgl. ADLOFF und THOMSON 1971, S. 53).

Nach ADLOFF und THOMPSON (1971) gab die Errichtung des CEP den entscheidenden Anstoß zu verschärften politischen Gegenbewegungen gegen die französische Dominanz, die sich zum Teil mit kulturellen Renaissance-Bewegungen vermischten. Der steigende Lebensstandard, die Schaffung von gut bezahlten Arbeitsplätzen im CEP durch den von Frankreich gesteuerten wirtschaftlichen Aufschwung sowie das Informationsdefizit bezüglich der Tests ließen allerdings nach einer anfänglichen Protestwelle den größten Teil der Bevölkerung wieder zunehmend in Passivität und Fatalismus (zwischenzeitliche Deprivation) verfallen. Dennoch blieb die Debatte um Unabhängigkeit und Autonomiestatus, seit 1950 geführt, immer ein zentraler Punkt in der politischen Diskussion in Französisch-Polynesien, ohne jedoch zunächst für die Bevölkerung zur Orientierung und Entscheidungsfindung beizutragen. In den 70er und frühen 80er Jahren jedoch manifestierte sich der politische Widerstand gegen die Fortführung der Tests gekoppelt mit der Forderung nach völliger interner Autonomie des Territoriums, deren Hauptvertreter die Führer der Koalition Front Uni, Francis SANFORT von der Te E'a Api und John Teariki der Te Here Ai'a waren. Die Meinung der französischen Regierung wurde von den konservativen Parteien vertreten, insbesondere der Tahoeraa Huiraatira unter Gaston FLOSSE, die sich 1976 mit der damals neu entstandenen RPR (Rassemblement pour la République) unter Jacques CHIRAC vereinigt. Zunächst unter SANFORT (1977), später noch zweimal unter FLOSSE (1984 und 1996) gelang ein Ausbau des Autonomiestatus. SANFORT ${ }^{139}$ erreichte dies unter Androhung des verstärkten

\footnotetext{
${ }^{138}$ Zum Steuersystem in Französisch-Polynesien vgl. JEHLE 1983, S. 358-360.

${ }^{139}$ Weder SANFORT noch andere Realpolitiker Französisch-Polynesiens (mit Ausnahme der in dieser Frage radikalen FLP Oscar TEMARUs, s. o.) vertraten jemals überzeugt die völlige Unabhängigkeit FranzösischPolynesiens von Frankreich. SANFORTs folgende Äußerung, die sich zwar auf das 1977iger Statut bezieht, hat in
} 
Einsatzes für die totale Unabhängigkeit, FLOSSE durch geschickte Verhandlungen mit der sozialistischen Regierung, die derzeit schon die Dezentralisierung der Departements vorantrieb und weitere Entscheidungsbefugnisse der Zentralregierung in Paris nach Französisch-Polynesien übertrug, nicht ohne das Wissen, sich auf diese Weise die Loyalität der dortigen Machthaber zu sichern (vgl. SHINEBERG 1988, S. 88 ff.).

Die heutige politische Situation in Französisch-Polynesien entzieht sich auf Grund einer schwer durchschaubaren Parteienlandschaft, einer weit verbreiteten Korruption, einer eingeschränkten Pressefreiheit ${ }^{140}$ und einer anderen Handhabe der demokratischen Möglichkeiten durch die Bevölkerung (Persönlichkeiten werden höher bewertet als Wahlprogramme, die Massenmedien Presse, Radio und Fernsehen ${ }^{141}$ haben eine starke - bei Wahlen oft ausschlaggebende Suggestivwirkung) weitgehend dem Verständnis des europäischen Beobachters. Als heute bedeutendste Parteien (vgl. Kap. 6.1.5) seien noch einmal die konservative RPR (Tahoeraa Huiraatira), geführt von Gaston FLOSSE, die von Oscar TEMARU geleitete sozialistische Befreiungsfront Polynesiens (FLP, Tavini Huriaatira) und die liberal-konservative Nouvelle Parti von Emile VERNAUDON genannt. Als einflussreiche Einzelpersonen in der Politik, die unbedeutenden Splitterparteien angehören, sind die Politiker BRAUN-ORTEGA und Daniel MILLAUD zu nennen (vgl. DELIUS 1990, S. 12 und IH-Länder aktuell 1998).

Die klassischen Bezeichnungen „konservativ", „liberal”, ,sozialistisch" sind mit Vorsicht zu interpretieren, da die Parteiprogramme - falls existent - und die politische Zielsetzung gemäß dem politischen Klima im Zeitablauf durchaus in extremem Maße variieren können. In Bezug auf eine Wiederbelebung des Kulturgutes der Maohi ist zunächst die erste rein polynesische Partei unter POUVANAA (s. o.) zu nennen, die sich konkret mit den damaligen realen gesetzlichen und demokratischen Möglichkeiten für eine verstärkte Vertretung autochthoner Interessen einsetzte.

ihrer Kernaussage in dieser Form bis heute Gültigkeit:

„The present statute ... has not yet been fully exploited. It should have been adopted ten years ago here as well as in New Caledonia and the New Hebrides ... For us, and for them independence (would be) anarchy. Everyone here would be wanting power, the 3000 employees of the Atomic Testing Centre would be out of a job. Public servants would not have their splendid salaries. We would have a flag, a national anthem, we would speak Tahitian, but thousands would be marching in the Avenue Bruat, demanding that we give them something to eat" (SHINEBERG 1988, S. 89).

\footnotetext{
${ }^{140}$ Die beiden wichtigsten Tageszeitungen (La Dépeche de Tahiti, Aufl. ca. 16.000; Les Nouvelles de Tahiti, Aufl. ca. 4000) befinden sich im Besitz des als konservativ geltenden Robert Hersant. Wöchentlich erscheinen die Tahiti Sun Press (Aufl. ca. 4000) und die Satirezeitung Le Canard Tahitien (vgl. IH-Länder aktuell 1/91, S. 2).

${ }^{141}$ In Französisch und Tahitisch sendet täglich Radio-Télé-Tahiti, Radio Télévision Francaise d'Outre-Mer betreibt seit 1965 eine Fernsehstation. Im Jahre 1988 gab es in Französisch-Polynesien 80.000 Radio- und 35.000 registrierte Fernsehgeräte (vgl. IH-Länder aktuell 1/91, S. 2).
} 
Zu gewalttätigen Ausschreitungen (Bombenlegung und Ermordung französischer Geschäftsleute) kam es unter den Anhängern der für die völlige Unabhängigkeit eintretenden Te Ta'ata Tahiti Tiama, deren Führer Charlie CHING (Maohi, ein Neffe POUVANAAs) aus diesen Gründen zu zwanzig Jahren Haft verurteilt wurde.

1982 kam es zur Einsetzung einer provisorischen Maohi-Regierung durch Tetua MAI, mit eigenem „Premierminister", Polizei und offiziellen Fahrzeugen, die solange von den französischen Behörden nicht ernst genommen wurde, bis sie begann, durch „Regierungsreisen" Kontakte zu knüpfen und Sympathien zu erwerben bei anderen pazifischen Regierungen, und ihre Mitglieder daraufhin zu Gefängnisstrafen verurteilt wurden (vgl. DANIELSSON 1983, S. 214).

Unter den heutigen bedeutenden Parteien (s. o.) treten die Ia Mana Te Nunaa und die Front de la Libération de la Polynésie (FLP) unter Oscar TEMARU für eine völlige Unabhängigkeit von Frankreich ein. Die Ia Mana Te Nunaa (,lasst das Volk die Macht ergreifen") wurde 1975 gegründet, versteht sich als sozialistisch, aber unabhängig von den Sozialisten Frankreichs. Die FLP, die insbesondere seit 1995/1996 eine wachsende Unterstützung der autochthonen Bevölkerungsschichten erfährt, unterscheidet sich in Bezug auf die grundlegenden Ziele ${ }^{142}$ nicht von der Ia Mana Te Nunaa, setzt aber ihre Schwerpunkte verstärkt in den Bereichen der eigenständigen wirtschaftlichen Entwicklung: Abschaffung der Atomtests, um insbesondere den Tourismussektor verstärkt ausbauen zu können, intensivere Nutzung der naturräumlichen Ressourcen (Fischfang, Landwirtschaft, Phosphatabbau), um den Handel damit zu forcieren (vgl. JADIN 1990, S. 15).

Da sich die FLP zudem auf das traditionelle Landrecht der Maohi beruft, werden im Rahmen der Parteiaktionen auch Landbesetzungen vorgenommen.

Uneinigkeit über politische Vorgehensweisen, sowie Streitigkeiten in Bezug auf die Erreichung der im Wesentlichen identischen politischen Ziele stehen einer Zusammenarbeit der drei Parteien (FLP, Ia Mana te Nunaa, Te Ta'ata Tahiti Tiama), die in stärkstem Maße die Interessen der autochthonen Bevölkerung vertreten, im Wege (PIERMONT 1985, S. 4).

Nach TEHEIURA (1984, S. 110) sollte sich eine politique culturelle im Wesentlichen entlang dreier Achsen orientieren:

\footnotetext{
${ }^{142}$ Oscar TEMARU sprach sich in diesem Zusammenhang in Anlehnung an die UN-Resolution Nr. 1514 (Recht auf Unabhängigkeit für koloniale Staaten) für ein Maohi Polynesia oder Maohinui (vgl. Kap. 7) aus (vgl. TEMARU 1988, S. 282 f.).
} 
,,- $\quad$ la conservation et la mise en valeur du patrimoine;

- $\quad$ la promotion de la création et le développement d'actions nouvelles avec élargissement du champ culturel à de nouveaux contenus, à de nouvelles expressions, à de nouvelles catégories de personnes; le renforcement du réseau culturel notamment en direction des archipels."

Die evangelische Kirche, sowie die Umweltschutzorganisation Ia Ora te natura und die „Liga der polynesischen Frauen" beziehen z. B. durch ihre Verurteilung der Atomtests politisch Position und können - da sie mehrheitlich durch Maohi vertreten werden - als Kulturträger der Autochthonen gelten (vgl. DELIUS 1986b).

Neu auf dem politischen Parkett ist die grüne Partei Heiura les Verts, die Fragen des Naturschutzes mit Fragen der kulturellen Identität der Maohi verbindet (vgl. TERIITAU 1999, S. 55). Seit ihrer Gründung 1997 konnte die Partei Heiura les Verts ihren extrem minoritären Status kaum verbessern, bringt aber erstmalig Umweltthemen in die politische Diskussion.

\subsubsection{Kulturelle Einrichtungen}

1917 wurde in Papeete die Société d'Études Océaniennes mit dem Ziel der genauen anthropologischen, ethnologischen, philologischen und historischen Erfassung des Kulturgutes der Maohi gegründet. Über lange Zeit europäischen Gelehrten vorbehalten dient die Société dank ihrer detaillierten Dokumentation heute auch polynesischen Forschern und Bürgern als Informationsquelle über ihre traditionelle Kultur (vgl. LAVONDES 1985, S. 145). Das frühere Musée de Papeete wurde ab 1963 u. a. unter der Mitwirkung des Centre ORSTOM und des Office de Développement du Tourisme umgewandelt in das heutige Musée de Tahiti et des Îles, welches zusammen mit dem 1980 offiziell ins Leben gerufenen Centre Polynésien des Sciences Humaines ,, Te Anavaharau” (dem Musée de Tahiti et des Illes angeschlossen) durch einen lokalen Verwaltungsrat repräsentiert wird, in dem die Société in starkem Maße vertreten ist. Auch hier ist die Kulturkonservierung unter zweierlei Aspekten zu sehen: Zum einen besteht die Gefahr der folkloristischen Degradierung für rein touristische Zwecke, zum anderen existieren die finanziellen und wissenschaftlichen Mittel, die Kulturgüter überhaupt erst zu erhalten (vgl. LAVONDES 1985, S. 146).

Des Weiteren ist die räumliche Dezentralisierung mit der Errichtung kleinerer Museen auf den Inseln Moorea und Raiatea, sowie den Marquesasinseln geplant. Im Zeitraum 1970-1980 wurden nicht zuletzt im Zuge der Erweiterung der Autonomie Französisch-Polynesiens folgende weitere Kulturinstitute ins Leben gerufen: 
- $\quad$ l'Académie Tahitienne (gegründet 1972), die sich mit der Erhaltung und Pflege der polynesischen Sprache beschäftigt ${ }^{143}$ und auch neuere Literatur auf diesem Gebiet fördert

- $\quad$ l'Office Territorial d'Action Culturelle (OTAC)

- $\quad$ le Conservatoire de Musique et d'Arts plastique

- $\quad$ le Centre Polynésien des Métiers d'Art

Auf den Marquesasinseln entstand die vorwiegend von Jugendlichen getragene Kulturgruppe Motu Haka.

Insgesamt gesehen lässt sich durch die Gründung von Institutionen, die in zunehmendem Maße auch von den Maohi selbst verwaltet und gefördert werden, ein positiver Selbstverstärkereffekt feststellen, da diese Institutionen ein verstärktes Interesse am eigenen Kulturgut nach sich ziehen, was wiederum kulturelle Aktivitäten und die Gründung neuer Interessensgemeinschaften auf diesem Gebiet begünstigt. Verschiedene kulturelle Gruppen orientieren sich bei der Rekonstruktion von Tänzen, Musik und Sportarten an dem in Museen und Bibliotheken dokumentierten Material (vgl. LAVONDES, S. 147 f.).

Der Académie Tahitienne und dem 1981 ins Leben gerufenen Centre de recherches et de réflexion sur la langue maohi (Träger ist die evangelische Kirche) ist es zu verdanken, dass die Sprache der Autochthonen bewahrt und gefördert wird, wobei die evangelische Kirche hierbei vorwiegend durch Eigeninteressen motiviert ist:

„En Polynésie, le maohi est toujours resté vigoureux. L'Église évangélique l'a conservé pour le culte, l'école du dimanche, les publication religieuses. On l'enseigne à l'école, il est présent chaque soir avec les actualités télévisées, il s'adapte à la vie moderne ...; tantôt on ,tahitianise' des mots français" (CHESNEAUX 1987, S. 155).

Im Mai 1987 wurde die Université Française du Pacifique gegründet. Einige Lehrstühle wirken durch Forschung und Lehre auf den Gebieten der Sprache, Geschichte und Literatur der Maohi ebenfalls bewahrend in Bezug auf deren Kulturgut.

Bei allen oben genannten Einrichtungen handelt es sich um Institutionen, die von der Territorialverwaltung eingerichtet und auch weitgehend finanziert sind. L'Office Territorial d'Action Culturelle, le Conservatoire de Musique et d'Arts plastique, und le Centre Polynésien des Métiers d'Art dienen ganz klar der „Inwertsetzung“ autochthonen Kulturerbes zu touristischen Zwecken. Auf den Kunsthandwerkmärkten setzen sich diejenigen Modelle durch, die sich am besten verkaufen. Diese Form der Kulturförderung ist also durchaus fragwürdig. In diesem Zusammenhang ist auch das alljährliche Heiva zu betrachten: Zeitlich gleichgeschaltet mit den französischen Feierlichkeiten zum 14. Juli werden die Darbietungen in Tanz, Musik,

\footnotetext{
${ }^{143}$ U. a. erfolgt auch die Konservierung polynesischer Legenden auf Tonträgern (vgl. O’REILLY 1982, S. 312).
} 
Kunsthandwerk, Sport, Tätowierung, Feuerläufen, mündlichen Erzählungen (in der Tradition der oralen Literatur) und traditioneller Medizin einerseits als wichtigster Beitrag zum Erhalt der kulturellen Identität (Angelina BONNO, Kulturministerin, 1997) andererseits als ,prostitution culturelle“ (Gabriel TETIARAHI 1999 ${ }^{144}$ ) bezeichnet.

An der Basis ist seit Mitte der 90er Jahre ein Revival in polynesischer Namensgebung, der Tätowierung und polynesischen Tänzen zu beobachten. Dieses sind Beispiele eines spontanen, nicht gesteuerten Ausdrucks indigener Kultur.

\subsubsection{Kulturelle Identität der Maohi}

Trotz des Bestehens (meist staatlicher) zahlreicher kultureller Einrichtungen, wird der Identitätsverlust der Maohi nach wie vor von ihnen artikuliert.

RAAPOTO (1988, S. 4 ff.) gibt auf den in Kap. 6.3 dargestellten Identitätsverlust der Autochthonen selbst folgende Antwort:

„I am a maohi. It's the programme of my life“ ...,,To call oneself maohi is to follow the same process as that which implies the entire genealogy in Polynesia, that is to say that one can affirm with certainty that one isn't hutu painu, a foreigner“..., ,Maohi is the community of all those who claim to be of the same past, culture and language which constitute the common trunk and which will have the same destiny“.

Bewusst wird in Abgrenzung zu europäischen Bezeichnungen Tahitianer oder Polynesier der Begriff Maohi (vgl. Kap. 6.2.2) gewählt und in Anknüpfung an die Vergangenheit für die Zukunft neu definiert.

„Le problème tahitien est un problème de devenir total, politique, social, culturel. Le recours à la tradition peut, en vue de ce devenir, constituer un avantage si elle est porteuse d'un dynamisme, si elle n'est pas seulement passéisme.“(ROBINEAU 1984, S. 19)

„La culture est l'avenir, l'espérance du Polynésien, et je ne parle pas, ici, que de la culture traditionnelle, mais bien également de celle que nous connaissons tous aujourd'hui, la culture contemporaine." (Auszug aus einem Interview im Mai 1984 mit Jacques TEHEIURA, Conseiller de Gouvernement, Bereich Erziehung und Kultur in Französisch-Polynesien; in ethnies 8/9/10, 1989, S. 109)

„We are not preaching a 'return to the past'; there are always retrograde minds eager to accuse. If the imagination can be defined as the faculty to create something new from something old, then it is our duty to understand, to become impregnated with our past, our culture, our language, to create a new world in our image and in our dimension. It isn't a matter of replacing something old by something different" (RAAPOTO 1988, S. $6)$.

\footnotetext{
${ }^{144}$ Interview mit Gabriel TETIARAHI 1999
} 
Aus diesen Zitaten, die dem Problem der Identität der Maohi angesichts der gegenwärtigen Realität Ausdruck verleihen, spricht die Erkenntnis, dass ein Zurückdrehen der Zeit oder irreale Veränderungswünsche an die gegebenen Umstände nicht die Ansatzpunkte für eine Neudefinition der kulturellen Identität der Maohi sein können. Eine Zukunftsbewältigung via Vergangenheitsbewältigung ist nur dann sinnvoll, wenn die autochthone Kultur (z. B. durch wissenschaftliche Forschung) in allen ihren fünf Dimensionen (s. o.) für den Ist-Zustand - von den Maohi selbst - neu definiert wird und davon ausgehend das kulturelle Potential weiterentwickelt wird, ohne sich der Realität zu verschließen.

Die Fähigkeit auf einer bikulturellen ${ }^{145}$ Ebene zu agieren, gelingt zwar den demi (hierin liegt auch ein Großteil ihres gesellschaftlichen und wirtschaftlichen Erfolges begründet), in der Regel aber nicht den Maohi. Im Rahmen einer - auch von der Basis getragenen, wenn auch noch verhaltenen - Renaissance Culturelle wird sich zeigen, in welche Richtung sich die Maohikultur entwickelt. Sowohl in der Politik (Oscar TEMARU) als auch in kulturbewahrenden Einrichtungen (Centre Polynésien des Sciences Humaines und der Académie Tahitienne) bestehen für die dort mitwirkenden und/oder arbeitenden Maohi Möglichkeiten der Einflussnahme auf die zukünftige Entwicklung.

\subsubsection{Europäische Rezeption}

Im Zusammenhang mit der kulturellen Selbstbestimmung der Maohi ist es von Interesse, die gegenseitige Wahrnehmung von Europäern und Maohi zu betrachten.

Die Vorstellungen von einem Paradies auf Erden sind schon sehr lange in der Menschheitsgeschichte zu beobachten, sie sind viel älter als der Südseemythos, der solchen Vorstellungen nur einmal mehr Nahrung lieferte (vgl. hierzu ausführlich RITZ 1983):

Sie [die Suche nach dem irdischen Paradies] ist eine Art halluzinatorischer Urwunsch der Menschheit, der im märchenhaft bunten, sorglosen, leichten, fernen Anderswo von der großen Harmonie träumt. [...] Im Gegensatz zum spielerischen Umgang mit historisch und gesellschaftlich wandelbaren Idealen, ist das Prinzip Hoffnung eine todernste existentielle Konstante der menschlichen Natur, die permanent mit dem noch nicht erfüllten Urwunsch umgeht. (s. BÖRNER 1984, S. 121)

Die auf vorchristliche Quellen zurückgehende Beschreibung des Garten Edens in der Bibel, sowie ein „Goldenes Zeitalter“ oder die „Glückseligen Inseln“ griechischer Autoren enthalten das Motiv eines glücklichen und sorglosen Anfangszustandes der Menschheit, welches in der

\footnotetext{
${ }^{145}$ „Erlernen von zwei ähnlichen oder auch gegensätzlichen Wert- und Normsystemen“ (RAMASWAMY 1985, S. 176).
} 


\section{Renaissance insbesondere durch T. MORUS' Utopia und T. CAMPANELLAs Sonnenstaat} (deren idealisierte Staatsbeschreibung im übrigen auf Inseln angesiedelt sind) eine Weiterverarbeitung erfährt und durch den Beginn der Entdeckungsgeschichte neuen Auftrieb erhielt: Genau in die Zeit, in der der Fortschrittsoptimismus Europas (Aufschwung der Naturwissenschaften, industrielle Revolution) seine ersten Kritiker fand, fiel die Entdeckung der Gesellschaftsinseln. Weniger durch den Engländer WALLIS, aber in verstärktem Maße seit dem Franzosen BOUGAINVILLE wurde durch entsprechende Berichte (die in ihrer Ungenauigkeit oder Unter-/Übertreibung genug Raum für Interpretationen ließen, vgl. hierzu auch ROLIN 1979) der Südseemythos geschürt, aus dem sich eine willkommene Gegenwelt zu einem Europa schaffen ließ, das Intellektuelle wie folgt empfanden:

\footnotetext{
„Übel unglücklicher Staatsverfassung, Erniedrigung ganzer Völker, Zerstörung durch blutige Kriege und unzähliges Elend, das je den einen Menschen zum Knechte des anderen macht“ (HEERMANN 1987, S. 7).
}

Eine von drei Deutschen gegründete „Geheime Gesellschaft“ hielt diesem Negativbild Europas die verklärte Projektion einer besseren Welt entgegen, wobei sich der weit entfernte Raum (weit entfernt sowohl in Bezug auf die Anzahl der Kilometer als auch bezüglich des sachlichen Verstehens in Ermangelung entsprechender wissenschaftlich fundierter Beschreibungen und unter kritikloser Übernahme der ersten Berichte) der Südsee dafür eignete, zum größtmöglichen Kontrast zu der eigenen negierten Gesellschaft ausgebaut zu werden:

\footnotetext{
„Aber es bleibt uns unbenommen, das Freye zu suchen, wenn Erdstöße unsere Wohnung zusammenwerfen; unser Planet hat noch tausend Winkel, wo Freyheit und Zufriedenheit sich Tempel bauen können, wenn Europa ihnen zu enge wird. Tausend fruchtbare Täler bieten die fernen Gestade von Neuholland uns an; tausend üppige Fluren lachen uns auf den Inseln der Südsee, auf den Freundschafts-, Gesellschafts-, Marquesas-Eilanden entgegen; ewiger Frühling, herrlicher Boden, köstliche Früchte, wimmelnde Meere, eine elysische Natur, und eine politische Lage, die uns auf Jahrhunderte Freyheit garantiert, locken uns dort hin! Wer sollte träge genug seyn, in welchem der Wunsch nicht lebhaft rege würde: ,dort möcht' ich hin!'““ (HEERMANN 1987, S. 7).
}

Dieser Text aus dem Jahre 1806, hat inhaltlich nichts an Aktualität eingebüßt. In Reaktion auf den auch in den jetzigen westlichen Gesellschaftssystemen vorhandenen psychologischen Bedarf nach einem entsprechenden Gegenpol, einer „Antialltagswelt“, vermarktet die Tourismusbranche das Südseeklischee (gemäß dem Motto „das Paradies ist immer dort, wo wir gerade nicht sind“) mit dem erwarteten Erfolg und liegt damit auch langfristig im Trend (vgl. Anl. $23 \mathrm{im}$ Anhang und das Konzept der „Imaginären Geographie“ in Kap. 2.5).

Die intellektuelle Kritik am Europa des 18. und 19. Jahrhunderts setzt der Verarmung und Verelendung breiter Bevölkerungsschichten auch das idealisierte Bild eines besseren Menschen entgegen: Das Stereotyp des edlen Wilden fand seine mehrfache Bearbeitung bei verschiedenen Autoren, als deren bekanntester Vertreter ROUSSEAU gilt. Seine Mitte des 18. Jahrhunderts erschienenen Ausführungen zu diesem Thema waren ihrerseits bereits eine Reaktion auf das zwi- 
schenzeitlich schon existente Gegenbild zum edlen Wilden, nämlich dem „,rohen Barbaren“, der „als Beispiel für die längst überwundene Vorstufe der eigenen Geschichte“ und „,gelegentlich der Tierwelt näher als den fortschrittlichen Europäern“ angesehen wurde (zu dieser Strömung ist T. HOBBES (Leviathan) zu rechnen, aber auch DEFOEs Roman Robinson Crusoe; VOLTAIRE äußerte sich zunächst in ähnlicher Richtung, differenzierte dann allerdings sein Bild vom „Wilden“). Die europäische Rezeption der Entdeckungen unterliegt keinem reinen erkenntnisorientierten Selbstzweck, sondern ist auch immer Mittel zur Durchsetzung von Interessen:

„Der gegensätzlichen Beurteilung der Wilden in der Missionars- und Reiseliteratur des 17. und frühen 18. Jahrhunderts entsprechen ... in der theoretischen Verarbeitung ethnographischer Daten ... zwei entgegengesetzte Interessensrichtungen: Eine gesellschaftskritische, die von den großen Utopisten (s. o.) und von MONTAIGNE, von den Jesuiten-Missionaren und von LOHOTAN in Kraft gesetzten Tradition folgend, den gesellschaftlichen ,Naturzustand' der Wilden - wenn nunmehr auch in vornehmlich polemischer Absicht - zum positiven Gegenbild der eigenen Gesellschaftsordnung erklärt, und eine objektivistische, die sich - in Reflexion der historischen Erfahrung des Kolonialismus und in der Regel mit dem Ziel seiner ideologischen Legitimierung ... darum bemüht, Erklärungsmodelle für die Rückständigkeit der Wilden gegenüber den Zivilisierten zu finden“" (HEERMANN 1987, S. 13).

Auch diese Gedankengänge sind bis heute in mehrfacher Abwandlung existent: Gesellschaften, die nicht der euro-amerikanischen Zivilisationsnorm entsprechen, werden als „Entwicklungsländer“" (s. o.: objektivistische Richtung) bezeichnet und es mangelt nicht an Theoriegebäuden, diese zu erklären und für die notwendige Anpassung an den westlichen Standard zu plädieren (vgl. hierzu auch Kap. 6.1.7). Auf der anderen Seite existiert auch heute noch die gesellschaftskritische Richtung (s. o.), die via idealisierter Darstellung fremder Kulturen die westliche Überzivilisation ablehnt. STEIN (1984) fasst die Verklärung von Ureinwohnern in einer Essay-Sammlung Die Edlen Wilden zusammen.

Oft werden heute autochthone Gesellschaften auch zunehmend zu „Ökoheiligen“ stilisiert, der klassische „edle Wilde“ also zum „ecologically noble savage“ (REDFORD 1991, S. 46) erweitert, von dem man Lösungen insbesondere in Bezug auf die von den westlichen Industrienationen induzierte Umweltproblematik erhofft und erwartet.

Auch der „moderne“ Tourist lässt sich maßgeblich bei seiner Reisemotivation vom Südseeklischee leiten, die einsame Insel ist bis heute ein unschlagbares Ideal:

„Viele scheinen reif für die Insel zu sein, wollen einmal wie Robinson Crusoe leben. Möglichst zu zweit - auf einer einsamen Insel. [...] Der Traum von der Insel der Träume lässt sich noch steigern, wenn einem die Insel auch selbst gehört. Sich eine eigene Insel kaufen und im Land des Lächelns wieder aufwachen." (s. OPASCHOWSKI 1998, S. 14) 
In der Malerei ist Paul GAUGUIN als überragende Gestalt zu nennen. Auf der Flucht vor der Einengung durch die Normen des europäischen Bürgertums war er auf Grund chronischen Geldmangels in Tahiti gerade auf dieses angewiesen ${ }^{146}$. GAUGUIN stirbt 1903 auf Hiva Oa in Armut und Krankheit; das von ihm gesuchte Paradies fand er nur zeitweilig ${ }^{147}$, es existierte vorwiegend in seiner Vorstellungswelt, die sich in seiner Kunst manifestierte: In hochstilisierter Form versucht er, das Bild einer ursprünglichen Kultur der Einheimischen durch seine von seinen eigenen Projektionen durchsetzte Darstellung der Insulaner wiederaufleben zu lassen. Bei genauerer Betrachtung seiner Bilder (vgl. Anl. 24 im Anhang) fällt auf, dass die von ihm dargestellten Menschen niemals lachen:

„supine, defeated, despairing and beautiful, his people gaze in a reverie into the lost past. They have no hope at all. They see nothing but the broken stones of their marae, their fallen idols, the great legendary war-canoes with their tattooed warriors in their elaborate robes, the forgotten dances and rituals of the arioi. They ask, 'D'où venons-nous? Qui sommes-nous? Où allons-nous?' and the answer is silence.“ (MOOREHEAD 1966, S. 95).

Eine besonders ironische Verarbeitung findet das Thema des „Aussteigers“ in Georges SIMENONs Roman: Touriste de bananes ${ }^{148}$. Der Protagonist Oscar Donadieu möchte vor den Übeln der Zivilisation fliehen und auf Tahiti in einer einsamen Hütte leben:

„Il voulait fuir les hommes et vivre d'une vie simple, labourer peut-être, apprendre comme les indigènes, à capturer les poisson au harpon..." (SIMENON 1938, S. 53)

Sein Unternehmen scheitert genau an den Annehmlichkeiten der Zivilisation, die er hinter sich lassen wollte, und endet im Desaster.

Die halbdokumentarische Erzählung „Les Immémoriaux“ von Victor SEGALEN aus dem Jahre 1907 beschreibt den Niedergang und letztendlichen Verlust des oral tradierten Wissens durch die evangelische Mission. Als Bewunderer und Zeitgenosse GAUGUINs ${ }^{149}$ beschreibt er als Gegner von Mission und Kolonisation ein poesievolles, mystisches und leicht verklärtes Bild der Maohi-

\footnotetext{
${ }^{146}$ RITZ (1983, S. 22 ff. und S. 107 ff.) bezeichnet dies treffend als die bis heute existente „Aussteigerparadoxie“, dass heißt der Zivilisationsflüchtling wird gerade von dieser umso schneller mit aller Härte der Realität - meist bruchgelandet auf der untersten Stufe der sozialen Leiter - eingeholt und befindet sich in noch größerer Abhängigkeit von den Restprodukten seiner verlassenen zivilisatorischen Heimat im materiellen Abseits: „Sie suchten Archaik und enden in Primitivität. Rationales Bewusstsein, eine Errungenschaft des Fortschritts, wird mit diesem gänzlich verworfen. Sie bauen eine neue Arche Noah, um die Auserwählten vor der Sündflut der Moderne zu retten, aber die Mannschaft besteht aus menschlichen Wracks.“

${ }^{147}$ GAUGUIN zeichnete in seinem Buch Noa Noa ein verklärtes Bild Polynesiens. (vgl. RHODE 1988, S. 94)

148 „C'est une expression à nous désigner certains passagers qui partent pour les îles avec l'idée d'y vivre une vie naturelle, loin du monde, sans souci d'argent, en se nourrissant de bananes et de noix de coco..." (SIMENON 1938, S. 18)

${ }^{149}$ vgl. hierzu ausführlich SEGALAN 1975
} 
Kultur (vgl. SCEMLA 1986), die gegen das neue geschriebene Wort der Kirche, gegen die Bibel, verliert:

„Voici la terre Tahiti. Mais où sont les hommes, qui le peuplent? Ceux-ci...Ceux-là...Des hommes Maori? Je ne les connais plus: ils ont changé de peau.“ (SEGALEN 1985)

Einen Überblick über die Rezeption Tahitis in der französischen Literatur gibt MARGUERON 1989.

Von COOK bis in die heutige Zeit ist die europäische Rezeption Französisch-Polynesiens und seiner Bewohner von Missverständnissen geprägt. RIGO (1997) legt eindrucksvoll dar, dass sich die grundlegende Wahrnehmung der Europäer in Bezug auf die Maohi im Wesentlichen kaum geändert hat:

„Cela montre seulement qu'ils ne peuvent pas voir autrement qu'ils ne voient, qu'ils ne peuvent pas penser l'impensé. Comment ne pas être frappé par cette homogénéité de la vision occidentale quand on note qu'à plus de deux siècles de distance, elle appartient aussi bien à un pasteur anglican qu'a un voyageur agnostique et qu'elle décrit une réalité aussi différente que les Ma'ohi adorateurs d'Oro ou les habitants chrétiens de la Polynésie contemporaine? Les observateurs ont changé radicalement, les observés aussi, la vision est restée la même.“"(s. RIGO 1997, S. 162)

Nach RIGO (1997) und SAURA (1998) hält sich hartnäckig folgende, von Vorurteilen geprägte

Sicht der Maohi: Kindlich, nur in der Gegenwart lebend, unstet, oberflächlich, schüchtern, körperbetont, gerne und viel redend, gläubig, trinkfest, schlechte Tischsitten und arbeitsscheu.

Die Maohi selbst sehen sich nach SAURA (1998) insbesondere im Kontrast zu den Europäern als spirituell, Moralisten, gastfreundlich, tolerant und gewaltfrei.

Tahiti selbst bleibt bis in die heutige Zeit als Ort der Imagination bestehen:

„Es hat den Anschein, als sei das latente utopische Wunschdenken im europäischen Bewusstsein, oder besser im Unterbewusstsein, immer dann besonders empfänglich und sensitiert, wenn die Epoche dem Primat eines intellektuellen Ethos sich verschreibt. [...] Und die Rezeption Tahitis ist ein eklatantes Beispiel dafür, dass die aufklärerische Philosophie von der ethisch verantwortlichen Verwirklichung der Perfektibilität des Menschen seine Urwünsche, seine halluzinatorischen Bilder von glückseligem Leben an einem paradiesischen Ort nicht mehr ersetzen konnte. [...] Er dient vielmehr als Katalysator für die eigenen Vorstellungen und Bedürfnisse und wird in der Imagination zum idealen Ort. Tahiti, mit all dem, was es an paradiesischen Qualitäten zu versprechen schien und scheint, ist immer eine Metapher gewesen, eine Denkfigur, die mehr mit der Wirklichkeit der eignen Wünsche und Hoffnungen zu tun hat als mit der Realität.” (s. BÖRNER 1984, S. 153) 


\subsubsection{Rezeption des Bildes vom Europäer durch die Maohi}

Über die Rezeption der Europäer durch die indigenen Bevölkerung ist weit weniger bekannt, da weniger schriftlich fixiert wurde. Nach SAURA (1998) ist auch die Wahrnehmung der Europäer durch die Maohi teilweise verzerrt:

- $\quad$ die Franzosen werden nach wie vor als kolonisierende Eindringlinge empfunden

- $\quad$ im Gegenzug wird alles, was aus Hawaii (und den USA) kommt, insbesondere von der jungen Generation geschätzt (Musik, Kleidung, Handzeichen „hang loose“)

- $\quad$ Tahiti wird nicht wirklich als ein Teil Frankreichs betrachtet

- $\quad$ Europäer gelten als individualistisch und geizig, Franzosen insbesondere als zu intellektuell und geschwätzig

Ein wesentlicher Unterschied in der gegenseitigen Wahrnehmung ist, dass westliche Wissenschaftler oder Schriftsteller oft meinten, sie wüssten, wie die Kultur der Maohi zu verstehen sei (vgl. RIGO 1997), während die Maohi diesen Versuch gar nicht wirklich unternommen haben, und auch den Weißen das Verständnis für ihre Kultur absprechen:

„Toi, Européen, tu fais de notre passé ton métier, tu en vis alors que nous en mourons. De notre passé nous ne savons plus rien et le peu que nous en savons encore, nous ne te le dirons pas. Tu étudies des pierres, mais nous sommes ce que tu ne peux comprendre. Rechercher le passé pour qu'un Européen l'apprenne à nos enfants qui parlent plus tahitien nous ne le voulons pas. Je préfère encore pour eux les explications des vieux qui n'existent plus. Ils sauront ce que les vieux ont su et garderont la nostalgie de leur être..." (GÉRARD zitiert nach PUTIGNY 1993, S. 16)

Hierbei war und ist das Bild des Fremden immer ein äußerst differenziertes: Der Fremde (ratere $=$ Reisender) wurde wahrgenommen als Weißer (popa'a), Chinese (tinito) oder Schwarzer (siki). Die Zuordnung zu einer bestimmten Religionsgruppe oder Region stand vor dem Herkunftsland. So wird ein französischer Jude eher als Jude wahrgenommen, als als Franzose (farani), ein Bretone als Bretone etc. (vgl. SAURA 1998, S. 77f).

Ein Merkmal der gegenseitigen Wahrnehmung ist kurioser Weise der Geruch: Maohi beurteilen Europäer als nicht gut riechend und umgekehrt (vgl. SAURA 1998, S. 68). 


\subsubsection{Zwischenbilanz}

Bei der Betrachtung der oben dargestellten Bereiche einer Renaissance Culturelle fällt auf, dass die Ansätze zur einer Neubelebung der autochthonen Kultur vielfach vorhanden sind. Uneinigkeit in der Parteienlandschaft, eine geringe, zielgerichtete Organisation von Basisgruppen, vorwiegend staatlich unterstützte Kulturinstitute verhindern eine stärkere Renaissance Culturelle. Niemand wird der Aufgabe, die Kultur der Maohi ,als Ganzheit neu zu gestalten und durch endogene Kräfte zu reaktivieren“ (WALLACE 1956, S. 761 ff.), dass heißt im Sinne einer tatsächlichen Renaissance Culturelle, gerecht.

Überregionale Zusammenschlüsse (z. B. die Südpazifik Kommission ${ }^{150}$, deren Mitglied Französisch-Polynesien ist), die einen Austausch und eine Forcierung dieser Thematik über die jeweiligen Grenzen hinweg (vgl. TETIARAHI 1990a) ermöglichen, könnten von Nutzen sein. Nicht eindeutig geklärt ist das Verhältnis der einzelnen Bewegungen und Strömungen zum Tourismus ${ }^{151}$. Der hier auftretende Zielkonflikt (Gefahr der Folklorisierung autochthonen Kulturguts - Partizipation an positiven Wirtschaftseffekten) ist unzureichend gelöst.

Ebenso besteht keine eindeutige Antwort auf die Frage, ob eine Renaissance Culturelle mit der Unabhängigkeit Französisch-Polynesiens verknüpft sein muss, oder ob sie losgelöst davon realisierbar ist. Es fehlt die Initialzündung, die die Verwandlung von „Glaube und Werten aus dem kognitiven, passiven Zustand in handlungsaktives Verhalten“ (RAMASWAMY 1985, S. 178) ermöglicht.

Die gegenseitige kulturelle Wahrnehmung von Maohi und (vorwiegend) Europäern war und ist von gegenseitigen Vorurteilen überlagert, die auch in den Klischees der Vergangenheit verhaftet sind. Dies ändert sich mit der jungen Generation, die, geprägt insbesondere durch die Medien, sich überwiegend an amerikanischen Konsum- und Verhaltensmustern orientiert.

Eine Bewertung oder Standortbestimmung der Reaktionsformen auf den akkulturativen Prozess bleibt schwierig, da die aktuellen gesellschaftlichen Strömungen vielschichtig und oft auch konträr sind.

\footnotetext{
${ }^{150}$ Die Südpazifik Kommission ist im Rahmen einer Renaissance Culturelle insofern ein gutes Forum zum Austausch und zur Durchsetzung gemeinsamer Interessen, da sie nicht nur wirtschaftliche und soziale Aspekte des Pazifischen Raumes zu ihrem Themen- und Arbeitsgebiet zählt, sondern auch Pflege, Erhalt und Austausch autochthonen Kulturguts (vgl. RATH 1982, S. 14; STANLEY 1987, S. 57 f.; de SAIVRE 1989, S. 113-115).

${ }^{151}$, ,Kulturpolitik, die Brauchtum und Tradition nur bei offiziellen Festlichkeiten oder als Touristenattraktion erhält, aber aus der Lebenswirklichkeit verdrängt, führt in die Folklorisierung“ (RAMASWAMY 1985, S. 181).
} 


\section{$\underline{6.5}$ Tourismus in Französisch-Polynesien}

Der Tourismus wurde und wird als wirtschaftliches Lösungsmodell für kleine Inselökonomien gefeiert. In seinen kulturellen Effekten wird er allerdings meist überwiegend negativ bewertet, insbesondere dann, wenn er eine gewisse Quantität übersteigt. Vor dem Hintergrund der historischen und aktuellen Entwicklung in Französisch-Polynesien soll ein differenziertes Bild dieses Wirtschaftssektors und der daraus erwachsenden Möglichkeiten für die indigene Bevökerung gezeichnet werden.

Unzweifelhaft ist der Tourismus die wichtigste wirtschaftliche Ressource der Inseln FranzösischPolynesiens (vgl. Kap. 6.1.3). 75\% der Deviseneinnahmen und 60\% der Investitionen sind dem Tourismus zuzuschreiben. Der Export lokaler Produkte erbringt nur 25\% der Deviseneinnahmen (s. ITSTAT 1998, S. 194 ff.). Ob und insbesondere in welcher Form touristische Kapazität und Infrastruktur weiter ausgebaut werden sollen, ist - nicht nur für die unterschiedlichen ethnischen Gruppen - eine Streitfrage.

\subsubsection{Struktur und Tendenzen des Tourismus in Französisch-Polynesien}

Der Tourismus ${ }^{152}$ in Französisch-Polynesien expandiert seit Beendigung der Atomtests ständig. In 1998 stiegen die internationalen Touristenankünfte auf 188.933 (1997: 180.440 und 1996: 163.774). Sie stiegen damit seit 1985 (122.086) um ca. 50\%, wobei dieser Anstieg extreme Unregelmäßigkeiten aufweist, die direkt in Zusammenhang mit den Atomtests stehen. Das Moratorium 1992 ließ die Zahlen ebenso steigen wie sie die Wiederaufnahme der Tests 1995/1996 wieder sinken ließ. Insbesondere japanische Touristen reagierten diesbezüglich sehr empfindlich. Bemerkenswert ist auch, dass Testserien auf der Seite der Nachfragenden extrem schnell vergessen werden. Mit der endgültigen Einstellung der Tests setzte ein kräftiges Wachstum der Zahlen ein.

Die durchschnittliche Aufenthaltsdauer blieb in den letzten Jahren gleich bei ungefähr 12 Tagen, ebenso die Anzahl an Gästezimmern bei ca. 3000, während die Bettenauslastung mit 59,2 \% 1998 einen Höchststand erreichte (1997: 54,1\% und 1996: 53,3\%). Zu den 188.933 Touristen kommen noch ca. 14.000 Tagesausflügler von Kreuzfahrtschiffen und stop-overn hinzu. Ca. 80\% der Touristen fliegen Französisch-Polynesien direkt an, während ca. 20\% im Rahmen einer 
Rundreise kommen. Ebenfalls weitgehend unverändert blieb in den letzen Jahren die Rangliste der Herkunftsländer: Aus Frankreich kamen 1998 knapp mehr Touristen (55.764) als aus den USA (48.132), gefolgt von Japan (13.489), Italien (10.193) und Neuseeland (9.207). Australien, Deutschland, Neukaledonien, Großbritannien und Argentinien gehören des Weiteren zu den zehn wichtigsten Herkunftsländern, wobei Italien, die USA und Argentinien die größten Wachstumsraten aufweisen.

84,39\% der Touristen übernachteten 1998 in Hotels, die anderen bei Verwandten/Bekannten. Letztere haben mit ca. 25 Tagen eine wesentlich höhere durchschnittliche Aufenthaltsdauer. Ein äußerst geringer Anteil der Touristen (1175) übernachtete auf eigenen Yachten oder gemieteten Booten.

Das wachsende Angebot an Kreuzfahrtschiffen verfügte 1999 über folgende Kapazitäten:

$\begin{array}{llll}\text { Haumana } & \text { 21 Kabinen } & 42 \text { Betten } & \text { Dauer: } 3-7 \text { Tage } \\ \text { Paul Gauguin } & 160 \text { Kabinen } & 320 \text { Betten } & \text { Dauer: } 1 \text { Woche } \\ \text { Renaissance } 3 & 342 \text { Kabinen } & 684 \text { Betten } & \text { Dauer: } 10 \text { Tage } \\ \text { Renaissance } 4 & 342 \text { Kabinen } & 684 \text { Betten } & \text { Dauer: } 10 \text { Tage }\end{array}$

Der Kreuzfahrttourismus entwickelte sich bezüglich der Anzahl der Schiffe, der Bettenkapazität und der Aufenthaltsdauer in den letzten Jahren erheblich.

Räumlich konzentrieren sich sämtliche touristische Aktivitäten auf Tahiti, Moorea und Bora Bora. Huahine, Raiatea-Tahaa, Tuamotus und Marquesas folgen in weitem Abstand, was durch folgende Kennzahlen von 1998 deutlich wird:

Tab. 6: räumliche Verteilung touristischer Aktivität

\begin{tabular}{|l|l|l|}
\hline Insel & Anzahl der Zimmer & $\begin{array}{l}\text { Touristenankünfte 1998 } \\
\text { (Schätzung des Service du } \\
\text { Tourisme) }\end{array}$ \\
\hline Tahiti & 1069 & 188.933 \\
\hline Moorea & 937 & 147.157 \\
\hline Bora Bora & 693 & 82.000 \\
\hline Huahine & 100 & 27.700 \\
\hline Raiatea-Tahaa & 80 & 10.300 \\
\hline
\end{tabular}

${ }^{152}$ Das nachfolgend genannte statistische Material stammt aus Erhebungen des Service du Tourisme. Davon abweichende Quellen sind gekennzeichnet. 


\begin{tabular}{|l|c|l|}
\hline Tuamotus & 122 & 15.033 \\
\hline Marquesas & 20 & - \\
\hline
\end{tabular}

Da alle internationalen Flüge über den Flughafen Faa'a abgewickelt werden, ist dort auch die Gesamtzahl aller Touristenankünfte zu nennen. Für die Marquesas liegen keine Schätzungen seitens des Service du Tourisme vor.

Air France transportierte 1998 28,46\% aller Touristen gefolgt von Air New Zealand (20,12\%), A.O.M. (19,54\%), Corsair (11,71\%) und Quantas (6,46\%). Die restlichen Transporte entfallen auf Lan Chile, Air Calédonie, Hawaiïan Air und Air Tahiti Nui. Ca. 80\% der Touristen fliegen Französisch-Polynesien direkt an, die anderen im Rahmen einer Rundreise. Der Trend Tahiti bei Welt- und Pazifikreisen anzufliegen nimmt - nicht zuletzt auf Grund verbesserter Möglichkeiten für Anschlussflüge - zu.

Saisonal liegen die Touristenankünfte in den letzten Jahren immer im Juli/August am höchsten (1998: 18.856/18.900), während der Tiefpunkt mit 12.398/13.243 im Januar/Februar liegt. Dies hängt direkt mit der Hauptferienzeit der Franzosen und der Italiener im Juli/August zusammen.

Bezüglich des Alters dominieren die 26-35jährigen (30,32\%), gefolgt von den 46-55jährigen (19,21\%) und den 36-45jährigen (19,05\%). Im Rahmen der beruflichen Zugehörigkeit sind leitende Angestellte/Freiberufler (25,24\%) und mittlere Angestellte/Techniker (22,75\%) die beiden stärksten Gruppen.

Laut ITSTAT ${ }^{153}$ beliefen sich 1998 die Ausgaben der Gesamtzahl der Touristen auf 39,7 Milliarden CFP ${ }^{154}$, was im Vergleich zu 1991 (22 Milliarden CFP) fast eine Verdopplung bedeutete. Hierbei sind die Ausgaben pro Kopf pro Aufenthalt mit 287.500 CFP bei den Italienern und 230.500 CFP bei den Franzosen am höchsten, was unter anderen auf die teurere Flugreise von Europa aus - im Vergleich zu den USA (220.000 CFP) und Japan (221.000 CFP) zurückzuführen ist.

In einer groß angelegten Erhebung identifizierte ITSTAT 1995 die Japaner mit 30.003 CFP als diejenigen Touristen, die pro Kopf und Tag das meiste Geld in Französisch-Polynesien lassen, gefolgt von Süd- und Nordamerika, Deutschland und den übrigen Europäern. Australier, Neuseeländer und insbesondere Franzosen (10.740 CFP) geben pro Kopf und Tag relativ wenig aus. Französisch-Polynesien ist eines der teuersten Reiseländer der Welt. So sind die Ausgaben pro Kopf und Tag fast fünfmal so hoch wie diejenigen eines Urlaubers auf Korsika.

\footnotetext{
${ }^{153}$ ITSTAT: Institut de la Statistique de la Polynésie française
} 
Knapp die Hälfte dieser Ausgaben, die in Französisch-Polynesien selbst getätigt wurden (d.h. ohne Anreise) entfielen 1995 laut ITSTAT auf die Unterkunft, weitere 15\% auf die Gastronomie und Lebensmittelgeschäfte, 11\% auf Shopping und ca. 27\% auf Exkursionen, lokalen Transport und Sport.

Eine Erhebung des Service du Tourisme ergab 1995, dass vom Tourismus 7458 Arbeitsplätze abhängen. 3125 entfielen auf Beherbergung, 888 auf Reisebüros, Touristentransport, Führungen und Verwaltung und weitere 3445 auf indirekt abhängige Beschäftigungen wie Transport, Verkauf und Gastronomie. Räumlich sind diese Arbeitsplätze auf Tahiti, Moorea und Bora Bora konzentriert.

Mit einer Touristendichte von 0,7 in 1996 (s. ITSTAT 1998) empfängt Französisch-Polynesien sehr viel weniger Touristen pro Einwohner als z. B. Fidschi $(2,4)$, aber mehr als Westsamoa $(0,3)$. Die große Entfernung von den touristischen Quellgebieten, das hohe Preisniveau und die Sprachbarriere zu den anglophonen Nachbarländern sind nach wie vor Faktoren, die eine stärkere Expansion des Tourismus in Französisch-Polynesien limitieren.

Das Überseeterritorium Französisch-Polynesien setzt - vor dem Hintergrund steigender Touristenankünfte - klar auf einen weiteren Ausbau des Sektors Tourismus. Nicht zuletzt die gesunkenen Flugpreise (-24\% von 1992-1996) und die endgültige Einstellung der Atomtests machen diese Destination auch für mittlere Einkommensschichten immer attraktiver. Im „Contrat de Développement 1994-1998“ und im „Programme stratégique 1996 pour le développement économique de la Polynésie dans le cadre de l'après-CEP“" der Territorialregierung ist der Tourismus jeweils als prioritärer Wirtschaftssektor eingestuft (s. ITSTAT 1998, S. 290). Ein gemeinsames Positionspapier von GIE Tahiti Animation, GIE Tahiti Tourisme und dem Service du Tourisme von 1994 sieht eine radiale Erweiterung der touristischen Kapazitäten in Französisch-Polynesien vor: in einem ersten Schritt sollen entsprechende Angebote auf Tahiti, Moorea und Bora Bora ausgebaut werden, dann auf Huahine, Raiatea und Rangiroa, in einem weiteren Schritt Tahaa, Maupiti, Fakarava, die Tuamotus und die Marquesas und zum Schluss auf den Austral- und Gambierinseln. Kleine Pensionen sollen gleichermaßen gefördert werden wie große Hotelanlagen. Ganz allgemein soll über die Förderung der Vielfalt von Umwelt und Kultur speziellen Zielgruppen maßgeschneiderte Angebote unterbreitet werden. Bestimmte

\footnotetext{
${ }^{154} 60$ CFP entsprechen in etwa einer D-Mark (Stand 1999)
} 
Schwerpunkte sind für Bora Bora im Bereich des Hochzeitsreisetourismus, für Raiatea im Tauchen und für Huahine im Naturtourismus benannt.

Nach wie vor besteht beim Bau neuer Hotels ein regionaler Schwerpunkt auf Tahiti, Moorea und Bora Bora und eine klare Favorisierung des „tourisme haut de gamme“ in Form von teuren Luxushotels. Konkret sind für Moorea ab 2000 der Bau des Outrigger Lagoon und des Cook's Bay geplant, für Bora Bora das Jardin d'Eden. Das Polynésia auf Bora Bora soll weiter ausgebaut werden.

In den Jahren 1997-1999 hat sich - auch ohne staatliche Förderung - der Sektor petite hôtelerie pensions de famille - logement chez l'habitant verstärkt entwickelt, was in FranzösischPolynesien zu einer Verstärkung des Angebots im oberen und unteren Marktsegment führte bei einem nach wie vor relativ geringem Angebot an Mittelklassehotels. 1997 gab es erstmalig eine Messe für kleine Beherbergungsbetriebe, den „Salon des pensions de famille et de l'herbergement chez l'habitant". Um ihre Situation weiter zu verbessern haben sich diese kleinen Betriebe inzwischen zu verschiedenen Verbänden zusammengeschlossen, da ihr Einfluss im Vergleich zu den großen Ketten immer noch sehr gering ist.

Tab. 7: Übersicht kleine Beherbergungsbetriebe (im Jahre 1999)

\begin{tabular}{|l|l|l|}
\hline Insel & Anzahl der Betriebe & Anzahl der Zimmer \\
\hline Tahiti & 24 & 129 \\
\hline Moorea & 16 & 115 \\
\hline Bora Bora & 13 & 102 \\
\hline Huahine & 18 & 104 \\
\hline Raiatea & 13 & 103 \\
\hline Tahaa & 9 & 39 \\
\hline Maupiti & 8 & 27 \\
\hline Tuamotus/Gambierinseln & 48 & 209 \\
\hline Australinseln & 13 & 64 \\
\hline Marquesas & 27 & 112 \\
\hline Summe: & $\mathbf{1 8 8}$ & $\mathbf{1 0 0 6}$ \\
\hline
\end{tabular}

Diese offiziellen Zahlen können als inzwischen viel zu niedrig angesetzt gesehen werden. Gerade 1999 wurden sehr viele kleine Familienpensionen eröffnet bzw. waren in Planung ${ }^{155}$.

Eine eigene Befragung 1998 (standardisierter Fragebogen) bei deutschen Anbietern der Destination Französisch-Polynesien ${ }^{156}$ ergab nur fünf verwertbare Rückläufe (bei 25

155 eigene Beobachtungen während des zweiten Aufenthalts 1999 
Aussendungen). Diese fünf Anbieter trafen allerdings weitgehend übereinstimmende Aussagen. Probleme bei der Vermarktung der Destination ist insbesondere das ungünstige PreisLeistungsverhältnis; Marktchancen werden eher langfristig gesehen. Vermarktet wird insbesondere das klassische Südseeimage (Inseln, weiße Sandstrände, glückliche Einheimische, süßes Nichtstun, etc), aber auch ein Abenteuerimage. Klassische Bildungsreisen mit einem hohen Anteil an kulturellen Inhalten spielen keine Rolle. Sanfter Tourismus wird überwiegend mit der Einhaltung von Umweltauflagen, bzw. allgemeinen ökologischen Aspekten gleichgesetzt. Dieser Form von Tourismus wird, wenn überhaupt, nur eine langfristige Perspektive eingeräumt. Die Reiseanbieter arbeiten vor Ort ausschließlich mit großen Hotels und etablierten Tour Operators zusammen. Ebenso klassisch sind die Marketingkanäle: Katalog, Directmailing, Anzeigen, Messen. Die Maohi spielen im Rahmen des touristischen Geschäfts insbesondere folgende Rollen: kulturelle Veranstaltungen, Reiseführer, direkter Kundenkontakt wegen „Exotikfaktor“, niedrig qualifizierte Tätigkeiten, Aushilfsjobs. Ein Anbieter gab an, dass sie auch auf der mittleren Managementebene eingesetzt werden. Bei aller Eindeutigkeit der Aussagen, muss darauf hingewiesen werden, dass 5 verwertbare Fragebögen nicht als repräsentativ gelten können. Die Ergebnisse sind eher als interessante Einzelaussagen zu werten.

Eine weitere Befragung (standardisierter Fragebogen, 300 Aussendungen) bei Beherbergungsbetrieben im gesamten Gebiet Französisch-Polynesiens 1997 und 1999 ergab 57 verwertbare Rückläufe. Die überwiegende Mehrheit der Betriebe konnte den Begriff des sanften/nachhaltigen Tourismus nicht einordnen oder missinterpretierte ihn als Naturtourismus ${ }^{157}$.

Zu dem gleichen Ergebnis kam Catherine BIDAULT, die im Juni 1999 als Praktikantin Hiti Taus eine detaillierte Umfrage bei ausgewählten, kleineren Beherbergungsbetrieben vornahm. Das Ergebnis zeigte, dass bei allen 11 Rückläufen die Begriffe „Ethnotourismus“ und „Nachhaltiger Tourismus“ nicht definiert werden konnten. „Ökotourismus“ wurde immerhin von sechs der befragten Pensionen mit Naturschutz in Zusammenhang gebracht.

In einer anderen Studie untersuchte ITSTAT 1997-1998 im Auftrag des Tourism Council of the South Pacific (TCSP) die Zufriedenheit der Besucher Französisch-Polynesiens. Hierin sind auch Angaben zur Vorbereitung und Motivation enthalten. Eine Reise nach Französisch-Polynesien

\footnotetext{
${ }^{156}$ Fragebogen, s. Anl. 1b im Anhang

157 ebenda
} 
wird demnach von langer Hand vorbereitet. Knapp die Hälfte der Touristen nehmen sich dafür mehr als drei Monate Zeit. Reisebüros, Freunde und Bekannte, sowie die Medien waren die wichtigsten Informationsquellen.

Bezüglich der Reisemotive rangieren Natur, Klima, freundliche Menschen und das Anliegen, sich einen Traum zu erfüllen, ganz oben (weit über die Hälfte der Befragten gaben diese Motive an). Weniger wichtig waren Wassersport oder die einheimische Kultur (jeweils knapp 30\%). 60,7\% der Befragten reisten als Paar, 19,4\% alleine, 13.5\% mit der Familie, 4,7\% mit anderen Freunden und nur 1,7\% in Gruppen an. Für 80\% war es der erste Aufenthalt in FranzösischPolynesien überhaupt. Der Pauschaltourismus (größter Anbieter ist Club Med mit über 20\%) überwog mit 53,5\% knapp vor dem Individualtourismus (46,5\%).

$88,1 \%$ besuchten Tahiti, 77,2\% Moorea, 36,1\% Bora Bora, 14,0\% Huahine, 12,1\% Rangiroa und 9,0\% Raiatea. Knapp die Hälfte der Touristen kam in Luxushotels, 1/3 in Mittelklassehotels und ca. 16\% in kleineren Beherbergungsbetrieben unter. Als Hauptaktivität wurde Shopping genannt, gefolgt von Spaziergängen und Exkursionen, Tauchen und kulturellen Aktivitäten.

Die Touristen äußerten sich sehr zufrieden zum Klima, zur Freundlichkeit der Menschen, zur Qualität der Strände, zu den Exkursionen, zum Wassersportangebot, zum kulturellen Angebot und zum Kunsthandwerks. Die Qualität der Unterkünfte und Restaurants wurde nicht ganz so gut bewertet (Ausnahme: Unterbringung auf Kreuzfahrtschiffen). Kritisch äußerten sich die Befragten zu dem hohen Preisniveau der Hotels, Taxis, Mietwagen, Restaurants und Souvenirs. Direkt nach den überteuerten Preisen wird der Verschmutzungsgrad von Lagune, Hotels und Straßen als Grund für Unzufriedenheit angegeben. Über $80 \%$ äußerten sich jedoch zufrieden über den Gesamtaufenthalt und würden die Destination weiterempfehlen; mehr als 60\% möchten wiederkommen.

Eine von mir vorgenommene Befragung ${ }^{158}$ (32 Einzelinterviews) in den Jahren 1997 und 1999 bestätigt die o.g. Ergebnisse in der Tendenz. Während die Studie von ITSTAT alle Touristen ohne Einschränkung als Zielgruppe hatte, beschränkten sich meine Interviews auf Gäste von kleinen Beherbergungsbetrieben. Dies hatte auch interessante Abweichungen im Ergebnis zur Folge: Die Aufenthaltsdauer war mit 2 Wochen (7 Befragte), 3 Wochen (11) bis zu 3 Monaten wesentlich länger. Nur 2 Befragte blieben 10 Tage oder weniger. 25 der Befragten reisten

\footnotetext{
${ }^{158}$ Fragebogen, s. Anlage 1a im Anhang
} 
individuell, 7 besuchten neben den Gesellschaftsinseln auch die Marquesas und 5 die Tuamotus. Bei den Erwartungen (Mehrfachnennungen waren möglich) dominierten Ausspannen (8), Kultur kennen lernen (7) und Natur erleben (5). 29 der Befragten hatten Kontakt zur lokalen Bevölkerung, davon 10 allerdings oberflächlich oder in einem rein ökonomischen Zusammenhang. 14 der Befragten beurteilten die lokale Bevölkerung als freundlich, 9 bezeichneten den Lebensrhythmus als ,easy going“ und 6-Mehrfachnennungen waren möglich - betonten die Gastfreundlichkeit. 16 gaben an, mit den Einheimischen intensive Gespräche geführt zu haben, während 4 die Sprachbarriere als Hindernis angaben. Befragt nach den Vorteilen der Bereisten, äußerte eine große Mehrheit von 28 Befragten, dass diese ausschließlich auf der ökonomischen Ebene existent seien. 27 wollten die Reise intensiv nachbereiten, die gleiche Anzahl konnte sich vorstellen, ebenfalls bereist zu werden. Letzteres verwundert nicht, da die Touristen selbst aus touristisch stark frequentierten Gebieten kamen, wie z. B. Paris, Berlin oder Ottawa. Begriffe wie sanfter Tourismus oder nachhaltiger Tourismus war 19 Befragten unbekannt. Unter Ökotourismus wurde in der Regel Naturtourismus verstanden. 3 waren der Ansicht, dass durch Bildung/Erziehung solche Tourismusformen an Gewicht gewinnen könnten, während weitere 3 meinten, dies könnte durch entsprechende, insbesondere eigene, Nachfrage passieren. 10 der Befragten blieben mit Gastgebern in Kontakt. Altersstruktur und Berufsgruppen unterschieden sich nicht wesentlich vom Durchschnitt, ebenso wenig die Hauptkritikpunkte: Preise, Umweltverschmutzung und Hygiene.

\subsubsection{Partizipation der Maohi am touristischen Prozess in Französisch-Polynesien}

Der Partizipationsgrad der Maohi ist auf allen Ebenen des Tourismussektors in FranzösischPolynesien gering. In Hotels und Restauration sind sie überwiegend auf den untersten Einkommens- und Entscheidungsebenen beschäftigt (Empfang, Zimmerservice, Bedienung) oder als Folkloregruppe ${ }^{159}$. Auch in den Einrichtungen, die die strategische Weiterentwicklung des Tourismus entscheidend beeinflussen wie Service du Tourisme, GIE Tahiti Tourisme oder GIE Tahiti Animation sind vorwiegend demi beschäftigt.

Insbesondere im Rahmen der Frage des Landrechts (vgl. Kap. 6.3.5) entstanden heftige Proteste der Maohi gegen diverse touristische Projekte: Auf Moorea wurden bis jetzt der Bau eines Luxushotels und eines Golfplatzes in der Bucht von Opunohu verhindert. Die Bevölkerung

${ }^{159} \mathrm{zu}$ Beschäftigungsverhältnis und ethnischer Zugehörigkeit werden keine statistischen Daten erhoben, die Angaben beruhen auf eigenen Beobachtungen und Rechercheinterviews 
entschied sich 1991 in einem Referendum dagegen. Die Umweltschutzorganisation Atuatu te natura verhinderte auf dem Rechtswege den weiteren Ausbau des Hotels Moana Beach, das weitere 20 Überwasserbungalows plante. Diese Konstruktionen rufen bei den Maohi darüber hinaus Amüsement hervor, da sie gegen jede Vernunft ungeschützt in die Lagune gebaut werden und von Wirbelstürmen regelmäßig beschädigt werden. Ein weiterer - letztendlich aber vergeblicher Protest richtete sich gegen den Bau des Hotels Meridien auf Tahiti, da es auf für die Ureinwohner heiligem Gelände gebaut werden sollte. Der Bauplatz wurde besetzt und Dank eines Formfehlers wurde die Baugenehmigung zunächst aufgehoben, was den Bau der Anlage aber nicht endgültig verhinderte (vgl. DELIUS 1993).

Die Ausbaggerung der Lagunen vor den Küsten Pihaena und Paopao auf Moorea ist aktueller Anlass der Proteste von Umweltaktivisten in Französisch-Polynesien. Bei Pihaena soll die Lagune zur Erweiterung des Moorea Lagoon Resort des Industriellen Louis WAN und seiner Firma Société Moorea Lagoon Resort ausgebaggert werden; hierzu sollen 10.000 Kubikmeter Sand der Lagune entnommen werden. Bei Paopao soll die Lagune zugeschüttet werden, um neue Über-Wasser-Bungalows zu errichten. Die Proteste werden von Greenpeace und der evangelischen Kirche in Französisch-Polynesien unterstützt (pazifik aktuell Mai 2000, S. 7 f.).

Die auf Bora Bora ansässige Naturschutz-Organisation „Atuatu Te Natura“ hat im Zeitraum 1987-1993 in mehreren, teilweise von ausländischen Geberorganisationen finanzierten Untersuchungen, die negativen Auswirkungen des Tourismus auf Bora Bora dargestellt. Sie wendet sich insbesondere gegen den weiteren, unkontrollierten Ausbau von Hotelanlagen auf Matira, gegen die ungeregelte Müllentsorgung, die Zerstörung der Lagune durch Ausbaggern und Verschmutzung, die zunehmende Privatisierung von Stränden und setzt sich für die stärkere Sensibilisierung der Bevölkerung, insbesondere der Jugendlichen in Bezug auf Umweltaspekte durch Bildungs- und Informationsveranstaltungen oder öffentliche Müllbeseitigungsaktionen ein. „Atuatu Te Natura“ favorisiert kleinere Tourismusprojekte, die Einkommen für lokale Familien schaffen (vgl. Atuatu Te Natura 1987, 1988 und 1993). 


\subsubsection{Die Sichtweise der Bereisten}

In aufwendigen Kampagnen wurde auch die autochthone Bevölkerung aufgerufen, sich im Tourismus als dem zukunftsweisenden Sektor zu engagieren und eine positive Einstellung dazu zu entwickeln (vgl. Anl. 25 im Anhang).

1999 wurden im Gebiet der Gesellschaftsinseln von der Verfasserin insgesamt 74

Einzelinterviews ${ }^{160}$ zur Sichtweise der Bereisten geführt. Auch diese Stichprobe ist weit davon entfernt, ein repräsentatives Ergebnis zu liefern, dennoch sind - auch bei dieser geringen Anzahl an Befragten - Tendenzen erkennbar. Befragt wurden zu über 90\% Maohi. Unter den restlichen 10\% demi und Chinesen überwog eine positive Haltung zu Tourismus, die sich meist aus deren geschäftlicher Verbindung mit diesem Bereich erklärt. Die einzelnen Interviews entwickelten sich trotz eines Frageleitfadens sehr unterschiedlich. Um eine Vergleichbarkeit der Ergebnisse zu schaffen, habe ich die Antworten kategorisiert in:

- überwiegend positive Bewertung des Tourismus/der Touristen

- Benennung von positiven und negativen Aspekten von Tourismus/Touristen

- überwiegend negative Bewertung des Tourismus/der Touristen

- gleichgültige Haltung gegenüber Tourismus/Touristen

Eine Aufteilung der jeweiligen Antworten ergab folgendes regionales Muster:

\begin{tabular}{|l|l|l|l|l|l|}
\hline & positiv & positiv/negativ & negativ & gleichgültig & Summe: \\
\hline Tahiti & 13 & 6 & 0 & 1 & 20 \\
\hline Moorea & 5 & 1 & 0 & 4 & 10 \\
\hline Bora Bora & 0 & 2 & 4 & 7 & 13 \\
\hline Raiatea & 4 & 4 & 0 & 5 & 13 \\
\hline Tahaa & 1 & 0 & 0 & 2 & 3 \\
\hline Huahine & 4 & 7 & 0 & 4 & 15 \\
\hline Summe: & 27 & 20 & 4 & 23 & $\mathbf{7 4}$ \\
\hline
\end{tabular}

Tab. 8: Sichtweise der Bereisten

Auffällig ist, dass z. B. auf Bora Bora, wo (auch insbesondere in Bezug zur relativ geringen Bevölkerungsdichte) nicht eine positive Einschätzung des Tourismus vorliegt und überwiegend eine negative, bzw. gleichgültige Haltung dominiert. Außer auf Bora Bora äußerte sich niemand explizit negativ über den Tourismus. Zwei weitere Werte fallen ins Auge: der hohe Anteil an positiver Gesamteinschätzung auf Tahiti und ein hoher Anteil an Befragten auf Huahine, die die

\footnotetext{
${ }^{160}$ Frageleitfaden, s. Anlage 1d im Anhang
} 
touristischen Effekte sehr differenziert mit sowohl positiven und als auch negativen Auswirkungen beschrieben.

Folgende Erklärungsmuster bieten sich an: Bora Bora ist von spürbaren Schäden durch den Tourismus betroffen: starke Zersiedelung durch Hotelbauten, Wassermangel und Verschmutzung der Lagune. Die vielfach scheinbar gleichgültige Haltung gegenüber dem Tourismus kann auch als stummer Protest gewertet werden. Dies wurde mir in Gesprächen mit Maohi, denen ich die Ergebnisse meiner Befragung erläuterte, bestätigt. Die Touristen in Papeete fallen im Stadtbild nicht sonderlich auf. Sie konzentrieren sich auf wenige Punkte (Hafenpromenade, Markthalle). Diejenigen, die auf Tahiti mit Touristen zu tun haben, leben davon; die übrigen haben im Wesentlichen keinen Kontakt und fühlen sich nicht gestört. Außerdem ist die Verweildauer der Touristen in Tahiti relativ gering, da in der Regel bald die großen Ressorts in Moorea und Bora Bora angesteuert werden. In Papeete ist auch keine Segregation von Touristen und Einheimischen zu betrachten. Beide Gruppen frequentieren im Wesentlichen gleichermaßen Cafés und Restaurants. In Huahine hält sich die touristische Nutzung noch in Grenzen. Es sind noch nicht zu viele Touristen pro Einwohner vorhanden. Vielfach habe ich aber gehört, dass man auf keinen Fall ein zweites Bora Bora werden möchte. Moorea ist auf dem Weg, in der touristischen Nutzung einen kritischen Punkt zu erreichen (den Bora Bora schon überschritten hat), während Raiatea und Tahaa noch relativ problemlos die jetzige Anzahl an Touristen verkraften können.

Die aus der obigen Tabelle erkennbaren Tendenzen werden durch folgende Beobachtung gestützt: Bei einer Umrundung Bora Boras mit einer Piroge gingen die einheimischen Führer nach kurzer Zeit dazu über, die Touristengruppe massiv zu verspotten.

Die kritischen Äußerungen zum Thema Tourismus bezogen sich in Bora Bora auf den sich verschärfenden Wassermangel und die zu hohe Anzahl an Touristen, die in dieser Menge als störend empfunden wurde.

In der Summe ist ein klarer Zusammenhang erkennbar: Mit steigender Touristendichte wächst die Ablehnung. Möchte man eine Art Rangfolge in der soziokulturellen Tragfähigkeit (vgl. ausführlich Kap. 2.2, insbesondere Abb. 7) der Gesellschaftsinseln aufstellen, so nimmt in der Abfolge Tahaa, Raiatea, Huahine, Tahiti, Moorea, Bora Bora die Bereitschaft ab, eine weitere Steigerung der Touristendichte kritiklos hinzunehmen. Die kulturelle Tragfähigkeit kann bei Moorea als erreicht und bei Bora Bora als überschritten gelten. 


\section{$\underline{\text { 6.6 Tourismusprojekte der Maohi in Französisch-Polynesien }}$}

Sind die Maohi im klassischen Tourismusbereich des ,,haut de gamme“ extrem selten vertreten, so steigt ihr Engagement im Bereich der kleineren Beherbergungsbetriebe, die in jüngerer Zeit stark zunehmen und nicht selten von Familien geführt werden. Als Sicherheit dient - gerade in der Anfangsphase - oft ein sicheres Einkommen (ein Familienmitglied arbeitet in der Administration oder bezieht eine staatliche Rente). Die Nichtregierungsorganisation Hiti Tau baut seit 1999 ein Netz von Familienpensionen auf.

\subsubsection{Die Nichtregierungsorganisation Hiti Tau}

Das Netzwerk Hiti Tau entstand 1992 nach dem französischen Vereinsrecht aus einem Zusammenschluss verschiedener indigener Basisgruppen mit der Zielsetzung die Interessenvertretung der „Nation Maohi“ in Französisch-Polynesien auf lokaler, nationaler und internationaler Ebene zu stärken. Hiti Tau bedeutet wörtlich soviel wie „Sonnenaufgang“ oder „die Sonne wird kommen“ und im übertragenen Sinne: „Zeit zu Handeln“. Die NGO ist weder politisch noch konfessionell gebunden und verfolgt das Ziel einer selbstbestimmten, nachhaltigen Entwicklung der Maohi im Sinne der Menschenrechte (vgl. auch zu den folgenden Informationen zu Struktur und Zielen: Selbstdarstellungen HITI TAU 1999). Darüber hinaus will man die Übernahme der Verantwortung seitens der französischen Regierung für die durch die Nuklearversuche entstandenen Schäden einfordern.

Die inzwischen über 50 Basis-NGOs sind Mitglieder des „Conseil national des ONG du pays Maohi“, des Entscheidungsgremiums von Hiti Tau, durch das alle drei Jahre auf einer Vollversammlung die Arbeitsschwerpunkte und Programme, sowie die Mitglieder des Koordinationskomitees festgelegt werden. Das Koordinationskomitee besteht aus den jeweiligen Verantwortlichen für die einzelnen Programme. Auf der letzten Vollversammlung des Conseil national am 8. Januar 1999 wurden folgende sechs Programmschwerpunkte festgelegt: 


\section{$\underline{1 . \text { Networking }}$}

- capacity-building ${ }^{161}$

- Ausbildung/Professionalisierung der Programmverantwortlichen

- Regionale und internationale Zusammenarbeit

\section{Menschenrechte}

- Nuklearversuche

- Rechte autochthoner Völker

- Geistiges und kulturelles Eigentum

\section{$\underline{\text { 3. Frauen und Entwicklung }}$}

- Monoïproduktion

- Kooperative Hotu Tiare Maohi (Zentrum der Monoïproduktion Hiti Taus auf Moorea)

- Herstellung von Stoffen

\section{Jugendliche}

- Vanilleanbau

- Jugendaustausch

\section{$\underline{\text { 5. Inseln unter dem Wind }}$}

- Ökotourismus

- Monoï- und Vanilleproduktion

\section{Marquesas}

- Kooperative Te Pua O Te Vao

- Produktion von Vanille, Monoï und Kunsthandwerk

Durch die Akquise von Geldern ausländischer Geberorganisationen (,Agences“) werden die einzelnen Programme und Aktivitäten vorwiegend finanziert, sollen aber langfristig in eine selbsttragende, nachhaltige Form übergehen. Die auf wirtschaftliche Aktivität hin ausgerichteten Maßnahmen orientieren sich an traditionellen Wirtschaftsweisen, die auch verstärkt vor der Phase

161 capacity-building meint Ausbildung und Qualifikation 
des CEP bestanden hatten. Neu ist hierbei nur der „Ökotourismus“, der erst seit 1999 an Bedeutung gewinnt.

Zur Finanzierung seiner Projekte nimmt Hiti Tau keine Gelder der Vereinten Nationen an, um der Forderung, Französisch-Polynesien wieder auf die Liste der Länder zu setzen, die entkolonisiert werden müssen, Ausdruck zu geben. Darüber hinaus werden auch keine Finanzmittel der Territorialregierung und des französischen Staates angenommen. Hiti Tau finanziert sich aus Privatspenden (ausgenommen sind hier politische Parteien und die Industrie), Geldern ausländischer NGOs, insbesondere aus dem Pazifik und Europa, Beiträgen der einzelnen Basisgruppen und zu einem immer größer werdenden Teil aus den erwirtschafteten Einnahmen eigener Projekte. Nicht zuletzt ein Rückgang des Engagements ausländischer Geberorganisationen nach der Einstellung der Atomtests bedingt die Verlagerung der Projekte Hiti Taus in Richtung ,gewinnträchtigerer“ Projekte, zu denen auch der Tourismus gehört.

Die sechs Programmverantwortlichen („leaders nationaux“) treffen sich jährlich einmal und führen die Beschlüsse des Conseil national durch. Das Zentrum Hiti Taus, das Secrétariat, befindet sich in Taravao auf Tahiti und wird geleitet von dem Vorsitzenden und Gründer Hiti Taus, Gabriel TETIARAHI. Im Sekretariat in Taravao finden Versammlungen, Fortbildungen, der Empfang internationaler Gäste in einem der beiden Gästehäuser und die zentrale Begleitung sämtlicher Projekte statt.

Als Programmschwerpunkte haben sowohl die Inseln unter dem Wind als auch die Marquesas eigene Unterstrukturen. Das Koordinationsorgan der Inseln unter dem Wind ist die NGO „Raro Matai“, der die Basisgruppen Tamarii Maeva Nui, Toohitu (Huahine), Hotu Rau, Fetii Teiva, Niuaemaha (Tahaa), Puna vai no Popora (Bora Bora) und Teonearue (Raiatea) angeschlossen sind. Das Pendant auf den Marquesas ist die NGO Fenua Enana, zu der wiederum drei Basisgruppen gehören: Tapavau nui (Ua Pou), Te Pua Enana (Nuku Hiva) und Atuona Nui (Hiva Oa). Eines der zentralen Projekte von Raro Matai ist das Ökotourismusprojekt Patu, während Fenua Enana sich insbesondere auf die landwirtschaftliche Kooperative Te pua o te vao konzentriert (Vanille- und Monoïproduktion). Te pua o te vao soll schon in 2004 wirtschaftlich Gewinne erwirtschaften, so dass die Kooperative nicht mehr auf die finanzielle Unterstützung Hiti Taus angewiesen ist. Das Projekt Patu hingegen steht noch ganz am Anfang. 
Zentrale Figur Hiti Taus ist der Gründer und langjährige Vorsitzende Gabriel TETIARAHI ${ }^{162}$. Ein Stipendium der Territorialregierung, mit dem er in Bordeaux Stadtplanung studierte, wurde ihm 1983 entzogen, da er öffentlich die Politik FLOSSEs gegenüber der indigenen Bevölkerung Französisch-Polynesiens kritisierte. Nach der Ablegung des Doktorexamens 1985 (das weitere Studium finanzierte er durch studentische Kredite) arbeitete er zunächst in der Administration im Bereich „urbanisme“, da das frühere Staatsstipendium dazu für mindestens 10 Jahre verpflichtete. 1992 gründete er die NGO Hiti Tau und wurde insbesondere auf Grund seiner internationalen Aktivitäten 1993 aus dem Staatsdienst entlassen. Seit 1995 Vorsitzender von PIANGO (Pacific Islands Association of Non-Governmental Organisations) schloss er internationale Kontakte und tat ausländische Geberorganisationen insbesondere in Frankreich, Deutschland und Neuseeland auf. Seine Führungsrolle rechtfertigte sich nicht nur durch den Vorsitz Hiti Taus und PIANGOs, sondern sie sei ihm auch von den Alten seines Volkes aufgetragen wurden:

„Ils m’ont convoqué et m'ont appris les noms des lieux, des vallées, des terres; ils m’ont enseigné les traditions et les légendes.“ (TETIARAHI 1996 zitiert nach BRÉSILLION 1996, S. 15)

„J'ai reçu le mana, c'est-à-dire le leadership spirituel et culturel. Il me revient de marcher le premier sur le feu. [...] Nous avons encore cette prédisposition à dialoguer avec l'histoire, à dialoguer avec des pierres, à attacher beaucoup d'importance au symbolique. [...] Avec tout ça, tu sais qui tu es.“ (TETIARAHI 1995 zitiert nach LESNES 1995)

Neben der Entwicklung wirtschaftlicher Alternativen zur CEP-Ökonomie, die den Maohi ihre kulturellen Wurzeln wiedergeben sollen, ist ein weiteres erklärtes Ziel die Aufklärung der Menschen, die „Entkolonisierung des Geistes“:

„The model of development represented by nuclear testing is not ours. What we are trying to do is to open the minds of people, to decolonize the mind. For me the most important effect of the nuclear testing is not on health, not on the environment - it is on the minds of people. They have forgotten what is possible, because they are not decolonized.“ (TETIARAHI 1997 zitiert nach RANSOM 1997, S. 11)

\subsubsection{Tourismusprojekte des Netzwerks Hiti Tau und andere Initiativen von Maohi}

Im Rahmen des neuen Programmschwerpunkts „Ökotourismus“ hat Hiti Tau ein Netzwerk von kleinen Familienpensionen aufgebaut mit dem regionalen Schwerpunkt Gesellschaftsinseln.

$\overline{162}$ TE TIA RAHI bedeutet „,der große Repräsentant“ (s. Nouvelles de Survival 1996, S. 7) 
Folgende acht Pensionen sind diesem Netzwerk angeschlossen:

\begin{tabular}{|l|l|}
\hline Insel & Pension \\
\hline Tahiti & Secretariat Taravao \\
\hline Moorea & Pension Maeva \\
\hline Bora Bora & Pauline Village \\
\hline Huahine & Chez Henriette, Pension Maeva \\
\hline Tahaa & $\begin{array}{l}\text { Projekt Patu auf Pueheru, Chez Mama Changaud, } \\
\text { Chez Jaqueline }\end{array}$ \\
\hline
\end{tabular}

Das Sekretariat in Taravao, von wo aus auch das Marketing realisiert wird, leitet die Touristen weiter zu den Pensionen auf den einzelnen Inseln.

Neben diesem Netzwerk existieren weitere kleine Beherbergungsbetriebe, die ebenfalls von Maohi betrieben werden, aber nicht zu Hiti Tau gehören:

\begin{tabular}{|l|l|}
\hline Insel & Pension \\
\hline Tahiti & Taaroa Lodge \\
\hline Tahaa & Topenu Village, Chez Louise, Chez Pascale \\
\hline Huahine & Camping Hubert et Cecéle \\
\hline
\end{tabular}

Diese Aufzählung ist längst nicht vollzählig, zumal zurzeit ständig weitere kleine Pensionen entstehen.

\subsubsection{Bewertung von Tourismusprojekten der Maohi nach Kriterien der Nachhaltigkeit}

Die Tourismusprojekte der Maohi werden in Anlehnung an das Modell von BECKER/JOB/WITZEL 1996 (vgl. Kap. 1) und den gtz-Leitfaden „Tourismus in der Technischen Zusammenarbeit“ (1999) (vgl. Anl. 26 im Anhang) bewertet. Hierbei ist eine lokale Ebene von der globalen zunächst zu unterscheiden, da die globalen Bewertungskriterien auf alle Projekte gleichermaßen zutreffen, während die lokalen differieren. Die Bewertungsskala ist aufgeteilt in sehr gering, gering, mittel, hoch und sehr hoch als Wertung der einzelnen Formen der Nachhaltigkeit. Vielfach spielt in die Bewertung der einzelnen touristischen Mikroprojekte auch die ökonomische, ökologische oder soziokulturelle Situation Gesamt-FranzösischPolynesiens oder der einzelnen Inseln hinein, d.h. die Betreiber der einzelnen Projekte können diese Faktoren (wie z. B. die generell fehlende Aufbereitung von Abwässern) nicht direkt selbst 
beeinflussen. Auf globaler Ebene werden insbesondere Akkulturationsindikator, Menschenrechtsindikator und Raumüberwindungsindikator untersucht.

\subsubsection{Bewertung auf der lokalen Ebene}

Folgende oben erwähnte Beherbergungsbetriebe sollen in Bezug auf lokale Kriterien der Nachhaltigkeit näher untersucht werden:
a) Taravao, Tahiti
b) Taaroa Lodge, Tahiti
c) Pauline Village, Bora Bora
d) Chez Henriette, Huahine
e) Pension Maeva, Huahine
f) Ariiura Camping Ecologique chez Hubert et Cecéle, Huahine
g) Projekt Patu, Tahaa
h) Chez Louise, Tahaa
i) Chez Mama Changaud, Tahaa

a) Taravao, Tahiti

Das Sekretariat und Zentrum Hiti Taus in Taravao (Bergseite ${ }^{163}$ ) verfügt über zwei miteinander verbundene Gästehäuser, in denen insgesamt 15 Gäste untergebracht werden können. In dem umgebenden Garten werden Vanille, Taro und Maniok angebaut. Taravao liegt schon im Einflussbereich der regenreichen Ostwinde und ist - wie die gesamte Ostküste - extrem feucht.

\section{1) ökonomische Faktoren:}

In Taravao werden durch den Tourismus drei Arbeitsplätze direkt geschaffen (ein Mann und zwei Frauen). Indirekt ergeben sich dadurch eine verstärkte Nachfrage insbesondere bei lokalen Lebensmittelläden und lokalem Transport. Taravao liegt in Tahiti extrem peripher, $60 \mathrm{~km}$ in beide Richtungen von Papeete entfernt. Da das Sekretariat darüber hinaus als „Verteilerkopf“ für die andere Pensionen im Netzwerk Hiti Taus fungiert, werden die entstandenen Beschäftigungsund Einkommenseffekte, sowie die indirekten wirtschaftlichen Auswirkungen weitergegeben an die anderen Inseln. Da den Touristen auch Projekte der Monoïproduktion und des Vanilleanbaus gezeigt werden, entstehen günstige Synergieeffekte für die landwirtschaftliche Produktion. 
Regional betrachtet sind die Einkommens-, Beschäftigungs- und sekundären wirtschaftlichen Effekte allerdings gering. In Planung ist darüber hinaus die Weiterbildung der in Tourismusbereichen beschäftigten Hiti Tau Mitglieder insbesondere in englischer Sprache (z. B. in Neuseeland oder Australien) und in tourismusfachlicher Hinsicht (AFOMETH).

Wertung: ökonomische Nachhaltigkeit: hoch

\section{2) ökologische Faktoren:}

Auf Grund der begrenzten Frequenz und Kapazitäten der örtlichen „trucks“ in Richtung Taravao wird häufig zur Abholung der Touristen vom Flughafen Faa'a und zu Ausflügen ein Pick up benutzt. Im Zusammenhang mit dem stark steigenden Verkehrsaufkommen in Tahiti bedeutet dies eine durch das touristische Projekt zusätzlich geschaffene Umweltbelastung. In der Pension selbst sind Flächenbedarf, Abfallaufkommen und Wasserverbrauch pro Tourist zwar gering, aber auch hier stellen fehlende Abwasserentsorgung (Waschmaschine entleert sich in den Garten), die Nicht-Nutzung regenerativer Energien und die Nichttrennung von Müll ${ }^{164}$ (Ausnahme: biologische Abfälle werden im Garten entsorgt) ein enormes Potential zur Verbesserung der ökologischen Nachhaltigkeit dar.

Wertung: ökologische Nachhaltigkeit: mittel

\section{3) soziokulturelle Faktoren:}

Die soziokulturelle Verträglichkeit des Projektes ist enorm hoch, da Hiti Tau selbst das Projekt in jeder Phase steuert und Gebäude und Gelände Hiti Tau gehören. So wird die Begrenzung auf Kleingruppen angestrebt und es werden an die Touristen gewisse Erwartungen herangetragen: die Touristen müssen die Sensibilität mitbringen, sich auf die andere Kultur einzulassen und das Fremde so respektieren wie es ist. Die beteiligten Maohi entscheiden selbst was und wie viel sie von ihrer Kultur zeigen. Hiti Tau möchte sich bewusst vom Postkartenimage absetzen und das Verständnis für die Kultur, Wirtschaftsweise und politische Situation der Einheimischen fördern.

\footnotetext{
${ }^{163}$ In Französisch-Polynesien wird zur Ortsangabe immer der Zusatz Bergseite (côté montagne) oder Meerseite (côté mer) gebraucht.

${ }^{164}$ In ganz Französisch-Polynesien existiert keine Mülltrennung. Die Einfuhr von Plastik-Einwegflaschen hat eine verheerende Wirkung auf allen Inseln. Nur auf Raiatea gibt es bisher Hinweisschilder, die die „Entsorgung“ von Müll im Straßengraben untersagen.
} 
Der Tourismus soll zudem immer eingebettet in das alltägliche Leben und verbunden mit anderen Formen der traditionellen Einkommenserzielung (z. B. Fischfang) bleiben und nicht zum Selbstzweck werden.

Wertung: soziokulturelle Nachhaltigkeit: sehr hoch

b) Taaroa Lodge, Tahiti

Die Taaroa Lodge befindet sich $18 \mathrm{~km}$ von Papeete an der trockeneren Westküste in Paea direkt am Meer. Sie besteht zurzeit aus einem Gästehaus mit einem Doppelzimmer und einem Schlafsaal für maximal acht Personen auf der ersten Etage. Zwei kleine Bungalows für 2-3 Personen sind in Planung. Das Gästehaus befindet sich in einem Garten, in dem sporadisch auch Nutzpflanzen wachsen (z. B. Brotfrucht). Das Besitzerehepaar gehört zu den demi (er: KanakiMaohi, sie: Französin-Maohi); beide sind nicht Mitglied im Netzwerk Hiti Tau.

\section{1) ökonomische Faktoren:}

Die Taaroa Lodge schafft zwei halbe Arbeitsplätze. Die Familie, der die Lodge gehört, wohnt auf dem selben Grundstück in ihrem eigenen Haus. Vater und Mutter leiten die Lodge im Nebenerwerb. Auch hier ergeben sich sekundäre wirtschaftliche Effekte für Lebensmittelhandel und lokalen Transport. Lokale Anbieter von Baustoffen profitieren, da die Lodge und auch die geplanten Bungalows vom Vater weitgehend selbst gebaut werden. Ein naher Snack profitiert ebenfalls von den Touristen in der Taaroa Lodge, die sich entweder selbst versorgen oder dort essen.

Wertung: ökonomische Nachhaltigkeit: hoch

\section{2) ökologische Faktoren:}

Auf Grund der Nähe zu Faa'a und Papeete ist die Frequenz der trucks häufiger, so dass diese von Touristen zur Anreise und zu Ausflügen gut genutzt werden können. Da die meisten internationalen Flüge mitten in der Nacht an- und abfliegen, werden die Touristen dennoch häufig mit dem Auto gefahren. Flächenbedarf, Abfallaufkommen und Wasserverbrauch pro 
Tourist sind zwar gering, aber Abwasserentsorgung über eine Kläranlage findet nicht statt ${ }^{165}$, Müll wird nicht getrennt und regenerative Energien werden nicht genutzt.

Wertung: ökologische Nachhaltigkeit: mittel

3) soziokulturelle Faktoren:

Die beiden Besitzer der Taaroa Lodge steuern die ohnehin geringe Anzahl der Gäste und lehnen auch schon einmal unsympathische Anfrager ab. Im Garten der Lodge sind traditionelle Symbole und Techniken zu finden, z. B. bei der Gestaltung der „Siestahütte“. Darüber hinaus erläutert das Ehepaar (ohne dies zu kommerzialisieren) alte Techniken, z. B. Ernte und Aufschlagen von Kokosnüssen, oder erzählt von Kultur und Geschichte. Allabendlich treffen sie sich mit Ihren Gästen im Garten zu Gesprächen oder gemeinsamem Essen. Der Name der Lodge (Taa Roa = oberster Gott) und die tahitianischen Namen der Kinder verweisen auf eine starke Verbundenheit mit der Tradition. Gäste und Gastgeber zeigen in der Regel großes Interesse an einem Dialog, so dass ein wirklicher Austausch zwischen Reisenden und Bereisten zu Stande kommt. Dies ist nur bei der derzeit geringen Gästezahl realisierbar.

Wertung: soziokulturelle Nachhaltigkeit: sehr hoch

c) Pauline Village, Bora Bora

Pauline Village liegt zirka sechs km südlich von Vaitape (Bergseite). Es existieren acht Bungalows, ein Schlafsaal für maximal acht Personen und ein Campingplatz. Die Besitzerin Pauline (sie ist Maohi) besitzt in Bora Bora noch ein Hotel und eine weitere größere Bungalowanlage. Pauline Village wird auch über Hiti Tau vermittelt.

\section{1) ökonomische Faktoren:}

In Administration und Service werden ein Vollzeit- und drei Teilzeitarbeitsplätze direkt geschaffen. Die Touristen in Pauline Village versorgen sich selbst über den nahen

${ }^{165}$ Französisch-Polynesien verfügt über keine Kläranlage. Die Abwässer werden mehr oder weniger direkt in die jeweilige Lagune eingeleitet 
Lebensmittelladen oder aus Vaitape. Die truck-Fahrer haben sich ganz auf die An- und Abfahrtzeiten der Touristen eingestellt.

Wertung: ökonomische Nachhaltigkeit: hoch

\section{2) ökologische Faktoren:}

Die Touristen bewegen sich mit dem truck, per Anhalter ${ }^{166}$ oder mit dem Fahrrad fort. Die Ringstraße um Bora Bora enthält kaum Steigungen. Vaitape ist von Pauline Village in weniger als einer Stunde zu erreichen; die gesamte Insel lässt sich in vier Stunden mit dem Fahrrad umrunden. Pauline Village vermietet Fahrräder und organisiert für die An- und Abreise einen truck. Abfallaufkommen und Wasserverbrauch sind pro Tourist zwar gering, aber Abwasser- und Müllentsorgung stellen zusammen mit den begrenzten Wasservorräten auf Bora Bora ein Problem dar, da die Kapazitäten der örtlichen Müllkippen kaum ausreichen, die Lagune schon stark verschmutzt ist und in trockenen Monaten das Wasser rationiert werden muss. Regenerative Energien werden nicht genutzt.

Wertung: ökologische Nachhaltigkeit: gering

\section{3) Soziokulturelle Faktoren:}

Die Besitzerin Pauline ist in der Regel nicht anwesend und die Touristen werden in keiner Weise sensibilisiert für Belange der Maohi. Pauline Village unterscheidet sich nicht von anderen kleinen bis mittleren Beherbergungsbetrieben aus Bora Bora. Die indigene Besitzerin und ihre Familie profitieren von dem ökonomischen Erfolg ihrer Anlagen.

Wertung: soziokulturelle Nachhaltigkeit: mittel

\footnotetext{
${ }^{166}$ Die Möglichkeit, sich per Anhalter fortzubewegen steigt mit zunehmendem Abstand von Tahiti. Auf Bora Bora stehen die Chancen, mitgenommen zu werden, noch relativ gut
} 
d) Chez Henriette, Huahine

Die Pension „Chez Henriette“ liegt einen Kilometer südlich vom Hauptort Fare auf der Meerseite. Henriette (Maohi) verfügt über sechs Bungalows - drei für bis zu vier Personen und weitere drei für bis zu zwei Personen. Die Bungalows waren früher im traditionellen Stil erbaut, nach dem letzten Wirbelsturm aber durch eine stilneutrale Architektur ersetzt worden. „Chez Henriette“ wird über Hiti Tau vermittelt.

\section{1) ökonomische Faktoren:}

In der Pension „Chez Henriette“ existieren drei Arbeitsplätze (1 Vollzeit, 2 Teilzeit).

Wirtschaftliche Sekundäreffekte ergeben sich für lokale Gastronomie, Lebensmittelläden und Transport. Der truck-Service ist extrem gering, so dass zu Ausflügen in der Regel Mopeds und Autos gemietet werden.

Wertung: ökonomische Nachhaltigkeit: hoch

\section{2) ökologische Faktoren:}

Einerseits ist die Pension vom Hafen in Fare aus zu Fuß erreichbar, andererseits sind die Touristen bei individuellen Ausflügen darauf angewiesen, ein Fahrzeug zu leihen, zumal der Verkehr insgesamt mit zunehmender Entfernung so gering wird, dass auch die Möglichkeit, sich per Anhalter fortzubewegen, wegfällt. Auch bei „Chez Henriette“ sind Müllaufkommen und Wasserverbrauch der Touristen nicht hoch, aber die Insel hat - genau wie Bora Bora - generell begrenzte Wasserressourcen, kein geregeltes Abwassersystem und ebenso wenig genutzte regenerative Energien.

Wertung: ökologische Nachhaltigkeit: mittel 
3) soziokulturelle Faktoren:

Bei „Chez Henriette“ ist die Touristenzahl zu hoch, als das eine verstärkte Auseinandersetzung mit dem einzelnen Reisenden stattfinden kann. Die Familie von Henriette profitiert aber ausschließlich von den Gewinnen. Ansonsten besteht kein Unterschied zu anderen kleineren Beherbergungsbetrieben auf Huahine.

Wertung: soziokulturelle Nachhaltigkeit: mittel

e) Pension Maeva, Huahine

Die Pension Maeva befindet sich auf dem Motu Mahare östlich des Ortes Maeva. Es existieren acht kleine Bungalows im traditionellen Stil direkt am Strand und ein Campingplatz. Die Pension Maeva befindet sich im Besitz der Familie Delors und wird auch über Hiti Tau vermittelt.

\section{1) ökonomische Faktoren:}

Die Pension beschäftigt insbesondere die Mitglieder der Familie Delors, somit werden vier Teilzeitarbeitsplätze geschaffen. Die Touristen können sich selbst versorgen oder in einem zentralen Essraum etwas essen. In jedem Fall entstehen wirtschaftliche Sekundäreffekte für lokale Lebensmittelläden und Transport (Auto-, Mopedverleih).

Wertung: ökonomische Nachhaltigkeit: hoch

\section{2) ökologische Faktoren:}

Die ökologischen Faktoren sind weitgehend identisch wie bei „Chez Henriette“, zusätzlich müssen Touristen bei An- und Abreise ein Auto (Leihwagen, Taxi, Transport durch die Familie) in Anspruch nehmen.

Wertung: ökologische Nachhaltigkeit: mittel 
3) soziokulturelle Faktoren:

Die Familienmitglieder bemühen sich, so weit es die Anzahl der Gäste zulässt, sich mit den einzelnen Touristen zu befassen. Da die ganze Familie auf dem Gelände der Pension wohnt, entstehen oft intensivere Gespräche zwischen Gast und Gastgeber. Finanziell profitiert ausschließlich die Familie von den Einkünften aus der Pension.

Wertung: soziokulturelle Nachhaltigkeit: hoch

f) Ariiura Camping Ecologique chez Hubert et Cecéle, Huahine

Der ökologische Campingplatz Ariiura von Hubert und Cecéle Bremond befindet sich an der südlichsten Spitze von Huahine Iti direkt am Strand, zirka eine Autostunde von Fare entfernt. Die gesamte Familie Bremond lebt mit drei Generationen auf dem Gelände, auf dem auch Nutzpflanzen gezogen werden (Taro, Maniok u.a.). Zehn kleine Bungalows im traditionellen Stil für jeweils zwei Personen befinden sich ebenfalls auf dem Gelände.

\section{1) ökonomische Faktoren:}

Alle Familienmitglieder (insgesamt sechs ohne die Kinder) arbeiten mit wechselnden Aufgaben auf dem Terrain. Die Touristen versorgen sich ausschließlich selbst durch Lebensmitteleinkäufe in Fare oder im nahe gelegenen Snack. Da der truck nur einmal am Tag nach Fare und zurück fährt, werden häufig Autos und Mopeds gemietet, zumal - außer nach Fare - überhaupt kein truck-Service besteht.

Wertung: ökonomische Nachhaltigkeit: hoch

\section{2) ökologische Faktoren:}

Da die ökologischen Rahmenbedingungen überall auf Huahine gleich sind, gilt für Ariiura Camping im Wesentlichen dasselbe wie für „Chez Henriette“ und für die Pension Maeva. Hinzu 
kommt noch eine extreme Wasserknappheit, speziell im Süden der Insel. Die Wasservorräte des Campingplatzes werden mit einem Tankwagen angeliefert und das Wasser ist mehrere Stunden am Tag gesperrt. Hubert und Cecéle haben neben dem Campingplatz einen Garten mit traditionellen Heilpflanzen (Projekt: „Back to Eden“) an der Bouraye Bay angelegt und sind aktive Mitglieder einer örtlichen Naturschutzorganisation. Sie ermahnen Besucher zum respektvollen und schonenden Umgang mit natürlichen Ressourcen. Darüber hinaus werden botanische Wanderungen angeboten.

Wertung: ökologische Nachhaltigkeit: hoch

3) soziokulturelle Faktoren:

Die Familie, die sich vorwiegend über die Einkünfte aus dem Campingplatz finanziert, klärt die Touristen auch über kulturelle Hintergründe auf: Die gesamte Anlage sei einem polynesischen Dorf nachempfunden mit einzelnen Fares jeweils zum Schlafen, Essen, Kochen und Waschen. Es entstehen oft lange Gespräche zwischen Gästen und Gastgeber. Dennoch haben Hubert und Cecéle die maximale Verweildauer auf ihrem Gelände auf 14 Tage beschränkt, um letztendlich nach einem befristeten Zeitraum der Nähe wieder eine gewisse Distanz zu den Touristen herzustellen. Der Kontakt bleibt aber nach der Abreise der Gäste oft über Jahre hin erhalten, zumal einige wiederkommen. Obwohl Ariiura Camping schon eingebunden ist in ein Netz internationaler Anbieter (z. B. Ikarus Reisen), wird das Projekt ausschließlich durch die Vorstellungen der Familie gesteuert.

Wertung: soziokulturelle Nachhaltigkeit: sehr hoch

g) Projekt Patu, Tahaa

Das Tourismusprojekt Hiti Taus „Patu“ befindet sich auf dem ca. $2000 \mathrm{~m}^{2}$ großen Motu Pueheru, nördlich von Patio, dem Hauptort der Insel Tahaa. Es gehört der Familie Hunter und verfügt über zwei kleine Touristenbungalows, zwei weitere sind in Planung. 


\section{1) ökonomische Faktoren:}

Die Familie Hunter lebt im Wesentlichen von Perlenzucht und dem Anbau von Vanille. Die Beherbergung von Touristen auf dem Motu geschieht im Nebenerwerb und unregelmäßig, da den anderen ökonomischen Tätigkeiten oft der Vorzug gegeben wird. Auf dem Motu gibt es zwar Wasser, aber es eignet sich nicht zum Trinken. Trinkwasser, sowie sämtliche Lebensmittel (mit Ausnahme von Fisch) und Baumaterialien müssen per Boot herangeschafft werden. Die Infrastruktur auf dem Motu ist noch sehr rudimentär (kein fließendes Wasser, kein Telefonanschluss, max. vier Personen können untergebracht werden); Energie ist allerdings vorhanden - sie wird über eine Photovoltaikanlage erzeugt. Sekundäre wirtschaftliche Effekte entstehen durch erhöhte Nachfrage für lokale Lebensmittelgeschäfte und Baubedarf. In geringem Umfang entstehen positive Effekte für die Hauptwirtschaftszweige der Familie, da direkt an die Touristen Vanille und Perlen verkauft werden können.

Wertung: ökonomische Nachhaltigkeit: mittel

\section{2) ökologische Faktoren:}

Die Anreise erfolgt mit dem familieneigenen Boot. Das leicht salzhaltige Wasser, das zum Waschen benutzt wird, wird mit einem Dieselgenerator gewonnen. Die übrige Elektrizität wird über die Photovoltaikanlage erzeugt. Die Müllentsorgung geschieht auf dem Motu selbst durch Verbrennen in einer Grube. Das Abwasser wird meist direkt in die Lagune geleitet.

Wasserverbrauch und Abfallaufkommen pro Tourist sind sehr gering. Ein Problem entsteht durch die massive Anschwemmung von Müll durch die Strömung von Tahaa. Im Südwesten des Motus wird fast täglich Unrat angespült.

Wertung: ökologische Nachhaltigkeit: mittel

\section{3) soziokulturelle Faktoren:}

Die Familie steuert das Angebot der Beherbergung auf dem Motu selbst und verfügt selbst über die erwirtschafteten Gewinne. Sprachbarrieren behindern den Austausch zwischen Gast und Gastgeber, da die Mutter etwas und der Vater gar kein Französisch spricht. Dennoch wird einiges 
vom Alltag der Familie vermittelt, da die Möglichkeit besteht, die Arbeit auf der Vanilleplantage, die Perlenzucht und den Fischfang kennen zu lernen.

Wertung: soziokulturelle Nachhaltigkeit: hoch

h) Chez Louise, Tahaa

Restaurant und Backpacker-Unterkunft von Louise befinden sich in Tiva auf Tahaa und damit an einem der Haltepunkte der Fähre von Raiatea. Das Restaurant liegt zur Meerseite hin, während das Gästehaus auf der anderen Seite der Straße auf der Bergseite ist. Beide gehören Louise und ihrer Familie.

\section{1) ökonomische Faktoren:}

Durch den gleichzeitigen Betrieb des Restaurants und der Unterkunft verdient Louise pro Tourist mehr als bei einer reinen Beherbergung. Da sie mit ihren niedrigen Preisen sowohl bezüglich des Restaurants als auch bezüglich der Unterkunft quasi ein Monopol auf Tahaa besitzt und mit den Tour-Operatern zusammenarbeitet, die die Touristen zu Ausflügen fahren, sind die ökonomischen Rahmenbedingungen sehr gut. Sekundäre wirtschaftliche Effekte entstehen hier für die Lebensmittelgeschäfte und für den lokalen Transport.

Wertung: ökonomische Nachhaltigkeit: sehr hoch

\section{2) ökologische Faktoren:}

Die generellen Rahmenbedingungen wie fehlende Abwasserentsorgung und ungeregelte Müllentsorgung auf Tahaa gelten auch für dieses Projekt. Wasserverbrauch und Müllaufkommen sind auch hier pro Tourist gering, regenerative Energien werden nicht genutzt. $\mathrm{Zu}$ Ausflügen muss in der Regel ein Auto oder ein Moped gemietet werden, da trucks äußerst selten fahren.

Wertung: ökologische Nachhaltigkeit: mittel 
3) soziokulturelle Faktoren:

Die Touristenzahl in Louises Restaurant und Unterkunft ist zu hoch, als dass sich ein wirklicher Austausch, der über Oberflächlichkeiten hinaus geht, entwickeln könnte. Immerhin ist die Familie einziger Profiteur ihrer eigenen touristischen Aktivitäten.

Wertung: soziokulturelle Nachhaltigkeit: mittel

i) Chez Mama Changaud, Tahaa

Die Ein-Zimmer-Übernachtungsmöglichkeit von Mama Changaud befindet sich in Haamene auf Tahaa. Das Zimmer befindet sich in der Privatwohnung der Familie.

1) ökonomische Faktoren:

Die Erwirtschaftung von Einkommen durch die Vermietung des Zimmers an Touristen dient dem beruflichen Nebenerwerb. Eine Haupteinkommensquelle der Familie ist der Vanilleanbau. Minimale wirtschaftliche Sekundäreffekte ergeben sich für Lebensmittelgeschäfte, lokalen Transport und die eigene Vanilleproduktion.

Wertung: ökonomische Nachhaltigkeit: gering

2) ökologische Faktoren:

Die ökologischen Bedingungen sind im Wesentlichen vergleichbar mit denjenigen von „Chez Louise" und sind - im Falle der Ungunstfaktoren wie mangelnde Abwasserentsorgung - nicht von den Betreibern der touristischen Mikroprojekte selbst zu verantworten.

Wertung: ökologische Nachhaltigkeit: mittel 
3) soziokulturelle Faktoren:

Die Familie profitiert ausschließlich von den Zusatzeinnahmen durch die Beherbergung. Der einzelne Gast wird in das Familienleben integriert und kann sich mit dem Alltag einer polynesischen Familie auseinandersetzen. Auf der anderen Seite sind auch von Seiten der Familie Zeit und Möglichkeiten vorhanden, sich mit dem Gast zu befassen.

Wertung: soziokulturelle Nachhaltigkeit: sehr hoch

\subsubsection{Bewertung auf der globalen Ebene}

Die akkulturative Wirkung durch den Tourismus ist im Vergleich zu anderen Faktoren wie CEP oder Massenmedien geringer einzuschätzen, zumal die Touristendichte mit Ausnahme von Tahiti, Moorea und Bora Bora im Vergleich zu anderen Destinationen im Pazifik äußerst gering ist. Da der Anteil der indigenen Bevölkerung mit 67\% sehr hoch ist, ist im Rahmen der touristischen Planung eine besondere Sensibilität gegenüber den Einheimischen geboten. Verstöße gegen die Menschenrechte finden in geringem Maße statt: Die Ureinwohnerorganisation Hiti Tau vielfach Schikanen seitens der Territorialverwaltung ausgesetzt ist. So werden Visa für ausländische freiwillige Helfer generell verweigert. Der größte Negativfaktor in der Bewertung der Nachhaltigkeit jeglicher touristischer Aktivitäten in Französisch-Polynesien ist der Raumüberwindungsindikator. Die unvermeidliche Flugreise vom touristischen Hauptquellgebiet Europa, bzw. von den USA und Japan, weist einen derart hohen Energieverbrauch und entsprechende Schadstoffemissionen auf, dass die ökologische Komponente bei der Bewertung jeglicher touristischer Aktivitäten in Französisch-Polynesien in der Summe im Sinne der Nachhaltigkeit negativ bewertet werden muss. Mit anderen Worten, auf Grund der Anreise mit dem Flugzeug, die von Europa in der Distanz um die halbe Erdkugel führt, kann man in Französisch-Polynesien nicht von einer nachhaltigen Form des Tourismus im ökologischen Sinne sprechen, da hier die globale ökologische Komponente die lokale völlig überlagert. 


\section{$\underline{6.7 \text { Zwischenbilanz }}$}

Der Tourismus in Französisch-Polynesien wird von allen gesellschaftlichen Gruppen im Wesentlichen bejaht, nur über die Form, bzw. die Intensität gibt es unterschiedliche Bewertungen. Während auf Grund prinzipiell begrenzter Ressourcen zum Tourismus als einkommenschaffende Maßnahme - vor dem Hintergrund einer durch eine dependente Transferökonomie überformte Volkswirtschaft - kaum wirkliche Alternativen bestehen, kann auch keine Diskussion über das „ob“, sondern nur über das „wie“ geführt werden.

Während staatliche Stellen den Tourismus, insbesondere den Luxustourismus (haut de gamme) fördern, geht eine wachsende Zahl an kleinen und Kleinstprojekten einen anderen Weg. Vor dem Hintergrund einer wachsenden Zahl an Individualtouristen besteht so die Möglichkeit, insbesondere für Maohi, die am klassischen Tourismus nur auf den unteren Ebenen partizipieren - eine selbstständige Existenz aufzubauen.

Der Begriff eines sanften/nachhaltigen Tourismus ist weder bei Beherbergungsbetrieben, noch bei Reiseveranstaltern, Bereisten oder Touristen hinreichend bekannt. Dies verwundert nicht, schließlich ist er in seinen drei Dimensionen sehr komplex. Vorstellungen von Ökotourismus werden als Naturtourismus interpretiert.

Die Tourismusprojekte Hiti Taus und die Initiativen anderer Maohi auf dem Gebiet der Betreibung kleiner Beherbergungsbetriebe bieten hoffnungsvolle Ansätze in Richtung einer nachhaltigen Form von Tourismus. Wenn auch durch die Fernreise ein Urlaub in FranzösischPolynesien niemals nachhaltig im ökologischen Sinne sein kann, so sind die in Kap. 6.3.3 bewerteten Projekte auf der soziokulturellen Ebene in hohem Maße und auf der ökonomischen Ebene teilweise nachhaltig. Für eine abschließende und endgültige Evaluation müssten die o.g. Projekte über einen längeren Untersuchungszeitraum hin beobachtet werden, zumal einige erst 1999 entstanden. 


\section{AKKULTURATIVE PROZESSE UND TOURISMUS IN ANDEREN REGIONEN DES PAZIFIK - EIN VERGLEICH}

Der Ablauf der Überformung der autochthonen Kulturen in anderen Regionen des Pazifik weist große Parallelen mit dem Prozess in Französisch-Polynesien auf. In Neuseeland, Hawaii, Fidschi und den Cook-Inseln bestand analog zu Französisch-Polynesien nach deren jeweiliger „Entdeckung“ zunächst ein sporadischer Kontakt (z. B. Wahlfänger) zur westlichen Welt. Mission und Kolonisation trugen in vergleichbarem Ausmaß zur Überformung der autochthonen Kulturen bei.

Der Tourismus im Pazifik war in Bezug auf die Ankünfte von den 20er Jahren des letzen Jahrhunderts bis nach dem zweiten Weltkrieg zahlenmäßig nicht nennenswert und spielte sich per Schiff ab. Die ab 1959 eingesetzten Düsenjets erlaubten erstmals das Erreichen pazifischer Ziele in einer stark verkürzten Reisezeit. Inbesodere Guam, Fidschi und Hawaii stiegen zu stark frequentierten touristischen Zielregionen auf (vgl. GLATTHAAR 1990, S. 86 f.) .

Auffällig bei den ethnischen Gruppen ist der wirtschaftliche Erfolg der jeweils eingewanderten Chinesen insbesondere in Hawaii, Fidschi und Französisch-Polynesien.

\section{Neuseeland}

WURZEL (1999, S. 4) teilt die Zeit des Kulturkontaktes zwischen Maori und Weißen in Neuseeland in fünf Zeitabschnitte ein:

- 1769-1840 Phase der ersten Kontakte (1769 Entdeckung durch Cook)

- 1840-1846 Periode des Vertrages von Waitangi

- 1847-1960 Assimilierungsphase

- Integrationsphase

- Perode der Maori-Renaissance

ALVES (1999, S. 3-11) gibt eine Überblick über die voreuropäische Kultur FranzösischPolynesiens.

Die Rolle der Mission war auch in Neuseeland ambivalent. Frühe, autochthone Glaubenssysteme wurden überformt oder zerstört. Die (wenn auch zum Teil vordergründige) Annahme des 
christlichen Glaubens erlaubte andererseits Maoris, die am unteren Ende der traditionellen polynesischen Gesellschaft standen, einen Ausbruch aus ihrer untergeordneten Stellung:

„Missionaries were less successful in their religious teaching, and soon complained of the lack of conviction in many nominally Christian. Indeed, much of the Maori enthusiasm was for reading and writing as a way to knowledge. Former slaves returning from the north could sometimes do what their chiefs could not, and ambitious men of low birth saw in these new accomplishments a way to advancement." (s. ALVES 1999, S. 14)

Mit dem Vertrag von Waitangi hatten die Maori ein - wenn auch umstrittenes Vertragswerk in der Hand, dass ihnen einen rechtlichen Anspruch auf Land sicherte. 1863 wurde der Vertrag von Waitangi durch den New Zealand Settlement Act faktisch gebrochen, wofür sich die britische Krone 1995 offiziell entschuldigte. Mehrere Gerichtsverfahren um Landstreitigkeiten wurden in der Folge zu Gunsten der Ureinwohner entschieden (vgl. ALVES 1999, 127 ff.). Eines der Hauptprobleme des Vertrages von Waitangi war die Nichtübertragbarkeit des englischen Wortlautes ins Maori, da entsprechende sprachliche Gegenstücke fehlten (vgl. B. KREISEL 1992, S. 189 f.)

Nach Dezimierung der Bevölkerungszahl und starken kulturellen Verlusten ist in Neuseeland in der Gegenwart durchaus eine Renaissance der Maori-Kultur (,Maoritanga“) zu beobachten:

„Im Protest äußern Maori seit den 70er Jahren ein neues Bewusstsein, eine Rückbesinnung auf ihre eigenen Werte und Traditionen. Ihre Forderung lautet: Weg von der Assimilation, Sozialhilfe und Abhängigkeit vom Wohlfahrtsstaat, hin zu einer kulturellen und wirtschaftlichen Emanzipation ihres Volkes." (s. B. KREISEL 1992, S. 206)

In diesem Zusammenhang erfuhren die Marae als gesellschaftliche und religiöse Zentren eine neue Aufwertung. Außerdem wurde das Maori 1987 offiziell dem Englischen als Landessprache gleichgestellt und verstärkt in die schulische Ausbildung integriert (vgl. B. KREISEL 1992, S. $208 \mathrm{f}$.

Fortan spielten Maori-Autoren mit Themen, die ihre eigene Kultur betrafen, eine verstärkte Rolle in der neuseeländischen Gegenwart. Neuere Tendenzen in Literatur, Theater und Film spiegeln diese Entwicklung wider (vgl. MARSDEN 1992, BALME 1992 und DAVIS 1992).

Eine zeitgenössische Reflektion des akkulturativen Prozesses in Neuseeland liefert der später auch verfilmte Roman „Once Were Warriors“von Alan DUFF (selbst Maori). In seiner Aussage in Neuseeland außerordentlich umstritten zeichnet der Roman eine schonungslose Situation der 
Ureinwohner, deren Lebenskonzept nicht taugt die (von weißen Regeln bestimmte) Realität zu meistern:

„Aus den - nach Duff - stilisierten Kulturidealen lassen sich keine Lebensmuster gewinnen, mit denen die Maori ihre Wirklichkeit in der Pakeha ${ }^{167}$-Kultur bewältigen können. Er beschreibt in seinem Roman das Dasein arbeitsloser, von staatlicher Unterstützung lebender Maori, die das Ghetto von Pine Block bewohnen. Ihr Leben ist durch Gewalt und Drogen gekennzeichnet. Missbrauch und Vergewaltigungen sind nicht außergewöhnlich. [...] Dadurch reduziert er Maori-Kultur auf eine archaische, für die heutige Gesellschaft ungeeignete Lebensform.“ (s. WURZEL, S. 75-76)

Bei allen Parallelen, die der akkulturative Prozess in Neuseeland mit dem in FranzösischPolynesien gemeinsam hat, so fällt die kulturelle Renaissance der Maori stärker aus, als diejenige der Maohi. Eine entsprechende politische Unterstützung dieses Prozesses in diesem Maße von offizieller Seite ist in Französisch-Polynesien nicht gegeben.

Nach Hawaii zählt Neuseeland zu den von Touristen am stärksten frequentierten Regionen im Pazifischen Inselraum. Auf Grund seiner relativen Größe zu Französisch-Polynesien, Hawaii, Fidschi oder den Cook-Inseln, ist die relative Tragfähigkeit größer, Massentourismus bisher nicht zu verzeichnen (vgl. KREISEL 1991, S. 317). Das Strand-Palme-Lagune-Klischee trifft auf Neuseeland nicht zu; demnach ist der Tourismus hier im Gegensatz zu Französisch-Polynesien eher auf Natur und ländliche Idylle ausgerichtet. Die folklorisierte Vermarktung der indigenen Kultur wiederum ist allen pazifischen Regionen gemeinsam.

\section{Hawaii}

Nach seiner „Entdeckung“ durch Cook (1778) durchlief auch Hawaii die typischen Stadien der Akkulturation: Sporadischer Kontakt zu Weißen - Mission (hauptsächlich Protestanten) Kolonialismus.

KREISEL (1984) beschreibt am Beispiel der Hawaii-Inseln u. a. die ungleiche Partizipation der verschiedenen ethnischen Gruppen an der wirtschaftlichen Entwicklung. Während Chinesen und Japaner (ursprünglich als Plantagenarbeiter nach Hawaii gekommen) im Laufe der Zeit den wirtschaftliche und sozialen Aufstieg schafften und mit den Weißen gleichziehen konnten, gelang dies anderen ethnischen Gruppen, so auch der autochthonen, hawaiianischen Urbevölkerung nicht.

\footnotetext{
${ }^{167}$ Pakeha ist die Maori-Bezeichnung für Weiße
} 
BENHAM und HECK (1998, S. 3 f.) interpretieren den heutigen Status der „Nativ Hawaiians“ am unteren Ende der gesellschaftlichen Skala als Folge des akkuturativen Prozesses verursacht durch die Weißen:

For Native Hawaiians, who were involuntarily colonized beginning with the increasing Western contact in the late 1700s and later conquered and annexed by the United States in 1893 [...], the result of prolonged contact with foreign values and government has been perhaps most devasting. Western domination has largely stripped us of our language, customs, social position, self-governance, and cultural identity.

Anhand von Konzepten wie „Intellekt“, „Spiritualität“, „Wissen“ und „Analyse“ zeigen BENHAM und HECK (1998, S.33), dass diese von Native Hawaiians mit völlig anderen, teils gegenläufigen Bedeutungen belegt sind, als die jeweilige westliche Interpretation. Für den anhaltenden Zustand der Marginalisierung der Ureinwohner infolge des kulturellen Verlustes machen sie insbesondere das Erziehungssystem nach Euro-Amerikanischem Muster verantwortlich und fordern daher einen stärkeren Einbezug indigener Denkweisen in pädagogische Ansätze (vgl. ebenda, S. 207 ff.).

Im Vergleich kann der akkulturative Prozess in Hawaii vielleicht als der „,vollständigste“ beurteilt werden. Die „Amerikanisierung“ drang in nahezu alle Lebensbereiche der Ureinwohner vor.

Von den Amerikanern als massentouristisches Ziel erschlossen, nimmt Hawaii mit weitem Abstand - nach Touristenankünften - den Spitzenplatz im pazifischen Raum ein. Der Tourismus wurde zum wichtigsten Wirtschaftszweig der Insel. Entsprechend ist die soziokulturelle Tragfähigkeit längst überschritten, was sich allerdings nicht in entsprechenden Umfragen äußerte. Befragungen der gesamten Bevölkerung Hawaiis in den 70er und 80er Jahren ergaben, dass der Tourismus insbesondere in seiner ökonomischen Funktion, aber auch in seinem kulturellen Beitrag von der Mehrheit der Bevölkerung positiv gewertet wurde (vgl. KAHRMANN 1995, S. $130 \mathrm{ff}$.).

Dies ändert sich, wenn man nur den Blickwinkel der autochthonen Hawaiianer untersucht:

„Diese fremdenfeindliche Einstellung wurzelt in den kolonialen Erfahrungen ethnischer Hawaiianer mit den Haole (Weißen). Ethnische Hawaiianer werden seit 1893 durch Weiße von ihrem Land vertrieben und ausgebeutet. Die gleichen Strukturen zeichnen sich auch heute in der Touristikindustrie ab: Ethnische Hawaiianer werden wegen eines Golfplatzes oder Hotels gezwungen, ihr Land zu verlassen. Die Invasion der Touristen auf Hawaii steht als Symbol für Landvertreibungen und die Bedrohung der polynesischen Lebensweise und Kultur, denn Land ist die Grundlage für diese Lebensweise. Auf die Touristen richtet sich der Groll der Polynesier, die Kontrolle über ihr Land verloren zu haben.“ (s. KAHRMANN 1995, S. 194) 
Französisch-Polynesien hat bisher weder einen derart starken akkulturativen Effekt, noch einen derartig starken Besucherzustrom zu verzeichnen, obwohl auch die Errichtung des CEP einen massiven Einschnitt in Kultur und Ökonomie bedeutete. Von der touristischen Infrastruktur Hawaiis mit seinem beispiellosen Aufstieg zu dem massentouristischen Ziel im pazifischen Inselraum ist Französisch-Polynesien weit entfernt, auch hat die autochthone Kultur der Maohi einen größeren kulturellen Handlungsspielraum als die Polynesier Hawaiis. Die folklorisierte Vermarktung der indigenen Kultur findet mit dem „Polynesian Cultural Center“ auf Oahu einen traurigen Höhepunkt (vgl. KREISEL 1991, S. 324).

\section{Fidschi}

Im Gegensatz zur Hawaii, Neuseeland, den Cook-Inseln und Französisch-Polynesien gehört Fidschi nicht zum polynesischen Kulturkreis, sondern zum melanesischen. Ebenfalls im Gegensatz zu o. g. Inseln wurde Fidschi 1970 von Großbritannien unabhängig. Die heutige ethnische Struktur weist eine im pazifischen Raum einmalige Besonderheit auf: die Hälfte der Bevölkerung stellen Inder, ehemals eingewanderte Kontraktarbeiter.

„Entdeckt““ von Abel Tasman, war es auch bei den Fidschi-Inseln wiederum Cook, der die genauere Erforschung des Gebietes in Gang setzte.

Die Überformung der traditionellen fidschianischen Gesellschaft führt MÜCKLER (1998, S. 42) zurück auf drei Prinzipien: Imperialismus, Missionierung und wirtschaftlicher Liberalismus.

Die ethnische Zusammensetzung der Bevölkerung Fidschis, bei der sich mit den autochthonen Fidschianern und den Indo-Fidschianern sich zwei in etwa gleich große ethnische Gruppen gegenüberstehen bietet bis heute Anlass für Spannungen zwischen den beiden Gruppen.

MÜCKLER (1998, S. 171 f.) sieht in der hierarchischen Struktur der traditionellen fidschianischen Gesellschaft eine der wichtigsten Ursachen für die heutige politische Instabilität, da alte verwandtschaftliche Verbundenheit in den kolonial importierten Verwaltungsapparat integriert wurden. Die autochthonen Fidschianer sichern sich politische und wirtschaftliche Privilegien und diskriminieren die Indo-Fidschianer zum Teil offen. Hierfür stehen Parolen wie „Indians go home“ und „Fiji for the Fijians“. Die Auseinandersetzungen gipfelten in mehreren Putschs; der jüngste am 18.5.2000 zielte auf die Absetzung der demokratisch gewählten Regierung mit einem indo-fidschianischen Ministerpräsidenten (vgl. FAUST 2000, S. 16). 
Die Spannungen zwischen beiden ethnischen Gruppen bleiben nicht ohne Einfluss auf den Tourismus:

\begin{abstract}
„Die fijianischen Kräfte glauben, im Tourismus eine Möglichkeit zu erkennen, ,traditionelle fijianische Werte' zu pflegen und gleichzeitig die Stellung der Fijianer in der Gesellschaft zu sichern bzw. zu stärken. In der Selbstdarstellung des Landes, die die Tourismuswerbung zwangsläufig erfordert, wird den Besuchern dabei eine homogene und harmonische Gesellschaft vorgegaukelt, die in Wirklichkeit sehr heterogen und spannungsgeladen ist.“ (s. FAUST/DICKMANN 1991, S. 86)
\end{abstract}

Der Tourismus als solcher trägt mit ca. 400.000 (2000) Ankünften in Fidschi 19\% zum Bruttoinlandsprodukt bei und stellt 10\% aller Arbeitsplätze (1994). Der weitere Ausbau dieses Wirtschaftszweiges soll die Abhängigkeit von den Zuckerexporten verringern (vgl. FAUST 1995, S. 7). Devisen, die durch den Tourismus erwirtschaftetet werden, bleiben allerdings kaum im Land, da ausländische Investoren (insbesondere Australier, Neuseeländer und Amerikaner) sich in das Tourismusgeschäft eingekauft haben (vgl. GLATTHAAR 1990, S. 86 f.)

Der kulturelle Wandel durch den Tourismus wird von der Bevölkerung sehr wohl wahrgenommen:

„Die Teilnahme an dem in Gemeinschaftsarbeit organisierten Fischfang - einem Bestandteil der dörflichen Subsistenzwirtschaft - werde durch den Tourismus immer mehr vernachlässigt. Die fidschianische Bauweise werde durch die westliche verdrängt. [...] Die Kleidung und das Aussehen, die nicht den fidschianischen Normen entsprechen, und der mangelnde Respekt gegenüber Älteren und Autoritätspersonen wurden bei Jugendlichen von vielen befragten Erwachsenen wahrgenommen und bemängelt.“ (s. KAHRMANN 1995, S. $120 \mathrm{f}$.).

\title{
Cook-Inseln
}

Nach ihrem „Entdecker“ benannt, durchliefen die Cook-Inseln ebenfalls die typischen Stadien der Akkulturation; besonderen Einfluss hatte - auch hier - London Missionary Society. 1965 wurden die Cook-Inseln in die volle innere Selbstverwaltung entlassen, wobei die Bevölkerung die neuseeländische Staatsbürgerschaft beibehielt.

Ein Vergleich der Touristendichte (Touristen pro Einwohner) zeigt die Cook-Inseln im mittleren Bereich: Hawaii: 4,4; Cook-Inseln: 1,1; Französisch-Polynesien: 0,6 und Fidschi: 0,3. (vgl. BRAUER 1989, S. 150). Inzwischen stieg die Touristendichte Fidschis auf 2,4, während Französisch-Polynesien fast gleich blieb mit 0,7 (s. ITSTAT 1998). 
Laut KAHRMANN (1995, S. 124 f.) beurteilen die Cook-Insulaner den Tourismus nicht negativ, halten aber einen weiteren stärkeren Ausbau für unnötig:

\begin{abstract}
„Sie betonten jedoch, dass die Tourismusindustrie in Zukunft nur noch geringfügig wachsen sollte, da eine zu große Ausdehnung der Industrie ihre gewohnte Lebensweise stören könnte, die sich auch heute noch an der traditionellen Subsistenzwirtschaft orientiere. Den Hintergrund für diese Argumentation bildet die Knappheit von Land auf den Cook-Inseln. Würden noch mehr Hotels gebaut, dann würde fruchtbares Land für die traditionelle Subsistenzwirtschaft wegfallen.“
\end{abstract}

\title{
Tonga
}

„Entdeckt“ durch TASMAN im Jahre 1616 durchlief auch Tonga die typischen Stufen der westlichen Einflussnahme und wurde 1970 von Großbritannien unabhängig. Die Bevölkerung von Tonga konnte teilweise dieser Einflussnahme widerstehen und zum Beispiel die Verfügung über das Land behalten. Der Widerstand gegen die Aufoktroierung eines fremden Rechtssystems war beträchtlich:

„Eine historische Betrachtung des Verteilungssystems lässt erkennen, dass die wenig erfolgreiche Durchführung der Landreformbestrebungen in einen Zusammenhang zu bringen ist mit der von Maude betonten Individualisierung von Landrechten. Obwohl eine detaillierte Untersuchung, inwieweit westliche (insbesondere britische) Rechtsnormen die tonganische Gesetzgebung beeinflusst haben, noch aussteht, kann aus der Ablehnung, die sowohl die Adelsklasse wie einfache Tonganer dem neuen Konzept individueller Rechte entgegenbrachten, geschlossen werden, dass die Reform sich nicht ausreichend an traditionellen Normen orientierten“" (s. WIEMER 1985, S. 165 f.).

Tonga und Amerikanisch-Samoa haben in etwa vergleichbare Touristenzahlen, liegen aber weit hinter Hawaii, Neuseeland oder Fidschi. Der akkultarative Druck durch den Tourismus dürfte daher geringer ausfallen, zumal er von der polynesischen Regierung (Tonga ist eine konstitutionelle Monarchie) selbst gesteuert werden kann.

\section{West-Samoa und Amerikanisch-Samoa}

Amerikaner und Deutsche teilten Samoa 1899 auf. Westsamoa wurde im Jahre 1962 unabhängig, während Amerikanisch-Samoa ein unincorparated territory der USA blieb.

Während Amerikanisch-Samoa in die völlige (finanzielle) Abhängigkeit der USA glitt ist

„West-Samoa ein unabhängiger und souveräner Staat, basierend auf einem Regierungssystem, das eine Sythese des samoanischen traditionellen politischen Systems und einer modernen parlamentarischen Regierungsform britisch-neuseeländischer Prägung darstellt. [...] Es ist anzunehmen, dass die samoanische Regierung den bereits eingeschlagenen Weg der Modernisierung in Form selektiver Anpassung weitergehen wird, um den Fortbestand des funktionierenden soziopolitischen Systems zu gewährleisten“ (s. FENSTERSEIFER 1994, S. 261). 
Der Handlungsspielraum für eine selbstbestimmte Gesellschaftsgestaltung und damit einer Verringerung akkulturativer Negativeffekte ist für West-Samoa größer als für AmerikanischSamoa. Aufgrund seiner Anbindung an die USA wird Amerikanisch-Samoa stärker touristisch frequentiert als West-Samoa. Beide liegen bezüglich der Touristenzahlen ebenso wie Tonga, hinter Hawaii, Neuseeland und Fischi.

Die Phase der westlichen Einflussnahme (Entdeckung, Missionierung, Kolonisation) verlief in den genannten Beispielen pazifischer Inselgruppen durchaus ähnlich. Das Ergebnis für ethnische Gruppen fiel höchst unterschiedlich aus: Während auf Hawaii die Gruppe der autochtonen nur noch einen verschwindend geringen Anteil unter verschiedensten ethnischen Gruppierungen darstellt, hat Tonga eine fast ausschließliche polynesische Bevölkerung und Fidschi beispielsweise, neben den Fidschianern ca. 50\% indischstämmige Bevölkerung.

Die langfristige Anbindung an eine Kolonialmacht (wie bei Amerikansich-Samoa und Französisch-Polynesien gegeben) trägt auch zur Höhe der Tourismuszahlen und zur Fortdauer akkulturativer Prozesse bei.

Zusammenfassend lässt sich feststellen, dass Hawaii vom akkulturativen Prozess und den negativen Auswirkungen des Tourismus im Vergleich am stärksten betroffen ist. AmerikanischSamoa, Fidschi, die Cook-Inseln und Französisch-Polynesien rangieren etwa im Mittelfeld, während Neuseeland seiner autochthonen Bevölkerung wohl die besten gegenwärtigen Rahmenbedingungen für eine Renaissance der indigenen Maori-Kultur lässt und Tonga und West-Samoa als am wenigsten tangiert von touristischen Einflüssen gelten können. Die Errichtung des CEP und die in Französisch-Polynesien durchgeführten Atomtest stellen allerdings einen in dieser Form einmaligen, desaströsen Eingriff in Kultur und Ökonomie dar. 


\section{KANN TOURISMUS FÜR INDIGENE VÖLKER EINE ZUKUNFTSFÄHIGE ENTWICKLUNG BEDEUTEN? - EIN AUSBLICK}

Es lässt sich feststellen, dass sich aus den komplexen Ursachen der Akkulturation differenzierte Konsequenzen ergeben haben, die die heutige Realität der Maohi in Französisch-Polynesien bestimmen: Bis auf die Sprache (die der wichtigste Identitätsträger der Maohi ist) und teilweise die Religion in allen anderen Kulturbereichen fast völlig akkulturiert, sind die Maohi die sozialen Verlierer im westlich-marktwirtschaftlichen Gesellschaftssystem. Eine „Renaissance Culturelle“ ist höchstens punktuell zu beobachten (vgl. Kap. 6.4.7). Die derzeitigen ökonomischen Rahmenbedingungen der dependenten Transferökonomie, die in dieser Form maßgeblich durch den CEP gestaltet wurde, bieten den Maohi zu wenig Spielraum, politisch, wirtschaftlich oder kulturell zu agieren:

\footnotetext{
„Es kann jedoch angenommen werden, dass die Gefahr eines verstärkten Auflebens von Sezessionsbewegungen in ... pazifischen Inselstaaten und -territorien nur gebannt werden kann, wenn dezentrale demokratische Institutionen geschaffen werden, die den traditionellen Systemen ökonomische Integration anzubieten vermögen und der ... Bevölkerung Spielraum im Entwicklungsprozess einräumen, den diese zur Sicherung ihrer Identität brauchen. ... Was die Entwicklungschancen der Mininationen betrifft, so sollten sich diese im regionalen Kontext wesentlich wirkungsvoller verwirklichen lassen“" (RATH 1984, S. 33).
}

Die Initiative zu einer Verbesserung der Situation der Ureinwohner kann nur von ihnen selbst ausgehen:

„In diesem Prozess können sie sich nur behaupten, wenn sie durch Selbstorganisation und politische Vertretung auf nationaler Ebene Einfluss nehmen. Die Voraussetzung dazu ist Bildung, die nicht zwangsläufig die eigene Identität untergraben muss. Sonst droht ... ein Abgleiten in eine bestenfalls geduldete Randexistenz.

Konservierungskonzepte wie für Naturschutzparks sind auf Menschen nicht anwendbar. ... ,Letztendlich müssen solche Gruppen jedoch, genau wie wir, die Freiheit zu eigenen Entscheidungen haben und die Verantwortung für die Konsequenzen tragen.'“ (LARENZ 1992, S. 30).

Im Zuge eines professionellen Lobbyings auf regionaler (z. B. das Netzwerk PIANGO, vgl. Kap. 6.6.1 oder die Bewegung Nuclear Free and independent Pacific/Pacific Concern Resource Center) und internationaler Ebene kann sich indirekt die Situation der Maohi langfristig verbessern. Neben der UN Working Group on Indigenous Populations - deren Wirksamkeit durch das Nationalstaatensystem der UN selbst begrenzt ist, und höchstens Fragen verstärkter Autonomie und keinesfalls die Unabhängigkeit erörtert - gewinnt die im Februar 1991 in Den Haag gegründete Unrepresented Nations and People Organization (UNPO) (vgl. DELIUS 1992a, S. 72), die sich als Alternative für indigene Völker zur UN versteht, zunehmend an Mitgliedern und Gewicht. 
Das Jahr 2002 wird von der UN als „International Year of Ecotourism“ deklariert (vgl. JOHNSTON 2000, S. 3). Längst existieren auch internationale Vereinbarungen und Absichtserklärungen, die zum Teil in Zusammenarbeit mit der CSD (Comission on Sustainable Development), die wiederum in der Tradition der Agenda 21 (verabschiedet auf der UNKonferenz „Umwelt und Entwicklung“ in Rio de Janeiro 1992, vgl. Kap. 4.2) steht: die „Charter for Sustainable Tourism“, die „Malé Declaration on Sustainable Tourism Development“, die „Berlin Declaration: Biological Diversity and Sustainable Tourism“ oder die „Umwelterklärung der deutschen Tourismuswirtschaft“. Das Verhältnis indigener Gruppen zum Ökotourismus ist auf internationaler Ebene allerdings nicht ungetrübt:

„In relation to tourism, all that can be said at this point regarding the $\mathrm{CBD}^{168}$ is that it is a potentially constructive instrument, now low on credibility. Indigenous peoples are losing their cultures and traditional territories to a potent new form of industry commercialisation called ecotourism, which often advances hand in hand with protected areas; meanwhile, governments are looking to that very model of ecotourism as an incentive for biodiversity conservation and benefit sharing." (s. JOHNSTON 2000, S. 3)

Beim 1997er Treffen des Südpazifikforums tagte zeitgleich das inzwischen dritte NGO Parallel Forum und richtete seinen Protest insbesondere gegen die Untätigkeit anlässlich des

Klimawandels:

„We were angered that Pacific peoples' concern on climate was overridden at the South Pacific Forum. [...] Australia and other industrialised nations failed to heed our voices.“ (s. NGO Parallel Forum Communique 1997 in PIANGO Link 1998, S. 4)

Indigene Gruppen sehen die Gefahr, in den aktuellen CSD- und CBD-Prozessen von den Entwicklungen überrollt zu werden, und beklagen die mangelnden Möglichkeiten zur Einflussnahme ihrerseits, zumal nur die Möglichkeit besteht, als NGO aufzutreten, nicht aber als „Nation“. Wachsende Kritik wird in diesem Zusammenhang auch an der zunehmenden Vermarktung geistigen Eigentums, dass heißt des traditionellen Wissens indigener Gruppen geäußert, indem Symbole, Namen, Heilpflanzen oder Kunst kommerziellen Zwecken zugeführt werden (vgl. Tok Blong Pasifik 1998/1999):

„The existing IPR ${ }^{169}$ system also does not recognize that some knowledge and some things are sacred and should be protected from commercialisation or commodification.“ (Indigenous Peoples' Biodiversity Network 1997 zitiert nach JOHNSTON 1999, S. 40).

Im November 1997 fand speziell zu Artikel 8 j der CBD ein „Workshop on Indigenous Peoples, Tourism and Biodiversity Conservation“" statt. Der Artikel 8 j wurde als nicht weit reichend

\footnotetext{
${ }^{168} \mathrm{CBD}=\mathrm{UN}$ Convention on Biological Diversity; umfassendes internationales Vertragswerk zum Schutz von Lebensformen. 1992 unterzeichnet im Rahmen der UNCED-Konferenz

${ }^{169}$ IPR = Intellectual Property Rights
} 
genug eingestuft, da indigene Gruppen nur ,geachtet“"werden, nicht aber aktiv an den Entscheidungsprozessen partizipieren sollten (vgl. KAMP 1998, S. 23 f.):

Artikel 8 j der Konvention über die biologische Vielfalt:

„Jede Vertragspartei wird, so weit möglich und sofern angebracht, im Rahmen ihrer innerstaatlichen Rechtsvorschriften Kenntnisse, Innovationen und Gebräuche einheimischer und ortsansässiger Gemeinschaften mit traditionellen Lebensformen, die für die Erhaltung und nachhaltige Nutzung der biologischen Vielfalt von Belang sind, achten, bewahren und erhalten, ihre breite Anwendung mit Billigung und unter Beteiligung der Träger dieser Kenntnisse, Innovationen und Gebräuche begünstigen und die gerechte Teilung der aus der Nutzung dieser Kenntnisse, Innovationen und Gebräuche entstehenden Vorteile fördern."

Im Zuge der Diskussionen um Erleichterungen im Welthandel für Dienstleistungen im Rahmen des GATS ${ }^{170}$-Abkommens, sollen Schranken, die lokale Dienstleistungssektoren bisher schützten, entfallen. Finanzschwache, einheimische Projekte - auch im Tourismussektor - würden mit verstärkten Schwierigkeiten durch ausländische Konkurrenz rechnen dürfen.

Neben verstärkter Einflussnahme auf internationaler Ebene, ist im lokalen Bereich eine weitere Optimierung der von Maohi initiierten touristischen Kleinprojekte möglich. Der hohen soziokulturellen Nachhaltigkeit stehen eine zu geringe Professionalität und ein teilweise mangelnder Umweltschutz gegenüber, die die ökonomische und ökologische Nachhaltigkeit neben exogenen Faktoren, s.o. - beeinträchtigen.

Die Tourismusprojekte der Maohi, die teilweise dem informellen Sektor ${ }^{171}$ zugehörig sind, weisen vielfach eklatante Mängel im Bereich des Managements auf. Dies beginnt bei fehlenden Englischkenntnissen, die eine Verständigung mit einem Großteil der potentiellen Kunden erschwert, und setzt sich fort über fehlende Ausbildung in Betriebsführung bis hin zu unzureichendem Marketing. Die Verbindung zu Messen und Veranstaltern in den ausländischen Quellgebieten fehlt meist ganz, ist aber nicht unbedingt nötig, da diese kleinen Pensionen meist en passant von Individualreisenden gebucht werden. Eine praxisnahe und kostengünstige Ausbildung vor Ort bietet die Association pour la Formation aux Métiers du Tourisme et de l'Hôtellerie (Afometh) in Kursmodulen an, die auch von Maohi inzwischen stark frequentiert ist. Eine langfristige Verbesserung der Kenntnisse über Umweltzusammenhänge ist auch durch das verstärkte Engagement von Naturschutzgruppen auf Bora Bora und Huahine zu erwarten, die sich auch gezielt an Schulkinder wenden. Die Besteuerung von Flugbenzin und/oder die

\footnotetext{
${ }^{170}$ GATS $=$ General Agreement on Trade Services

${ }^{171}$ zum informellen Sektor in Französisch-Polynesien vgl. ausführlich BLANCHET 1980
} 
Weiterentwicklung sparsamerer Flugzeuge werden die negativen Auswirkungen des Ferntourismus auf die ökologische Nachhaltigkeit weder mittel- noch langfristig lösen.

Die Maohi haben trotz der Schwächen ihrer touristischen Projekte durchaus die Chance, durch einen selbst initiierten und selbst gesteuerten Tourismus Einkommen zu erwirtschaften und auf der Basis relativer wirtschaftlicher Unabhängigkeit die Richtung ihrer kulturellen Entwicklung selbst zu bestimmen. Auch wenn die Entwicklung eigeninitiativer Projekte im Umfeld einer dependenten Transferökonomie schwierig erscheint, überwiegen eindeutig die Chancen: Der Tourismus kann mit bestehenden landwirtschaftlichen Aktivitäten verknüpft werden oder zur Vermittlung von Kenntnissen über die eigene Kultur genutzt werden. Französisch-Polynesien verfügt im Zuge weltweit steigender Touristenzahlen über ein wachsendes Potential an Individualreisenden, die eine Unterbringung in kleinen Pensionen bevorzugen. Die „Imaginäre Geographie“"Französisch-Polynesiens wird auch in Zukunft Reisende insbesondere aus dem „Selbstverwirklichungsmilieu“ anziehen (vgl. Kap. 2 und 3.2). Die Werbung läuft hauptsächlich über Mundpropaganda, einschlägige Reiseführer, Schilder an der Straße und Flyer. Andererseits sorgen die hohen Kosten für die Anreise und den Aufenthalt vor Ort dafür, dass FranzösischPolynesien niemals eine so hohe Touristen-pro-Einwohner-Dichte aufweisen wird wie die englischsprachigen Nachbardestinationen.

Dass Tourismusprojekte indigener Gruppen im Sinne der Nachhaltigkeit funktionieren können, beweisen entsprechende Beispiele aus anderen Regionen (vgl. Kap. 5). Die Initiativen der Maohi in Französisch-Polynesien weisen viel versprechende Teilerfolge auf. Die existierende dependente Transferökonomie behindert allerdings diesen Prozess. Erst im Rahmen der seit 1992 bzw. 1996 verstärkt geführten ,,après-CEP“-Diskussion (vgl. Kap. 6.3.7) wird überhaupt ernsthaft über Alternativen oder Modifikationen zum bestehenden Wirtschaftsmodell nachgedacht. Eine abschließende Bewertung der Nachhaltigkeit ihrer Projekte wäre erst nach einer langjährigen Evaluation bei gleichzeitiger Weiterentwicklung der bisherigen Nachhaltigkeitsindikatoren möglich. Während die Indikatorenbildung in ökologischer und ökonomischer Hinsicht noch relativ einfach ist, gestaltet sie sich im soziokulturellen Bereich schwieriger, was nicht zuletzt auf die Problematik der Einkreisung des Begriffs Kultur zurückzuführen ist. Interessant und wichtig bleibt in diesem Zusammenhang der Einbezug indigener Vorstellungen von „Entwicklung“ und „Nachhaltigkeit“.

Die Existenz touristischer, in Ansätzen nachhaltiger Tourismusprojekte in FranzösischPolynesien ist natürlich nicht auf die indigene Gruppe der Maohi beschränkt. Franzosen, 
Chinesen und demi betreiben ebenfalls kleinere Pensionen. Generell gilt auch, dass die eindeutige Zuordnung einzelner ethnischer Gruppen zu bestimmten Berufsbereichen (z. B. Franzosen in der Administration, Chinesen im Handel vgl. Kap. 6.1.6) mehr und mehr aufweicht. Touristische Mikroprojekte, die der Idee der Nachhaltigkeit nahe kommen, expandieren in FranzösischPolynesien generell. Dieser Prozess wird insbesondere durch zwei wesentliche Faktoren allerdings gebremst: Die Begrenztheit der touristischen Nachfrage (Preisniveau, Entfernung, Sprache) und die Existenz massiver Transferzahlungen seitens Frankreichs, die wirtschaftliche Eigeninitiativen auf individueller Basis behindern. Zudem fließen öffentliche Förderungen nach wie vor in touristische Prestige-, d.h. Großprojekte; kleinere Betriebe haben selbst bei Schäden durch Wirbelstürme Schwierigkeiten, Entschädigungen zu bekommen.

Welche Rolle touristische Mikroprojekte in Französisch-Polynesien spielen werden, ist schwer vorherzusagen. Bleibt die dependente Transferökonomie bestehen, werden sie in einer volkswirtschaftlich unbedeutenden Nische verharren. Nimmt ihre Zahl im Zuge einer hypothetischen Steigerung der Touristenankünfte massiv zu, lässt der nachhaltige Charakter dieser Wirtschaftsform nach. Es ist eher anzunehmen, dass die derzeitige Expansion der Anzahl touristischer Kleinbetriebe sich auf einem bestimmten Niveau einpendelt, zumal auch nur ein Teil der Touristen solche Unterkünfte nachfragen. Ökonomisch nachhaltig sinnvoll wäre dann eine Vertiefung der Verknüpfung mit anderen Wirtschaftsbereichen wie Landwirtschaft und Kunsthandwerk.

Ob der Tourismus (sei er nun nachhaltig oder nicht) zusammen mit anderen, bestehenden Wirtschaftszweigen Französisch-Polynesiens, z. B. dem Export von Perlen und anderen landwirtschaftlichen Produkten, die Inseln Französisch-Polynesiens ,,ernähren“ könnte, ist mehr als fraglich, da die öffentlichen Zahlungen Frankreich zurzeit einen Großteil der Arbeitsplätze und Sozialleistungen bereitstellen. Ein vorsichtiger und schrittweiser Abbau der Transferzahlungen könnte generell zu neuen ökonomischen Impulsen führen. Dies ist allerdings von politischer Seite her nicht gewünscht. 


\section{ZUSAMMENFASSUNG}

Als Ziel der vorliegenden Arbeit wurde unter Kap. 1.1 die Identifizierung und Bewertung von Konzepten und räumlichen Auswirkungen einer Form des Tourismus, die den Ansprüchen der sozialen und ökologischen Verträglichkeit genügt und von indigenen Gruppen initiiert wurde, vor dem Hintergrund des historisch-kulturellen Wandels in Französisch-Polynesien definiert.

$\mathrm{Zu}$ diesem Zwecke wurden zunächst zentrale Begriffe wie Kultur, Kulturwandel, Tourismus und Nachhaltigkeit definiert, nicht ohne auf die Problematik der „,kulturellen Hermeneutik“ hinzuweisen.

Ebenso wurde die grundlegende Struktur des Welttourismus beleuchtet, die sowohl in Bezug auf das Angebot als auch auf die Nachfrage nachhaltiger Tourismusformen diesen nur eine Nischenfunktion zuweist.

Bezüglich der Reisemotivation wurde die „Imaginäre Geographie“ als ein wesentliches Moment definiert: Nicht das Erleben der Realität im Reiseland wird angestrebt, sondern die Bestätigung einer Fiktion.

Die Beschreibung der voreuropäischen Gesellschaft der Maohi ergab, dass diese eine differenzierte, komplexe Kultur aufwies, die auch genügend Raum für Kunst, Literatur, Sport, Musik, Tanz, Drama, „Tourismus“ und simple Technologien ließ. Das voreuropäische sozioökonomische System war selbsttragend und stabil.

Die Untersuchung der kulturellen Überformung der fünf Faktoren Wirtschaft, Sprache, Recht, Religion und Gesellschaft ergab, dass der Grad der Akkulturation, die durch den Kontakt mit der westlichen Welt ausgelöst wurde, in Französisch-Polynesien variiert: So sind die Bereiche Wirtschaft, Gesellschaftsstruktur stärker akkulturiert als das Recht und dieses wiederum viel stärker als Religion und Sprache.

Bei der Betrachtung Französisch-Polynesiens im Vergleich zu anderen pazifischen Inselgruppen fällt auf, dass die voreuropäische Struktur nicht untypisch für das Gebiet des polynesischen Dreiecks war und sich auch in Bezug auf die akkulturative Wirkung der ausländischen Einflussnahme Parallelen ziehen lassen. 
Die Errichtung des CEP und die Durchführung der Atomtests führte in Französisch-Polynesien zu einer artifiziellen, dependenten Transferökonomie in Französisch-Polynesien, die auch als ARAB-System (ARAB = Atomic Rent, Aid, Bureaucracy) bezeichnet wird. Dieser ökonomische Status Quo behindert wirtschaftliche Eigeninitiative. Außerdem bedingt er durch seinen dependenten Charakter entwicklungsländertypische Strukturen in Französisch-Polynesien.

In der gegenwärtigen Gesellschaft Französisch-Polynesiens sind Ansätze zu einer Neubelebung der autochthonen Kultur vielfach vorhanden. Uneinigkeit in der Parteienlandschaft, eine geringe, zielgerichtete Organisation von Basisgruppen und vorwiegend staatlich unterstützte Kulturinstitute verhindern eine stärkere Renaissance Culturelle.

Die oben genannten Parameter schafften die Rahmenbedingungen für eine Untersuchung touristischer Mikroprojekte der Maohi. Zu deren Bewertung wurde das Leitbild eines zukunftsfähigen Tourismus, das die drei gleichwertigen Komponenten der ökologischen, der ökonomischen und soziokulturellen Nachhaltigkeit beinhaltet herangezogen. Das Nachhaltigkeitsmodell von BECKER/JOB/WITZEL und der gtz-Leitfaden für Tourismus in der Technischen Zusammenarbeit wurden in abgewandelter Form auf die Projekte angewandt. Als Ergebnis lässt sich festhalten, dass durch die Fernreise ein Urlaub in Französisch-Polynesien niemals nachhaltig im ökologischen Sinne sein kann, aber die bewerteten Projekte auf der soziokulturellen Ebene in hohem Maße und auf der ökonomischen Ebene teilweise nachhaltig sind.

Dies eröffnet auf Grund des generierten Einkommens den Maohi auch eine kulturelle Selbstbestimmung und deutet eine potentielle Neuausrichtung der Maohi-Kultur an.

Ein Ansteigen eines nachhaltigen Tourismus in Französisch-Polynesien wird durch folgende Faktoren begünstigt:

- zunehmende Initiativen bezüglich mikrotouristischer Projekte seitens der Maohi

- Ansätze einer Renaissance Culturelle und damit steigendes Selbstbewusstsein der indigenen Kultur

- Die „Imaginäre Geographie“ Französisch-Polynesiens

Begrenzend wirken insbesondere: 
- die Struktur des Welttourismus, bzw. die relativ geringe Nachfrage nach nachhaltigen, touristischen Projekten

- die dependente Transferökonomie

Die hohen Preise, die große Entfernung von touristischen Quellgebieten und die Sprachbarriere wirken sich in gewisser Weise neutral auf einen nachhaltigen Tourismus aus. Sie begrenzen zwar die Touristenzahl insgesamt, lassen aber dennoch Steigerungsraten von Touristen aus dem Selbstverwirklichungsmilieu, der Klientel für nachhaltigen Tourismus, zu.

Auch langfristig werden diese touristischen Mikroprojekte, selbst in der Verflechtung mit anderen Wirtschaftszweigen wie Landwirtschaft und Kunsthandwerk nur einen geringen Beitrag zur Wirtschaftskraft Französisch-Polynesiens beitragen (können), es sei denn, sie verlieren den Charakter ihrer Nachhaltigkeit. 


\section{LITERATURVERZEICHNIS}

Adams, H.: Tahiti, Memoires of Ari' i Taimai. Memoires of Marau Taaroa, Last Queen of Tahiti. New York. Scholars' Facsimiles and Reprints. 1947.

Adloff, R. und Thompson, V.: The French Pacific Islands. French Polynesia and New Caledonia. Los Angelos/London. 1971.

Alves, Dora: The Maori And The Crown. An Indigenous People's Struggle für SelfDetermination. Westport/London. Greenwood Press. 1999.

Antoine, C.; Guille, G.; Guillot, H. und Munschy, M.: La croûte océanique et les points chauds de la Polynésie française (Océan Pacifique central). In: Geologie de la France. BRGM/SGF. Orléans. 2000.

Amed, Stephan und Tora: Ecuador. In: Ellenberg, Ludwig/Beier, Birgit/Scholz, Marion: Ökotourismus. Reisen zwischen Ökonomie und Ökologie. Heidelberg, Berlin, Oxford. Spektrum Akademischer Verlag. 1997. S. 235 - 240.

Antweiler, Christoph.:

- $\quad$ u. a. (Hrsg.): Ethnologische Beiträge zur Entwicklungspolitik. Bonn. PAS. 1987.

- Kulturevolution als transgenerationaler Wandel. Berlin. Reimer. 1988.

- Über das bloße Lamento hinaus. Vom Nutzen der Ethnologie in der Natur- und Menschenrechtsarbeit. In: infoemagazin. Zeitschrift für Ökologie und „Vierte Welt”. 1/1992. S. 33-35.

Arnberger, E.: Die tropischen Inseln des Indischen und Pazifischen Ozeans. Wien. 1988.

Arki, Mostafa: Kulturveränderungen wohin?. In: Kulturveränderung wohin? Dienste in Übersee (Hrsg.). Reihe dü-scriptum. Stuttgart. 1990. S. 41-46.

Assmann, Aleida und Harth, Dietrich: Kultur als Lebenswelt und Monument. Frankfurt am Main. Fischer. 1991.

Atuatu Te Natura (Hrsg.):

- 3 dossiers écologiques de Bora Bora. Bora Bora. 1987, 1988.

- Le tourisme, une richésse en peril. Bora Bora. 1993.

Bachimon, Philippe: Tahiti entre mythes et réalités. Éditions du Comité des Travaux Historiques et Scientifiques. 1990.

Balme, Christopher: „Pacific Overtures”: Interkulturelle Tendenzen im zeitgenössischen Theater Neuseelands. In: und Marsden, P. H. et al. (Hrsg.): Neuseeland im Pazifischen Raum. Reihe Pazifik Forum. Band 3. Aachen. Verlag der Augustinusbuchhandlung. 1992. S. 243259. 
Baumgartner, Christian und Röhrer, Christine: Nachhaltigkeit im Tourismus. Verlagsgemeinschaft Manz Verlag Schulbuch, Bohmann Buchverlag, Fortis Verlag FH, Bildung Sauerländer. Wien, Köln, Aarau/Bern.1998.

Baré, J.-F.:

- Le Malentendu Pacifique. Des premières rencontres entre Polynésiens et Anglais et de ce qui s'ensuivit avec les Françaises jusqu'à nos jours. Paris. 1985.

- Tahiti, les temps et les pouvoirs. Pour un anthropologie historique du Tahiti posteuropéen. Paris. ORSTOM. 1987.

Bargatzky, T.: Die Rolle des Fremden beim Kulturwandel. Hamburger Reihe zur Kultur und Sprachwissenschaft Bd. 12. Hamburg. 1978.

Barley, Nigel: Die Raupenplage. dtv. München. 1998.

Beaglehole, J. C. (Hrsg.): The Journals of Captain Cook on His Voyages of Discovery. Cambridge. Hakluyt Society. 1955.

Becker, Christoph; Job, Hubert und Witzel, Anke: Tourismus und nachhaltige Entwicklung. Wissenschaftliche Buchgesellschaft. Darmstadt. 1996.

Bell, T. A.. The Metamorphosis of Tahiti: Change and Tradition in a Transforming Landscape. In: Yearbook of the Association of Pacific Coast Geographers. Bd. 35. 1973. S. 103-113.

Bellwood, Peter:

- The Polynesians. Prehistory of an Island People. London. 1978.

- Frühe Landwirtschaft und die Ausbreitung des Austronesischen. In: Spektrum der Wissenschaft Dossier. Heidelberg. 2000. S. 65 - 71.

Benham, Maenette K.P. und Heck, Roland, H.: Culture ans Educational Policy in Hawai' $i$. The Silencing of Native Voices. London. Lawrence Erlbaum Associates. 1998.

Benvenuto, Sergio: Sehnsucht nach Differenz. Globalisierungsdebatte und das Bedürfnis nach Unterschieden. In: Lettre Internationale. Sommer/1999. S. 16-19.

Bertram, Jutta: Die Ausrottung des Schönen. Wege und Irrwege der europäischen Tourismuskritik. In: Stock, Christian (Hrsg.): Trouble in Paradise. Tourismus in die Dritte Welt. Freiburg, Breisgau. Verl. Informationszentrum Dritte Welt. Düsseldorf. Verl. Haus Altenberg. 1997.

Berry, John W.: Acculturation as Varieties of Adaption. In: Padilla, Amado M. (Hrsg): Acculturation. Theory, Models and Some New Findings. Boulder. Westview Press. 1980. S. 9-25. 
Biggs, B: The Past Twenty Years in Polynesian Linguistics. In: Highland, G. A. u. a. (Hrsg.): Polynesian Culture History - Essays in Honour of K. P. Emory. Bernice P. Bishop Museum Special Publication 56. 1967. S. 303-322.

Bierstedt, Alexander: Darwins Erben und die Vielfalt der Kultur. Frankfurt/M, Berlin, Bern, New York, Paris, Wien. Lang. 1997.

Birkmann, Jörn/Koitka, Heike/Kreibich, Volker/Lienenkamp, Roger: Indikatoren für eine nachhaltige Raumentwicklung. Dortmund. Institut für Raumplanung der Universität Dortmund. 1999.

Blanchet, G.:

- L'économie de la Polynésie française de 1960 à 1980. Paris. Editions de 1'ORSTOM. 1985.

- Réflexions sur la notion de secteur non structuré et son application dans les pays en voie de développement. In: Cahiers O.R.S.T.O.M. Sci. Hum. Vol. XVII. Nos. 1-2. 1980. S. 1318.

Bockway, R. W.: The Origin of the Polynesians. Some Recent Evidences. In: Journal of Human Evolution. Heft 12. London. 1983. S. 501-503.

Bonno, Angelina: Vorwort im offiziellen Programm zum Heiva 1997. Ministère de la Culture Polynésie Française. Tahiti. 1997.

Borg, J.: Cost of French Nuclear Testing. In: Jane's Defence Weekly. Coulston. 1989. S. 517.

Börner, Klaus, H.: Auf der Suche nach dem irdischen Paradies. Frankfurt. Wörner. 1984.

Bovis, E. de: Tahitian Society before the Arrival of the Europeans. Second Edition. Hawaii. The Institute for Polynesian Studies, Brigham University - Hawaii Campus. 1980.

Boucke, Andreas: Neue Pfade im Dschungel Guatemalas. Möglichkeiten nachhaltiger Nutzung. In: Ökozidjournal Nr. 16. Gießen. Focus Verlag. 1998. S. 17-21.

Brauer, Christiane: Südseeinseln - Touristenziele mit ökologischen Problemen. In: Euler, Claus (Hrsg.): ,Eingeborene' ausgebucht. Ökologische Zerstörung durch Tourismus. Giessen. Focus Verlag. 1989. S. 149-158.

Braun, Gerald und Rösel, Jakob: Kultur und Entwicklung. In: Nohlen, Dieter und Nuscheler, Franz (Hrsg.): Handbuch der Dritten Welt. Bd. 1. Bonn. Verlag J. H. W. Dietz Nachf. GmbH. 1992. S. 250-268.

Breidenbach, Joana und Zukrigel, Ina: Tanz der Kulturen. Kulturelle Identität in einer globalisierten Welt. Verlag Antje Kunstmann GmbH. München. 1998.

Bremond, Hubert.: Tahiti Today - Poem. In: Pollock, N. J. u. a. (Hrsg.): French Polynesia: a Book of Selected Readings. Suva. Institute of Pacific Studies of the South Pacific. 1988. 
Brenner, Matthias: Patagonien - Land des Windes und der Naturwunder. Ökodiplomaten vermitteln zwischen Schutz und Nutzung. In: Ökozidjournal Nr. 16. Gießen. Focus Verlag. 1998. S. 9-14.

Breuel, Birgit (Hrsg.): Agenda 21. Vision: Nachhaltige Entwicklung. Frankfurt/Main, New York. Campus Verlag. 1999.

Brésillion, Thierry: Gabriel Tetiarahi Le ,Managitateur'. In: FDM 123. Mai 1996. S. 14-15.

Brocker, Manfred und Nau, Heino Heinrich (Hrsg.): Ethnozentrismus. Möglichkeiten und Grenzen des interkulturellen Dialogs. Darmstadt. Wissenschaftliche Buchgesellschaft. 1997.

Brumlik, Micha: Die Entwicklung der Begriffe ,Rasse”, ,Kultur” und „Ethnizität” im sozialwissenschaftlichen Diskurs. In Dittrich, Eckhard und Radke, Frank-Olaf (Hrsg.): Ethnizität. Opladen. Westdeutscher Verlag. 1990. S. 179-190.

Brysk, A.: Acting Globally: Indian Rights and International Politics in Latin America. In: van Cott, D.-J. (Hrsg.): Indigenous Peoples and Democracy in Latin America. New York. St. Martin's Press. 1994.

Buchholz, H. J.:

- Australien - Neuseeland - Südpazifik. Fischer Länderkunde. Bd. 10. Frankfurt am Main. Fischer. 1984.

- Die intra- und extraregionalen Beziehungen der südpazifischen Inselstaaten. In: Erdkunde Bd. 42. 1988. S. 136-146.

- Grundstrukturen und entwicklungspolitische Problemstellungen im Südpazifik. Dezember 1986. Institut für Internationale Begegnungen e. V. Arbeitspapier zur Vorbereitung der Fachkonferenz „Neue Ansätze der Entwicklungszusammenarbeit mit südpazifischen Ländern” im Mai 1987.

- (Hrsg.): New approaches to development co-operation with south pacific countries. Saarbrücken/Fort Lauderdale: Breitenbach. 1987.

Buchwald, Rainer und Dilger, Robert: Wissenschaftlicher Tourismus: Imperialismus im Forscherlook. In: Euler, Claus (Hrsg.): ,Eingeborene' ausgebucht. Ökologische Zerstörung durch Tourismus. Giessen. Focus Verlag. 1989. S. $40-55$.

Bühl, Walter, L: Kulturwandel. Für eine dynamische Kultursoziologie. Darmstadt. Wissenschaftliche Buchgesellschaft. 1987.

BUND/Misereor (Hrsg.): Zukunftsfähiges Deutschland - ein Beitrag zu einer global nachhaltigen Entwicklung. Basel, Bosten, Berlin. Birkhäuser Verlag. 1996.

\section{Bundesstelle für Außenhandelsinformation:}

- EWG-Entwicklungsfonds Ausschreibungen der assoziierten Länder und Hoheitsgebiete. Nr. 23. Vorhaben: Ausbau des Hafens von Papeete. 1959. 
- EWG-Entwicklungsfonds Ausschreibungen der assoziierten Länder und Hoheitsgebiete. Nr. 86. Gegenstand der Leistung: Bau und Ausstattung des General-Krankenhauses von Französisch-Polynesien in Papeete. 1963.

Burkhard, Christoph: Unter einem Sombrero - ,Öko'-Tourismus in Costa Rica. In Blätter des iz3w. Nr. 214. Juni/Juli 1996. S. 20-21.

Burmeister, Hans-Peter (Hrsg.): Auf dem Weg zu einer Theorie des Tourismus. Loccumer Protokolle. 1998.

Buschmann, J. C. É.: Aperçu de la langue des Îles Marquises et de la langue Tahitienne. Berlin. Luderitz. 1843.

Buske, N.:

- Caesium-134 at Moruroa. Search technical services. September 1990.

- Radioactivity in Plankton outside the IZ-mile Exclusion Zone of the French Nuclear Test Site. Report of the 1990 Scientific Mission of the Rainbow Warrior. Davenport. 1991.

Bußmann, H.: Lexikon der Sprachwissenschaft. Stuttgart. Kröner. 1983.

Castanier, Corinne: L'etat radiologique des atolls. In: Centre de Documentation et de Recherche sur la Paix et les Conflits: Essais nucléaires français en Polynésie: exigence de vérité et propositions pour l'avenir. Actes du colloque 20 février 1999. Lyon. 1999. S. 95134.

Centre de Documentation et de Recherche sur la Paix et les Conflits (Hrsg.): Essais nucléaires français en Polynésie: exigence de vérité et propositions pour l'avenir. Actes du colloque 20 février 1999. Lyon. 1999.

Chadourne, M.: Le Lyrisme des Tahitiens. In: Bulletin de la Société des Études Océaniennes. Papeete. 1922. S. 64-77.

Chaussin, Patrick: Synthèse opérée à partir des résultats de l'Enquête de Satisfaction TCSP 97-98. Papeete. Oktober 1999.

Chesneaux, Jean:

- Transpacifiques. Observations et considérations diverses sur les terres et les archipeles du Grand Océan. Cahiers Libres. Paris. La Découverte. 1987.

- Tahiti après la bombe. Quel avenir pour la Polynésie? Paris. L’Harmattan. 1995.

- und Maclellan, Nic: After Moruroa. France in the South Pacific. Melbourne/New York. Ocean Press. 1998.

Clarin, R.: Population of French Polynesia. In: Population. No. 4/5. V 27. Paris. 1972. S. 703-727. 
Cole, R. V. und Parry, T. G. : Selected Issues in Pacific Island Development. Canberra. 1986. S. 3.

Connell, J: Indépendance, dépendance et fragmentation dans le Pacific Sud. In: L'Espace Géographique 11. No. 4. 1982. S. 252-258.

Coppenrath, G.: Les Chinois de Tahiti. De l'aversion d l'assimilation 1856-1966. Publication de la Société des Océanistes No. 21. Paris: 1967.

van Cott, D.-J. (Hrsg.): Indigenous Peoples and Democracy in Latin America. New York. St. Martin's Press. 1994

Crocombe, R.G.:

- (Hrsg.): Politics in Polynesia. Suva. Institute of Pacific Studies of the Universitiy of the South Pacific. 1983.

- (Hrsg.): Land Tenure in the Pacific. 3. Auflage. Suva. 1987.

- Trägheit durch Abhängigkeit. Entwicklungshilfe im Südpazifik. In: Der Überblick 21. Stuttgart 1985. S. 24-26.

\section{Danielsson, B:}

- Under a Cloud of Secrecy: the French Nuclear Tests in the Southeastern Pacific. In: Ambio VoI. 13. No. 5-6. Oxford. 1984. S. 336-341.

- French Polynesia, Nuclear Colony. In: Crocombe, R.G.: (Hrsg.): Politics in Polynesia. Suva. Institute of Pacific Studies of the Universiriy of the South Pacific. 1983. S. 195-221.

- Moruroa: Hide and Seek around a Leak. In: Pacific News Bulletin. January 1991. S. 3 f.

Davis, Geoffrey V.: „Other Halfs”: Geschichtsbewusstsein und ethnische Problematik im zeitgenössischen neuseeländischen Film. In: und Marsden, P. H. et al. (Hrsg.): Neuseeland im Pazifischen Raum. Reihe Pazifik Forum. Band 3. Aachen. Verlag der Augustinusbuchhandlung. 1992. S. 279-304.

Davis, J.: A Tahitian and English Dictionary with Introductory Remarks on the Polynesian Language and a Short Grammer of the Tahitian Dialect: With an Appendix. Facsimile of 1851. Tahiti. 1985.

Delesalle, B. u. a. (Hrsg.): French Polynesian Coral Reefs, Reef Knowledge and Field Guides. 5th International Coral Reef Symposium. Tahiti 1985. Vol. 1. Paris. 1985.

Delius, Ulrich:

- Der Widerstand gegen die französische Atommacht. In: Informationszentrum Dritte Welt (Hrsg.): Die Militarisierung des Pazifik. Freiburg. 1986a. S. 199-208.

- Frankreich - eine nukleare Kolonialmacht. In: Informationszentrum Dritte Welt (Hrsg.): Die Militarisierung des Pazifik. Freiburg. 1986b. S. 156-174. 
- Frankreichs Atomtest-Moratorium löst nicht Tahitis Probleme. Manuskript für pogrom Nr. 166. Juli/August 1992b.

- Maohi kämpfen um Landrechte. Tahitianer fürchten Europäischen Binnenmarkt. In: pogrom Nr. 157. 1991. S. 56-58.

- SOS Moruroa. Französische Atomtests im Pazifik. Göttingen. 1990.

- Tahiti - Französisch-Polynesien. Südseeparadies unter dem Atompilz. Reihe pogrom. Gesellschaft für bedrohte Völker (Hrsg.). Göttingen/Wien. 1982.

- Vergessene Völker erheben ihre Stimme. In: pogrom Nr. 165. 1992a. S. 72.

- Touristen statt Bomben. Umstrittene Tourismus-Förderung auf Tahiti. In: pogrom Nr. 169. 1993. S. 62-64.

\section{Deutsche Gesellschaft für Technische Zusammenarbeit (gtz) GmbH:}

- Nachhaltiger Tourismus und Entwicklungszusammenarbeit. Eschborn. 1997.

- Tourismus in der Technischen Zusammenarbeit. Eschborn. 1999.

Dittrich, Eckhard und Radke, Frank-Olaf (Hrsg.): Ethnizität. Opladen. Westdeutscher Verlag. 1990.

Dodd, E.: Polynesian Seafaring. Lymington. Nautical Publishing Company Limited. 1972.

Doumenge, J. P.: Demographic, Economic, Socio-Cultural and Political Facts nowadys in the French Pacific Territories. In: GeoJournal No. 2. Vol. 16. Dordrecht. 1988. S. 143156.

Draghun, W. u. a.: Politisches Lexikon Asien, Australien, Pazifik. München. Beck. 1989.

Dworschak, Helmut: Kulturdiskurse. Zum Verhältnis von Tourismus und indigener Kultur. Münster/New York. Waxmann.1994.

Ellenberg, Ludwig/Beier, Birgit/Scholz, Marion: Ökotourismus. Reisen zwischen Ökonomie und Ökologie. Heidelberg, Berlin, Oxford. Spektrum Akademischer Verlag. 1997.

Ellis, W.: Polynesian Researches During a Residence of Nearly Eight Years in the Society and Sandwich Islands. 4 vols. London. Second Edition. 1831.

Emory, K. P.:

- East Polynesian Relationships: Settlement Pattern and Time Involved as Indicated by Vocabulary Arguments. In: Journal of the Polynesian Society 72. Wellington. 1963. S. 78100.

- The Societies. In: Pollock, N. J. u. a. (Hrsg.): French Polynesia: a Book of Selected Readings. Suva. Institute of Pacific Studies of the South Pacific.1988. S. 3257. 
Enzensberger, Hans Magnus: Eine Theorie des Tourismus. In: ders.: Einzelheiten IBewusstseins-Industrie. Frankfurt. 1964. S. 179-205.

Erdmann, Claudia:

- Aborigines und Tourismus im Australischen Nordterritorium. In: W. Kreise1/P. H. Marsden (Hrsg.): First Peoples, First Voices. Indigene Völker zwischen Fremdbestimmung und Selbstbehauptung. Reihe Pazifik Forum. Band 5. Aachen. Verlag der Augustinusbuchhandlung. 1995. S. 107-126.

- Aborigines und Tourismus im australischen Nordterritorium - Bereiste oder Unternehmer? In: Kreisel, W./Vossen, J und Dickmann, F. (Hrsg.): Traumwelt und Wirklichkeit. Reihe Pazifik-Forum. Band 2. Aachen. Verlag der Augustinusbuchhandlung. 1991. S. 127-143.

Euler, Claus (Hrsg.): Eingeborene - ausgebucht. Ökologische Zerstörung durch Tourismus. Giessen. Focus Verlag. 1989.

\section{European Center on Pacific Issues (Hrsg.):}

- France admits explosions caused atoll damage in French Polynesia. In: Europe-Pacific Solidarity Bulletin. Volume 7. Number 3. May/June 1999.

- Comité de Suivi Moruroa et nous established in French Polynesia. In: Europe-Pacific Solidarity Bulletin. Volume 8. Number 2. April/May/June 2000.

Faust, Heiko:

- und Dickmann, Frank: Fiji - Die Indo-Fijianer und der Tourismus. In Kreisel, W./Vossen, J. und Dickmann, F. (Hrsg.): Traumwelt und Wirklichkeit. Reihe PazifikForum. Band 2. Aachen. Verlag der Augustinusbuchhandlung. 1991. S. 67-89.

- $\quad$ Tourism in a Developing Country. The Case of Fiji. In: OneEurope Magazine. No. 8. 1995. S. 7-8.

- Verstädterung in Fiji. Reihe Pazifik Forum. Band 6. Aachen. Mainz. 1996.

- Putsch in Fiji. In: Pacific News Nr. 15. 2000. S. 16-18.

Feinberg, R.: Polynesian Seafaring and Navigation. Kent/London. 1988.

Fensterseifer, Christel: Die Wirkung kolonialzeitlicher Vorgaben auf sozioökonomische Wandlungs- und regionale Entwicklungsprozesse südpazifischer Inselländer am Beispiel von West-Samoa und Amerikanisch-Samoa. Dissertation. Hannover. 1994.

Fentrup, Klaus: Die ökonomische Bedeutung des internationalen Tourismus für die Entwicklungsländer. Hamburg. 1979.

Fieldhouse: Nuclear Battlefields. Cambridge. Massachusetts. Balinga Publisching Company. 1985. 
Fillitz, Thomas/Gingrich, Andre/Rasuly-Paleczek, Gabriele: Kultur. Identität. Macht. Frankfurt am Main. Verlag für Interkulturelle Kommunikation. 1993.

Fischer, Hans:

- (Hrsg.): Feldforschungen. Berlin. Reimer 1988.

- Ethnologie. Einführung und Überblick. Reimer Verlag. Berlin. 1988.

- Warum Samoa? Touristen und Tourismus in der Südsee. Berlin. 1984.

Firth, S.: Nuclear Playground. South Sea Books. Pacific Islands Studies Program. Center for Asian and Pacific Studies. Honolulu. University of Hawaï. 1987.

FR. 10.1.98: DNA-Test widerlegt Thor Heyerdahl.

Furnas, J. C.: Anatomy of Paradies. o. J. S. 280-281.

Freyer, Walter: Tourismus. 4. erg. und aktualisierte Auflage. München, Wien. Oldenbourg. 1993.

\section{Garret, J.:}

- More Evidence of Radioactivity. In: Pacific News Bulletin. December 1990. S. 3

- und Robie, D.: Moruroa: Evidence of Radioactivity Surfacing. In: Pacific News Bulletin. November 1990. S. 2.

Geertz, Clifford: Spurenlesen: der Ethnologe und das Entgleiten der Fakten. München. Beck. 1997.

Gerdes, Peter: Feucht, grün und ruhig. Tropischer Sommer in Australiens „, Top End”. In: NZZ. 8.1.98.

GIE Tahiti Animation/GIE Tahiti Tourisme/Service du Tourisme: Plan de developpement strategique du tourisme en Polynésie français. Tahiti. Oktober 1994.

Gomane, J.-P.: France and the Pacific: An Impressionist Policy. In: The Pacific Review No. 10. Oxford. 1989. S. 334-338.

Gonsalves, Paul: Reflektionen über eine Reise. Tourismuskritik im Süden. In: Stock, Christian (Hrsg.): Trouble in Paradise. Tourismus in die Dritte Welt. Freiburg, Breisgau. Verl. Informationszentrum Dritte Welt. Düsseldorf. Verl. Haus Altenberg. 1997.

Görlich, Sylvia: IH-Länder aktuell. Frankreich-Übersee II, Französisch-Polynesien. Munzinger Archiv. 39/98.

Gordon, Milton M.: Assimilation in American Life. The Role of Race, Religion, and National Origins. New York. Oxford University Press. 1964.

Green, R. C.: 
- Linguistic Subgrouping within Polynesia: the Implications for Prehistoric Settlements. In: Journal of the Polynesian Society 75. Wellington. 1966. S. 6-38.

- The Immediate Origins of the Polynesians. In: Highland, G. A. u. a. (Hrsg.): Polynesian Culture History - Essays in Honour of K. P. Emory. Bernice P. Bishop . Museum Special Publication 56. 1967. S. 215-240.

- et. al.: Archeology on the Island of Moorea, French Polynesia. Anthropological Paper No. 51. pt. 2. American Museum of Natural History. New York. 1967.

Greschat, Hans-Jürgen: Mana und Tapu. Die Religion der Maori auf Neuseeland. Berlin. Reimer. 1980.

Grimmel, E.: Die Folgen der französischen Atomtests im Südpazifik. (Auszug aus einer Studie). In: Aktion Atomtest Stopp. Bonn. 1992. S. 21-23.

Groh, Arnold: Kultureller Verlust. Mechanismen und Interventionsmöglichkeiten. Dissertation. Universität Bielefeld. 1997.

Gunson, N.: A Note on the Difficulties of Ethnohistorical Writing, with Special Reference to Tahiti. In: Journal of the Polynsian Society 72. Wellington. 1963. S. 415-419.

Günther, Armin: Reisen als ästhetisches Projekt. Über Formenwandel touristischen Erlebens. In: Hartmann, Hans A. und Haubl, Rolf (Hrsg.): Freizeit in der Erlebnisgesellschaft. Amüsement zwischen Selbstverwirklichung und Kommerz. Opladen. Westdeutscher Verlag. 1996. S. $95-124$.

Hammelehle, Jürgen: Zum Beispiel Tourismus. Göttingen. Lamuv Verlag. 1995.

Handy, E. S. C.: The Problem of Polynesian Origins. In: Bernice P. Bishop Museum Occasional Papers No. 9. Honolulu. 1930. S. 1-27.

Hanefeld, Jürgen: Aus Bereisten werden Reisende - Neue Märkte in Asien. In: Kreib, Jörn und Ulbrich, Angela (Hrsg.): Gratwanderung Ökotourismus: Strategien gegen den touristischen Ausverkauf von Kultur und Natur. Gießen. Focus Verlag. 1997. S. 81 - 82.

Hartmann, Hans A. und Haubl, Rolf (Hrsg.): Freizeit in der Erlebnisgesellschaft. Amüsement zwischen Selbstverwirklichung und Kommerz. Opladen. Westdeutscher Verlag. 1996.

Hauff, V. (Hrsg.): Unsere gemeinsame Zukunft. Der Brundtland-Bericht der Weltkommission für Umwelt und Entwicklung. Greven. 1987.

Hauser-Schäublin, Brigitta: Vom Reisen und vom Verstehen. In: Forschung und Lehre. 3/99. S. 139-142.

Häusler, Nicole und Rieländer, Klaus: Konsequenzen des Tourismus. Göttingen. AIW. 1995. 
Haußmann, André/Mies, Frederike, Sollner, Kerstin und Wacker, Alexander: Gütesiegel für umweltverträglichen und sozialverantwortlichen Tourismus. Heilbronn. Verlag Wissenschaftliche Arbeiten für die Praxis. 1992.

Harborth, Hans-Jürgen: Sustainable Development - Dauerhafte Entwicklung. In: Handbuch der Dritten Welt. Dieter Nohlen, Franz Nuscheler (Hrsg.). Verlag J.H.W. Dietz Nachf. 1992.

Harding, T. G. und Wallace, B. J. (Hrsg.): Cultures of the Pacific. New York/London. 1970.

Henseling, Christine/Eberle, Ulrike/Grießkammer, Rainer: Soziale und ökonomische Nachhaltigkeitsindikatoren. Freiburg. Ölo-Institut. 1999.

Heermann, L: Mythos Tahiti. Südsee - Traum und Realität. Berlin. 1987

Hein, Wolfgang (Hrsg.): Tourism and Sustainable Development. Schriften des Deutschen Übersee-Instituts Hamburg. Nr. 41. Hamburg. 1997.

Heine-Geldern, R.: Urheimat und früheste Wanderungen der Austronesier. In: Anthropos. Heft 27. 1932. S. 543-619.

Hennig, Christoph: Reiselust. Touristen, Tourismus und Urlaubskultur. Suhrkamp Taschenbuch Verlag. 1999.

Henry, T.: Ancient Tahiti Based on Material Recorded by J. M. Orsmond. Honolulu. Bernice P. Bishop Museum Bulletin 48. 1928.

Herz, D. (Bearb.): IH-Länder aktuell. Frankreich-Übersee II, Französisch-Polynesien. Munzinger Archiv: 1/91.

Highland, G. A. u. a. (Hrsg.): Polynesian Culture History - Essays in Honour of K. P. Emory. Bernice P. Bishop Museum Special Publication 56. 1967.

Hilder, B.: Primitive Navigation in the Pacific. In: Golson, J. (Hrsg.): Polynesian Navigation. 1962. S. 81-97.

Hirschberg, W. (Hrsg.): Neues Wörterbuch der Völkerkunde. Berlin. Reimer. 1988.

Hiti Tau (Hrsg.):

- Communiqué pour la presse. Genf. 27.5.95

- Déclaration solennelle. Papeete 1995.

Hohl, R. (Hrsg.): Die Entwicklungsgeschichte der Erde. 7. Auflage. Leipzig. Brockhaus. 1981.

Hopfenbeck, Waldemar und Zimmer, Peter: Umweltorientiertes Tourismusmanagement: Strategien, Checklisten, Fallstudien. Landsberg/Lech. Verlag Moderne Industrie. 1993.

Horx, Matthias: Das Zunkunftsmanifest. Econ \& List. Düsseldorf und München. 1999. 
Isenberg, Wolfgang (Hrsg.): Kathedralen der Freizeitgesellschaft. Kurzurlaub in Erlebniswelten. Trends, Hintergründe, Auswirkungen. Bensberger Protokolle 83. 2. erw. Auflage. Bergisch Gladbach. Thomas-Morus-Akademie. 1998.

ITSTAT (Hrsg.):

- Les Tableaux de l'Economie Polynésienne. Papeete. 1998.

- Statistiques Touristiques. Papeete. 1991 - 1998.

Informationszentrum Dritte Welt (Hrsg.): Blätter des iz3w. Nr. 214. Juni/Juli 1996.

Inglehart, Ronald: Modernisierung und Postmodernisierung. Frankfurt am Main/New York. Campus Verlag. 1998.

Iwersen-Sioltsidis, Susanne und Iwersen, Albrecht: Tourismuslehre. Bern, Stuttgart, Wien. Haupt. 1997.

Jadin, Pierre.:

- Das tropische Frankreich - Die französischen DOM-TOM. In: Entwicklungspolitische Korrespondenz (EPK). Heft 2. 1990. S. 12-14.

- Die DOM-TOM - Frankreichs integrierte Dritte Welt. Probleme und Perspektiven hochsubventionierter und außengesteuerter Entwicklungsgesellschaften am Beispiel von Martinique, Réunion und Französisch-Polynesien. Dissertation. Friedrich-AlexanderUniversität Erlangen-Nürnberg. 1994

Jafari, Jafar: The Socio-Economic Costs of Tourism to Developing Countries. In: Annals of Tourism Research 1. 1974. S. 227-259.

Jamet, R. u. Trichet, J.: Etude du Milieu terrestre des atolls de la Polynésie Française. Caractéristiques et potentialités agricoles. In: Cahiers ORSTOM. Serie Pédalogie. Vol XXIII. No. 4. Paris. 1988. S. 275-293.

Jehle, E.: The Tax System of Tahiti (French Polynesia) - a Brief Survey. In: Bulletin for International Fiscal Documentation No. 8. Vol 37. 1983. S. 358-360.

Job, Hubert: Lässt sich Nachhaltigkeit im Fern-Tourismus bilanzieren? In: Kreib, Jörn und Ulbrich, Angela (Hrsg.): Gratwanderung Ökotourismus: Strategien gegen den touristischen Ausverkauf von Kultur und Natur. Gießen. Focus Verlag. 1997. S. 190- 203.

Job, Hubert und Leisch, Harald: Nepal. In: Ellenberg, Ludwig/Beier, Birgit/Scholz, Marion: Ökotourismus. Reisen zwischen Ökonomie und Ökologie. Heidelberg, Berlin, Oxford. Spektrum Akademischer Verlag. 1997. S. 129 - 136.

Johnston, Alison:

- Indigenous Peoples \& Tourism. Overview of Intellectual Property Issues. In: Contours. Hong-Kong. Vol. 9. No. 1. 1999. S. $38-41$. 
- Tourism and Biodiversity Conservation. Possibilities with Indigenous Peoples. In: Contours. Hong-Kong. 2000. Vol. 10. Nos. 1-2. S. 3 - 6.

Joly-Segalen, Annie/Lelong, Dominique: Gauguin dans son dernier décor et autres textes de Tahiti. Montpellier. Fata Morgana. 1975.

Joralemon, V.: Collective Land Tenure and Agricultural Development. A Polynesian Case (Tubuai). In: Pollock, N. u. a. (Hrsg.): French Polynesia: a Book of Selected Readings. Suva. Institute of Pacific Studies of the University of the South Pacific. 1988. S. 154-180.

Jungk, Robert. Wie viel Touristen pro Hektar Strand? Plädoyer für ,,sanftes Reisen”. In: Geo. Heft 10. 1980. S. 154-156.

Jungschat, Michael: Tourism and Sustainable Development in Costa Rica. In: Hein, Wolfgang (ed.): Tourism and Sustainable Development. Schriften des Deutschen ÜberseeInstituts Hamburg. Nr. 41. Hamburg 1997. S. 153-184.

Kahrmann, Christiane: Hoffen auf den reichen Strand. Tourismus in der Südsee. Die einheimische Sichtweise. Berlin. Dietrich Reimer Verlag. 1995.

Kamp, Christina: Nachhaltiger Tourismus im Rio-Folgeprozess. In: Ökozidjournal Nr. 16. Gießen. Focus Verlag. 1998. S. 22-25.

Kaspar, Claude: Die Tourismuslehre im Grundriss. Bern/Stuttgart/Wien. Haupt. 1991.

Kasparek, M.: Tourismusförderung in Vorhaben der deutschen

Entwicklungszusammenarbeit. Beispiel aus der Projektarbeit der gtz und anderer Durchführungsorganisationen. In: Rauschelbach, Burghard (Hrsg): (Öko-) Tourismus: Instrument für eine nachhaltige Entwicklung? gtz. Heidelberg. Kasparek. 1998. S. 65 - 76.

Keefe, Susan Emily: Acculturation and the Extended Family Among Urban Mexican Americans. In: Padilla, Amado M. (Hrsg): Acculturation. Theory, Models and Some New Findings. Boulder. Westview Press. 1980. S. 85-110.

Kellat, Dieter: Physische Geographie der Meere und Küsten. Stuttgart/Leipzig. Teubner. 1999.

Kievelitz, Uwe: Ethnotourismus: Ursachen, Formen und Wirkungen interkultureller Kurzkontakte. In: Euler, Claus (Hrsg.): ,Eingeborene' ausgebucht. Ökologische Zerstörung durch Tourismus. Giessen. Focus Verlag. 1989. S. 29 - 39.

Kirstges, Torsten: Sanfter Tourismus. München/Wien. Oldenbourg. 1992.

Klinkhammer, U.: Kultureller und kulturlandschaftlicher Wandel in Tahiti. Unveröffentlichte Magisterarbeit. Geographisches Institut der RWTH Aachen. 1991.

Koch, G.: Das Eigentum auf den Gesellschaftsinseln. In: Zeitschrift für vergleichende Rechtswissenschaft 61. Köln. Ferdinand Enke Verlag. 1959. S. 57-100.

Koch, Walter A.: The Nature of Culture. Bochum. Brockmeyer. 1989. 
Kolbe, Carsten: Von Goldgräbern, Waldschützern und Schildkrötenräubern. In: Ökozidjournal Nr. 16. Gießen. Focus Verlag. 1998. S. 4-8.

Köhler, M.: Akkulturation in der Südsee. Die Kolonialgeschichte der Karolinen und der Wandel ihrer sozialen Organisation. Frankfurt. 1982.

Kohnen, Brigitte: Akkulturation und kognitive Kompetenz. Münster/New York/München/Berlin. Waxmann. 1998.

Krafft, F. et al.: Wissenschaft im Spannungsfeld zwischen den Kulturen. Bayreuth 1987.

Kreisel, Bettina: 150 Jahre nach Waitangi - Die Maori in Neuseeland. In: und Marsden, P. H. et al. (Hrsg.): Neuseeland im Pazifischen Raum. Reihe Pazifik Forum. Band 3. Aachen. Verlag der Augustinusbuchhandlung. 1992. S. 189-211.

Kreisel, Werner:

- Die ethnischen Gruppen der Hawaii-Inseln. Ihre Entwicklung und Bedeutung für Wirtschaftsstruktur und Kulturlandschaft. Wiesbaden. Franz Steiner Verlag. 1984.

- Pazifischer Inselraum. Tabu, Mission. Rückbesinnung. In: Praxis Geographie Heft 9. 1989. S. 44-47.

- Die pazifische Inselwelt. Wissenschaftliche Länderkunden Bd. 38. Darmstadt. Wissenschaftliche Buchgesellschaft. 1991.

- Plattentektonik und Vulkanismus. Die Großstrukturen des Pazifischen Raumes. In: Geographische Rundschau. Braunschweig. Westermann. Heft Nr. 11/1991. S. 630 - 635.

- Nossen, J und Dickmann, F. (Hrsg.): Traumwelt und Wirklichkeit. Reihe Pazifik-Forum. Band 2. Aachen. Verlag der Augustinusbuchhandlung. 1991.

- und Marsden, P. H. et al. (Hrsg.): Neuseeland im Pazifischen Raum. Reihe Pazifik Forum. Band 3. Aachen. Verlag der Augustinusbuchhandlung. 1992.

- und Marsden, P. H. (Hrsg.): First Peoples, First Voices. Indigene Völker zwischen Fremdbestimmung und Selbstbehauptung. Reihe Pazifik Forum. Band 5. Aachen. Verlag der Augustinusbuchhandlung. 1995.

- /Hoppe und Michael/Reeh, Tobias: Mega-Trends im Tourismus - Auswirkungen auf Natur und Umwelt. Berlin. Umweltbundesamt (Hrsg.). 2000.

Krezdorn, Rolf: Bhutan. In: Ellenberg, Ludwig/Beier, Birgit/Scholz, Marion: Ökotourismus. Reisen zwischen Ökonomie und Ökologie. Heidelberg, Berlin, Oxford. Spektrum Akademischer Verlag. 1997. S. 137 - 144.

Kreib, Yörn: Die Guten kommen! Der Dritte Welt Handel steigt ins Urlaubsgeschäft ein. In: Kreib, Jörn und Ulbrich, Angela (Hrsg.): Gratwanderung Ökotourismus: Strategien gegen den touristischen Ausverkauf von Kultur und Natur. Gießen. Focus Verlag. 1997. S. 44 - 59. 
Kreib, Jörn und Ulbrich, Angela (Hrsg.): Gratwanderung Ökotourismus: Strategien gegen den touristischen Ausverkauf von Kultur und Natur. Gießen. Focus Verlag. 1997.

Kroeber, A. und Kluckhohn, Clyde.: Culture - A Critical Review of Concepts and Definitions. New York. Vintage Books. 1952.

Krippendorf, Jost:

- Die Landschaftsfresser. Bern/Stuttgart. 1975.

- IZimmer, Peter und Glauber, Hans (Hrsg.): Für einen anderen Tourismus. Frankfurt am Main. Fischer Taschenbuch Verlag. 1989.

- Die Ferienmenschen. Neuausgabe. Bern. Zytglogge Verlag. 1996.

Krosigk, Friedrich von:

- Determinanten französischer Südpazifik-Politik. Frankreichs Isolation im Südpazifik. In: Asien Nr. 21. Hamburg. 1986. S. 89-100.

- u.a.: Südsee - Inselwelt im Umbruch. Einzelstaatlicher und regionaler Wandel im Südpazifik. Erlanger Forschungen. Reihe A. Geisteswissenschaften. Bd. 44. Erlangen. Univ.-Bibliothek Erlangen-Nürnberg.1988.

- und Jadin, Pierre: Die Französischen Überseegebiete - Paradoxien eines Entwicklungsexperiments. Schriften des Deutschen Übersee-Instituts Hamburg. Nr. 29. Hamburg. Deutsches Übersee-Institut. 1994

Kuntz-Brunner, R.: Der Triumph der Subjektivität. In: Deutsches Allgemeines Sonntagsblatt Nr. 13. 29.03.91.

Langevin, Christine: Tahitiennes. De la tradition à l'integration culturelle. Paris. L'Editions Harmattan. 1990.

La Farge, J.: Reminiscences of the South Seas. London. 1914.

Larenz, A.: Öko-Heilige oder: Renaissance der Naturvölker. In: infoemagazin. Zeitschrift für Ökologie und,,Vierte Welt”. 1/1992. S. 30-32.

Lavondes, A.: Culture et indentité nationale en Polynésie. Cahiers - ORSTOM. Serie Sciences Humaines Vol. 21. Paris. 1985. S. 137-150.

Ledbury, Richard: Sustainable Tourism: A Review and the Research Agenda. In: Hein, Wolfgang (Hrsg.): Tourism and Sustainable Development. Schriften des Deutschen ÜberseeInstituts Hamburg, Nr. 41. Hamburg 1997.

Le Pensec, L.: Une politique pour L'Outre-Mer Français. In: Defense nationale No. 46. 1990. S. 9-23.

Lesnes, Corine: Gabriel Tetiarahi, l'homme mana. Le Monde. 2.10.95 
Leser, H. u. a. (Hrsg.): Wörterbuch der Allgemeinen Geographie. 4. Auflage. Bd. 1 u. 2. Braunschweig/München. dtv/Westermann. 1989.

Levy, R.: Self and Identity. In: Pollock, N. J. u. a. (Hrsg.): French Polynesia: a Book of Selected Readings. Suva. Institute of Pacific Studies of the South Pacific. 1988. S. 8-29.

Lévy-Strauss, Claude: Traurige Tropen. Frankfurt am Main. Suhrkamp. 1996.

Linton, Ralph: Gesellschaft, Kultur und Individuum. Frankfurt am Main. Fischer Verlag. 1974.

Lohmann, Dietrich: Mogelpackung Ökotourismus. In der Tourismusdebatte helfen allein harte Indikatoren. In: ökozidjournal Nr. 18. 2/99. Gießen. Focus Verlag.

Lucas, W.: L'identité culturelle du peuple polynésien et sa renaissance contemporaine. In: ethnies 8/9/10 1989. S. 104-108.

Manu-Tahi, Ch. Teriiteanuanua: Le Mystère de l'Univers Maohi. Tahiti. Les Éditions VEIA RAI. 1992.

Margueron, Daniel: Tahiti dans toute sa littérature. Paris. L’Harmattan. 1989.

Marsden, Peter H.: Neuseelands Selbstverständnis im Spiegel der Lyrik. In: und Marsden, P. H. et al. (Hrsg.): Neuseeland im Pazifischen Raum. Reihe Pazifik Forum. Band 3. Aachen. Verlag der Augustinusbuchhandlung. 1992. S. 213-242.

Mauer, D.: L'Église Protestante a Tahiti. Paris. Nouvelles Editions Latines. 1970.

Merceron, François (Hrsg.): Atlas de Tahiti et de la Polynésie Française. 3. Auflage. Singapur. Les Éditions du Pacifique. 1996.

Miersch, Michael: Der tote Elefant ist nützlich. In: Der Spiegel. 12/97. S. 82-84.

Moerenhout, J. A.:

- Voyage aux Iles du Grand Ocean. 2 vols. 1837.

- The Fatal Impact. London. Hamish Hamilton. 1966.

Morrison, J.: The Journal of James Morrison Boatswain's Mate of the Bounty describing the Mutiny and subsequent Misfortunes of the Mutineers together with an account of the Island of Tahiti. London. The Golden Cockerel Press. 1935.

Mückler, Hermann: Fidschi zwischen Tradition und Transformation. Frankfurt/M. IKO Verlag. 1998.

Mühlberg, Dietrich: Woher wir wissen, was Kultur ist. Berlin. VEB. 1983.

Müllenmeister, Horst Martin: 
- Sanft reisen - pauschal reisen? Der sanfte Tourismus und der organisierte Massentourismus. In: Steinecke, Albrecht (Hrsg.): Tourismus - Umwelt - Gesellschaft. Wege zu einem sozial- und umweltverträglichen Reisen. Bielefelder Tourismus-Lektionen. Sommersemester 1988. Institut für Freizeitwissenschaft und Kulturarbeit e.V. 2. unveränderte Auflage. Bielefeld. IFKA. 1992.

- Zivilisation und Mobilität. Der Beitrag der Kulturanthropologie zur Tourismuswissenschaft. In: Würbel, Andres und Soika, Johannes (Red.): Phänomen Tourismus. Bergisch Gladbach. Thomas-Morus-Akademie Bensberg. 1998. S. 25-50.

Müller, Hansruedi: Freizeit und Tourismus. Bern. FIF. 1999.

Mundt, Jörn W.: Einführung in den Tourismus. München/Wien. R. Oldenbourg Verlag. 1998.

Münzel, M.: Die Bedrohung außereuropäischer Kulturen durch unsere Wissenschaft. In: Krafft, F. et al.: Wissenschaft im Spannungsfeld zwischen den Kulturen. Bayreuth 1987.

Nevermann, H. u. a.: Die Religionen der Südsee und Australiens. Die Religionen der Menschheit Bd. 5. Stuttgart/Berlin/Köln/Mainz. 1968.

Newbury, C.:

- Aspects of Cultural Change in French Polynesia: The Decline of the Ari'i. In: Pollock, N. J. u. a. (Hrsg.): French Polynesia: a Book of Selected Readings. Suva. Institute of Pacific Studies of the South Pacific. 1988. S. 58-77.

- Tahiti Nui. Change and Survival in French Polynesia 1767-1945. Honolulu. 1980.

Niekisch, Manfred: Ökotourismus - Die neue Zauberformel? In: Kreib, Jörn und Ulbrich, Angela (Hrsg.): Gratwanderung Ökotourismus: Strategien gegen den touristischen Ausverkauf von Kultur und Natur. Gießen. Focus Verlag. 1997. S. 14 - 29.

Nohlen, Dieter.: Lexikon Dritte Welt. Reinbeck. Rowohlt. 1989.

Nohlen, Dieter und Nuscheler, Franz (Hrsg.):

- Handbuch der Dritten Welt. Bd. 8. Ostasien und Ozeanien. Unterentwicklung und Entwicklung. 2. überarbeitete und ergänzte Ausgabe. Hamburg. Hoffmann und Campe. 1983.

- Handbuch der Dritten Welt. Bd. 1. Bonn. Verlag J. H. W. Dietz Nachf. GmbH. 1992.

Nuscheler, F.: Struktur- und Entwicklungsprobleme der südpazifischen Inselwelt. In: Nohlen, D. und Nuscheler, F. (Hrsg.): Handbuch der Dritten Welt. Bd. 8. Ostasien und Ozeanien. Unterentwicklung und Entwicklung. 2. überarbeitete und ergänzte Ausgabe. Hamburg. Hoffmann und Campe. 1983. S. 212-254.

NZZ. 19.8.98: Polynesien laut Genforschern von Taiwan aus bevölkert.

O’Grady, Ron: Zwischenlandung Dritte Welt. Verlag Otto Lembeck. 1982. 
Olmedo, Esteban L.: Quantitative Models of Acculturation. In: Padilla, Amado M. (Hrsg): Acculturation. Theory, Models and Some New Findings. Boulder. Westview Press. 1980. S. 27-45.

Oliver, D. L.: Ancient Tahitian Society. 3 Bd. Honolulu. 1974.

Opaschowski, Horst W.:

- Tourismusforschung. Opladen. Leske und Budrich. 1989.

- Umwelt, Mobilität und Tourismus. BAT-Freizeitforschungsinstitut. Hamburg. 1998.

- Wir schaffen Glückseligkeit! Anspruch und Wirklichkeit künstlicher Freizeit- und Ferienwelten. In: Isenberg, Wolfgang (Hrsg.): Kathedralen der Freizeichgesellschaft. Kurzurlaub in Erlebniswelten. Trends, Hintergründe, Auswirkungen. Bensberger Protokolle 83. 2. erw. Auflage. Bergisch Gladbach. Thomas-Morus-Akademie. 1998. S. 11 -34 .

- Tourismus im 21. Jahrhundert. BAT-Freizeitforschungsinstitut. Hamburg. 1999.

O’ Reilly, P.

- und Rettmann, E.: Bibliographie de Tahiti et de la Polynésie Française. Paris. Musée de l'Homme. 1967.

- Le Tahiti Catholique. Paris. Société des Oceanistes. 1970.

- Tahiti. La vie de chaque jour. Paris. 1982.

Orlovius-Wessely, Anita: Future made by tourism? Die Tourismuskritik muss institutionalisiert werden. In: Ökozidjournal Nr. 17. Gießen. Focus Verlag. 1999. S. 44-50.

Padilla, Amado M. (Hrsg): Acculturation. Theory, Models and Some New Findings. Boulder. Westview Press. 1980.

Panoff, M.: Tahiti Métisse. Paris. Denoel. 1989.

Pardon, Kai: Begegnung in der Fremde ja - zu Hause nein danke? In: Kreib, Jörn und Ulbrich, Angela (Hrsg.): Gratwanderung Ökotourismus: Strategien gegen den touristischen Ausverkauf von Kultur und Natur. Gießen. Focus Verlag. 1997. S. 138 - 151.

Pazifik-Informationsstelle (Hrsg.):

- Moruroaatoll wird geräumt. In: pazifik aktuell. Nr. 36. Neuendettelsau. 1996. S. 13-14.

- Frankreich ratifiziert Atomtest-Vertrag. In: pazifik aktuell. Nr. 37. Neuendettelsau. 1998. S. 10-11.

- Geringe radiologische Belastung? In: pazifik aktuell. Nr. 38. Neuendettelsau. 1998. S. 1314. 
- Neue Studie bestätigt alte Befürchtungen. In: pazifik aktuell. Nr. 40. Neuendettelsau. 1999. S. 13.

- Französisch-Polynesien: Protest gegen Ausbaggerung der Lagune. In: pazifik aktuell. Nr. 44. Neuendettelsau. 2000. S. 7-8.

Pierce, W. David und Warford, Jeremy J. : World without End. Economics, Evironment and Sustainable Development. New York. Oxford University Press. 1993.

PIANGO Link: NGO Parallel Forum Communique. Nadi, Fiji/Wellington, Neuseeland. 1998. S. 4.

\section{Piermont, D.:}

- Französisch-Polynesien. Frankreichs Kolonie im Südpazifik. In: Blätter des iz3w. Heft 135. 1986. S. 16-20.

- Mit der „,Greenpeace” nach Moruroa. In: Blätter des iz3w. Heft 130. 1985. S. 3-5.

Pollock, N. J. u. a. (Hrsg.): French Polynesia: a Book of Selected Readings. Suva. Institute of Pacific Studies of the South Pacific. 1988.

Poirine, Bernard:

- Les petites economies insulaires: theorie et strategies de developpement. Paris. L'Harmattan. 1995.

- Tahiti. Stratégie pour l'après-nucléaire. De la rente atomique au développement. Paris. L'Harmattan. 1996.

Popcorn, F.: Der Popcorn-Report. Trends für die Zukunft. München. 1992.

Posner, Roland:

- What ist Culture? Towards a Semiotic Explication of Anthropological Concepts. In: Koch, Walter A.: The Nature of Culture. Bochum. Brockmeyer. 1989. S. 240-295.

- Kultur als Zeichensytem. Zur semiotischen Explikation kulturwissenschafticher Grundbegriffe. In: Assmann, Aleida und Harth, Dietrich: Kultur als Lebenswelt und Monument. Frankfurt am Main. Fischer. 1991, S. 37-74.

Prahl, Hans-Werner: Freizeitsoziologie: Entwicklungen, Konzepte, Perspektiven. München. Kösel. 1977.

Pritchard, G.: The Agressions of the French at Tahiti and Other Islands in the Pacific. Auckland. Auckland University Press. 1983.

Putigny, Bob: Le Mana. Tahiti. Éditions Avant et Après.1993.

Raapoto, Jean-Marius: Dimension Orale du Reo Maohi aux Iles de la Société. Strasbourg. Papeete. 1997. 
Raapoto, T. A.: Maohi: On being Tahitian. In: Pollock, N. J. u. a. (Hrsg.): French Polynesia: a Book of Selected Readings. Suva. Institute of Pacific Studies of the South Pacific, 1988. S. 3-7.

Rallu, J.-L.: Situation demographique de la Polynésie Française. In: Population 2/1980. Paris. S. 385-415.

Ramaswamy, M. Krischke: Ethnologie für Anfänger. Eine Einführung aus entwicklungspolitischer Sicht. Westdeutscher Verlag. Opladen. 1985.

Ranft-Panek, B.: Konfrontation und Anpassung. Sozioökonomische Veränderungen und ihr Einfluss auf den Kulturwandel bei den australischen Aborigines. Mundus-Reihe Ethnologie Bd. 13. Bonn. Holos. 1990.

Ransom, David: Decolonizing the Mind. In: New Internationalist. Juni 1997. S. 11

Rath, G.: Integrations- und Desintegrationstendenzen im Südpazifik. In: Asien Nr. 12. Hamburg. 1984. S. 20-36.

Ratter, Beate M. W.: Belize. In: Ellenberg, Ludwig/Beier, Birgit/Scholz, Marion: Ökotourismus. Reisen zwischen Ökonomie und Ökologie. Heidelberg, Berlin, Oxford. Spektrum Akademischer Verlag. 1997. S. 219 - 228.

Rauschelbach, Burghard (Hrsg): (Öko-) Tourismus: Instrument für eine nachhaltige Entwicklung? gtz. Heidelberg. Kasparek.1998.

Ravault, F:

- Land Problems in French Polynesia. In: Pollock, N. J. u. a. (Hrsg.): French Polynesia: a Book of Selected Readings. Suva. Institute of Pacific Studies of the South Pacific. 1988. S. 112-153.

- Papeari. L'Organisation de l'Espace dans un district de la côte sud de Tahiti. Paris. ORSTOM. 1980.

Redford, K. H.: The Ecologically Noble Savage. In: Cultural Survival Quarterly. Vol. 15. 1/91. S. 46-48.

Renn, Ortwin; Knaus, Anja; Kastenholz, Hans: Wege in eine nachhaltige Zukunft. In: Breuel, Birgit (Hrsg.): Agenda 21. Vision: Nachhaltige Entwicklung. Frankfurt/Main, New York. Campus Verlag. 1999. S. 17-74.

Ribbe, J. u. Tomczak, M.: An Impact Assessment for the French Nuclear Weapon Test Sites in French Polynesia. In: Marine Pollution Bulletin. No. 11. V 21. London. 1990. S. 536-542.

Richter, Dieter: Kulturkontakt. In: Burmeister, Hans-Peter (Hrsg.): Auf dem Weg zu einer Theorie des Tourismus. Loccumer Protokolle. 1998. S. 143-147. 
Rigo, Bernhard: Lieux-dits d'un maletendu culturel. Analyse anthropologique et philosophique du discours occidental sur l'altérité polynésienne. Tahiti. Au Vent des Îles Éditions. 1997.

Ritz, H.: Die Sehnsucht nach der Südsee. Bericht über einen europäischen Mythos. 2. Auflage. Göttingen. Muriverlag. 1983.

Robertson-Wensauer, Carolin Y.: Multikulturalität-Interkulturalität? Probleme und Perspektiven der multikulturellen Gesellschaft. Baden-Baden. Nomos. 2000.

Robineau, C.: Tradition et modernité aux îles de la Société. Livre I: Du coprah à l'atome. Mém. ORSTOM No. 100. Paris. 1984.

Rohde, Petra-Angelika: Paul Gauguin auf Tahiti. Rheinfelden. Schäuble. 1988.

Rolin, O.: Bougainville and the Mirage of Tahiti. In: Histoire No. 8. Paris. 1979. S. 74-76.

Romeiß-Stracke, Felizitas:

- Zukünftige Bedingungen von Freizeit und Tourismus. In Krippendorf, Jost; Zimmer, Peter und Glauber, Hans (Hrsg.): Für einen anderen Tourismus. Frankfurt am Main. Fischer Taschenbuch Verlag. 1989. S. 29-37.

- Tourismus - gegen den Strich gebürstet. München/Wien. Profil. 1998.

Rudolph, Wolfgang: Ethnos und Kultur. Zitiert in: Fischer, Hans: Ethnologie. Reimer. Berlin. 1988. S. 39-60.

Ruff, T. A.:

- Bomb Tests Attack the Food Chain. In: Bulletin of the Atomic Scientists No. 46. Chicago. 1990. S. 32-34.

- Ciguatera in the Pacific: a Link with Military Activities. In: The Lancet. January 1989. S. 201-204.

Safai-Grodd, Gabriele: Entwicklungshilfe als Instrument des gelenkten Kulturwandels. In: Antweiler, Christoph u. a. (Hrsg.): Ethnologische Beiträge zur Entwicklungspolitik. Bonn. PAS. 1987. S. 163-174.

Sahlins, M. D.:

- Social Stratification in Polynesia. American Ethnological Society Momograph 29. Seattle/London. 1958.

- Poor Man, Rich Man, Big-Man, Chief Political Types in Melanesia and Polynesia. In: Harding, T. G. und Wallace, B. J. (Hrsg.): Cultures of the Pacific. New York/London. 1970. S. 203-215.

Saivre, D. de: La Commission du Pacifique Sud. In: ethnies 8/9/10 1989. S. 113-115. 
Salmon, J.: La culture en Polynésie. Entretien avec Jacques Teheiura. (Mai 1984). In: ethnies 8/9/10 1989. S. 109-112.

Saura, Bruno:

- Des Tahitiens, des Français, leurs représentations réciproques aujourd'hui. Tahiti. Les Essais Christian Gleizal Editeur. 1998.

- Politique et religion à Tahiti. Tahiti. Éditions Polymages - Scoop. 1993.

Scemla, Jean: Les Immemoriaux de Victor Segalen. Tahiti. Éditions Haere Po No Tahiti. 1986.

Schawinski, Roger: Die sozioökonomischen Faktoren des Fremdenverkehrs in Entwicklungsländern: der Fall Guatemala. Bern/Stuttgart. 1973.

Scherer, Brigitte: Tourismus. Reinbek bei Hamburg. Rowohlt Taschenbuch Verlag. 1995.

Scherrer, Christian E.: Tourismus und selbstbestimmte Entwicklung-ein Widerspruch: das Fallbeispiel Tansania. Berlin. Dietrich Reimer Verlag. 1988.

Schiwy, G.: Die „Natur der Kultur” bei Teilhard de Chadin. In: Koch, Walter A.: The Nature of Culture. Bochum. Brockmeyer. 1989. S. 469-479.

Schloemer, Achim: Nachhaltiger Tourismus? - Ein Beitrag zur Evaluation aktueller Konzeptionen für ländliche Regionen Mitteleuropas. Sankt Augustin. Academia-Verlag. 1999.

Schmall, Susanne: Provinz Pastaza in Ecuador. In: Ellenberg, Ludwig/Beier, Birgit/Scholz, Marion: Ökotourismus. Reisen zwischen Ökonomie und Ökologie. Heidelberg, Berlin, Oxford. Spektrum Akademischer Verlag. 1997. S. 241 - 248.

Schmied-Kowarzik, Wolfdietrich: Das Verstehen fremder Kulturen. In: Schweppenhäuser, Gerhard und Gleiter, Jörg H. (Hrsg.): Kultur - philosophische Spurensuche. Weimar. Universitätsverlag. 2000. S. 62 - 80.

Scholz, Marion: Proyecto Paria in Venezuela. In: Ellenberg, Ludwig/Beier, Birgit/Scholz, Marion: Ökotourismus. Reisen zwischen Ökonomie und Ökologie. Heidelberg, Berlin, Oxford. Spektrum Akademischer Verlag. 1997. S. 249 - 258.

Schönherr, S. und Simson, U.: Innovationsfixierung, Kultur und Entwicklungszusammenarbeit. In: Internationales Afrikaforum. 21. Jg. 1/85. S. 75-81.

Schulze, Gerhard: Die Erlebnisgesellschaft. Frankfurt/New York. 1992.

Schwarzenbeck, F.: Frankreichs Überseeterritorien im Südpazifik. In: Asien. Heft 8. Hamburg. 1983. S. 42-56.

Schweppenhäuser, Gerhard und Gleiter, Jörg H. (Hrsg.): Kultur - philosophische Spurensuche. Weimar. Universitätsverlag. 2000. 
Segalen, Victor: Les Immémoriaux. Paris. Éditions du Seuil. 1985.

Seger, L: Wenn die Geister wiederkehren. Weltdeutung und religiöses Bewusstsein in primitiven Kulturen. München. Piper. 1982.

Seithel, Friderike: Von der Kolonialanthropologie zur Advocacy Anthropology: Zur Entwicklung einer kooperativen Forschung und Praxis von EthnologInnen und indigenen Völkern. Hamburg. Lit. 2000.

Service du Tourisme: Statistiques Touristiques 1998. Papeete. 1999.

Sharp, A.: Polynesian Navigation to Distant Islands. In: Harding, T. G. und Wallace, B. J. (Hrsg.): Cultures of the Pacific. New York/London. 1970. S. 13-19.

Shaw, E. (Hrsg.): French Nuclear Testing in the Pacific. A Partial Chronology of the French Presence in the Pacific 1838-1990. Greenpeace Pacific Campaign. Auckland. 1990.

Shineberg, B.: The Image of France. In: Pollock, N. J. u. a. (Hrsg.): French Polynesia: a Book of Selected Readings. Suva. Institute of Pacific Studies of the South Pacific. 1988. S. 78-99.

Simenon, George: Touriste de bananes. Éditions Gallimard. 1938.

Siemers, G.: Die südpazifischen Inseln. In: Draghun, W. u. a.: Politisches Lexikon Asien, Australien, Pazifik. München. Beck. 1989. S. 309-340.

Sinoto, Y. H. u. McCoy, P. C.: Excavations of an Archaic Habitation Site on Huahine, Society Islands. Preliminary Report. 1975 Excavation Manuiscript. Papeete. 1976.

Société des Études Océaniennes (Hrsg.): Généalogies commentées des arii des Îles de la Société. Tahiti. Polytram. 1996.

Stanley, J.: The South Pacific Commission. In: Buchholz, H. J.: (Hrsg.): New approaches to development co-operation with south pacific countries. Saarbrücken/Fort Lauderdale: Breitenbach. 1987. S. 57-68.

Stein, Gerd: Die edlen Wilden. Frankfurt. Fischer Taschenbuch Verlag. 1984.

Steinecke, Albrecht (Hrsg.):

- Tourismus - Umwelt - Gesellschaft. Wege zu einem sozial-und umweltverträglichen Reisen. Bielefelder Tourismus-Lektionen. Sommersemester 1988. Institut für Freizeitwissenschaft und Kulturarbeit e.V. 2. unveränderte Auflage. Bielefeld. IFKA. 1992.

- Erlebnis- und Konsumwelten. München/Wien. Oldenbourg. 2000.

Stingl, M.: Die Kunst der Südsee. Leipzig. 1985.

Stock, Christian (Hrsg.): Trouble in Paradise. Tourismus in die Dritte Welt. Freiburg, Breisgau. Verl. Informationszentrum Dritte Welt. Düsseldorf. Verl. Haus Altenberg. 1997. 
Stradas, Wolfgang und Behrens-Egge, Mathias: Ecotourism in African Rain Forests: The Examples of Ivory Coast and the Central African Republic. In: Hein, Wolfgang (ed.): Tourism and Sustainable Development. Schriften des Deutschen Übersee-Instituts Hamburg. Nr. 41. Hamburg 1997. S. 125-152.

Streich, J.: Betrifft Greenpeace: gewaltfrei gegen die Zerstörung. 2. Auflage. München. Beck. 1987.

Suliman, Mohamed: Sustainable Germany, a Blue-Print for Progress. März 1995.

Szapocznik, José und Kurtines, William: Acculturation, Biculturalism and Adjustment Among Cuban Americans. In: Padilla, Amado M. (Hrsg): Acculturation. Theory, Models and Some New Findings. Boulder. Westview Press. 1980. S. 139-159.

Tagupa, W. E.:

- Centre d'Expérimentations du Pacifique 1963-1973: A Decade of Debate in French Polynesia. In: Australian Outlook No. 1. Vol. 28. Canberra. 1974. S. 36-43.

- Electoral Behavior in French Polynesia, 1977 - 1982. In: Political Science No. 1. V 35. Wellington. 1983. S. 38-57.

- Some Aspects of Modern Politics and Personality in French Polynesia. In: Journal of Pacific History V 9. Canberra. 1974. S. 135-145.

Temaru, O.: Maohinui (French Polynesia). The Need for Independence. In: Pollock, N. J. u. a. (Hrsg.): French Polynesia: a Book of Selected Readings. Suva. Institute of Pacific Studies of the South Pacific. 1988. S. 275-283.

Teriitau, Angèle: Quelles perspectives d'avenir pour un développement soutenable de la Polynésie? In: Centre de Documentation et de Recherche sur la Paix et les Conflits: Essais nucléaires français en Polynésie: exigence de vérité et propositions pour l'avenir. Actes du colloque 20 février 1999. Lyon. 1999. S. 55-59.

Tetiarahi, Gabriel:

- Perspectives économiques, sociales et sanitaires. In: Centre de Documentation et de Recherche sur la Paix et les Conflits: Essais nucléaires français en Polynésie: exigence de vérité et propositions pour l'avenir. Actes du colloque 20 février 1999. Lyon. 1999. S. 6062.

- Legimité et souveraineté dans les îles du pacifique Maohi Nui. Contribution à la conférence universitaire PIPSA sise à Monash University, Victoria 16-17-18 décembre 1991.

- Maohi, Maori, Aborigines, Rapa Nui ... du combat pour la digneté des peuples autochthones du Pacifique. Paris. 1990a.

- Maohi People's Land Rights in French Polynesia. Information to the Working Group „,tomite fenua” Evangelical Church. Papeete. 1990b. 
- Milieu urbain et compétition socio-culturelle dans le Pacific Sud: le cas de la Polynésie Française. In: ethnies 8/9/10 1989a. S. 81-87.

- Pacific Land Problem, Nuclear and Environment. Information to the Working Group „tomite fenua” Evangelical Church. Papeete. 1989b.

- Papeete: un example de croissance urbaine accélérée. In: Cahiers d'Outre-Mer No. 4. Bordeaux. 1983. S. 324-372.

- The Society Islands - Squeezing out the Polynesians. In: Pollock, N. J. u. a. (Hrsg.): French Polynesia: a Book of Selected Readings. Suva. Institute of Pacific Studies of the South Pacific. 1988. S. 100-111.

Thomson, V.: The French Pacific Islands. Berkeley. 1971.

Tietze, W. (Hrsg.): Westermann Lexikon der Geographie. Braunschweig. Westermann. S. 357.

Tischner, H.: Kulturen der Südsee. Einführung in die Völkerkunde Ozeaniens. Hamburg. 1958.

Tok Blong Pasifik: The Traditional Knowledge of Pacific Peoples. Victoria. Dezember 1998/Februar 1999.

Torres-Matrullo, Christine M.: Acculturation, Sex-Role Values and Mental Health Among Mainland Puerto Ricans. In: Padilla, Amado M. (Hrsg): Acculturation. Theory, Models and Some New Findings. Boulder. Westview Press. 1980. S. 111-137.

Tüting, Ludmilla:

- Trekkingtourismus in Nepal. Das „Annapurna Conversation Area Project” als hoffnungsvoller Ansatz. In: Euler, Claus (Hrsg.): ,Eingeborene' ausgebucht. Ökologische Zerstörung durch Tourismus. Giessen. Focus Verlag. 1989. S. 112 - 132.

- Alte und neue Heilssuchende im Himalaja. Was Einheimische und Ausländer unter „Urlaub” verstehen! In: Kreib, Jörn und Ulbrich, Angela (Hrsg.): Gratwanderung Ökotourismus: Strategien gegen den touristischen Ausverkauf von Kultur und Natur. Gießen. Focus Verlag. 1997. S. $152-153$.

Uschtrin, Cornelia und Cwik, Hans-Jürgen: Südpazifik. Inselstaaten und Territorien: eine Auswahlbibliographie. Deutsches Übersee Institut. 1999.

Vayda, Andrew P.: Environment and cultural behavior: ecological studies in cultural anthropology. Garden City. New York. Natural History Press. 1969.

Vielhaber, A.: Reisende und Bereiste: Soziale Verantwortung beim Tourismus in Entwicklungsländern. In: Rauschelbach, Burghard (Hrsg): (Öko-)Tourismus: Instrument für eine nachhaltige Entwicklung? gtz. Heidelberg. Kasparek.1998. S. 57 - 64.

Vigneron, E.: The Epidemiological Transition in an Overseas Territory: Disease Mapping in French Polynesia. In: Social Science and Medicine Vol 29 (8). New York. 1989. S. 913-922. 
Vink, G.E. u. a.: „Hot Spots: heiße Flecken auf der Erde.” In: Spektrum der Wissenschaft. Heft 6. 1985. S. 62-72.

Von Funke: Unterwegs in dringenden spirituellen Geschäften. In: SZ. 6.4.99.

Vorlaufer, Karl : Tourismus in Entwicklungsländern. Darmstadt. Wissenschaftliche Buchgesellschaft. 1996.

Vester, Heinz-Günter: Tourismustheorie. Soziologische Wegweiser zum Verständnis touristischer Phänomene. München/Wien. Profil. 1999.

de Vries, Pieter und Seur, Han: Moruroa and Us. Poynesians' experiences during Thirty Years of Nuclear Testing in the French Pacific. Lyon. Centre de Documentation et de Recherche sur la Paix et les Conflits. 1997.

Wallace, A. F. C.: Revitalization Movements. In: American Anthropologist No 58. 1956. S. 761-774.

Weber-Schäfer, Peter: „,Eurozentrismus” contra ,Universalismus”. Über die Möglichkeiten, nicht-europäische Kulturen zu verstehen. in: Brocker, Manfred und Nau, Heino Heinrich (Hrsg.): Ethnozentrismus - Möglichkeiten und Grenzen des interkulturellen Dialogs. Wissenschaftliche Buchgesellschaft. Darmstadt. 1997. S. 241-255.

Wernhart, Karl R.:

- Auswirkungen der Zivilisationstätigkeit und Missionierung in den Kulturen der Autochthonen - am Beispiel der Gesellschaftsinseln. In: Europäisierung der Erde. Wiener Beiträge zur Geschichte der Neuzeit Bd. 7. 1980. S. 120-146.

- Konstanz und Wandel. Notations zur sozialen Evolution in Französisch-Polynesien. In: Fillitz, Thomas/Gingrich, Andre/Rasuly-Paleczek, Gabriele: Kultur. Identität. Macht. Frankfurt am Main. Verlag für Interkulturelle Kommunikation. 1993. S. 13-33.

Wirthmann, A.: Inseltypen in Polynesien. In: Würzburger Geographische Arbeiten. Heft 12. Würzburg. 1964. S. 177-190.

Wiemer, Hans-Jürgen: Agrarstrukturen in Tonga. Sozialökonomische Schriften zur Ruralen Entwicklung. Bd. 61. Göttingen. Herodot. 1985.

Wöhler, Karlheinz: Kulturangebote zwischen Authentizität und Inszenierung: Kommt der raumlose Tourismus? Lüneburg. Materialien zur Tourismuswissenschaft 28. 1999.

von Wogau, Peter: Prüfung des Fair-Travel Konzeptes. Bericht. Internes Papier. Fair Trade. Freiburg. 1998.

\section{World Tourism Organization:}

- Business and Marketing Plans of National Tourism Administrations. London/New York. 1994. 
Wresky, H.-P.: Gesundheitliche Folgen der Atombombenversuche im Pazifik. In: DeutschPazifische Gesellschaft. Bulletin S 36. München. 1987. S. 50-60.

Würbel, Andres und Soika, Johannes (Red.): Phänomen Tourismus. Bergisch Gladbach. Thomas-Morus-Akademie Bensberg. 1998.

Wurzel, Tobias: Das Problem der Maori-Identität in A. Duffs „,Once Were Warriors”. Magisterarbeit. Philosophische Fakultät der Christian-Albrechts-Universität zu Kiel. 1999.

Ziehr, W.: Hölle im Paradies. Entdeckung und Untergang der Südseekulturen. Wien/Düsseldorf. Econ. 1980.

Ziemer, K.: Französisch-Polynesien. In: Nohlen, D. und Nuscheler, F. (Hrsg.): Handbuch der Dritten Welt. Bd. 8. Ostasien und Ozeanien. Unterentwicklung und Entwicklung. 2. überarbeitete und ergänzte Ausgabe. Hamburg. Hoffmann und Campe. 1983. S. 406-413.

o. V. Atlas of the South Pacific. Second Edition. Department of Lands and Survey. Wellington. Government Printing Office. 1986.

o. V. Call for Independant Study in French Polynesia. In: Wise News. Amsterdam. February 1991. S. 2.

o. V. David gegen Goliath. Die Völker des Pazifik zwischen Selbstbestimmung und Nuklearkolonialismus. pogrom Nr. 134. Zeitschrift für bedrohte Völker. 1987.

o. V. French Nuclear Testing 1960-1988. Nuclear Weapon Data Center. Working Paper 89-1.

o. V. Frontièrs, Limites et Statuts. Approche géopolitique du Pacifique Sud. In: Atlas des îles et etats du Pacifique Sud. GIP Rechus Publ. 1988.

o. V. La Polynésie Française dans le Pacifique. Atlas de Tahiti et de la Polynésie Française. Editions du Pacifique. 1988.

o. V. Le Grand Représentant. In: Nouvelles de Survival. Frühjahr 1996. S. 7-8.

o. V. Moruroa. Großes Geheimnis. In: Der Spiegel. 41/1990. S. 262-268.

o.V. Testimonies. Witness of French Nuclear Testing in the South Pacific. Greenpeace International. 1990.

o.V. Uranopfer: Aborigines - Lakota - Navajos - Pueblos - Western Shoshone - Völker des Pazifik - Namibia - Armenier - Basken - Sami. pogrom Nr. 135. Zeitschrift für bedrohte Völker. 1987.

o. V. Zweihundert Jahre Deklaration der Menschenrechte. 1789-1989. pogrom Nr. 146. Zeitschrift für bedrohte Völker. 1989.

\section{Websites:}

www.frankreich-experte.de www.odci.gov/cia/publications/factbook/index.html 


\section{VERZEICHNIS DER ABBILDUNGEN UND TABELLEN IM TEXT}

Abb. 1 Becker, Christoph; Job, Hubert und Witzel, Anke: Tourismus und nachhaltige Entwicklung. Wissenschaftliche Buchgesellschaft. Darmstadt. 1996. S. 5.

Abb. 2 Hein, Wolfgang (Hrsg.): Tourism and Sustainable Development. Schriften des Deutschen Übersee-Instituts Hamburg, Nr. 41. Hamburg 1997. S. 371.

$\underline{\text { Abb. } 3}$ Vorlaufer, Karl : Tourismus in Entwicklungsländern. Darmstadt. Wissenschaftliche Buchgesellschaft. 1996. S. 230.

Abb. 4a-c Becker, Christoph; Job, Hubert und Witzel, Anke: Tourismus und nachhaltige Entwicklung. Wissenschaftliche Buchgesellschaft. Darmstadt. 1996. S. 134-138.

Abb. 5 Cooper und Jackson 1989. S. 378; zitiert in Dworschak, Helmut: Kulturdiskurse. Zum Verhältnis von Tourismus und indigener Kultur. Münster/New York. Waxmann.1994. S. 19.

Abb. 6 Vorlaufer, Karl : Tourismus in Entwicklungsländern. Darmstadt. Wissenschaftliche Buchgesellschaft. 1996. S. 198/199.

Abb. 7 Vorlaufer, Karl : Tourismus in Entwicklungsländern. Darmstadt. Wissenschaftliche Buchgesellschaft. 1996. S. 207.

$\underline{\text { Abb. } 8}$ Vorlaufer, Karl : Tourismus in Entwicklungsländern. Darmstadt. Wissenschaftliche Buchgesellschaft. 1996. S. 45.

$\underline{A b b .9}$ Deutsche Gesellschaft für Technische Zusammenarbeit (gtz) GmbH: Tourismus in der Technischen Zusammenarbeit. Eschborn.1999. S. 29.

Abb. 10 Vorlaufer, Karl : Tourismus in Entwicklungsländern. Darmstadt. Wissenschaftliche Buchgesellschaft. 1996. S. 5.

Abb. 11 Kievelitz, Uwe: Ethnotourismus: Ursachen, Formen und Wirkungen interkultureller Kurzkontakte. In: Euler, Claus (Hrsg.): ,Eingeborene’ ausgebucht. Ökologische Zerstörung durch Tourismus. Giessen. Focus Verlag. 1989. S. 33. 
Abb. 12 Kievelitz, Uwe: Ethnotourismus: Ursachen, Formen und Wirkungen interkultureller Kurzkontakte. In: Euler, Claus (Hrsg.): ,Eingeborene’ ausgebucht. Ökologische Zerstörung durch Tourismus. Giessen. Focus Verlag. 1989. S. 34.

Abb. 13 Crocombe, R.G.: (Hrsg.): Politics in Polynesia. Suva. Institute of Pacific Studies of the University of the South Pacific. 1983. S. 191.

$\underline{\text { Abb. } 14}$ Buchholz, H. J.: Australien - Neuseeland - Südpazifik. Fischer Länderkunde, Bd. 10. Frankfurt am Main: Fischer. 1984. S. 106.

$\underline{\text { Tab. } 1}$ Jungk, Robert. Wie viel Touristen pro Hektar Strand? Plädoyer für ,,sanftes Reisen “. In: Geo. Heft 10. 1980. S. 155.

$\underline{T a b .} 2$ Mundt, Jörn W.: Einführung in den Tourismus. München/Wien. R. Oldenbourg Verlag. 1998. S. 412.

$\underline{\text { Tab. } 3}$ nach: Nuscheler, F.: Struktur- und Entwicklungsprobleme der südpazifischen Inselwelt. In: Nohlen, D. und Nuscheler, F. (Hrsg.): Handbuch der Dritten Welt, Bd. 8. Ostasien und Ozeanien. Unterentwicklung und Entwicklung. 2. überarbeitete und ergänzte Ausgabe. Hamburg: Hoffmann und Campe. 1983. S. 408 und ITSTAT 1998.

Tab. 4 nach Ziemer. K.: Französisch-Polynesien in Nohlen, D. und Nuscheler, F. (Hrsg.): Handbuch der Dritten Welt. Bd. 8. Ostasien und Ozeanien. Unterentwicklung und Entwicklung. 2. überarbeitete und ergänzte Ausgabe. Hamburg. Hoffmann und Campe. 1983. S. 406 und ISTAT 1998.

Tab. 5 nach Ruff, T. A.: Ciguatera in the Pacific: a Link with Military Activities. In: The Lancet. January 1989. S. 203.

$\underline{\text { Tab. } 6}$ Schätzung des Service du Tourisme. Papeete. 1999.

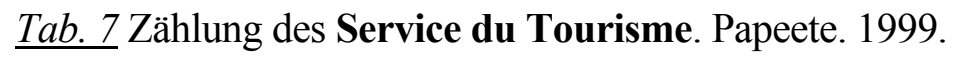




\section{VERZEICHNIS DER ANLAGEN IM ANHANG}

Anl. 1a-d Fragebögen der Zielgruppen Betreiber touristischer Infrastruktur und Reisende, sowie Frageleitfäden Experten und Bereiste.

Anl. 2 Breuel, Birgit (Hrsg.): Agenda 21. Vision: Nachhaltige Entwicklung. Frankfurt/Main, New York. Campus Verlag. 1999. S. 20.

Anl. 3 Fragebogen TRANSFAIR, von Wogau, Peter: Prüfung des Fair-Travel Konzeptes. Bericht. Internes Papier. Fair Trade. Freiburg. 1998.

Anl. $4 a$ Karte auf der Basis von : o. V. Frontières, Limites et Statuts. Approche géopolitique du Pacifique Sud. In: Atlas des îles et états du Pacifique Sud. GIP Rechus Publ. 1998. S. 99.

$\underline{\text { Anl. } 4 b}$ Basis: ITSTAT 1998

\section{Anl. 5 Basis: www.odci.gov/cia/publications/factbook/index.html}

Anl. 6 Kreisel, Werner: Die pazifische Inselwelt. Wissenschaftliche Länderkunden. Bd. 38. Darmstadt. Wissenschaftliche Buchgesellschaft. 1991. S. 80.

Anl. 7 Stingl, M.: Die Kunst der Südsee. Leipzig. 1985. S. 249.

$\underline{\text { Anl. } 8}$ Baré, J. F. : Tahiti, les temps et les pouvoirs. Pour un anthropologie historique du Tahiti post-européen. Paris. ORSTOM. 1987. S. 160, 161.

Anl. 9, 10 Bovis, E. de: Tahitian Society before the Arrival of the Europeans. Second Edition. Hawaii. The Institute for Polynesian Studies. Brigham University. Hawaii Campus. 1980. S. 41, 45.

Anl. 11a Ravault, F.: Papeari. L'Organisation de l'Espace dans un district de la côte sud de Tahiti. Paris. ORSTOM. 1980. S. 28.

$\underline{\text { Anl. } 11 b}$ o. V. La Polynésie Française dans le Pacifique. Atlas de Tahiti et de la Polynésie Française. Editions du Pacifique. 1988. S. 8. 
Anl. 12 Merceron, François (Hrsg.): Atlas de Tahiti et de la Polynésie Française. 3. Auflage. Singapur. Les Éditions du Pacifique. 1996. S. 9.

Anl. 13 Nevermann, H. u. a.: Die Religionen der Südsee und Australiens. In: Die Religionen der Menschheit. Bd. 5. Stuttgart, Berlin, Köln, Mainz. 1968. S. 21.

Anl. 14 Emory, K. P.: The Societies. In: Pollock, N. J. u.a. (Hrsg.): French Polynesia: a Book of Selected Readings. Suva. Institute of Pacific Studies of the South Pacific. 1988. S. 44, 45.

Anl. 15 Newbury, C.: Tahiti Nui. Change und Survival in French Polynesia 1767-1945. Honolulu. 1980. S. 274.

Anl. 16a,b Blanchet, G.: L'économie de la Polynésie française de 1960 à 1980. Paris. Éditions de l'ORSTOM. 1985. S. 41, 67.

Anl. 17 Baré, J.-F.: Tahiti, les temps et les pouvoirs. Pour un anthropologie historique du Tahiti post-européen. Paris. ORSTOM. 1987. S. 374.

Anl. 18 Tetiarahi, G.: Maohi People's Land Rights in French Polynesia. Information to the Working Group. „tomite fenua”. Evangelical Church. Papeete. 1990b. S. 1-3.

Anl. 19 o. V. French Nuclear Testing 1960-1988. Nuclear Weapon Data Center. Working Paper 89-1. S. 46.

Anl. 20 o. V. Frontières Limites et Statuts. Approche géopolitique du Pacifique Sud. In : Atlas des îles et états du Pacifique Sud. GIP Rechus Publ. 1988. S. 98.

Anl. 21 Bremond, H. : Tahiti Today-Poem. In: Pollock, N. J. u. a. (Hrsg.): French Polynesia: a Book of Selected Readings. Suva. Institute of Pacific Studies of the South Pacific. 1988. S. 2.

Anl. 22 o. V. Testimonies. Witness of French Nuclear Testing in the South Pacific. Greenpeace International. 1990. S. 19. 
$\underline{\text { Anl. } 23}$ o. V. Tahiti und seine Inseln. Prospekt des Pacific Reisebüros, Karlsruhe.

Anl. 24 Moerenhout, J. A.: The Fatal Impact. London. Hamish Hamilton. 1966. S. 86.

Anl. 25 Bachimon, Philippe: Tahiti entre mythes et réalités. Éditions du Comité des Travaux Historiques et Scientifiques. 1990. S. 337.

Anl. 26 Deutsche Gesellschaft für Technische Zusammenarbeit (gtz) GmbH: Tourismus in der Technischen Zusammenarbeit. Eschborn. 1999. S. 83-85. 


\section{ABKÜRZUNGSVERZEICHNIS}

ACAP Annapurna Conservation Area Project

AKP (-Staaten): im Lomé-Abkommen mit der EU assoziierte Staaten Afrikas, der

Karibik und des Pazifik

ARAB Atomic Rent, Aid, Bureaucracy

BIA Base Interarmées des Sites

BUND Bund für Umwelt und Naturschutz Deutschland

CBD Convention on Biological Diversity

CBST Community Based Sustainable Tourism

CEA Commissariat à l'Energie Atomique

CEP Centre d'Expérimentation du Pacifique

CFP Cour de Franc Pacifique

CNRS Centre Nationale de la Recherche Scientifique

CSD Commission on Sustainable Development

DAM Direction des Applications Militaire

D.A.R.T. Dortmunder Arbeitskreis Raumplanung und Tourismus

DIRCEN Direction des Centres d'Expérimentation Nucléaires

DSIR Department of Scientific and Industrial Research (Neuseeland)

DTS Direction de Travaux et Services

ERW Enhanced Radiation Warhead

FAO Food and Agriculture Organisation

FLP Front de la Libération de la Polynésie

FOA Swedish National Defense Research Institute (Übersetzung)

GATE Gemeinsamer Arbeitskreis Tourismus und Ethnologie

GATS General Agreement on Trade Services

GEPA Gesellschaft zur Förderung der Partnerschaft mit der Dritten Welt

gnr

GOEN Groupement Opérationnel des Expérimentation Nucléaires

GPI Genuine Progress Indicator

gtz

ILO

Deutsche Gesellschaft für Technische Zusammenarbeit

IITF Institut für Integrativen Tourismus und Freizeitforschung

IPR Intellectual Property Rights

ITB Internationale Tourismus Börse

ITSTAT Institut Statistique de la Polynésie Française

LDC Less Developed Countries

LLDC Least Developed Countries

IRBM Intermediate-Range Ballistic Missile

LTBT Limited Test Ban Treaty

MIRAB Migration, Remittance, Aid, Bureaucracy

MSAC Most Seriously Affected Countries

NFI Naturfreunde International

NIC Newly Industrialised Countries

NGO Non Governmental Organisation

NWD Nuclear Weapons Data Center

NRDC Natural Resources Defence Council

OECD Organization for Economic Cooperation and Development

ÖTE Ökologischer Tourismus in Europa 
OPEC Organization of the Petroleum Exporting Countries

OPIP Organización de Pueblos Indígenas de Pastaza

ORSTOM Office de la Recherche Scientifique et Technique Outre-Mer

OTAC Office Territoriale d'Action Culturelle

PIANGO Pacific Islands Association of Non-Governmental Organisations

RDPT Rassemblement Démocratique du Peuple Tahitien

ugL unterentwickelt gehaltene Länder

UNSCEAR United Nations Scientific Committee on the Effects of Atomic Radiation

SLBM Submarine-Launched Ballistic Missile

SMCB Service Mixte de Contrôle Biologique

SMSR Service Mixte de Sécurité Radiologique

TCSP Tourism Council of the South Pacific

TVS-REST Thai Volunteer Service and Responsible Ecological Social Tours

VDC Verkehrsclub Deutschland

WHO World Health Organisation

WTO World Tourism Organisation

WTTC World Travel Organisations 


\section{ANLAGEN}

Anl. 1a: Standardisierte Umfrage „Reisende“6
1) Alter: $\square<20 \mathrm{~J}$
$\square 20-30 \mathrm{~J}$
$\square 30-40 \mathrm{~J}$
$\square 40-50 \mathrm{~J}$
$\square 50-60 \mathrm{~J}$
$\square>60$

2a) Beruf (Sparte): $\square$ kaufmännisch/juristisch $\square$ technisch $\square$ medienrelevant/journalisitsch

$\square$ Sonstiges, und zwar:

$\square$ sozial/medizinisch $\square$ künstlerisch

$\square$ Schüler/Student $\quad \square$ Rentner

2b) Beruf (Funktion): $\quad \square$ Führungskraft $\quad \square$ Abteilungsleitung $\quad \square$ mittlere Ebene $\square$ ausführende Ebene

3) Wann waren Sie zuletzt in FP? $\square$ vor $1 \mathrm{Jahr} \quad \square$ innerhalb der letzen 5 Jahre $\square$ vor über 5 Jahren

4) Was hat Sie motiviert, gerade dieses Land zu bereisen?

$\square$ Kultur, und zwar speziell:

$\square$ Natur, und zwar speziell:

5) Das wie vielte Mal waren Sie dort? $\square \quad \begin{array}{lllllll}1 & \square & 2 \mathrm{x} & \square & 3 \mathrm{x} & \square & 4 \mathrm{x}\end{array} \quad$ mehr als $4 \mathrm{x}$

6) Wie lange haben Sie sich in FP aufgehalten?

$\square$ stopover $\square 1$ Woche $\square 2$ Wochen $\square 3$ Wochen $\square 4$ Wochen $\square 5$ Wochen

$\square 6$ Wochen $\square$ über 6 Wochen

7) Welche Aktivitäten haben Sie unternommen?

$\square$ Besichtigungen, und zwar

$\square$ Sport, und zwar

$\square$ Kulturelle Aktivitäten, und zwar

$\square$ Sonstiges, und zwar

\section{8) Reisen Sie}

$\square$ pauschal?, wenn ja, mit welchem Veranstalter? oder $\square$ individuell?

9) Welche Reiseroute hatten Sie?

10) Welche Inselgruppen habe Sie bereist? 
$\square$ Gesellschaftsinseln

$\square$ Australinseln

$\square$ Tuamotuinseln

$\square$ Gambierinseln

$\square$ Marquesasinseln

\section{1) Wie haben Sie sich auf die Reise vorbereitet?}

$\square$ traditionelle Reiseführer, und zwar:

$\square$ alternative Reiseführer, und zwar:

$\square$ Berichte von Freunden und Bekannten, die FP bereist hatten

$\square$ Ich habe Bekannte in FP

$\square$ Sonstiges, und zwar

$\square$ gar nicht, weil

12) Welche Erwartungen hatten Sie an die Reise?

$\square$ Kennenlernen einer anderen Kultur, Lebensweise

$\square$ Sport, und zwar

$\square$ Entspannung durch

$\square$ Sonstiges, und zwar

$\square$ gar keine

13) Entsprachen die Gegebenheiten vor Ort Ihren Vorstellungen und Erwartungen?

$\square \mathrm{ja}$

$\square$ teilweise

$\square$ nein, weil

Begründung: 
14) Hatten Sie auf Ihrer Reise Kontakt zur einheimischen Bevölkerung?

$\square$ ja, und zwar

$\square$ nein

15) Welchen Eindruck hatten Sie von Land und Leuten?

16) Hat ein Austausch stattgefunden zwischen den Einwohnern FPs und Ihnen?

$\square$ ja, und zwar folgendermaßen:

$\square$ nein

17) Empfanden Sie Ihre Reise als eine Bereicherung?

$\square$ ja, und zwar in folgender Hinsicht

$\square$ nein

18) Denken Sie, daß FP oder die von Ihnen besuchte Bevölkerung etwas von Ihrer Reise hatten (materiell oder immateriell)?

$\square$ ja, und zwar:

$\square$ nein

19) Haben Sie die Reise nachbereitet?

$\square$ ja, und zwar durch:

$\square$ nein 
20) Können Sie sich vorstellen in ähnlicher Form bereist zu werden?

$\square$ ja

$\square$ nein

Begründung:

21) Kennen Sie den Begriff des „sanften“ Reisen?

$\square$ ja, ich verstehe darunter:

$\square$ nein

22) Was müsste geschehen, damit sich solche Formen des Reisens durchsetzen? Was können Sie persönlich dazu beitragen?

23) Hielten Sie nach der Reise Kontakt zu Ihren Gastgebern im Reiseland?

Kommentar

Ich stehe für ein vertiefendes, persönliches Interview

$\square$ zur Verfügung, meine Telefonnummer ist:

$\square$ nicht zur Verfügung

Datum Anschrift

Name Unterschrift 
1) Welche touristischen Angebote haben Sie bezüglich FP?

2) Sehen Sie für FP kurz-, mittel- oder langfristig einen Markt in D?

3) Welches Image von FP vermarkten Sie?

4) Was verstehen Sie unter „sanftem Tourismus“?

5) Sehen Sie im „sanften Tourismus“ eine Marktnische (kurz-, mittel-, langfristig)?

6) Mit welchen in FP ansässigen Branchen arbeiten Sie zusammen?

$\square \quad$ Gastronomie, und zwar:

$\square \quad$ Hotellerie, und zwar:

$\square \quad$ Tour Operator, und zwar:

$\square \quad$ Transportunternehmen, und zwar:

$\square \quad$ Sonstige, und zwar:

7) Wie würden Sie grob Ihre Marketingstrategie bezüglich FP umschreiben?

8) Welche Marktposition halten Sie bezüglich des FP-Angebots?

\section{Kommentar}

Ich stehe für ein vertiefendes, persönliches Interview

$\square$ zur Verfügung, meine Telefonnummer ist:

$\square$ nicht zur Verfügung

Datum

Anschrift

Name

Unterschrift/Firmenstempel 
Anl. 1c: Interviewleitfaden „Experten“

1) Kennen Sie den Begriff des „,Sanften Reisens“? Was verstehen Sie darunter?

2) Was könnten a) Reisende, b) Bereiste, c) Reiseunternehmer aus Ihrer Sicht dazu beitragen?

3) Worin liegen Schwierigkeiten in der Umsetzung, worin liegen Chancen?

4) Können Sie solche Ansätze - theoretischer oder praktischer Natur - in FP benennen?

\section{Anl. 1d: Interviewleitfaden „Bereiste“}

- Generelle Einschätzung des „Tourismus“

- Generelle Einschätzung der „Touristen“ (nach Herkunftsländern)

- Partizipationsgrad am Tourismus

- soziale Stufe

- Akkulturation/Kulturverlust

- Umwelt

- Vorteile durch Tourismus

- Nachteile durch Tourismus

- Menge der Touristen

- Trends, zukünftige Erwartungen 


\section{Anl. 2: Definitionen der Nachhaltigkeit}

- Eine Entwicklung, die dazu geeignet ist, eine dauerhafte Befriedigung menschlicher Bedürfnisse und eine Verbesserung der menschlichen Lebensqualität zu verwirklichen (ALLEN 1980)

- unbegrenztes Überleben der menschlichen Spezies, Lebensqualität über rein biologisches Überleben hinaus und die Fortdauer aller Komponenten der Biosphäre, auch der Bestandteile, die anscheinend keinen Vorteil für die Menschen bieten (BROWN/FLAVIN/POSTEL 1991)

- ein Modell für soziale und struktur-ökonomische Umgestaltung, welche die ökonomischen und gesellschaftlichen Vorteile der jetzt lebenden Menschen optimiert, ohne das wahrscheinliche Potential für ähnliche Vorteile in der Zukunft zu gefährden (GODDLAND/LEDDEC 1987)

- die Konstanz des natürlichen Kapitalstocks und die Möglichkeit, auch zukünftig von dessen Zinsen zu leben (PEARCE/MARKANDYA/BARBIER 1993)

- ein Prinzip, das auf die Anordnung hinauslaufen muss, die Produktionskapazität für eine unbestimmte Zukunft zu schützen (SOLOW 1992)

- ein positiver sozioökonomischer Wandel, der die ökologischen und sozialen Systeme nicht schwächt, von denen die Gesellschaft und ihre Teilgruppen abhängig sind (REES 1988)

- eine Entwicklung, die die Bedürfnisse der Gegenwart befriedigt, ohne die Fähigkeit zukünftiger Generationen zu gefährden, ihre eigenen Bedürfnisse zu befriedigen (BRUNDTLAND 1987)

- ein Konzept, das darauf ausgerichtet ist, dass die natürliche Umwelt und der damit verbundene Kapitalstock an natürlichen Ressourcen so weit erhalten werden muss, dass die Lebensqualität zukünftiger Generationen gewährleistet bleibt (AKADEMIE FÜR TECHNIKFOLGEABSCHÄTZUNG 1993)

Quelle: Breuel, Birgit (Hrsg.): Agenda 21. Vision: Nachhaltige Entwicklung. Frankfurt/Main, New York. Campus Verlag. 1999. S. 20. 


\section{Anl. 3 Fragebogen Transfair}

A. Haben Sie bereits eine/mehrere Reisen in ein Drittweltland (nicht Türkei und südlicher Mittelmeerraum) gemacht?

B. Können Sie sich vorstellen, in den nächsten 3 Jahren „ziemlich sicher“ oder „wahrscheinlich“ eine Urlaubsreise in ein Drittweltland (nicht Türkei und südlicher Mittelmeerraum) zu unternehmen?

C. Was streben Sie auf einer Urlaubsreise an (Bitte setzen Sie Prioritäten zwischen 1-hoch und 5-niedrig):

- den Horizont erweitern und etwas für die Kultur und Bildung tun

- Kontakte mit der einheimischen Bevölkerung zu haben

- Abschalten und ausspannen

- Frische Kraft sammeln

- Anderes (bitte geben Sie selbst weitere Punkte an, die Ihnen wichtig erscheinen)

D. Im Folgenden beschreibe ich Ihnen die Art der Reise mit ihren Charakteristika, bevor ich Ihnen weitere Fragen stelle:

1. Dauer der Reise ist 3 Wochen

2. Schwerpunkt der Reise ist der Besuch einer Vereinigung von Produzenten, die bereits Produkte mit dem Transfer Gütesiegel verkaufen und mit der GEPA in Handelsbeziehungen stehen

3. Ziele der Reisen sind: menschliche Begegnung und Förderung des interkulturellen Austauschs, die Verbesserung der Einkommenssituation für die Produzentenfamilien sowie Erholung und Erweiterung des Horizontes für die Reisenden

4. Zurzeit wird an folgende Länder gedacht: Costa Rica (Kaffee), Mexiko (Öko-Kaffee), Kenia (Schmuck, Textil, Leder), und die Philippinen (Rohrzucker)

5. Dort haben die Reisenden 2 Wochen Gelegenheit, die Lebenswirklichkeit der Produzenten bei der Arbeit und in ihren Familien kennen zu lernen, darüber zu reflektieren und auch mit den Gastgebern die Sehenswürdigkeiten der Umgebung anzusehen

6. Die letzten 4 Tage verbringen die Reisenden am Meer oder einem See

7. Ein fließend deutsch sprechender Reisebegleiter ist während des ganzen Aufenthalts mit der Reisegruppe zusammen

8. Die Größe der Gruppe ist zwischen 5 und 10 Personen

9. Es gibt Vollpension, für Übernachtung ist gesorgt: etwa 14 Tage wohnt man in einfachen Gästehäusern der Produzentenvereinigung, oder auch in Häusern der Produzenten. 5 Tage wird die Gruppe in Mittelklassehotels untergebracht.

10. Für die Reisen wird eine Vor- und auch eine Nachbereitung angeboten.

11. Die Programmgestaltung kann auch flexibel gehandhabt werden: Gruppen, die sich zu einer solchen Reise zusammenschließen, können die Reisen auch in Absprache mit dem Fair Trade Verein und den Produzentengruppen individuell gestalten

E. Wäre eine solche Reise sinnvoll und hilfreich für Ihre Arbeit? (Diese Frage ist nur an die 3.Welt-Laden-Besitzer und-Mitarbeiter zu stellen) 
F. Meinen Sie, dass eine solche Reise für Ihre Kunden von Interesse wäre? Wie hoch schätzen Sie das Potential ein? (Diese Frage ist nur an die 3.Welt-Laden-Besitzer und Mitarbeiter zu stellen)

G. Eine solche Reise würde zwischen DM 4.000,- und 5.000,- kosten. Bedenken Sie, dass allein die Flugkosten zwischen DM 1.200 und 1.500 betragen. Könnten Sie eine solche Reise finanzieren? Wären Sie daran interessiert, eine solche Reise mitzumachen? Wenn die Antwort nein ist: Bis zu welchem Preis könnten Sie sich vorstellen, eine solche Reise mitzumachen?

H. Welche von den genannten Ländern - Mexiko, Costa Rica, Kenia und den Philippinen würden Sie am meisten interessieren?

I. Welche anderen Länder würden Sie auch interessieren?

J. Welche Erzeugnisse würden Sie beim Besuch von Produzentenvereinigungen mehr interessieren:

- landwirtschaftliche Produkte:

- Kaffee bzw. Öko-Kaffee

- Pecannüsse

- Tee

- Rohrzucker

- Honig

oder

- handwerkliche Erzeugnisse

oder

- Beides etwa gleich?

Quelle: von Wogau, Peter: Prüfung des Fair-Travel Konzeptes. Bericht. Internes Papier. Fair Trade. Freiburg. 1998. 


\section{Anl. $4 a$ Der lineare Urbanraum Papeetes}

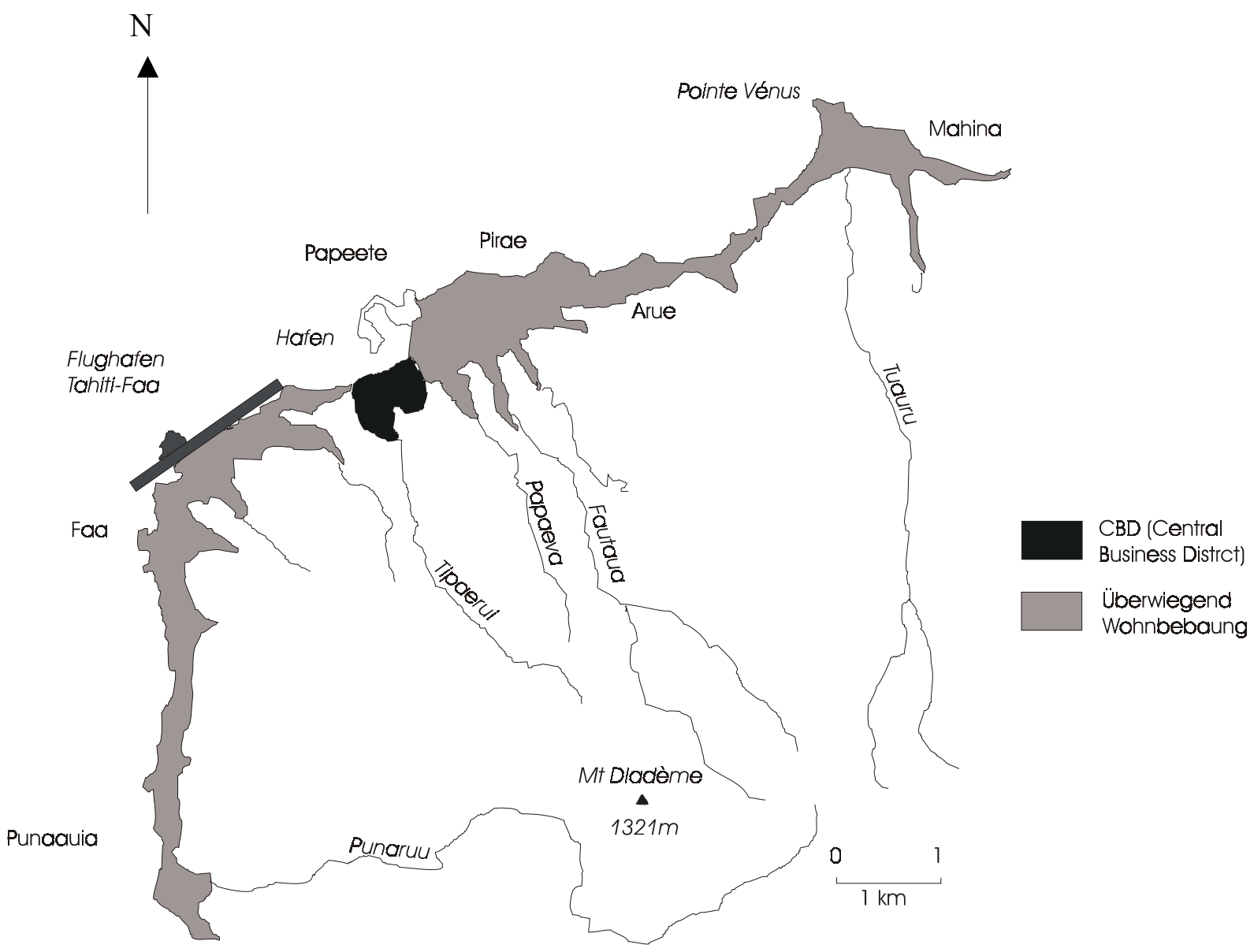

Deutlich erkennbar ist die zunehmende Ausdehnung der Wohnbebauung auf die Flusstäler.

Basis: o. V. Frontières, Limites et Statuts. Approche géopolitique du Pacifique Sud. In: Atlas des îles et états du Pacifique Sud. GIP Rechus Publ. 1998. S. 99. 

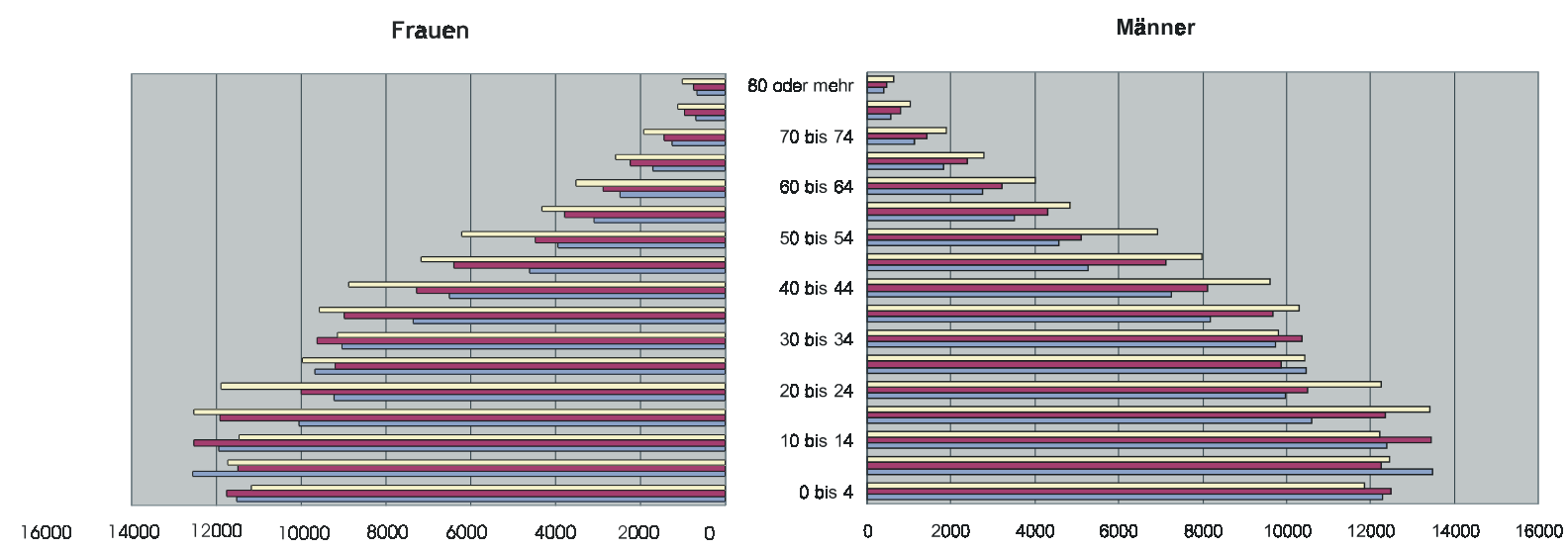

obere Reihe: 2007 (Prognose) mittlere Reihe: 2002 (Prognose) untere Reihe: 1997
Summe der Gesamtbevölkerung: 256.693

Summe der Gesamtbevölkerung: 239.539

Summe der Gesamtbevölkerung: 220.720

Basis: ITSTAT 1998

Anl. 5 Vergleich Pro-Kopf-Einkommen (GDP per capita in \$)

\begin{tabular}{|l|l|}
\hline USA & $33.900(1999)$ \\
\hline Japan & $23.400(1999)$ \\
\hline Frankreich & $23.300(1999)$ \\
\hline Neuseeland & $17.400(1999)$ \\
\hline Griechenland & $13.900(1999)$ \\
\hline Französisch-Polynesien & $10.800(1997)$ \\
\hline Palau & $8.800(1999)$ \\
\hline Fidschi & $7.300(1999)$ \\
\hline Polen & $7.200(1999)$ \\
\hline Cook-Inseln & $5.600(1999)$ \\
\hline Solomonen & $2.650(1999)$ \\
\hline Papua Neuguinea & $2.500(1999)$ \\
\hline Samoa & $2.100(1999)$ \\
\hline Wallis und Futuna & $2.000(1995)$ \\
\hline Marshall Islands & $1.670(1998)$ \\
\hline Vanuatu & $1.300(1999)$ \\
\hline
\end{tabular}


Anl. 6

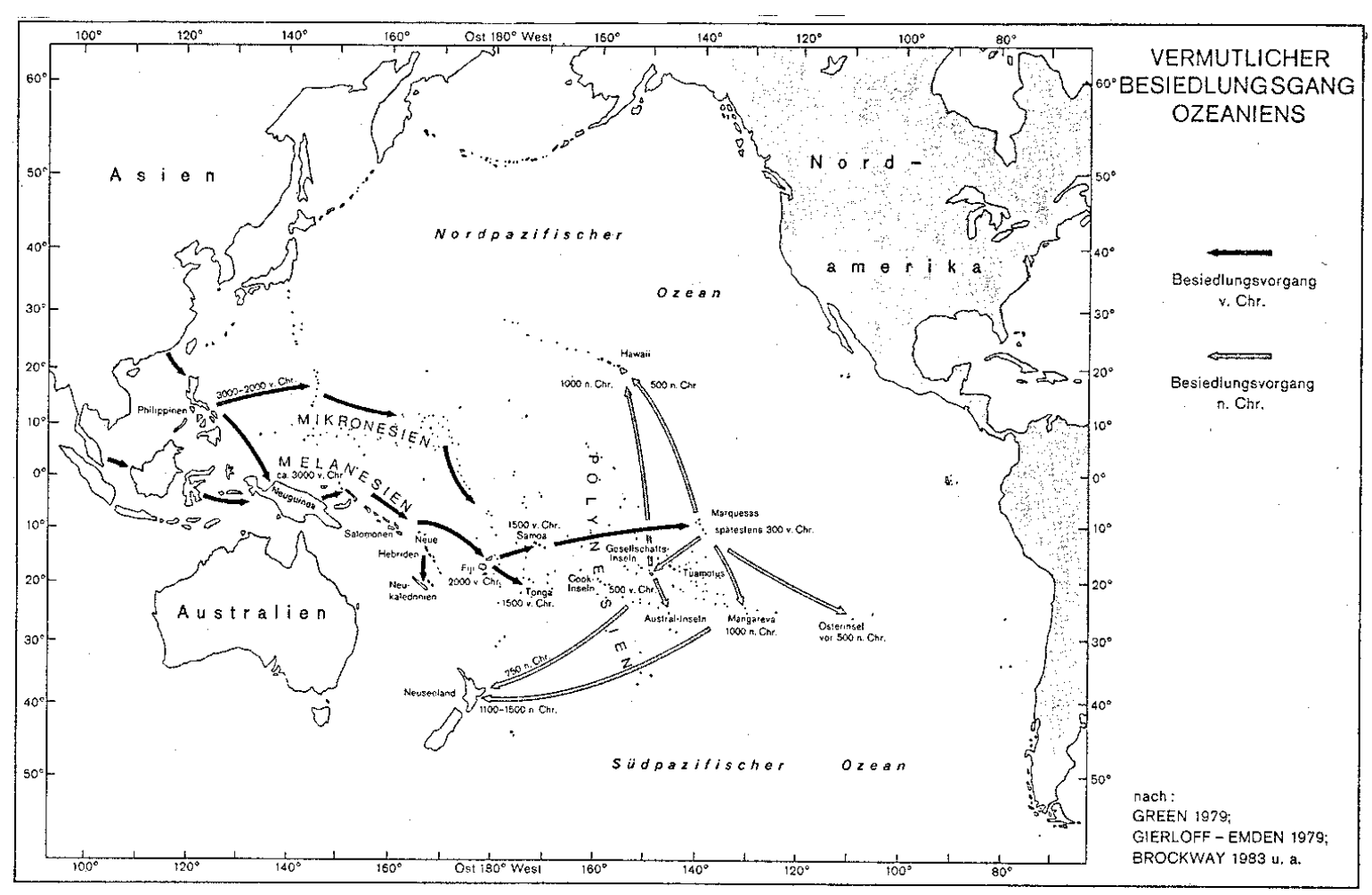

Quelle: Kreisel, Werner.: Die pazifische Inselwelt. Wissenschaftliche Länderkunden. Bd. 38. Darmstadt. Wissenschaftliche Buchgesellschaft. 1991. S. 80. 


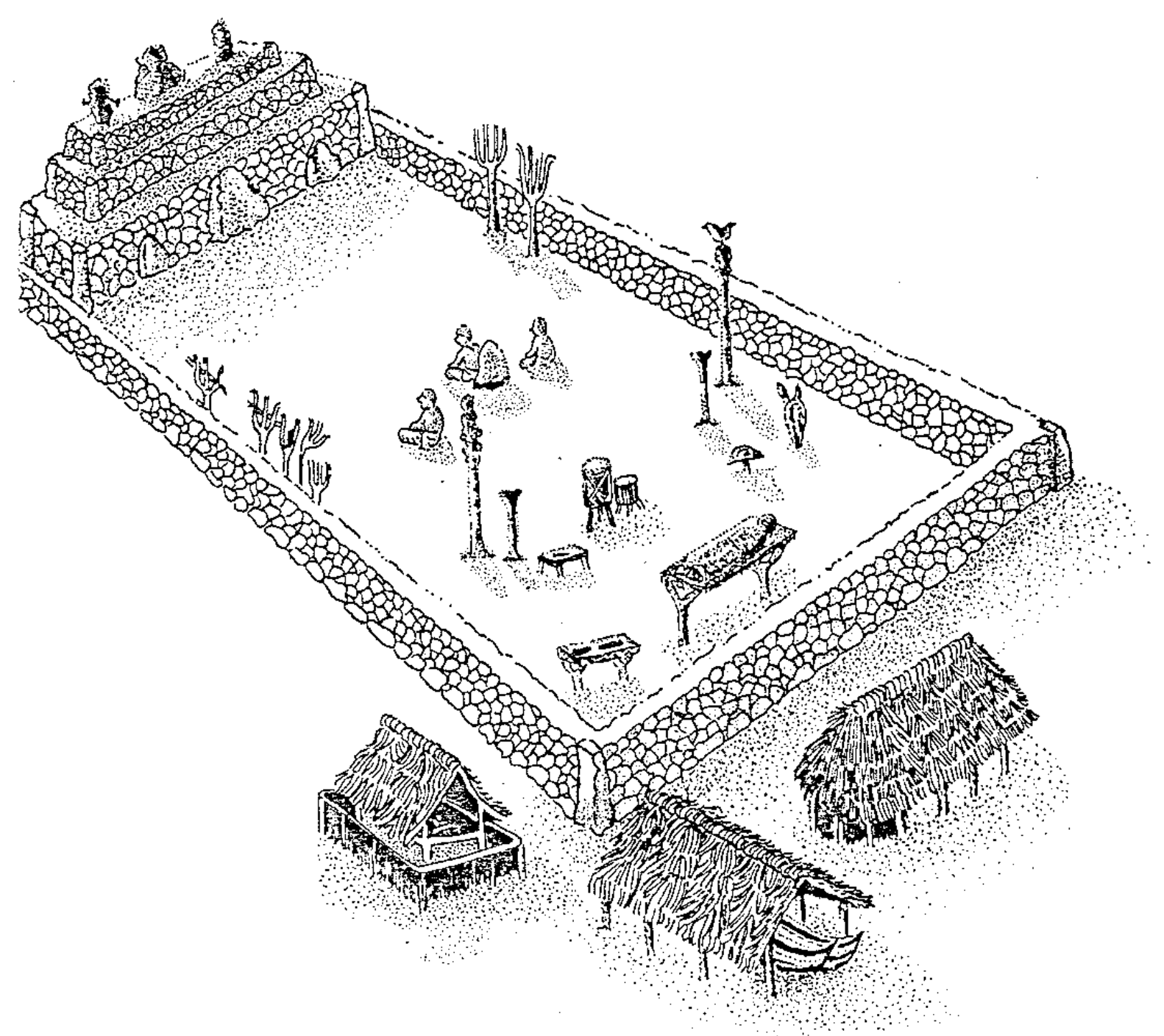

„Polynesische Kultarchitektur. So sahen die Marae, die großen offenen Tempelanlagen Tahitis aus. Oben der allerheiligste Teil der Kultstätte, der Ahu genannte Altar, auf dem Götterfiguren aufgestellt sind. In der Mitte sitzen drei dem Ahu zugewandte, ein Stück hinter ihnen stehen Zeremonialtrommeln. Unter dem Schutzdach der mittleren der außerhalb des eigentlichen Tempelbezirks errichteten Hütten wurden Totenboote aufbewahrt. Nach einer Rekonstruktion der französischen Forscherin A. Lavondes.“ 
Anl. 8 Die Errichtung der Missionsstationen orientierte sich an den Standorten der Marae (Anfang des 19. Jahrhunderts)

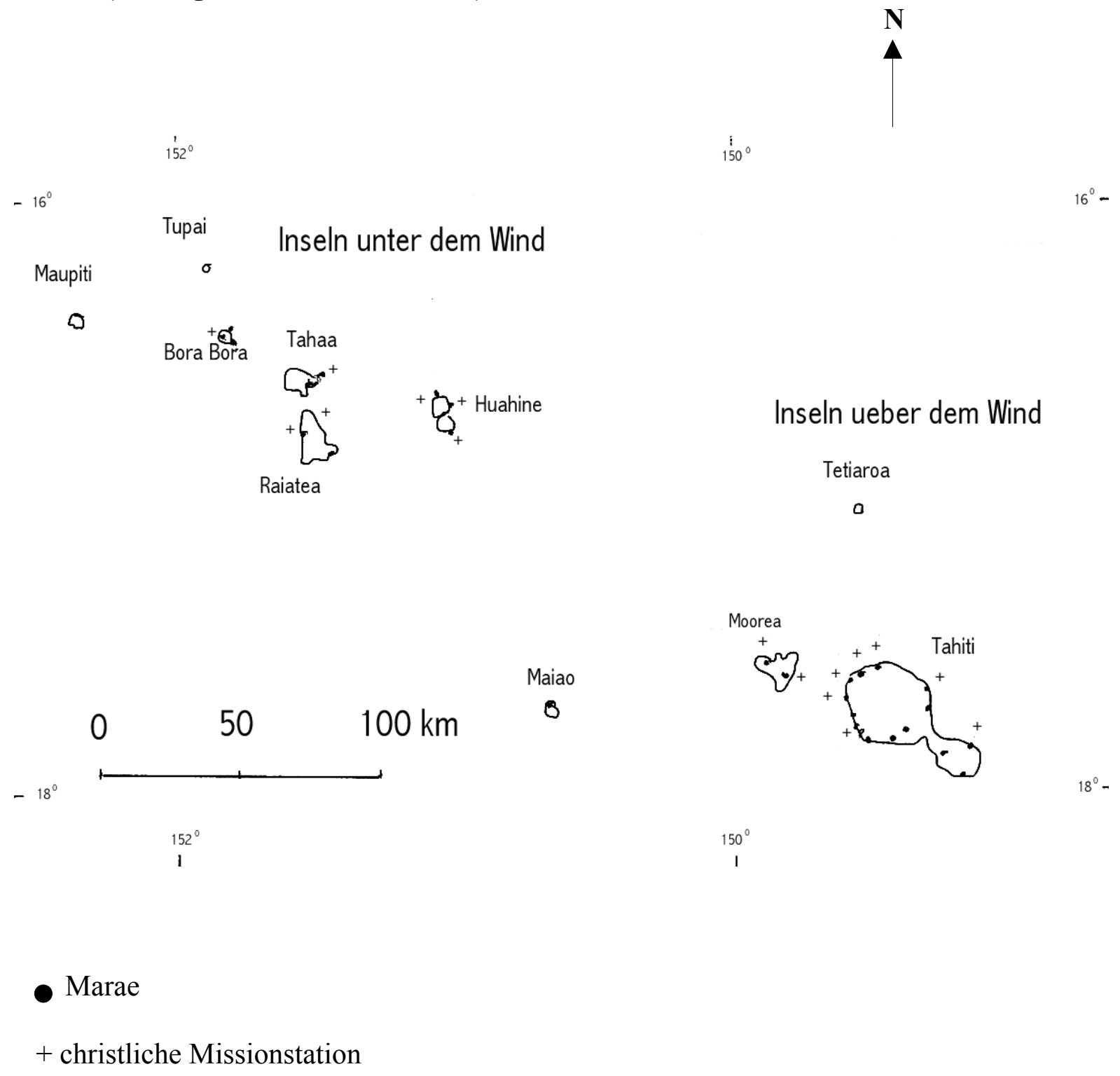

Basis: Baré, J. F. : Tahiti, les temps et les pouvoirs. Pour un anthropologie historique du Tahiti post-européen. Paris. ORSTOM. 1987. S. 160, 161. 
Anl. 9 Verschiedene religiöse Strömungen im voreuropäischen Französisch-Polynesien

\begin{tabular}{|l|l|l|}
\hline Name des Gottes & Insel, auf der er angebetet wurde & Marae, das ihm gewidmet ist \\
\hline Oro & Bora Bora & Tevaitoa \\
\hline Oro & Raiatea & Opoa \\
\hline Oro & Tahiti & fast alle Marae \\
\hline Taaroa & Tupuaimanu & \\
\hline Tane & Huahine & Matairea \\
\hline Tane & Morea & Matairea \\
\hline Tane & Tahaa & Auroa \\
\hline Raa & Tupai & \\
\hline Tauteni & Bora Bora & Anau Distrikt \\
\hline Temearoo & Bora Bora & Morotetini \\
\hline Tuu i vahiau & Maupiti & Morotetini \\
\hline
\end{tabular}

Während der dritten Periode der ari’i, kurz vor der Entdeckung Französisch-Polynesiens durch die Europäer, existierten unterschiedlichste religiöse Strömungen parallel. Eine Vielzahl von Göttern wurde auf den verschiedenen Inseln angebetet.

\section{Anl. 10 Religiöse Funktionsträger bei Gottesdiensten}

1. Vorsteher des Marae, in dessen Namen und zu dessen Gunsten die Zeremonie abgehlten wurde

2. Der Hochpriester und seine Helfer, die einfache Priester waren

3. Prediger

4. Bote

5. Träger und Wächter von Kultgegenständen

6. Besessene und Zauberer

Oftmals herrschte unter den Funktionsträgern bei Gottediensten eine hierarchische Arbeitsteilung.

Quelle Anl. 9, 10: Bovis, E. de: Tahitian Society before the Arrival of the Europeans. Second Edition. Hawaii. The Institute for Polynesian Studies. Brigham University. Hawaii Campus. 1980. S. 41, 45. 
Anl. 11a Die früheren Bezirke von Tahiti (nach P. Rey Lescure, 1970)

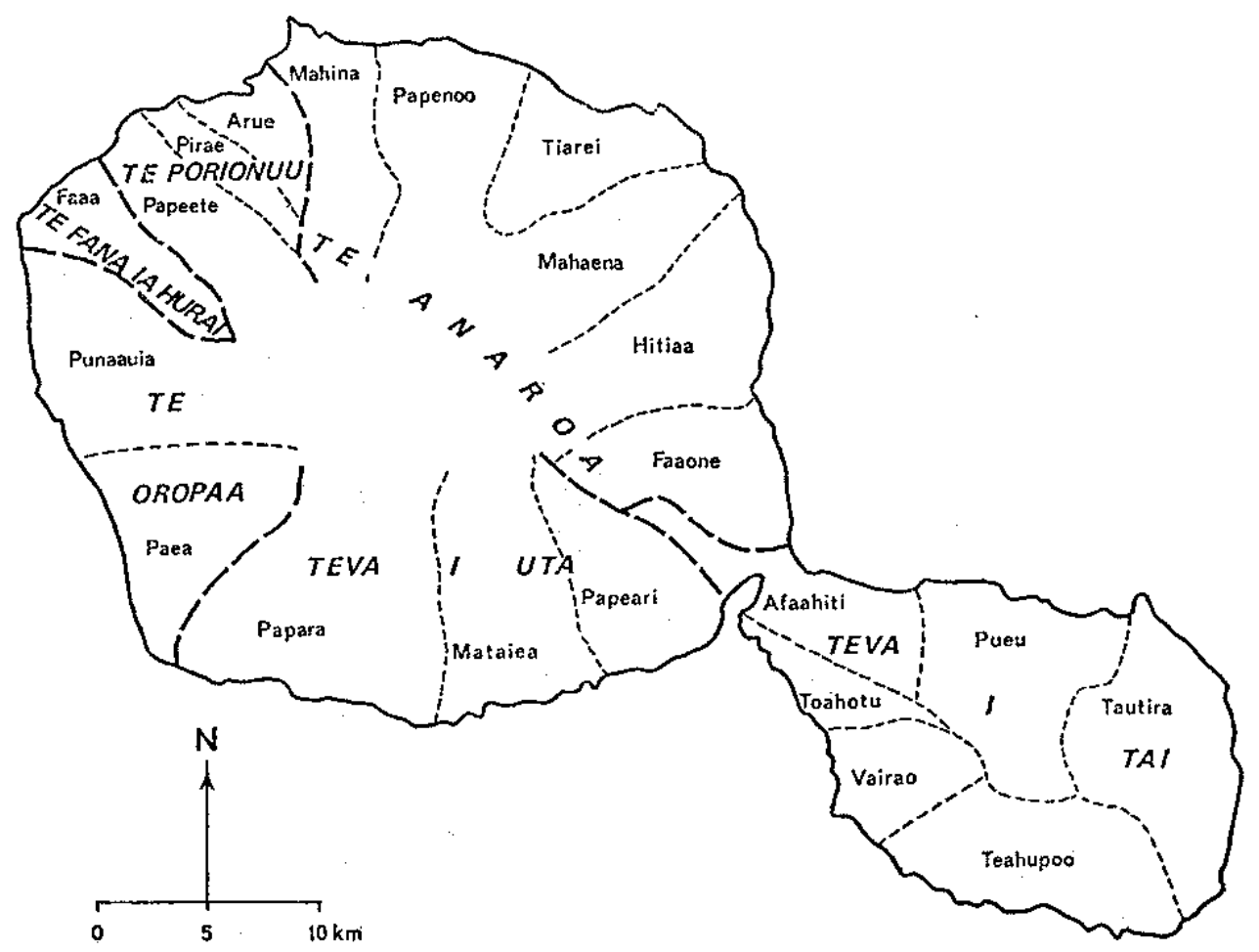

Quelle: Ravault, F.: Papeari. L'Organisation de l'Espace dans un district de la côte sud de Tahiti. Paris. ORSTOM. 1980. S. 28.

\section{Anl. $11 b$ Die jetzige kommunale Struktur der Inseln unter dem Wind}
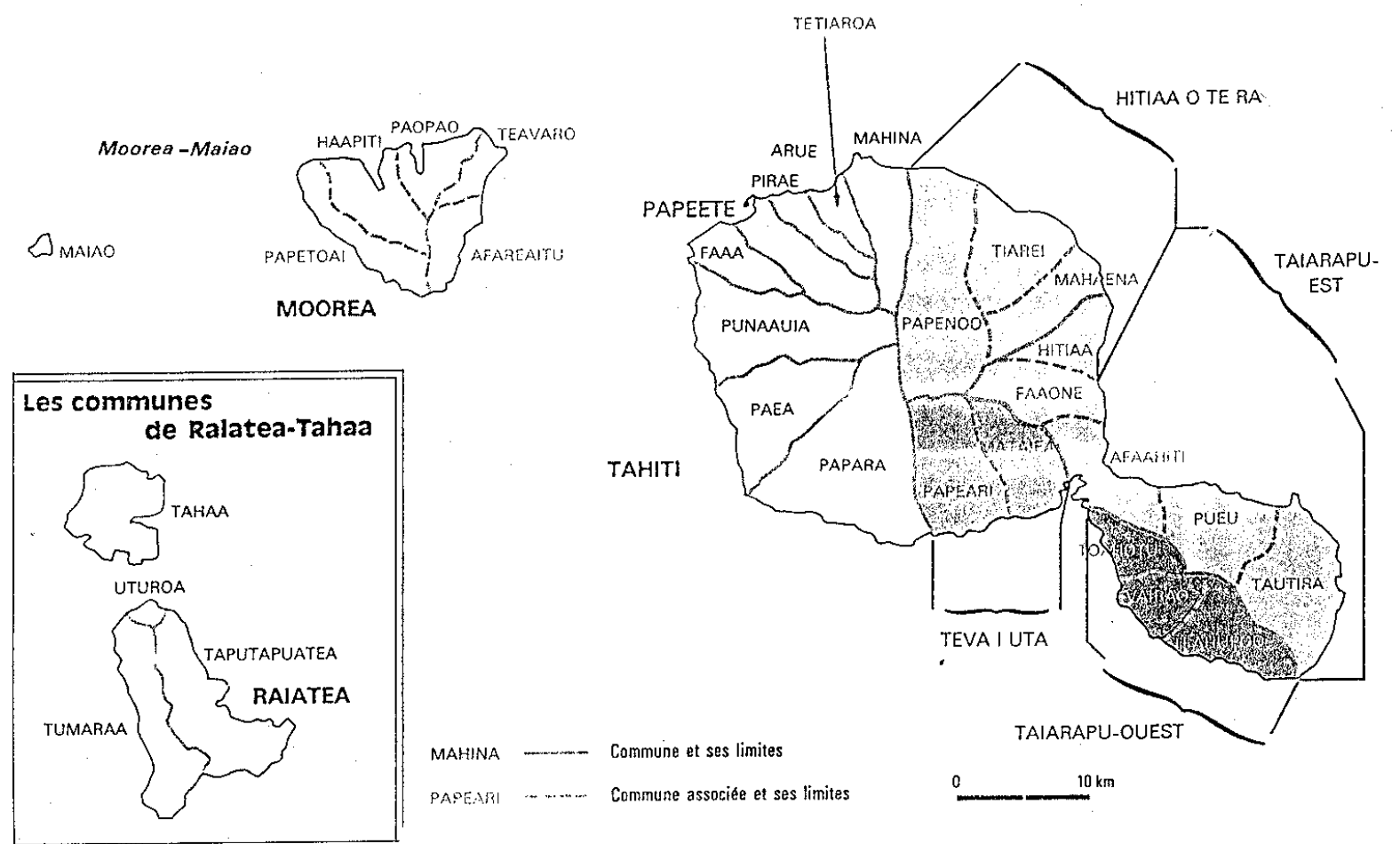

Quelle : o. V. La Polynésie Française dans le Pacifique. Atlas de Tahiti et de la Polynésie Française. Editions du Pacifique. 1988. S. 8. 
Anl. 12 Dialektgrenzen

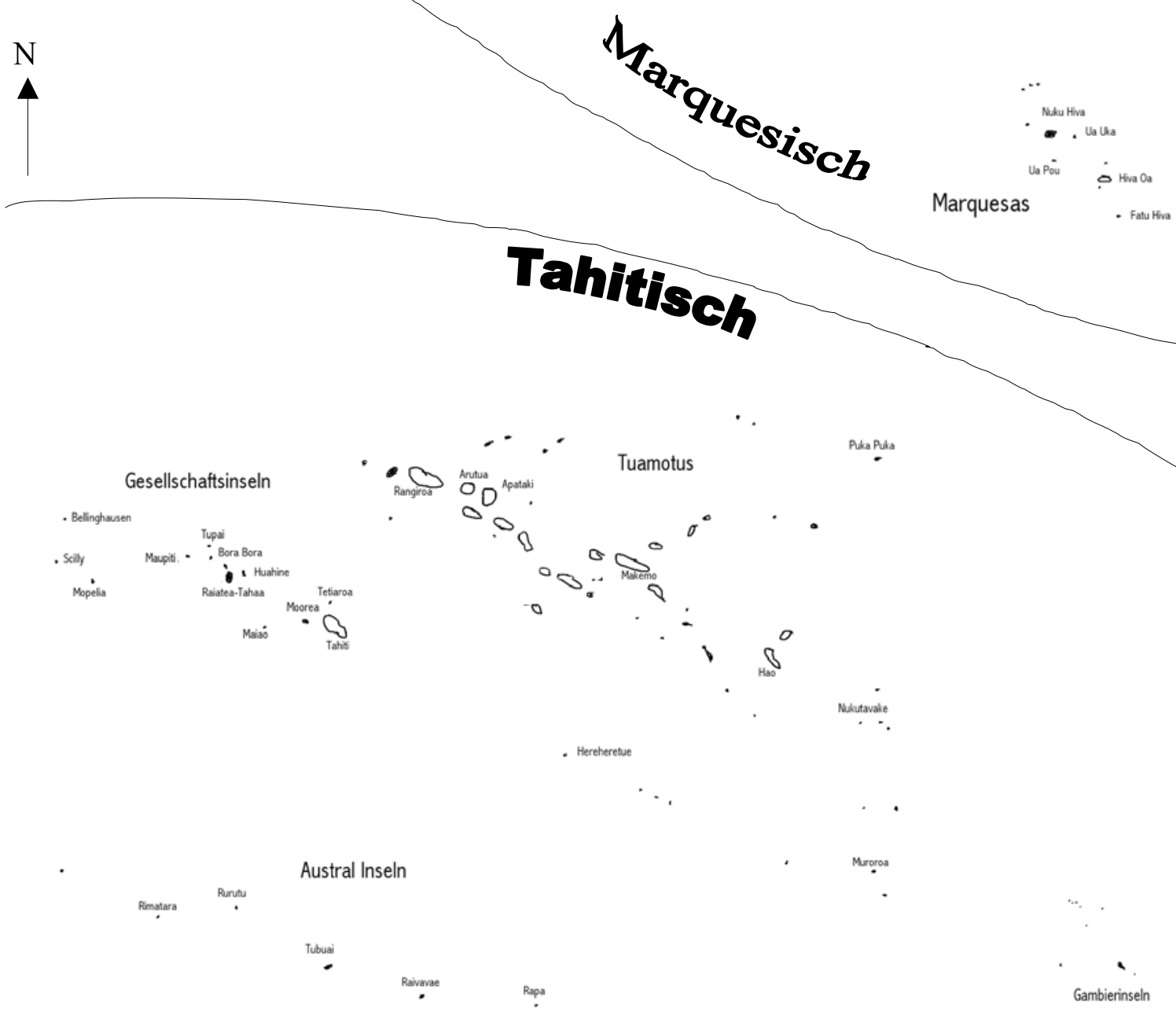

Basis: Merceron, François (Hrsg.): Atlas de Tahiti et de la Polynésie Française. 3. Auflage. Singapur. Les Éditions du Pacifique. 1996. S. 9. 


\section{Anl. 13 Schöpfungsmythos der Maohi als Beispiel mündlich tradierter Literatur}

\section{Dieser Text wurde 1822 auf Tahiti aufgezeichnet und preist Taaroa:}

„Taaroa war der Ahn aller Götter. Er schuf alles. Seit undenklichen Zeiten war der große Taaroa der Tahi-tumu (der Ursprung). Taaroa entwickelte sich selbst in der Einsamkeit; er war sein einziger Erzeuger und hatte weder Vater noch Mutter. Seine Gestalten waren unzählig: Taaroa oben, Taaroa unten, Taaroa im Stein...Das sind die Eigenschafen Taaroas: Großer Taaroa, die Wahrheit, der die Erde bewegt, der große Taaroa, der den Sünden und den bösen Kräften ein Ende setzte; der große Taaroa als Grund, der große Taaroa mit dem grenzenlosen Ruhm, Taaroa mit dem sicheren Gebot, Taaroa vom klaren Himmel, Taaroa, der Beförderer, Taaroa über der Riffeinfahrt, Taaroa, der auslöscht, Taaroa, dessen Fluch den Tod bedeutet. Unzählig waren Taaroas Formen, aber es gab nur einen Taaroa in der Höhe, unten und in den Finsternissen. Taaroa hielt sich in seiner Muschel und im Dunkel Millionen von Jahren auf. Diese Muschel war wie ein Ei, das sich im unendlichen Raum bewegte, ohne Himmel, ohne Erde, ohne Meer, ohne Mond, ohne Mond, ohne Sonne, ohne Sterne. Alles war in der Finsternis; es war eine dichte und dauernde Dunkelheit. Rumia war der Name der Muschel Taaroas.“

Quelle: Nevermann, H. u. a.: Die Religionen der Südsee und Australiens. In: Die Religionen der Menschheit. Bd. 5. Stuttgart, Berlin, Köln, Mainz. 1968. S. 21. 
Anl. 14 Beispiele verschiedener Formen von Petroglyphen, die auf Maraesteinen gefunden wurden
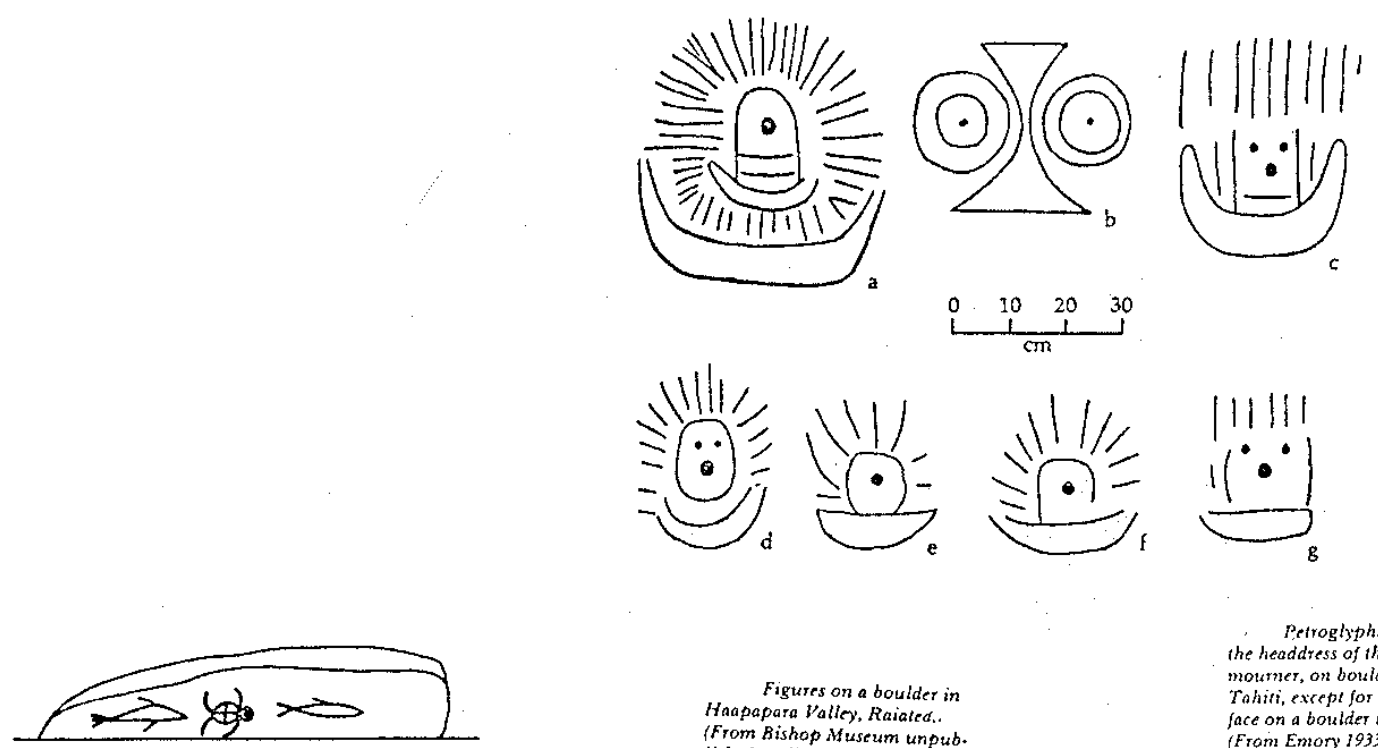

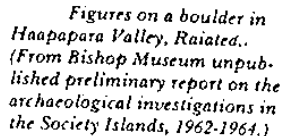

Petrogtyphs representing the heddress of the chief

moume, on botiders at Vaiote, pace on a boulder in Faca, Tahiti. (Fron Enory 1933.)
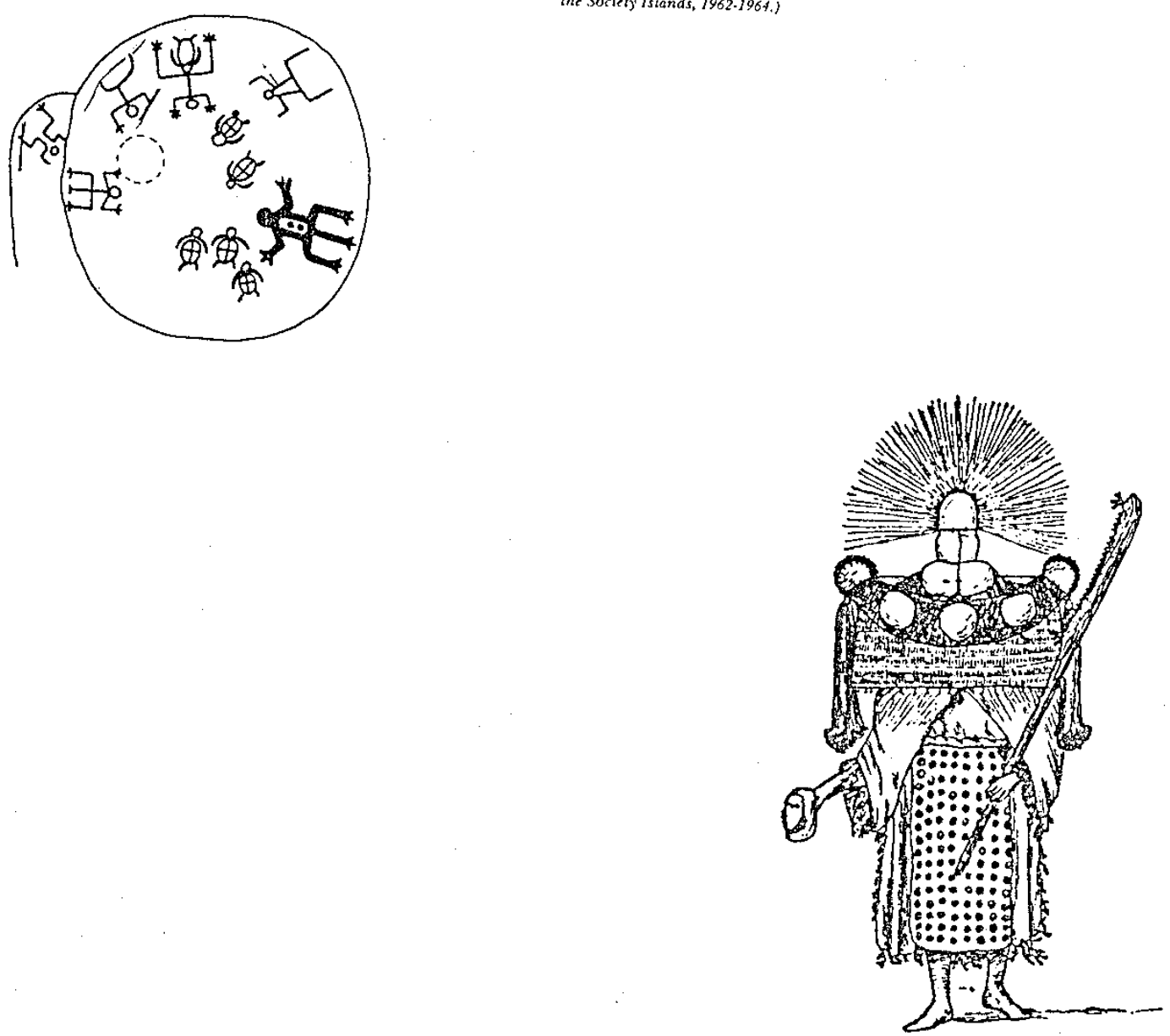

Quelle: Emory, K. P.: The Societies. In: Pollock, N. J. u.a. (Hrsg.): French Polynesia: a Book of Selected Readings. Suva. Institute of Pacific Studies of the South Pacific. 1988. S. 44, 45. 
Anl. 15 Bevölkerungsentwicklung (indigen und gesamt) ausgewählter Inselgruppen Französisch-Polynesiens

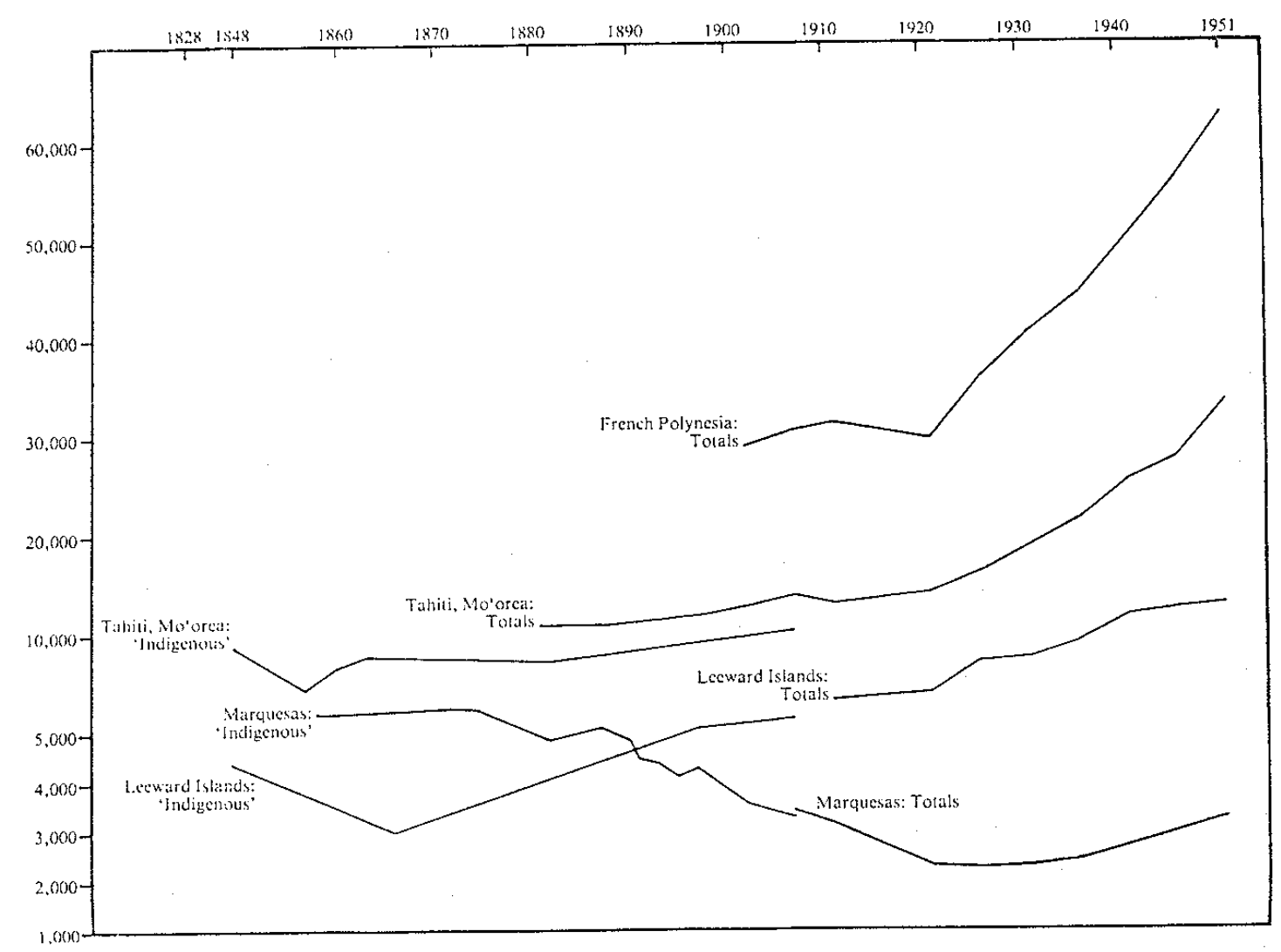

Quelle: Newbury, C.: Tahiti Nui. Change und Survival in French Polynesia 1767-1945. Honolulu. 1980. S. 274. 
Anl. 16a Migration: Verschiebung der prozentualen Anteile der Bevölkerung auf den Inseln über dem Wind

\begin{tabular}{|l|l|l|l|}
\hline Jahr & $\mathbf{1 9 6 2}$ & $\mathbf{1 9 6 7}$ & $\mathbf{1 9 7 1}$ \\
\hline $\begin{array}{l}\text { Inseln über dem } \\
\text { Wind }\end{array}$ & 61,6 & 67,2 & 70,9 \\
\hline davon & & & \\
\hline $\begin{array}{l}\text { Agglomaration von } \\
\text { Papeete }\end{array}$ & 42,0 & 50,1 & 54,7 \\
\hline Andere Inseln & 38,4 & 32,8 & 29,1 \\
\hline Summe & 100,0 & 100,0 & 100,0 \\
\hline
\end{tabular}

Anl. $16 b$ Entwicklung der Summe der öffentlichen Ausgaben in \% des Bruttoinlandsprodukts

\begin{tabular}{|l|l|l|l|l|l|l|l|l|l|l|l|}
\hline & $\mathbf{1 9 7 0}$ & $\mathbf{1 9 7 1}$ & $\mathbf{1 9 7 2}$ & $\mathbf{1 9 7 3}$ & $\mathbf{1 9 7 4}$ & $\mathbf{1 9 7 5}$ & $\mathbf{1 9 7 6}$ & $\mathbf{1 9 7 7}$ & $\mathbf{1 9 7 8}$ & $\mathbf{1 9 7 9}$ & $\mathbf{1 9 8 0}$ \\
\hline $\begin{array}{l}\text { CEP/CEA/ } \\
\text { Armee }\end{array}$ & 37 & 33 & 33 & 32 & 27 & 24 & 24 & 19 & 16 & 17 & 19 \\
\hline Verwaltung & 27 & 33 & 34 & 37 & 28 & 33 & 33 & 33 & 34 & 37 & 40 \\
\hline Summe & 64 & 66 & 67 & 69 & 55 & 57 & 57 & 52 & 50 & 54 & 59 \\
\hline
\end{tabular}

Quelle Anl. 16a, b: Blanchet, G.: L'économie de la Polynésie française de 1960 à 1980. Paris. Éditions de l'ORSTOM. 1985. S. 41, 67.

Anl. 17 Beziehung zwischen wirtschaftlichen Aktivitäten und soziokulturellen Kategorien

\begin{tabular}{|c|c|c|c|}
\hline \multirow[t]{2}{*}{ Export } & Import & $\begin{array}{l}\text { wirtschaftliche und } \\
\text { politische Rahmenbedingungen }\end{array}$ & Franzosen \\
\hline & $\nabla$ & $\begin{array}{l}\text { Import, Export, Transport, } \\
\text { Großhandel, Dienstleistungen, } \\
\text { Grundbesitz }\end{array}$ & $\begin{array}{l}\text { Franzosen } \\
\text { demi } \\
\text { Briten } \\
\text { Chinesen }\end{array}$ \\
\hline $\begin{array}{l}\text { Landwirt- } \\
\text { Schaftliche } \\
\text { Produkte }\end{array}$ & $\begin{array}{l}\text { Verbrauchs- } \\
\text { und Investi- } \\
\text { tionsgüter }\end{array}$ & $\begin{array}{l}\text { Einzelhandel, landwirtschaftliche } \\
\text { Produktion }\end{array}$ & $\begin{array}{l}\text { Chinesen } \\
\text { Polynesier }\end{array}$ \\
\hline
\end{tabular}

Quelle: Baré, J.-F.: Tahiti, les temps et les pouvoirs. Pour un anthropologie historique du Tahiti post-européen. Paris. ORSTOM. 1987. S. 374. 


\title{
Anl. 18 Kodifizierung indigener Landrechte durch die protestantische Kirche
}

\author{
Native Land Evangelization: Transformation or conservation.
}

From 1819 to 1842 , the Protestant missionaries codify the land traditions, strictly respecting the 7 laws which made up their structures.

\section{Land is sacred}

The religious structure, the marae represents the title deed. Link of the inevitable genealogical tree, each stone symbolises the family connected to the marae. Extracted from the primary marae, volcanic stones are used as boundary marks, named „otia fenua”, when a new territory is conquered.

\section{Land is inalienable and imprescriptible}

Foster land cannot be sold, for a religious edifice cannot be sold, because a family clan cannot be sold. Landed property is, for time immemorial, owned by one and same clan. The provisional occupation of a land does not give right to title deed.

\section{Land is no individual property}

It is a family heritage, „fenua fetii”, ruled by birthright. Birthright exerts its influence for the allocation of the individual rights of user. To each one is attributed a ,vauvau”. Land and family are one and same thing. When a child has been given birth to in a clan, his placenta was wrapped up in a leaf of the „,auti pu fenua" - a sacred plant - or put in a shell of „maoa” - a seafood found on the coral reefs - it is then, either planted in the family soil, or thrown down the outer slopes of the coral reef.

4. Dichotomy between what is above the ground and what is in the soil, ,papa”.

The Maohi fundamentally distinguishes, cultivations set on the ,vauvau”. Any member of the clan has an inalienable residing right over what is on the ground, this right being a family birthright.

\section{Land cannot be divided}

On a „fenua fetii”, exploitation rights are always individual, but the supervision of the landed property is collective.

6. The lagoon may be subjected to a private appropriation

Properties have two forms: the emerged land and the underwater land.

\section{The ,rahui"}

To provide for one's needs in time of scarcity, the society uses the process of the prohibition. When it is imposed, people are not allowed to harvest, to fish, or to dive during certain periods.

At least, at the beginning of the conversion process, the missionaries set down in writing a tradition which have in their opinion no contradiction with the customs of the chosen people of the Bible. They introduce the principle of separating the judicial power from the political power. 
Anl. 19 Risse im Atoll Moruroa

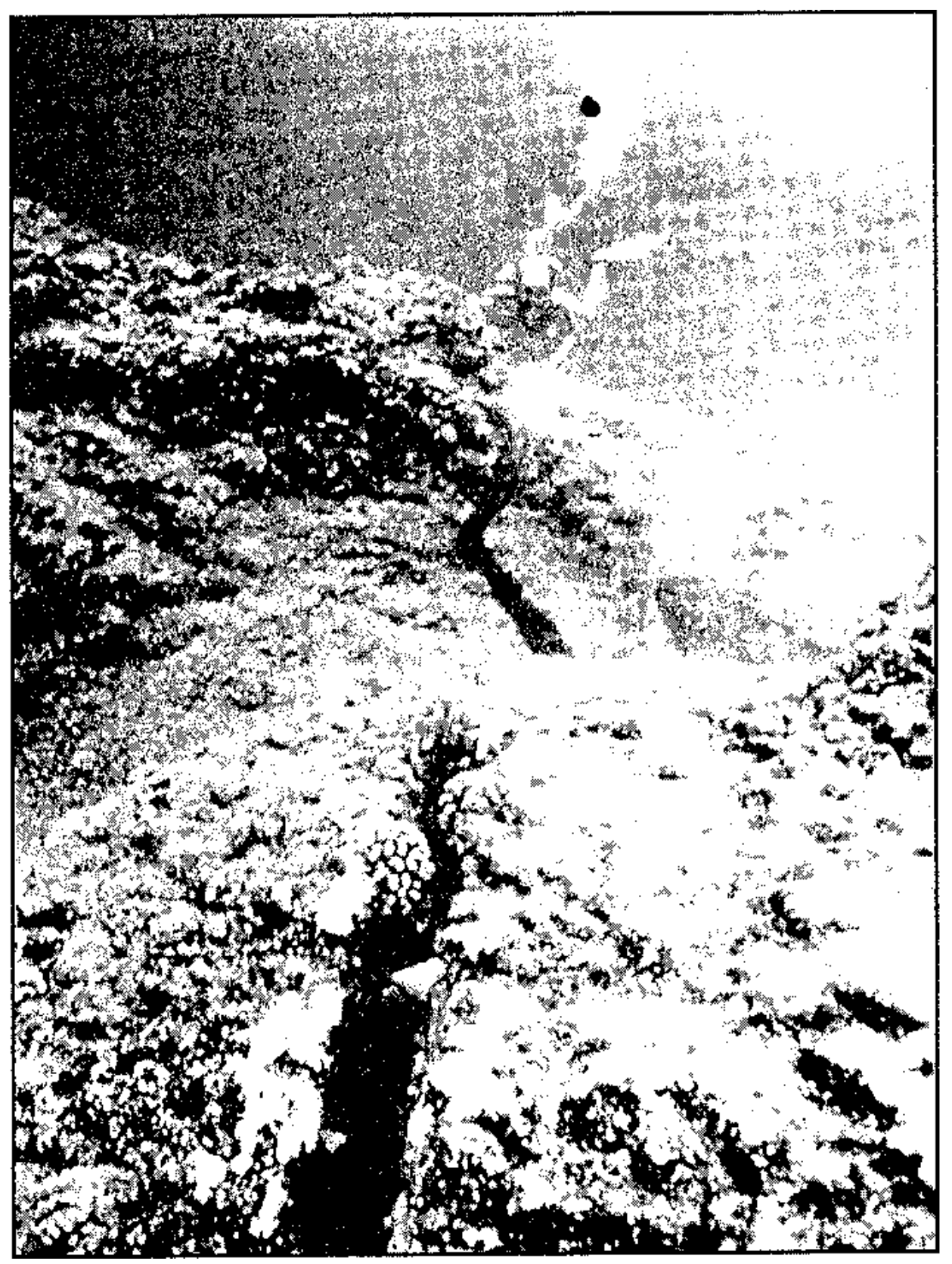

„No independent scientific team has been permitted to undertake a thorough investigation of Moruroa. However, three brief investigations, including one led by Jacques Cousteau, visiting only places allowed by the French authorities, have revealed deep cracks and fissures and evidence of underwater slips and subsidence." 

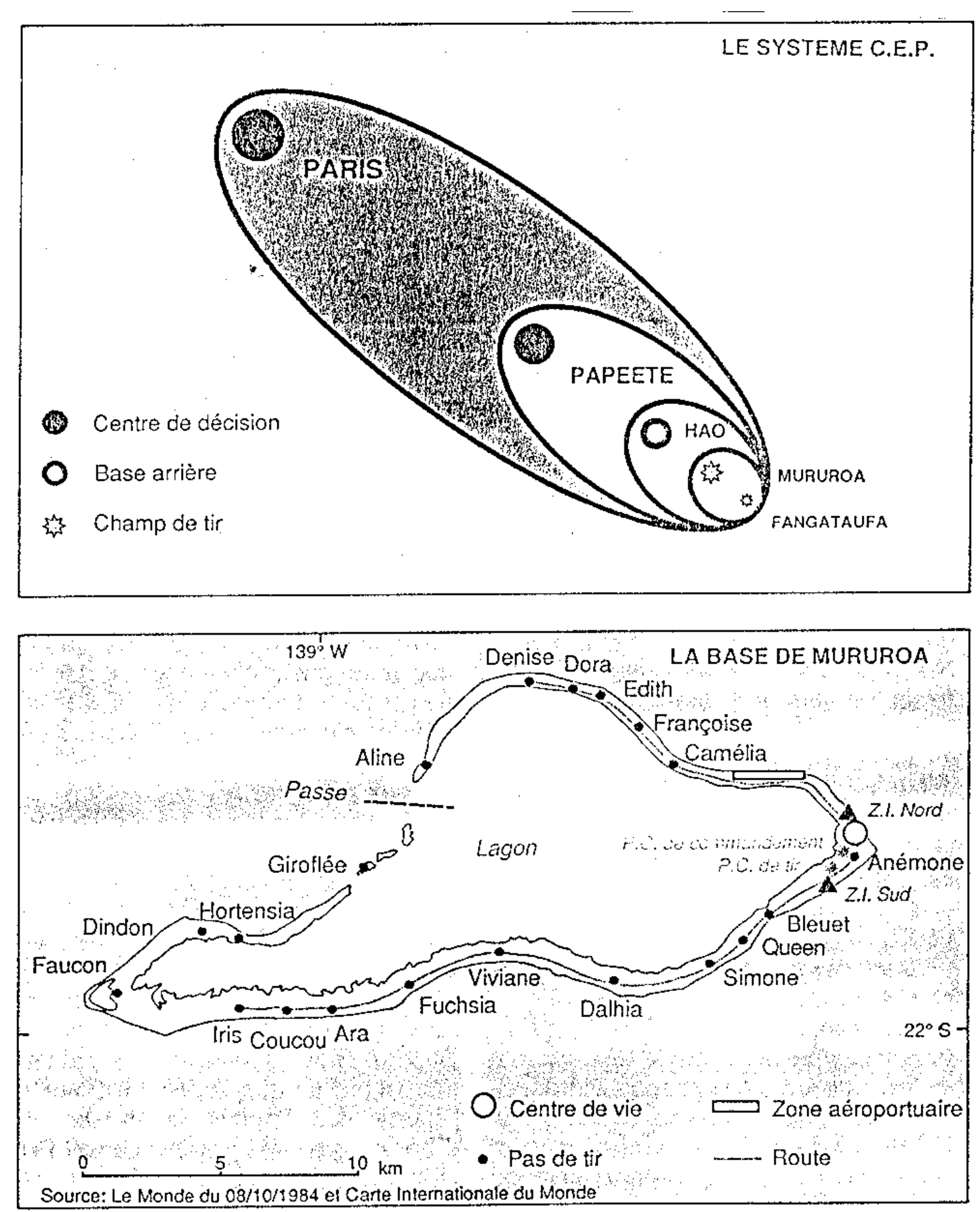

Quelle : o. V. Frontières Limites et Statuts. Approche géopolitique du Pacifique Sud. In : Atlas des îles et états du Pacifique Sud. GIP Rechus Publ. 1988. S. 98. 
Anl. 21 Beispiel der Reflektion der gegenwärtigen kulturellen Entwurzelung der Maohi

$\underline{\text { Tahiti Today }}$

Look, with your eyes

The beauty of nature

Which is deteriorating.

Listen, with your ears,

The harmonious sound of the languages

Which is fading away.

Inhale, with your nose

The soft perfume of the flowers

Which is growing thin.

Taste, with your mouth

The nectar of the fruits of the earth

Which is becoming insipid.

Touch, with your hands

All the splendour of the country

Which is disintegrating.

Hubert Bremond

Quelle: Bremond, H. : Tahiti Today-Poem. In: Pollock, N. J. u. a. (Hrsg.): French Polynesia: a Book of Selected Readings. Suva. Institute of Pacific Studies of the South Pacific. 1988. S. 2. 
Anl. 22 Ciguatera-Kreislauf
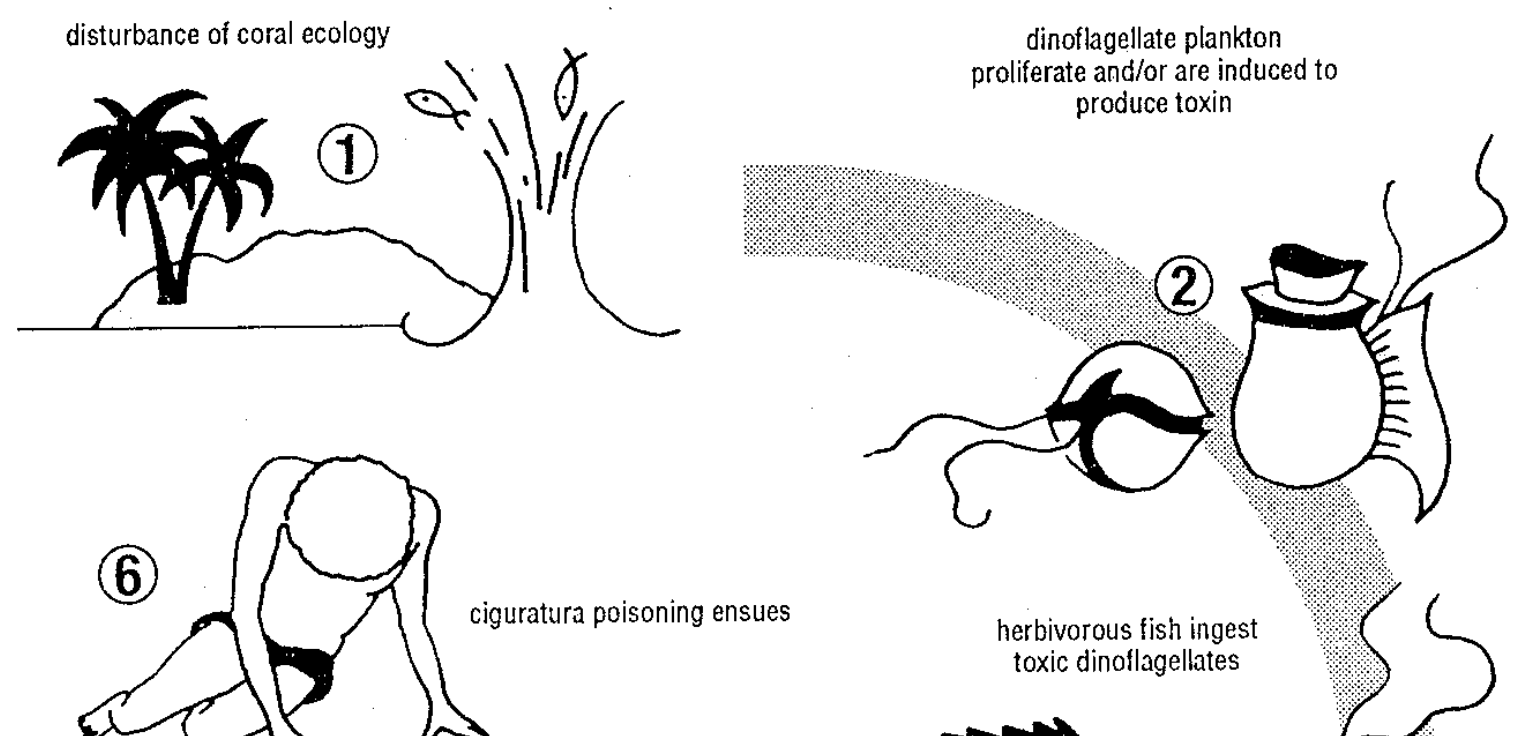

(6)
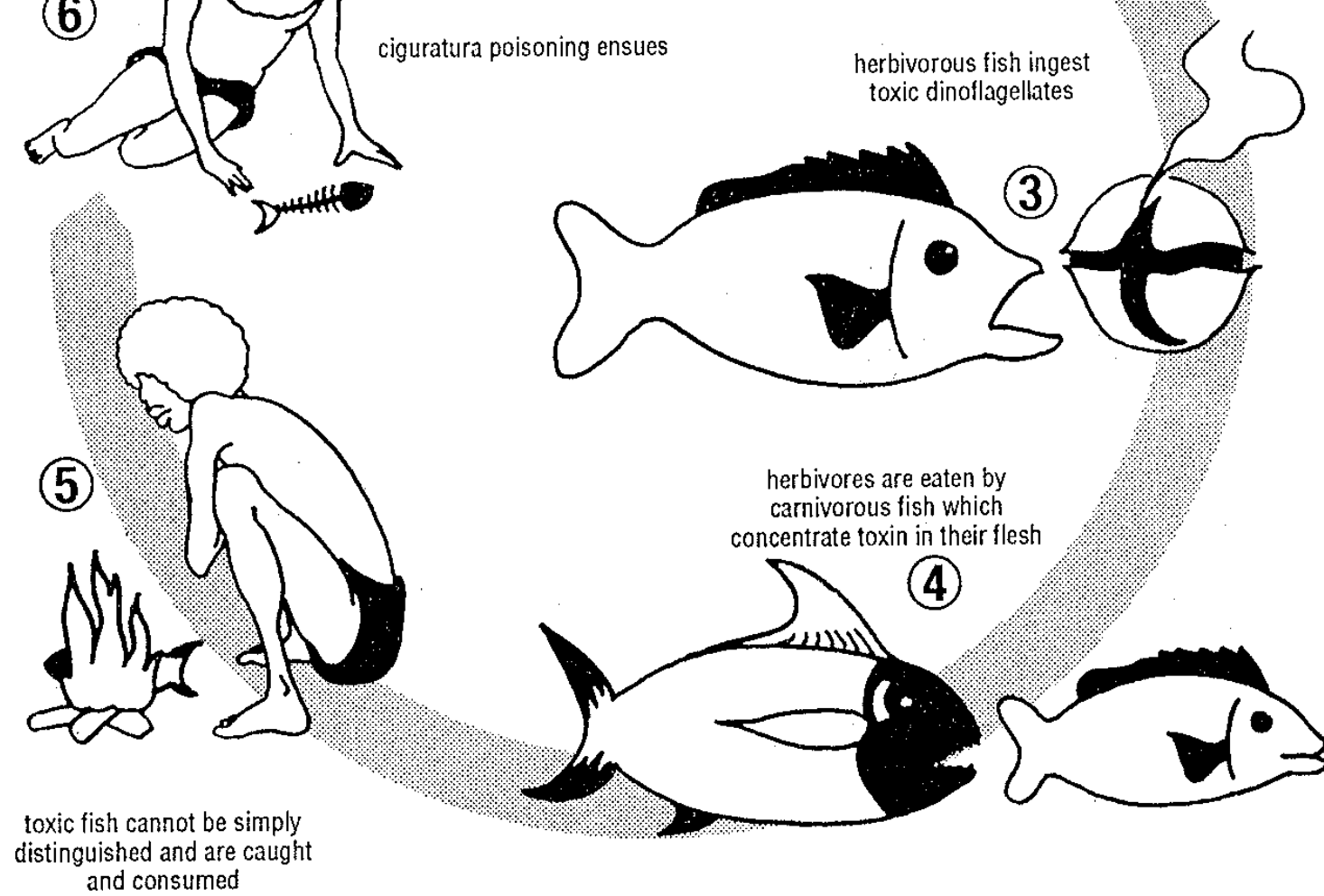

herbivorous fish ingest toxic dinoflagellates

(5) carnivorous fish which
concentrate toxin in their flesh

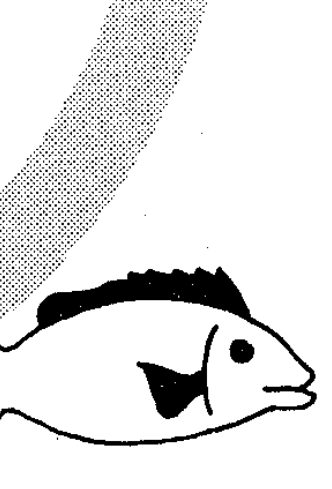

distinguished and are caught

$$
\text { and consumed }
$$

Quelle: o. V. Testimonies. Witness of French Nuclear Testing in the South Pacific. Greenpeace International. 1990. S. 19. 
Anl. 23 Vermarktung des Südseeklischees
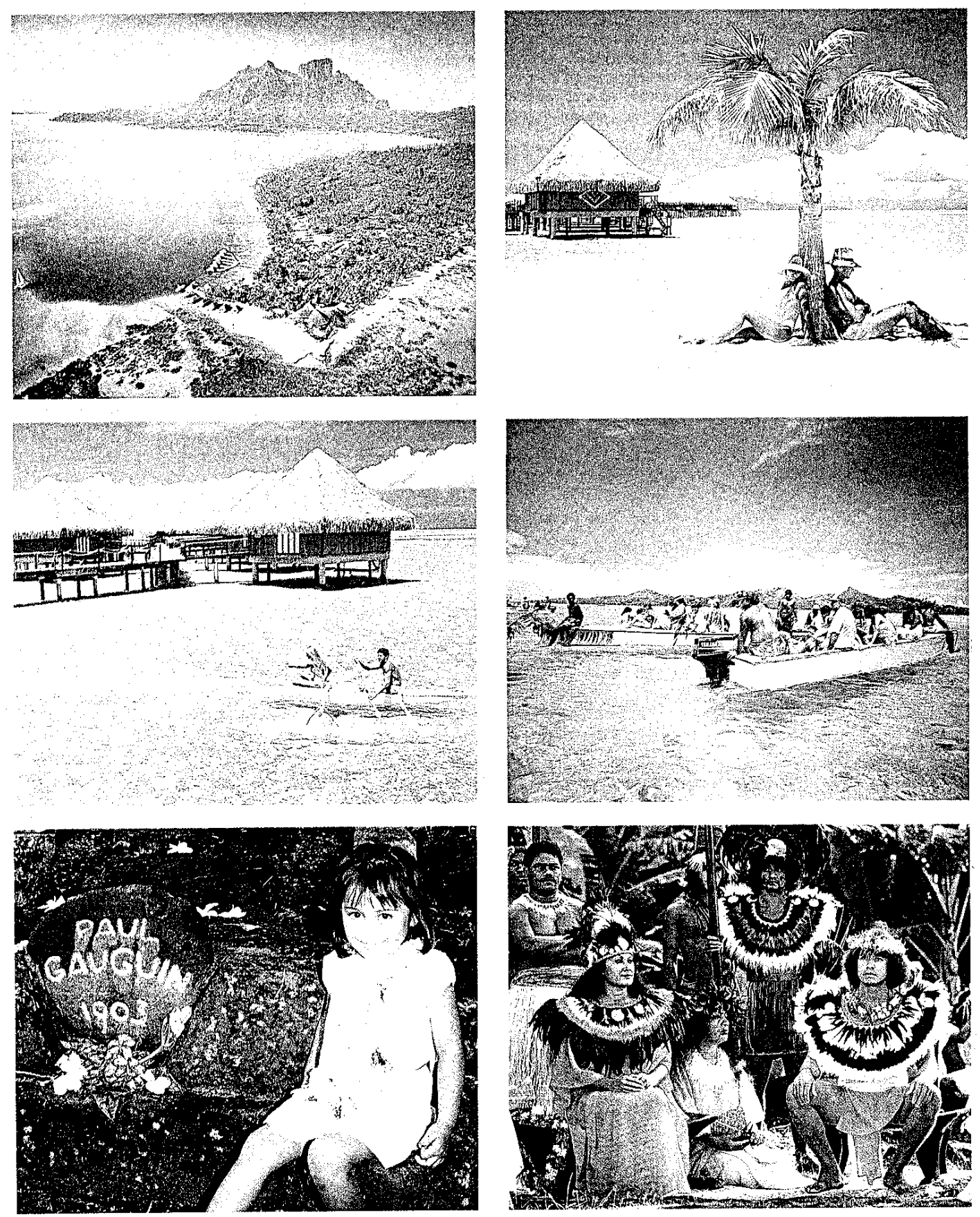

Quelle: o. V. Tahiti und seine Inseln. Prospekt des Pacific Reisebüros, Karlsruhe. 
Anl. 24 Bild Gauguins, das die desolate Situation der Ureinwohner reflektiert

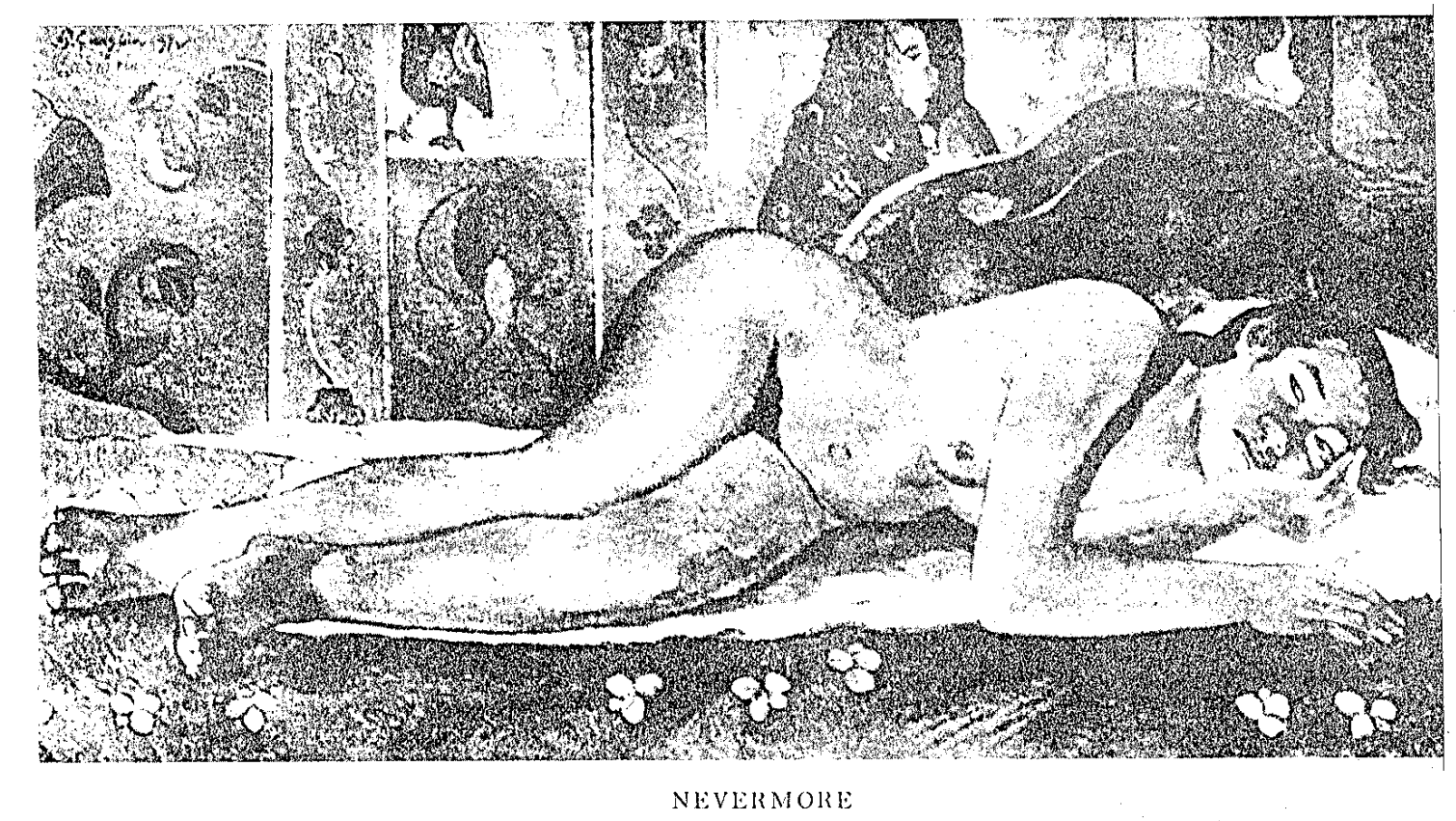

Quelle : Moerenhout, J. A.: The Fatal Impact. London. Hamish Hamilton. 1966. S. 86. 
Anl. 25 Werbebroschüre der Territorialregierung Französisch-Polynesiens

Procurez-vous cette brochure Apprenez ce que le tourisme nous apporte aujourd'hui et nous apportera demain.

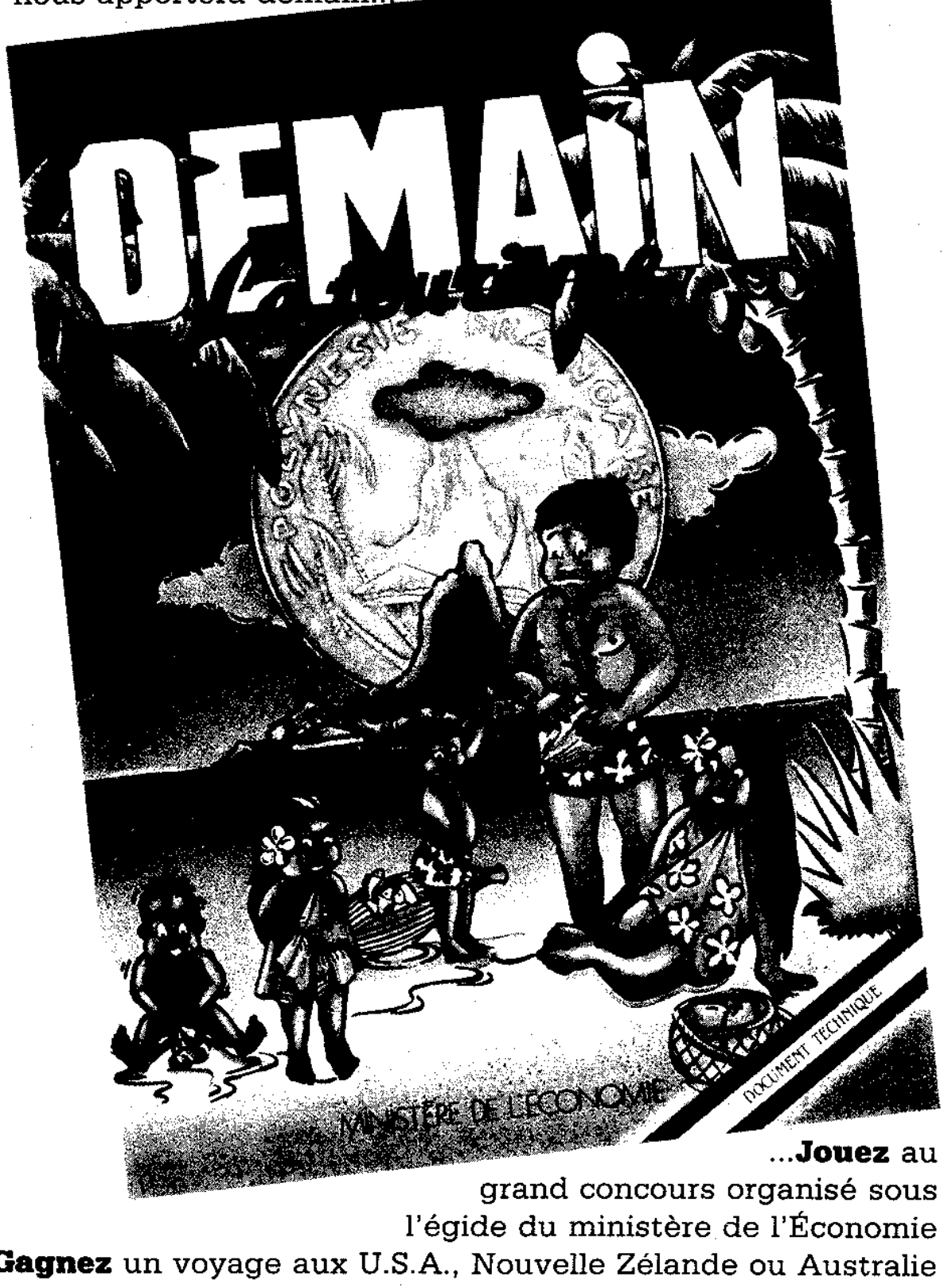

Couverture d'une brochure du ministère territorial de l'Économie destinée aux Polynésiens (Papeete, 1986).

Quelle: Bachimon, Philippe: Tahiti entre mythes et réalités. Éditions du Comité des Travaux Historiques et Scientifiques. 1990. S. 337. 


\section{Anl. 26 gtz-Frageleitfaden zu den Nachhaltigkeitsfaktoren Umweltverträglichkeit, sozio- kulturelle Verträglichkeit und ökonomische Benefits für die Zielgruppen}

\section{Umweltverträglichkeit}

Transport, Beherbergungsbetriebe, Dienstleistungen, Touristische Aktivitäten

- Landschaftsverbrauch (alle Infrastruktureinrichtungen)?

- Energieverbrauch (Anteil erneuerbarer Energiequellen)?

- Wasserverbrauch (Konkurrenz zur lokalen Bevölkerung; oft stark begrenzte Ressource)?

- Abwasserentsorgung (zentral oft nicht vorhanden; geringe Akzeptanz dezentraler Abwasserbehandlung)?

- Müllvermeidung, -recycling, -entsorgung?

- Lärm, Abgase (abhängig von Transportmitteln, Energieverbrauch, etc.)?

- Trophäensammlung, Fotojagd und sonstige Aktivitäten wie Rafting, Climbing, Mountainbiking, Trekking, Birding etc. (geschützte Arten, Vertreibung der zukünftigen lebenden Fauna)?

- Beeinträchtigung des ökologischen Gleichgewichts?

\section{Soziokulturelle Verträglichkeit}

\section{Gesellschaft, Kultur}

- Verschärfung sozialer Gegensätze?

- Akkulturation durch Demonstrationseffekte (Vorurteilsverstärkung oder -abschwächung auf beiden Seiten)?

- Veränderung des Wertesystems innerhalb der Gesellschaft (Zerstörung des Sozialgefüges)?

- Soziale Entwurzelung durch Migration (Ab- oder Zuwanderung bei touristischer Erschließung der Region)?

- Zunahme von Prostitution und Kriminalität?

- Verbesserung oder Verschlechterung der gesellschaftlichen Situation der Frauen?

- Erforschung, Renovierung und Schutz oder Zerstörung historischer Stätten?

- Stärkung nationaler Identität oder Ausverkauf von Kulturschätzen?

- (Wieder)-Belebung des Kunsthandwerks (Finanzielle Abhängigkeit von Monopolhändlern oder eigenständige Vermarktung durch HandwerkerInnen)?

- Pflege traditioneller Feste oder Kommerzialisierung von Folkloreshows? 


\section{Benefits für die Zielgruppen}

Deviseneinnahmen, Beschäftigungs- und Einkommenseffekte, sekundäre wirtschaftliche Auswirkungen

- Höhe des touristischen Devisenabflusses (Verteilung der Veranstalter, gesteigerte Importe für Luxus- und Konsumgüter, Energieträger)?

- Vertikale und horizontale Verteilung der Einkommenszuwächse (Für wen: Frauen, Männer, Jugendliche)?

- Schaffung von Dauerarbeitsplätzen mit möglichst ganzjähriger Beschäftigung (Für wen: Frauen, Männer, Jugendliche)?

- Höhe der Investitionen, die für die Arbeitsplatzbeschaffung erforderlich sind?

- Schaffung von Aus- und Fortbildungsmöglichkeiten (Für wen: Frauen, Männer, Jugendliche)?

- Verhinderung von Wanderung aus peripheren Räumen in die Ballungsräume/Schaffung neuer Zuwanderungszentren?

- Starkes Lohngefälle von den (oft ausländischen) leitenden Angestellten zu den unteren (meist einheimischen) Lohngruppen?

- Stärkung oder Schwächung der lokalen bzw. regionalen Wirtschaft (Baugewerbe, Handel, Transportwesen, Handwerk, Landwirtschaft, Fischerei etc.)?

- Stärkung des informellen Sektors (Zunahme der Verdienstmöglichkeiten insgesamt unter gleichzeitigem Anstieg unsicherer und volkswirtschaftlich nicht sehr produktiver Einkommensquellen)?

- Verbesserung/Verschlechterung der von der ansässigen Bevölkerung genutzten Infrastruktur (Auswirkungen auf Frauen, Männer, Jugendliche)?

- Preissteigerung für Konsumgüter der lokalen Bevölkerung?

- Steigerung kommunaler/staatlicher Steuereinnahmen?

- Verstärkung einseitiger Abhängigkeit vom Tourismusgeschäft (lokale, öffentliche und private Wirtschaft begibt sich in Abhängigkeit der Investitions-, Verhaltens-, Preis- und Angebotsvorstellungen ausländischer Tourismusunternehmen)? 